\title{
Der richterliche Rechtsschutz im Rahmen der Rechtmäßigkeitskontrolle bei Grundrechtseingriffen
}

Eine rechtsvergleichende Analyse des kolumbianischen Falls

\author{
Dissertation zur Erlangung des Doktorgrades \\ der Juristischen Fakultät der Georg-August-Universität zu \\ Göttingen
}

vorgelegt

von

John E. Zuluaga Taborda LL.M.

Aus Medellín/Kolumbien

Göttingen 2016 
Berichterstatter: Prof. Dr. Dr. h.c. Kai Ambos

Mitberichterstatter: Honorarprofessor Dr. Stefan König

Tag der mündlichen Prüfung: 20.01.2017 
Meiner Familie 


\section{Vorwort}

Diese Dissertation lag der Juristischen Fakultät der Georg-August-Universität zu Göttingen im Sommersemester 2016 vor. Rechtsprechung, Literatur und Gesetzgebung konnten bis zum April 2016 berücksichtigt werden.

Meinem Doktorvater, Herrn Professor Dr. Dr. h.c. Kai Ambos, gilt in besonderer Weise mein ganz herzlicher Dank. Er hat mich sehr unterstützt und mir durch seine wertvolle Betreuung großes Vertrauen entgegengebracht. An seinem Lehrstuhl waren zu jeder Zeit die wichtigsten Voraussetzungen für ein internationales wissenschaftliches Arbeiten gewährleistet, von denen ich zunächst als wissenschaftliche Hilfskraft und später als Mitglied des Centro de Estudios de Derecho Penal y Procesal Penal Latinoamericano (CEDPAL) ganz besonders profitieren durfte. Herrn Professor Dr. Stefan König gebührt der Dank für die zügige Erstellung des Zweitgutachtens.

Ein besonderer Dank gilt Herrn Dr. Manfredo Koessl, der mich schon zu Beginn meiner Promotion in Deutschland sehr motivierte. Herrn Jörn Halling (M. iur.), dessen beeindruckende rechtsvergleichende Kenntnisse mir einen wesentlichen Teil der Arbeit ermöglicht haben. Herrn Dr. Szymon Swiderski, der meinen Fragen zum deutschen Straf- und Strafprozessrecht geduldig Rede und Antwort stand und mich überdies als Teil seiner Familie herzlich aufnahm. Daneben schulde ich Frau Dr. María Laura Böhm besonderen Dank für ihre unermüdliche Unterstützung und fortwährende Motivierung.

$\mathrm{Zu}$ danken habe ich auch dem Deutschen Akademischen Austauschdienst (DAAD) für die Förderung meiner Forschungstätigkeit in Göttingen durch ein vollständiges Master- und Promotionsstipendium, das mir ermöglichte, den LL.M. erfolgreich zu absolvieren und meine wissenschaftliche Arbeit fortzusetzen.

Ich danke Frau Lena Gebauer und Herrn Jerre Sander, die durch ihre gewissenhaften Korrekturen unmittelbaren Anteil an der Fertigstellung der Arbeit hatten. Darüber hinaus danke ich der gesamten Abteilung für die freundliche, motivierende wie auch tatkräftige Unterstützung.

Auch an kolumbianischen Universitäten habe ich durch fruchtbare Diskussionen große Unterstützung erfahren. Hierfür habe ich Herrn Professor Fernando Velásquez, Herrn Pro- 
fessor Dr. Ricardo Molina, Herrn Professor Dr. Armando Calle Calderón und Herrn Dr. Professor Hernando Londoño zu danken. Mein Dank gebührt auch vielen weiteren Freunden, die mich in vielerlei Hinsicht unterstützt haben.

Mein abschließender Dank gilt meiner Familie, die mich während meines Aufenthalts in Deutschland mit unendlicher Liebe aus weiter Ferne unterstützte.

Göttingen, im Oktober 2017

John E. Zuluaga Taborda 


\section{Inhaltsverzeichnis}

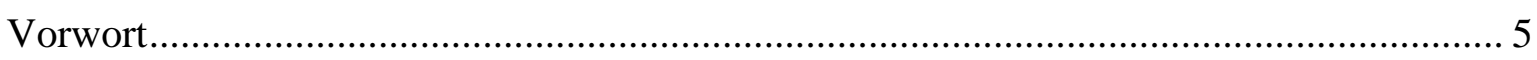

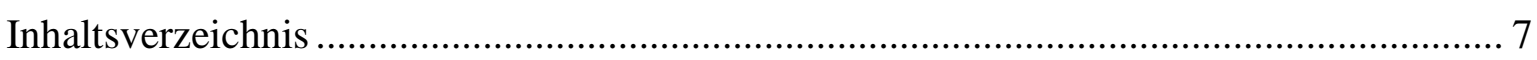

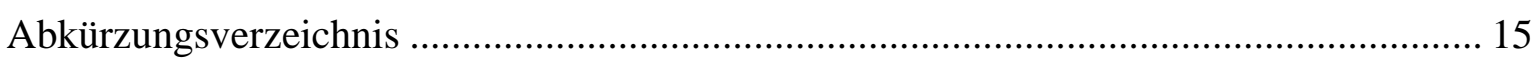

§1. Einleitung: Der richterliche Rechtsschutz im Ermittlungsverfahren................... 19

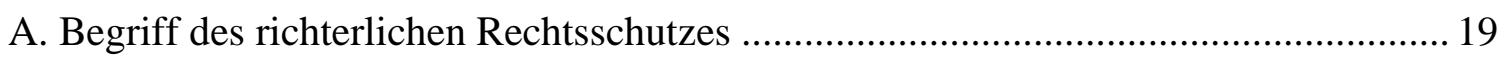

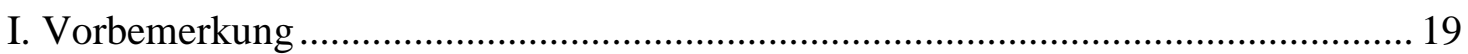

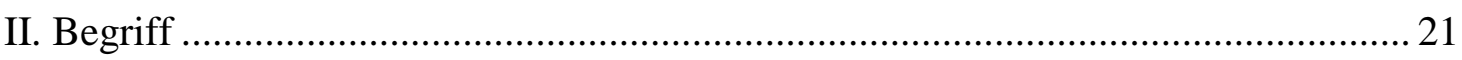

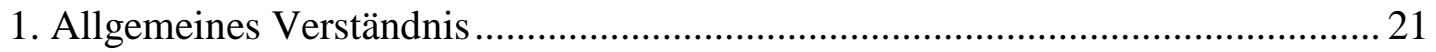

2. Differenzierte Begriffsbestimmungen ............................................................ 24

B. Überblick über die Erscheinungsformen des Rechtsschutzes ................................... 27

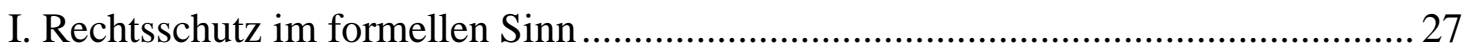

1. Der präventive Rechtsschutz durch Richtervorbehalte ....................................2 27

2. Der repressive Rechtsschutz durch Rechtsbehelfe ................................................ 30

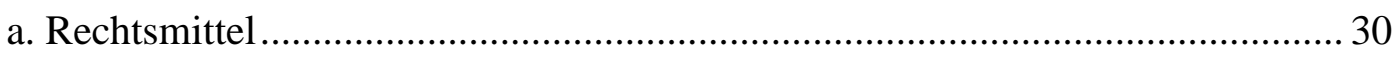

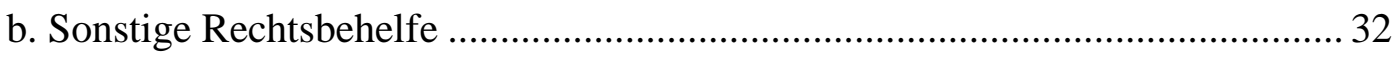

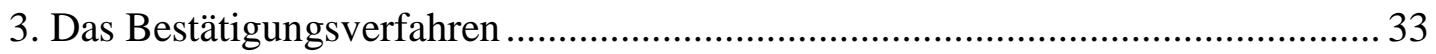

II. Rechtsschutz im materiellen Sinn .................................................................... 34

1. Verfahrensrechtliche Kautelen und Schutzvorkehrungen ..................................... 34

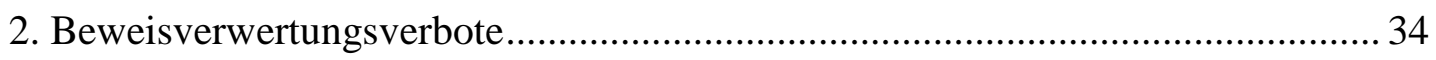

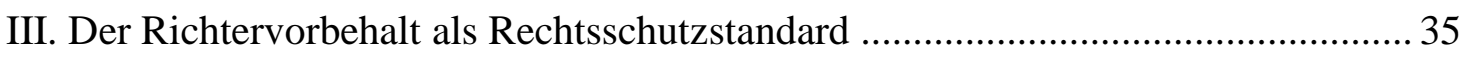

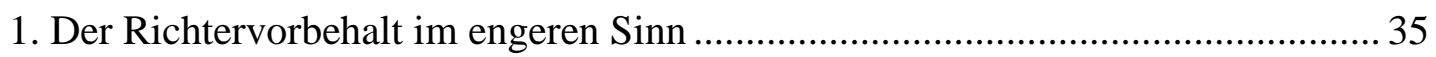

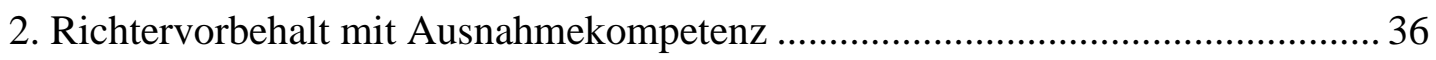

3. Originäre Anordnungskompetenz der nichtrichterlichen Ermittlungsbehörden ... 38

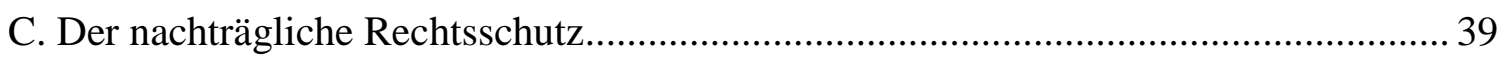

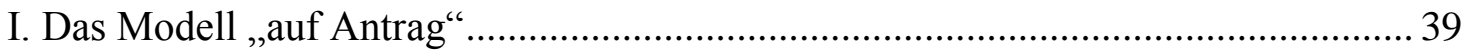

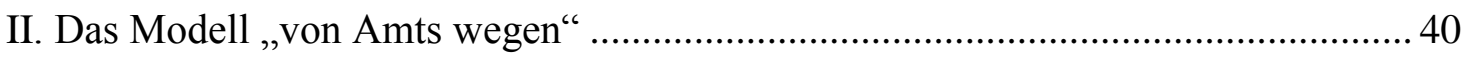

D. Überblick über das richterliche Rechtsschutzsystem in Kolumbien ............................ 42

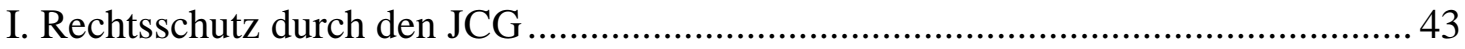

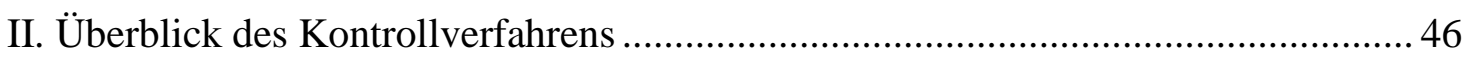

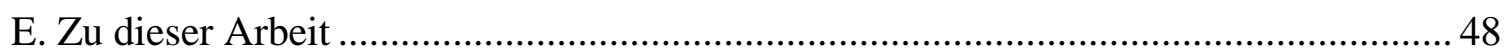

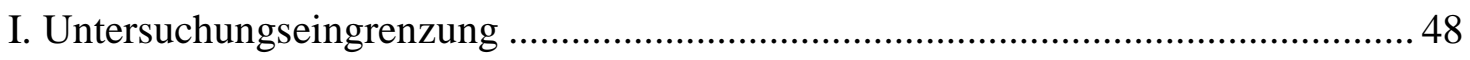

II. Zu dem Vorgehen der Arbeit - Ziele und Gang der Forschung ............................ 51

Erster Teil: Das Rechtsschutzsystem im kolumbianischen, strafrechtlichen Ermittlungsverfahren.

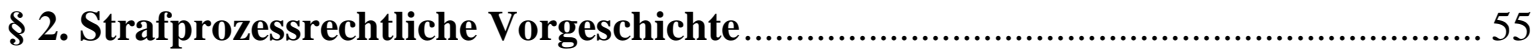

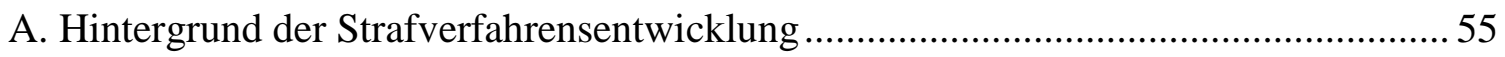

B. Strafprozessrechtliche Reaktionen auf die Gewalt ................................................... 58

I. Sicherheitsstatut (Dekret 1923 vom 06.09.1978) ....................................................59 


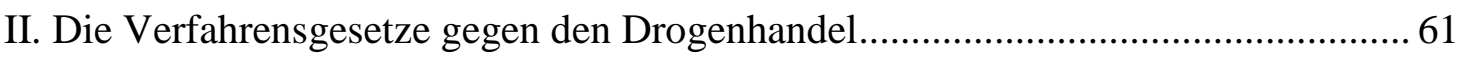

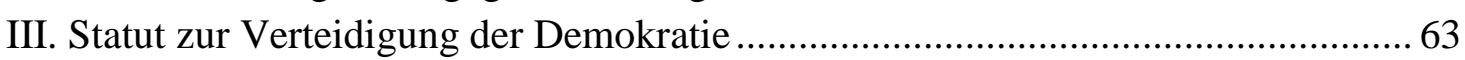

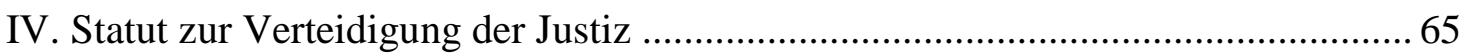

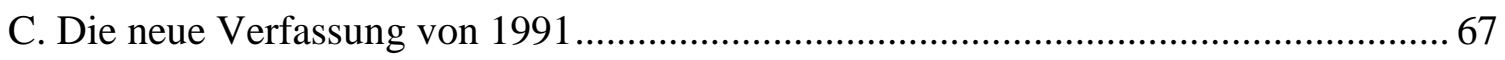

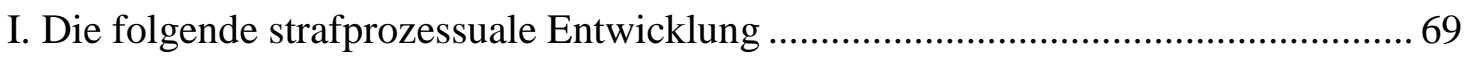

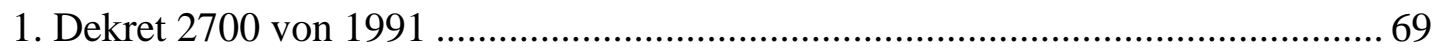

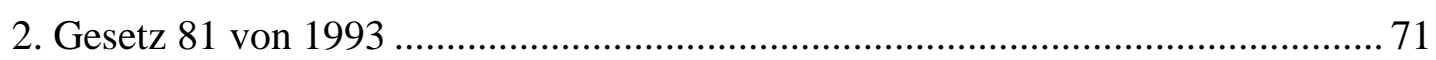

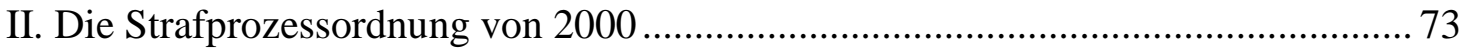

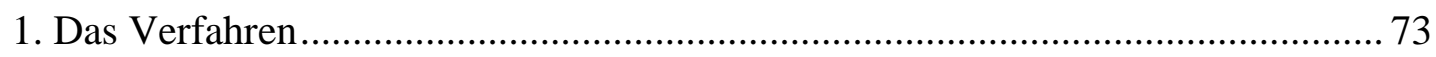

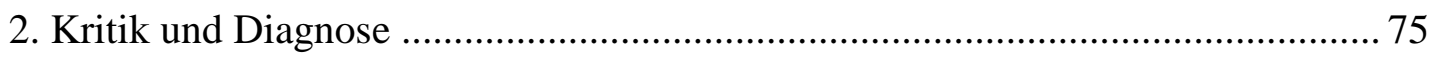

3. Politischer Kontext der Strafprozessrechtsreform von 2002 ............................. 76

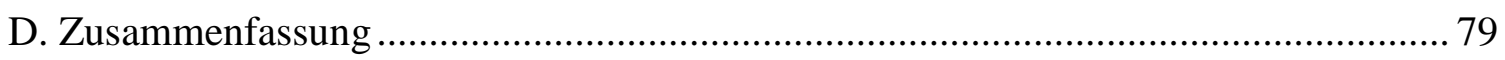

§ 3. Das strafrechtliche Ermittlungsverfahren in Kolumbien ...................................... 81

A. Charakterisierung des ,neuen“ Ermittlungsverfahrens ............................................. 81

I. Verfassungsrechtliche Grundlagen des Ermittlungsverfahrens.............................. 82

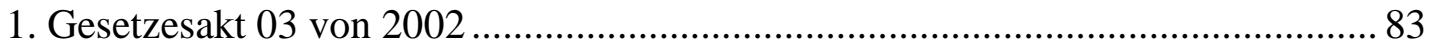

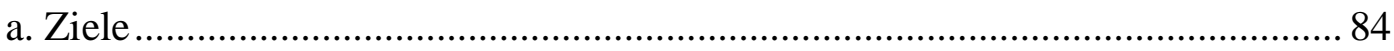

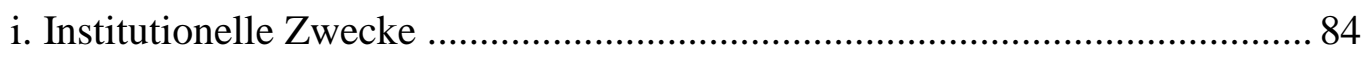

ii. Strafprozessuale Zwecke ................................................................... 85

b. Auswirkungen der Verfassungsreform auf die Auslegung strafprozessrechtlicher

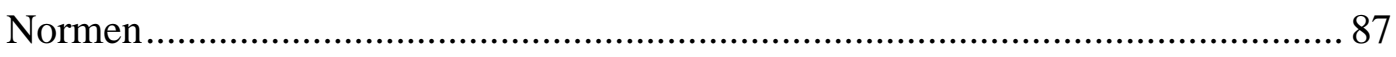

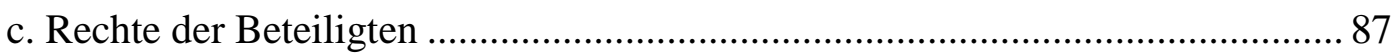

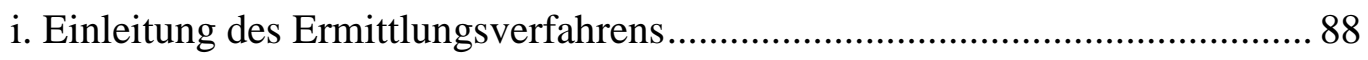

ii. Erhebung der Anklage und Beibringung von Beweisen .............................. 88

iii. Ermächtigung zur Anordnung von Zwangsmitteln .................................... 89

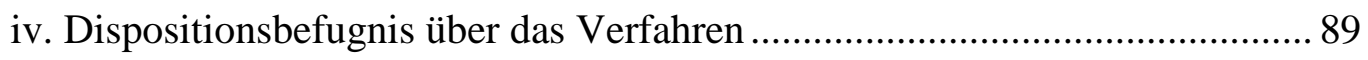

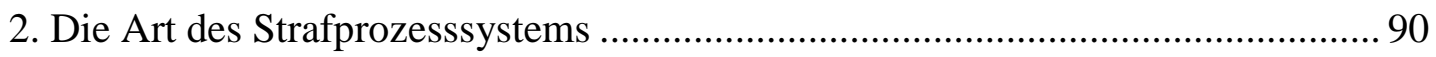

a. Trennung von Ermittlungs- und Hauptverfahren ............................................ 91

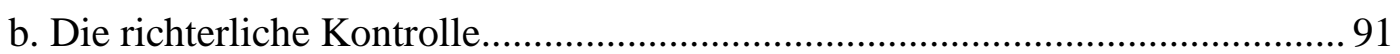

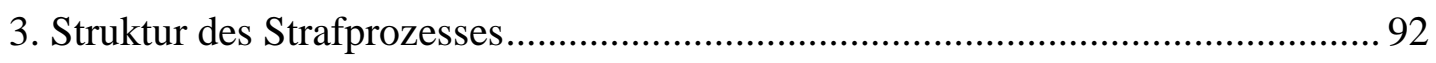

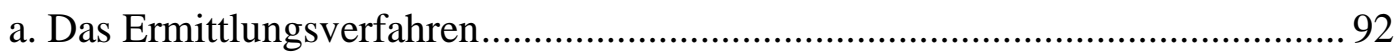

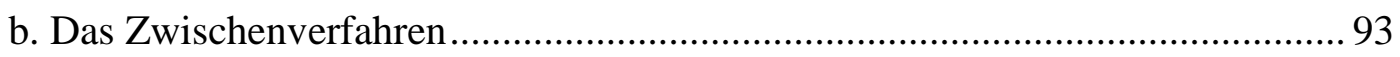

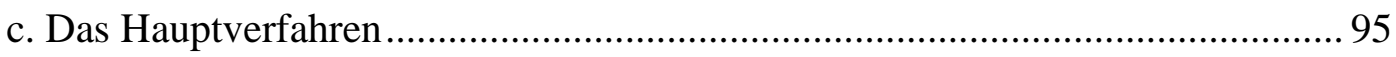

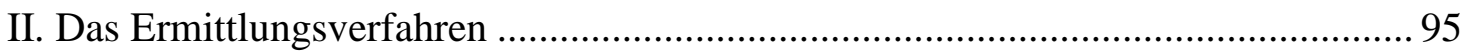

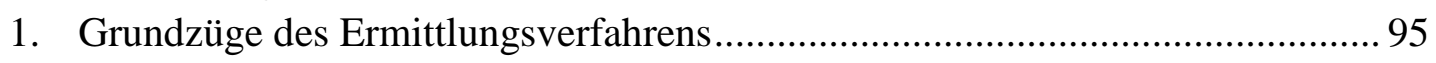

a. Unterwerfung unter das Legalitätsprinzip ................................................. 96

b. Unterwerfung unter die richterliche Kontrolle.............................................. 96

c. Unterwerfung unter das Geheimhaltungsgebot ............................................ 96

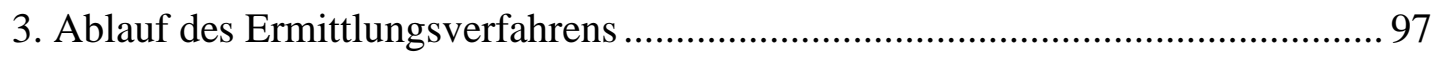

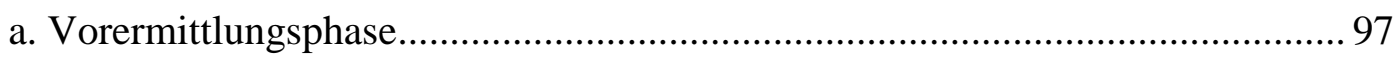

b. Die Beschuldigung (Formulación de imputación) .............................................. 99

c. Ermittlungen im engeren Sinn ................................................................... 100 


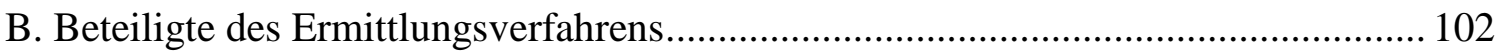

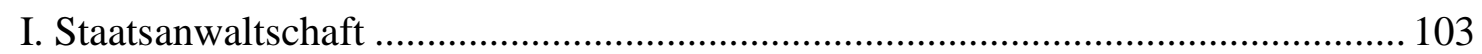

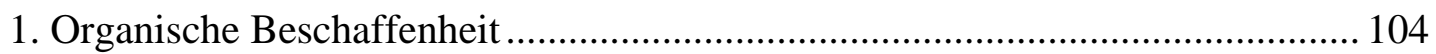

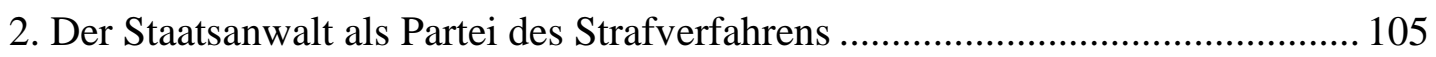

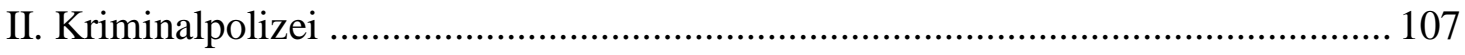

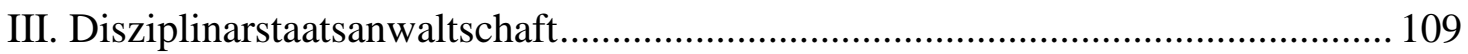

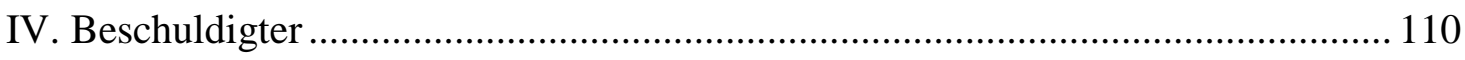

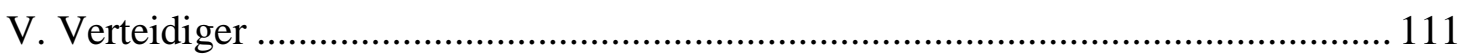

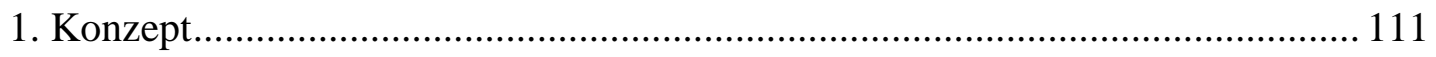

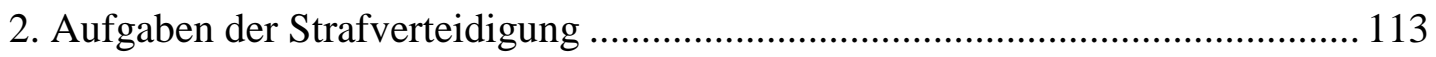

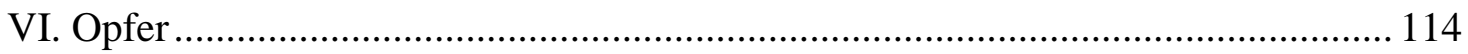

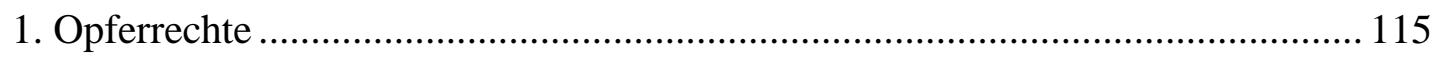

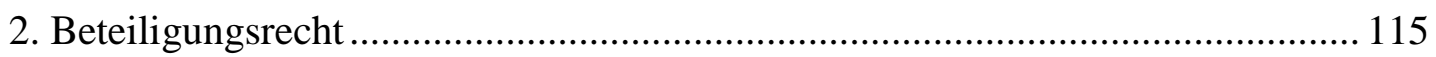

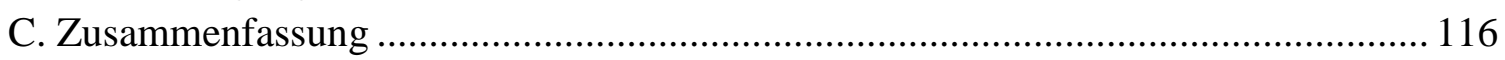

§ 4. Der Richter zur Kontrolle der Garantien (Juez de Control de Garantías) ........ 119

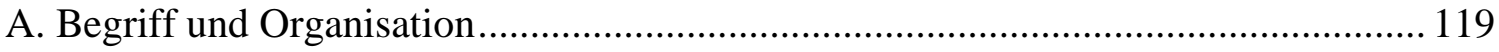

B. Funktion und Aufgaben des Richters zur Kontrolle der Garantien ......................... 121

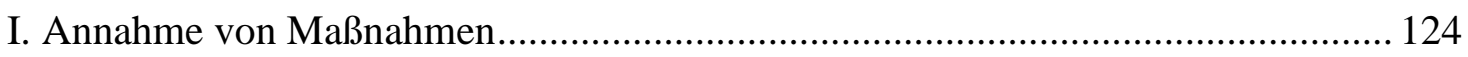

II. Anordnungen und Verhältnismäßigkeitsgrundsatz .......................................... 125

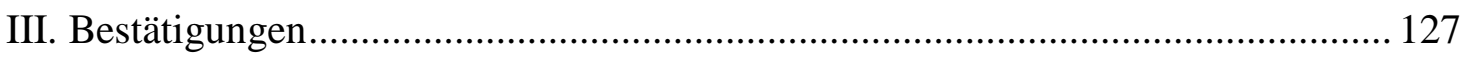

IV. Der Aushilfsrichter zur Kontrolle der Garantien ........................................... 128

C. Grundrechtseingriffe mit nachträglicher Überprüfung ........................................... 129

I. Anhörungen zur nachträglichen Überprüfung der Rechtmäßigkeit ........................ 129

II. Nachträgliche Kontrolle („Controles posteriores“) der Ermittlungshandlungen ... 132

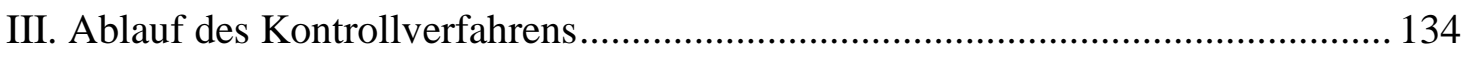

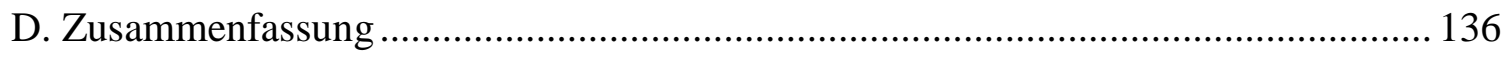

§ 5. Nachträglicher Rechtsschutz gegen Maßnahmen zur Beschränkung der

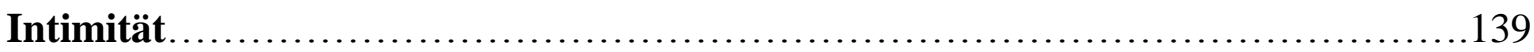

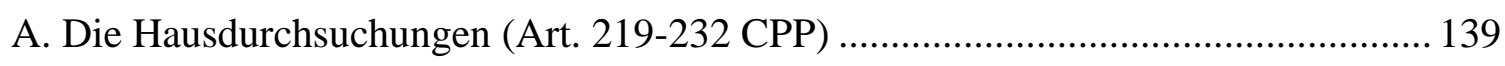

I. Gründe der Maßnahmen und Relevanzüberprüfung .............................................. 140

II. Überprüfung der Achtung der Grundrechte ..................................................... 141

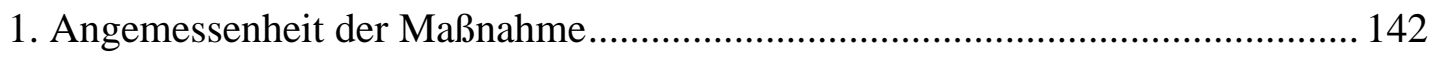

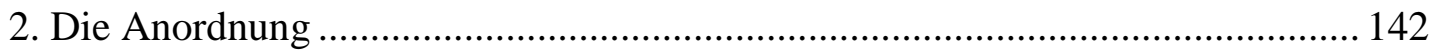

3. Ausnahmen des Anordnungserfodernisses ................................................... 144

a. Das Einverständnis des Rechtsinhabers des beeinträchtigten Guts oder desjenigen, der ein durch die Durchführung der Maßnahme beeinträchtigtes Interesse hat (Art. 230 Nr. 1 CPP) ............................................................... 145

b. Die vernünftige Erwartung eines Eingriffs in die Intimitätsphäre (Art. 230 Nr. 2

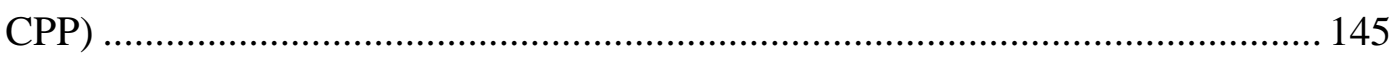

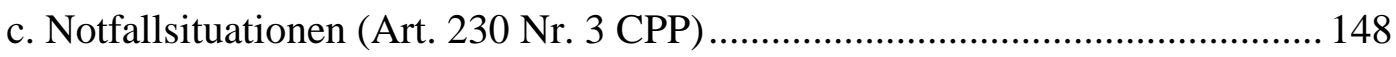

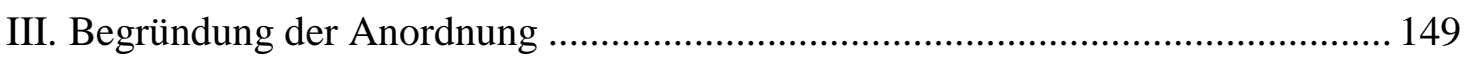




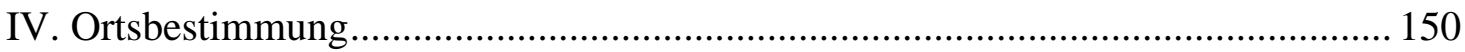

V. Nachträgliche gerichtliche Überprüfungsanhörung ............................................ 152

1. Ablauf der Überprüfungsanhörung...................................................................... 153

2. Hauptproblem der materiellen und formellen Überprüfung (Art. 237 CPP)....... 154

B. Die Personenüberwachung (Art. 239 CPP) .......................................................... 155

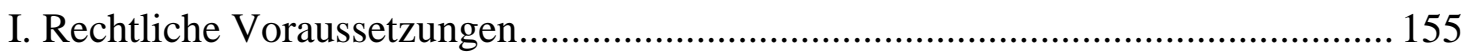

1. Anordnung des Staatsanwalts aufgrund von fundierten Anhaltspunkten............. 155

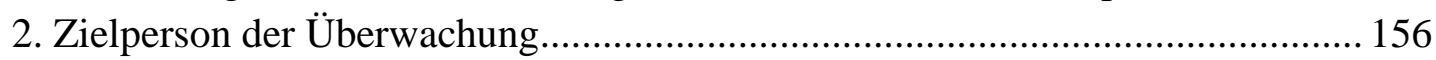

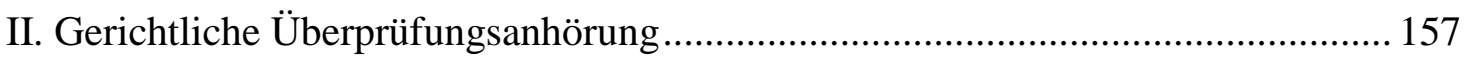

III. Die Überwachungsmaßnahmen an Sachen (Art. 240 CPP)................................. 158

C. Verdeckte Ermittlungen (Art. 241-243 CPP) ........................................................... 159

I. Analyse und Infiltrierung einer kriminellen Organisation (Art. 241 CPP) .............. 159

II. Einsatz verdeckter Ermittler (Art. 242 CPP) ........................................................ 160

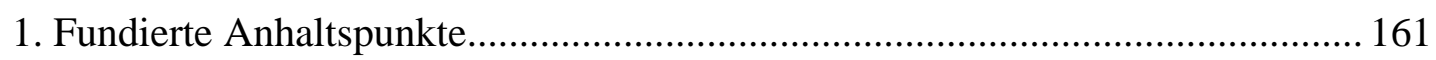

2. Person des verdeckten Ermittlers .................................................................... 162

III. Überwachung von Übergaben/Lieferungen (entrega vigilada) (Art. 243 CPP) ... 164

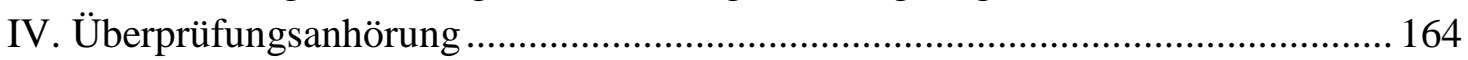

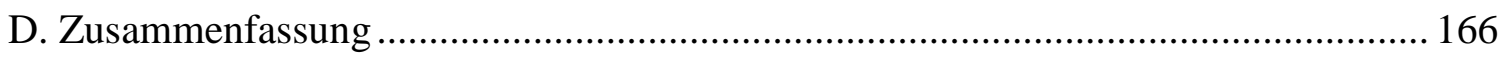

§ 6. Nachträglicher Rechtsschutz gegen Maßnahmen zur Beschränkung der Unverletzlichkeit der Kommunikation und der Freiheit ............................................. 169

A. Eingriff in die postalische Kommunikation (Art. 233 CPP) ……………………...... 169

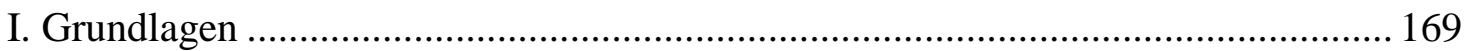

1. Rechtmäßigkeit des Gegenstandes der Maßnahme ........................................... 169

2. Gegenstand des Eingriffs in die postalische Kommunikation (Art. 233 CPP)... 170

II. Ausführung des Eingriffs in die postalische Kommunikation ................................. 171

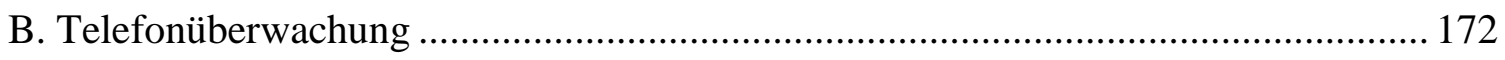

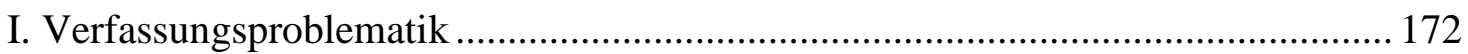

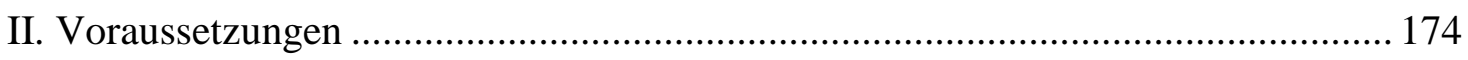

1. Zweck und Gegenstand der Überwachung .......................................................... 174

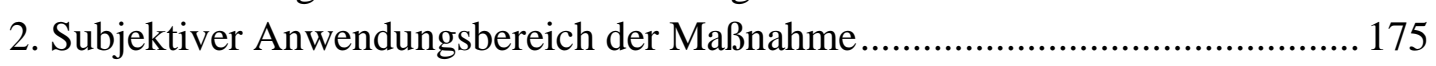

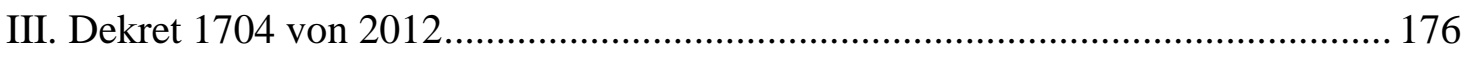

IV. Nachträgliche gerichtliche Überprüfungsanhörung............................................ 176

C. Nachträglicher Rechtsschutz gegen Maßnahmen zur Beschränkung der Freiheit .... 178

I. Festnahme mit Ausnahmekompetenzen .......................................................... 178

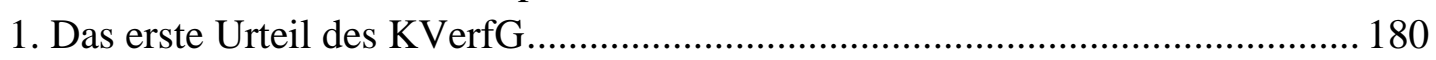

2. Rechtliche Wiedereinführung der Ausnahmekompetenz zur Festnahme............. 181

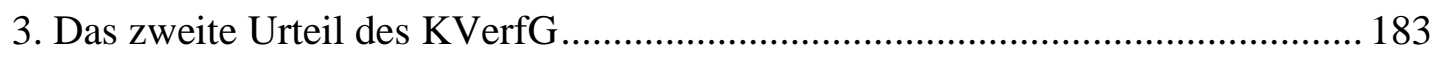

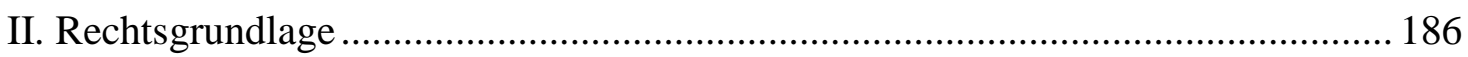

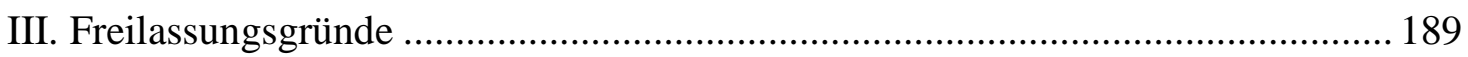

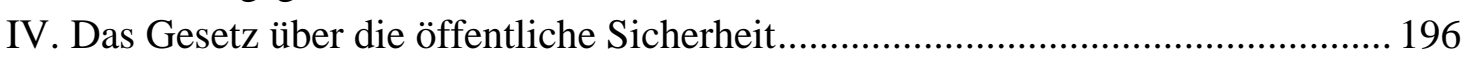

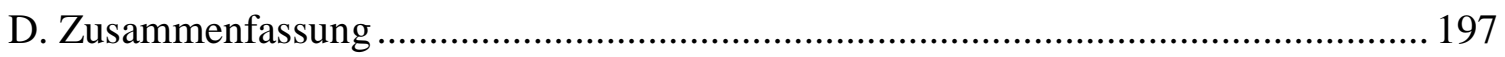


Zweiter Teil: Probleme bei der Feststellung der Rechtswidrigkeit eines Ermittlungseingriffes

§ 7. Die sog. „motivos fundados“ als Voraussetzung von Ermittlungsmaßnahmen . 199

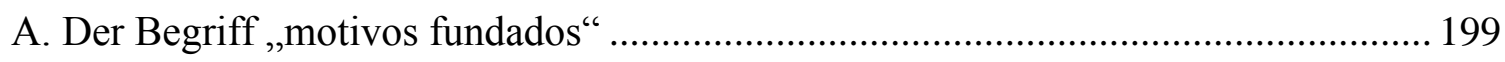

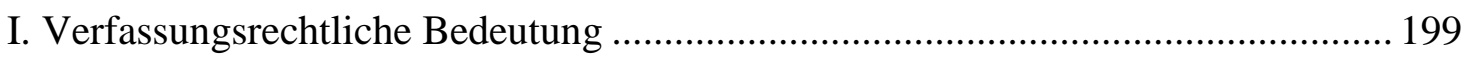

II. Systematische Lage im aktuellen CPP ................................................................ 203

1. Fundament, um Präventivmaßnahmen anzuordnen (Art. 83 Abs. 2, 91 Abs. 1 und 101 Abs. 1 CPP) ........................................................................................ 204

2. Grundlage für weitere Ermittlungsmaßnahmen (Art. 213-250, 383 Abs. 2 CPP)

3. Begründung der Freiheitsbeschränkung (Art. 297, 308-311 CPP) .................... 210

4. Grundlage für die Beweissicherung (Art. 284 Nr. 3 CPP) ................................. 212

B. Auslegung des Begriffes ,motivos fundados“ in der Rechtsprechung...................... 213

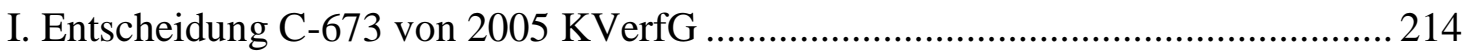

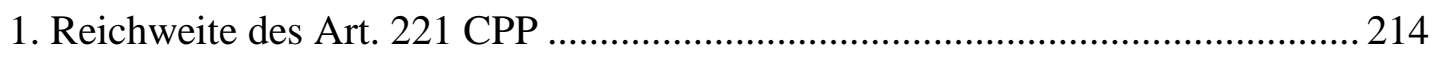

2. Rechtmäßigkeitskontrolle seitens des JCG.................................................... 216

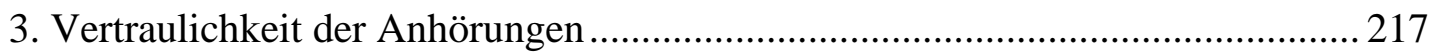

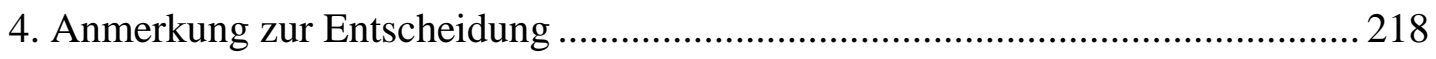

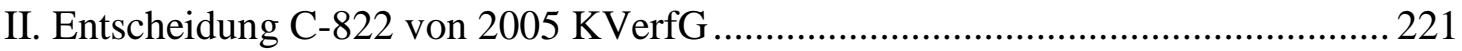

1. Grundlage für die vorausgehende richterliche Anordnung .............................. 222

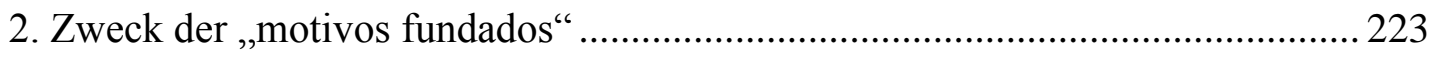

3. „Motivos fundados“ vs. Unschuldsvermutung................................................... 225

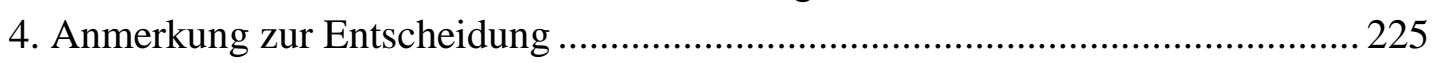

III. Entscheidung C-336 von 2007 KVerfG........................................................ 228

1. Grundlage für die Ausnahme von der vorausgehenden richterlichen Anordnung

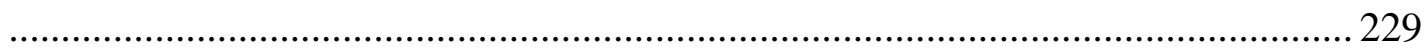

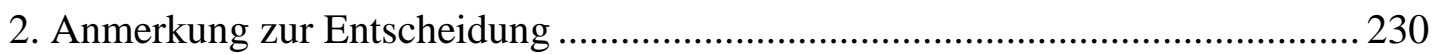

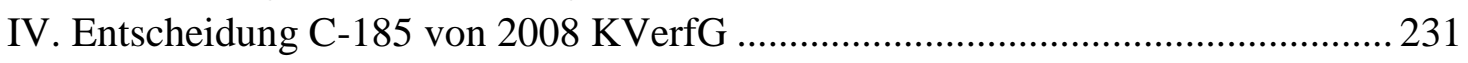

1. Forderung nach Konkretisierung der ,motivos fundados““............................... 232

2. Anmerkung zur Entscheidung ......................................................................... 234

C. Systematischer Überblick der ausgewählten Rechtsprechung ................................. 236

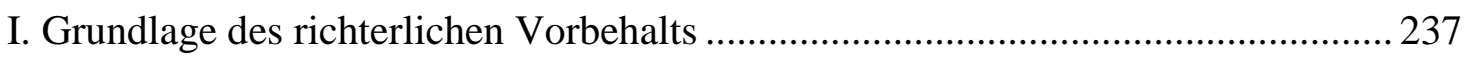

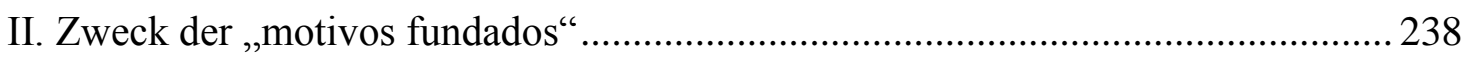

III. Beweisunterstützung für ,,motivos fundados“ ‘................................................ 238

IV. Vertraulichkeit der Anhörungen zur Legalitätskontrolle................................... 239

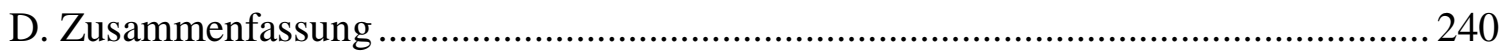

§ 8. Die Lehre des Tatverdachts als rechtsvergleichender Parameter ...................... 243

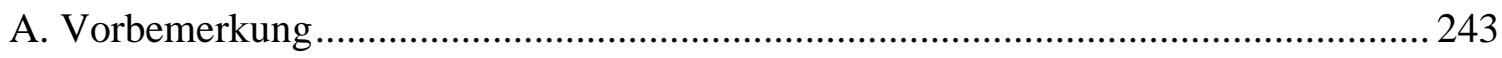

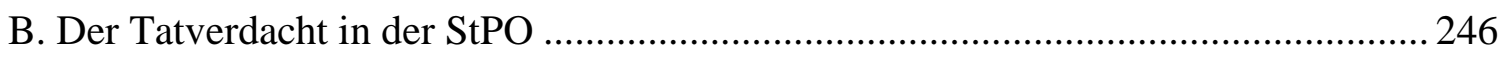

I. Voraussetzung eines Verdachtsverständnisses ..................................................... 248

II. Bestimmungsansätze eines Begriffes .............................................................. 252 


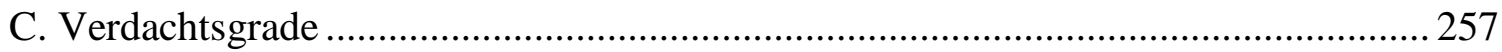

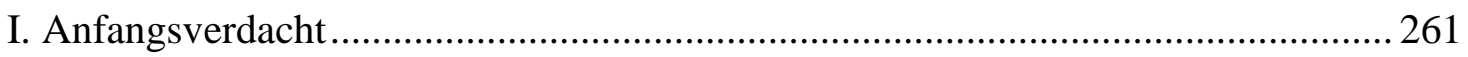

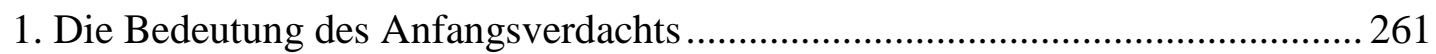

2. Anfangsverdacht und Vorermittlung ................................................................. 266

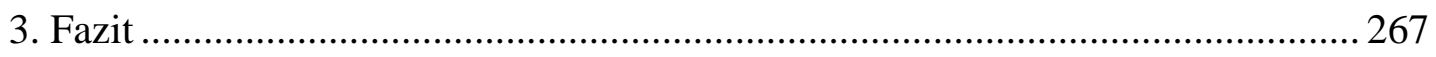

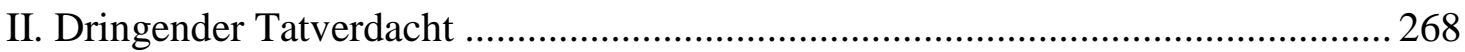

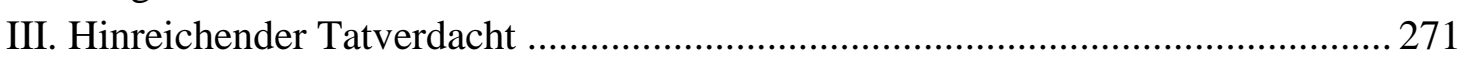

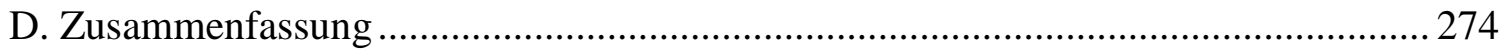

§ 9. Die sog. „motivos fundados“ im Vergleich mit dem Tatverdacht........................ 277

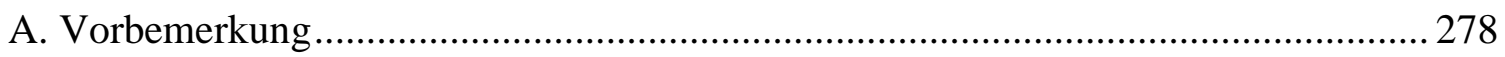

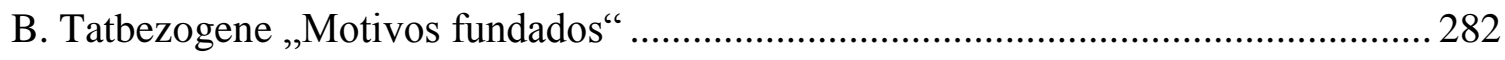

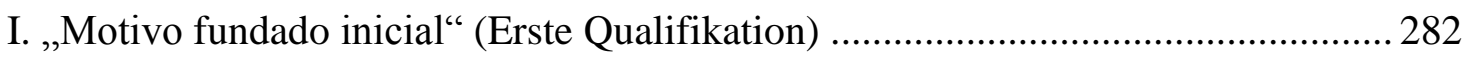

1. Funktion in dem Verfahrensabschnitt ............................................................ 282

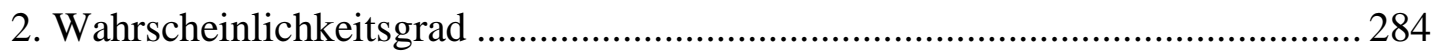

II. Bewertung der einleitenden Ermittlungsergebnisse ........................................... 286

1. Das sog. ,programa metodológico“ (Art. 207 CPP) .......................................... 286

2. Maßnahmen im Rahmen der Vorermittlung .................................................... 288

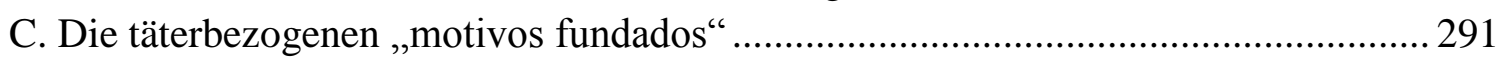

I. Begründungsgrad für die Anordnung von Grundrechtseingriffen: die sog. „motivos razonablemente fundados“ (Zweite Qualifikation)................................................ 291

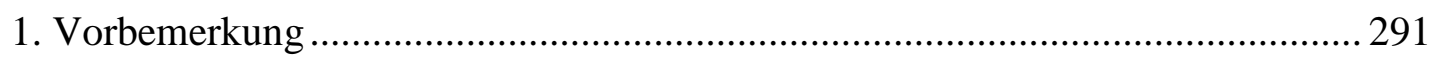

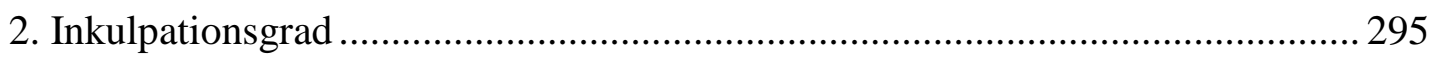

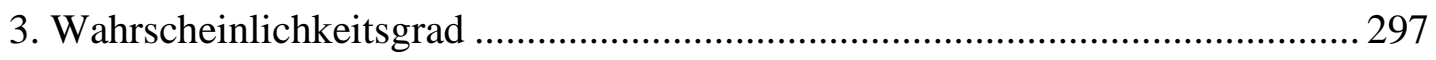

II. ,Motivos fundados“ für die Erhebung der Anklage (Dritte Qualifikation) ........... 299

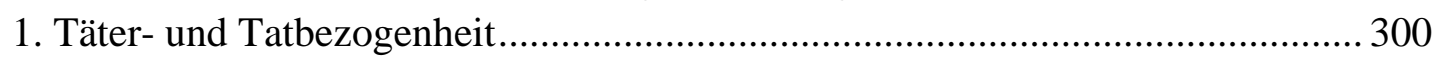

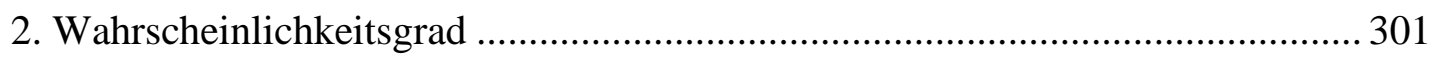

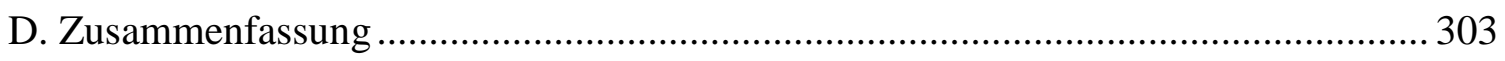

§ 10. Probleme der Kontrolle von „motivos fundados“ durch den JCG ..................... 305

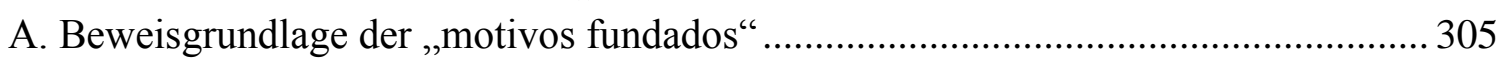

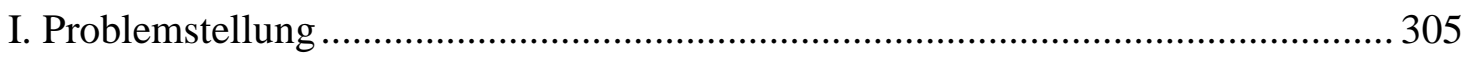

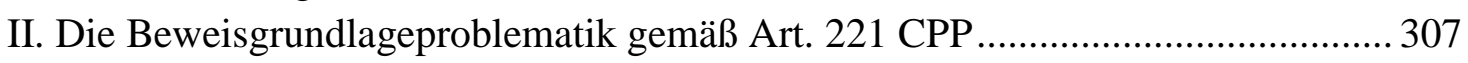

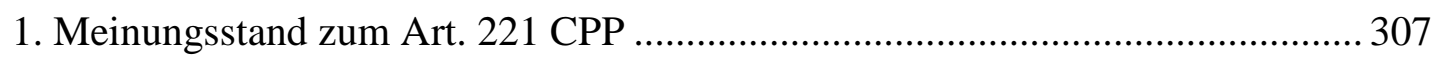

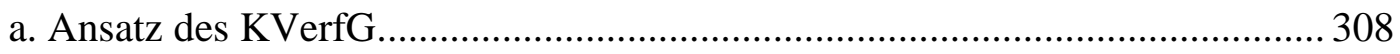

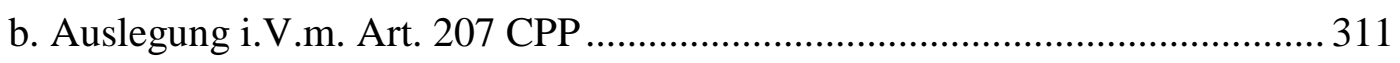

2. Kritische Überlegung zu Beweismitteln gem. Art. 221 CPP ............................. 313

a. Die eidesstattliche Erklärung von Zeugen oder Informanten .......................... 315

b. Bericht der Kriminalpolizei.................................................................. 317

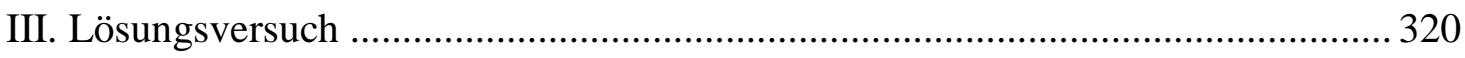

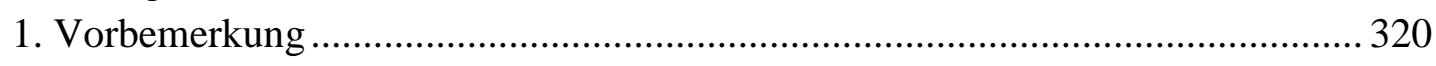

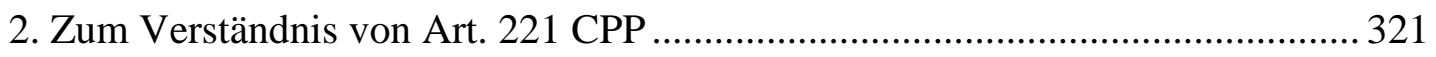

a. Diskussionsbasis eines restriktiven Ansatzes .............................................. 321 
b. Zur Beweisbegründung von ,motivos fundados“،......................................... 324

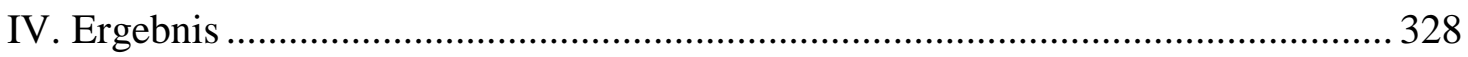

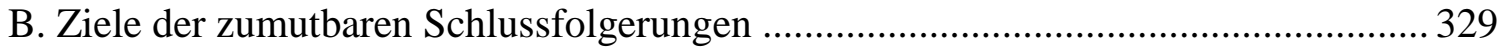

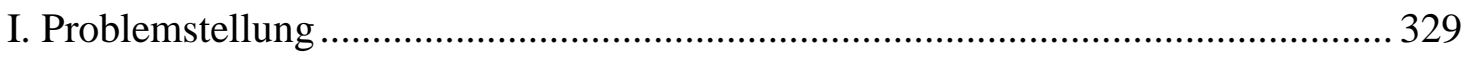

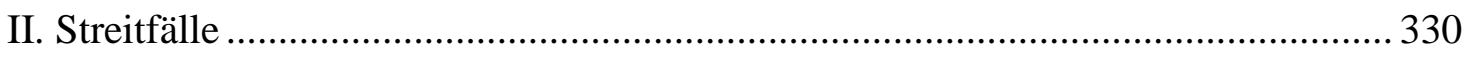

1. Zumutbare Schlussfolgerungen bzgl. der Begehung von Straftaten ................... 332

2. Zumutbare Schlussfolgerungen über das Vorhandensein von tauglicher

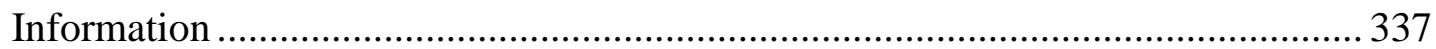

3. Kritische Überlegung zu Schlussfolgerungen im CPP ..................................... 340

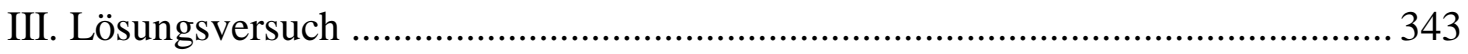

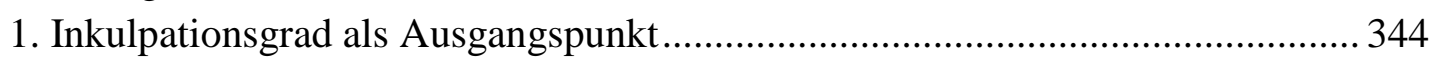

2. Bestimmbarkeit der Tauglichkeit von Informationen ..................................... 346

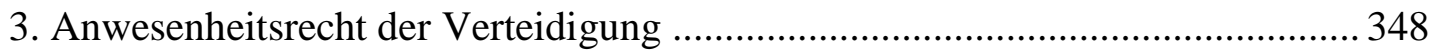

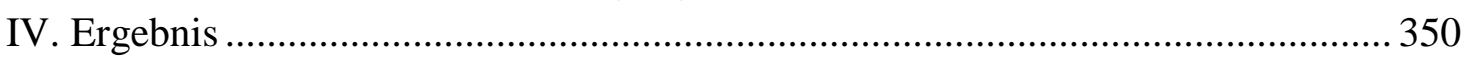

C. Effektive richterliche Kontrolle der ,motivos fundados"? ...................................... 351

I. Polizeiliche Vormachtstellung in der Bestimmung der ,, motivos fundados““.......... 351

II. Die unzureichende Überprüfung von Ermittlungen ........................................... 354

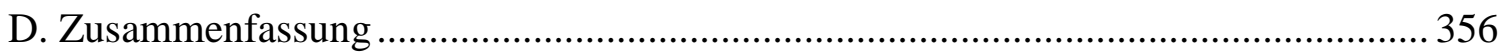

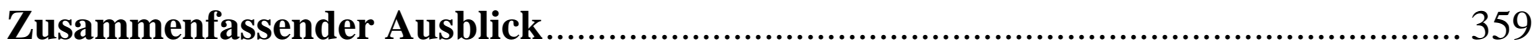

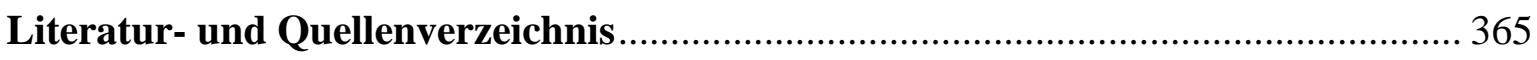

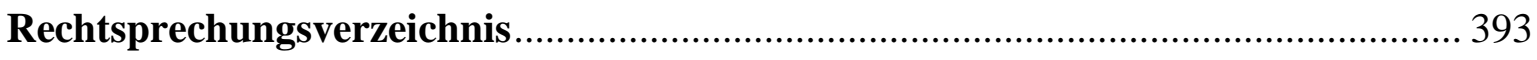

Anlage 1: Der Gang des Strafverfahren (Gesetzt 906 v. 2004) ........................................ 398

Anlage 2: Übersicht über den Ermittlungsmaßnahmen im kolumbianischen

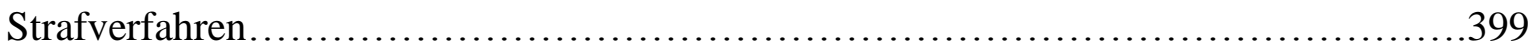




\begin{abstract}
Abkürzungsverzeichnis
Die im Rahmen dieser Arbeit verwendeten Abkürzungen orientieren sich grundsätzlich an den Vorgaben von Kirchner, Abkürzungsverzeichnis der Rechtssprache 7. Aufl., Berlin u.a., De Gruyter, 2013. Die im Literaturverzeichnis aufgeführten kolumbianischen Zeitschriften sowie Organisationen und Einrichtungen sind in der Arbeit durch die Angabe der Anfangsbuchstaben der Namen zitiert. Auf folgende Abkürzungen wird besonders hingewiesen:
\end{abstract}

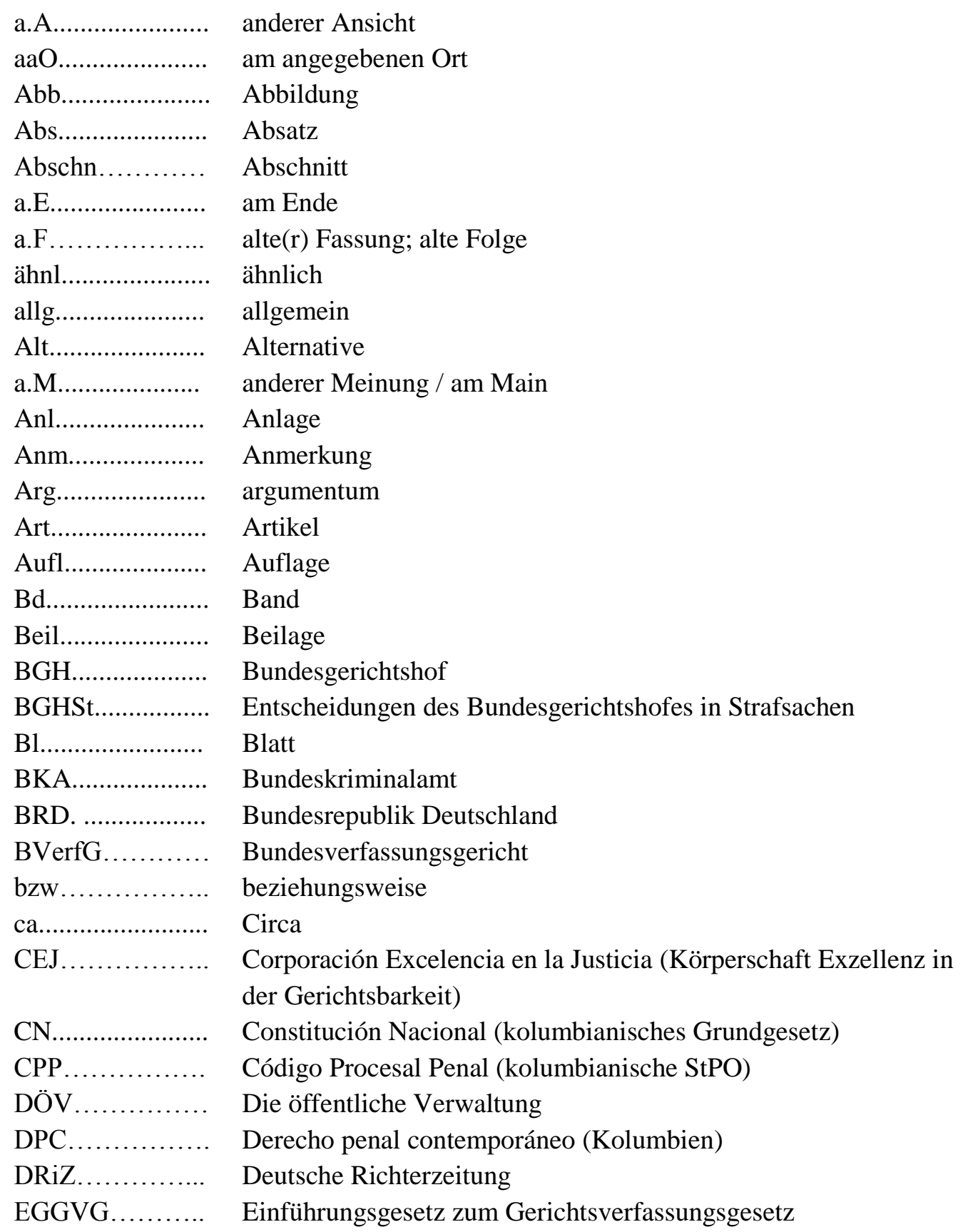




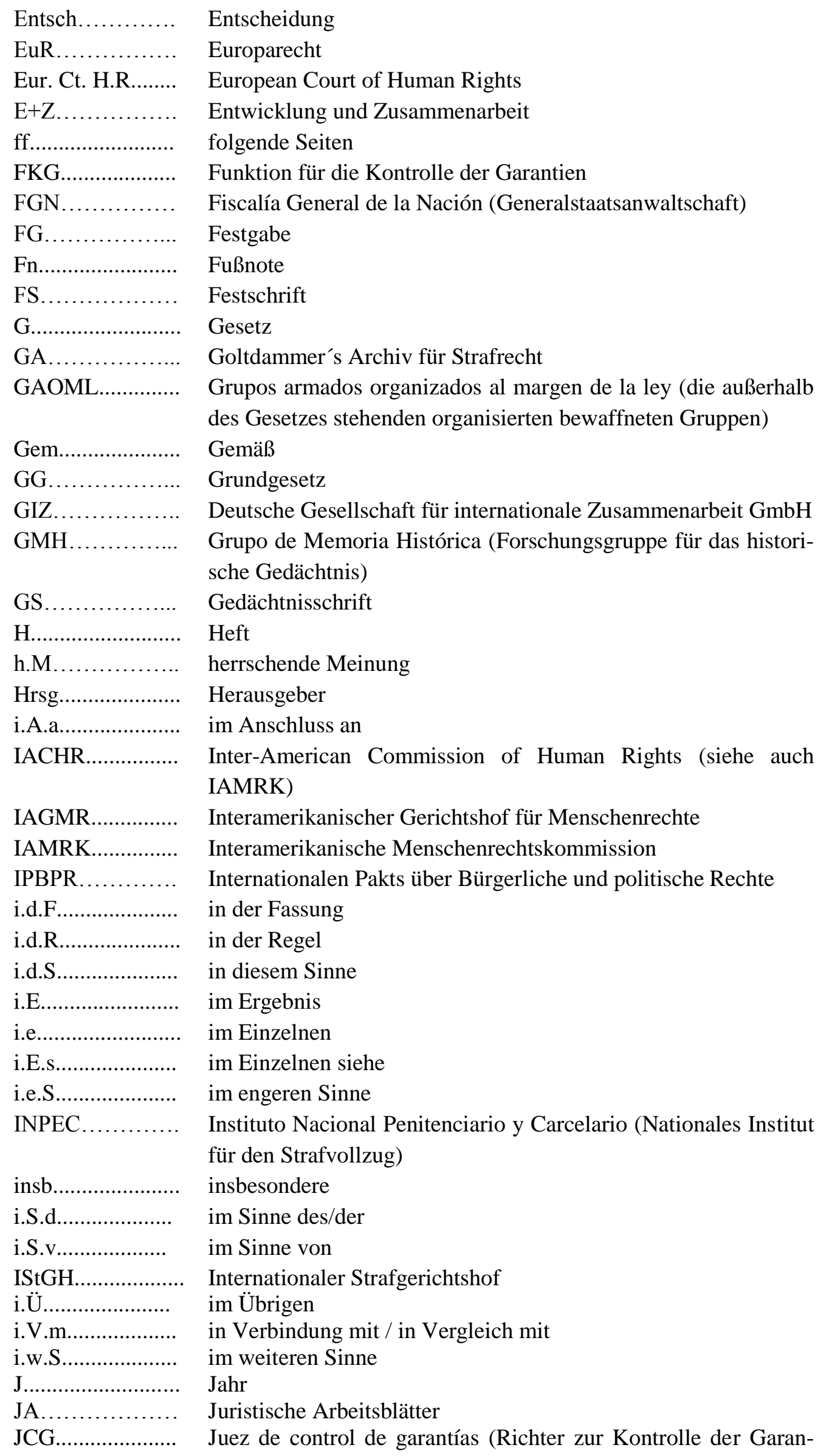




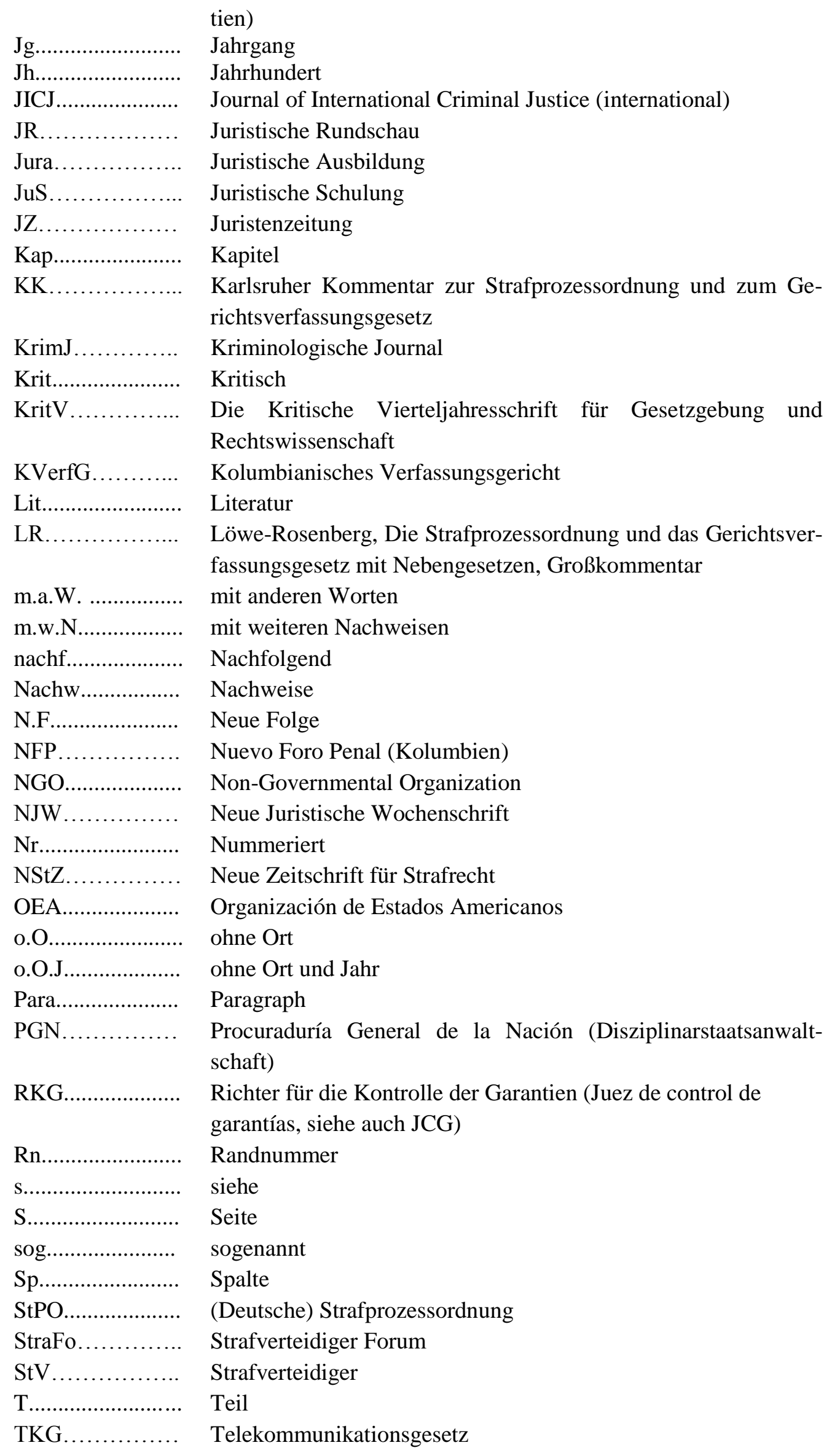




\begin{tabular}{|c|c|}
\hline USA........................ & United States of America \\
\hline u.a.......................... & unter anderen \\
\hline U-Haft.................... & Untersuchungshaft \\
\hline Usw......................... & und so weiter \\
\hline u.U..... & unter Umständen \\
\hline Verf... & Verfasser; Verfahren \\
\hline VerfG............. & Verfassungsgericht \\
\hline $\mathrm{Vgl} \ldots \ldots . .$. & Vergleich \\
\hline VN... & Vereinte Nationen \\
\hline VwGO.................... & Verwaltungsgerichtordnung i. d. F. v. 16.08.2001 \\
\hline $\mathrm{zB} \ldots \ldots \ldots \ldots \ldots \ldots \ldots \ldots$ & zum Beispiel \\
\hline ZIS......................... & Zeitschrift für Rechtspolitik \\
\hline ZRP. & Zeitschrift für internationale Strafrechtsdogmatik \\
\hline ZStW...................... & Zeitschrift für die gesamte Strafrechtswissenschaft \\
\hline z.T........................ & zum Teil \\
\hline Zust......................... & Zustimmung \\
\hline Zutr......................... & zutreffend \\
\hline Zw......................... & zweifelnd; zweifelhaft \\
\hline
\end{tabular}




\section{§1. Einleitung: Der richterliche Rechtsschutz im Ermittlungsverfahren}

\section{A. Begriff des richterlichen Rechtsschutzes}

\section{Vorbemerkung}

Das strafrechtliche Ermittlungsverfahren lässt sich als ein Szenario beschreiben, in dem sich die Spannung zwischen den Grundrechten des Strafverdächtigen und dem Interesse an der Durchführung einer effektiven Strafverfolgung bzw. das Verhältnis von Staat und Individuum widerspiegelt, da die Beweiserhebung im Rahmen der staatlichen Wahrheitssuche durch die Ermittlungshandlungen intensive Grundrechtseingriffe auslöst. ${ }^{1}$ Aus diesem Grund ist die Mitwirkung eines unabhängigen Dritten, eines Richters, an dem Anordnungsverfahren entscheidend, um das staatliche Übergewicht zu beschränken. Die Kontrollbefugnis, die dem Richter zugewiesen ist, konkretisiert das Rechtsstaatsprinzip und stellt eine Basis für die Ausbalancierung des Machtsystems dar. Bzgl. der Ausführung des ius puniendi ist nicht nur die Unabhängigkeit des Richters zur Lösung eines Falls charakteristisch. Es ist auch entscheidend, dass die Gerichtsbarkeit die Beachtung der Grundrechte des Strafverdächtigen gewährleistet, weil sich hierdurch ihre Legitimation bestimmt. Eine weitere Ausprägung des Rechtsstaatsprinzips ist dadurch gegeben, dass die Gerichtsbarkeit an Gesetz und an die Wahrheitsforschung bei der Entscheidung eines konkreten Falls gebunden ist. ${ }^{2}$

Der Wirkungsbereich der richterlichen Kontrolle von staatlichen Grundrechtseingriffen stellt jedoch ein Diskussionsfeld dar, in welchem die Intensität des Einschreitens des Richters in die Ermittlungshandlungen schwerpunktmäßig erörtert wird und gegenteilige Ansichten vertreten werden. Einerseits gibt es Auffassungen, die kein oder nur ein minimales richterliches Einschreiten unterstützen. Diese Ansichten beschreiben eine weniger liberale,

\footnotetext{
${ }^{1}$ Dazu ausführlich Eser (Hrsg.), 2004, S. 10 ff.; Als „ewige Spannung“ Sax/Grundrechte III/2, S. 909 f.; zur klassischen Polarität „effektive Strafrechtspflege und Schutz des Einzelnen“ vgl. Schoreit, DRiZ 1987, S. 464 ff.; Schwarz, Jura 2007, S. 334 ff.; s. auch Glaser, 2008, S. 1 f.; Warntjen, KJ 2006, S 276 f.; Gärditz, 2003, S. 83 ff.; dazu noch Roxin/Schünemann, 2014 § 2 Rn. 4; Hassemer 2009, S. 15 f; Hassemer, StV 1990, S. 328 ff.; zu den unterschiedlichen Begriffsbestimmungen der Wahrheit vgl. Stübinger, 2008, S. 392 ff.; Löffelmann, 2008, S. 23 f.; 98 f.; zu den wesentlichen Entwicklungslinien vom Strafrecht und der Kriminalpolitik an der Jahrtausendwende s. Hassemer, Jahrtausendwende 2000, S. 17 ff.;

2 Vgl. u.a. Jung, 2001, S. 18; Gössel, 2007, S. 21; bzgl. des Legalitätsprinzips im Strafverfahren vgl. Deiters, 2006, S. 113 ff.; Döhring, 1999, S. 78 ff.; den verfassungstheoretischen Grundlagen entsprechen andere im Strafverfahren verbindliche Grundsätze wie das Fairnessprinzip, das Offizialprinzip, das Akkusationsprinzip, das Legalitätsprinzip und der Ermittlungsgrundsatz, die die Durchführung der Strafverfolgung in der Ermittlungsphase bestimmen, dazu Roxin/Schünemann, 2014, § 2 Rn. 9; ausführlich Ferrajoli, 2004, S. 537 ff.
} 
dafür eine effektivitätsorientiertere Strafverfahrensauffassung, nach welcher der Richter wenn überhaupt - eine Abwägungsfunktion hinsichtlich der Nützlichkeit von Grundrechtseingriffen hat oder auch als ein dem Ermittlungsverfahren fremdes Subjekt bezeichnet wird. ${ }^{3}$ Dieser Ansicht steht die h.M. gegenüber, die eine solche Kontrolle als eine notwendige Überwachungsfunktion, als Ausdruck des modernen demokratischen Verfassungsparadigmas versteht, in dem der Richter den staatlichen Handlungsräumen Grenzen setzt und als Beschützer der Rechte des Individuums fungiert. ${ }^{4}$

Die letztgenannte Auffassung bezeichnet den richterlichen Rechtsschutz als eine Unerlässlichkeit zur Gewährleistung einer rechtsstaatlich geeigneten Ermittlungstätigkeit, welche die Überprüfung der Rechtsbeeinträchtigungen erfordert. Die richterliche Kontrolle stellt i.d.S. eine zum Rechtsschutz gegen ermittlungsstaatliche Rechtsüberschreitungen dienende besondere Garantie dar. Aus dieser Perspektive ist die richterliche Kontrolle ein besonderes Merkmal der modernen Strafverfahrenssysteme, welches die Wahrung der Grundrechte des Betroffenen und damit die Rechtmäßigkeit der Strafverfolgung gewährleisten soll. ${ }^{5}$

Als Rechtmäßigkeitsparameter lässt sich gerade an der richterlichen Ermittlungskontrolle deutlich das Leistungsvermögen der Strafverfolgungsbehörden bzgl. des Schutzes der Grundrechte bemessen. ${ }^{6}$ Darüber hinaus wird das Rechtskulturniveau eines bestimmten Strafverfolgungssystems bzgl. des Schutzes der Verfassung als Barriere gegen die Exzesse der Staatsmacht widergespiegelt. ${ }^{7}$ Durch diese Begrenzungsleistung kommt die klassische Funktion des Richters als Schützer der Grundfreiheiten zum Ausruck. Die vorbehaltene richterliche Mitwirkung bestimmt zugleich die Unterordnung des staatlichen Machtsapparats unter den Richter hinsichtlich der Durchsetzung von Ermittlungsmaßnahmen.

\footnotetext{
${ }^{3} \mathrm{Zu}$ der Problematik der Abwägung zwischen Effektivität der Strafrechtspflege und Beschuldigtenrechte vgl. Patz, 2009, S. 106 ff.; dazu Orozco Abad/Gómez Albarello 1999, S. 54 ff.; i.d.S. und bzgl. der Verdachtsdogmatik Zabel ZIS 7-8/2014, S. 341, 346. Für das Problem der Güterabwägung Löffelmann, 2008, S. 110 ff.; zu den Entwicklungslinien der Marginalisierung der Unabhängigkeit der dritten Gewalt im System des Strafrechts vgl. Fornauf, 2010, S. $99 \mathrm{ff}$.

${ }^{4}$ Vgl. Roxin/Schünemann, 2014, § 6 Rn. 1; Sachs/Degenhart, 2014, Art. 101 GG Rn. 5 ff.; zu den historischen Grundlagen des gesetzlichen Richters in europäischen Staaten s. Bohn, 2011, S. 19 ff.; Seif, 2003, S. 81 ff.; dazu ausführlich Ferrajoli, 2010, S. 11 f.; auch Guerrero Peralta 2006, S. 21 f ; Aponte Cardona 2006, S. 23.

${ }^{5}$ Vgl. ausführlich Ferrajoli 2004, S. 537 ff.; s. auch Glaser, 2008, S. 6 f.; Hassemer 1997, S. 63 ff.; Gössel 2007, S. $21 \mathrm{ff}$.

${ }^{6}$ Vgl. Ferrajoli 2004, S. 574-603; Zuluaga Co-Herencia Vol 4 Nr. 6, S. 135.

${ }^{7}$ I.d.S. Roxin/Schünemann, 2014, § 2 Rn. 1 (,Das Strafverfahrensrecht ist der Seismograph der Staatsverfassung."); Hierzu vgl. Noltenius, ZStW 122 (2010), S. 604 ff.; Sax/Grundrechte III/2, S. 909 ff.; BVerfGE 32, 373 [383]. 


\section{Begriff}

\section{Allgemeines Verständnis}

Obwohl die richterliche Mitwirkung zum Schutz von Grundrechten gegen Zwangsmaßnahmen eine zentrale Bedeutung für die Rechtsstaatlichkeit der Strafverfolgung hat, beinhaltet diese Kennzeichnung kein umfassendes konzeptionelles Verständnis unter Zugrundelegung von verfassungs- und strafverfahrensrechtlichen Verankerungen. Die Versuche einer Begriffsbestimmung, die mit allgemeiner Gültigkeit die Bedeutung und die Verwendung des Begriffes des Rechtsschutzes im Ermittlungsverfahren umfasst, liefern kaum weiterführende Aufschlüsse. ${ }^{8}$ Die Bildung einer allgemeinen begrifflichen Erläuterung trifft sich auf dogmatischem Wege mit normativen Einschränkungen. Die verfassungsrechtlichen Stellungen der Rechtsschutzgarantie und der richterlichen Instanz, die die Erscheinungsform und Wirkungsweise der Ermittlungsverfolgung bestimmen, zeigen ebenso Unterschiede im Vergleich zwischen den Rechtssystemen. ${ }^{9}$

Vergeblich ist auch die Suche nach einer umfassenden Regelung in den verschiedenen Strafprozessordnungen, aus denen sich eine begriffliche Umschreibung herleiten lässt. In der deutschen StPO sind die Regelungen des Rechtsschutzes gegen strafprozessuale Grundrechtseingriffe während des Ermittlungsverfahrens unübersichtlich. ${ }^{10}$ Darüber hinaus finden sich geregelte Rechtsmittel, die nach dem EGGVG und nach der VwGO die Möglichkeit einräumen, den Betroffenen vor strafprozessualen Grundrechtseingriffen zu schützen. ${ }^{11}$ Diese Lage wurde durch die Rechtsprechung entsprechend der Vorgaben des BVerfG behoben, um die Lückenhaftigkeit der gesetzlich differenzierten Regelungen zu beseitigen. ${ }^{12}$ Dadurch wurde mithilfe der Rechtsprechung eine Vereinheitlichung des verteilten Rechtsmittelsystems nicht nur gegen bevorstehende und noch andauernde Ermitt-

\footnotetext{
${ }^{8}$ Bachmann, 1994, S. 50; i.d.S. Prechtel, 1995, S. 1 bzgl. des Begriffs des Ermittlungsrichters.

${ }^{9}$ Für die verfassungsrechtlichen Verankerungen in den Mitgliedstaaten der EU siehe Tonne, 1997, S. 47 ff.; Haratsch, 2007, S. 15 ff.; auch aus einer rechtsvergleichenden Perspektive Nijboer, in Doran/Jackson (Hrsg.) 2000, S. 24-26; dazu auch Guerrero Peralta, 2007, S. 177-187.

${ }^{10}$ I.d.S. Hartmann/Schmidt, 2016, S. 266; Roxin/Schünemann, 2014, § 29 Rn. 11; Volk/Engländer, 2013, § 10 Rn. 75 (ebd. in der span. Fassung, s. Volk, 2015); Kühne, 2015, § 32 Rn. 553; Kindhäuser, 2016, § 29 Rn. 2; Krey, 2006, S. 496; zu den Entwicklungsstufen des Rechtsschutzes gegen strafprozessuale Grundrechtseingriffe in Deutschland s. Amelung, BGH-FS (2000), Bd. IV, S. 911 ff.

${ }^{11}$ Deshalb kann die deutsche Regelung des Rechtsschutzes gegen Eingriffe im Ermittlungsverfahren als lückenhaft bezeichnet werden. Vgl. Laser, NStZ 2001 S. 124; zugleich Volk/Engländer, 2013, § 10 Rn. 75 (ebd. in der span. Fassung, s. Volk, 2015).

${ }^{12}$ Vgl. BVerfGE 96, 27 = NJW 1997, 2165 ff.; dazu Laser, NStZ 2001, S. 121.
} 
lungsmaßnahmen, sondern auch gegen bereits erledigte Anordnungen geschaffen. ${ }^{13} \mathrm{Ob}$ wohl die Rechtsprechung die unübersichtliche Gesetzeslage moniert hat, sind Reformvorschläge nicht umgesetzt worden. ${ }^{14}$

Ein Einblick in die verschiedenen Strafprozessrechtssysteme des kontinentaleuropäischen Rechtskreises bietet zudem keinen einheitlichen Bezugspunkt hinsichtlich der richterlichen Rechtsschutzsystematik. Verglichen mit den einzelnen Verfahrensarten anderer Länder finden sich nicht nur große Unterschiede zu der deutschen StPO, sondern die Lage des Rechtsschutzes ist vergleichsweise nicht besser reguliert. In Ländern wie Belgien, Frankreich und Holland sind Themen wie die gerichtliche Zuständigkeit, Verteidigungsrechte und die Polizeikontrolle im Ermittlungsverfahren noch zu reformieren. ${ }^{15}$ Auf der EUEbene ist der Stand des Rechtsschutzes nicht besonders hoch. Eine andere Beurteilung des Rechtsschutzsystems ist auch nicht möglich aufgrund der durch den Vertrag von Lissabon vorgenommenen Änderungen, welche zweifelhafte Dienste zum Schutz der Rechte zu leisten scheinen. ${ }^{16}$ Die gleiche Problematik besteht bei den latinoamerikanischen Strafprozessordnungen, obwohl ein großer Teil der Länder die AMRK unterzeichnet hat und es zahlreiche völkerrechtliche Übereinkommen zum Schutz der Menschenrechte gibt. ${ }^{17}$ Bei den lateinamerikanischen Verfassungen gilt in der Regel das Fairnessprinzip (Art. 8 AMRK) und es gibt zahlreiche Vorschriften, die auf den Schutz der Individualsphäre durch die Bestimmung der Unverletzbarkeit der persönlichen Freiheit, den Schutz von Brief-, Post- und

\footnotetext{
${ }^{13}$ Vgl. BVerfGE 96, 44 ff. = NJW 1997, 2165 ff.; BVerfG NJW 1998, 2131 f.; BVerfG Beschl. v. 5.5.2000 2 BvR 2212/99 <juris>; s. auch Krack, Jura 2001, S. 737 ff.; Jozik/Kunze, Jura 1990, S. 296 ff; zum Rechtsschutz gegen bereits erledigte Anordnungen in Kolumbien s. ausführlich infra § 5. Nachträglicher Rechtsschutz gegen Maßnahmen zur Beschränkung der Intimität und § 6. Nachträglicher Rechtsschutz gegen Maßnahmen zur Beschränkung der Unverletzlichkeit der Kommunikation und der Freiheit.

${ }^{14}$ Vgl. Kühne, 2015, § 32 Rn. 553 mit Fn. 2 m.w.N.

${ }^{15}$ Vgl. Nijboer, in Doran/Jackson (Hrsg.) 2000, S. 29. Für andere EU-Mitgliedstaaten s. Tonne, 1997, S. 47 ff, zusammenfassend S. 142 f. Zur historischen Entwicklung polizeilicher Aufgabenwahrnehmung im Kontext versammlungsspezifischer Vorfeldmaßnahmen in Europa s. Steinforth, 2015, S. 47 ff.; bzgl. der Ausdehnung von Ermittlungsmethoden im europäischen Strafprozessrecht vgl. ausführlich Hauck, 2015, S. 17 ff.

${ }^{16}$ Vgl. Kotzur, EuR-Bei 1 2012, S. 7; auch Thiele, EuR 2010, S. 30 ff.; Everling, EuR-Bei 1 2009, S. 71; Schröder, DÖV 2009, S. 61 ff.; Obwexer 2009 S. 237 ff.; Schima, 2009, S. 325 ff. Für die Darstellung des Grundrechtsschutzes in Europa als kooperative Arbeit s. Haratsch, 2007, S. 15 ff.; zur historischen Entwicklung des Rechtsschutzes in Deutschland und in der EU Weiß, 2011, S. 9 ff. Für einen Überblick des Ermittlungsrichters bei den Gerichten in der EU und die Regelung des Richtervolbehaltes s. Hecheltjen, 2007, S. 10 ff.

${ }^{17}$ Durch die AMRK wurden die Unterzeichnerstaaten verpflichtet, die Bestimmungen der Konvention auf alle Personen unter der Jurisdiktion dieser Staaten anzuwenden. Siehe die grundlegenden Übereinkommen des Inter-Amerikanischen Menschenrechtssystems hier: http://www.oas.org/en/iachr/mandate/basic_documents.asp. (zuletzt geprüft am 30.05.2016). 
Fernmeldegeheimnis und des Hausrechts zielen, die nur ausnahmsweise aufgrund eines Gesetzes beeinträchtigt werden dürfen. Dennoch sind die Rechtseingriffskompetenzen der Staatsanwaltschaft in einigen Ländern ausgedehnt. ${ }^{18}$

Allerdings gibt es eine generelle Tendenz, im Richter einen Grundrechtsschützer zu sehen, weil er als rechtsprechendes Kontrollorgan gegenüber der Staatsanwaltschaft im Ermittlungsverfahren dient, soweit die unter Richtervorbehalt stehenden Grundrechtseingriffe von ihm angeordnet werden. ${ }^{19}$ In diesem Sinne hebt sich der richterliche Rechtsschutz im Ermittlungsverfahren durch die Grenzbestimmung von Ermittlungshandlungen der Staatsanwaltschaft und Polizei ab. ${ }^{20}$ Aus dieser Perspektive wird der richterliche Rechtsschutz als Schutzfunktion zur Wahrung der Grundrechte des Strafverdächtigen bzw. als Grenze der Intensität von Grundrechtseingriffen verstanden. ${ }^{21}$ Es geht um eine Beschränkung der Ermittlungshandlungen, mit denen die Grundrechte verletzt oder gefährdet werden können. Aufgrund dessen versteht man gemeinhin den Rechtsschutz als den gerichtlichen Schutz gegen Rechtsbeeinträchtigungen. ${ }^{22}$ Damit ist gemeint, dass sich die von den Gerichten ausgeübte staatliche Entscheidungs- und Zwangsgewalt zur Verwirklichung von Ansprüchen oder Rechtspositionen des Einzelnen zur Verfügung stellt. ${ }^{23}$ Ein dazu passendes Verständnis des Rechtsschutzes wird in verschiedenen Auffassungen im Schrifttum vertreten, in denen die Anrufung des Gerichts mit dem Rechtsschutzbegriff verbunden wird. ${ }^{24}$

\footnotetext{
${ }^{18}$ Vgl. Ambos, 2009, S. 249; Maier/Ambos/Woischnik, 2000, S. 849; bzgl. der Ausdehnung heimlicher Ermittlungsmethoden im europäischen Strafprozessrecht vgl. Hauck, 2015, S. 17 ff.; Hamm, StV 2001, S. 81 ff. Für eine vergleichende Analyse des polizeilichen Ermessens auf der europäischen Ebene siehe Jehle, 2006, S. 20 ff.; zum Einfluss der Polizei auf die Entscheidung der Staatsanwaltschaft Schlachetzki, 2003, S. 45 ff.; zu einer Rechtsvergleichung der rechtlichen Rahmenbedingungen in den USA und Deutschland s. Lützner, 1999, S. 27 ff., 281 ff. und im Rahmen des Schutzes der persönlichen Freiheit (Deutschland-Schweiz) Premissl, 2008, S. 34 ff.; zur Entwicklung der Erweiterung der staatsanwaltschaftlichen Sanktionskompetenz in Deutschland s. Hüls, 2007, S. 186 ff.; auch Jasch, 2003, S. 98 ff.

${ }^{19}$ Im Gegenteil zur Leistung als Amtshilfe für die Staatsanwaltschaft vgl. Brüning, ZIS 7/2008 S. 343 f.; zur Problematik der gerichtlichen Kontrolle des staatsanwaltschaftlichen Ermittlungsverfahrens in seiner Gesamtheit siehe Rieß, FS Geerds 1995, S. $501 \mathrm{ff}$.

${ }^{20}$ Vgl. Menger, 1954, § 17, S. 55; Stephan, 1967, S. 60; aus straftheoretischer Sicht Ferrajoli, 2004, S. 537 ff.; zum Verhältnis von Staatsanwaltschaft und Polizei siehe u.a. Schlachetzki, 2003, S. 45 ff.; Schröder, 1996, S. 55 ff.; Rüping, ZStW 95 (1983), S. 894 ff.

${ }^{21}$ Brüning, 2005, S. 81; Lin, 1998, S. 244; Ferrajoli, 2004, S. 578 f; Guerrero Peralta, 2006, S. 42.

${ }^{22}$ Vgl. Hölscher, 2001, S. 11; Bachmann, 1994, S. 50; Lorenz, 1973, S. 1; Menger, 1954, S. 55.

${ }^{23}$ Stephan, 1967, S. 60; dieses Verständnis liefert Stoff zur Verwendung des Begriffes in einem umfassenderen Sinn, siehe z.B. Peter, 1985, S. 116: „umfassendes System von Ansprüchen, Rechten und Schutzeinrichtungen".

${ }^{24}$ Vgl. Roxin/Schünemann, 2014, § 29 Rn. 12 f.; Bachmann, 1994, S. 51 und Fn. 126 m.w.N.
} 


\section{Differenzierte Begriffsbestimmungen}

Ein allgemeines Verständnis des Rechtsschutzbegriffs ist noch nicht gegeben, wenn es um die subjektive und materielle Reichweite und die Art und Weise des Rechtsschutzes geht. Eine abstrakte Ausgestaltung findet sowohl normative als auch methodische Beschränkungen, da einerseits die Ziele und Verankerungen in jedem Rechtssystem verschieden sind und sich andererseits die Strafverfahren unterschiedlich durchsetzen. Aus diesem Grund richten sich die Versuche einer Begriffsbestimmung grundsätzlich auf eine Differenzierung des formellen und materiellen Sinns des Rechtsschutzes. ${ }^{25}$ Mithilfe dieser konzeptuellen Trennung wird zunächst die formelle Vorstellung verbunden, nach welcher der Schutz seitens des Rechts, d.h. des objektiven Rechts oder der subjektiven Rechte, gewährleistet wird. Dieses Verständnis erkennt zwei Formen des Schutzes: einerseits in einem engeren Sinn, nach dem der Rechtsschutz mittels des Justizapparats bzw. der gerichtlichen Tätigkeit verbürgt wird, und andererseits in einem weiteren Sinn, wonach außergerichtliche Stellen rechtlich schützen dürfen. ${ }^{26}$ Diese formelle Erfassung des Rechtsschutzes stellt die Rechtsdurchsetzung, d.h. das Prozessrecht, über das materielle Recht, jedoch folgt daraus kein Verzicht auf die materielle Seite des Rechtsschutzes, da die Interessen der Einzelnen nach diesem Standpunkt nur im Zusammenhang mit der Gesamtheit der Regelungen bzw. Normen (materielles Recht) geschützt werden können. Im Unterschied zum Schutz im formellen Sinn findet sich der Schutz durch das Recht (im materiellen Sinn). ${ }^{27}$

Die als Rechtsschutz im formellen Sinn bezeichnete Auffassung gewährleistet bei Rechtsverletzungen durch die öffentliche Gewalt den Weg zu den Gerichten ${ }^{28}$ und findet in der Regel ihre Verankerung in der Rechtsweggarantie. Die Rechtsweggarantie wird auch als Rechtsschutzgarantie bezeichnet, weil sie den Schutz des Rechts durch Kontrollinstanzen bzw. durch die Gerichte gewährleistet. ${ }^{29}$ Neben dieser formellen Bezeichnung wird aber

\footnotetext{
${ }^{25}$ Vgl. Hebrok, 2007, S. 113 ff.; Hölscher, 2001, S. 11; Bachmann, 1994, S. 51 ff.; Welp, 1976, S. 10; Lorenz, 1973, S. 1; Dütz, 1970 S. 9; Stephan, 1967 S. 41.

26 Vgl. Bachmann, 1994, S. 51; Lorenz, 1973, S. 1 und Fn. 1 m.w.N.; Dütz, 1970, S. 9; Bettermann/Grundrechte III/2, S. 779.

${ }^{27}$ Bachmann, 1994, S. 51; Lorenz, 1973, S. 1; zum materiellen Rechtsschutz s. auch Fn. 2 m.w.N.

${ }^{28}$ Vgl. Sachs/Sachs, 2014, Art. 19 GG Rn. 11; Hebrok, 2007, S. 113 ff.; Hölscher, 2001, S. 11 Fn. 58 m.w.N; Lin 1998, S. 66; Bachmann, 1994, S. 51; Köster, 1992, S. 46; Lorenz, 1973, S. 1; Kalsbach, 1967, S. 5 f.

${ }^{29}$ Rabe von Kühlewein, 2001, S. 274; Bachmann, 1994, S. 51; Buermeyer, 1975, S. 12 f.; zu den Leitlinien der Rechtsschutzgarantie des Art. 19 Abs. 4 GG s. u.a. Michael, 2016, § 29 Rn. 866 ff.; SchmidtBleibtreu/Hofmann/Henneke/Hofmann, Art. 19 GG Rn. 30 ff.; Mangoldt/Klein/Starck/Huber, Art. 19 GG Rn. 331 ff.; Pieroth/Schlink, 2014, § 26 Rn. 1095 ff.; Mittag, 2009, S. 186 ff.; Brüning, 2005, 126 ff.; Voßkuhle, 1993, S. 146 ff.; Schenke, JZ 1988, S. 317 ff.; Lorenz, Jura 1983, S. 393 ff.; Fezer, Jura 1982, S. 18 ff. 
auch vom Rechtsschutz im materiellen Sinn gesprochen, der den Schutz menschlicher Interessen durch das Recht bzw. Normen des materiellen Rechts beinhaltet. ${ }^{30}$ Entsprechend dazu unterscheidet man zwischen Primär- und Sekundärrechtsschutz. Diese beiden Formen des Rechtsschutzes zielen darauf ab, einerseits entweder die Rückgängigmachung oder Vorbeugung der Rechtsbeeinträchtigungen und -verletzungen zu bewirken oder andererseits die Schäden auszugleichen. ${ }^{31}$

Das gebräuchlichste Verständnis vom Rechtsschutz ist dasjenige im formellen Sinn. ${ }^{32}$ Dieses umschließt zwei Funktionsformen. Einerseits den sog. repressiven Rechtsschutz, der nach der bereits eingetretenen Rechtsverletzung eingreift. Diese Art des Rechtsschutzes knüpft zunächst an die Verletzung eines Rechts an, die durch die rechtswidrige Anordnung oder Vollziehung einer Staatstätigkeit begangen wurde. ${ }^{33}$ Vom repressiven Rechtsschutz wird der sog. präventive Rechtsschutz unterschieden, der vor noch nicht eingetretenen, jedoch bereits drohenden Rechtsverletzungen schützt. ${ }^{34}$ Der präventive Rechtsschutz kann durch verschiedene Formen ausgestaltet werden: zum einen durch die Zulassung vorbeugender Klagen und Anträge, zum anderen durch die Mitwirkung eines Richters im Anordnungsverfahren eines Grundrechtseingriffes in Form des Vorbehaltes einer richterlichen Entscheidung (Richtervorbehalt). ${ }^{35}$

Gewöhnlich wird in den Verfahrensordnungen repressiver Rechtsschutz als Musterrechtsschutz aufgenommen, d.h., dem Rechtsschutz Suchenden wird zuerst das Abwarten der ihn belastenden Anordnung abverlangt, um sich daraufhin an die Gerichte wenden zu kön-

\footnotetext{
${ }^{30}$ Vgl. Hebrok, 2007, S. 123 ff.; Hölscher, 2001, S. 12; Lorenz, 1973, S. 1.

${ }^{31}$ Vgl. Tonne, 1997 S. 33, nach dem formeller und materieller Sinn dem Primär- und Sekundärrechtsschutz entsprechen und eine solche Einordnung in den Mitgliedstaaten der EU unterstützt wird; s. auch Fn. 28 m.w.N.

${ }^{32}$ Hebrok, 2007, S. 113; Hölscher, 2001, S. 11 mit Fn. 61 m.w.N.; Rieß/Thym, GA 1981, S. 189; Amelung, NJW 1979, S. 1687; Schenke, NJW 1976, S. 1816.

${ }^{33}$ Vgl. Scholz, VVD StRL 34 (1976), S. 155 (prinzipiell repressiver Gerichtsschutz); Lorenz, 1973, S. 136 und Fn. 1 m.w.N.; Arndt, FG-Schmid (1962), S. 13; Menger, 1954, S. 136. Für einen Überblick über die Rechtsfolgen fehlerhafter Eingriffe s. Benfer/Bialon, 2010, S. $413 \mathrm{ff}$.

${ }^{34}$ Hebrok, 2007, S. 113 ff.; Hölscher, 2001, S. 12; Bachmann, 1994, S. 51; Welp, 1976, S. 10 f.; Lorenz, 1973, S. 126; Stephan, 1967 S. 41.

${ }^{35}$ Hölscher, 2001, S. 12; Bachmann, 1994, S. 52; Welp, 1976, S. 11; zur Entstehung und Systematik des Richtervorbehalts s. Rabe von Kühlewein, 2001, S. 27 ff.; Rabe von Kühlewein, GA 2002 S. 637 ff.; Müller, 2009, S. 50 ff.; Talaska, 2007, S. 25 ff.; Brüning, 2005, S. 81 ff.; Gusy, GA 2003, S. 672 ff.; Lin, 1998 , S. 210 ff.; Roxin, StV 1997, S. 654 ff.; Hilger, JR 1990, S. 485 ff.; Hilger, Meyer GS (1990), S. 209 ff.; Kintzl, DriZ 2004, S. 83 ff.; zur Entwicklung des Richtervorbehalts im Verhaftungsrecht Ollinger, 1997, S. 32 ff.
} 
nen. ${ }^{36}$ Der präventive Rechtsschutz durch die Zulassung vorbeugender Klagen hingegen ist dem Strafprozessrecht in seiner Allgemeinkonzeption eher fremd. ${ }^{37}$ Das Strafverfahrensrecht bestimmt lediglich ausnahmsweise vorbeugende Klagen oder Anträge und sieht im Gegenteil dazu in einer großen Anzahl Richtervorbehalte vor. Die zahlreich geschaffenen Richtervorbehalte werden teilweise als unvermeidlich vorgeschrieben angesehen, womit die grundsätzliche Wahlfreiheit des Gesetzgebers restringiert wird. Verfassungsrechtlich umfasst der Richtervorbehalt einerseits die rechtsprechende Tätigkeit und andererseits die Fälle der Anordnungen von Grundrechtseingriffen. ${ }^{38}$

Eine ähnliche Rechtsschutzauffassung findet sich auch in anderen Rechtssystemen. Der italienische giudice per le indagini preliminari übt beispielsweise eine Garantie- und Kontrollfunktion aus, die aufgrund seiner Entscheidungsbefugnisse als richtervorbehaltene Funktion ausgeübt werden darf. ${ }^{39}$ Der Rechtsschutz bedeutet richterliche Kontrolle derjenigen Ermittlungshandlungen, die in Grundrechte eingreifen. Die Grundrechtseingriffe sollen vom Richter entschieden werden, um auch die verfassungsrechtlichen Zwecke des Strafverfahrensrechts zu schützen. ${ }^{40}$ Vergleichbar ist die kolumbianische Ansicht bzgl. des richterlichen Rechtsschutzes, der ebenfalls als eine vorbehaltene Richterfunktion angesehen wird. Die Kontrolle von Ermittlungshandlungen durch den Richter zur Kontrolle der Garantien (Juez de Control de Garantías) dient der Überprüfung der Einhaltung der Rechte und der Gewährleistung verfassungsrechtlich geschützter Garantien des Straftatverdächtigen im Rahmen der Beweiserhebung zur Wahrheitssuche. Der JCG überprüft Ermittlungshandlungen auf ihre Recht- und Verfassungsmäßigkeit und entscheidet letztendlich über die Zulässigkeit von solchen Ermittlungshandlungen, die zu Grundrechtseingriffen führen. ${ }^{41}$ Die kolumbianische Rechtsschutzkonzeption hat ihre verfassungsrechtliche Veranke-

\footnotetext{
${ }^{36}$ Hebrok, 2007, S. 113; Bachmann, 1994, S. 51; Lorenz, 1973, S. 136 und Fn. 2 m.w.N.; Arndt, FG-Schmid (1962), S. 13.

37 Vgl. Hebrok, 2007, S. 114; Bachmann, 1994, S. 52; Bei Roxin/Schünemann, 2014, § 29 D II 1 hier wird der präventive Rechtsschutz als Rechtsschutz vor Erledigung der Maßnahme verstanden.

${ }^{38}$ Müller, 2009, S. 113 ff.; Talaska, 2006, S. 54; Brüning, 2005, S. 123; Rabe von Kühlewein, 2001, S. 53; Lin, 1998, S. 216.

${ }^{39}$ Maiwald, 2009, § 17 I 1; Ferraioli, 2001, S. 94.

${ }^{40}$ Ferraioli, 2001, S. 94; ähnl. Guerrero Peralta, 2007, S. 183.

41 Guerrero Peralta, 2007, S. 41; Bernal/Montealegre, 2004, S. 160; vgl. ausführlich infra $\S$ 4. Der Richter zur Kontrolle der Garantien (Juez de Control de Garantías). 
rung in Art. 250 der Verfassung, der die Kompetenzen des JCG im Rahmen seiner grundrechtsschützenden Funktion normiert. ${ }^{42}$

Aus diesem Begriffsüberblick lässt sich allg. erkennen, was unter dem richterlichen Rechtsschutz verstanden werden kann. Daher ist wichtig hervorzuheben, dass der Schutz durch den Richter gegen Rechtsbeeinträchtigungen, der gemeinhin als Rechtsschutzbegriff bezeichnet wird, seine besondere Bedeutung einerseits durch seine verfassungsrechtliche Verankerung und andererseits durch die verschiedenen Ausgestaltungsformen erhält. Verfassungsrechtlich ist der richterliche Rechtsschutz eine Kontrollinstanz der Zwangsmaßnahmen bzw. eine Schutzinstanz für den Straftatverdächtigen gegen die Grundrechtseingriffe, daher wird er als Garantie bezeichnet. Dabei wird der Rechtsschutz auch als Instrument verstanden, das die notwendige Balance zwischen der Effektivität der Ermittlungshandlungen und dem Rechtsschutz des Verdächtigen schafft. Zusammengefasst ist der richterliche Rechtsschutz eine Schutzgarantie, die ein legitimes Ermittlungsverfahren sichert und eine Balance zwischen Effektivität und Rechtsschutz ermöglicht.

\section{B. Überblick über die Erscheinungsformen des Rechtsschutzes}

Der Rechtsschutz im formellen Sinn sieht zwei Formen der richterlichen Einschaltung vor. Der präventive Rechtsschutz wird erstens grundsätzlich mit einer Anordnungsentscheidung eines Grundrechtseingriffs durchgesetzt, die in der Regel dem Richter vorbehalten ist. Der repressive Rechtsschutz wird zweitens durch Rechtsbehelfe, die sich primär nach der Art der Zwangsmaßnahme unterscheiden (Beschwerde und Antrag auf richterliche Entscheidung), durchgesetzt. Drittens ist der nachträgliche Rechtsschutz zu nennen, der grundsätzlich durch ein Bestätigungsverfahren der Grundrechtseingriffe durchgeführt wird. Der Rechtsschutz im materiellen Sinne wird durch verschiedene Kautelen und Schutzvorkehrungen gewährleistet, wie z.B. die Anwesenheitsrechte vom Beschuldigten oder Verteidiger, Zeugnisverweigerungsrechte oder die Belehrungspflicht der Strafverfolgungsorgane. ${ }^{43}$

\section{Rechtsschutz im formellen Sinn}

\section{Der präventive Rechtsschutz durch Richtervorbehalte}

Beim präventiven Rechtsschutz geht es um die Abschreckung vor Rechtsverletzungen bzw. die Bereitstellung einer richterlichen Mitwirkung gegen die noch nicht eingetretenen,

\footnotetext{
${ }^{42}$ Vgl. dazu infra § 3. A. I. Verfassungsrechtliche Grundlagen des Ermittlungsverfahrens.

${ }^{43}$ Vgl. dazu Hebrok, 2007, S. 124; Bachmann, 1994, S. 56.
} 
aber bereits drohenden Rechtsverletzungen. ${ }^{44}$ Der im Strafprozessrecht gewährte präventive Rechtsschutz unterscheidet sich von dem im Verwaltungsrecht angebotenen vorbeugenden Rechtsschutz. ${ }^{45}$ Es handelt sich nicht um eine einstweilige Rechtsgwährung, falls ein besonderes Rechtsschutzbedürfnis des Klägers nach vorbeugendem Rechtsschutz besteht. ${ }^{46}$ In einer sich davon unterscheidenden Weise wird im Strafprozessrecht eine antizipierte Mitwirkung des Richters angeboten, von dem die Durchführung einer Ermittlungsmaßnahme angeordnet werden muss. Die richterlichen Anordnungen von bestimmten Ermittlungsmaßnahmen entsprechen den sog. „Richtervorbehalten“, die zum Teil durch das Grundgesetz zwingend vorgeschrieben werden. ${ }^{47}$

Im deutschen Rechtssystem finden sich verfassungsrechtliche Richtervorbehalte, die zum einen gem. Art. 92 GG nur von Richtern wahrgenommen werden dürfen ${ }^{48}$, und zum anderen bzgl. der Anordnungen von Wohnungsdurchsuchungen ${ }^{49}$ und Freiheitsentziehungen ${ }^{50}$, die ebenfalls (grundsätzlich) dem Richter vorbehalten sind ${ }^{51}$ und sich nach ihrer Umsetzung in der StPO wiederfinden lassen ( $§ 105$ Abs. 1 bzw. 114, 125 StPO). Daneben sieht die StPO auch andere Richtervorbehalte für den Erlass bestimmter Maßnahmen vor. ${ }^{52}$ Das Anordnungsrecht steht zunächst dem Organ zu, das die Befugnis bzw. Erlaubnis hat, die Ermittlungsmaßnahme durchzusetzen. Die Anordnung ist damit die Rechtsgrundlage der Rechtseingriffe. Wenn es eine solche Anordnung nicht gäbe, wäre die Maßnahme rechtswidrig und die Beweise unverwertbar. ${ }^{53}$

\footnotetext{
${ }^{44}$ Hölscher, 2001, S. 12; Bachmann, 1994, S. 51; Welp, 1976, S. 10 f.; Bettermann/Grundrechte III/2, S. 781.

${ }^{45}$ Vgl. Bachmann, 1994, S. 52., nach dem im Verwaltungsrecht grundsätzlich dem repressiven Rechtsschutzmodell gefolgt wird.

${ }^{46}$ Bachmann, 1994, S. 52 und Fn. 133 m.w.N.

${ }^{47}$ Vgl. dazu Wildhagen, 2011, S. 42 ff.; Müller, 2009, S. 20 f.; Talaska, 2007, S. 54 ff.; Brüning, 2005, S. 123 ff.; Rabe von Kühlewein, 2001, S. 79 ff.; Bachmann, 1994, S. 52 ff.; bzgl. des Richtervorbehalts s. supra Fn. 29 m.w.N.

${ }^{48}$ Bachmann, 1994, S. 64; zur gesetzlichen Grundlage vgl. Müller, 2009, S. 113-168; Gusy, JZ 1998, S. 167 ff.

49 Bzgl. der Regeln für Wohnungsdurchsuchungen und ihrer Änderung durch die Rechtsprechung des BVerfG siehe Rabe von Kühlewein, NStZ 2015, S. 618 ff.; die Ausdehnung des Eingriffs in das Wohnungsgrundrecht wurde schon als Tendenz in der Rechtsprechung dargestellt, siehe Amelung, StV 2001, S. 132.

${ }^{50}$ Für die allgemeinen Anforderungen des GG und bzgl. des Art. 104 GG vgl. Heidebach, 2014, 124 ff., 197 ff.

${ }^{51}$ Art. 13 Abs. 2 GG bzw. Art. 104 Abs. 2 S. 1 GG sehen die Einschaltung des Richters vor dem tatsächlichen Eingriff vor. Zum Eingriff unter Richtervorbehalt s. Maunz/Dürig/Papier, 2016, Art. 13 GG Rn. 21 ff.; Sachs/Kühne, 2014, Art. 13 GG Rn. 27 ff., jeweils m.w.N.

${ }^{52}$ Müller, 2009, S. 23 ff.; Bachmann, 1994, S. 64; Lin, 1998, S. 250 f.

${ }^{53}$ Benfer/Bialon, 2010, S. 416 ff.; Hölscher, 2001, S. 22; Prechtel, 1995, S. 66; Bachmann, 1994, S. 56 f. 
Ebenso entwickelt das kolumbianische Rechtssystem zwei Ebenen der Verankerung des Grundsatzes des Richtervorbehalts. Einerseits werden die Richtervorbehalte auf der Verfassungsebene in den Art. 28, 30 und $32 \mathrm{CN}$ eingeführt, welche die Beschränkungen der persönlichen Freiheit beinhalten. Neben diesen Artikeln enthält die Verfassung in Art. 250 die bedeutendste Regelung des Grundsatzes der Richtervorbehalte und führt die Figur des Richters zur Kontrolle der Garantien (Juez de Control de Garantías) ein. ${ }^{54}$ Aufgrund dieser Norm ist der JCG für die Rechtmäßigkeitskontrolle von Hausdurchsuchungen, Beschlagnahmen und Abhörmaßnahmen von der Staatsanwaltschaft (Art. 250 Nr. 2 CN) und für die Maßnahmen zur Beschränkung der Freiheit verantwortlich (Art. 250 Nr. 1 CN). Andererseits empfängt und entwickelt der CPP jeden dieser Grundrechtseingriffe. ${ }^{55}$

Der Richter kann auf unterschiedliche Weise in das Anordnungsverfahren eingeschaltet werden. ${ }^{56}$ Es ist zu unterscheiden, wann im Laufe des Anordnungsverfahrens eine richterliche Tätigkeit ausgeübt wird. Die Mitwirkungshandlung des Richters im Anordnungsverfahren einer Zwangsmaßnahme lässt sich nach Art, Inhalt, Zweck, Wirkung und Kreis der handlungsbefugten Personen differenzieren und untergliedern. ${ }^{57}$ Grundsätzlich werden in der Strafverfahrenslehre zwei Einschaltungsmöglichkeiten unterschieden: die Fälle des Richtervorbehalts und das richterliche Bestätigungsverfahren. ${ }^{58}$ Die präventiven richterlichen Mitwirkungshandlungen bestehen einerseits aus Anordnungen und andererseits aus nachträglichen Bestätigungen. $\mathrm{Zu}$ den vorherigen Mitwirkungshandlungen sind diejenigen Fälle zu zählen, in denen der Richter im Rahmen der Anordnung von Grundrechtseingriffen zu einer Entscheidung aufgefordert wird. Handelt es sich hingegen um nachträgliche Mitwirkungshandlungen, entscheidet der Richter erst nach der Anordnung einer Zwangsmaßnahme durch einen staatsanwaltschaftlichen bzw. polizeilichen Antrag. ${ }^{59}$ Die richterliche Bestätigung kommt dann einer ex nunc Entscheidung der noch nicht beendeten Ermitt-

\footnotetext{
${ }^{54}$ Vgl. infra § 4. Richter zur Kontrolle der Garantien (Juez de control de Garantías).

${ }^{55}$ Dies soll an anderer Stelle thematisiert werden. Vgl. infra § 5. Nachträglicher Rechtsschutz gegen Maßnahmen zur Beschränkung der Intimität und $\S$ 6. Nachträglicher Rechtsschutz gegen Maßnahmen zur Beschränkung der Unverletzlichkeit der Kommunikation und der Freiheit.

${ }^{56}$ Glaser, 2008, S. 17 ff.; Talaska, 2007, S. 54 f.; Rabe von Kühlewein, 2001, S. 410.

${ }^{57}$ Vgl. Prechtel, 1995, S. 65; Brüning, 2005, S. 150 f; Hellamnn, 2006, § 5.

${ }^{58}$ Vgl. u.a. Brüning, 2005, S. 150 f., 166 f., 184 f.; Hölscher, 2001, S. 22 ff.; Prechtel, 1995, S. 128 f., 157 f.

${ }^{59}$ Brüning, 2005, S. 73-75; Hölscher, 2001, S. 13; Lin, 1998, S. 43; Prechtel, 1995, S. 65.
} 
lungshandlung gleich. ${ }^{60}$ Sowohl auf die Anordnungskompetenz als auch auf den nachträglichen richterlichen Rechtsschutz wird nachher ausführlich eingegangen. ${ }^{61}$

\section{Der repressive Rechtsschutz durch Rechtsbehelfe}

\section{a. Rechtsmittel}

Gegen bereits eingetretene Rechtsverletzungen kommen zahlreiche Rechtsbehelfsmöglichkeiten in Betracht. ${ }^{62}$ Dieser Weg ist schon wegen Artikel 8 AEMR anerkannt. Gemeint ist also der „Anspruch auf einen wirksamen Rechtsbehelf bei den zuständigen innerstaatlichen Gerichten gegen Handlungen, durch die seine ihm nach der Verfassung oder nach dem Gesetz zustehenden Grundrechte verletzt werden“.63 Dieses Recht räumt die Möglichkeit ein, bei Rechtsverletzungen vor dem Gericht zu klagen, und spiegelt die Notwendigkeit wider, die Justizverwaltung umfassend zu kontrollieren. Die Rechtsmittel sind im strafrechtlichen Ermittlungsverfahren vor allem ein Überprüfungsmittel, mit dem die Übereinstimmung einer Ermittlungstätigkeit mit dem Gesetz oder mit der Verfassung von einem hierarchisch höheren Gericht bestimmt wird. ${ }^{64}$ Ziel dieser Bestimmung ist es, die Rechtskraft bzw. die Rechtmäßigkeit eines Grundrechtseingriffs, der entweder von dem Richter, der Staatsanwaltschaft oder der Polizei angeordnet wurde, ${ }^{65}$ festzulegen. Die Bestimmung der Entscheidungsbehörde gibt vor, welche Rechtsbehelfe in Betracht kommen.

Theoretisch besteht die Möglichkeit, dass der richterliche Rechtsschutz gewährt wird, wenn es Verfahrensfehler im Vorverfahren gibt, die zur Revision durch retrospektive Fehlerkompensation führen. ${ }^{66}$ Ein solcher Rechtsschutz liegt nicht hauptsächlich in der Revision selbst, sondern in der Anerkennung des Beweisverwertungsverbotes. ${ }^{67}$ Obwohl die Revision und auch die Berufung im Strafprozessrecht als Rechtsbehelfe gegen richterliche Entscheidungen vorgesehen sind, stellen diese beiden hinsichtlich der Rechtsschutzmöglichkeiten im Ermittlungsverfahren die weniger verwendeten Rechtmittel dar. Die Be-

\footnotetext{
${ }^{60}$ Vgl. Glaser, 2008, S. 228 ff.; Brüning, 2005, S. 184 f; Prechtel, 1995, S. 157 f.

${ }^{61}$ Vgl. infra $\S 1$ B. III. Der Richtervorbehalt als Rechtsschutzstandard und C. Der nachträgliche Rechtsschutz.

${ }^{62}$ Vgl. dazu Hebrok, 2007, S. 113 ff.; Hölscher, 2001, S. 13 f.; Köster, 1992, S. 85.

${ }^{63}$ Art. 8 AEMR verfügbar auf Deutsch unter http://www.un.org/depts/german/grunddok/ar217a3.html (zuletzt geprüft am 30.05.2016).

${ }^{64}$ Hebrok, 2007, S. 113; Hölscher, 2001, S. 24; zu den Rechtsbehelfen im Strafverfahren Pickenpack, 2012,

S. 5 ff.; Engländer, Jura 2010, S. 414 ff.;

${ }^{65}$ Hölscher, 2001, S. 24 ff.; Lin, 1998, S. 46, jeweils m.w.N.

${ }^{66}$ Hölscher, 2001, S. 25; Jäger, 2003, S. 93; Bachmann, 1994, S. 53.

${ }^{67}$ Hölscher, 2001, S. 24; i.d.S. Bachmann, 1994, S. 53. 
schwerde wird als das relevanteste repressive Rechtsmittel im Ermittlungsverfahren angesehen. ${ }^{68}$ Mithilfe der Beschwerde können alle Entscheidungen des Ermittlungsrichters beanstandet werden. ${ }^{69} \mathrm{Im}$ Strafprozessrecht besteht eine gemeinsame Ausgestaltung, nach der die Beschwerde unter zwei Prämissen eingelegt werden kann. Zunächst ist es notwendig, dass die Zwangsmaßnahme gerichtlich, d.h. vom Ermittlungsrichter, angeordnet wird. Zweitens soll die Beanstandung nicht nur die Art und Weise der Durchführung der Maßnahme, sondern auch die gerichtliche Anordnung als solche umfassen. ${ }^{70}$

${ }^{68}$ Bachmann, 1994, S. 53; Köster, 1992, S. 24; Ellersiek, 1981, S. 42.

${ }^{69}$ Burghardt, JuS 2010, S. 606; Hölscher, 2001, S. 24; Lin, 1998, S. 46 ff.; Bachmann, 1994, S. 53; Amelung, 1976, S. 19 ff.

${ }^{70}$ Vgl. Heimgartner, 2011, S. 365; Engländer, Jura 2010, S. 415; Kühne, 2015, Rn. 558 ff.; Bornmann, 2008, S. 46 ff., die beschreibt, wie die Beschwerde sich vom Rechtsmittel mit Wiederholungscharakter zum Rechtsmittel mit Überprüfungscharakter entwickeln könnte. 


\section{b. Sonstige Rechtsbehelfe}

Bzgl. einzelner staatsanwaltschaftlicher Ermittlungsmaßnahmen kommt in den Strafprozessordnungen ein besonderer Rechtsbehelf, d.h. der Antrag auf gerichtliche Entscheidung, in Betracht. Die richterliche Entscheidung darf beantragt werden, wenn der Grundrechtseingriff von der Staatsanwaltschaft oder den Ermittlungsbehörden angeordnet worden ist und die Art und Weise der Durchführung als Beanstandungsgegenstand tauglich ist. ${ }^{71}$ In der deutschen StPO sind Rechtsbehelfe beispielsweise in zweifacher Ausgestaltung vorgesehen. Einerseits gibt es diejenigen Rechtsbehelfe, die auf richterliche Entscheidung beim zuständigen Amtsgericht (Ermittlungsrichter) erhoben werden. ${ }^{72}$ Davon zu unterscheiden sind diejenigen Maßnahmen, für die die Landgerichte bzw. - in besonderen Ausnahmefällen - die Oberlandesgerichte oder gar der Bundesgerichtshof zuständig sind. ${ }^{73}$ Eine besondere Bedeutung für das Verständnis des Rechtsschutzes im Ermittlungsverfahren haben die rechtlich anerkannten Möglichkeiten, gegen eine staatsanwaltschaftliche Entscheidung im Rahmen der Ausnahmekompetenzen vorzugehen, da die Staatsanwaltschaft oder Ermittlungsbehörden aufgrund dieser Eingriffsbefugnisse den intensivsten Grundrechtseingriff ausführen dürfen. In diesem Zusammenhang stellt dieses repressive Rechtsschutzmittel die einzige Möglichkeit dar, eine Ermittlungsmaßnahme anzufechten.

Es ist festzustellen, dass der Rechtsschutz gegen Grundrechtseingriffe zusätzliche Erscheinungsmöglichkeiten aufweist. Einerseits ist besonders auf die Verfassungsbeschwerde im Zusammenhang mit Grundrechtsverletzungen im Vorverfahren hinzuweisen, im Rahmen derer es auch zugelassen ist, sich mithilfe eines Verfassungsgerichts gegen eine Verletzung von Grundrechten oder grundrechtsgleichen Rechten durch Akte der Staatsanwaltschaft oder Ermittlungsbehörden zu wehren. Die Gründe einer solchen Gestaltung der Verfassungsbeschwerde liegen erstens bei der Sicherung und Durchsetzung subjektiver Rechte und zweitens bei dem generalpräventiven Grundrechtsschutz und somit bei der Einhaltung

\footnotetext{
${ }^{71}$ Burghardt, JuS 2010, S. 607; Engländer, Jura 2010 S. 415; Kühne, 2015, Rn. 567; Kramer, 2009, S. 325 ff.; Hebrok, 2007, S. 120 f.; Hölscher, 2001, S. 25; Bachmann, 1994, S. 54;

${ }^{72}$ Hellmann, 2006, § 5 Rn. 177; Hölcher, 2001, S. 25; Nach Bachmann, 1994, S. 54 haben diese Fälle gemeinsam, dass es insbesondere um den Antrag gegen Maßnahmen mit Dauerwirkung geht.

${ }^{73}$ Hölscher, 2001, S. 26; Bachmann, 1994, S. 54; Hellmann, 2006, § 177 Rn. 5; Vgl. ausführlich Gläser, 2008, S. 43 ff., 121 ff. bzgl. § 98 Abs. 2 Satz 2 StPO. In Deutschland gibt es daneben einen generalklauselartigen § 23 EGGVG, der Rechtsschutz gegen Maßnahmen der Justizbehörden auf dem Gebiet der Strafrechtspflege gewährt und für den das Oberlandesgericht zuständig ist. Diese Rechtsschutzmöglichkeit tritt subsidiär zurück, sodass die Gerichte, die ordentlich entscheiden sollen, wegen anderer Verordnungen angerufen werden können. 
des objektiven Verfassungsrechts. ${ }^{74}$ Alle Grundrechtsträger dürfen die Verfassungsbeschwerde aufgrund der Verletzung eines Grundrechts erheben. Der Schutz der Grundrechte wird durch die Feststellung der Verfassungswidrigkeit eines Aktes der Ermittlungsgewalt oder durch die Aufhebung einer verfassungswidrigen Ermittlungsanordnung erreicht. ${ }^{75}$ Es geht dabei nicht um eine umfangreiche Überprüfung, sondern lediglich um eine Nachprüfung auf verfassungswidriges Handeln, die wegen der Subsidiarität des Verfassungsbeschwerdeverfahrens eingeschränkt ist. ${ }^{76}$ Andererseits kommen die sog. formlosen Rechtsbehelfe in Betracht, die eine innerdienstliche Selbstüberprüfung der Ermittlungsbehörden zur Folge haben. Im Ermittlungsverfahren werden die Gegenvorstellung und die Aufsichtsbeschwerde als formlose Rechtsbehelfe betrachtet, die durch ihre Formlosigkeit, Unmittelbarkeit und Unentgeltlichkeit gekennzeichnet sind. ${ }^{77}$

\section{Das Bestätigungsverfahren}

Im Falle des Rechtsschutzes mit nachträglichem Charakter können unterschiedliche Rechtsschutzmöglichkeiten berücksichtigt werden. Bei einem ausschließlichen oder grundsätzlichen Richtervorbehalt, mit dem ein Eingriff angeordnet wird, haben die Betroffenen die Möglichkeit, das in $\S \S 304 f f$. StPO normierte Rechtsmittel der Beschwerde zu nutzen. Falls eine antizipierte Kontrolle aufgrund der Ausnahmekompetenz der Staatsanwaltschaft oder ihrer Ermittlungspersonen nicht ausgeführt werden kann, kann entweder eine nachträgliche verpflichtende Herbeiführung des Richters von dem Beamten angeordnet werden oder eine mögliche Anrufung des Richters durch den Betroffenen erfolgen. Bei solchen nachträglichen Rechtsschutzmöglichkeiten wird zwischen zwei Modellen differenziert: dem Modell „,auf Antrag“ und dem Modell „,von Amts wegen“. ${ }^{78}$ Bei der richterlichen Bestätigung wird der Richter nach der Entscheidung der nicht richterlichen Strafverfolgungsbehörden, die im Rahmen der Ausnahmekompetenz getroffen und vollzogen wurde, tätig. Die richterliche Bestätigung wird dann nach dem Beginn, aber vor dem Ende des Grundrechtseingriffs getroffen. ${ }^{79}$ In der Literatur wird vertreten, dass die richterlichen Bestäti-

\footnotetext{
${ }^{74}$ Vgl. Hebrok, 2007, S. 122; Köster, 1992, S. 77.

${ }^{75}$ Hebrok, 2007, S. 122; Bachmann, 1994, S. 55.

${ }^{76}$ Hebrok, 2007, S. 122; Nach Hölscher, 2001, S. 26 ist es auch möglich, für den Betroffenen prinzipiell Dienstaufsichtsbeschwerde oder Gegenvorstellung zu erheben (allg. möglich).

77 Bachmann, 1994, S. 55 f., nach seiner Meinung ,gibt es keinen abschließenden Typenzwang der formlosen Rechtsbehelfe, vielmehr handelt es sich bei der üblichen Einteilung um eine empirisch gewachsene Systematisierung." (Fn. 149).

${ }^{78}$ Brüning, 2005, S. 186; Lin, 1998, S. 184; Prechtel, 1995, S. 158 jeweils m.w.N.

${ }^{79}$ Brüning, 2005, S. 184; Prechtel, 1995, S. 67.
} 
gungen bloß eine nachträgliche Durchführung der richterlichen Primärkompetenz darstellen, weshalb sie bzgl. ihrer Rechtsnatur als richterliche Anordnungen angesehen werden. ${ }^{80}$ Es wird hervorgehoben, dass die Bestätigungen durch einen unabhängigen und unbeteiligten Ermittlungsrichter ausgeübt werden müssen, um die Gesetzmäßigkeit bzw. Zulässigkeit und Rechtmäßigkeit der Fortdauer einer Maßnahme zu gewährleisten. Demnach stellen die richterlichen Bestätigungen Rechtsprechungsakte im materiellen und formellen Sinne dar, weil sie bestimmen, was rechtens ist und von einem unabhängigen Dritten in einem normierten Verfahren ausgesprochen werden. ${ }^{81}$

\section{Rechtsschutz im materiellen Sinn}

\section{Verfahrensrechtliche Kautelen und Schutzvorkehrungen}

Der Rechtsschutz wird im materiellen Sinn verstanden, wenn Individualinteressen durch das Recht geschützt werden sollen. Ein solches Individualinteresse stellt beispielsweise das Anwesenheitsrecht des Wohnungsinhabers im Falle einer Wohnungsdurchsuchung dar. Auch die Erforderlichkeit des Anfangsverdachts als Bedingung für die Anordnung einer Zwangsmaßnahme dient dem Schutz der Individualinteressen. Im Ermittlungsverfahren lassen sich zahlreiche verfahrensrechtliche Vorbehalte und Schutzvorkehrungen als Ausprägungen des Schutzes des Individualinteresses finden, wie beispielsweise die Belehrungspflichten der Strafverfolgungsorgane, die Zeugnisverweigerungsrechte, die Anwesenheitsrechte von Beschuldigten und Verteidigern etc. ${ }^{82}$

\section{Beweisverwertungsverbote}

Durch die Beweisverwertungsverbote hat die Gewährleistung des Rechtsschutzes eine zunehmende Unterstützung bekommen. ${ }^{83}$ Die Begründung von solchen Rechtsschutzformen ist noch umstritten, weil bisher noch nicht eindeutig geklärt ist, wie das Vorliegen von Beweisverwertungsverboten bzgl. einer Zwangsmaßnahme auf das Ermittlungsverfahren rückwirken kann. ${ }^{84}$

\footnotetext{
${ }^{80}$ I.d.S. Prechtel, 1995, S. 122; So auch Brüning, 2005, S. 187; Rabe von Kühlewein, 2001, S. $26,93$.

${ }^{81}$ Prechtel, 1995, S. 122; bzgl. des Rechtsprechungscharakters der richterlichen Anordnung vgl. Brüning, 2005, S. 81 ff.; Rabe von Kühlewein, 2001, S. 109 ff.

${ }^{82} \mathrm{Vgl}$. Hölscher, 2001, S. 12; Bachmann, 1994, S. 56.

${ }^{83}$ Vgl. Hebrok, 2007, S. 123 ff.; Schröder, 1992, S. 35; Amelung, 1990, S. 24 ff.; vgl. dazu auch Roxin/Schünemann, 2014, § 9 Rn. 22-23.

${ }^{84}$ Vgl. dazu Ambos, 2010, S. 40 ff.; Hölscher, 2001, S. 12 m.N. Fn. 71; Bachmann, 1994, S. 56 ff.; Knauth, JuS 1979, S. 339. 
Das Thema der Verwertungsverbote wird in der Regel im Hauptverfahren oder in der Revisionsinstanz berücksichtigt. Zurzeit ist aber erkennbar, dass die Verwertungsverbote auch im Vorverfahren eine wichtige Rolle spielen. ${ }^{85}$ Die Diskussionsrichtung umfasst nicht die Beweisproblematik im Sinne einer Überzeugungsbildung, es geht vielmehr um eine Verdachtsklärung, die weitere Ermittlungshandlungen begründen kann. ${ }^{86}$ Obwohl diesbezüglich zahlreiche Differenzen existieren, wird im Allgemeinen vertreten, dass eine Information, die einem Verwertungsverbot unterliegt, im Ermittlungsverfahren nicht als Grundlage für eine Anordnung zu einem Grundrechtseingriff dienen kann. ${ }^{87}$

\section{Der Richtervorbehalt als Rechtsschutzstandard}

Die Anordnungskompetenz, mit der ein Grundrechtseingriff durch den Richter erlaubt werden kann, kann in drei grundsätzliche Gruppen untergliedert werden. ${ }^{88}$ Zuerst ist die ausschließlich dem Richter vorbehaltene Anordnung bzw. der ausschließliche Richtervorbehalt zu nennen. Daneben finden sich Anordnungen, für deren Anweisung ebenfalls der Richter zuständig ist, die aber bei Gefahr im Verzug auch durch die Ermittlungsbehörden erlassen werden können. Solche Anordnungen werden als grundsätzlicher Richtervorbehalt mit Ausnahmekompetenz bezeichnet. Schließlich sind noch diejenigen Anordnungen anzuführen, für die die Ermittlungsbehörden eine besondere Entscheidungsbefugnis darüber haben, ob eine Gefahr im Verzug gegeben ist oder nicht.

\section{Der Richtervorbehalt im engeren Sinn}

Alle in der StPO vorgesehenen Eingriffe in Rechtsgüter eines Individuums haben auf die richterliche Anordnung zu erfolgen. Die vorbehaltene Richterentscheidung wird von der zuständigen vollziehenden Gewalt beantragt, damit eine Zwangsmaßnahme nach einer richterlichen Gestaltung ausgeführt werden darf. ${ }^{89}$ Durch den Richtervorbehalt wird gewährleistet, dass ein strafprozessualer Grundrechtseingriff zulässig bzw. rechtmäßig ist.

\footnotetext{
${ }^{85}$ Bachmann, 1994, S. 57 m.N. Fn. 53; Knauth, JuS 1979, S. 339; Amelung, 1990, S. 11.

${ }^{86}$ Für die Einordnung und historische Entwicklung des Richtervorbehalts siehe Aschmann, 1999, S. 27 ff.; auch Bachmann, 1994, S. 57; Rogall, ZStW 91 (1979), S. 1, 8.

${ }^{87}$ Hölscher, 2001, S. 13; Amelung, 1990, S. 70; dazu infra § 8. C. I. 1. Die Bedeutung des Anfangsverdachts. ${ }^{88}$ Müller, 2009, S. 14f; Lin, 1998, S. 39; Bachmann, 1994, S. 64 ff.; Hölscher, 2001, S. 14 ff.; Prechtel, 1995, S. 78 ff und Brüning, 2005, S. 73 sprechen von den konkurrierenden Kompetenzen als eine vierte Gruppe; Rabe von Kühlewein, 2001, S. 85 f. spricht von einem ausschließlichen Richtervorbehalt, von dem Richtervorbehalt mit Gefahrdelegation, von der vorherigen richterlichen Zustimmung und von dem Richtervorbehalt mit Delegationsbefugnis.

${ }^{89}$ Vgl. Müller, 2009, S. 20; Talaska, 2007, S. 36; Brüning, 2005, S. 73; Rabe von Kühlewein, 2001, S. 86; Prechtel, 1995, S. 75; Geppert, DRiZ 1992, S. 405 ff.
} 
Bei der Prüfung des staatsanwaltlichen Antrags auf Anordnung einer Zwangsmaßnahme werden die Ermittlungshandlungen bzw. die nichtrichterlichen Strafverfolgungsorgane kontrolliert und auch die Grundrechte, die mit dem Eingriff verletzt werden können, geschützt. ${ }^{90}$ Eine solche Einschaltung des Richters bewirkt, wie bereits erwähnt, einen präventiven Rechtsschutz, mit dem vor der staatsanwaltschaftlichen bzw. polizeilichen Ermittlungshandlung die Wahrung der Grundrechte und die Zulässigkeit bzw. Rechtmäßigkeit der Ermittlungshandlung abgesichert werden sollen.

In der StPO sind folgende Anordnungen, die einem solchen Richtervorbehalt unterliegen, vorgesehen: die Pressebeschlagnahme ( $\S \S 94,98,97$ Abs. 5 S. 2), die Untersuchungshaft (§ 112), die Anstaltsbeobachtung ( $\$ 81$ ), die körperliche Untersuchung bei einem Minderjährigen mit Zeugnisverweigerungsrecht ( $\$ 81$ c Abs. 5 S. 1), die vorläufige Entziehung der Fahrererlaubnis ( $\S 111 \mathrm{a})$, die Sicherstellung eines periodischen Druckwerkes ( $\S 111 \mathrm{~b}$, 111n Abs. 1 S. 1), das vorläufige Berufsverbot ( $\$ 132 \mathrm{a})$, die Rasterfahndung beim Pressedatenabgleich ( $\S 98$ a, 98b Abs. 1 S. 7, 97 Abs. 5 S. 2), der Einsatz technischer Mittel ( 100c Abs. 1 N. 3), die DNA-Analyse ( $\S 81 \mathrm{e}, 81 \mathrm{f}$ Abs. 1 S. 1) und die DNAIdentitätsfeststellung ( $\$ 81 \mathrm{~g}$, Abs. 3). Zum ausschließlichen Richtervorbehalt gehören sowohl die sonstigen richterlichen Haftentscheidungen (beispielsweise $\S \S 114 \mathrm{ff}, 128 \mathrm{ff}, 230$ StPO) als auch die Anordnung der einstweiligen Unterbringung ( $\$ 126 \mathrm{a}$ StPO). ${ }^{91}$

\section{Richtervorbehalt mit Ausnahmekompetenz}

Der Richtervorbehalt mit Ausnahmekompetenz umfasst unterschiedliche Anordnungsmöglichkeiten, die entweder durch den Richter oder die Staatsanwaltschaft sowie durch ihre Ermittlungspersonen bei Gefahr im Verzug wahrgenommen werden können. ${ }^{92}$ Die Ausnahmekompetenz des Richtervorbehalts besteht in den Fällen der Gefahr im Verzug, d.h. bei bestimmten Maßnahmen, die ohne den grundsätzlich vorgeschriebenen Richtervorbehalt durch die Staatsanwaltschaft oder durch ihre Ermittlungspersonen angeordnet werden können. Gefahr im Verzug liegt vor, wenn die vorherige Einholung der richterlichen Ent-

\footnotetext{
${ }^{90}$ Brüning, 2005, S. 77; Asbrock, ZRP 1998, S. 17 f.; vgl. ausführlich Rabe von Kühlewein, 2001, S. 271 ff.

${ }^{91}$ Vgl. Glaser, 2008, S. 21; Brüning, 2005, S. 73; dazu auch Hölscher, 2001, S. 14; Bachmann, 1994, S. 64 f.

92 Müller, 2009, S. 17; Lin, 1998, S. 40; Prechtel, 1995, S. 76; Brüning, 2005, S. 73; zum Verhältnis von richterlicher und staatsanwaltschaftlicher Anordnungskompetenz im Eilfall siehe Schnarr, NStZ 1991, S. 210 ff. 
scheidung den Erfolg der Maßnahme vereiteln oder gefährden würde. ${ }^{93}$ In diesen Fällen muss zwischen der Ausnahmekompetenz ausschließlich für die Staatsanwaltschaft und der Ausnahmekompetenz für die Staatsanwaltschaft und ihre Ermittlungspersonen unterschieden werden. ${ }^{94}$ Bei der Ausnahmekompetenz wird auch teilweise von Eilkompetenz gesprochen, womit jedoch kein sachlicher Unterschied gemeint ist. ${ }^{95}$

Es gibt zunächst Eingriffsbefugnisse, die nur der Staatsanwaltschaft zustehen. In diesen Fällen liegt dann keine Ausnahmekompetenz für die Ermittlungspersonen i.S.d. § 152 Abs. 2 GVG vor. ${ }^{96}$ Solche Ausnahmekompetenzen finden sich in der StPO mit der Anordnung der Leichenöffnung und der Ausgrabung einer Leiche (§ 87 Abs. 4 S. 1, 2), der Anordnung zum Abgleich und zur Übermittlung personenbezogener Daten (§ 98b Abs. 1 S. 1), der Postbeschlagnahme ( $(100$ Abs. 1), der Telefonüberwachung (§ 100b Abs. 1), der Gebäudedurchsuchung bei anderen Personen zur Ergreifung des Beschuldigten (§ 105 Abs. 1 S. 2), der Beschlagnahme und dem Arrest zur Sicherstellung von Verfalls- und Einziehungsgegenständen ( $§ 111$ e Abs. 1 S. 1), der Beschlagnahme ( $\$ 111$ n Abs. 1 S. 2), dem Erlass eines Steckbriefes ( $\$ 131$ Abs. 1) und der Vermögensbeschlagnahme bei Staatsschutzdelikten ( 443 Abs. 2). ${ }^{97}$ Bei diesen aufgeführten Maßnahmen ist zu beachten, dass eine richterliche Bestätigung der staatsanwaltlichen Anordnung nach 3 Tagen zwingend ist, damit jene nicht an Wirksamkeit verliert. ${ }^{98}$

Es gibt auch einen Richtervorbehalt mit einer Ausnahmekompetenz der Staatsanwaltschaft und ihrer Ermittlungspersonen. Damit sind Eingriffe gemeint, die von einem Richter angeordnet werden können, aber auch bei Gefahr im Verzug sowohl durch die Staatsanwaltschaft als auch durch ihre Ermittlungspersonen laut $§ 152$ Abs. 2 StPO veranlasst werden können. ${ }^{99}$ Es wird zwischen Maßnahmen, die keine richterliche Bestätigung erfordern, und

\footnotetext{
${ }^{93}$ Brüning, 2005, S. 179; Einmahl, NJW 2001, S. 1393 ff.; Rabe von Kühlewein, 2001, S. 193; Nelles, 1980, S. 122 ff.; bzgl. der Überprüfbarkeit von Gefahr im Verzug vgl. Ostendorf /Brüning, NJW 2001, S. 1121 und JuS 2001, S. 1063 ff.

${ }^{94}$ Lin, 1998, S. 40; Prechtel, 1995, S. 56 f; Brüning, 2005, S. 73.

${ }^{95}$ Lin, 1998, Fn. 72; Hilger, Meyer GS (1990), S. 209 ff.; krit. zur exzessiven Anwendung der Eilkompetenz (auch aus Sicht des BVerfG) Asbrock, KritV 1997, S. 258 ff.; die Kontrollwirkung des Richtervorbehalts wird auch in Frage gestellt, s. Krüger, DRiZ 2004, S. 247 ff.; Backes/Gusy, 2003, S. 123 f.

${ }^{96}$ Brüning, 2005, S. 73; Lin, 1998, S. 41.

${ }^{97}$ Vgl. dazu Lin, 1998, S. 41; Rabe von Kühlewein, 2001, S. 86; Bachmann, 1994, S. 67 f.

${ }^{98}$ Glaser, 2008, S. 23; Brüning, 2005, S. 73; Bachmann, 1994, S. 67; a.A. Hölscher, 2001, S. 23.

${ }^{99}$ Müller, 2009, S. 17; Lin, 1998, S. 41; Prechtel, 1995, S. 58; Helles, 1980, S. 19; zum Rechtsschutz gegen polizeiliche Maßnahmen vgl. Schoch, Jura 2001, S. 628 ff.; zur Begrenzung antizipierter Strafverfolgung durch den Anfangsverdacht siehe Rudolph, 2005, S. 168 ff.
} 
Grundrechtseingriffen, die in der StPO eine richterliche Bestätigung vorsehen, unterschieden. ${ }^{100}$ Keine richterliche Bestätigung ist in der StPO bei der Durchsuchung ( $\S 102,103$ Abs. 1 S. 1, 105 Abs. 1), der körperlichen Untersuchung (§ 81c, 81a), der Sicherstellung beweglicher Sachen ( $\S 111$ b, 111e Abs. 1), der Kontrollstellen (§ 111), der Öffentlichkeitsfahndung ( $\S 131 \mathrm{a}$ Abs. 3, 131c Abs. 1 S. 1) und der Veröffentlichung von Bildern ( $\S 131 \mathrm{~b}, 131 \mathrm{c}$ Abs. 1 S. 1) vorgesehen. Eine richterliche Bestätigung ist nicht zwingend notwendig etwa bei der Beschlagnahme ( $\S 94,98$ Abs. 2 S. 1) und der Sicherstellung ( $\S$ 111b, 111c abs. 2 S. 1). Eine zwingende Bestätigung ist in den Fällen der Sicherstellung nicht periodischer Druckwerke ( $\S 111$ b, 111n Abs. 1 S. 3), der Schleppnetzfahndung ( 163d), des Einsatzes technischer Mittel ( $§ 100$ c Abs. 1 Nr. 2, 100d Abs. 1), des Einsatzes eines verdeckten Ermittlers ( $\S \S 110 a, 110 b$ Abs. 2 S. 4) und der Veröffentlichung von Bildern in den Medien ( $\S 131$ c Abs. 2 S. 1) erforderlich. Der Zeitraum, in dem die Bestätigung einzuholen ist, beträgt eine Woche. ${ }^{101}$

Es existieren des Weiteren einige Maßnahmen, in deren Rahmen eine Konkurrenzsituation bzgl. ihrer Anordnungskompetenz herrscht. Es gibt keine vorrangige ermittlungsrichterliche Kompetenz, sondern es können Staatsanwaltschaft und Ermittlungsrichter nebeneinander zuständig sein, um über einen Grundrechtseingriff zu entscheiden. ${ }^{102}$ Die Maßnahme, für die in gleicher Weise der Richter und die nichtrichterlichen Strafverfolgungsbehörden originär anordnungsbefugt sind, sind in der StPO die Folgenden: Ausschreibung zur Festnahme (§ 131 Abs. 1) und Öffentlichkeitsfahndung (§ 131 Abs. 3). ${ }^{103}$

\section{Originäre Anordnungskompetenz der nichtrichterlichen Ermitt- lungsbehörden}

Darüber hinaus sind die Maßnahmen anzuführen, die in die ausschließliche Kompetenz der nichtrichterlichen Strafverfolgungsorgane fallen. Es gilt zwischen den originären Kompetenzen der Staatsanwaltschaft, der Polizei bzw. der Ermittlungspersonen und deren Ausnahmekompetenzen (bspw. bei Gefahr im Verzug) zu unterscheiden. ${ }^{104}$ Zum einen sind in

\footnotetext{
${ }^{100}$ Brüning, 2005, S. 73; Bachmann, 1994, S. 68.

${ }^{101}$ Brüning, 2005, S. 73; vgl. auch Glaser, 2008, S. 24; Rabe von Kühlewein, 2001, S. 86; Bachmann, 1994, S. 68 f.; Böse, FS Amelung (2009), S. 575 ff.

102 Brüning, 2005, S. 74; Prechtel, 1995, S. 78.

${ }^{103}$ Brüning, 2005, S. 74, bei der Öffentlichkeitsfahndung besteht keine originäre Anordnungskompetenz der Polizei, sondern eine Ausnahmekompetenz für Ermittlungspersonen i.S.d. § 152 Abs. 2 GVG mit 24 Stunden zur staatsanwaltlichen Bestätigung.

${ }^{104}$ Müller, 2009, S. 14f; Brüning, 2005, S. 75; Lin, 1998, S. 41; Prechtel, 1995, S. 78. 
der StPO die vorläufige Festnahme ( $(127)$, die erkennungsdienstliche Maßnahme ( $\$ 81 \mathrm{~b})$, die Identitätsfeststellung ( $§ 163$ b), der Einsatz technischer Mittel ( 100 c Abs. 1 Nr. 1) eingegliedert. Bei der Ausschreibung zur Festnahme (§ 131 Abs. 2) ist zu berücksichtigen, dass nur die Staatsanwaltschaft und ihre Ermittlungspersonen, aber nicht die Polizei für deren Anordnung zuständig sind. ${ }^{105}$ Zum anderen darf nicht nur die Staatsanwaltschaft anordnen, sondern auch die Ermittlungspersonen im Rahmen ihrer Ausnahmekompetenz bei Gefahr im Verzug, wobei aber zwingend eine staatsanwaltschaftliche Bestätigung eingeholt werden muss, damit die Anordnung wirksam bleibt. Dazu gehören in der StPO der Einsatz verdeckter Ermittler ( $\S$ 110a, 110b Abs. 1 S. 2), die Öffentlichkeitsfahndung ( $\S \S$ 131b, 131c Abs. 2 S. 2) und die längerfristige Observation ( $\$ 163$ Abs. 3 S. 2).

\section{Der nachträgliche Rechtsschutz}

\section{Das Modell „,auf Antrag“}

Bei dem Modell „,auf Antrag“ hat der Betroffene wegen einer aufgrund einer Ausnahmekompetenz angeordneten Maßnahme das Recht auf die Beantragung einer richterlichen Entscheidung, wodurch der Ermittlungsrichter nachträglich die Maßnahme kontrolliert. ${ }^{106}$ Folgende Vorteile dieses Modells sind hervorzuheben: Zum einen wird das Rechtsschutzinteresse des Betroffenen berücksichtigt, zum anderen wird ihm überhaupt die Möglichkeit der Anrufung des Richters eröffnet. Außerdem ist es dadurch möglich, dass das Gericht nicht in Fällen tätig werden muss, in denen der Betroffene ausreichend geschützt ist. ${ }^{107}$ Die StPO enthält nur zwei Vorschriften, die eine richterliche Bestätigung auf Antrag des Betroffenen vorsehen: $\S 98$ Abs. 2 S. 2 und $\S 111$ e Abs. 2 S. $3 .{ }^{108}$ Eine besondere Auseinandersetzung wird über die rückwirkende richterliche Kontrolle laut § 98 Abs. 2 S. 2 StPO der nichtrichterlichen Beschlagnahmeanordnung geführt. ${ }^{109}$ Zurzeit wird dazu tendiert, dass es möglich sei, in $\S 98$ Abs. 2 S. 2 StPO eine Rechtsgrundlage für den nachträglichen Rechtsschutz i.S.d. Art. 19 Abs. 4 GG gegen alle andauernden und erledigten Maßnahmen zu finden. „Dabei kann sowohl die Zulässigkeit der weiteren Aufrechterhaltung als auch rückwirkend die Rechtmäßigkeit der nichtrichterlichen Anordnung auf Antrag des Be-

\footnotetext{
105 Glaser, 2008, S. 25; Brüning, 2005, S. 75; Rabe von Kühlewein, 2001, S. 85 f.; Bachmann, 1994, S. 64.

106 Lin, 1998, S. 43; Brüning, 2005, S. 186; Hölscher, 2001, S. 22.

${ }^{107}$ Bachmann, 1994, S. 107; Lin, 1998, S. 43.

${ }^{108}$ Dazu ausführlich Glaser, 2008, S. 121 ff.; auch Brüning, 2005, S. 186; Lin, 1998, S. 42.

109 Vgl. ausführlich Glaser, 2008, S. 65 ff.; dazu auch Brüning, 2005, S. 189; Amelung, StV 2002, S. 163 ff.; Amelung, BGH-FS (2000), Bd. IV, S. 927 f.; Prechtel, 1995, S. 113 f.
} 
troffenen überprüft werden. ${ }^{\text {"110 }}$ Somit kann festgehalten werden, dass die richterliche Bestätigung auf Antrag des Betroffenen dem nachträglichen Rechtsschutz i.S.d. Art. 19 Abs. 4 GG dient. ${ }^{111}$

\section{Das Modell „,von Amts wegen“}

Bei dem Modell ,von Amts wegen“ handelt es sich um eine gesetzliche Pflicht der Staatsanwaltschaft binnen eines bestimmten Zeitraums die richterliche Bestätigung der jeweiligen Ermittlungshandlung einzuholen. Die Schutzmöglichkeit des Betroffenen bei beweissichernden Maßnahmen bleibt nach einer nichtrichterlichen Anordnung intakt. Der Richter entscheidet nicht rückwirkend über die Durchführung einer Maßnahme, sondern über ihre Aufrechterhaltung, was verfassungsrechtlich vorbehalten ist. Dabei wird das richterliche Bestätigungsverfahren, das von der Staatsanwaltschaft veranlasst wird, als eine Ausprägung des Richtervorbehalts bezeichnet. ${ }^{112}$ Das Modell „von Amts wegen“ ermöglicht auch im Ermittlungsverfahren, dass die verfassungsrechtlich normierten primären Anordnungskompetenzen des Richters und eine möglichst vollständige Wahrheitsermittlung in Fällen von Maßnahmen zur Beweissicherung ins Gleichgewicht gebracht werden. ${ }^{113}$ Bei diesem Modell wird eine richterliche Anordnung im Prinzip nicht durchgeführt, aber die Grundrechtseingriffe, die von dem nichtrichterlichen Strafverfolgungsorgan angeordnet wurden, können nur für eine bestimmte Zeit wirksam bleiben, weil die nichtrichterliche Ausnahmekompetenz nur vor zeitbedingten Beweisverlusten schützen soll. Deshalb ist bei der Wahrnehmung einer Maßnahme bei Gefahr im Verzug in Fällen einer nichtrichterlichen Ausnahmekompetenz zu beachten, dass die Zuständigkeit des Richters zur Anordnung einer Maßnahme nicht beseitigt wird. ${ }^{114}$

Auch bei dieser Art der Mitwirkung wird der Ermittlungsrichter erst aktiv, nachdem zuvor im Wege der Eilkompetenz eine Entscheidung der Staatsanwaltschaft oder der Polizei ge-

\footnotetext{
${ }^{110}$ Brüning, 2005, S. 186; zu einer verfassungskonformen Auslegung i.V.m. Art 19 Abs. 4 GG siehe Glaser, 2008, S. 241 ff.; vgl. auch Prechtel, 1995, S. 160 f.

111 Obwohl die in Art. 19 Abs. 4 GG verbürgte Inanspruchnahme von dem Rechtsschutz ohne Kenntnis des Betroffenen vom jeweiligen Eingriff nicht möglich ist, vgl. hierzu Eisenberg, NJW 1993, S. 85 ff.; zu dem Art. 19 Abs. 4 GG s. supra Fn. 29 m.w.N.; zum Rechtsschutz gegen den Richter bzw. Rechtsprechungsakte Hößlein, 2007, S. 180 ff.; Schenke, JZ 2005, S. 116 ff.; Voßkuhle, 1993, S. 146 ff.; zum Rechtsschutz gegen polizeiliche Maßnahmen vgl. Schoch, Jura 2001, S. $628 \mathrm{ff}$.

${ }^{112}$ Rabe von Kühlewein, 2001, S. 26; Lin, 1998, S. 43; Brüning, 2005, S. 187 („Der Richter entscheidet in eigener Verantwortung über die erneute Anordnung und damit über die Aufrechterhaltung des entsprechenden strafprozessualen Grundrechtseingriffs.")

${ }^{113}$ Rabe von Kühlewein, 2001, S. 93; Brüning, 2005. S. 187.

${ }^{114}$ Brüning, 2005, S. 187; Hölscher, 2001, S. 23; Prechtel, 1995, S. 159. 
troffen und vollzogen wurde. ${ }^{115}$ Dass das Antragsrecht für die richterliche Bestätigung nicht einheitlich geregelt ist, stellt eine Besonderheit der StPO dar. ${ }^{116}$ In jedem Fall soll die Staatsanwaltschaft in den Fällen, die einen strafprozessualen Grundrechtseingriff mit Dauerwirkung beinhalten, das Bestätigungsverfahren veranlassen. ${ }^{117}$ Die Mitwirkungsform der „Zustimmung“ wurde erstmals mit $§ 110$ b Abs. 2 StPO für bestimmte Einsätze eines verdeckten Ermittlers eingeführt. Obwohl Zustimmung im allgemeinen juristischen Sprachgebrauch eine vorherige Einwilligung im Gegensatz zur Genehmigung als nachträgliche Billigung bedeutet, ${ }^{118}$ kann sie dennoch - insofern sprachlich inkonsequent - nachträglich erfolgen, soweit Gefahr in Verzug besteht, sodass es sich in diesem Fall faktisch ebenfalls um eine richterliche Bestätigung handelt. ${ }^{119}$ Im Falle der Freiheitsentziehung i.S.d. Art. 104 Abs. 2 GG stellt die richterliche Bestätigung eine Entscheidung über ihr Fortbestehen dar. $^{120}$

Die Literatur nennt zwei Zwecke des richterlichen Bestätigungsverfahrens. Zum einen dient die richterliche Bestätigung dazu, die Rechte des Betroffenen i.S.d. Art. 19 Abs. 4 GG nachträglich zu schützen, insbesondere wenn das Bestätigungsverfahren auf Antrag des Betroffenen in Gang gebracht wird. ${ }^{121}$ Zum anderen soll beim Bestätigungsverfahren von Amts wegen die verfassungsrechtlich notwendige primäre Anordnungskompetenz des Richters bei beweissichernden Grundrechtseingriffen gewahrt werden. ${ }^{122}$

Der Prüfungsumfang des Ermittlungsrichters hängt von der Art der Maßnahme ab. ${ }^{123} \mathrm{Im}$ Gegensatz zu den präventiven Rechtskontrollen betreibt der Ermittlungsrichter bei den Ermittlungshandlungen, die bereits von der Staatsanwaltschaft vorgenommen wurden, nur eine Kontrolle mit eingeschränktem Prüfungsumfang. Er beschränkt sich auf die Zulässigkeit der Maßnahme im konkreten Fall. ${ }^{124}$ Dagegen richten sich verschiedene Meinungen, die damit argumentieren, dass $\S 98$ Abs. 2 S. 2 StPO die Möglichkeit eröffnet, auch rückwirkend Entscheidungen nicht nur über die Zulässigkeit, sondern auch über die Rechtmä-

\footnotetext{
115 Vgl. Brüning, 2005, S. 184; Hölscher, 2001, S. 193 ff.

${ }^{116}$ Vgl. Prechtel, 1995, S. 158; Bachmann, 1998, S. 103.

117 Vgl. Hellmann, 2006, Rn. 190; LR/Volker Erb, § 162 Rn. 8b.

118 Vgl. Prechtel, 1995, S. 67 m.w.N.

${ }^{119}$ Vgl. Brüning, 2005, S. 184; Rabe von Kühlewein, 2001, S. 92.

${ }^{120}$ Hölscher, 2001, S. 44; KK/Nack § 104 Rn. 6, § 105 Rn. 15 ff.

${ }^{121}$ Vgl. Hellmann, 2006, Rn. 185; Prechtel, 1995, S. 118.

${ }^{122}$ Brüning, 2005, S. 186; Prechtel, 1995, S. 18; Bachmann, 1994, S. 107.

${ }^{123}$ Hellmann, 2006, Rn. 188; dazu Brüning, ZIS 7/2008, S. 341 f.; Prechtel, 1995, S. 223 ff.

${ }^{124}$ Kindhäuser, 2016, § 4 Rn. 36; Meyer-Goßner/Schmitt, § 162 Rn. 14.
} 
ßigkeit zu treffen. ${ }^{125}$ In diesem Fall wäre auch der Kontrollrahmen strenger, denn der Richter müsste überprüfen, ob die Ermittlungshandlung und die entsprechende staatsanwaltschaftliche Anordnung rechtmäßig oder rechtswidrig waren und ob zum Zeitpunkt seiner Entscheidung die Voraussetzung für die jeweilige Anordnung gegeben war.

\section{D. Überblick über das richterliche Rechtsschutzsystem in Kolumbien}

Das Rechtsschutzsystem in Kolumbien ähnelt dem deutschen Rechtsschutzmodell in mehrfacher Hinsicht. Obwohl der CPP kein einheitliches und abgeschlossenes System des gerichtlichen Rechtsschutzes entwickelte, kann der richterliche Rechtsschutz gegen Ermittlungsmaßnahmen anhand dreier Kriterien klassifiziert werden. Als erstes stellt sich die Frage der Anordnungskompetenz: Hier ist zwischen der richterlichen und der nichtrichterlichen Anordnungskompetenz zu unterscheiden. Dann wird der Kontrollgegenstand betrachtet: Dabei kann es sich um die Anordnung der Maßnahme oder die Art und Weise der Durchführung handeln. Zuletzt ist der Zeitpunkt der gerichtlichen Überprüfung von Bedeutung: In diesem Sinne ist zwischen der vorherigen und der nachträglichen Kontrolle zu differenzieren. Dieses Rechtsschutzmodell hat seine Grundlage in Art. $250 \mathrm{CN}$, der im Rahmen einer Strafprozessrechtsreform ${ }^{126}$ im Jahre 2004 den ,,akkusatorischen Strafprozess“" eingeführt hat, womit die Aufgaben der Leitung des Ermittlungsverfahrens sowie der letztendlichen Entscheidung über die Anklageerhebung vom Richter auf die Staatsanwaltschaft übergegangen sind. ${ }^{127}$

Wie oben angegeben ist, wurde die Institution des sog. „Juez Control de Garantias“ geschaffen („Richter zur Kontrolle der (verfahrensrechtlichen) Garantien)“, der für die richterliche Überprüfung der Rechtmäßigkeit von Ermittlungshandlungen der Staatsanwaltschaft zuständig ist, um dem Beschuldigten oder anderen von Ermittlungshandlungen Be-

\footnotetext{
${ }^{125} \mathrm{Zu}$ dieser Unterscheidung s. Brüning, ZIS 7/2008, S. 341 m.w.N.; auch dazu Brüning, 2005, S. 188; Bachmann, 1998, S. 207; Prechtel, 1995, S. 113; Amelung, 1976, S. 28.

${ }^{126}$ Dies ist das Ergebnis einer mittels des Gesetzesaktes 03 des Jahres 2002 durchgeführten Verfassungsreform. Die neue Strafprozessordnung, „Código procesal penal (CPP)“ ist im Gesetz 906 des Jahres 2004 normiert. Vgl. infra § 3. A. I. 1. Gesetzesakt 03 von 2002.

${ }^{127}$ Art. 250 CN und Art. 66, 113-117, 142 und 200 CPP. Einer der Hintergründe dieser Entscheidung ist die Erkenntnis, dass die Entscheidung über die Anklageerhebung durch den später auch im Strafverfahren urteilenden Richter in gewissem Maße zu einer Vorherbestimmung des Urteils führen kann, etwa weil der Richter nicht durch einen späteren Freispruch seine vorherige Entscheidung der Anklageerhebung, die schließlich die Überzeugung von der Schuld des Angeklagten erfordert, korrigieren möchte. Abgesehen hiervon ist die Einführung des akkusatorischen Strafprozesses aber auch im Lichte einer zunehmenden US-Amerikanisierung des kolumbianischen Straf(prozess-)rechts zu sehen, welche im Rahmen eines Hilfsprojekts der USAID zur Verbesserung des kolumbianischen Justizsystems angestoßen wurde.
} 
troffenen Rechtsschutz zu gewähren. ${ }^{128}$ Die wesentliche Aufgabe des JCG ist folglich, den Straftatverdächtigen insbesondere vor Grundrechtsverletzungen durch staatliches Handeln im Rahmen der Wahrheitssuche zu schützen sowie die gesammelten Beweise und die Stichhaltigkeit des Straftatverdachts zu überprüfen. ${ }^{129}$ Die Kontrolle von Ermittlungshandlungen durch den JCG soll die Überprüfung der Einhaltung der Rechte und der verfassungsrechtlich geschützten Garantien des Straftatverdächtigen im Rahmen der Beweiserhebung zur Wahrheitssuche gewährleisten. ${ }^{130}$

Kolumbien hat sich bei der Einführung des JCG vor allem am deutschen Modell des Ermittlungsrichters orientiert. Dieses hielt man für am geeignetsten, um die notwendige Balance zwischen Effektivität der Ermittlungshandlungen einerseits und dem Rechtsschutz des Verdächtigen andererseits herzustellen. ${ }^{131}$ Dementsprechend überprüft der JCG Ermittlungshandlungen auf ihre Recht- und Verfassungsmäßigkeit und entscheidet letztendlich über die Zulässigkeit von solchen Ermittlungshandlungen, die zu Grundrechtseingriffen führen. ${ }^{132}$ Die bei Ermittlungshandlungen typischerweise beeinträchtigten Grundrechte sind zum Beispiel die persönliche Fortbewegungsfreiheit, das Recht auf einen ordnungsgemäßen Ablauf des Ermittlungsverfahrens und das Recht des Verdächtigen und seiner Familie auf informationelle Selbstbestimmung. ${ }^{133}$ Es handelt sich um eine Kontrolle sowohl der formellen als auch der materiellen Rechtmäßigkeit der Ermittlungshandlungen, ${ }^{134}$ welche sich am Verhältnismäßigkeitsprinzip orientiert. ${ }^{135}$

\section{Rechtsschutz durch den JCG}

Das aus Art. $250 \mathrm{CN}$ abgeleitete Rechtsschutzmodell wird im Grunde durch die richterliche Kontrolle von Ermittlungsmaßnahmen durch den JCG entwickelt. Schutzvarianten wie der formlose Rechtsbehelf werden weder von dem CPP noch von der Strafprozesslehre berücksichtigt. Auch die Verfassungsbeschwerde hat eine sehr begrenzte Schutzreichweite aufgrund der mangelnden Unmittelbarkeit bzgl. einer Grundrechtsverletzung. In der Aus-

\footnotetext{
${ }^{128}$ Vgl. Art. 250 Nr. 1, 2, 3 CN und Art. 39, 153 CPP; dazu infra § 4. Der Richter zur Kontrolle der Garantien (Juez de Control de Garantías).

${ }^{129}$ Vgl. u.a. Aponte Cardona, 2006, S. 23; Bernal Cuellar/Montealegre Lynett, 2013 T. I, S. 267 ff.; CSJ, 2005, S. 21; Guerrero Peralta, 2006, S. 30; Guerrero Peralta, 2004, S. 188.

${ }^{130} \mathrm{Vgl}$. infra $\S 4$. B. Funktion und Aufgaben des Richters zur Kontrolle der Garantien.

${ }^{131}$ I.d.S. insbesondere Aponte Cardona, 2006, S. 23.

${ }^{132}$ Bernal Cuellar/Montealegre Lynett, 2013 T. I, S. 267 ff.

${ }^{133} \mathrm{Vgl}$. Aponte Cardona, 2006, S. 76-87

${ }^{134}$ KVerfG, Entsch. C-1092 v. 2003, Abschn. „Consideraciones de la Corte“.

135 Guerrero Peralta, 2006, S. 155 ff.; Aponte Cardona, 2006, S. 26-44.
} 
übung der richterlichen Kontrolle durch den JCG wird der präventive und repressive Charakter des Rechtsschutzes entweder durch die Anordnung (Vorabkontrolle) oder die Bestätigung (nachträgliche Kontrolle) der Ermittlungsmaßnahmen vereint. Die Kontrolle der Maßnahmen durch den JCG verwirklicht den Grundsatz des Richtervorbehalts für die Eingriffe in Grundrechte und den jeweiligen gerichtlichen Rechtsschutz gegen Ermittlungsmaßnahmen. Der JCG wurde durch den Gesetzesakt 03 von 2002 eingeführt, welcher die Artikel 116, 250 und 251 der kolumbianischen Verfassung änderte. Der neu gefasste Art. 250 normiert die Kompetenzen des JCG im Rahmen seiner grundrechtsschützenden Funktion nunmehr wie folgt:

a) das Ergreifen von Maßnahmen zur Sicherstellung, dass der Beschuldigte im Strafverfahren erscheint, zur Beweissicherung und zum Schutz der Gesellschaft und der Opfer der betreffenden Straftat (Art. 250 Nr. 1), ${ }^{136}$

b) die nachträgliche Kontrolle von bereits durch die Staatsanwaltschaft erfolgten Hausdurchsuchungen, Beschlagnahmen, Überwachungen von Telekommunikationsmitteln spätestens innerhalb von 36 Stunden nach der staatsanwaltlichen Ermittlungsanordnung oder Beendigung der zu kontrollierenden Maßnahme (Art. 250 Nr. 2), ${ }^{137}$

und c) die Zustimmung (vorherige Einwilligung) zu grundrechtserheblichen Maßnahmen der Staatsanwaltschaft zwecks Sicherung von Beweismitteln (Art. 250 Nr. 3). ${ }^{138}$

Diese Kompetenzen des JCG wurden durch das Gesetz 906 des Jahres $2004^{139}$ weiter ausgestaltet. Das Handeln des JCG erfolgt nicht ex-oficio, sondern auf Ersuchen der Staatsanwaltschaft, des durch die Ermittlungshandlung beeinträchtigten Verdächtigen oder der Dis-

\footnotetext{
${ }^{136}$ Art. 250 Nr. 1 CN: ,medidas necesarias que aseguren la comparecencia de los imputados al proceso penal, la conservación de la prueba y la protección de la comunidad, en especial, de las víctimas." (dt. Übersetzung d. Verf.)

${ }^{137}$ Art. 250 Nr. 2: „Adelantar registros, allanamientos, incautaciones e interceptaciones de comunicaciones. En estos eventos el juez que ejerza las funciones de control de garantías efectuará el control posterior respectivo, a más tardar dentro de las treinta y seis (36) horas siguientes.“ (dt. Übersetzung d. Verf.). Aufgrund der Zuständigkeit zur nachträglichen Kontrolle von Ermittlungsmaßnahmen werden auch Festnahmen sowie Maßnahmen auf Grundlage des Opportunitätsprinzips durch den JCG überprüft. Vgl. § 4. B. III. Bestätigungen.

${ }^{138}$ Art. 250 Nr. 3: „Asegurar los elementos materiales probatorios, garantizando la cadena de custodia mientras se ejerce su contradicción. En caso de requerirse medidas adicionales que impliquen afectación de derechos fundamentales, deberá obtenerse la respectiva autorización por parte del juez que ejerza las funciones de control de garantías para poder proceder a ello.“ (dt. Übersetzung d. Verf.).

${ }^{139}$ Vgl. infra § 3. I. 2. Die Art des Strafprozesssystems und 3. Struktur des Strafprozesses. 
ziplinarstaatsanwaltschaft (,Ministerio Publico“). ${ }^{140}$ Es obliegt dem Ersuchenden, dem JCG die tatsächlichen und rechtlichen Gründe seines Ersuchens darzulegen und diese hinreichend zu belegen. ${ }^{141}$ An dieser Stelle soll nochmals darauf hingewiesen werden, dass der JCG im Rahmen der Rechtmäßigkeitskontrolle auch und vor allem die Verfassungsmäßigkeit der Ermittlungshandlung untersucht und insofern eine unmittelbar grundrechtsschützende Funktion wahrnimmt. ${ }^{142}$ Aus diesem Grund ist eine dem JCG vorgebrachte Angelegenheit auch stets eine dringliche, sodass er seine Entscheidung gemäß Art. 160 CPP sofort während der Anhörung zu treffen hat. ${ }^{143}$

Der Rechtsschutz in Form von Rechtmäßigkeitskontrollen seitens des JCG beinhaltet eine formelle und materielle Überprüfung der Ermittlungsmaßnahme. ${ }^{144}$ Die formale Kontrolle umfasst die Überprüfung der Anhaltspunkte, mit denen die Anordnung einer Maßnahme begründet wird. ${ }^{145}$ Diese Art der Kontrolle erfolgt sowohl mit den vorherigen Kontrollen für die Genehmigung einer Maßnahme als auch mit der nachträglichen Überprüfung der Art und Weise des Vollzugs derselben. Die materielle Kontrolle beinhaltet die Nachprüfung der Durchführung der Maßnahme, weshalb sie in erster Linie in den nachträglichen Kontrollen auftritt. In diesem Sinne ist die Art der vorherigen Kontrolle vergleichbar mit der Überprüfung der Rechtmäßigkeit der Anordnung einer Ermittlungsmaßnahme, durch die die Existenz des jeweiligen Tatverdachtsniveaus in Deutschland überprüft wird, d.h. das Vorliegen von zureichenden tatsächlichen Anhaltspunkten oder die Verurteilungswahrscheinlichkeit. ${ }^{146}$ Die materielle Kontrolle ist mit dem Rechtsschutz gegen die Art und Weise des Vollzugs bzw. mit der Kontrolle der Rechtmäßigkeit der Vollstreckung einer Maßnahme vergleichbar. ${ }^{147}$

\footnotetext{
${ }^{140}$ Vgl. CSJ, 2005, S. 30; dazu infra § 3. B. III. Disziplinarstaatsanwaltschaft.

${ }^{141}$ Vgl. KVerfG, Entsch. C-673 v. 2005, Abschn. „Consideraciones de la Corte“; dazu infra § 7. B. I. Entscheidung C-673 von 2005 KVerfG; bzgl. der Beweisbarkeit von tatsächlichen und rechtlichen Gründen infra $\S 10$. A. Beweisgrundlage der ,,motivos fundados“.

142 KVerfG. Entsch. C-1092 v. 2003, Abschn. „Consideraciones de la Corte“.

${ }^{143}$ Art. 160 Abs. 1 CPP: „Término para adoptar decisiones. Salvo disposición en contrario, las decisiones deberán adoptarse en el acto mismo de la audiencia. Para este efecto el juez podrá ordenar un receso en los términos de este código.“ („Frist zur Entscheidungsfindung. Sofern nichts anderes vorgesehen ist, sollten die Entscheidungen in der mündlichen Anhörung getroffen werden. Zu diesem Zweck kann der Richter eine Pause unter den Bedingungen dieser Strafprozessordnung anordnen.“ -dt. Übersetzung d. Verf.-).

${ }^{144} \mathrm{Vgl}$. dazu infra $§ 4$. C. III. Ablauf des Kontrollverfahrens.

${ }^{145}$ Dazu ausführlich infra $§ 7$. Die sog. ,,motivos fundados“ als Voraussetzung von Ermittlungsmaßnahmen.

${ }^{146}$ Vgl. ausführlich infra § 9. Die sog. ,motivos fundados“ im Vergleich mit dem Tatverdacht.

${ }^{147}$ Vgl. dazu Kühne, 2015, Rn. 564 ff.; Glaser, 2008, S. 41, f., 49 f.
} 


\section{II. Überblick des Kontrollverfahrens}

Das Gesetz 906 des Jahres 2004 bestimmt, dass der JCG im Rahmen einer Vorverhandlung entscheidet, die nicht mehr Gegenstand des späteren Strafverfahrens werden soll (Art. 153 CPP $){ }^{148}$ d.h., er entscheidet über die Rechtmäßigkeit von bei Hausdurchsuchungen und Telekommunikationsüberwachungen durch die Staatsanwaltschaft gesammelten Beweismitteln (1), über die Beweissicherung (2), über die Anordnung notwendiger Maßnahmen zum Schutz von Opfern und Zeugen (3), über den Antrag der Staatsanwaltschaft auf Anordnung einer Sicherungsmaßnahme (4) sowie über den Antrag des Verdächtigen oder der Disziplinarstaatsanwaltschaft auf deren Aufhebung (5), über Pfändungen (6), über die Formulierung der Anklagepunkte (7), über die Rechtmäßigkeit der Anwendung des Opportunitätsprinzips (8) sowie letztlich über Anträge auf Entlassung aus der Untersuchungshaft (9).

Im Rahmen der nachträglichen Kontrolle von Ermittlungshandlungen ${ }^{149}$ entscheidet der JCG in Anhörungen in der Ermittlungsphase ${ }^{150}$ über a) Haftanträge gegen den Beschuldigten (Art. 297 CPP), b) Mittel zur Beschaffung von Beweisen gegen den Willen des Beschuldigten (Stimmerkennungsmaßnahmen, Entnahme von Speichelproben) (Art. 249 CPP), c) Verfahrensweisen (Untersuchung auf Spermaspuren, Blutentnahme) im Falle von Sexualdelikten oder Delikten gegen die körperliche Unversehrtheit, die zu Beweiszwecken eine körperliche Untersuchung des Opfers erfordern (Art. 250 CPP), körperliche Untersuchungen (Art. 247 CPP) und Durchsuchungen von Personen (Art. 248 CPP). Bei der Autorisierung oder nachträglichen Kontrolle von Ermittlungshandlungen überprüft der JCG nicht bloß die Notwendigkeit der Maßnahme für den Ermittlungserfolg, sondern auch die Sachdienlichkeit sowie die tatsächliche und juristische Begründetheit des Grundrechtsein-

\footnotetext{
${ }^{148}$ Art. 153 CPP: „Las actuaciones, peticiones y decisiones que no deban ordenarse, resolverse o adoptarse en audiencia de formulación de acusación, preparatoria o del juicio oral, se adelantarán, resolverán o decidirán en audiencia preliminar, ante el juez de control de garantías.“ („Die Handlungen, Anträge und Entscheidungen, die nicht in der Anhörung zur Anklageerhebung, Vorbereitungsanhörung der Hauptverhandlung oder in der Hauptverhandlung selbst angeordnet, entschieden oder ergriffen werden, werden in einer Voranhörung vor dem Richter zur Kontrolle der Garantien beschlossen.“ -dt. Übersetzung d. Verf.-).

${ }^{149} \mathrm{Vgl}$. infra § 5. Nachträglicher Rechtsschutz gegen Maßnahmen zur Beschränkung der Intimität und § 6. Nachträglicher Rechtsschutz gegen Maßnahmen zur Beschränkung der Unverletzlichkeit der Kommunikation und der Freiheit.

${ }^{150}$ Vgl. dazu ausführlich Vanegas Villa, 2007, S. 33 ff.; Zapata Betancur, 2007, S. 113 ff. 
griffs. ${ }^{151}$ Nur wenn sich neue Tatsachen ergeben, kann der gleiche JCG wiederholt bzw. ein anderer JCG wegen derselben Angelegenheit angerufen werden. ${ }^{152}$

Grundsätzlich wird die Anhörung vor dem JCG durch die Staatsanwaltschaft eingeleitet. Sie kann aber ausnahmsweise in dringlichen Fällen, in denen die Staatsanwaltschaft nicht erreichbar ist, durch die Polizei beantragt werden. ${ }^{153}$ Der JCG legt Datum und Uhrzeit der Anhörung fest und teilt diese demjenigen, der diese gefordert hat sowie der Disziplinarstaatsanwaltschaft mit. ${ }^{154}$ In der Anhörung legt derjenige, der diese gefordert hat, die tatsächlichen und rechtlichen Gründe für seine Forderung dar und stützt diese mit Beweisen und sonstigen Erkenntnismitteln. ${ }^{155}$ Die Kontrolle der tatsächlichen Gründe besteht darin, das Vorhandensein der Tatsachen zu überprüfen (sachliche Umstände), und mit den rechtlichen Gründen wird festgestellt, ob die Entscheidung über die Anordnung im Einklang mit der von dem CPP für jede Maßnahme eingeführten Rechtsgrundlage steht (zumutbare Schlussfolgerung und hohe Angemessenheit). ${ }^{156}$ Die zustimmende oder ablehnende Entscheidung des JCG über die Forderung ist Rechtsmitteln zugänglich. ${ }^{157}$

${ }^{151}$ CSJ, 2005, S. 30; KVerfG, Entsch. C-1092 v. 2003, Abschn. „Consideraciones de la Corte“; dazu infra § 7. Die sog. ,motivos fundados“ als Voraussetzung von Ermittlungsmaßnahmen.

${ }^{152}$ Der JCG entscheidet über die Rechtmäßigkeit der Ermittlungsmaßnahme, aber es ist umstritten, ob er über die Verwertbarkeit der mit der Maßnahme gesammelten Beweise entscheiden darf: dagegen CSJ, 2005, S. 31; dafür Bernal Cuellar/Montealegre Lynett, 2013 T. I, S. 285.

${ }^{153}$ Art. 246 CPP: ,[...]. La policía judicial podrá requerir autorización previa directamente al juez, cuando se presenten circunstancias excepcionales que ameriten extrema urgencia, en cuyo caso el fiscal deberá ser informado de ello inmediatamente.“ (,Die Kriminalpolizei darf eine vorherige Genehmigung direkt von dem Richter beantragen, wenn sich außergewöhnliche Umstände ergeben, die äußerste Dringlichkeit erfordern, in diesem Fall soll der Staatsanwalt unverzüglich informiert werden.“-dt. Übersetzung d. Verf.-).

${ }^{154}$ CSJ, 2005, S. 37; FGN, 2005, S. 74.

155 Art. 221 Abs. 1 CPP; dazu infra § 10. A. II. II. Die Beweisgrundlageproblematik gemäß Art. 221 CPP; Der JCG und / oder die Staatsanwaltschaft dürfen auch den vorgebrachten Zeugen und Gutachter befragen (Art. 221 Abs. 2 CPP).

${ }^{156}$ Für die Bestimmung der sog ,,motivos fundados“ s. KVerfG, Entsch. C-024 v. 1994, Abschn. „Consideraciones de la Corte"; dazu infra § 7. A. I. Verfassungsrechtliche Bedeutung.

${ }^{157}$ Art. 238 CPP: „Impugnabilidad de la decisión. La decisión del juez de control de garantías será susceptible de impugnación, en los eventos previstos en esta ley. Si la defensa se abstuvo de intervenir en la audiencia, podrá solicitar en otra audiencia preliminar o durante la audiencia preparatoria la exclusión de las evidencias obtenidas.“ („Anfechtbarkeit der Entscheidung. Die Entscheidung des Richters zur Kontrolle der Garantien wird Gegenstand der Anfechtung in den in diesem Gesetz vorgesehenen Fällen. Wenn die Verteidigung sich der Mitwirkung in der Anhörung enthielt, kann sie in einer weiteren Voranhörung oder bei der Vorverhandlung den Ausschluss der gesammelten Beweismittel beantragen.“ -dt. Übersetzung d. Verf.-). 


\section{E. Zu dieser Arbeit}

\section{Untersuchungseingrenzung}

Sowohl in Deutschland als auch in Kolumbien findet im Ermittlungsverfahren die Ausführung des Rechtsschutzes im Richter ihren wichtigsten Vertreter. Die Kontrolle der Ermittlungshandlungen auf ihre Rechtmäßigkeit erfolgt in der deutschen StPO einerseits durch die Staatsanwaltschaft selbst und andererseits durch den Ermittlungsrichter. Da grundsätzlich die Staatsanwaltschaft die Herrschaft über das Ermittlungsverfahren innehat und selbst die Rechtmäßigkeit der Ermittlungshandlungen kontrolliert, ist eine Zustimmung oder eine Anrufung des Ermittlungsrichters für besondere Fälle vorbehalten. ${ }^{158}$ So stehen gegen Zwangsmittel bereits im Vorverfahren Rechtsbehelfe zur Verfügung. Handelt es sich insbesondere um die Anordnung der Maßnahme als solche, welche von der StA, deren Ermittlungspersonen oder der Polizei entweder in eigener oder in (hilfsweiser) Eilkompetenz erlassen wird, so erlaubt die StPO nur in einigen Fällen ausdrücklich die Anrufung des Richters. ${ }^{159}$ Dem Betroffenen muss möglich sein, die Rechtmäßigkeit der Anordnung der Maßnahme bzw. die Art und Weise ihrer Durchführung gerichtlich überprüfen zu lassen. Für diese Entscheidung ist im Ermittlungsverfahren der Ermittlungsrichter zuständig. ${ }^{160}$

Wie oben erwähnt, besteht in Kolumbien eine wesentliche Aufgabe des JCG also darin, den Straftatverdächtigen insbesondere vor Grundrechtsverletzungen durch staatliches Handeln im Rahmen der Wahrheitssuche zu schützen sowie die gesammelten Beweise und die Stichhaltigkeit des Straftatverdachts zu überprüfen (Art. 153 ff. CPP). Die Kontrolle von Ermittlungshandlungen durch den JCG soll bewirken, dass die Prüfung eines Tatverdachts, also im Wesentlichen die Wahrheitssuche durch Beweiserhebung, unter Einhaltung der Rechte und verfassungsrechtlich geschützten Garantien des Straftatverdächtigen erfolgt. ${ }^{161}$ Es handelt sich wie bereits beschrieben um eine Kontrolle sowohl der formellen als auch der materiellen Rechtmäßigkeit, die sich am Verhältnismäßigkeitsprinzip orientiert. Jedoch ist die Stellung des JCG vor den nachträglichen Überprüfungen der Ermittlungshandlungen

\footnotetext{
${ }^{158}$ Vgl. u.a. AnwK-StPO/Walther, § 162 Rn. 12 ff.; Geppert, DRiZ 1992, S. 405, 409; Brüning, 2005, S. 28; Talaska, 2007, S. 51 ff.; Prechtel, 1995, S. 63 ff.; Roxin/Schünemann, 2014, § 9 Rn. 29.

${ }^{159}$ Beulke, 2008, Rn. 323; Volk/Engländer, 2013, § 8 Rn. 2 (ebd. in der span. Fassung, s. Volk, 2015). Nur zwei Vorschriften, die eine richterliche Bestätigung auf Antrag des Betroffenen vorsehen, sind in der StPO enthalten: $\S 98$ Abs. 2 S. 2 und § 111e Abs. 2 S. 3.

${ }^{160}$ Meyer-Goßner/Schmitt, § 162 Rn. 7; HK-StPO/Zöller, § 162 Rn. 5 ff.

${ }^{161} \mathrm{Vgl}$. Aponte Cardona, 2006, S. 23; Bernal Cuellar/Montealegre Lynett, 2013 T. I, S. 265 ff.; CSJ, 2005, S. 21; Guerrero Peralta, 2006, S. 30; Guerrero Peralta, 2004, S. 188. 
eine sehr fragliche Rechtsschutzmethode, wenn es um die Begrenzung der staatsanwaltschaftlichen Machtausübung gem. der verfassungsrechtlichen Funktion der Judikatur geht.

Die nachträglichen Kontrollen durch den JCG finden für eine größere Anzahl von Ermittlungsmaßnahmen Anwendung, da sie in der kolumbianischen Strafprozessordung (CPP) nicht nur ausnahmsweise vorgesehen sind, sondern vielmehr den Regelfall darstellen. ${ }^{162}$ Viele dieser insofern ohne richterliche Zustimmung erfolgten grundrechtserheblichen Ermittlungsmaßnahmen wie vorläufige Festnahmen, Hausdurchsuchungen und Entnahmen von DNA-Proben sind in Kolumbien zentrale Elemente der Ermittlungstätigkeit. ${ }^{163}$ Wenngleich der JCG sowohl die formelle als auch die materielle Rechtmäßigkeit kontrolliert, wohingegen in Deutschland gemäß der h.M. mit der ermittlungsrichterlichen Bestätigung bloß die Zulässigkeit geprüft wird, ist die Wirksamkeit des Grundrechtsschutzes durch den JCG dennoch sehr beschränkt. Einerseits wird die Zulässigkeit (oder die Rechtmäßigkeit) der staatsanwaltschaftlichen Ermittlungshandlungen nur sehr beschränkt kontrolliert. Andererseits erlaubt die Anwendung des Verhältnismäßigkeitsgrundsatzes dem JCG, jeden Grundrechtseingriff aufgrund eines vermeintlich großen Nutzens für den konkreten Ermittlungserfolg als gerechtfertigt anzusehen. ${ }^{164}$ Darüber hinaus ist die nachträgliche Rekonstruktion und Bewertung der tatsächlichen Anhaltspunkte für die Vornahme der Ermittlungshandlung anhand der zum Eingriffszeitpunkt vorliegenden Umstände schwer vorzunehmen, da die bereits durch die fragliche Maßnahme erzielten Ermittlungserfolge gedanklich hinweggedacht werden müssen. Dies führt fast zwangsläufig zu einer reinen Ermessensentscheidung des JCG. ${ }^{165}$

Die Effektivität des Grundrechtsschutzes von Strafverdächtigen im Ermittlungsverfahren wird auch aufgrund der folgenden Faktoren eingeschränkt. Einerseits geschieht dies durch die Faktoren bzgl. der Gründe für die Entscheidung und bzgl. des Überprüfungsverfahrens

\footnotetext{
162 Vgl. dazu u.a. Zapata Betancur, 2007, S. 133 ff.; Aponte Cardona, 2006, S. 64 ff.; Guerrero Peralta, 2006, S. 91 ff.; Guerrero Peralta, 2004, S. 188; CSJ, 2005, S. 31 ff.; Bernal Cuellar/Montealegre Lynett, 2013 T. I, S. 265 ff. und T. II, S. 105 ff.

${ }^{163}$ Vgl. Espitia Garzón, 2010, S. 273 ff.; Cuello Iriarte, 2008, S. 215 ff.; López Calvo, 2008, S. 125 ff.; Guerrero Peralta, 2007, S. 335 ff.; Bernal Cuellar/Montealegre Lynett, 2013 T. I, S. 287 ff.; FGN, 2005, S. 31 ff.

${ }^{164}$ Dazu und für die vollständige Kritik vgl. Zuluaga, Boletin GLIPGö 5 (2013), S. 23 ff.; Zuluaga, CoHerencia Vol. 4 Nr. 6 (2007) S. 133 ff.

${ }^{165}$ Vgl. Zuluaga, Boletin GLIPGö 5 (2013), S. 23 ff.; Urbano Martínez, 2011, S. 135 ff.; CEJ, 2010, S. 115 ff.; Zuluaga, Co-Herencia Vol. 4 Nr. 6 (2007) S. 133 ff.; Calle Calderón, NFP 67 (2005), S. 167; Rivera Loaiza, RDP 40, S. 47.
} 
von Ermittlungshandlungen seitens der Staatsanwaltschaft und ihrer Ermittlungsbehörden. Diese Flexibilisierung der Ausübung der richterlichen Kontrolle von Ermittlungshandlungen geht einher mit einer Umdeutung des Mündlichkeitsgrundsatzes (Art. 9 CPP), welcher eigentlich die Verwirklichung weiterer Maximen des Strafprozesses wie etwa das Recht, zu den vorgebrachten Beweisen Stellung nehmen zu dürfen, garantieren soll (Bestandteil des Anspruchs auf rechtliches Gehör) (Art. 15 CPP), das Unmittelbarkeitsprinzip (Art. 16 CPP) und den Grundsatz der Öffentlichkeit (Art. 18 CPP). ${ }^{166}$ Wenn insofern die Anhörungen durch den JCG nicht ermöglichen, mittels des Mündlichkeitsprinzips und seiner Vorteile, wie z.B. die Unmittelbarkeit und die Widerspruchsmöglichkeit der Parteien, eine kritische Würdigung der Ermittlungshandlung vorzunehmen, ist die Kontrollfunktion des JCG hinsichtlich willkürlicher Ermittlungsmaßnahmen sehr beschränkt. ${ }^{167}$

Ein weiterer Kritikpunkt an den nachträglichen Kontrollen durch den JCG basiert auf der Frage, wie der Öffentlichkeitsgrundsatz angesichts der Tendenz, presummarische und summarische Geheimnisse zu akzeptieren ${ }^{168}$, und angesichts des expansiven Einsatzes der Kommunikationsmedien, die regelmäßig unzureichend geprüfte Informationen durchsickern lassen, gewahrt werden soll. ${ }^{169}$ Die Einführung eines gerichtlichen Kontrollverfahrens, das ebenfalls die Einhaltung des Öffentlichkeitsgrundsatzes überprüft, bringt aber keine erhöhte Objektivität der Kontrolle und Effektivität des Grundrechtsschutzes für die von der Ermittlungshandlung Betroffenen mit sich. Denn der unter Waffengleichheit stattfindende Streitprozess zwischen Staatsanwaltschaft und Verteidigung über die vorgebrachten Beweise zur Rechtfertigung der Ermittlungsmaßnahme, der dem Richter eine bestmögliche Bewertungsgrundlage eröffnen soll, ist eine Fiktion. ${ }^{170}$ Vor allem ist es angesichts der

\footnotetext{
166 Die Unmöglichkeit, ein vernünftiges Urteil zu bilden und die Erkenntnismittel in einem Wechselwirkungsprozess zwischen den Parteien zu bilden, ist ein weiterer Aspekt, der den demokratischen Charakter der neuen Prozessordnung widerlegt. Denn die Herangehensweise des JCG an die Überprüfung von Verdachtsmomenten und Beweismitteln basiert auf der Fiktion, die von ihm durchgeführten Anhörungen seien ein störfreier Bereich, der eine vollkommen unbeeinflusste Kontrolle der Ermittlungsmaßnahmen ermögliche.

${ }^{167}$ Vgl. Zuluaga, Co-Herencia Vol. 4 Nr. 6 (2007) S. 133 ff.; Calle Calderón, NFP 67 (2005), S. 167.

${ }^{168}$ An der neuen kolumbianischen Strafprozessordnung ist besonders besorgniserregend, dass Art. 237 eine nachträgliche Kontrolle rechtsbeschränkender Ermittlungsmaßnahmen durch den JCG vorsieht, und zwar ohne Wahrung des Öffentlichkeitsgrundsatzes und des Grundsatzes, zu den vorgebrachten Beweisen Stellung nehmen zu können. Das kolumbianische Verfassungsgericht erklärte teilweise den später durch Gesetz 1142 v. 2011 reformierten Art. 237 CPP für verfassungswidrig (Vgl. KVerfG. Entsch. C-025 v. 2009, Abschn. „Consideraciones de la Corte").

${ }^{169}$ Zur Problematik im deutschen Strafverfahren vgl. Neuling, 2005, S. 109 ff., 250 (bzgl. des Rechtsschutzes des Beschuldigten vor allgemein-vorverurteilender Öffentlichkeitsarbeit im Ermittlungsverfahren).

${ }^{170}$ Bzgl. der Relevanz von Erkenntnismitteln vgl. KVerfG, Entsch. C-185 v. 2008; dazu infra § 10. A. II. Die Beweisgrundlageproblematik gemäß Art. 221 CPP.
} 
Beteiligung der Medien am öffentlichen Prozess vor dem JCG wahrscheinlich, dass undifferenziert über Ermittlungserfolge berichtet wird, auch wenn die im Verfahren diskutierten Ermittlungsmaßnahmen, die zu dem Erfolg führten, möglicherweise die Grundrechte des Verdächtigen massiv verletzen.

Andererseits sind die richterlichen Überprüfungen von Grundrechtseingriffen und der Rechtsschutz gegen Ermittlungshandlungen aufgrund der Verpolizeilichung und der Präventivorientierung der Ermittlungstätigkeit defizitär. Insofern ist die ex post Kontrolle durch den JCG lediglich die Kontrolle des Widerhalls/Echos von Menschenrechtsverletzungen und darüber hinaus Instrument einer Politik, die den Ermittlungserfolg in der Verbrechensbekämpfung über die fundamentalen Rechte des Verdächtigen stellt. Der JCG scheint als Institution zur nachträglichen Kontrolle kein Garant für Rechtssicherheit und Grundrechtsschutz zu sein, vielmehr stellt er ein Instrument der Polizei im Rahmen der Verbrechensbekämpfung dar. Bei der nachträglichen Kontrolle hängt die Entscheidung des JCG zudem oftmals von Faktoren ab, die für eine Manipulation durch die Polizei besonders anfällig sind. Des Weiteren kann der Verteidiger häufig die von der Staatsanwaltschaft vorgebrachten Argumente für die Rechtmäßigkeit der Ermittlungshandlung nicht widerlegen, weil entweder vorgebracht wird, dass gewisse Dinge aus Staatsschutzinteresse geheim zu halten sind, oder weil er sich nicht hinreichend vorbereitet hat. Diese Problematik wird durch die Vielzahl der logistischen Probleme der Institutionen, die am Verfahren teilnehmen, vergrößert. ${ }^{171}$

\section{Zu dem Vorgehen der Arbeit - Ziele und Gang der Forschung}

Die größte Problematik sowohl in der kolumbianischen Strafrechtspraxis als auch in der Strafrechtswissenschaft stellt die Kontrolle von nichtrichterlich angeordneten Ermittlungsmaßnahmen dar, die als ex post Kontrolle oder nachträglicher Rechtsschutz bezeichnet wird. ${ }^{172}$ Fraglich ist vor allem, ob eine nachträgliche Mitwirkung des JCG an einer nichtrichterlich angeordneten Ermittlungshandlung überhaupt die Rechte des Straftatverdächtigen wirksam zu schützen vermag. ${ }^{173}$ Der zentrale Streitpunkt liegt in der begrenzten Überprüfungsmöglichkeit des Richters durch das ex post Einschreiten, in dem er die Gründe bzw. tatsächlichen Anhaltspunkte für die staatsanwaltschaftliche Anordnung einer Er-

\footnotetext{
${ }^{171}$ Zuluaga, Boletín GLIPGö 5 (2013), S. 32 ff.; Zuluaga, Co-Herencia Vol. 4 Nr. 6 (2007) S. 143.

${ }^{172}$ Aponte Cardona, 2006, S. 77; Guerrero Peralta, 2007, S. 198.

${ }^{173}$ Calle Calderón, NFP 67 (2005), S. 167; Rivera Loaiza, RDP 40, S. 47; Zuluaga, Co-Herencia Vol. 4 Nr. 6 (2007), S. 140.
} 
mittlungsmaßnahme bewertet. Die vorliegende Arbeit beschäftigt sich diesbezüglich mit der richterlichen Kontrolle der Begründetheit (formelle Kontrolle) von nichtrichterlich angeordneten Grundrechtseingriffen bzw. mit der richterlichen Überprüfung der aufgrund von staatsanwaltschaftlichen Ausnahmekompetenzen angeordneten Maßnahmen im kolumbianischen Ermittlungsverfahren. Der Fokus der Arbeit liegt auf der Art und Weise der Kontrolle von den fundierten Anhaltspunkten (,motivos fundados“), die die Anordnung eines Grundrechtseingriffs begründen müssen. Es geht nicht um die Frage, ob überhaupt eine entsprechende Kategorie des Rechtsschutzes erforderlich ist und wie dieser ausgestaltet wird. Vielmehr gilt es zu untersuchen, ob und wie die Kontrolle der Begründetheit einer Ermittlungsmaßnahme in Kolumbien wegen der Beweisbeschränkungen im Ablauf der Ermittlungskontrolle vor dem JCG eine zweckmäßige Kontrolle gegen Zwangsmaßnahmen darstellt, welche einen effektiven Rechtsschutz bewirken soll.

Das Augenmerk liegt dabei auf der effektiven Ableitung eines richterlichen Rechtsschutzes durch die formelle Kontrolle von fundierten Anhaltspunkten durch den JCG im kolumbianischen Ermittlungsverfahren. Ziele der vorliegenden Arbeit sind erstens, einen begrifflichen Rahmen zu entwickeln, mit dem die verfahrens- und strafrechtlich-theoretischen Voraussetzungen, die die Existenz und die Praxis des richterlichen Rechtsschutzes im kolumbianischen Strafprozessrecht begründen, bestimmt werden können, und zweitens den Mechanismus des Rechtsschutzes in Form des JCG kritisch zu analysieren und die Frage nach der Wirksamkeit der Überprüfung der Begründetheit von Ermittlungshandlungen für den Schutz des Verdächtigen vor möglichen Grundrechtsverletzungen zu beantworten. Daraufhin soll untersucht werden, ob die Kontrolle von fundierten Anhaltspunkten durch den JCG in Kolumbien im Ablauf der Ermittlungskontrolle und die Kontrolle anderer Probleme vieler kolumbianischer Strafprozessinstitutionen eine mangelhafte Rechtsschutzmethode darstellen.

Die Arbeit ist in zwei wesentliche Teile untergliedert. Einleitend wurde in diesem Kapitel schon der Begründungsrahmen beschrieben, um die Grundlagen des richterlichen Rechtsschutzes im Ermittlungsverfahren zu erfassen. Das Verständnis von Art und Durchsetzung der richterlichen Kontrolle als Rechtsschutz gegen strafrechtliche Ermittlungshandlungen entwickelte sich aus einem verfassungs- und strafprozessrechtlichen Ansatz, aus dem die Existenz und die Grundlage abgeleitet wurden. Ziel dieses Kapitels war es, einen begrifflichen Rahmen zu entwickeln, mit dem die verfahrens- und strafrechtlich-theoretischen Vo- 
raussetzungen, die die Existenz und die Praxis des richterlichen Rechtsschutzes im Ermittlungsverfahren begründen, bestimmt werden können. Damit wurden einerseits die Bestimmung der Grundlagen und die Begründung des Begriffs „richterlicher Rechtsschutz“ und andererseits eine begriffliche Erfassung der Tragweite des Terminus im Ermittlungsverfahren an sich beabsichtigt. Insgesamt sollte ein Überblick über den Sinn und Zweck der richterlichen Kontrolle von Ermittlungshandlungen als Mittel des Grundrechtsschutzes im Ermittlungsverfahren geschaffen werden.

Im ersten Teil wird das Rechtsschutzsystem im kolumbianischen Ermittlungsverfahren beschrieben. Dazu werden die wesentlichen Rechtsnormen in ihren unterschiedlichen Ausgestaltungen dargestellt, die die Aufgaben und die Ausübung dieses Systems regeln. Vor der Schilderung der strafrechtlichen Ermittlungsregelungen im CPP wird ein Überblick über die Vorgeschichte des Strafverfahrens in Kolumbien gegeben ( $\$ 2)$. Dieser beinhaltet die Darstellung der vor der Verfassung von 1991 geltenden Strafverfahrensmodelle (Sicherheitsstatut, Verfahrensgesetze gegen den Drogenhandel, Statut zur Verteidigung der Demokratie und Statut zur Verteidigung der Justiz) sowie die Strafprozessordnungen, die nach der Verfassung von 1991 erlassen wurden und durch das Dekret 2700 von 1991, das Gesetz 81 von 1993 und die Strafprozessordnung von 2000 einen niedrigeren Rechtsschutzstandard aufweisen. Anschließend folgt die Charakterisierung des kolumbianischen Ermittlungsverfahrens ( $(3)$, indem auf die verfassungsrechtlichen Grundlagen des Ermittlungsverfahrens bzw. des Gesetzesaktes 03 von 2002, auf den Zweck, die Grundzüge und den Ablauf sowie die Beteiligten des Ermittlungsverfahrens eingegangen wird. Diesbezüglich wird dem Richter zur Kontrolle der Garantien (§ 4) besonders große Aufmerksamkeit gewidmet, insbesondere seiner Bedeutung, Organisation, Funktion und seinen Aufgaben in der strafprozessrechtlichen Systematik des CPP. Schließlich werden die Erscheinungsformen des nachträglichen Rechtsschutzes im Ermittlungsverfahren geschildert. Hierbei werden besonders die Maßnahmen betrachtet, die einen intensiven Eingriff in Grundrechte zur Folge haben. Einerseits handelt es sich dabei um Maßnahmen zur Beschränkung der Intimität (§ 5), nämlich die Hausdurchsuchungen (Art. 219-232 CPP), die Personenüberwachung (Art. 239 CPP) und die verdeckten Ermittlungen (Art. 241-243 CPP), andererseits um Maßnahmen zur Beschränkung der Unverletzlichkeit der Kommunikation und der Freiheit ( $\$$ ), nämlich um den Eingriff in die postalische Kommunikation (Art. 233 CPP), die Telefonüberwachung und die Maßnahmen zur Beschränkung der Freiheit. 
Im zweiten Teil werden die wichtigsten Probleme bzgl. der Feststellung der Rechtswidrigkeit von Eingriffen in die Grundrechte im kolumbianischen Ermittlungsverfahren dargestellt. Ziel dieses Teils ist es, die formelle Kontrolle der Ermittlungshandlungen, mit der mehr als die bloße Zulässigkeit überprüft wird, zu diskutieren. Wie schon erwähnt wird erörtert, ob die richterliche Kontrolle von fundierten Anhaltspunkten in Kolumbien wegen der Beweisbeschränkungen im Ablauf der Ermittlungskontrolle eine mangelhafte Rechtsschutzmethode darstellt. Der Schwerpunkt dieses Teils liegt auf den sog. fundierten Anhaltspunkten (,motivos fundados"), auf die sich die Anordnung oder Bestätigung einer Ermittlungsmaßnahme stützen soll. Die sog. ,motivos fundados“ werden zunächst als Voraussetzung von Ermittlungsmaßnahmen im CPP dargestellt (§ 7) und an dieser Stelle werden die Bedeutung des Begriffes und seine Auslegung in der Rechtsprechung des KVerfG erklärt. Nach der Begriffsbestimmung erfolgt die Untersuchung der Grundlage für eine rechtsvergleichende Analyse derselben. In diesem Kontext gibt es ausreichende Hinweise in der Lehre des Tatverdachts in der StPO (§ 8). Im Hinblick auf die rechtsvergleichende Würdigung der „,motivos fundados“ werden die Voraussetzung des Tatverdachts, die Bestimmungsansätze dieses Begriffes und die Verdachtsgrade dargelegt. Aus diesem Strafverfahrensrahmen erschließen sich die Parameter zum Vergleich der ,motivos fundados“( $§$ 9). Die rechtsvergleichende Analyse ermöglicht die Differenzierung zweier Grade von fundierten Anhaltspunkten: die tatbezogenen und die täterbezogenen „motivos fundados“. Angesichts dieser Abstufung werden die wichtigsten Probleme der richterlichen Kontrolle der ,motivos fundados“ durch den JCG diskutiert ( $\$ 10)$. Insbesondere im Rahmen des Begründungsgrades für die Anordnung von mittleren und intensiven Grundrechtseingriffen werden einerseits die Beweisgrundlageproblematik gemäß Art. 221 CPP und andererseits die Ziele der zumutbaren Schlussfolgerungen diskutiert, welche sich aus den fundierten Anhaltspunkten ergeben und aus denen sich die Verübung von Straftaten und das Vorhandensein von tauglichen Informationen ergeben müssen. Abschließend werden Vorschläge für eine effektive richterliche Kontrolle der „motivos fundados“ entwickelt mit dem Ziel, die unzureichende Überprüfung von Ermittlungen zu berichtigen. 


\section{Erster Teil: Das Rechtsschutzsystem im kolumbianischen, strafrechtlichen Ermittlungsverfahren}

\section{$\S 2$. Strafprozessrechtliche Vorgeschichte}

\section{A. Hintergrund der Strafverfahrensentwicklung}

Die bewaffnete Gewalt ist eine kontinuierliche Praxis in der politischen Historie Kolumbiens. ${ }^{174}$ Als primäres Mittel der Sozialkontrolle hat sie eine Gewaltwirtschaft hervorgebracht, die in individueller oder kollektiver Form zur Lösung verschiedener gesellschaftlicher, wirtschaftlicher und politischer Probleme eingesetzt wird, welche wiederum gerade erst durch diese Gewalt geschaffen und verstärkt wurden. ${ }^{175}$ Bestimmte soziale Akteure, darunter auch der Staat, haben die Gewalt als vorherrschendes Mittel in ihre Strategien zur Aufrechterhaltung und Verbesserung ihrer jeweiligen sozialen, politischen und wirtschaftlichen Stellung miteinbezogen. ${ }^{176}$

Die soziale und wirtschaftliche Exklusion, verstärkt durch einen starken Lokalismus, Konservatismus und Abschottung, sowie ein überaus schwacher und in Frage gestellter Staat, ${ }^{177}$ in dem sich wirtschaftliche Eliten kooptieren und der in synergistischer Beziehung zur Gebrechlichkeit eines aufrührerischen politischen Systems steht, charakterisieren eine kolumbianische Gesellschaft, die die Gewalt als überwiegenstes Mittel zur Lösung ihrer Probleme betrachtet. ${ }^{178}$

Verschiedene politische Vorgänge und Phänomene, die sich in der ersten Hälfte des 20. Jahrhunderts ereigneten, haben, auch wenn sie nicht die gegenwärtigen Gründe für das Andauern der Gewalt in Kolumbien darstellen, gleichwohl die Entstehung des bewaffneten

\footnotetext{
174 Vgl. Koessl, 2014, S. 132 ff.; Guzmán Campos/Fals Borda/Umaña Luna B. I, 2012, S. 35 ff.; Pécaut, 2001, S. 26 ff.

${ }^{175}$ Für die Gewalt als Werkzeug in der Strategie der Gewaltakteure vgl. Koessl, 2014, S. 132 ff. (Soziales Feld), 143 ff. (Politisches Feld), 152 ff. (Wirtschaftliches Feld); Bzgl. der Veralltäglichung von Gewalt in Kolumbien Waldmann, 2002, S. $201 \mathrm{ff}$.

${ }^{176}$ Koessl, 2014, S. 115; i.d.S. Jaramillo, Estudios Políticos 10 (1997), S. 150-159.

177 Zahlreiche Definitionsversuche haben dieses Phänomen zu erfassen versucht: als einen abwesenden Staat; Failed State; Partially Failing State; Staat ohne Souveränität oder mit umstrittener Souveränität; Staat mit multiplen Souveränitäten; prekären Staat mit mehr Territorium als Staat; einen chronisch schwachen Staat; anomischen Staat; primitiven Staat; vgl. dazu Koessl, 2014, S. 113 m.w.N.

${ }^{178}$ Koessl, 2014, S. 126, 240; Bzgl. der Interdependenz zwischen der Schwäche des Staates und der Gewalt in Kolumbien s. Aponte Cardona, 2004, S. 29 ff. Für die These der Gewaltkultur s. Waldmann, 2002, S. 213.
} 
Konflikts bedingt. ${ }^{179}$ In diesem Zeitraum ereigneten sich zunächst die als „Epoche der Violencia“ titulierten, bewaffneten Auseinandersetzungen zwischen der Liberalen und der Konservativen Partei. In ihrem Rahmen kam es zu Morden, Verfolgungen, Aggressionen und zur Zerstörung von Privatbesitz, sowie zu terroristische Methoden, welche zur Einschüchterung des Gegenübers und zur politischen Polarisierung der Gesellschaft eingesetzt wurden, ohne dass jemals offiziell eine Bürgerkriegserklärung vorlag ${ }^{180}$. Dies hat unter anderem zum gewaltsamen Tod von schätzungsweise 200.000 bis 300.000 Menschen sowie zur gewaltsamen Vertreibung von mehr als 2 Millionen Personen geführt, was fast einem Fünftel der damaligen kolumbianischen Gesamtbevölkerung entspricht, die zu dieser Zeit ca. 11 Millionen Menschen zählte. ${ }^{181}$ Die „Violencia“ endete erst im Jahr 1958 durch den Koalitionsschluss der Liberalen und Konservativen Partei zur sogenannten „Frente Nacional“ (Nationale Front), welche es diesen beiden traditionellen Parteien erlaubte, sich bei dem Amt des Staatspräsidenten nacheinander abzuwechseln und die übrigen offiziellen Ämter in gleichem Verhältnis zu besetzen. ${ }^{182}$ Dem Gebrauch von Gewalt als Ausdrucksmittel politischer Inkonformität wurde hierdurch allerdings kein Ende gesetzt, vielmehr intensivierte sich der bewaffnete Konflikt in den darauffolgenden 60 Jahren. Denn dadurch, dass die politische Basis der beiden traditionellen Parteien und die Landbevölkerung im Machtgeflecht der „Frente Nacional“ keine Berücksichtigung fanden, traten nun linksgerichtete Guerillabewegungen als neuer Konfliktakteur in Erscheinung. ${ }^{183}$ Hierbei ist vor allem die Guerrillagruppe „Bewaffnete Revolutionäre Streitkräfte Kolumbiens“ (Fuerzas Armadas Revolucionarias de Colombia - FARC) zu nennen, die zu Beginn dieser Dekade ihren gewaltsamen Kampf aufnahm. ${ }^{184}$

Darüber hinaus gewannen in den Folgejahren zwei weitere Komponenten in der Gewaltgeschichte Kolumbiens an Bedeutung. Zum einen übernahm der Drogenhandel ab Mitte der Siebzigerjahre eine bedeutende Rolle im gesellschaftlichen und politischen Geschehen. Der Anbau von Marihuana wurde von zunächst kleinen Anpflanzungen in kurzer Zeit auf

\footnotetext{
179 Vgl. ausführlich $G M H, 2013$, S. 112 ff.; s. auch den Bericht der „historischen Kommission über den bewaffneten Konflikt und seine Opfer" (Comisión Histórica del Conflicto Armado y sus Víctimas - CHCV). Für eine kritische Anmerkung des Berichts s. Ambos/Zuluaga, E+Z 2015/07, S. 34 f.

${ }^{180}$ Dazu GMH, 2013, S. 112 ff.; Guzmán Campos/Fals Borda/Umaña Luna, 2012 B. I, S. 53 ff.; Aponte Cardona, 2004, S. $49 \mathrm{ff}$.

${ }^{181}$ Vgl. GMH, 2013, S. 115; Guzmán Campos/Fals Borda/Umaña Luna, 2012 B. I, S. 316 ff.

182 Vgl. Koessl, 2014, S. 111; Aponte Cardona, 2004, S. 52 f.; Krauthausen, 1997, S. 314, 316.

${ }^{183}$ Vgl. GMH, 2013, S. 118 ff., 200 ff.; Aponte Cardona, 2004, S. 53.

184 GMH, 2013, S. 117 f.; Bzgl. der Begründung der Guerrillas in Kolumbien s. Guzmán Campos/Fals Borda/Umaña Luna, 2012 B. I, S. 175 ff.; Pécaut, 2001628 ff. 
immer größere Areale ausgedehnt, um der steigenden Nachfrage insbesondere aus den Vereinigten Staaten nachzukommen, bis er Ende der Siebzigerjahre zunehmend vom Kokainhandel verdrängt wurde, dessen Produktion und Kommerzialisierung sich in eine überaus erträgliche Geld- und Machtquelle verwandelte. In diesem Zeitraum entstanden in Medellín und Cali die sog. „Drogenkartelle“ und mit diesen eine neue Form organisierter Kriminalität und Quelle der Gewalt in Kolumbien. Der Drogenhandel hat sich für die in Kolumbien agierenden bewaffneten Gruppen als überaus zweckmäßig und als Überlebensbedingung erwiesen, da sie bis heute die aus diesem erzielten Finanzmittel benötigen, um selbstständig agieren und sich dem Druck an dem Verhandlungstisch oder einer militärischen Niederlage widersetzen zu können. ${ }^{185}$

Zum anderen begannen Landbesitzer in verschiedenen Regionen des Landes angesichts der prekären Sicherheitslage, welche durch die gewaltsamen Aktionen - seien es die der Guerrilla oder die des organisierten Verbrechens - geschaffen wurde, Heerscharen von Leibwächtern zu beschäftigen oder sog. Selbstverteidigungskräfte zu bilden. In einigen Fällen erhielten sie dabei Unterstützung des kolumbianischen Militärs. ${ }^{186}$ Einige dieser Gruppen sollten sich im weiteren Verlauf $\mathrm{zu}$ heterogen strukturierten paramilitärischen Gruppen weiterentwickeln, die sich zum Ziel nahmen, jeden einzuschüchtern oder zu eliminieren, den sie als politischen Feind betrachteten. Auf diese Weise wurden sie zu einem der wichtigsten Protagonisten in der gewaltsamen politischen Realität Kolumbiens. Die Strategie, die gesellschaftliche und politische Basis der Guerrilla auszulöschen, hat dem bewaffneten Konflikt und dessen Auswirkung auf die Zivilbevölkerung eine neue Dimension gegeben. Die eingesetzten Maßnahmen - Massaker, Folter, gewaltsames Verschwindenlassen - waren in Kolumbien nicht nur bereits wohl bekannte Mittel, sondern erwiesen sich für diese Gruppen als überaus effektiv, um die Zivilbevölkerung einzuschüchtern. ${ }^{187}$

In diese Gewaltdynamik reihen sich gegenwärtig auch viele Mitglieder der in Folge eines Abkommens aus dem Jahre 2003 offiziell demobilisierten, paramilitärischen Gruppen ein, die in als bandas criminales - BACRIM (kriminelle Banden) bezeichneten, illegalen bewaffneten Gruppen weiter agieren bzw. sich in diesen neu zusammengefunden haben. Dies geschieht unter anderem deshalb, weil der kolumbianische Staat größtenteils die den De-

185 Vgl. Koessl, 2014, S. 131; Zinecker, 2004, S. 25, für die die Drogen den Staat anonymisiert haben, aber nicht die Ursache des Krieges oder der Gewalt sind.

${ }^{186}$ GMH, 2013, S. 139 ff.; ausführlich Koessl, 2014, S. 163 ff.

${ }^{187}$ Für die Statistiken des bewaffneten Konflikts in Kolumbien und die Modalitäten der Gewalt GMH, 2013, S. $42 \mathrm{ff}$. 
mobilisierten ursprünglich versprochenen Maßnahmen zu deren Wiedereingliederung in die Gesellschaft nicht vollzogen und zur Beendigung der Gewalt notwendige strukturelle Reformen nicht in Angriff genommen hat. ${ }^{188}$ Die Wiederbewaffnung und Neugruppierung Demobilisierter hat bislang jedes in Kolumbien sowohl mit Paramilitärs als auch mit Guerrilleros in Angriff genommene Projekt zur Demobilisierung, Entwaffnung und Wiedereingliederung (Desmovilización, Desarme y Reinserción - DDR) begleitet. ${ }^{189}$ Als Hauptgrund hierfür wird angeführt, dass der jüngst weitgehend gescheiterte Versuch zur Demobilisierung der Paramilitärs ebenso wie die bisherigen DDR-Projekte stets partielle Maßnahmen zur Beseitigung einzelner Konfliktakteure im Kontext eines im Übrigen andauernden bewaffneten Konflikts waren, in dem die politische und gesellschaftliche Kontrolle aller illegalen bewaffneten Gruppen nie durchbrochen und die ökonomischen Anreize des Drogenhandels und der „Schattenwirtschaft“ nicht beseitigt werden konnten. ${ }^{190}$

\section{B. Strafprozessrechtliche Reaktionen auf die Gewalt}

Vor diesem Hintergrund der politischen und gesellschaftlichen Instabilität hat auch der Staat, genauso wie die anderen Konfliktakteure, die Antwort vor allem im Gebrauch bewaffneter Gewalt gesucht. Der juristische Rahmen hierfür wurde dabei zumeist durch das Ausrufen des sog. „Belagerungszustandes“ (Estado de sitio) geschaffen, eine Rechtsfigur, die in Kolumbien dem Kriegszustand gleichkommt, und somit den bewaffneten Streitkräften die Vornahme tiefgreifender Repressionsmaßnahmen zubilligt und dadurch den Schutz individueller Bürgerrechte auf ein Maß zurechtstutzt, welches nur mit der Lage in einem autoritären Regime vergleichbar ist. ${ }^{191}$ Bezeichnend für die Situation Kolumbiens ist, dass die Rechtsfigur des „Belagerungszustands“ (Art. 121 Verfassung von 1886) bzw. nunmehr die des „Zustands innerer Aufruhr“ (conmoción interior) (Art. 213 Verfassung von 1991) und die damit einhergehende, weitgehende Aussetzung der verfassungsmäßig garantierten bürgerlichen Rechte in 30 der vergangenen letzten 40 Jahre der kolumbianischen Geschichte fast ununterbrochen Bestand hatten und unter dem Deckmantel der Aufstandsbekämpfung und der Verfolgung der organisierten Kriminalität zu systematischen Menschen-

\footnotetext{
188 Vgl. Koessl, 2014, S. 186; Dabei ist zu beachten, dass die gegenwärtigen Wiederbewaffnungen demobilisierter Kombattanten kein Einzelfall sind, sondern vielmehr eine ständig wiederkehrende Erscheinung in Kolumbiens Gewalthistorie sind. Dazu Zuluaga/Koessl DPC 37 (2012), S. 33 ff.

189 Vgl. Zuluaga/Koessl DPC 37 (2012), S. 24 ff.; Ambos, 2010 a, S. 68 ff.; dazu auch Bastidas, e.V. \& Kolumbienkampagne Berlin (Hrsg.) 2007, S. 22-29; Beck, 2008, S. 39-48.

${ }^{190} \mathrm{Vgl}$. Zuluaga/Koessl DPC 37 (2012), S. 11 und Fn. 17 m.w.N.

191 Vgl. GMH, 2013, S. 200 f. (zwischen 1949 und 1991 stand Kolumbien mehr als 30 Jahre unter Belagerungszustand); s. auch Aponte Cardona, 2004, S. 63 f. 
rechtsverletzungen durch staatliche Hoheitsträger geführt haben. ${ }^{192}$ Die Ausrufung des Sonderzustands hat sich bis heute als ein bewährtes Mittel für die staatlichen Sicherheitskräfte erwiesen, die Ausgestaltung der inneren Ordnung in die eigene Hand zu nehmen.

Der „Zustand innerer Aufruhr" hat auch wiederholt den verfassungsrechtlichen Rahmen zur Verabschiedung verschiedener strafrechtlicher und strafprozessualer Sondergesetze gebildet, wobei insbesondere die als „Sicherheitsstatuten“ bezeichneten Rechtsverordnungen in umfassender Weise die polizeilichen Kompetenzen und die Regeln des Strafverfahrens modifiziert haben und in verschiedenen Gesetzen eine Vielzahl von Sonderermächtigungen zur Aufrechterhaltung der öffentlichen Ordnung eingeführt haben. ${ }^{193}$ Es ist dabei geradezu charakteristisch für Kolumbien, dass eigentlich zur Strafverfolgung verabschiedete Sonderbefugnisse darüber hinaus auch zu anderen Zwecken eingesetzt bzw. missbraucht wurden, wie z.B. um arbeitsrechtlichen Konflikten, parteipolitischen Auseinandersetzungen, zivilen Protesten, Studentenaufständen, „Terrorismus“ bzw. „Narcoterrorismus“, sowie dem Anstieg der gewöhnlichen Kriminalität entgegenzutreten. Die Strafverfahrensordnung war hierbei vor allem durch die Ausdehnung der Militärgerichtsbarkeit auf Zivilpersonen betroffen. Des Weiteren wurden die Kompetenzen der Polizei im Ermittlungsverfahren erheblich erweitert und die Rechte Inhaftierter beschränkt. ${ }^{194}$

\section{Sicherheitsstatut (Dekret 1923 vom 06.09.1978)}

Die Verhängung des Belagerungszustandes zur unkontrollierten Ausdehnung der Kompetenzen der Sicherheitsorgane und zur systematischen Beschneidung der Bürgerrechte erlangte vor allem in den Siebzigerjahren einen Höhepunkt. ${ }^{195}$ Insbesondere die Jahre 1974 bis 1978 waren einerseits von zunehmender sozialer Unzufriedenheit und Polarisierung und andererseits von gewaltsamen Aktionen linksgerichteter Aufstandsbewegungen wie dem Nationalen Befreiungsheer $(E L N)$, den bewaffneten revolutionären Streitkräften Kolumbiens $(F A R C)$ und der Bewegung „19. April“ (M-19) geprägt. In diesem Kontext wurde erstmals am 27.10.1976 durch das Dekret 2131 der Belagerungszustand erklärt, um effektiv Proteste der Ärzte niederzuschlagen, welche zur kolumbianischen Sozialversicherungs-

\footnotetext{
192 Mit fünf Folgen: 1. Verlust vieler Menschenleben und Ausführungen vieler Menschenrechtsverletzungen, 2. rechtliche Instabilität, Einführung von Sonderstrafgesetzen, 3. Schwächung der ordentlichen Justiz und 4. die Etablierung einer nicht konsistenten Kriminalpolitik (GMH, 2013, S. 201).

${ }^{193}$ Vgl. GMH, 2013, S. 211 ff.; Aponte Cardona, 2004, S. 64 ff.

${ }^{194}$ Dazu ausführlich Pérez/Vanegas/Álvarez, 1997, S. 213 ff.

195 Für einen Überblick der Dauer und Begündung des Ausnahmezustands zwischen 1957 und 1992 vgl. García Villegas, Caleidoscopio B. I 2004, S. 327.
} 
anstalt gehörten. Kurz darauf folgte das Dekret 2194 von 1976, welches die Möglichkeit eröffnete, Personen bis zu einem Jahr unter Arrest zu stellen, die Schusswaffen oder Munition angefertigt, verkauft, beschafft oder getragen haben. ${ }^{196}$ Der Anwendungsbereich dieser Regelung wurde dann durch das Dekret 2195 von 1976 u.a. auf Personen ausgedehnt, die an öffentlichen Orten Bildmaterial aufhängen, auf öffentlichen Straßen und Wegen den Verkehr behindern oder den Ablauf öffentlicher Veranstaltungen stören. ${ }^{197}$

Am 06.09.1978, und damit nur einen Monat, nachdem Julio Turbay Ayala das Amt des Präsidenten übernommen hatte, folgte dann das als „Sicherheitsstatut“ (Estatuto de Seguridad) bezeichnete Dekret 1923, um den wiederholten und verschärften „Störungen der öffentlichen Ordnung, die einen Zustand genereller Unsicherheit schaffen und in Morden, Entführungen, Aufstand, Meuterei oder Zusammenrottung münden“ entgegentreten zu können. ${ }^{198}$ Das Sicherheitsstatut als Sonderrechtsordnung zur Aufrechterhaltung der öffentlichen Ordnung und zum Kampf gegen Subversion lieferte die rechtliche Grundlage für ein besonders repressives und autoritäres Agieren der staatlichen Sicherheitskräfte. Durch seine 16 Artikel wurde das bestehende Strafrechtssystem verschärft, indem die Strafen für Verhaltensweisen, die mit der Beeinträchtigung der öffentlichen Ordnung im Zusammenhang stehen, erhöht wurden und den Polizeiinspektoren und -kommandanten sowie den Bürgermeistern gerichtliche Kompetenzen übertragen wurden. Das Sicherheitsstatut ermöglichte darüber hinaus die Aburteilung von Zivilisten durch die Militärgerichtsbarkeit vor sog. „Kriegsräten“ (Consejos de Guerra) und erlaubte dem Militär, selbst in das strafrechtliche Ermittlungsverfahren einzugreifen, ${ }^{199}$ d.h. insbesondere ohne richterliche Anordnungen Hausdurchsuchungen, Telekommunikationsüberwachungen und Ingewahrsam-

\footnotetext{
${ }^{196}$ Vgl. dazu García Villegas, Caleidoscopio B. I 2004, S. 322; Gallón Giraldo, 1979, S. 115.

${ }^{197}$ Nur ein Jahr später sah sich der Staat angesichts eines lange andauernden und das öffentliche Leben schwerwiegend beeinträchtigenden Generalstreiks der Arbeiterklasse erneut gezwungen, den Belagerungszustand zu verhängen.

198 Vgl. Dekret 1923 v. 1978, Considerando, Abs. 4: „Que periódicamente se han venido reiterando y agudizando las causas de perturbación del orden público, que crean un estado de inseguridad general y degeneran en homicidios, secuestros, sedición, motín o asonada, o en prácticas terroristas dirigidas a producir efectos políticos encaminados a desvirtuar el régimen republicano vigente o en la apología del delito, [...];“" (,Von Zeit zu Zeit haben die Ursachen der Störung der öffentlichen Ordnung wieder aufgetreten und verschärft, die einen Zustand der allgemeinen Unsicherheit bauen und zu Mord, Entführung, Aufstand, Aufruhr oder Zusammenrottung oder zu terroristischen Praktiken mit politischen Effekte, um die aktuelle republikanische Regime zu untergraben, oder zur Apologie der Verbrechen führen“ "-dt. Übersetzung d. Verf.) .

${ }^{199}$ Vgl. dazu GMH, 2013, S. 132 ff.; Aponte Cardona, 2004, S. 64. 
nahmen ${ }^{200}$ durchzuführen.

Ergänzt wurde das „Sicherheitstatut“ dann durch das Dekret 2144 von 1978, welches das Militär zur Zollkontrolle ermächtigte, das Dekret 0070 von 1978, welches die Kompetenzen zur Vernehmung und Ingewahrsamnahme von Verdächtigen erweiterte, und das Dekret 2482 von 1979, welches die Militärgerichte auch bei Prozessen gegen Zivilisten von der Verpflichtung entband, die Akten der Verteidigung vorzulegen. Das Sicherheitsstatut führte somit $\mathrm{zu}$ einer fortschreitenden Militarisierung des Justizwesens und seine Anwendung wurde begleitet von Folter, Unterdrückung und Beschränkung der Meinungsfreiheit. ${ }^{201}$

\section{Die Verfahrensgesetze gegen den Drogenhandel}

Der illegale Drogenhandel ist einer der vorrangigen Gründe für den Einsatz von Gewalt und hat direkten Einfluss auf das gesellschaftliche, politische und wirtschaftliche Geschehen. Der Kampf gegen dieses Phänomen, ebenso wie die dargestellte Behandlung weiterer Probleme der öffentlichen Sicherheit und Ordnung, wurde bislang in erster Linie durch den Erlass von Sondergesetzen gesteuert, die den Exekutivorganen umfassende Eingriffsermächtigungen in Grundrechte einräumten, welche ohne oder nur mit einer sehr beschränkten richterlichen Kontrolle ausgeübt werden konnten. Diese Ausweitung freiheitsbeschränkender Kompetenzen unter dem Vorwand einer effektiveren Bekämpfung des Drogenhandels wird vor allem anhand zweier Gesetzeswerke deutlich, die die Strafprozessrechtsgeschichte Kolumbiens geprägt haben. Auf der einen Seite ist das Gesetz 17 von 1973 zu nennen, welches erstmals Verhaltensweisen unter Strafe stellte, die mit Drogen oder anderen physische oder psychische Abhängigkeit generierenden Substanzen in Zusammenhang standen. Insbesondere wurden Anbau, Handel sowie das Schaffen von Anreizen zum Gebrauch von Drogen und die Einrichtung entsprechender Örtlichkeiten sanktioniert. Zudem gewährte das Gesetz dem Staatspräsidenten für den Zeitraum von einem Jahr extraordinäre Kompetenzen, um unter anderem ,ein Statut auszuarbeiten, das vollständig das Drogenphänomen [...] hinsichtlich Kontrolle, Prävention, Repression, und Rehabilitation regelt.“202 Auf der anderen Seite wurde dann in Ausübung dieser Kompetenzen als „das erste offizielle nationale Betäubungsmittelstatut" (Estatuto Nacional de Estupefacientes) das

\footnotetext{
${ }^{200}$ Vgl. Aponte Cardona, 2006 b, S. 486 f.; García Villegas, Caleidoscopio B. I 2004, S. 323.

${ }^{201} G M H, 2013$, S. 133, 200, 208. Für einen statistischen Überblick über die Menschenrechtsverletzungen zwischen 1966 und 1998 siehe Proyecto Colombia nunca más, 2003, S. 13.

${ }^{202}$ Gesetz 17 von 1973, Art. 9 Nr. 1: „elaborar un estatuto que regule íntegramente el fenómeno de las drogas o sustancias que producen dependencia física o síquica (estupefacientes y sicotrópicos), en sus aspectos de control, prevención, represión y rehabilitación.“(dt. Übersetzung d. Verf.).
} 
Dekret 1188 von 1974 erlassen, welches dem Staat die alleinige Kontrolle über Herstellung, Aufbewahrung und Vertrieb von Drogen und von anderen physische oder psychische Abhängigkeit erzeugenden Substanzen übertrug, einschlägige, erzieherische Programme und Werbekampagnen konzipierte und die Schaffung eines „Nationalen Betäubungsmittelrates“ anordnete. Darüber hinaus legte dieses Dekret Strafen für diejenigen fest, die gegen das Statut verstießen, und erlaubte die Beschlagnahme jeglicher Mittel, die die Produktion, den Transport und den Verkauf der gegenständlichen Substanzen ermöglichten. ${ }^{203}$ Dieses Statut wurde allerdings obsolet, als über das Gesetz 30 von 1986 ein neues Statut erlassen wurde, welches den Kampf gegen den Drogenhandel und gegen die illegal errichteten Gruppierungen gemeinsam regelte. ${ }^{204}$

Die Struktur des Gesetzes 30 von 1986 entspricht grundsätzlich derjenigen des Dekrets 1188 von 1974. Beide Regelwerke verfolgten den Ansatz, die Materie vollständig zu normieren, und behandelten in ihren jeweils 9 Kapiteln nahezu identische Aspekte, im Einzelnen aber auf in einigen Punkten unterschiedliche Weise, insbesondere in straf(prozess)rechtlicher Hinsicht. So wurde die Strafverfolgungskompetenz in der ersten Instanz (Ermittlungsverfahren und Strafprozess) den höchsten Administrativorganen auf Departmentebene (Governeur, Intendant, Kommissar) bzw. dem Oberbürgermeister von Bogotá übertragen, die das Ermittlungsverfahren entweder selbstständig einleiten konnten oder die Einleitung eines solchen Verfahrens der jeweiligen Rechtsabteilung des Departments übertragen durften (Art. 68 lit. a). Dadurch wurde die Verweisung des Ermittlungsverfahrens an die Polizeibehörden ermöglicht, wohingegen die Kompetenz zur Durchführung des Strafprozesses und Urteilsfindung nicht delegiert werden konnten (Art. 68 lit. f). Das Regelwerk sah des Weiteren die Möglichkeit zur Festnahme und Inhaftierung des Verdächtigen vor (Art. 68 lit. b) und gab für die Durchführung des Ermittlungsverfahrens Fristen vor, die zu kurz waren, um eine ernsthafte Tatsachenermittlung zu betreiben. Die Frist zum Beweisantritt vor Gericht betrug für den Fall, dass der Verdächtige nicht bereits die Frist von 48 Stunden zur Vorlage der Entlastungsbeweise versäumte, lediglich 5 Tage ab

\footnotetext{
${ }^{203}$ Dieses Statut erhöhte die Strafen für die bestehenden Delikte, kriminalisierte erneut ,Beisichführen` und persönlichen Konsum (Ambos, 1993, S. 166).

${ }^{204}$ Für eine Zusammenfassung des neuen Betäubungsmittelstatuts s. Ambos, 1993, S. 480 f. (Annex I A); auch Velásquez Velásquez, 1989, S. 11 ff. Für eine kritische Anmerkung Londoño Berrio, NFP 33 (1986), S. $289 \mathrm{ff}$. 
dem Zeitpunkt der Festnahme (Art. 68 lit d). ${ }^{205}$

Hinsichtlich der Durchführung des Strafverfahrens verstießen die Vorgaben des Gesetzes 30 von 1986 radikal gegen liberale Strafverfahrensgrundsätze, ${ }^{206}$ indem sie ein summarisches Schnellverfahren vorsahen, in dem eine Tatsachenermittlung kaum möglich und ein faires Verfahren ausgeschlossen waren, und der Angeklagte durch die Kompetenzverweisung an Administrativorgane seinem gesetzlichen Richter entzogen wurde. Darin lag ein klarer Verstoß gegen den damals geltenden und die richterliche Zuständigkeit abschließend regelnden Titel XV der Verfassung von $1886 .{ }^{207}$

\section{Statut zur Verteidigung der Demokratie}

Trotz der beschriebenen, gesetzgeberischen Maßnahmen zur Bekämpfung von Gewalt und Drogenhandel war die zweite Hälfte der Achtzigerjahre geprägt von einer Vielzahl terroristischer Anschläge und massiver Gewalt. Zum einen wurden in dieser Periode zahlreiche Morde an Führern und Mitgliedern linksgerichteter Organisationen verübt, insbesondere an den Mitgliedern aus den Reihen der Partei „Unión Patriotica“. ${ }^{208}$ Zum anderen mehrten sich Terrorakte der Guerrillagruppen und der Drogenkartelle. Um dieser Intensivierung der Gewalt begegnen zu können, setzten die staatlichen Institutionen ihre bisherige Strategie fort. In diesem Sinne sollten der Erlass des Ausnahmezustands und die dadurch ermöglichten legislativen Sonderkompetenzen die öffentliche Sicherheit wiederherstellen und die politische Macht gewährleisten. So wurden die Strafrahmen erhöht, neue Straftatbestände und Qualifikationsmerkmale geschaffen, erhebliche Teile der Strafgerichtsbarkeit dem Militär übertragen, Strafverfahren vereinfacht und die Kompetenzen ausgeweitet, Hausdurchsuchungen, Telekommunikationsüberwachungen und Festnahmen ohne vorherige richterliche Anordnung durchzuführen. ${ }^{209}$ Viele dieser für den Ausnahmezustand durch Sonderdekrete eingeführten Regelungen wurden später in die ordentliche Gesetzgebung übernommen. ${ }^{210}$ Die gesetzgeberischen Sonderkompetenzen wurden dabei nicht nur genutzt, um Drogenbanden und illegale bewaffnete Gruppierungen zu bekämpfen, sondern auch um sonstige Erscheinungsformen sozialer Spannungen, wie Demonstrationen und Streiks,

\footnotetext{
${ }^{205}$ Für eine Darstellung des mit dem neuen Betäubungsmittelstatut verbundenen prozessualen Rechts siehe Ambos, 1993, S. $181 \mathrm{ff}$.

${ }^{206}$ Sogar mit einer undifferenzierten Behandlung von Herstellern, einfachen Konsumenten und Großdealern. Vgl. Aponte Cardona, 2006 b, S. 294 f; Aponte Cardona, 2004, S. 65.

${ }^{207}$ I.d.S. Velásquez Velásquez, 1989, S. 23.

${ }^{208}$ Vgl. Koessl, 2014, S. 145 f.; GMH, 2013, S. 142 und Fn 91 m.w.N; Bonilla, 1993, S. 2 ff.

${ }^{209} \mathrm{Vgl}$. GMH, 2013, S. 213; Velásquez Velásquez, NFP 40 (1988), S. $155 \mathrm{ff}$.

${ }^{210}$ Vgl. Aponte Cardona, 1994, S. 65 f.; Ambos, 1993, S. 166 f.
} 
durch Zwangsmittel unter Kontrolle bringen zu können, wobei oftmals eine tatsächliche oder auch nur vermeintliche Infiltrierung zivilgesellschaftlicher Bewegungen durch Guerillagruppen vorlag.

In diesem Zusammenhang ist allen voran das unter der Regierung des Staatspräsidenten Virgilio Barco während des Ausnahmezustands erlassene „Statut zur Verteidigung der Demokratie oder Antiterrorismus-Statut" (Estatuto de Defensa de la Democracia o Estatuto Antiterrorista) zu nennen, welches sich aus drei Einzeldekreten (Dekret 180, 181 und 182 von 1988) zusammensetzt. ${ }^{211}$ Dessen wesentlichen, materiell-rechtlichen Neuerungen bestanden darin, dass bereits das Bilden einer auf die Durchführung von Auftragsmorden oder Terrorakten abzielenden Gruppe unter Strafe gestellt wurde und die Beihilfe zu einem Terrorakt als Straftatbestand typifiziert wurde. ${ }^{212}$ Daneben wurde die Möglichkeit eröffnet, finanzielle Belohnungen für das Verschaffen von Informationen, die der Aufklärung von Straftaten dienen, zu gewähren. ${ }^{213}$ Außerdem wurden die Ermittlungsbehörden dahingehend reformiert, dass innerhalb der Kriminalpolizei Spezialeinheiten zur Verfolgung von Straftaten, die die öffentliche Ordnung beeinträchtigen, geschaffen wurden (Unidades Especializadas para el Orden Público), und die Möglichkeit eröffnet wurde, auch sonstige Mitglieder der staatlichen Sicherheitskräfte als sog. „Hilfskräfte der Justiz für die öffentliche Ordnung“" (Auxiliares de la Justicia de Órden Público) in die Ermittlungsarbeit miteinzubeziehen (Art. 39). Darüber hinaus dehnte das Statut die bislang der Kriminalpolizei vorbehaltenen Kompetenzen, wie z.B. die Festnahme ohne richterliche Anordnung oder die Durchführung von Hausdurchsuchungen, auf alle Kräfte des Militärs, der Polizei und des Inlandsgeheimdienstes „D.A.S.“ aus lediglich mit der Einschränkung, dass die entsprechende Ermittlungsmaßnahme „dringend erforderlich“ sein müsse (Art. 40). Ebenfalls ermächtigte das Statut die Kriminalpolizei, die Telegraphie- und Telefondienstleister anzuweisen, Mitschnitte von Telefonaten und übermittelten Nachrichten zu erstellen, deren Inhalt zur Aufdeckung geplanter oder zur Aufklärung begangener, terroristischer Straftaten führt (Art. 47). Ferner wurde die Möglichkeit zur Erwirkung einer Haftprüfung beschnitten (Dekret 182 von 1988), was mit der Vermeidung von Strafvereitelung begründet wurde. Des Weiteren wurde eine Sonderjustiz für die öffentliche Ordnung (Justicia Especial de Órden Público) (Dekret 181 von 1988) geschaffen.

\footnotetext{
${ }^{211}$ Vgl. Aponte Cardona, 2004, S. 65; Velásquez Velásquez, NFP 40 (1988), S. 155 ff.

${ }^{212}$ Bzgl. der Betätigung mit der Bekämpfung des Terrorismus s. Aponte Cardona, 2006 b, S. 297 ff.

${ }^{213}$ Vgl. Aponte Cardona, 2006 b, S. 298 ff.; Aponte Cardona, 2004, S. 65. 
Das Statut stieß auf weitreichende Kritik, weil es entgegen den Vorgaben der damaligen Verfassung, die für die Festnahme und Registrierung des Wohnsitzes einer Person ausdrücklich eine vorherige, schriftliche, richterliche Anordnung forderte, zur Durchführung dieser Maßnahmen bereits ausreichen ließ, dass ein Angehöriger der Polizei, des Militärs oder des Inlandsgeheimdienstes einen Straftatverdacht gegeben sah. Diesbezüglich wurde auch vorgebracht, die Prüfung des Vorliegens eines Straftatverdachts führe zu einer inhaltlichen Überforderung der genannten Sicherheitskräfte, da diese nicht über eine entsprechende, berufliche Ausbildung verfügen würden. ${ }^{214}$ Vor diesem Hintergrund könne allenfalls das Ertappen auf frischer Tat, keinesfalls aber die Einschätzung „,dringende Erforderlichkeit“ die vorherige, schriftliche, richterliche Anordnung der Festnahme entbehrlich machen. Dieser Kritik folgend urteilte schließlich auch der Oberste Kolumbianische Gerichtshof, dass die Aufhebung des Gebots der vorherigern, schriftlichern, richterlichern Anordnung durch die Ziffern a) und b) des Artikels 40 des Statuts verfassungswidrig sei, da diese die Rechte auf Freiheit, auf den Schutz der Privatsphäre und die Unverletzlichkeit der Wohnung verletze, welche Grundprinzipien des freiheitlichen Rechtsstaats darstellen würden. ${ }^{215}$

\section{Statut zur Verteidigung der Justiz}

Um in stärkerem Maße Amtsträger und insbesondere Angehörige der Strafjustiz, allen voran Strafrichter, zu schützen, die Ende der Achtzigerjahre verstärkt Gewalttaten ausgesetzt waren, und um darüber hinaus die Strafjustiz effizienter zu gestalten, die Arbeit der Kriminalpolizei auf allen Ebenen zu stärken sowie die Strafverfolgungskompetenzen der Militärgerichtsbarkeit zu festigen und den Einfluss der Exekutive auf strafrichterliche Entscheidungen dauerhaft sicherzustellen, wurde im Jahr 1990 das Dekret 2790 oder das „Statut zur Verteidigung der Justiz“ (Estatuto para la defensa de la justicia) erlassen. Dieses übernahm zahlreiche Maßnahmen der Sonderregelungen, die in den vorherigen Ausnahmezuständen getroffen worden waren. ${ }^{216}$

Dieses Statut stellte ein eigenes Strafgesetzbuch dar, welches parallel zum ordentlichen Strafgesetzbuch existierte, und dessen normative Struktur auf die Geheimhaltung von strafrechtlichen Entscheidungen und Entscheidungsträgern gerichtet war. Damit ging eine systematische Beschneidung strafprozessualer Rechte und Garantien auf allen Ebenen ein-

\footnotetext{
${ }^{214}$ Vgl. Velásquez Velásquez, NFP 40 (1988), S. 156 f.

215 Oberster Kolumbianischer Gerichtshof, Entsch. No. 21 v. 03.03.1988, Berichterstatter Fabio Moran Díaz. ${ }^{216}$ Vgl. GMH, 2013, S. 217; Aponte Cardona, 2006 b, 301 ff.; Velásquez. Velásquez, NFP 51 (1991), S. 3 ff.
} 
her. ${ }^{217}$ In strafprozessualer Hinsicht intensivierte das Statut vor allem die inquisitorische Ausrichtung des Strafverfahrens mittels folgender Maßnahmen: a) es sah die Inhaftierung des Verdächtigen ab Beginn des Vorermittlungsverfahrens bis zur Rechtskraft des Urteils vor; b) es führte das schriftliche Verfahren sowie die ,geheime Beweisführung“ ein , in der die Identität von Zeugen und der beteiligten Strafverfolgungsorgane (Art. 22, 24, 31, 33, 37 und 50) verdeckt wurde, und sog. „Richter ohne Gesicht“ (juezes sin rostro) (Art. 37, 38, 39, 43, 47 bis 51, u.a.) ihre Entscheidungen anonym trafen. Dadurch wurden die Grundsätze des kontradiktorischen Strafprozesses, der in mündlichen und öffentlichen Verhandlungen geführt wird und in dem die Waffengleichheit zwischen den Parteien gewährleistet wird, vollständig aufgehoben. Zudem schaffte das Statut das Erfordernis der Anklagerhebung ab, sodass das Strafverfahren nach Abschluss der Vorermittlungen durch die Kriminalpolizei (Art. 23 ff.) durch Beschluss des Ermittlungsrichters (Juez de instrucción) eingeleitet wurde (Art. 31). ${ }^{218}$

Auf diese Weise war sowohl für die Anklage als auch für die Urteilsfindung jeweils ein Richter zuständig. Auch war es der Richter, der eigenständig und in absoluter Geheimhaltung Beweise erhob und würdigte. ${ }^{219}$ Das Statut sah des Weiteren vor, dass Hausdurchsuchungen mithilfe einer schriftlichen Anordnung des Leiters der sog. „Ermittlungseinheit der öffentlichen Ordnung“ (Unidad Investigativa de Orden Público) durchgeführt werden konnten, sofern aus örtlichen oder zeitlichen Gründen das vorherige Einholen einer richterlichen Anordnung nicht möglich war, und zudem schwerwiegende Anhaltspunkte oder glaubwürdige Aussagen bzgl. gerade erst begangener Straftaten vorlagen, die Zerstörung oder Unterdrückung von Beweismitteln zu befürchten war, oder die Flucht eines Straftäters verhindert werden sollte. Zwar war über die Anordnung und Durchführung der Zwangsmaßnahmen ${ }^{220}$ Protokoll zu führen (Art. 24), allerdings konnte sowohl dem Beschuldigten als auch dessen Strafverteidiger und den Justizbediensteten der Einblick in dieses verwehrt werden (Art. 37). In den Ermittlungsverfahren der „Gerichtsbarkeit für Öffentliche Ordnung“ konnte außerdem nur der richterliche Beschluss über den Abschluss des Ermittlungsverfahrens angefochten und für nichtig erklärt werden und dies auch nur mit dem

\footnotetext{
${ }^{217}$ Aponte Cardona, 2006 b, S. 301 („Es stellte die Synthese aller gesetzgeberischen Maßnahmen, die in den vorangegangenen Ausnahmezuständen getroffen wurden, dar, bzw, wie bereits das Gesetz 30 von 1986, aller gesetzgeberischen Maßnahmen die aufgrund der Logik des Ausnahmezustands erlassen wurden.").

${ }^{218}$ Velásquez Velásquez, NFP 51 (1991), S. 7; bzgl. der Zuständigkeiten s. Ambos, 1993, S. 184 f.

${ }^{219}$ Velásquez Velásquez, NFP 51 (1991), S. 8; bzgl. der Geheimhaltungstechniken s. Ambos, 1993, S. 188 f.

${ }^{220}$ Dazu ausführlich Ambos, 1993, S. 190-198. („Alle Bestimmungen wurden zu ordentlichen Gesetzen, außer der Einschränkung des habeas corpus") 
Argument, dass dem Richter die notwendige Zuständigkeit fehle (Art. 52).

\section{Die neue Verfassung von 1991}

Die aktuell in Kolumbien geltende Verfassung von 1991 ersetzte die Verfassung von 1886 und gilt als größte demokratische Errungenschaft Kolumbiens. ${ }^{221}$ Sie wurde am 4. Juli 1991 in Bogota anlässlich einer Staatskrise, die man meinte auf diesem Wege lösen oder mindern zu können. Denn zu diesem Zeitpunkt existierten in Kolumbien drei grundlegende Probleme: Die Zunahme des Drogenhandels und damit zwangsläufig verbunden der Anstieg von Gewalt und Korruption; eine politische Krise, die sich vor allem darin auszeichnete, dass seit Beendigung der Violencia durch die Vereinbarung der Frente Nacional das Land ausschließlich von den beiden traditionellen Parteien (Liberale und Konservative Partei) beherrscht wurde, deren Legitimation darunter litt, dass sie kaum noch die Interessen der Gesellschaft repräsentierten, und quasi keine Möglichkeit zur politischen Teilnahme außerhalb dieses Zweiparteiensystems bestand; und schließlich die Intensivierung des bewaffneten Konflikts zwischen den Guerillagruppen auf der einen und dem Staat und den paramilitärischen Gruppen auf der anderen Seite. ${ }^{222}$ Die Verschärfung der politisch motivierten Gewalt durch illegale bewaffnete Gruppen hatte seit den Achtzigerjahren ein hohes $\mathrm{Maß}$ an Verletzung und Beschränkung der Menschenrechte hervorgebracht. Gleichsam ursächlich hierfür war aber auch der Staat selbst durch die Anwendung einer Strategie des „schmutzigen Krieges“ und die verschiedenen verabschiedeten gesetzlichen Regelungen, die zur Wiederherstellung der öffentlichen Ordnung im Rahmen des Ausnahmezustands geschaffen wurden. ${ }^{223}$

Die Entstehungsgeschichte der neuen Verfassung war dabei zum einen dadurch geprägt, dass ihr ein Friedensprozess mit der Guerillagruppe M-19 voranging. Auf der anderen Seite ging sie auf eine soziale, in erster Linie von einer Studentenbewegung eingeleitete Initiative zurück, die eine schwerwiegende, allgemeine Unzufriedenheit mit dem mehr als ein Jahrhundert alten Verfassungswerk von 1886 ausdrückte. Diese Initiative erreichte, dass bei den Wahlen des Jahres 1990 neben den 6 ursprünglich vorgesehenen Stimmzetteln (für Senat, Kammer, Parlament auf Department-Ebene, lokale Verwaltungsräte, Stadtverordne-

\footnotetext{
${ }^{221}$ Vgl. GMH, 2013, S. 218 f.; ausführlich Bernal Cuellar/Montealegre Lynett, 2013 T. I, S. 56 ff.

${ }^{222}$ Dazu GMH, 2013, S. 218 f.; bzgl. der Verfassung und der Beendigung der Gewalt siehe Lemaitre Ripoll, 2009, S. $121 \mathrm{ff}$.

${ }^{223}$ Der Ausnahmezustand wurde immer wieder erneut ausgerufen und hatte sich daher in der zweiten Hälfte des 20 Jahrhunderts in einen Dauerzustand verwandelt; Bzgl. des „schmutzigen Krieges“vgl. GMH, 2013, S. $15,140,142$.
} 
tenversammlung und Bürgermeister) ein siebter Stimmzettel (,,la septima papeleta“) beigefügt wurde, mit dem für die Einberufung einer verfassungsgebenden Nationalversammlung (Asamblea Nacional Constituyente) gestimmt werden konnte. ${ }^{224}$ In dieser erlangten auch Minderheiten Sitze, die traditionell kaum oder nicht repräsentiert wurden, wie zum Beispiel die indigenen Gruppen, Frauenrechtsbewegungen und nicht-katholische Religionsgemeinschaften. Daher bedeutete die Verabschiedung der Verfassung von 1991 für viele Kolumbianer die Inangriffnahme eines neuen Staatsprojekts, welches der Erlangung von Frieden, der sozialen Gerechtigkeit und der Abkehr von der Zweiparteienherrschaft dienen sollte.

Die breite Beteiligung verschiedener Gesellschaftsgruppen führte damit schließlich zu einer Verfassung mit einem detailliert ausgestalteten Katalog von Grundrechten, weitläufig ausgestalteten Mechanismen zum Schutz dieser Rechte und Regelungen zur Verbesserung der Möglichkeiten politischer Teilhabe. Als eine der ersten Verfassungen in Lateinamerika erkannte die Verfassung von 1991 neben den Grundrechten soziale und wirtschaftliche Rechte als solche an und erklärte Kolumbien ausdrücklich zum Sozialstaat. Auch die Schaffung von Mechanismen zum Grundrechtsschutz ist als Erfolg hervorzuheben ${ }^{225}$. Denn neben der Einrichtung eines eigenen Verfassungsgerichts wurde mit dem Rechtsmittel der sog. „Accion de Tutela“ dem Bürger die Möglichkeit eingeräumt, eine mögliche Grundrechtsverletzung direkt und unmittelbar vor den eigens hierfür zuständigen Richtern zu rügen, ohne zuerst den in Kolumbien überaus langwierigen Rechtsweg erschöpfen zu müssen. ${ }^{226}$

Auch in strafverfahrensrechtlicher Hinsicht brachte die Verfassung von 1991 Neuerungen. Als solche am bedeutsamsten war die Einrichtung einer Generalstaatsanwaltschaft (Fiscalia General de la Nación), der gemäß Art. 250 der Verfassung von 1991 die Aufgaben der Ermittlung und die darauf folgende Anklage von Straftaten bzw. die Einstellung des Ermittlungsverfahrens zugeteilt wurden. Es handelte sich dabei um eine Neuerung, die im Folgenden durch eine Reform der kolumbianischen Strafprozessordnung auf einfachge-

\footnotetext{
224 90\% der Wahlberechtigten stimmten zu Gunsten dieses Vorschlags und nach einer verfassungsrechtlichen Prüfung des Obersten Gerichtshofs wurde die gewünschte verfassungsgebende Nationalversammlung einberufen; ausführlich dazu $G M H, 2013$, S. 149 ff.

${ }^{225}$ Vgl. Bernal Cuellar/Montealegre Lynett, 2013 T. I, S. 67 ff.

${ }^{226}$ Darüber hinaus wurden mit dem Büro des Bürgerbeauftragten (Defensoría del Pueblo) und dem Obersten Richterrat (Consejo Superior de la Judicatura) weitere wichtige Institutionen zur Stärkung der Rechtsstaatlichkeit geschaffen. 
setzlicher Ebene erst noch umgesetzt werden musste. ${ }^{227}$ Insbesondere die Frage der Zuordnung der Generalstaatsanwaltschaft zur judikativen oder zur exekutiven Gewalt wurde von der verfassungsgebenden Nationalversammlung intensiv diskutiert, wobei sich letztendlich die erstgenannte Alternative durchsetzte und demzufolge in Art. 116 der Verfassung ausdrücklich festgelegt wurde, dass die Generalstaatsanwaltschaft als Rechtsprechungsorgan dient. $^{228}$

\section{Die folgende strafprozessuale Entwicklung}

\section{Dekret 2700 von 1991}

Nach Erlass der Verfassung von 1991 wurde durch das Dekret 2700 von 1991 auch eine neue Strafprozessordnung verabschiedet. ${ }^{229} \mathrm{Um}$ den neuen, verfassungsrechtlichen Vorgaben gerecht zu werden, wurde ein dreigliedriges Verfahren eingeführt bestehend aus: (i) einem Vorermittlungsverfahren vor der FGN, an dessen Ende ein Beschluss entweder über dir Einstellung des Verfahrens wegen eines Strafverfolgungshindernisses (resolucion inhibitatoria) oder über die Eröffnung des Ermittlungsverfahrens stand; (ii) dem anschließenden Ermittlungsverfahren durch die Generalstaatsanwaltschaft, welches bei dem Fehlen des hinreichenden Tatverdachts zur Einstellung des Verfahrens und andernfalls zur Erhebung der Anklage führte; (iii) das Hauptverfahren, welches mit dem Strafurteil des Erkenntnisrichters endete. ${ }^{230}$ Das Anklagemonopol war mithin auf die FGN übergegangen, die die alleinige Zuständigkeit für die Durchführung des Vorermittlungs- und Ermittlungsverfahrens besaß und ohne richterliche Beteiligung Ermittlungsmaßnahmen wie die Anordnung der Untersuchungshaft und die Beschlagnahme von Gütern zur Entschädigung der Opfer beschließen konnte (Art. $250 \mathrm{CN}$ ). ${ }^{231}$ Dabei sollten die Staatsanwälte unparteiisch agieren, d.h. zwecks Entscheidung über Anklagerhebung/Einstellung des Verfahrens auch

\footnotetext{
${ }^{227}$ Vgl. Bernal Cuellar/Montealegre Lynett, 2013 T. I, S. 209 ff.

${ }^{228}$ Art. 116 CN: „La Corte Constitucional, la Corte Suprema de Justicia, el Consejo de Estado, el Consejo Superior de la Judicatura, la Fiscalía General de la Nación, los Tribunales y los Jueces, administran Justicia. También lo hace la Justicia Penal Militar.“ El Acto Legislativo 02 de 2015, artículo 26, sustituyo la expresión señalada en cursiva por la expresión „Comisión Nacional de Disciplina Judicial.“ („Das Verfassungsgericht, der Oberste Gerichtshof, der Staatsrat, der Oberste Rat des Richteramts, die Generalstaatsanwaltschaft, die Gerichte und Richter, Recht sprechen. Soeben die Militärstrafjustiz. Der Gesetzesakt 02 von 2015, Art. 26, ersetzte den in Kursivschrift markierten Ausdruck durch „Nationale Kommission für Justiz Disziplin“ -dt. Übersetzung d. Verf./Herv. i. Orig.); zur Diskussion in Deutschland vgl. u.a. Koller, 1997, S. 311 ff.;

229 Bei der neuen Strafprozessordnung wurde die Gerichtsbarkeit der öffentlichen Ordnung in der ordentlichen strafrechtlichen Gesetzgebung eingeführt. Vgl. Aponte Cardona, 2006 b, S. 382 ff.

${ }^{230}$ Vgl. Espitia Garzón, 2015, S. 18-24; Bernal Cuellar, 1992, S. 47 ff.

${ }^{231} \mathrm{Vgl}$ dazu infra § 3. B. I. Staatsanwaltschaft; s. auch Molina López, 2012, S. 132 ff.
} 
Sachverhaltsmomente ermitteln, die den Beschuldigten gegebenenfalls entlasten könnten.

Ihre Aufgabe während des ersten Verfahrensabschnitts, dem Vorermittlungsverfahren (indagación o investigación previa), war es, „die Maßnahmen zu ergreifen, die notwendig sind, um festzustellen, ob sich ein amtlich bekannt gewordener Sachverhalt ereignet hat; ob dieser einen Straftatbestand erfüllt; ob der Strafverfolgung ein Strafverfolgungshindernis entgegen steht, und um die Beweise zu sammeln, die zur Feststellung der Identität und Individualisierung des Täters oder Teilnehmers unerläßlich sind.“232 Der spezifische Zweck des Vorermittlungsverfahrens lag dabei darin bei Zweifeln hinsichtlich des Vorliegens der notwendigen Voraussetzungen für die Einleitung eines Ermittlungsverfahrens, ein Mindestmaß an Beweismaterial zur Feststellung einer Straftat zu sammeln. Da es insofern nicht darum ging, konkret die Strafbarkeit des Verdächtigen/Beschuldigten festzustellen, sondern nur um die Frage, ob Anhaltspunkte dafür gegeben sind, dass ein Sachverhalt vorliegt, der einen Straftatbestand erfüllt, war auch die Beweisermittlung in dieser Phase beschränkt (materielle Beschränkung der Ermittlungskompetenz). „Folglich fand das Vorermittlungsverfahren seinen Abschluss, (a) wenn eine Sachlage bestand, die für die Eröffnung eines Ermittlungsverfahrens oder für den Erlass eines Einstellungsbeschlusses wegen eines Strafverfolgungshindernisses ausreichend war, oder b) die Ermittlungsfrist abgelaufen ist. “233 Die Strafprozessordnung beschränkte hierbei die Ermittlungskompetenz der Kriminalpolizei auf Taten, bei denen der vermeintliche Täter auf frischer Tat ertappt wurde (Art. 312). ${ }^{234}$

Sollte das Vorermittlungsverfahren zur Eröffnung des Ermittlungsverfahrens führen, begann letzteres mit der Vernehmung des Beschuldigten (indagatoria) (Art. 352) oder gegebenenfalls mit der Erklärung der Abwesenheit des Beschuldigten (declaración como persona ausente) (Art. 356). Auch hier lag die Zuständigkeit für die Beweisermittlung bei der Generalstaatsanwaltschaft, konnte allerdings auf die Kriminalpolizei übertragen werden,

\footnotetext{
232 Art. 319 Dekret 2700 v. 1991: „Pretenderá adelantar las medidas necesarias tendientes a determinar si ha tenido ocurrencia el hecho que por cualquier medio haya llegado a conocimiento de las autoridades; si está descrito en la ley penal como punible; la procedibilidad de la acción penal y practicar y recaudar las pruebas indispensables con relación a la identidad o individualización de los autores o partícipes del hecho." (dt. Übersetzung d. Verf.)

${ }^{233}$ KVerfG, Entsch. C-412 v. 1993, Abschn. „Consideraciones de la Corte“.

${ }^{234}$ Art. 312 Dekret 2700 v. 1991: „En los casos de flagrancia y en el lugar de los hechos, los servidores públicos que ejerzan funciones de policía judicial, podrán ordenar y practicar pruebas, sin que se requiera providencia previa.“ („In den Fällen auf frischer Tat und am Ort des Geschehens dürfen die Amtssträger, die Funktionen der Kriminalpolizei ausüben, ohne vorherige Entscheidung Beweise anordnen und erheben." -dt. Übersetzung d. Verf.-).
} 
wovon allerdings folgende Ermittlungsmaßnahmen ausgeschlossen waren: Festnahmen, Hausdurchsuchungen, Telekommunikationsüberwachungen, Maßnahmen, die die Intimssphäre des Beschuldigten beeinträchigten, und die Vernehmung des Beschuldigten (Art. 313 Abs. 2).

\section{Gesetz 81 von 1993}

Die strafprozessualen Maßnahmen, die zu Beginn der Neunzigerjahre im „Kampf gegen die Gewalt" getroffen worden waren, wurden durch weitere Reformen des Straf(prozess)rechts komplementiert. Mit diesen wurde die Möglichkeit geschaffen, den Beschuldigten oder Verurteilten Strafmilderungen bzw. eine Reduzierung verhängter Strafen anzubieten, um jene zu einer Zusammenarbeit mit den Strafverfolgungsorganen zu bewegen und somit das Strafverfahren zu beschleunigen. So wurden mit dem Gesetz 81 von 1993 die Rechtsfiguren Plea Bargaining, Guilty Plea und die Prozessabsprache in die kolumbianische Strafprozessordnung eingeführt, ${ }^{235}$ sodass ein Angeklagter, der sich zu den in der Anklageschrift vorgeworfenen Straftaten schuldig bekannte, in einem Schnellverfahren abgeurteilt werden konnte (sentencia anticipada) (Art. 3). Um eine Verhandlung zwischen der Staatsanwaltschaft und dem Angeklagten durchführen zu können, wurde darüber hinaus eine eigene Anhörung geschaffen (Art. 4), die zu einer Herausnahme einer Straftat aus der Anklage oder zu einem Verzicht auf Anklage wegen der Verwirklichung eines Qualifikationstatbestands oder besonders schweren Falls führen konnte. Darüber hinaus wurde durch das Gesetz 81 von 1993 die Möglichkeit der Übertragung der Beweisaufnahme auf die Kriminalpolizei weiter ausgestaltet (Art. 12), Fristen für die Durchführung des Vorermittlungs- und Ermittlungsverfahrens eingeführt (Art. 41 und 42) sowie die Regelungen zur Anordnung des Hausarrests modifiziert. Zudem wurde eine Kronzeugenregelung (sog. „Política de sometimiento a la justica“) geschaffen, mit der der Beschuldigte im Austausch gegen eine Strafmilderung motiviert werden sollte, Informationen zu preiszugeben, die die Auflösung organisierter Banden ermöglichen sollten. ${ }^{236}$ Von diesen Neuerungen war insbesondere die vorher nicht geregelte Möglichkeit der Übertragung der Beweisermittlung auf die Kriminalpolizei (Art. 12 Abs. 4) von Bedeutung. ${ }^{237}$

\footnotetext{
${ }^{235}$ Vgl. Bernal Cuellar, 1995, S. 519 ff.

${ }^{236}$ Vgl. dazu GMH, 2013, S. 223 ff.; Uprimny Yepes, Caleidoscopio B. I 2004, S. 383 ff.

${ }^{237}$ Art. 12 Abs. 4 Gesetz 81 v. 1993: „Los funcionarios de la Fiscalía no podrán comisionar a las corporaciones judiciales, pero podrán hacerlo para la práctica de cualquier prueba o diligencia a otros funcionarios judiciales o de policía judicial, conforme a lo dispuesto en el presente Código.“ („Beamten der Staatsanwaltschaft dürfen nicht die Rechtsorgane beauftragen, zwar dürfen sie weitere Justizbehörden oder die Kriminal-
} 
Kritisiert wurde dabei vor allem, dass die Ausdehnung der Ermittlungskompetenz auf die Kriminalpolizei gegen die Grundrechte des Beschuldigten verstoße, da laut Verfassung die einzig hierfür zuständige Institution die Generalstaatsanwaltschaft sei. Das KVerfG befand allerdings in seiner Entscheidung C- 396 aus dem Jahr 2004, dass darin kein Verfassungsverstoß liege, „da es um das Handeln in konkreten Fällen geht, in denen es nicht möglich ist, dass der Kompetenzträger die Funktion selbst wahrnimmt. “238 Laut dem KVerfG müsse jede derartige Beauftragung als ,ein besonderes Verfahren verstanden werden, welches darauf gerichtet ist, dass eine Amtspflicht pflichtgemäß durch einen anderen Amtsträger als den normalerweise Zuständigen erfüllt wird, soweit die Umstände die Erfüllung durch Letzteren nicht zulassen.“239

Mit diesen Argumenten wurde die Beauftragung zu einer Delegierung der Hoheitsgewalt abgelehnt, da sie nicht die Aufgabe der judiziellen Zuständigkeit, die im Falle der Staatsanwaltschaft die Ermittlung und die Anklage ist, beinhaltet. Dem Gericht zufolge stelle die Konkretisierung und Bestimmung des Mandats oder Auftrags ein Verfahren dar, welches dem Ermessen der Kriminalpolizei entzogen war und der Generalstaatsanwaltschaft erlaubte, sich die Entscheidung in denjenigen Bereichen vorzubehalten, die zu ihrer ausschließlichen Kompetenz gehörten. Nach der Auffassung des Verfassungsgerichts beruht die Beweisermittlung kraft Auftrags

„auf verschiedenen Gründen, vor allem faktischer Natur, wie die Notwendigkeit, die entsprechende Handlung außerhalb des Zuständigkeitsgebiets des Beauftragenden wahrzunehmen, die Arbeitsbelastung im Dezernat des Beauftragenden, und die Dringlichkeit der Beweisermittlung [...], deren Heranziehung im Rahmen der Voraussetzungen [...] der entsprechenden Rechtsnorm stattfinden muss, und, selbstverständlich, nicht zum Regelfall werden darf, der die vorrangige Funktion -Ermittlung und Anklage- auf Funktionäre außerhalb der Staatsanwaltschaft überträgt [...], worin eine offen gegen die Verfassung verstoßende Delegierung der Zuständigkeit läge.“240

polizei zur Erhebung anderer Beweise beauftragen, gemäß den Bestimmungen dieser Strafprozessordnung.“ dt. Übersetzung d. Verf.-).

${ }^{238}$ KVerfG, Entsch. C-396 v. 1994, Abschn. „Consideraciones de la Corte“ („ya que se trata de actuar en casos concretos en los que es imposible que el titular de la función la ejerza directamente“) (dt. Übersetzung d. Verf.).

${ }^{239}$ KVerfG, Entsch. C-396 v. 1994, Abschn. „Consideraciones de la Corte“ („procedimiento especial destinado al debido cumplimiento de una diligencia judicial por funcionario distinto de aquel a quien corresponde normalmente, ante circunstancias que impiden su ejecución directa por éste.") (dt. Übersetzung d. Verf.).

${ }^{240}$ KVerfG, Entsch. C-396 v. 1994, Abschn. „Consideraciones de la Corte“: ,obedece a muy diversas razones, 
Somit wurde seit dem Dekret 2700 von 1991 und durch das Gesetz 83 von 1993 das justizielle Monopol zur Beeinträchtigung von Grundrechten in der Ermittlungsphase durch die der Kriminalpolizei gewährten Kompetenzen zur Durchführung der Beweisermittlung relativiert. Auf diesem Wege konnte die Kriminalpolizei ohne Anordnung des Staatsanwalts oder des Ermittlungsrichters die Beweisermittlung übernehmen mit Ausnahme derjenigen Fälle, in denen die schriftliche Anordnung einer richterlichen Instanz Wirksamkeitsvoraussetzung war. Für den Schutz der Rechte des Beschuldigten stellte dies eine heikle Entwicklung dar, da keine unmittelbare oder nachträgliche Kontrolle durch eine richterliche Gewalt vorgesehen war. Nach der Strafprozessordnung hatte einzig die Generalstaatsanwaltschaft die Zuständigkeit, Beweisermittlungshandlungen im Ermittlungsverfahren zu überprüfen, was zu einer deutlichen Ausweitung polizeilicher Eingriffe in die Beschuldigtenrechte führte.

\section{Die Strafprozessordnung von 2000}

\section{Das Verfahren}

Mit dem Gesetz 600 aus dem Jahr 2000 wurde schließlich eine neue Strafprozessordnung geschaffen, die -abgesehen von redaktionellen Änderungen und Aktualisierungen- weitestgehend dem Dekret 2700 von 1991 entsprach, gegenüber diesem aber auch einige Neuerungen enthielt, wie die Abschaffung der speziellen Anhörung zum Aushandeln einer Strafe (audiencia de negociación de penas), die Einführung einer das Urteil vorbereitenden Anhörung, die Möglichkeit, die im Beschluss zur Zulassung der Anklage vorgenommene, rechtliche Qualifizierung nachträglich zu modifizieren sowie die Abschaffung der Möglichkeit zur Verbindung von Strafverfahren. ${ }^{241}$ Dabei wurde der Strafprozess in eine vorprozessuale und zwei prozessuale Phasen unterteilt. Auf der einen Seite standen die Vorermittlungs- und Ermittlungsphase (investigación previa e instrucción), die von Schriftform und Geheimhaltung geprägt waren und in denen sich Ermittlungs-, Anklage- und Entschei-

\footnotetext{
generalmente de orden fáctico, como la necesidad de llevar a cabo la actuación respectiva fuera del territorio jurisdiccional del comitente, la acumulación de trabajo en el despacho de quien comisiona y la urgencia de la prueba [...], cuyo uso debe enmarcarse dentro de los presupuestos e hipótesis que la respectiva norma legal consagre y, claro está, sobre la base de que no puede convertirse en regla general que desplace la función principal -investigación y acusación- a manos de funcionarios ajenos a la Fiscalía y de manera permanente, ya que ello implicaría una delegación de jurisdicción abiertamente inconstitucional.“" (dt. Übersetzung d. Verf.).

${ }^{241}$ Das Ziel dieser Neuerungen war es, die Strafjustiz zu beschleunigen und effektiver zu machen. Vgl. Espitia Garzón, 2015, S. 27-36; auch KVerfG, Entsch. C-646 v. 2001, Abschn. „Consideraciones de la Corte“.
} 
dungsbefugnisse auf die Generalstaatsanwaltschaft konzentrierten; das gerichtliche Verfahren hingegen war öffentlich, mündlich und setzte sich aus einer vorbereitenden Verhandlung und einer Hauptverhandlung zusammen. Diese Struktur des Strafverfahrens ist somit heterogen, da sie gleichzeitig -im Rahmen des Ermittlungsverfahrens- inquisitorische sowie -im Rahmen der Hauptverhandlung- akkusatorische Elemente enthält. ${ }^{242}$

Die Strafprozessordnung übertrug dabei der Kriminalpolizei besondere Ermittlungskompetenzen, mit denen deren Mitglieder ,,vor der gerichtlichen Anordnung der Handlungen und unter Anleitung und Kontrolle des unmittelbar Vorgesetzten Beweismaterial sammeln, Informationsanalyse betreiben, diejenigen vernehmen durften, von denen sie dachten, dass sie Kenntnis von der möglichen Verwirklichung einer Straftat haben könnten“" (Art. 314). ${ }^{243}$ Darüber hinaus erlaubte das Gesetz, dass die Kriminalpolizei autonom die Beweisermittlung anordnete und durchführte „,in Fällen, in denen ein Täter auf frischer Tat und am Tatort ertappt wird oder, wenn aus Gründen bestätigter, höherer Gewalt der Generalstaatsanwalt oder dessen Delegiere die Vorermittlung noch nicht einleiten konnten“ (Art. 315). ${ }^{244}$ Wie auch in der vorherigen Strafprozessordnung vorgesehen war es gemäß Gesetz 600 von 2000 allein die FGN, die derartige Handlungen unmittelbar kontrollierte, und die die Kriminalpolizei darüber hinaus auch beauftragen konnte, die eigentliche Beweisermittlung und sonstigen Maßnahmen zur Aufklärung der Tat vorzunehmen. Das Gesetz erlaubte dabei ein Höchstmaß an Flexibilität, indem es zugestand, dass die Beauftragung über jedweden Kommunikationsweg erfolgen konnte und die Kriminalpolizei zudem ihre Handlungen ,auf die Ermittlung weiterer Beweise und Vornahme von Ermittlungshandlungen ausdehnen konnte, die in Erfüllung des Auftrags aufgetaucht sind, außer es handelt sich um Festnahmen, Hausdurchsuchungen, Telekommunikationsüberwachungen, die das Recht auf Intimität verletzen“ (Art. 316). ${ }^{245}$

Die Staatsanwaltschaft war während des Ermittlungsverfahrens eine Institution mit weit-

\footnotetext{
${ }^{242}$ Vgl. Espitia Garzón, 2015, S. 27-36; Bernal Cuellar/Montealegre Lynett, 2002, s. 133 ff.

${ }^{243}$ Art. 314 Gesetz 600 v. 2000: ,antes de la judicialización de las actuaciones y bajo la dirección y control del jefe inmediato, allegar documentación, realizar análisis de información, escuchar en exposición o entrevista a quienes considere pueden tener conocimiento de la posible comisión de una conducta punible." (dt. Übersetzung d. Verf.).

${ }^{244}$ Art. 315 Gesetz 600 v. 2000: ,en los casos de flagrancia y en el lugar de su ocurrencia o cuando por motivos de fuerza mayor acreditada no pueda el Fiscal General de la Nación o sus delegados iniciar la investigación previa." (dt. Übersetzung d. Verf.).

${ }^{245}$ Art. 316 Gesetz 600 v. 2000: ,a la práctica de otras pruebas técnicas o diligencias que surjan del cumplimiento de la comisión, ex-cepto capturas, allanamientos, interceptación de comunicaciones, las que atenten contra el derecho a la intimidad.“ (dt. Übersetzung d. Verf.). 
reichenden Kompetenzen, bei deren Ausübung sie nur beschränkter Kontrolle unterlag. Am umstrittensten waren hierbei ihre Möglichkeiten zur Anordnung von Sicherungsmaßnahmen (Art. 113 Nr. 2) und zur Einstellung des Ermittlungsverfahrens ohne richterliche Überprüfung (Art. 113 Nr. 4). Auch Maßnahmen, die ursprünglich dem Richter vorbehalten waren, konnten von der Staatsanwaltschaft vorgenommen werden. Diese Konzentration von Kompetenzen in der Person des Staatsanwalts während des Ermittlungsverfahrens durchbrach das institutionelle Gleichgewicht, da dieser gegen den Beschuldigten ohne vorherige oder nachträgliche richterliche Kontrolle Zwangsmaßnahmen durchführen konnte. Es sollte folglich einzig die Annahme, dass die Staatsanwaltschaft sich ausreichend selbst kontrollieren werde, den Schutz der Beschuldigtenrechte gewährleisten. Zu dieser Vermengung von Funktionen der Staatsanwaltschaft, die während des Ermittlungsverfahrens gleichzeitig als Richter und Partei agierte, kam als weiteres Übel hinzu, dass in diesem Verfahrensabschnitt die Prinzipien der Mündlichkeit und Öffentlichkeit nicht verwirklicht wurden.

\section{Kritik und Diagnose}

Dieses prozessrechtliche Modell geriet in eine Krise, inbesondere wegen der Exzesse der FGN bei dem Gebrauch ihrer Ermittlungskompetenzen und der allgemeinen, durch die Anhäufung von Akten verursachten Dauer der Prozesse. ${ }^{246}$ Die Antwort hierauf lieferte eine Verfassungsreform, die die Grundlage für die Entwicklung eines tendenziell akkusatorischen Systems schuf, und die aufgrund der großen Kritik an dem durch das Gesetz 600 von 2000 geregelten Prozessrecht in die Wege geleitet wurde. Vor allem wurde behauptet, die FGN verletze mißbräuchlich die Rechte der strafrechtlich Verfolgten. Nach dem Gesetz 600 von 2000 hatte die FGN nämlich unter anderem die Befugnis, selbstständig dem strafrechtlich Verfolgten Sicherungsmaßnahmen aufzuerlegen. ${ }^{247}$ Dies führte zu notorischen, exzessiven Beschränkungen der persönlichen Freiheit durch die Anordnung der Untersuchungshaft. Die Rolle der FGN im Ermittlungsverfahren als Partei, die ermittelte und anklagte, und als (Ermittlungs-) Richter, der Eingriffe in die persönliche Freiheit des Beschuldigten anordnete, wurde als Beleg dafür gewertet, dass im Ermittlungsverfahren das Recht auf Unparteilichkeit nicht gewahrt sei. ${ }^{248}$ Wie aus der Gesetzesbegründung des Gesetzesaktes 03 von 2002 hervorgeht, liegt eine eindeutige Verletzung der in internationalen

\footnotetext{
${ }^{246}$ Vgl. Vélez Osorio, 2012, S. 49 f.; Gómez Osorio, Estado actual de la justicia colombiana, 2003, S. 116.

${ }^{247}$ Vgl. Bernal Cuellar/Montealegre Lynett, 2002, S. 165 ff.; Martínez Rave, 2002, S. 445 ff.

${ }^{248}$ Vgl. Vélez Osorio, 2012, S. 52; Gómez Osorio, Estado actual de la justicia colombiana, 2003, S. 117.
} 
Veträgen und verfassungsmäßig verbürgten Rechte des Beschuldigten auf persönliche Freiheit und Unparteilichkeit vor, ,wenn [der Staatsanwalt] eine Sicherungsmaßnahme oder Festnahme anordnet, also eine Entscheidung justiziellen Charakters trifft.“249

Die letztgenannte rechtliche Einschätzung wurde zum wesentlichen Argument für die Einleitung des Projekts zur Verfassungsreform mit dem Ziel, das Recht auf persönliche Freiheit, die Unschuldsvermutung und die Menschenwürde zu gewährleisten. ${ }^{250}$ Daher ordnete die Verfassungsreform an, dass eine Verfügung zur Beeinträchtigung der persönlichen Freiheit eines Beschuldigten nur noch mit schriftlicher, richterlicher Anordnung erfolgen dürfe und zudem strengere Maßstäbe an die Bewertung der zugrunde liegenden Beweislage zu setzen seien. ${ }^{251}$ Hiermit wurde die problematische rechtliche Lage des Beschuldigten dahingehend gelöst, dass nunmehr -zwangsläufig- die Anordnung der Untersuchungshaft nicht mehr als einziges Mittel in Betracht gezogen werden konnte, um einen Verdächtigen formal zum Gegenstand des Ermittlungsverfahrens zu machen. Mit der Einführung der Voraussetzung, dass eine Beweisgrundlage gegeben sein muss, auf die sich der Verdacht gegen den Verfolgten stützt, wurde außerdem ein objetkives Kriterium geschaffen, mit dessen Hilfe die Rechtmäßigkeit freiheitsbeschränkender Maßnahmen bewertet werden konnte.

\section{Politischer Kontext der Strafprozessrechtsreform von 2002}

Die angesprochene Verfassungsreform erfolgte am 19.12.2002 durch den Gesetzesakt 03 von 2002 und fiel mit dem Beginn der Amtszeit des Staatspräsidenten Álvaro Uribe Vélez zusammen, der sich zum Ziel gesetzt hatte, sein Programm der „Politik der demokratischen Sicherheit" (política de seguridad democrática) umzusetzen. Ein Kernpunkt dieses Programms war, im gesamten Land die Präsenz und Aktivitäten der staatlichen Sicherheitsorgane zu stärken. Zudem sollte aber die Gewährleistung der öffentlichen Sicherheit nicht nur Aufgabe der Staatsorgane sein, sondern auch eine Pflicht der Bürger, deren Kooperation dabei helfen sollte, die im Land aktiven, illegalen bewaffneten Gruppen erfolgreich zu bekämpfen. ${ }^{252}$ Der im Namen der Politik der demokratischen Sicherheit geführte „Kampf

\footnotetext{
${ }^{249}$ Gesetzblatt 134 von 24.04.2002, Gesetzesbegründung, Nr. II. A: „cuando [el fiscal] profiere una medida de aseguramiento, cuando ordena una captura, en fin, cuando toma decisiones de carácter judicial, es clara la afectación del principio de imparcialidad del juzgador, en desmedro de los tratados internacionales y de las propias garantías que la Carta consagra." (dt. Übersetzung d. Verf.).

${ }^{250}$ Gesetzblatt 134 von 24.04.2002, Gesetzesbegründung, Nr. V. D. 3.

${ }^{251}$ Gesetzblatt 134 von 24.04.2002, Gesetzesbegründung, Nr. V. D. 3.

${ }^{252}$ Die Beteiligung der Bürger sollte dabei über die Einrichtung sogenannter Kooperantennetzwerke, die 
gegen die Kriminalität“ und der „Krieg gegen den Terrorismus“ gingen mit der Forderung nach höherer Effektivität der Strafjustiz und Stärkung des ius puniendi einher und konterkarierten die durch die Verfassungsreform eingeleiteten Bemühungen zur Verbesserung des Rechtsschutzes der Beschuldigten. ${ }^{253}$ Dies äußerte sich einerseits darin, dass die Möglichkeit der Kriminalpolizei, Ermittlungsmaßnahmen ohne Anordnung des Staatsanwaltes durchzuführen, verstärkt wurde, andererseits wurde die Rolle der Strafgerichte bei der Kontrolle zahlreicher polizeilich-präventiver Maßnahmen beschränkt. ${ }^{254}$

Die Eingliederung derartiger sog. extraprozessualer Maßnahmen, d.h. der polizeilichen Aktivitäten ohne richterliche Kontrolle, in das strafrechtliche, staatliche Eingriffssystem, folgte der Auffassung, dass auf diese Weise der Kampf gegen Kriminalität und die Gewährleistung der öffentlichen Sicherheit effektiver ausgestaltet werden könne. Das ursprüngliche Ziel der Verfassungsreform, die Defekte des vorherigen Strafprozessrechts bzgl. des Schutzes der Beschuldigtenrechte zu beseitigen, wurde insoweit durch die Notwendigkeit überlagert, das Strafprozessrecht den neuen Vorgaben der Politik der demokratischen Sicherheit anzupassen. Somit wurde zwar mit dem Gesetz 906 von 2004 eine Strafprozessordnung geschaffen, die allerdings -im Widerspruch zu der ursprünglichen Intention- mit einer Reihe von Regelungen versehen war, die dazu dienen sollten, die Befugnisse der FGN auszuweiten und somit die Kriminalitätsbekämpfung effektiver zu gestalten. Der beste Beleg hierfür ist, dass der Generalstaatsanwaltschaft auch in dieser neuen Strafprozessordnung Befugnisse gewährt wurden, die eigentlich dem Ermittlungsrichter zustehen sollten, d.h. die Befugnis, Festnahmen, Hausdurchsuchungen, und Telekommunikationsüberwachungen anzuordnen, also erhebliche Grundrechtseingriffe ohne richterlichen Vorbehalt vornehmen zu können. ${ }^{255}$

Die Anpassung des Strafprozessrechts an die Vorgaben der „Politik der demokratischen Sicherheit“" war zugleich Ergebnis von Kompromissen zwischen den Regierungen Kolumbiens und der Vereinigten Staaten, die darauf abzielten, das kolumbianische Rechtssystem in allen Bereichen zu stärken. Im Wesentlichen sollte die Antidrogenpolitik und die wirt-

\footnotetext{
Auslobung finanzieller Belohnungen für Informanten, und die Schaffung bäuerlicher Soldateneinheiten erfolgen. Zudem sollten Mitglieder der bewaffneten Gruppen zur Aufgabe bewegt werden und der staatliche Militärhaushalt wurde erheblich erhöht. Vgl. GMH, 2013, S. 179 f.

${ }^{253}$ Für eine Darstellung der demokratischen Sicherheitspolitik als Kriminalpolitik s. Muñoz Tejada, 2015, S. 103 ff.; Bzgl. des Einflusses der demokratischen Sicherheitspolitik in dem Gesetz für Gerechtigkeit und Frieden vgl. Ambos, 2010 a, Rn. 63.

${ }^{254}$ Vgl. Muñoz Tejada, 2015, S. 166 ff.; Vélez Osorio, 2012, S. 45 ff.

255 Vgl. Zuluaga, Boletin GLIPGö 5 (2013), S. 23 ff.; Vélez Osorio, 2012, S. 45 ff.
} 
schaftliche Öffnung Kolumbiens durch Steigerung der (Rechts-) Sicherheit für Investoren vorangetrieben werden. Der bekannteste dieser Kompromisse war der sog. „Plan Kolumbien“ (Plan Colombia), der noch unter Federführung Bill Clintons und des damaligen kolumbianischen Präsidenten Andrés Pastrana Arango ausgearbeitet worden ist und der von Kolumbien unter anderem den Übergang zu einem akkusatorischen Strafprozesssystem verlangte. Dementsprechend führt das Übereinkommen aus:

„Kolumbien hat sich verpflichtet, Rechtsstaatlichkeit zu respektieren, und wird das Justizsystem in allen Bereichen weiter stärken. Dies beinhaltet die Unterstützung beim fortwährenden Übergang zu einem akkusatorischen System (welches mündliche Prozesse und effektive Ermittlungen beinhaltet) und zu einer Beschleunigung der Prozesse im gesamten Justizsystem mit dem Ziel, sicherzustellen, dass allgemein Zugang zur Justiz besteht unabhängig vom geographischen Standort oder der Höhe des Einkommens. “256

Die Strafprozessrechtsreform fand sich mithin in einem Kontext wieder, in dem die Kriminalitätskontrolle auch als eine Form der Sicherstellung ausländischer Investitionen und der Stärkung des Markts verstanden wurde, und in dem die Hilfen der amerikanischen Regierung für die staatlichen Sicherheitskräfte und die Justizverwaltung bedeutsam waren. ${ }^{257}$ Die US-amerikanische Hilfestellung war dabei aber nicht in erster Linie durch den Kampf gegen den Drogenhandel und Terrorismus an sich motiviert, sondern vom Schutz der sich in Kolumbien befindenden Ölfelder und Pipelines. ${ }^{258}$ Sie wurde in Kolumbien akzeptiert, angenommen und umgesetzt mit dem Hinweis, dass „, Kolumbien auch im Hinblick auf die zukünftige Unterzeichnung von Freihandelsabkommen [...] aus seinem Justizsystem ein Wettbewerbsinstrument und einen Verbündeten bei der Entwicklung [des Landes] machen kann. “259

\footnotetext{
${ }^{256}$ Presidencia de la República „"Plan Colombia": Plan para la Paz, la prosperidad y el fortalecimiento del Estado, Presidente de la República, Andrés Pastrana Arango, edición de octubre de 1999, Capítulo IV: „Colombia se ha comprometido a respetar el Estado de derecho y seguirá fortaleciendo todos los aspectos de su sistema judicial. Esto incluye el apoyo para la transición continua a un sistema acusatorio (incluidos procesos verbales e investigaciones eficaces) y a una mayor agilidad de proceso en todo el sistema judicial, con el fin de asegurar que habrá acceso universal a la justicia sin importar la ubicación geográfica o nivel de ingresos.“ („Plan Colombia“ Plan für Frieden, Wohlstand und Stärkung des Staates, Präsident der Republik Andrés Pastrana Arango, Ausgabe Oktober 1999, Kapitel IV -dt. Übersetzung d. Verf.-).

${ }^{257}$ Vgl. Velásquez Velásquez, Revista Berbiquí 29 (2005), S. 5 f.; Vélez Osorio, 2012, S. 55.

${ }^{258}$ Vgl. Iturralde, 2010, S. 313; Vélez Osorio, 2012, S. 56.

${ }^{259}$ González Cuervo, El Tiempo, 11.10.2003: „tampoco en la víspera de suscribir tratados de libre comercio, puede darse mañas con procesos interminables que alejan la inversión y el empleo. A partir de la reforma constitucional que anuncia el Gobierno (sic), Colombia puede hacer de su sistema judicial un instrumento de competitividad y un aliado del desarrollo." 


\section{Zusammenfassung}

Die bewaffnete Gewalt ist eine kontinuierliche Praxis in der politischen Historie Kolumbiens und die vorherrschende Rechtfertigung der Reformen des Strafverfahrens. Von der sog. „Epoche der Violencia“, bis hin zur „Frente Nacional“ (Nationale Front), der Erscheinung von Guerillabewegungen und paramilitärischen Gruppen bis hin zur Verstärkung des Drogenhandels ist die Gewalt ein überwiegender Grund für die Ausweitung der Befugnisse der Polizei zur Intervention in die Grundrechte gewesen. Der juristische Rahmen hierfür wurde dabei zumeist durch das Ausrufen des sog. „Belagerungszustands“ (Estado de sitio) geschaffen. Der „Zustand innerer Aufruhr“ hat zur Verabschiedung der als „Sicherheitsstatuten“ bezeichneten Rechtsverordnungen geführt, unter denen das Sicherheitsstatut, das offizielle nationale Betäubungsmittelstatut, das Statut zur Verteidigung der Demokratie und das Statut zur Verteidigung der Justiz die Wichtigsten waren. Die Ausdehnung der Militärgerichtsbarkeit auf Zivilpersonen und die Erweiterung der Kompetenzen der Polizei im Ermittlungsverfahren führten zu der Verkündung einer Verfassung im Jahr 1991 mit einem detailliert ausgestalteten Katalog von Grundrechten, weitläufig ausgestalteten Mechanismen zum Schutz dieser Rechte und Regelungen zur Verbesserung der Möglichkeiten politischer Teilhabe. Auch in strafverfahrensrechtlicher Hinsicht brachte die Verfassung von 1991 Neuerungen. Als solche am bedeutsamsten war die Einrichtung einer Generalstaatsanwaltschaft. Diese Neuerung wurde im Folgenden durch eine Reform der kolumbianischen Strafprozessordnung auf einfachgesetzlicher Ebene durch das Dekret 2700 von 1991 umgesetzt, die durch weitere Reformen des Straf(prozess)rechts nämlich durch die Gesetze 81 von 1993 und 600 von 2000 komplementiert wurde. Dieses prozessrechtliche Modell geriet in eine Krise, insbesondere wegen der Exzesse der Staatsanwaltschaft bei dem Gebrauch ihrer Ermittlungskompetenzen und der allgemeinen, durch die Anhäufung von Akten verursachten Dauer der Prozesse. Die Antwort hierauf lieferte eine Verfassungsreform, die die Grundlage für die Entwicklung eines tendenziell akkusatorischen Systems schuf und am 19.12.2002 durch den Gesetzesakt 03 von 2002 erfolgte. 


\section{§ 3. Das strafrechtliche Ermittlungsverfahren in Kolumbien}

\section{A. Charakterisierung des „neuen“ Ermittlungsverfahrens}

Das Ermittlungsverfahren im „neuen” kolumbianischen Strafprozess wird durch den in der Verfassung von 1991 vorgegebenen verfassungsrechtlichen Rahmen bedingt, der die Grenzen seiner Durchführung festgelegt, somit direkt Einfluss auf dessen praktische Umsetzung nimmt. ${ }^{260}$ Die Grundlagen für das Einholen und Aufbewahren von Beweismitteln sind verfassungsrechtlich vorgegeben und in der aktuellen Strafprozessordnung (Gesetz 906 von 2004) näher ausgestaltet. Sowohl der Kompetenzrahmen der Beteiligten und die Regeln, die das Sammeln von Beweisen normieren, als auch andere Maßnahmen der Staatsanwaltschaft und der Kriminalpolizei im Ermittlungsverfahren müssen in Übereinstimmung mit den verfassungsmäßig und menschenrechtlich verbürgten Rechten und Prinzipien interpretiert und ausgeübt werden. $^{261}$ Verfassungskonformität bedeutet, dass die Wahrheitsfindung im kolumbianischen Strafprozess auf keinen Fall durch unangebrachte Eingriffe in die Grundrechte des Beschuldigten erfolgen darf. Dass das Verhalten der verschiedenen am Strafverfahren teilnehmenden Organe und Institutionen verfassungsmäßigen Schranken unterworfen ist, die auch Grundrechtseingriffe im Ermittlungsverfahren von bestimmten Voraussetzungen abhängig machen, ist dem Geltungsanspruch des Rechts auf Achtung der Menschenrechte und der notwendigen hierarchischen Struktur der Rechtsordnung geschuldet. $^{262}$

Letzteres ergibt sich im Wesentlichen aus Art. 4 der $\mathrm{CN}$, nach dem die Verfassung die Norm der Normen ist und jede Behörde die Anwendung einer Norm oder Vornahme einer Maßnahme unterlassen kann, wenn sie befindet, dass diese der Verfassung widersprechen würde (Ausnahme der Verfassungswidrigkeit). ${ }^{263}$ In Bezug auf das Ermittlungsverfahren

\footnotetext{
${ }^{260}$ Vgl. Bernal Cuellar/Montealegre Lynett, 2013 T. I, S. 144; KVerfG, Entsch, C-217 v. 1996, Abschn. „Consideraciones de la Corte“.

${ }^{261} \mathrm{Vgl}$. Art. $93 \mathrm{CN}$ : „Los tratados y convenios internacionales ratificados por el Congreso, que reconocen los derechos humanos y que prohíben su limitación en los estados de excepción, prevalecen en el orden interno.“ („Völkerrechtliche Verträge und Übereinkommen, die vom Parlament ratifiziert wurden, die Menschenrechte erkennen und ihre Einschränkung in Ausnahmezuständen verbieten, überwiegen in der innerstaatlichen Rechtsordnung." -dt. Übersetzung d. Verf.-).

${ }^{262}$ Vgl. Bernal Cuellar/Montealegre Lynett, 2013 T. I, S. 74 ff.

${ }^{263}$ Art. 4 CN: „La Constitución es norma de normas. En todo caso de incompatibilidad entre la Constitución y la ley u otra norma jurídica, se aplicarán las disposiciones constitucionales.“(dt. Übersetzung d. Verf.).
} 
und die Pflicht des Staats zur Wahrheitsfindung zwecks Findung eines gerechten Urteils finden sich diese Vorgaben in den Verfassungsnormen zur Verantwortlichkeit des Einzelnen für Gesetzesverletzungen (Art. 6), dem Verbot der Todesstrafe (Art. 11), dem Verbot unmenschlicher oder herabsetzender Behandlung (Art. 12), dem Recht auf Intimität (Art. 15), dem Verbot willkürlicher Festnahmen (Art. 28), dem Recht auf einen fairen Prozess (Art. 29.), dem Habeas Corpus-Grundsatz (Art. 30), dem Recht auf ein Rechtsmittel (Art. 31), den Regelungen zur Festnahme bei auf frischer Tat ertappt (Art. 32), dem Recht, sich nicht selbst belasten zu müssen (Art. 33), und dem Verbot von Verbannung und lebenslanger Strafe (Art. 34) wieder. Dieser verfassungsrechtliche Rahmen zur Anwendung der staatlichen Strafgewalt bestimmt die Art und Weise, wie mit einer Straftat umzugehen ist, und stellt die strafrechtlichen Grundsätze eines demokratischen Rechtsstaats dar. Die CN gibt insoweit eindeutig ein Strafverfahrensmodell vor, in dem das Ermittlungsverfahren und die Wahrheitsfindung in vollständigem Einklang mit den Beschuldigtenrechten zu erfolgen haben. ${ }^{264}$

Das Ziel, dies zu gewährleisten und das natürliche Spannungsverhältnis zwischen dem Recht der Opfer auf und der Pflicht des Staats zur Wahrheitsfindung und dem Schutz der Rechte des Beschuldigten zu lösen, stellte die Grundlage für die vom kolumbianischen Gesetzgeber mit dem Gesetzesakt 03 von 2002 in Angriff genommenen Reformen dar. Mit diesen wurde ein Strafprozessrecht mit ,akkusatorischer Tendenz“ geschaffen, in dem der Richter, insbesondere während des Ermittlungsverfahrens, die spezielle Rolle des Schutzwächters über die Rechte des Beschuldigten einnimmt. ${ }^{265}$

\section{Verfassungsrechtliche Grundlagen des Ermittlungsverfahrens}

Mit dem Gesetzesakt 03 von 2002 wurde die CN dahingehend reformiert, dass die Voraussetzungen für ein tendenziell akkusatorisches Strafprozesssystem geschaffen wurden. Nach dem neuen Modell bedurfte jeder Eingriff in die Grundrechte des Beschuldigten durch die Staatsanwaltschaft oder durch andere Ermittlungsorgane einer richterlichen Entscheidung in Form der Anordnung oder der Bestätigung der Maßnahme, in deren Rahmen die Vereinbarkeit mit den verfassungsrechtlichen Vorgaben geprüft wird

\footnotetext{
${ }^{264}$ Vgl. Guerrero Peralta, 2007, S. 37 ff.; siehe u.a. KVerfG, Entsch. T-546 v. 2000, Abschn. „Consideraciones de la Corte“; KVerfG, Entsch. T-039 v. 1996, Abschn. „Consideraciones de la Corte“.

${ }^{265}$ Vgl. Bernal Cuellar/Montealegre Lynett, 2013 T. I, S. 225 ff.; Guerrero Peralta, 2007, S. 177 ff. 
(Richtervorbehalt). ${ }^{266}$ Die Betonung der Notwendigkeit einer richterlichen Entscheidung über grundrechtsberührende Ermittlungsmaßnahmen ist ein Aspekt, der das besagte Modell von den akkusatorischen Prozessmodellen in Amerika und Kontinentaleuropa unterscheidet. ${ }^{267}$ Die Ausgestaltung entspricht keinem adversatorischen Modell in dem Sinne, dass zwei Parteien sich unter gleichen Bedingungen gegenüberstehen, von denen die eine, die Anklagebehörde, versucht, die Strafbarkeit des Angeklagten nachzuweisen, während dieser versucht, seine Unschuld $\mathrm{zu}$ belegen. ${ }^{268} \mathrm{Im}$ Folgenden soll die Charakteristika der aufgrund der Verfassungsreform entwickelten neuen Strafprozessordnung beschrieben werden:

\section{Gesetzesakt 03 von 2002}

Der Gesetzesakt 03 von 2002 reformierte die Verfassungsartikel 116, 250 und 251, um die verfassungsrechtlichen Grundvoraussetzungen zur Überwindung der Defizite des alten Strafprozessmodells zu schaffen, insbesondere der „Ineffizienz im Kampf gegen die

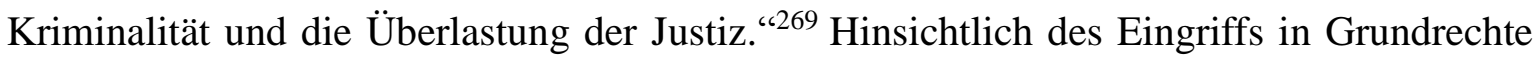
während des Strafprozesses führte die genannte Verfassungsreform ein Grundmodell zur Wahrung strafprozessualer Garantien ein. In diesem Rahmen wurde eine Instanz mit der Bezeichnung Richter zur Kontrolle der Verfahrensgarantien (Juez de Control de Garantias) eingeführt. ${ }^{270}$ Als Grundelemente dieses Modells sind die Folgenden zu nennen: (i) die Anwendung des Grundsatzes „nemo judex sin actore“; (ii) der justizielle Charakter der Ermittlungs- und Anklagebehörde; (iii) der Richter zur Kontrolle der Verfahrensgarantien; (iv) die Einführung des Opportunitätsprinzips und (v) die Ermächtigung der FGN zur Auferlegung von Maßnahmen, die das Recht auf Intimität beschränken, allerdings mit

\footnotetext{
${ }^{266} \mathrm{Vgl}$. dazu supra § 1. D. Überblick über das richterliche Rechtsschutzsystem in Kolumbien und infra § 4. B. Funktion und Aufgaben des Richters zur Kontrolle der Garantien.

${ }^{267}$ I.d.S. KVerfG, Entsch. C-591 v. 2005, Abschn. ,2.2. Características esenciales y propias del nuevo sistema procesal penal colombiano". Für die Charakterisierung von akkusatorischen Prozessmodellen s. Ambos, Jura 30 (2008), S. 586 ff.; Ambos, Proceso penal y sistemas acusatorios, 2008, S. 49-72 m.w.N.

${ }^{268} \mathrm{Vgl}$. KVerfG, Entsch. C-591 v. 2005, Abschn. ,2.2. Características esenciales y propias del nuevo sistema procesal penal colombiano“; KVerfG, Entsch. C-873 v. 2003, Abschn. 3.4.4. „Análisis de los cambios introducidos por el Acto Legislativo“; dazu infra § 3. A. I. 2. Die Art des Strafprozesssystems.

${ }^{269}$ Dazu supra § 2. C. II. 2. Kritik und Diagnose.

${ }^{270}$ Der JCG überwaht die Eingriffe in die Grundrechte des Beschuldigten und die Ausübung von Ermittlungsmaßnahmen. Vgl. dazu supra § 1. D. I. Rechtsschutz durch den JCG und ausführlich infra § 4. Der Richter zur Kontrolle der Garantien (Juez de Control de Garantías).
} 
nachträglicher richterlicher Kontrolle. ${ }^{271} \mathrm{Zu}$ den mit der Reform verfolgten Zielen zählte die Trennung zwischen Ermittlungs- und Hauptverfahren, womit wichtige Änderungen einhergingen, wie die Ausweitung des Rechts auf einen unparteiischen Richter und ein schnelleres Verfahren (siehe infra a. Ziele). Ebenso wurden dadurch, dass die Grundsätze dieses Modells Verfassungsrang erhielten, spezifische Parameter für die Auslegung und Anwendung der strafprozessualen Normen geschaffen (siehe infra b. Auswirkungen für die Auslegung des Strafgesetzes). Außerdem wurden auch die Kompetenzen der verschiedenen, am Strafprozess Beteiligten bestimmt (siehe infra c. Befugnisse der Beteiligten).

\section{a. Ziele}

Wie bereits erwähnt, war das vorrangige Ziel der Reformen durch den Gesetzesakt 03 von 2002, die Ineffizienz des Strafprozesssystems zu überwinden. Der Kontext, in dem die Ineffizienz der Strafjustiz diskutiert wurde, war zudem geprägt von der Forderung nach mehr strafrechtlichen Eingriffen zur Lösung verschiedener Probleme der öffentlichen Sicherheit, die Kolumbien zu diesem Zeitpunkt durchlebte. Daneben wurde reklamiert, dass sowohl auf Seiten der Angeklagten wie auch der Opfer Verfahrensrechte fehlten. ${ }^{272}$

\section{i. Institutionelle Zwecke}

(aa) Stärkung der Ermittlungsfunktion der FGN im Sinne einer Konzentration auf die Beweiserhebung. Im vorherigen Strafprozessmodell galt das Gebot einer umfassenden Ermittlung, folglich musste die Staatsanwaltschaft alles ermitteln, was den Beschuldigten be- und entlasten könnte (Art. 20 Gesetz 600 von 2000). ${ }^{273}$ Sie hatte daher nicht nur die Ermittlungen zu leiten, sondern fungierte gleichzeitig als Anklagebehörde, Verteidigung und Richter im Ermittlungsverfahren, was zweifelsohne die Wahrnehmung ihrer prinzipiellen Funktion erschwerte. Als Lösung für dieses Problem wurde die Zuständigkeit der Staatsanwaltschaft für die Entscheidung über Eingriffe in Grundrechte des

\footnotetext{
${ }^{271}$ Vgl. KVerfG, Entsch. C-591 v. 2005, Abschn. ,2.2. Características esenciales y propias del nuevo sistema procesal penal colombiano“; KVerfG, Entsch. C-873 v. 2003, Abschn. 3.4.4.3. „Los rasgos estructurales del procedimiento penal.“

${ }^{272} \mathrm{Vgl}$. Aponte Cardona, 2006 b, S. $411 \mathrm{ff}$.

${ }^{273}$ Art. 20 Gesetz 600 von 2000 „Investigación integral. El funcionario judicial tiene la obligación de investigar tanto lo favorable como lo desfavorable a los intereses del imputado“(„Integrales bzw. vollständiges Ermittlungsprinzip. Die Amtsperson hat die Pflicht, sowohl das Belastende als auch das Entlastende zu den Interessen des Beschuldigten zu untersuchen.“- -dt. Übersetzung d. Verf.-); dazu KVerfG, Entsch. C-760 v. 2001, Abschn. „Consideraciones de la Corte“.
} 
Beschuldigten aufgehoben, um eine Fokussierung auf die Aufgaben der Ermittlung und Anklage zu gewährleisten. Dies erlaubte den Ermittlern, sich auf ihre Amtspflicht zur Beweiserhebung und Dokumentation ihrer Ermittlungsmaßnahmen zu spezialisieren. Man versprach sich hiervon, dass die Staatsanwaltschaft ihre Ermittlungstätigkeit effizienter und erfolgreicher betreiben würde. ${ }^{274}$

(bb) Entlastung der Gerichte. Auf der einen Seite erfolgte dies durch den Übergang von einem schriftlich zum mündlich geführten Strafprozess und somit die Gewährleistung des Rechts auf ein schnelles Verfahren ohne ungerechtfertigte Verzögerungen. ${ }^{275}$ Auf der anderen Seite durch die Inkorporierung von Mechanismen zur vorzeitigen Verfahrensbeendigung wie das Opportunitätsprinzip, wodurch die Strafjustiz vereinfacht, beschleunigt und effektiver gestaltet und insbesondere im Bereich kleiner und mittlerer Kriminalität entlastet werden sollte. ${ }^{276}$

\section{ii. Strafprozessuale Zwecke}

(aa) Einführung des Richters zur Kontrolle der Verfahrensgarantien. Der Gesetzesakt 03 von 2002 schuf den Richter zur Kontrolle der Verfahrensgarantien (Art. 250 Nr. 2 CN), dem die Aufgabe zukam (i) die Staatsanwaltschaft bei der Anwendung des Opportunitätsprinzips zu überwachen; (ii) freiheitsbeschränkende Maßnahme einer Vorabkontrolle zu unterziehen und (iii) Maßnahmen wie die Feststellung der persönlichen Daten, Hausdurchsuchungen und Telekommunikationsüberwachungen nachträglich zu kontrollieren.

(bb) Einführung des Anklagegrundsatzes. Durch die Einführung des Anklagegrundsatzes ist eine klare Trennlinie einerseits zwischen den Funktionsbereichen Ermittlung und Anklage und andererseits zwischen der Rechtsprechung zu ziehen, um den Strafprozess an die internationalen Standards zur richterlichen Unabhängigkeit gemäß Art. 8 AMRK anzupassen. In dem neuen akkusatorischen Modell ist der Beschuldigte/Angeklagte nun nicht mehr nur passiver Beteiligter, wie dies unter Geltung des Gesetzes 600 von 2000 der Fall war, sondern er hat sogar schon vor Erhebung der Anklage Möglichkeiten zur aktiven

\footnotetext{
${ }^{274}$ KVerfG, Entsch. C-591 v. 2005, Abschn. 2.2.; KVerfG, Entsch. C-873 v. 2003, Abschn. 3.4.2.2.

${ }^{275}$ KVerfG, Entsch. C-591 v. 2005, Abschn. 2.2.

${ }^{276}$ KVerfG, Entsch. C-591 v. 2005, Abschn. 2.2.
} 
Beteiligung am Verfahren. ${ }^{277}$ Ohne die Unschuldsvermutung umzukehren, verteilen sich daher die prozessualen Befugnisse auf die Staatsanwaltschaft und den Beschuldigten, dem es zusteht, mit eigenem Vorbringen die Vorwürfe der Anklage anzugreifen ebenso wie diejenigen der Opfer, die ebenfalls Beteiligungsmöglichkeiten erhalten haben.

(c) Einführung des öffentlichen, mündlichen, kontradiktorischen und konzentrierten Hauptverfahrens. Ziel der Einführung des Mündlichkeitsgrundsatzes war es, nicht nur die Strafjustiz zu beschleunigen, sondern auch die Diskussion über Vorwürfe und Beweismittel unmittelbarer zu machen und hierdurch sowohl Fehlurteile als auch Straflosigkeit zu vermeiden. ${ }^{278}$ Aus diesem Grund finden nach der neuen Strafprozessordnung solche Beweismittel keine Beachtung, die nicht in öffentlicher, mündlicher und konzentrierter Form vorgebracht wurden, ohne dass die Gegenseite auf sie unmittelbar vor dem Erkenntnisrichter reagieren konnte. Die Einführung des Mündlichkeitsgrundsatzes sollte außerdem bewirken, dass die richterliche Entscheidung der Kontrolle der Beteiligten, der Medien und der Gesellschaft insgesamt unterliegt.

(d) Modifizierung des Beweisrechts. Die Modifizierung des Strafprozessrechts betraf auch das Beweisrecht, da das vormals geltende Prinzip, nach dem die von der FGN ab der Vorermittlungsphase erhobenen und vorgebrachten Beweise auch die Grundlage für das Strafurteil darstellten, dadurch ersetzt wurde, dass wegen der nunmehr eingeführten Unmittelbarkeits- und Konzentrationsmaxime die Beweismittel dem Erfordernis der in einem öffentlichen und mündlichen Hauptverfahren durchgeführten Beweisaufnahme unterliegen. ${ }^{279}$ Die Beweise aus dem Ermittlungsverfahren taugen somit zwar als Grundlage für die Entscheidung über die Vornahme bestimmter Ermittlungsmaßnahmen, aber sie können nicht die Grundlage des Strafurteils bilden, wenn sie nicht auch im Rahmen des Hauptverfahrens eingeführt wurden. ${ }^{280}$

(e) Einführung des Opportunitätsprinzips. Gemäß dem durch Gesetzesakt 03 von 2002 geänderten Artikel 250 der Verfassung soll das Opportunitätsprinzip nur ausnahmsweise angewendet werden. Es unterliegt der Kontrolle der Verfahrensgarantien durch den hierfür

\footnotetext{
${ }^{277}$ KVerfG, Entsch. C-591 v. 2005, Abschn. 2. „La práctica de pruebas anticipadas, en circunstancias excepcionales no vulnera el principio de inmediación de la prueba en un sistema acusatorio“; dazu Bernal Cuellar/Montealegre Lynett, 2013 T. I, S. 226.

${ }^{278}$ KVerfG, Entsch. C-591 v. 2005, Abschn. 2.2.

${ }^{279}$ KVerfG, Entsch. C-591 v. 2005, Abschn. 2.; s. auch Entsch. C-1154 v. 2005, Abschn. „Consideraciones de la Corte“; C-059 v. 2010, Abschn. „Consideraciones de la Corte“.

${ }^{280}$ KVerfG, Entsch. C-591 v. 2005, Abschn. 2.; C-059 v. 2010, Abschn. „Consideraciones de la Corte“; dazu Cuello Iriarte, 2008, S. 682 ff. 
zuständigen Richter unter Beteiligung der Disziplinarstaatsanwaltschaft (Procuraduría) sowie des Opfers der vermeintlichen Straftat, welches vor der Entscheidung anzuhören ist. ${ }^{281}$ Zudem wird die Anwendung des Opportunitätsprinzips durch eine Verfügung der FGN behördenintern näher ausgestaltet. ${ }^{282}$

\section{b. Auswirkungen der Verfassungsreform auf die Auslegung strafpro- zessrechtlicher Normen}

Nach dem Grundsatz der Einheit der verfassungsmäßigen Ordnung (Art. $4 \mathrm{CN}$ ) sind die aufgrund der Verfassungsreform eingeführten Neuerungen verfassungskonform auszulegen. Bei der Normauslegung sind mithin nicht nur die Normen der Strafprozessordung zu beachten, sondern auch diejenigen des Gesetzesakts 03 von 2002 und die übrigen Normen der $\mathrm{CN}$, $\mathrm{zu}$ denen wegen des Grundsatzes des „Verfassungsblocks““ (bloque de contitucionalidad) gemäß Art. 93 (Vorrang internationaler Verträge und Abkommen) insbesondere auch Art. 8 (Verfahrensgarantien), Art. 9 (Legalitätsprinzip und Rückwirkungsverbot) und Art. 27.2 (Aussetzung von Vertragspflichten) der AMRK gehören, ebenso wie Art. 4 (Aussetzung von Vertragspflichten) und Art.15.1 (Rückwirkungsverbot) des IPBPR. ${ }^{283}$ Aus diesem Grund wurde auch in Art. 3 der aktuell geltenden Strafprozessordnung (Gesetz 906 von 2004) ausdrücklich geregelt, dass die von Kolumbien ratifizierten internationalen Abkommen und Verträge, die sich auf Menschenrechte beziehen, Vorrang haben und deren Geltung auch nicht im Falle eines Notstands beschränkt werden kann. ${ }^{284}$ Mittelbar sind daher für die Auslegung der Strafprozessrechtsnormen auch die Gutachten des IAGMR, vereinzelte Resolutionen der Generalversammlung der VN, insbesondere diejenigen, die sich auf Opferrechte, richterliche Unabhängigkeit und Häftlingsrechte beziehen, ebenso wie die Stellungnahmen und Empfehlungen weiterer internationaler Organisationen zu Fragen des Menschenrechtsschutzes und des humanitären Völkerrechts mit heranzuziehen. ${ }^{285}$

\section{c. Rechte der Beteiligten}

\footnotetext{
${ }^{281}$ KVerfG, Entsch. C-591 v. 2005, Abschn. 2.2.; dazu ausführlich Molina López, 2012, S. 157 ff.

282 Vgl. Beschluss der FGN 6657 von 2004, Art. 1 ff.; dazu Forero Ramírez, 2013, S. 273

${ }^{283}$ Vgl. KVerfG, Entsch. C-591 v. 2005, Abschn. 2.2.; Guerrero Peralta, 2007, 37 ff.

${ }^{284}$ Art. 3 CPP: ,, Prelación de los tratados internacionales. En la actuación prevalecerá lo establecido en los tratados y convenios internacionales ratificados por Colombia que traten sobre derechos humanos y que prohíban su limitación durante los estados de excepción, por formar bloque de constitucionalidad."

${ }^{285}$ KVerfG, Entsch. C-591 v. 2005, Abschn. 2.2.
} 
Zur Umsetzung des Akkusationsprinzips und der grundsätzlichen Prinzipien des Hauptverfahrens hat die Verfassungsreform auch die Kompetenzen der am Prozess teilnehmenden Akteure modifiziert. $\mathrm{Zu}$ den wichtigsten Neuerungen zählen dabei die folgenden:

\section{i. Einleitung des Ermittlungsverfahrens}

Die Kompetenz zur Einleitung des Ermittlungsverfahrens liegt beim Staat in Form der FGN. Privatpersonen und andere staatliche Institutionen können die zuständige Behörde durch eine Anzeige (Art. 67 CPP), Sonderpetition (Art. 75 CPP) oder Strafantrag (querella) (Art. 71 CPP) von einem möglicherweise strafbaren Verhalten in Kenntnis setzen. Die Ermächtigung zur Durchführung des Ermittlungsverfahrens liegt ebenfalls bei der FGN (Art. 66 CPP). Der reformierte Art. $250 \mathrm{CN}$ verpflichtet diese, „die Strafsache einzuleiten und die Ermittlung des möglicherweise die Merkmale einer Straftat erfüllenden Verhaltens vorzunehmen, wenn ausreichende Beweggründe und faktische Umstände vorliegen, die das Vorliegen eines solchen möglich erscheinen lassen“. ${ }^{286}$ Die Norm führt mithin eine Voraussetzung für die Einleitung eines Ermittlungsverfahrens ein: Es müssen belastbare Motive und Anhaltspunkte ${ }^{287}$ vorliegen, die auf eine Straftat hindeuten.

\section{ii. Erhebung der Anklage und Beibringung von Beweisen}

Das Anklagemonopol liegt bei der Staatsanwaltschaft, nicht allerdings die Disposition zur Einstellung des Ermittlungsverfahrens, die nach der Verfassungsreform dem Erkenntnisrichter auf Antrag der Staatsanwaltschaft vorbehalten ist (Art. 250 Nr. $5 \mathrm{CN}$ ). Zur Erhebung von Beweisen sind sowohl die Staatsanwaltschaft als auch der Angeklagte und der Richter ermächtigt; allerdings wurden mit Nummer 4 und dem letzten Absatz des Artikels $250 \mathrm{CN}$, welcher durch den Gesetzesakt 03 von 2002 geändert wurde, in beweisrechtlicher Hinsicht elementare Änderungen eingeführt. Die Grundsätze der Unmittelbarkeit (Art. 8 (k), 16, 379 CPP) und der Kontradiktion (Art. 15, 378 CPP) verlangen, dass die Beweisaufnahme vor dem Richter im Rahmen des Hauptverfahrens stattfindet, und bieten außerdem der Staatsanwaltschaft wie der Verteidigung das Recht,

\footnotetext{
${ }^{286}$ Art. 250 CN: ,adelantar el ejercicio de la acción penal y realizar la investigación de los hechos que revistan las características de un delito que lleguen a su conocimiento, siempre y cuando medien suficientes motivos y circunstancias fácticas que indiquen la posible existencia del mismo." (dt. Übersetzung d. Verf.); dazu infra $§ 7$ A. I. Verfassungsrechtliche Bedeutung und Fn. 613.

${ }^{287}$ Bzgl. der fundierten Anhaltspunkte s. ausführlich infra § 7. Die sog. ,motivos fundados“ als Voraussetzung von Ermittlungsmaßnahmen. 
auf die von der Gegenseite vorgebrachten Beweise zu reagieren. ${ }^{288}$ In beweisrechtlicher Hinsicht ist auch hervorzuheben, dass der Gesetzesakt 03 von 2002 insbesondere erlaubt, während des Ermittlungsverfahrens in die Rechte des Beschuldigten durch Kommunikationsüberwachung, Feststellungen zur Person, Hausdurchsuchungen und Beschlagnahmen einzugreifen, ohne dass es hierzu einer vorherigen richterlichen Anordnung bedarf. ${ }^{289}$ Jedoch hat eine nachträgliche richterliche Überprüfung innerhalb der folgenden 36 Stunden zu erfolgen, um die Rechtmäßigkeit der Maßnahme und die Verwertbarkeit der erhobenen Beweise zu bestimmen (Art. 250 Nr. 2 CN).

\section{iii. Ermächtigung zur Anordnung von Zwangsmitteln}

Auch die Ermächtigung zur Anordnung von Zwangsmitteln wurde reformiert. Als allgemeiner Grundsatz dürfen freiheitsbeschränkende Maßnahmen wie die Festnahme nur vom JCG auf entsprechenden Antrag der Staatsanwaltschaft angeordnet werden. In Ausnahmefällen jedoch kann nach dem Gesetz die Staatsanwaltschaft Festnahmen auch ohne vorherige richterliche Anordnung durchführen, wobei aber innerhalb der nachfolgenden 36 Stunden eine Überprüfung der Maßnahme durch den JCG zu erfolgen hat (Art. 300 CPP, geändert durch Art. 21 Gesetz 1142 von 2007). ${ }^{290}$ Darüber hinaus erfordert die neue Strafprozessordnung, dass auch durch den JCG auf Antrag der Staatsanwaltschaft freiheitsbeschränkende Maßnahmen nur angeordnet werden dürfen, wenn diese notwendig sind, um sicherzustellen, dass der Beschuldigte vor Gericht erscheint (Art. 308 (3) CPP), bei Verdunkelungsgefahr (Art. 309 CPP), sowie zum Schutz der Allgemeinheit (Art. 310 CPP) und insbesondere zum Schutz des Opfers der vermeintlichen Straftat (Art. $311 \mathrm{CPP}){ }^{291}$

\section{iv. Dispositionsbefugnis über das Verfahren}

Die Ausgestaltung der Befugnis, über den Prozess $\mathrm{zu}$ entscheiden, wurde ebenfalls modifiziert, indem auf Verfassungsebene das Opportunitätsprinzip eingeführt wurde. ${ }^{292}$ Auch wenn ausreichende rechtliche und faktische Gründe für eine Anklageerhebung

\footnotetext{
${ }^{288}$ Vgl. KVerfG, Entsch. C-1154 v. 2005, Abschn. „Consideraciones de la Corte“; auch Bernal Cuellar/Montealegre Lynett, 2013 T. II, S. $810 \mathrm{ff.}$

${ }^{289}$ Dazu infra § 5. Nachträglicher Rechtsschutz gegen Maßnahmen zur Beschränkung der Intimität.

${ }^{290}$ Dazu infra § 6. C. Nachträglicher Rechtsschutz gegen Maßnahmen zur Beschränkung der Freiheit.

291 Diese Einschränkungen sollten dazu dienen, derartige Maßnahmen den verfassungsmäßig gebotenen Schranken zu unterwerfen. Vgl. KVerfG, Entsch. C-185 v. 2008, Abschn. „Consideraciones de la Corte“; dazu infra § 7. B. IV. Entscheidung C-185 von $2008 \mathrm{KVerfG.}$

${ }^{292}$ Vgl. Molina López, 2012, S. 157 ff.; Mestre Ordóñez, 2011, S. 186 ff.; Guerrero Peralta, 2007, S. 270 ff.
} 
vorliegen, ermöglicht dieses dem Staat, von einer Strafverfolgung in denjenigen Fällen abzusehen, in denen dies ,gesetzlich vorgesehen“ ist und sich „im Rahmen der staatlichen Kriminalpolitik“" befindet. ${ }^{293}$ Es wurde mittlerweile auch durch Gesetz 1312 von 2009 näher ausgestaltet und tritt neben das Absehen vom Strafverfahren, die Streitschlichtung oder das Geständnis des Täters, die ebenfalls Gründe für die Einstellung des Ermittlungsverfahrens darstellen. Die Anwendung des Opportunitätsprinzips kommt vor allem in Fällen in Betracht, in denen der Gesetzgeber aufgrund kriminalpolitischer Wertung der Rechtsgutsverletzung weniger Bedeutung zumisst, es sich um Delikte gegen die öffentliche Verwaltung handelt oder die Straftat in der Verletzung von Amtspflichten innerhalb des Justizsystems besteht, soweit hierfür eine disziplinarrechtliche Sanktion zu erwarten ist und das Ausmaß der Rechtsgutsverletzung im konkreten Fall gering ist (Art. 324 CPP). ${ }^{294}$

\section{Die Art des Strafprozesssystems}

Die eingeführte akkusatorische Ausrichtung des kolumbianischen Strafprozesses entspricht keinem adversatorischen Modell, welches den Prozess als Streit zwischen zwei Parteien „auf Augenhöhe“ begreift, ${ }^{295}$ da der Richter in jenem nicht bloß die Rolle des unparteiischen Schiedsrichters übernimmt und außerdem an diesem auch das Opfer und die Disziplinarstaatsanwaltschaft aktiv teilnehmen. ${ }^{296}$ Auch im Ermittlungsverfahren sind die Parteien nicht mit den gleichen Rechten ausgestattet und die Aufgabe des Richters, sei es der JCG oder der Erkenntnisrichter, geht über die Überwachung der Einhaltung der Prozessförmlichkeiten hinaus. Die Rolle des Richters im Ermittlungs- und Hauptverfahren ist ein Unterscheidungsmerkmal des kolumbianischen Strafprozesses. ${ }^{297}$ Trotz seiner reduzierten Kontrollfunktion in Bezug auf einige Ermittlungsmaßnahmen fungiert der Richter als Hüter der Rechte des Beschuldigten oder Angeklagten sowie der Rechte der

\footnotetext{
${ }^{293}$ Art. 321 CPP: „Principio de oportunidad y política criminal. La aplicación del principio de oportunidad deberá hacerse con sujeción a la política criminal del Estado.“ („Opportunitätsprinzip und Kriminalpolitik. Die Anwendung des Opportunitätsprinzips soll unter Beachtung der Kriminalpolitik des Staates gemacht werden.“- -dt. Übersetzung d. Verf.-).

${ }^{294}$ Es ging dem Gesetzgeber bei der Einführung des Opportunitätsprinzips vor allem darum, die Strafgerichtsbarkeit von Bagatelldelikten zu entlasten. Für die Rechtsgründe zur Anwendung des Opportunitätsprinzips; s. Mestre Ordóñez, 2011, S. 229 ff.

${ }^{295}$ Vgl. Guerrero Peralta, 2007, S. 80 ff.; s. infra § 3. A. I. 2. a. Trennung von Ermittlungs- und Hauptverfahren.

${ }^{296}$ KVerfG, Entsch. C-591 v. 2005 , Abschn. 2.2.

${ }^{297}$ Siehe infra § 3. A. I. 2. b. richterliche Kontrolle und § 4. B. Funktion und Aufgaben des Richters zur Kontrolle der Garantien.
} 
Opfer. Ebenso sieht das neue akkusatorische Strafprozessmodell eine aktive Teilnahme des Beschuldigten bereits vor Erhebung der Anklage vor. Die Charakteristika des kolumbianischen Strafprozessmodells sind die folgenden:

\section{a. Trennung von Ermittlungs- und Hauptverfahren}

Die Trennung von Ermittlungs- und Hauptverfahren ist aufgrund des Akkusationsprinzips geboten, welches durch den Gesetzesakt 03 von 2002 eingeführt wurde. Dem Strafrichter kommt dabei die Aufgabe zu, die Einhaltung der gesetzes- und verfassungsmäßig verbürgten Verfahrensrechte zu kontrollieren und nach dem mündlichen Verfahren das Urteil zu fällen. Diese Trennung hat in dem Prozessmodell eine besondere Relevanz, da sie einerseits die richterliche Unabhängigkeit gegenüber den Verfahrensbeteiligten bestimmt und andererseits die Verwirklichung grundsätzlicher Verfahrensrechte im mündlichen Hauptverfahren erlaubt. ${ }^{298}$ Dabei sind zwei verschiedene Arten von Strafrichtern mit unterschiedlichen Funktionen in die Strafverfolgung involviert. Zum einen derjenige, dessen Aufgabe es ist, die Einhaltung der Verfahrensrechte und den Schutz der persönlichen Freiheiten des Beschuldigten vor der Anklageerhebung zu überwachen (JCG), und zum anderen der Richter, der dafür verantwortlich ist, das Hauptverfahren voranzutreiben und ein faires Verfahren zu gewährleisten (Erkenntnisrichter).

\section{b. Die richterliche Kontrolle}

Die richterliche Kontrolle im akkusatorischen Strafprozess fokussiert sich auf die Überwachung derjenigen Akte, die einer richterlichen Ermächtigung bedürfen oder die in der Beschränkung von Rechten oder juristischen Bewertung bestehen. Die richterliche Kontrolle soll nicht nur die Erfüllung formeller Anforderungen sicherstellen, sondern auch die effektive Verwirklichung der auf dem Spiel stehenden Grundrechte garantieren. ${ }^{299}$ Dies hat wichtige Auswirkungen auf das Ermittlungsverfahren, denn das bedeutet auch, dass die Staatsanwaltschaft und die Kriminalpolizei diejenigen Handlungen vornehmen dürfen, die keinen Grundrechtseingriff beinhalten (Grundsatz der freien Gestaltung des Ermittlungsverfahrens). Die Möglichkeit der richterlichen ex ante und ex post Kontrolle und der Umstand, dass die FGN auch verfassungsgemäß Bestandteil der judikativen

\footnotetext{
${ }^{298}$ Vgl. KVerfG, Entsch. C-1643 v. 2000; T-593 v. 2002; C-1024 v. 2002; C-288 v. 2012, C-870 v. 2014.

299 Vgl. KVerfG, Entsch. C-637 v. 2005, Abschn. VI. 3; dazu auch Zuluaga, Co-Herencia Vol. 4 Nr. 6 (2007), S. $133 \mathrm{ff}$.
} 
Gewalt ist, verdeutlichen, dass das Ermittlungsverfahren im kolumbianischen Strafprozess als gerichtliches und nicht als verwaltungsbehördliches Verfahren einzuordnen ist. ${ }^{300}$

\section{Struktur des Strafprozesses}

Die durch Gesetzesakt 03 von 2002 vorgegebene Struktur des Strafprozesses wurde durch Gesetz 906 von 2004 umgesetzt. Danach wird der Strafprozess grundlegend in drei Etappen unterteilt: Das Ermittlungsverfahren, in dem die Behörden eine Voruntersuchung vornehmen und danach die Beweisermittlung zur Vorbereitung der Anklage durchführen; ein Zwischenverfahren nach Abschluss des Ermittlungsverfahrens, in dem sich die Parteien auf das bevorstehende Hauptverfahren vorbereiten und schließlich das Hauptverfahren, in dem der Richter basierend auf den in diesem vorgebrachten und debattierten Beweismitteln zu der Überzeugung von dem Vorliegen einer Straftat gelangt und den Angeklagten verurteilt oder andernfalls diesen freispricht.

\section{a. Das Ermittlungsverfahren}

Bevor eine detaillierte Beschreibung der Ermittlungsphase durchgeführt wird, ist es wichtig, ihre Funktion und Unterschiede $\mathrm{zu}$ anderen Phasen im Rahmen des Strafverfahrens $\mathrm{zu}$ beachten. Das Ermittlungsverfahren beginnt mit einem Vorermittlungsverfahren, welches nach der Anzeige einer Straftat oder der anderweitigen Kenntniserlangung von einer solchen durch die Staatsanwaltschaft eingeleitet wird. ${ }^{301}$ Der Zweck dieses Vorermittlungsverfahrens ist es, das Vorliegen eines juristisch relevanten Sachverhalts $\mathrm{zu}$ erforschen und diesen einer tatbestandsmäßigen Einordnung zu unterziehen. Darüber hinaus gilt es festzustellen, ob Strafverfolgungshindernisse der Aufnahme eines Strafverfahrens bereits von vornherein entgegenstehen. Außerdem soll der Täter oder Teilnehmer des vermeintlich strafbaren Verhaltens hinreichend identifiziert und individualisiert werden. ${ }^{302}$

Das Ermittlungsverfahren ist diejenige Phase, in der der zuständige Staatsanwalt mithilfe der Kriminalpolizei versucht, die Beweislage zu bekräftigen auf Grundlage der in der Vorermittlungsphase eingeholten physischen Beweismittel oder legal erhaltenen Informationen, die als Grundlage für die Erhebung der Beschuldigung (formulación de

\footnotetext{
${ }^{300}$ Vgl. dazu Bernal Cuellar/Montealegre Lynett, 2013 T. I, S. 16 ff.; krit. Mestre Ordóñez, 2011, S. 60 ff.

${ }^{301}$ Siehe infra § 3. A. II. 3. a. Vorermittlungsphase.

${ }^{302}$ Vgl. dazu Guerrero Peralta, 2007, S. 230 ff. 
imputación) dienten. ${ }^{303}$ Das primäre Ziel dieser Phase ist es, einen Ermittlungsstand zu schaffen, anhand dessen die Entscheidung getroffen werden kann, ob der vermeintliche Täter oder Teilnehmer angeklagt wird, die Ermittlungen einzustellen sind oder das Opportunitätsprinzip angewendet wird. Die Ermittlungen im engeren Sinne beginnen mit der Erhebung der Beschuldigung ${ }^{304}$ und erstrecken sich auch auf die mündliche Hauptverhandlung, in deren Verlauf bis dahin unbekannte Beweismaterialien, physische Beweismittel oder Informationen auftauchen können, die von den Parteien ausnahmsweise gemäß Art. 344 CPP im Rahmen der Beweisaufnahme in der mündlichen Hauptverhandlung in den Prozess eingeführt werden dürfen. (siehe infra Anlage 1).

\section{b. Das Zwischenverfahren}

In formeller Hinsicht markiert die Einreichung der Anklageschrift das Ende des Ermittlungsverfahrens und den Beginn eines Zwischenverfahrens, nach dessen Beendigung die mündliche Hauptverhandlung folgen soll. Dementsprechend ist das primäre Ziel des Zwischenverfahrens, diejenigen Themen einzugrenzen, die im Rahmen der Hauptverhandlung diskutiert werden sollen, und diejenigen Punkte festzulegen, auf die sich die Beweisaufnahme zwecks Bildung einer richterlichen Überzeugung konzentrieren soll. Es geht insofern in dem Zwischenverfahren vor allem darum, die strafrechtliche Debatte vor dem Erkenntnisrichter von vornherein auf das zu beschränken, was für die Frage der strafrechtlichen Verantwortlichkeit des Beschuldigten relevant ist. ${ }^{305}$ Die Beweismaterialien, auf deren Grundlage sich die richterliche Überzeugung bilden soll, werden dabei erst in dem Moment ihrer Zulassung durch den Erkenntnisrichter zu tauglichen Beweismitteln. Die Staatsanwaltschaft in ihrer Eigenschaft als Anklagebehörde besitzt nämlich nicht die funktionelle Zuständigkeit, um festzulegen, was als Beweismittel im technischen Sinne im Prozess anerkannt werden soll. Die durch Ermittlungsmaßnahmen der Staatsanwaltschaft, wie z.B. durch Hausdurchsuchungen, erlangten Beweismaterialien werden mithin nur insoweit Grundlage des Strafurteils, als dass der Richter diese zulässt und sie im Rahmen des Hauptverfahrens in Ausübung des Unmittelbarkeitsgrundsatzes wertet.

\footnotetext{
${ }^{303}$ Siehe ausführlich infra § 3. A. II. 3. b. und c. und § 9. B. II. 2. Maßnahmen im Rahmen der Vorermittlung.

${ }^{304}$ Siehe infra § 3. A. II. 3. b. Die Beschuldigung (Formulación de imputación).

${ }^{305}$ Vgl. Urbano Martínez, 2013, S. 52; auch mit kritischen Anmerkungen dazu Urbano Martínez, 2011, S. $233 \mathrm{ff}$.
} 
Die Anklageschrift ist das prozessuale Instrument, mit dem der Staatsanwalt dem zuständigen Richter förmlich die Anklage gegen eine bestimmte Person unterbreitet, von der angenommen wird, sie habe in strafrechtlich verantwortlicher Weise einen Straftatbestand verwirklicht oder sich daran beteiligt (Art. 336 u. 337 CPP). Innerhalb von drei auf den Erhalt der Anklageschrift folgenden Tagen soll der zuständige Richter dann eine spezielle Anhörung zur Anklage (die sog. audiencia de acusación) einberufen, in der die betroffene Anklage erhoben wird (Art. 338 CPP). Diese Anhörung ist in dem Strafverfahren insbesondere dafür vorgesehen, dass die Staatsanwaltschaft die Beweismaterialien präsentiert, die sie als Beweismittel in den Prozess einzuführen gedenkt, um die Unschuldsvermutung des Beschuldigten zu widerlegen. $\mathrm{Zu}$ Beginn der Anhörung händigt der zuständige Richter den Parteien die Anklageschrift aus und erteilt nacheinander der Staatsanwaltschaft, der Disziplinarstaatsanwaltschaft und der Verteidigung das Wort, damit diese in mündlicher Form etwaige Zuständigkeitsrügen, Strafverfolgungshindernisse etc. vortragen können und ihre Ansichten zur Anklageschrift präsentieren können, bzw. damit die Staatsanwaltschaft diese erläutern, ergänzen oder unverzüglich korrigieren kann, sollte sie nicht in einer Weise verständlich sein, dass sie den Anforderungen des Art. 377 CPP genügt. ${ }^{306}$ Unmittelbar danach erhält die Staatsanwaltschaft das Wort, damit sie die entsprechende Anklageschrift verliest (Art. 339 CPP). Danach und vor Beendigung der Anhörung 1) fügt der Erkenntnisrichter die Korrekturen in die vorgelesene Anklageschrift ein, 2) billigt oder weist die zwischen den Parteien getroffenen Absprachen ab und 3) stellt, sofern die Voraussetzungen des Art. 343 CPP vorliegen, das Verfahren unter Auflagen ein.

Entsprechend den im Rahmen der Anklageanhörung gefundenen Ergebnissen, setzt der Erkenntnisrichter für einen Zeitpunkt frühestens 15 und spätestens 30 Tage nach dieser Anhörung eine zweite Anhörung fest, die sog. vorbereitende Anhörung ("audiencia preparatoria"), deren Ziel es ist, die im Rahmen der mündlichen Hauptverhandlung aufzunehmenden Beweise festzulegen und einen Termin zur Urteilsverkündung zu bestimmen. An der vorbereitenden Anhörung nehmen der Staatsanwaltschaft, der Angeklagte, dessen Strafverteidiger, Vertreter des Ministeriums für öffentliche Angelegenheiten und ein ein Vertreter der Opfer (Art. 355 CPP) teil, die unter Leitung des Richters Stellung zum Ablauf der Beweiserhebung nehmen ${ }^{307}$. Außerdem ordnet der Richter an, dass die Verteidigung die eigenen Beweismittel offenlegt sowie dass sowohl

\footnotetext{
${ }^{306}$ Für das Anklageverfahren s. Bernal Cuellar/Montealegre Lynett, 2013 T. II, S. 775 ff.

${ }^{307}$ Vgl. Bernal Cuellar/Montealegre Lynett, 2013 T. II, S. 791 ff.; krit. Urbano Martínez, 2011, S. 253 ff. 
Staatsanwaltschaft als auch Verteidigung alle Beweismittel benennen, die sie im Rahmen der öffentlichen, mündlichen Hauptverhandlungen einzubringen gedenken. An dieser Stelle entscheidet der Erkenntnisrichter auf Antrag der Parteien schließlich darüber, welche der benannten Beweise er für erheblich und zulässig erachtet (Art. 357 CPP) und schließt solche, die diese Voraussetzungen nicht erfüllen, auf Antrag der Disziplinarstaatsanwaltschaft aus dem Prozess aus (siehe infra Anlage 1).

\section{c. Das Hauptverfahren}

Nach der Beendigung der vorbereitenden Anhörung bestimmt der Erkenntnisrichter den Zeitpunkt des Beginns der Hauptverhandlung, welcher innerhalb der nächsten 30 Tage liegen soll (Art. 365 CPP). Die Hauptverhandlung ist öffentlich und mündlich. In ihrem Rahmen werden 1) unter direkter Beteiligung des Angeklagten die Beweismittel unter Beachtung der Prinzipien der Unmmittelbarkeit und Kontradiktion aufgenommen und gewürdigt, wobei 2) die Beweise gemäß der Konzentrationsmaxime in ihrer Gesamtheit gewürdigt werden, welche dem Richter und je nach Fall den Geschworenen in relativ kurzer Zeit im Rahmen eines einzigen Verfahrensabschnitts ein Gesamtbild vermittelt und ihnen erlaubt, ihre Entscheidung auf die Gesamtheit der zur Verfügung stehenden Beweise zu stützen, und es wird 3), ebenfalls öffentlich eine Entscheidung über die strafrechtliche Verantwortung des Angeklagten getroffen. ${ }^{308}$ (siehe infra Anlage 1).

\section{Das Ermittlungsverfahren}

\section{Grundzüge des Ermittlungsverfahrens}

Das Ermittlungsverfahren im kolumbianischen Strafverfahren hat im Wesentlichen drei Ziele: Erstens soll auf Grundlage der gesammelten Beweise ein konkret Beschuldigter ermittelt werden, der mit hinreichender Wahrscheinlichkeit eine Straftat verwirklicht hat, sodass ein Hauptverfahren Aussicht auf eine Verurteilung bietet. ${ }^{309}$ Zweitens soll es dem Recht auf Verteidigung genügen, indem Eingriffe in Grundrechte der richterlichen Entscheidung unterstellt werden, dem Beschuldigten in Anwesenheit des JCG die strafrechtlichen Vorwürfe eröffnet werden und ihm außerdem die Möglichkeit gegeben wird, zu aus-

\footnotetext{
${ }^{308}$ Bzgl. des Verfahrens in der Hauptverhandlung s. Bernal Cuellar/Montealegre Lynett, 2013 T. II, S. 806 ff.

${ }^{309}$ Vgl. KVerfG, Entsch. T-653 v. 2014, Abschn. „Consideraciones de la Corte“; T-020 v. 2002, Abschn. „Consideraciones de la Corte“; Bernal Cuellar/Montealegre Lynett, 2013 T. I, S. 249.
} 
nahmsweise bereits in diesem Stadium eingebrachten Beweisen Stellung zu nehmen. ${ }^{310}$ Drittens soll das Ermittlungsverfahren die Staatsanwaltschaft in die Lage versetzen, ihre Rolle als Anklagebehörde wahrzunehmen. ${ }^{311}$ Um diese Ziele zu erreichen, basiert die Durchführung des Strafverfahrens auf folgenden Grundsätzen:

\section{a. Unterwerfung unter das Legalitätsprinzip}

Die FGN ist verpflichtet, ihre Strafverfolgungsgewalt wahrzunehmen und strafrechtliche Ermittlungen einzuleiten, wenn sie Kenntnis von Umständen erlangt, die das Vorliegen einer Straftat möglich erscheinen lassen (Art. 366 CPP). Der Staat übt also seine Strafgewalt außer bei Antragsdelikten unabhängig von einem Strafverfolgungsinteresse des Verletzten aus. Nur ausnahmsweise erlaubt die Verfassung der FGN, die Strafverfolgung abzulehnen, zu unterbrechen oder einzustellen und zwar in denjenigen Fällen, für die gesetzlich die Anwendung des Opportunitätsprinzips vorgesehen ist. ${ }^{312}$

\section{b. Unterwerfung unter die richterliche Kontrolle}

Die Strafjustiz in Person des JCG hat die Funktion sicherzustellen, dass die von dem Verfahren berührten Rechte des Beschuldigten respektiert und nicht über das gesetzlich erlaubte Maß hinaus beeinträchtigt werden. Dementsprechend ist der JCG in die rechtliche Überprüfung der von der Staatsanwaltschaft vorgenommenen Ermittlungsmaßnahmen eingebunden, namentlich der Erfassung persönlicher Daten, Hausdurchsuchungen, Beschlagnahmen, Telekommunikationsüberwachungen, Festnahmen, der Auferlegung von Sicherungsmaßnahmen und sonstiger Maßnahmen, die die Grundrechte des Beschuldigten beeinträchtigen. Ebenso obliegt ihm die Rechtmäßigkeitskontrolle über die Anwendung des Opportunitätsprinzips (Art. $250 \mathrm{CN}$ ). Insofern nimmt der JCG eine wesentliche Rolle für das Funktionieren eines Rechtssystems ein, welches den Eingriff in persönliche Freiheiten dem richterlichen Vorbehalt unterwirft. ${ }^{313}$

\section{c. Unterwerfung unter das Geheimhaltungsgebot}

\footnotetext{
${ }^{310}$ Bernal Cuellar/Montealegre Lynett, 2013 T. I, S. 255 ff.; dazu infra § 10. B. III. 3. Anwesenheitsrecht der Verteidigung.

${ }^{311}$ Vgl. KVerfG, Entsch. C-873 v. 2003, Abschn. 3.4.2.1.; Guerrero Peralta, 2007, S. 244.

312 Molina López, 2012, S. 157 ff.; Mestre Ordóñez, 2011, S. 186 ff.; dazu supra § 3. A. I. 1. c. iv. Dispositionsbefugnis über das Verfahren.

${ }^{313}$ Dazu ausführlich infra § 4. B. Funktion und Aufgaben des Richters zur Kontrolle der Garantien; s. auch infra Anlage 2. Übersicht über die Ermittlungsmaßnahme im kolumbianischen Strafverfahren. 
Dass bestimmte justizielle Maßnahmen im Strafverfahren der Geheimhaltung unterliegen, ist u.a. den verfassungsrechtlichen Verpflichtungen der Ermittlungsorgane geschuldet, was insbesondere in Art. $250 \mathrm{CN}$ zum Ausdruck kommt. Dieser verpflichtet die FGN, für den Schutz der Opfer, Zeugen und sonstigen Beteiligten einzutreten und diejenigen Maßnahmen zu ergreifen, die die Wiederherstellung des beeinträchtigten Rechts und den Ersatz der durch das Delikt verursachten Schäden ermöglichen. Allerdings hat auch der Beschuldigte ein verfassungsrechtlich verbürgtes Recht, den konkreten strafrechtlichen Vorwurf zu kennen, dem er ausgesetzt ist, sowie die Beweise, auf die sich dieser stützt. ${ }^{314}$ Dieses Recht ist in dem Recht auf Verteidigung und in dem Recht auf einen fairen Prozess (Art. $29 \mathrm{CN}$ ) verbürgt und verpflichtet dementsprechend den Staat, den Beschuldigten im Rahmen der Vorermittlungen zur Vernehmung zu laden, sobald ein Straftatverdacht gegen ihn besteht. $^{315}$

\section{Ablauf des Ermittlungsverfahrens}

\section{a. Vorermittlungsphase}

Die Staatsanwaltschaft ermittelt in einer ersten Vorermittlungsphase den vorliegenden Sachverhalt und grenzt die allgemeinen strafrechtlich relevanten Aspekte ein. Da die Verifizierung des Tathergangs nicht immer einfach ist und die gegebenen Umstände die Identifizierung einer Strafrechtswidrigkeit erschweren können, ist es das Ziel der Vorermittlungen, durch die Staatsanwaltschaft und die Kriminalpolizei die rechtlichen Konturen der Tat, die Gegenstand des Ermittlungsverfahrens sein soll, abzustecken. ${ }^{316}$ Die Vorermittlungsphase beginnt mit der Anzeige einer Straftat oder mit dem Moment, in dem die FGN von dem Vorliegen eines möglicherweise strafbaren Verhaltens auf sonstige Weise Kenntnis erlangt hat. Der Staatsanwalt wertet dann die ihm vorliegenden Informationen aus und stellt ein sogenanntes ,methodologisches Ermittlungsprogramm“ auf, welches die Ermittlungsmaßnahmen beinhaltet, mittels derer der Wahrheitsgehalt der Strafanzeige, das tatsächliche Vorliegen des angezeigten Verhaltens, dessen Einordnung als tatbestandsmäßiges Verhalten, die Identität der Täter und Teilnehmer sowie die

\footnotetext{
${ }^{314}$ Vgl. dazu KVerfG, Entsch. T-213 v. 2004, Abschn. „Consideraciones de la Corte“.

315 Vgl. KVerfG, Entsch. C-150 v. 1993; C-412 v. 1993; C-475 v. 1997; T-181 v. 1999; C-1711 v. 2000; C033 v. 2003.

${ }^{316}$ Vgl. KVerfG, Entsch. C-1194 v. 2005, Abschn. „Consideracines“; C-127 v. 2011, Abschn. „Consideraciones de la Corte".
} 
Verfolgbarkeit der Tat geprüft werden sollen. ${ }^{317}$ Insofern wird die Vorermittlungsphase zwar regelmäßig durch die Strafanzeige veranlasst, als reine Vorverfahrensphase ist es jedoch ihr Ziel, zu einem förmlichen Ermittlungsverfahren zu gelangen. In dieser Phase geht es also in erster Linie darum, die Motive und Umstände aufzuklären, die das betreffende menschliche Verhalten als deliktisch, d.h. als objektiv und subjektiv tatbestandsmäßig, erscheinen lassen. ${ }^{318}$ Diese Phase dauert im Allgemeinen so lange an, bis die Staatsanwaltschaft die Einstellung der Strafverfolgung anordnet (Art. 79 CPP) oder andernfalls die Beschuldigung formuliert (formulación de la imputación) (Art. 286 CPP). ${ }^{319}$

Grundsätzlich beschäftigt sich die Staatsanwaltschaft in dieser Phase auch nicht mit der Frage der Konkurrenzen oder mit möglichen Strafausschließungsgründen, da im kolumbianischen akkusatorischen Strafprozess die strafrechtliche Verantwortlichkeit erst im Hauptverfahren im Einzelnen geklärt wird. Von diesem Grundsatz existieren jedoch Ausnahmen und zwar dann, wenn von Beginn an deutliche Hinweise auf das Vorliegen eines Strafausschließungsgrunds hindeuten und es im konkreten Fall möglich erscheint, dies im Rahmen der Vorermittlungen $\mathrm{zu}$ verifizieren. In diesen Fällen hat die Staatsanwaltschaft auch die Prüfung solcher in Betracht kommenden Strafausschließungsgründe vorzunehmen und je nach Ergebnis der Prüfungen bereits im Vorermittlungsverfahren bei dem Erkenntnisrichter die Einstellung der Strafverfolgung zu beantragen. $^{320}$ Eine weitere Möglichkeit, die Strafverfolgung bereits in der Vorermittlungsphase zu beenden, bietet in den gesetzlich ausdrücklich geregelten Fällen das Opportunitätsprinzip (Art. 324 CPP, dieser ist modifiziert durch Art. 2 des Gesetzes 1312 von 2009), wobei die letztendliche Entscheidung hierüber dem JCG obliegt. Anders als zuvor findet die Vorermittlungsphase dabei im akkusatorischen Strafprozess auch nicht mehr vollständig geheim unter Ausschluss jeglicher Mitwirkung der weiteren Prozessbeteiligten statt. ${ }^{321}$ Denn zur Wahrung des Rechts des Verdächtigen auf Verteidigung wird diesem bereits zu Beginn seiner Vernehmung in der Vorermittlungsphase

\footnotetext{
317 Vgl. Art. 207 CPP; dazu infra § 9. B. II. 1. Das sog. ,programa metodológico“.

${ }^{318}$ Siehe dazu Bernal Cuellar/Montealegre Lynett, 2013 T. I, S. 248 ff.; Guerrero Peralta, 2007, S. 230 ff.

${ }^{319}$ Siehe infra § 3. A. II. 3. b. Die Beschuldigung (Formulación de imputación).

${ }^{320}$ Vgl. KVerfG, Entsch. C-920 v. 2007, Abschn. „Consideraciones de la Corte“; C-648 v. 2010, Abschn. „Consideraciones de la Corte“; C-1154 v. 2005, Abschn. „Consideraciones de la Corte“.

${ }^{321}$ Vgl. KVerfG, Entsch. C-150 v. 1993; C-412 v. 1993; C-475 v. 1997; T-181 v. 1999; C-1711 v. 2000; C033 v. 2003. 
mitgeteilt, dass gegen ihn strafrechtliche Ermittlungen stattfinden, und was ihm vorgeworfen wird. Auch den Opfern der Straftat steht ihrerseits das Recht zu, an dem Vorermittlungsverfahren beteiligt zu werden, um ihr Recht auf Wahrheit, Reparation und Gerechtigkeit verfolgen zu können. ${ }^{322}$

\section{b. Die Beschuldigung (Formulación de imputación)}

Nach Abschluss der Vorermittlungen kann die Staatsanwaltschaft vor dem JCG die Beschuldigung des Straftatverdächtigen vornehmen (Formulación de Imputación). Gemäß Art. 286 CPP handelt es sich bei der Erhebung der Beschuldigung um „denjenigen Akt, mit dem die FGN der betreffenden Person im Rahmen einer Anhörung vor dem JCG mitteilt, dass sie wegen einer Straftat beschuldigt wird.“323 Die Staatsanwaltschaft nimmt die Beschuldigung vor, wenn sich ,aus den materiellen Beweismitteln, den physischen Beweisstücken oder den in legaler Weise erlangten Informationen vernünftigerweise ergibt, dass der Beschuldigte Täter oder Teilnehmer des Delikts ist, wegen dem ermittelt wird.“324 $\mathrm{Ab}$ diesem Moment erlangt der Verdächtige die Qualität eines Beschuldigten (Art. 126 CPP) und damit die Befugnis, die Beschuldigtenrechte wahrzunehmen (Art. 130 CPP), die ihm aufgrund der von Kolumbien ratifizierten internationalen Menschenrechtsverträge, der Verfassung und einfachen Gesetze zustehen. Die Staatsanwaltschaft ist dabei verpflichtet, die Identität des Beschuldigten nochmals zu überprüfen, um Justizirrtümer zu vermeiden (Art. $128 \mathrm{CPP})$.

Der Akt der Beschuldigung erfordert in faktischer Hinsicht, dass dem Verdächtigen der Sachverhalt, bzgl. dessen ermittelt werden soll, mitgeteilt wird, sowie in normativer Hinsicht, dass ihm die strafrechtliche Einordnung des Sachverhalts erläutert wird. Die faktischen und normativen Elemente der Beschuldigung sollen den Beschuldigten in die Lage versetzen, die möglicherweise zu erwartende Strafe unter Berücksichtigung etwaiger

\footnotetext{
${ }^{322}$ Vgl. KVerfG, Entsch. SU-1184 v. 2001, Abschn. „Consideraciones de la Corte“; Guerrero Peralta, 2007, S. $214 \mathrm{ff}$.

${ }^{323}$ Art. 286 CPP: „Concepto. La formulación de la imputación es el acto a través del cual la Fiscalía General de la Nación comunica a una persona su calidad de imputado, en audiencia que se lleva a cabo ante el juez de control de garantías." (dt. Übersetzung d. Verf.).

324 Art. 287 CPP: „Situaciones que determinan la formulación de la imputación. El fiscal hará la imputación fáctica cuando de los elementos materiales probatorios, evidencia física o de la información legalmente obtenida, se pueda inferir razonablemente que el imputado es autor o partícipe del delito que se investiga." (dt. Übersetzung d. Verf.).
} 
Strafminderungsgründe abschätzen zu können, und ihm die Möglichkeit geben, sich angemessen verteidigen zu können. ${ }^{325}$

Sobald die Beschuldigung erfolgt ist, erhält die Verteidigung die Möglichkeit, die notwendigen Schritte zur Sammlung beweiserheblicher Informationen und Materialien einzuleiten, um eine Verteidigungsstrategie auszuarbeiten. Hieraus folgt jedoch nicht, dass der Verdächtige nicht bereits vor der Beschuldigung, also während der Vorermittlungsphase, sein Recht auf Verteidigung wahrnehmen kann. ${ }^{326}$ Der Staatsanwalt hat seinerseits zu beachten, dass mit der Beschuldigung die Frist von 90 Tagen zu laufen beginnt, innerhalb der er Anklage zu erheben, die Einstellung zu beantragen oder die Anwendung des Opportunitätsprinzips zu beantragen hat (Art. 175 CPP, dieser modifiziert durch Art. 49 des Gesetzes 1453 von 2011). Das bedeutet, dass er in der Lage sein muss, sich innerhalb dieser Frist dahingehend festzulegen, ob mit hinreichender Wahrscheinlichkeit ein strafrechtlich relevanter Sachverhalt vorliegt und ob der Beschuldigte Täter oder Teilnehmer ist.

\section{c. Ermittlungen im engeren Sinn}

Die Ermittlungsphase ist derjenige Abschnitt, in dem der abgeordnete Staatsanwalt mit Unterstützung der Kriminalpolizei versucht, die Beweislage auf Grundlage der für die Vornahme der Beschuldigung verwerteten physischen Hinweise und Informationen zu erhärten. ${ }^{327}$ Die Ermittlungen im engeren Sinn beginnen ab der Vornahme der Beschuldigung und können sich auch noch über den Moment der Anklageerhebung hinaus in die Hauptverhandlung hinein erstrecken, soweit bis dahin noch nicht bekannte physische Beweismittel oder Informationen auftauchen, die dann entsprechend dem letzten Absatz des Art. 344 CPP ausnahmsweise noch im Rahmen der Hauptverhandlung eingeführt werden können, wenn der Erkenntnisrichter unter Berücksichtigung des Rechts auf eine angemessene Verteidigung und nach Anhörung der Parteien entscheidet, dies zuzulassen. ${ }^{328}$

\footnotetext{
${ }^{325}$ Bernal Cuellar/Montealegre Lynett, 2013 T. II, S. $128 \mathrm{ff}$.

${ }^{326}$ KVerfG, Entsch. C-025 v. 2009, Abschn. „Consideraciones de la Corte“.

${ }^{327}$ Vgl. Bernal Cuellar/Montealegre Lynett, 2013 T. II, S. 81 ff.; Avella Franco, 2007a, S. 76 ff.; KVerfG, Entsch. C-118 v. 2008, Abschn. „Preclusión de la investigación y sistema penal acusatorio“, Abs. 8 ff. m.w.N.

${ }^{328}$ Art. 344 letzter Absatz: „Sin embargo, si durante el juicio alguna de las partes encuentra un elemento material probatorio y evidencia física muy significativos que debería ser descubierto, lo pondrá en conocimiento del juez quien, [...].“ (Wenn jedoch während der Hauptverhandlung eine der Parteien ein bedeutendes Beweismittel findet, das offengelegt werden müsste, wird es dem Richter zur Kenntnisnahme gebracht, $[\ldots]$ ). (Übersetzung d. Verf.). 
Andererseits hat der Beschuldigte im Rahmen der Anhörung zur Vornahme der Beschuldigung $\mathrm{zu}$ entscheiden, ob er die ihm von der Staatsanwaltschaft entgegengebrachten Vorwürfe akzeptiert (Aceptación de Cargos) oder sie zurückweist. Akzeptiert er diese vollumfänglich, wird sogleich auch die Erhebung der Anklage protokolliert (Art. 293 CPP). Nur wenn er die Vorwürfe zurückweist, beginnt am Tag nach der Vornahme der Beschuldigung das eigentliche Ermittlungsverfahren und dementsprechend die Ermittlungen im engeren Sinn. Ebenso wie die Staatsanwaltschaft hat auch der Beschuldigte oder dessen Verteidigung im Ermittlungsverfahren das Recht, Beweismittel zu suchen, zu identifizieren und zu sammeln. ${ }^{329}$ Auf den Antrag hin, diese zu untersuchen, und mit der Bestätigung der Staatsanwaltschaft, dass es sich bei dem Antragsteller um einen Beschuldigten bzw. dessen Verteidiger handelt, werden die gesammelten Beweismittel, soweit dies nach Art des Beweismittels in Betracht kommt, in das jeweilige Nationale Institut für Rechtsmedizin und Forensik (Instituto Nacional de Medicina Legal y Ciencias Forenses) gebracht, wo diese gegen Empfangsbestätigung entgegenzunehmen und zu prüfen sind“ (Art. $268 \mathrm{CPP}) .{ }^{330}$

Die Frist, innerhalb der die Staatsanwaltschaft das Opportunitätsprinzip anwenden, die Anklage präsentieren oder die Einstellung des Verfahrens beantragen muss, beträgt 90 Tage beginnend mit dem Tag, der auf die Erhebung der Beschuldigung folgt (Art. 175 CPP). Bei Nichteinhaltung der Frist verliert der Staatsanwalt die Zuständigkeit für den bestimmten Fall. Derjenige Staatsanwalt, der in der Folge auf Anordnung des Vorgesetzten des zu ersetzenden Staatsanwalts an dessen Stelle tritt, unterliegt der gleichen Frist, wobei diese jedoch mit der Zuteilung des Falls an den neuen Staatsanwalt beginnt. Verstreicht auch diese Frist ohne Ergebnis, hat die Disziplinarstaatsanwaltschaft (Procuraduría) bei dem Erkenntnisrichter die Einstellung des Verfahrens zu beantragen und der Beschuldigte ist unverzüglich auf freien Fuß zu setzen. ${ }^{331}$

\footnotetext{
${ }^{329}$ Bernal Cuellar/Montealegre Lynett, 2013 T. I, S. 685; siehe u.a. KVerfG, Entsch. C-980 v. 2010; C-012 v. 2013; C-016 v. 2013; C-034 v. 2014.

${ }^{330}$ Art. 268 CPP: „Facultades del imputado. El imputado o su defensor, durante la investigación, podrán buscar, identificar empíricamente, recoger y embalar los elementos materiales probatorios y evidencia física. Con la solicitud para que sean examinados y la constancia de la Fiscalía de que es imputado o defensor de este, los trasladarán al respectivo laboratorio del Instituto Nacional de Medicina Legal y Ciencias Forenses, donde los entregarán bajo recibo.“ (dt. Übersetzung d. Verf.).

${ }^{331}$ Siehe infra § 3. B. III. Disziplinarstaatsanwaltschaft.
} 


\section{B. Beteiligte des Ermittlungsverfahrens}

Prozesssubjekte des kolumbianischen Strafprozesses sind der Richter, der Staatsanwalt, die Kriminalpolizei, die Verteidigung, der prozessierte Verdächtige, Beschuldigte, Angeklagte oder Verurteilte, das Opfer und die schadenersatzpflichtigen Dritten (terceros civilmente responsables). Diese sind Inhaber jeweiliger spezifischer Rollen, die ihnen aufgrund eines legitimen Interesses oder einer Verpflichtung zur Rechtsanwendung bzgl. der Lösung des durch das Delikt verursachten Konflikts zu Teil werden. Im Strafprozesssystem des Gesetzes 906 von 2004 existiert der Begriff des Prozesssubjekts nicht, es wurden dort die Begriffe „Partei“ oder „die Beteiligten“ (Art. 113 ff.) aufgenommen. Die Begriffe „Partei“ oder „Beteiligter“ erfassen neben den Prozesssubjekten als Personen mit rechtlichem Interesse an dem Prozess auch Personen wie Zeugen oder den jeweiligen Vertreter der Disziplinarstaatsanwaltschaft (Procuraduría), der als verfassungsmäßig gebotener Beteiligter erachtet wird, da er ,„...] als Verteidiger der Rechtsordnung, der öffentlichen Ordnung und der verfassungsmäßigen Rechte und Garantien“332 auftritt (Art. 109 CPP). Insbesondere in Titel IV des 1. Buchs des CPP wird die Bezeichnung „Parteien und Beteiligte“ (Partes e Intervinientes) verwendet und voneinander abgegrenzt. Während in einem akkusatorischen System der Begriff „Parteien“ auf den Staatsanwalt und die Verteidigung beschränkt sein muss, erfasst der Begriff „Beteiligte“ alle weiteren Inhaber prozessualer Befugnisse wie die Opfer, Zeugen, Geschworenen (Art. 250 Nr. 7 CN) und die Disziplinarstaatsanwaltschaft.

Unter dem Konzept der Partei im akkusatorischen Strafprozesssystem versteht die strafprozessrechtliche Doktrin in Kolumbien das Subjekt, welches konkreten gerichtlichen Schutz in Anspruch nimmt oder vor dem konkreter gerichtlicher Schutz in Anspruch genommen wird, wodurch das betreffende Subjekt legitimiert wird, zu disputieren bzw. sich zu verteidigen. ${ }^{333}$ Die Ausfechtung des Disputs wird dabei vom Kontradiktionsgrundsatz geleitet, welcher voraussetzt, dass die Partei aktiv an dem Prozess teilnehmen kann, wodurch sie sich von der Rolle der anderen Beteiligten unterscheidet. Anders verhält es sich bei den Beteiligten, da deren Teilnahme für das Entstehen eines Prozessrechtsverhältnisses nicht unabdingbar ist. Deren Teilnahme ist nur dann notwendig, wenn sie in dem Prozess ein Interesse geltend machen wollen (Opfer) oder sie für die

\footnotetext{
${ }^{332}$ Art. 109 CPP: „El Ministerio Público. El Ministerio Público intervendrá en el proceso penal cuando sea necesario, en defensa del orden jurídico, del patrimonio público, o de los derechos y garantías fundamentales.“ (dt. Übersetzung d. Verf.).

${ }^{333}$ Vgl. dazu KVerfG, Entsch. T-293 v. 2015, Abschn. 5 ff.; Reyes Medina, 2009, S. 53 f.

102
} 
durch die Straftat verursachten Schäden zivilrechtlich verantwortlich sind (zivilrechtlich verantwortlicher Dritter) oder weil eine zusätzliche Kontrollinstanz in dem Strafprozess für erforderlich erachtet wird (Vertreter der Disziplinarstaatsanwaltschaft).

\section{Staatsanwaltschaft}

Die Staatsanwaltschaft nimmt an dem Strafprozess als staatliches Strafverfolgungsorgan und Anklagebehörde (Art. 249-253 CN) teil. Als solche ist sie Partei des Strafprozesses (Art. 133-117 CN). Der Staatsanwalt als institutioneller Akteur ist gemäß Art. $249 \mathrm{CN}$ in die institutionelle Struktur der FGN eingegliedert, die Teil der Justizverwaltung ist und in Verwaltung und Haushalt Unabhängigkeit genießt. ${ }^{334}$ Als Teil der Justizverwaltung treffen die FGN unter anderem folgende Aufgaben und Verpflichtungen: a) Sie hat „[...] die Gleichheit der Beteiligten im Verlauf der Strafverfolgung sicherzustellen und insbesondere diejenigen Personen zu beschützen, die sich aufgrund ihrer wirtschaftlichen, physischen oder mentalen Verfassung in einer deutlich erkennbaren schwachen Stellung befinden“ (Art. 4 CPP). ${ }^{335}$ b) Die auf Seiten der FGN an der Strafverfolgung teilnehmenden Personen „[...] haben dabei ohne jegliche Ausnahme mit absoluter Loyalität und nach den Grundsätzen von Treu und Glauben zu handeln“ (Loyalitätspflicht) (Art. 12 CPP) ${ }^{336}$; c) Sie unterliegt ferner der Neutralitätspflicht, sodass sie ihr Handeln nach objektiven und transparenten Kriterien auszurichten hat, die auf die korrekte Anwendung von Recht und Verfassung abgestimmt sind..$^{337}$

\footnotetext{
${ }^{334}$ Art. 249 letzter Absatz CN: „La Fiscalía General de la Nación forma parte de la rama judicial y tendrá autonomía administrativa y presupuestal.“ („Die Generalstaatsanwaltschaft ist Teil der Justiz und hat Verwaltungs- und Finanzautonomie.“ -dt. Übersetzung d. Verf.-).

${ }^{335}$ Art. 4 CPP: „Igualdad. Es obligación de los servidores judiciales hacer efectiva la igualdad de los intervinientes en el desarrollo de la actuación procesal y proteger, especialmente, a aquellas personas que por su condición económica, física o mental, se encuentren en circunstancias de debilidad manifiesta." (dt. Übersetzung d. Verf.)

${ }^{336}$ Art. 12 CPP: „Lealtad. Todos los que intervienen en la actuación, sin excepción alguna, están en el deber de obrar con absoluta lealtad y buena fe." (dt. Übersetzung d. Verf.).

${ }^{337}$ Art. 115 CPP: „Principio de objetividad. La Fiscalía General de la Nación, con el apoyo de los organismos que ejerzan funciones de policía judicial, adecuará su actuación a un criterio objetivo y transparente, ajustado jurídicamente para la correcta aplicación de la Constitución Política y la ley.“ („Grundsatz der Objektivität. Die Generalstaatsanwaltschaft mit der Unterstützung der Körper, die Funktionen der Kriminalpolizei ausüben, wird das Vorgehen an ein objektives und transparentes Kriterium anpassen, das zur richtigen Anwendung der Verfassung und des Gesetzes rechtlich angepasst wird.“-dt. Übersetzung d. Verf.-). Für die Grundlagen der Objektivitätspflicht im Ermittlungsverfahren vgl. Combe, 2007, S. 51 ff.
} 


\section{Organische Beschaffenheit}

Wenngleich sie der Justizverwaltung untersteht, ist die FGN innerhalb dieser Struktur gleichwohl in ihren Funktionen, ihrer Verwaltung und Haushaltsführung autonom und unabhängig. ${ }^{338}$ Art. 251 Nr. 3 CN legt fest, dass die FGN ,[...] gemäß den Prinzipien einer einheitlichen Führung und hierarchischen Struktur die Kriterien und Positionen, die die Staatsanwaltschaft annehmen soll, zu bestimmen hat, ohne dabei jedoch die Autonomie der zuständigen Staatsanwälte, die diese in dem gesetzlich festgelegten Rahmen genießen, zu verletzen. “339 Aufgrund dieser Norm handeln die zuständigen Staatsanwälte daher stets als Repräsentanten der FGN in hierarchischer Abhängigkeit von ihren jeweiligen Vorgesetzten und des Generalstaatsanwalts. Der hierarchische Aufbau manifestiert sich dabei sowohl in administrativer als auch in disziplinarischer und funktioneller Hinsicht und schlägt sich auch in strafprozessualer Hinsicht nieder, da der Generalstaatsanwalt die generellen Leitlinien der Ermittlungstätigkeit sowie das Vorgehen im Einzelfall vorgibt, wohingegen die Situationen, in denen der zuständige Staatsanwalt Autonomie genießt, den Ausnahmefall darstellen. ${ }^{340}$

In jedem Fall muss das Handeln eines jeden Staatsanwalts aber mit dem sog. „Statutarischen Gesetz der Justizverwaltung“ (Ley Estatutaria de la Administración de Justicia) im Einklang stehen, welches bestimmt: „Die Justiz ist unabhängig und autonom in der Ausübung ihrer verfassungsrechtlichen und gesetzlichen Fuktion als Justizverwaltung.“ Ebenso wird festgestellt, dass „kein in der Verwaltungs- oder Justizordnung hierarchisch Vorgesetzter irgendeinen Justizfunktionär dahingehend auffordern, anleiten oder beraten darf, dass er ihm Ergebnis oder Kriterien seiner Entscheidung aufzwingt.“341 In all denjenigen Akten des zuständigen Staatsanwalts, die jurisdiktioneller Natur sind, insbesondere solchen mit Grundrechtsberührung, findet das

\footnotetext{
${ }^{338}$ Sie ist nach präzisen Kriterien einheitlich geführt und hierarchisch aufgebaut; s. dazu u.a. KVerfG, Entsch. C-387 v. 2014; C-873 v. 2003; C-775 v. 2001.

339 Art. 251 Nr. 3 CN: „Asumir directamente las investigaciones y procesos, cualquiera que sea el estado en que se encuentren, lo mismo que asignar y desplazar libremente a sus servidores en las investigaciones y procesos. Igualmente, en virtud de los principios de unidad de gestión y de jerarquía, determinar el criterio y la posición que la Fiscalía deba asumir, sin perjuicio de la autonomía de los fiscales delegados en los términos y condiciones fijados por la ley.“ (dt. Übersetzung d. Verf.).

${ }^{340}$ Vgl. Bernal Cuellar/Montealegre Lynett, 2013 T. I , S. 172; Reyes Medina, 2009, S. 55.

${ }^{341}$ Art. 5 des Gesetzes 270 von 1996: „Autonomía e independencia de la rama judicial. La Rama Judicial es independiente y autónoma en el ejercicio de su función constitucional y legal de administrar justicia.

Ningún superior jerárquico en el orden administrativo o jurisdiccional podrá insinuar, exigir, determinar o aconsejar a un funcionario judicial para imponerle las decisiones o criterios que deba adoptar en sus providencias.“ (dt. Übersetzung d. Verf.).
} 
Hierarchieprinzip daher insoweit keine Anwendung, als dass der Generalstaatsanwalt dem im Einzelfall zuständigen Staatsanwalt die Entscheidung nicht vorschreiben darf. ${ }^{342}$ In Übereinstimmung mit Art. 228 und $230 \mathrm{CN}$ sind die Staatsanwälte bei derartigen Entscheidungen nur dem Gesetz unterworfen. ${ }^{343}$

\section{Der Staatsanwalt als Partei des Strafverfahrens}

Im Rahmen der strafrechtlichen Ermittlungen nimmt der Staatsanwalt im Wesentlichen verschiedene Aufgaben wahr. Er leitet zum einen die Kriminalpolizei an, indem er ihre durchgeführten Ermittlungstätigkeiten steuert und auswertet. ${ }^{344}$ Des Weiteren hat er im Rahmen der Anhörungen im Vorermittlungsverfahren (audiencias preliminares) das Recht, die Durchführung von Vorab-Anhörungen, nachträglichen Anhörungen oder Zwischenanhörungen zur Kontrolle der Garantien zu beantragen. ${ }^{345}$ Als Vertreter des Strafverfolgungsinteresses ist er drittens für den Schutz von Opfern und Zeugen verantwortlich (Art. 114 Nr. 6 CPP). Darüber hinaus ist der Staatsanwalt derjenige, der die gerichtlichen Maßnahmen zur Betreuung der Opfer, zur Wiederherstellung des Rechts (restablecimiento del derecho) und zur ganzheitlichen Entschädigung (reparación integral) beantragt (Art. 250 Nr. 6 CN). In den Aufgabenbereich des Staatsanwalts fällt ebenfalls, das Erscheinen der Straftatverdächtigen sicherzustellen, indem er die hierzu notwendigen Sicherungsmaßnahmen bei dem JCG beantragt (art. $116 \mathrm{CN}$ ). Jedoch kann die FGN im Rahmen der Grenzen des Art. 300 CPP $^{346}$ ausnahmsweise auch eine Festnahme selbst anordnen.

Ursprünglich war in den Art. 2 und 300 des Gesetzes 906 von 2004 eine grundsätzliche Befugnis der FGN, eine Festnahme ohne vorherige richterliche Anordnung durchzuführen, vorgesehen, die aber vom KVerfG für verfassungswidrig erklärt wurde. ${ }^{347}$ Daraufhin wurden diese Vorschriften jedoch im Rahmen einer Gesetzesreform durch das Gesetz 1142 von 2007 modifiziert, indem in den vierten Absatz des Art. 2 des Gesetzes 906 von 2004

\footnotetext{
${ }^{342}$ Siehe Reyes Medina, 2009, S. 55 mit einer Liste der Grundrechtseingriffe.

${ }^{343}$ Dies gilt in erster Linie für die Ermittlungsmaßnahmen wie die Anordnung einer Hausdurchsuchung, (Tele)kommunikationsüberwachung, Personenüberwachung, Einsatz verdeckter Ermittler etc.

${ }^{344}$ KVerfG, Entsch. C-591 v. 2005, Abschn. „Consideraciones de la Corte“; Bernal Cuellar/Montealegre Lynett, 2013 T. II, S. 87 ff.

${ }^{345}$ Bernal Cuellar/Montealegre Lynett, 2013 T. II, S. 192 ff.; Guerrero Peralta, 2007, S. 146 ff.

${ }^{346}$ Siehe dazu ausführlich infra § 6. C. Nachträglicher Rechtsschutz gegen Maßnahmen zur Beschränkung der Freiheit.

${ }^{347}$ KVerfG, Entsch. C-730 v. 2005; C-799 v. 2005 und C-1001 von 2005, Abschn. „Consideraciones de la Corte“.
} 
der folgende Passus aufgenommen wurde: „Jedenfalls ist eine Kontrolle der Rechtmäßigkeit [der Festnahme] durch den Richter zur Kontrolle der Garantien unverzüglich, spätestens aber innerhalb von 36 Stunden zu beantragen“, 348 wodurch implizit wieder eine Festnahmebefugnis der FGN für Ausnahmen eingeführt wurde. Der Absatz wurde vom KVerfG unter bestimmten Voraussetzungen für verfassungsmäßig befunden, dass die Rechtmäßigkeitskontrolle nicht nur spätestens innerhalb von 36 Stunden beantragt, sondern auch durchgeführt werden muss. ${ }^{349}$ Ebenso wurde Art. 300 des Gesetzes 906 von 2004 durch Art. 21 des Gesetzes 1142 von 2007 so abgeändert, dass die FGN eine Festnahme anordnen darf, sofern diese schriftlich erfolgt, wenn ein Grund für die Anordnung einer Untersuchungshaft vorliegt, also Beweise vorliegen, die vernünftigerweise auf eine Täterschaft oder Teilnahme des Betroffenen schließen lassen, und einer der folgenden besonderen Gründe vorliegt:

1. Die drohende Gefahr, dass die Person sich versteckt, flüchtet oder sich von dem Ort, an dem die Ermittlungen stattfinden, entfernt;

2. eine begründete Wahrscheinlichkeit bzgl. einer Verdunklung von Beweismitteln besteht;

3. Eine Gefahr für die Gesellschaft, die Gemeinschaft oder das Opfer dahingehend besteht, dass ohne die Festnahme eine Straftat der Person zu befürchten ist.

Auch diese Modifikation wurde vom KVerfG für verfassungsgemäß befunden. ${ }^{350}$

Zusammenfassend stehen die Befugnisse der FGN, bestimmte Strafverfolgungsmaßnahmen vorzunehmen, insofern unter dem Vorbehalt einer richterlichen Rechtmäßigkeitskontrolle. Eine Festnahme darf sie nur ausnahmsweise beim Vorliegen besonderer, gesetzlich vorgesehener Gründe anordnen, wobei auch diese spätestens innerhalb von 36 Stunden richterlich auf ihre Rechtmäßigkeit zu kontrollieren ist. Ebenso ist für die Befugnis, im Rahmen der Ermittlungen eine Registrierung, eine Hausdurchsuchung, eine Beschlagnahme und eine Telekommunikationsüberwachung anzuordnen, eine Einschränkung des Richtervorbehalts in der Form vorgesehen, dass auch

\footnotetext{
${ }^{348}$ Art. 2 Abs. 4 CPP: „En todos los casos se solicitará el control de legalidad de la captura al juez de garantías, en el menor tiempo posible, sin superar las treinta y seis (36) horas siguientes." (dt. Übersetzung d. Verf.)

${ }^{349}$ KVerfG, Entsch. C-163 v. 2008, Abschn. „Consideraciones de la Corte“.

${ }^{350}$ KVerfG, Entsch. C- 185 v. 2008, Abschn. „Consideraciones de la Corte“. 
hier nur eine nachträgliche richterliche Kontrolle auf Grundlage der Anordnungsgründe und Resultate der Maßnahme innerhalb von 36 Stunden durchzuführen ist. ${ }^{351}$

\section{Kriminalpolizei}

Die Kriminalpolizei ist nach Art. 200 Abs. 3 CPP keine bestimmte Einheit, sondern eine „Funktion, die staatliche Institutionen ausüben, um die strafrechtlichen Ermittlungen zu unterstützen, und bei der sie funktionell der FGN unterstehen.“352 Die Kriminalpolizei ist mit anderen Worten keine Bezeichnung für die Einheit für technische Ermittlungen (Cuerpo Técnico de Investigación) und die Nationalpolizei (Art. 201 CPP), sondern eine Aufgabe, die von verschiedenen staatlichen Organen wahrgenommen wird, um die Ermittlungen zu unterstützen, sei es in technischen, wissenschaftlichen oder operativen Fragen. ${ }^{353}$ Die Kriminalpolizei als Aktivität kann aus eigenem Betreiben oder auf Anordnung des die Ermittlungen leitenden Staatsanwalts erfolgen. Zu den staatlichen Institutionen, die Aufgaben der Kriminalpolizei wahrnehmen, gehören das Büro der Disziplinarstaatsanwaltschaft (Procuraduría General de la Nación), der oberste Rechnungshof (Contraloría General de la República), die Verkehrspolizei (autoridades de tránsito), sonstige öffentliche Kontroll- und Überwachungsbehören, die nationalen und regionalen Direktoren der Justizvollzugsbehörde (INPEC), die Leiter der Justizvollzugsanstalten im Sinne des Justizvollzugsgesetzes (Código Penitenciario y Carcelario) sowie Polizeibeamte und Bürgermeister (Art. 202 CPP).

Wenn die vorgenannten Beamten im Rahmen ihrer Funktionen von einer Straftat Kenntnis erlangen, haben sie dies der FGN mitzuteilen, damit diese die Koordinierung, rechtliche Prüfung und technisch-wissenschaftliche Verifizierung des diesbezüglichen Vorgehens übernehmen kann (Art. 205 CPP). Ebenso kann der die Ermittlungen leitende Staatsanwalt je nach den Anforderungen der Ermittlungen seine Mitarbeit anordnen. Die Straßenverkehrspolizei ist im Rahmen ihrer kriminalpolizeilichen Funktionen befugt, Beweise im Zusammenhang mit Verletzungen und Tötungen im Straßenverkehr zu

\footnotetext{
${ }^{351}$ Siehe ausführlich infra § 5. Nachträglicher Rechtsschutz gegen Maßnahmen zur Beschränkung der Intimität und § 6. Nachträglicher Rechtsschutz gegen Maßnahmen zur Beschränkung der Unverletzlichkeit der Kommunikation und der Freiheit.

${ }^{352}$ Art. 200 Abs. 3 CPP: „Por policía judicial se entiende la función que cumplen las entidades del Estado para apoyar la investigación penal y, en el ejercicio de las mismas, dependen funcionalmente del Fiscal General de la Nación y sus delegados." (dt. Übersetzung d. Verf.).

${ }^{353}$ Vgl. dazu Gonzalez Mongui, 2007, S. 55 ff.; FGN, 2005a, S. 12 ff.
} 
erheben. ${ }^{354}$ Ebenso sind die nationalen und regionalen Direktoren der INPEC, die Leiter und Angestellten der Justizvollzugsanstalten, befugt, kriminalpolizeiliche Funktionen für in-flagranti ertappte Delikte in den Justizvollzugsanstalten wahrzunehmen. ${ }^{355}$ Ferner sind auch die örtlichen Bürgermeister und Polizeiinspektoren an den Orten, an denen keine Kriminalpolizei und keine Nationalpolizei vorhanden ist, ermächtigt, Maßnahmen wie die Inspizierung von Leichen und Tatorten, Vernehmungen, und weitere Maßnahmen zur Beweiserhebung vorzunehmen, die sie sodann der nächstgelegenen Staatsanwaltschaft zu übermitteln haben. ${ }^{356}$

Die Kriminalpolizei ist bei Ausübung der Ermittlungstätigkeit der Koordination durch die FGN unterstellt, darf grundsätzlich nicht ohne richterliche oder staatsanwaltschaftliche Anordnung tätig werden und muss gemäß Gesetzesakt 03 von 2002 bzw. Art. 250 Num. 8 $\mathrm{CN}$ ferner durch die FGN angeleitet werden. Auch bedürfen freiheitsbeschränkende Maßnahmen gemäß Art. 15 und $28 \mathrm{CN}$ stets einer Koordination durch die Staatsanwaltschaft sowie einer Prüfung durch den JCG. Nach Art. 205 CPP:

„unternehmen die Beamten, die in Ausübung ihrer kriminalpolizeilichen Funktion eine Anzeige, Beschwerde oder sonstige Mitteilung von Tatsachen erhalten, die auf das mögliche Vorliegen eines Straftatbestandes schließen lassen, unmittelbar alle dringenden Maßnahmen, wie die Untersuchung des Tatorts, die Inspizierung eines Leichnams, Befragungen und Vernehmungen. Außerdem identifizieren, sammeln und sichern sie materielle Beweismaterialien und physische Nachweise und nehmen schriftlich, in Tonoder Videoaufzeichnung die Vernehmungen und Befragungen auf und unterwerfen sich einer Gewahrsamskette gegenseitiger Kontrolle.“357

Art. 205 CPP, dritter Absatz, schreibt diesbezüglich ferner vor, dass die „Kriminalpolizei der zuständigen Staatsanwaltschaft innerhalb von 36 Stunden über die Vornahme von dringenden Maßnahmen und von deren Ergebnissen Bericht zu erstatten hat, damit die

\footnotetext{
${ }^{354}$ Vgl. KVerfG, Entsch. T-687 v. 2004; C-429 v. 2003, Abschn. „Consideraciones de la Corte“.

${ }^{355}$ Vgl. Art. 202 Nr. 5 CPP; Lozada Bustos, 2003, S. 41; dazu Art. 41 Gesetz 65 von 1993.

${ }^{356}$ Vgl. Art. 202 Nr. 6 CPP; Lozada Bustos, 2003, S. 40.

357 Art. 205 Abs. 1 CPP: "Actividad de policía judicial en la indagación e investigación. Los servidores públicos que, en ejercicio de sus funciones de policía judicial, reciban denuncias, querellas o informes de otra clase, de los cuales se infiera la posible comisión de un delito, realizarán de inmediato todos los actos urgentes, tales como inspección en el lugar del hecho, inspección de cadáver, entrevistas e interrogatorios. Además, identificarán, recogerán, embalarán técnicamente los elementos materiales probatorios y evidencia física y registrarán por escrito, grabación magnetofónica o fonóptica las entrevistas e interrogatorios y se someterán a cadena de custodia." (dt. Übersetzung d. Verf.). 
Staatsanwaltschaft die Leitung, Koordinierung und Kontrolle der Ermittlungen übernehmen kann. “358

\section{Disziplinarstaatsanwaltschaft}

Das Ministerium für Öffentliche Angelegenheiten (Ministerio Público) ist ebenfalls eine Behörde, die ermächtigt ist, in allen Phasen des Strafverfahrens teilzunehmen. Die Funktionen des Ministeriums für Öffentliche Angelegenheiten werden dabei vom Büro der Disziplinarstaatsanwaltschaft (Procuraduría General de la Nación) wahrgenommen und auf lokaler Ebene von den Disziplinarbehörden der Gemeinde oder des Distrikts, soweit es sich um Verfahren vor dem Strafrichter, den allgemeinen Gerichtskammern des Kreises und der Gemeinde und den jeweiligen Staatsanwaltschaften handelt (Art. 109 Abs. 2 CPP). Deren Beteiligung am Strafprozess ist sehr umstritten, da man eigentlich annehmen können sollte, dass das Verfahren tendenziell akkusatorisch ist und daher die richterlichen Entscheidungen ausschließlich von der Staatsanwaltschaft und der Verteidigung angegriffen werden können, aber nicht von dritter Stelle wie der „Procuraduria“ im Auftrag des Ministeriums für Öffentliche Angelegenheiten. ${ }^{359}$ Die verfassungsrechtliche Grundlage der Rolle des Ministeriums für Öffentliche Angelegenheiten liegt in Art. 118, 250 und $277 \mathrm{CN}$, die bekräftigen, dass die „Procuraduría General de la Nación“ weiterhin die ihr durch die Verfassung von 1991 zukommenden Aufgaben wahrnähme, die da wären: Beteiligung am Prozess zur Verteidigung der Rechtsordnung, der öffentlichen Interessen und der Grundrechte und Grundrechtsgarantien. In der Weiterentwicklung dieser verfassungsrechtlichen Vorgaben teilt Art. 111 CPP dem Ministerium für Öffentliche Angelegenheiten Funktionen zu, wie zum Beispiel dafür Sorge zu tragen, dass die Rechte der Opfer, der Zeugen, der Geschworenen und der weiteren Verfahrensbeteiligten geachtet werden. Ebenso kommt ihm die Aufgabe zu, den wirksamen Schutz der Beteiligten zu verifizieren, an denjenigen Anhörungen teilzunehmen, in denen die Durchsetzung des Strafanspruch zur Disposition steht (z.B. Geständnis von Anklagepunkten, sog. „aceptación de cargos“) $^{\text {, }}$ und dabei zu prüfen, dass der geäußerte Wille der tatsächliche ist und die Rechte der Betroffenen nicht verletzt werden. Ferner hat es zu kontrollieren, dass

\footnotetext{
358 Art. 205 Abs. 3 CPP: „Sobre esos actos urgentes y sus resultados la policía judicial deberá presentar, dentro de las treinta y seis (36) horas siguientes, un informe ejecutivo al fiscal competente para que asuma la dirección, coordinación y control de la investigación." (dt. Übersetzung d. Verf.).

${ }^{359}$ Krit. Calle Calderon, NFP 67 (2005), S. 173 f.; Bazzani Montoya, in Estado Actual de la justicia colombiana (2003), S. $149 \mathrm{f}$.
} 
bei der Anwendung des Opportunitätsprinzips die Prinzipien von Wahrheit und Gerechtigkeit geachtet werden. ${ }^{360}$

Im Rahmen des CPP kommt dem Ministerium für Öffentliche Angelegenheiten des Weiteren die Aufgabe zu, Verweisungsanträge zu stellen (Art. 47), Beschwerden gegen Amtsträger einzureichen (Art. 61), Schutzmaßnahmen für Minderjährige oder behinderte Opfer zu beantragen (Art. 92), die Eröffnung des Verfahrens zur umfänglichen Entscheidung $\mathrm{zu}$ beantragen (Art. 102), im Rahmen seiner kriminalpolizeilichen Funktionen vorläufige Beweisaufnahmen zu beantragen (Art. 112 y 284), nach Erschöpfung der Möglichkeit zur Stellung von Beweisanträgen durch die Parteien ausnahmsweise Zulassung von Beweismitteln zu beantragen (Art. 357), den Austausch des Verteidigers beim Vorliegen eines Interessenkonflikts zu beantragen (Art. 122), auf die Zulassung von Rechtsmitteln zu drängen (Art. 184), die Revision zu beantragen (Art. 193), die Einstellung des Verfahrens wegen Ablaufs der Ermittlungsfrist zu beantragen (Art. 294) oder beim Vorliegen der in Art. 332 vorgesehen Gründe diese bei der Anhörung zur Entscheidung über die Verhängung der entsprechenden Maßnahmen darzulegen (Art. 306), die von der Staatsanwaltschaft im Rahmen der Anhörung zur Kontrolle der Rechtmäßigkeit der Anwendung des Opportunitätsprinzips eingeführten Beweise zu hinterfragen (Art. 327), an der Anhörung zur Entscheidung über die Einstellung des Verfahrens mitzuwirken (Art. 333), die Anklageschrift entgegenzunehmen und sich an der entsprechenden Anhörung zu beteiligen (Art. 339), bei dem Richter den Ausschluss, die Zurückweisung oder die Nichtzulassung von Beweismitteln zu beantragen (Art. 359), Einwände bei Befragungen zu erheben (Art. 395), nach der Zeugenvernehmung zusätzliche Fragen zum vollen Verständnis des Sachverhalts zu stellen, ohne dass es dem Ministerium erlaubt ist, hierdurch Defizite der Befragung und des Kreuzverhörs auszugleichen oder zu überwinden (Art. 397), Einwände hinsichtlich der Verantwortlichkeit des Beschuldigten zu erheben (Art. 443).

\section{Beschuldigter}

Im kolumbianischen Strafverfahren gibt es keine einzige Bestimmung, wer ein Strafverfolgter ist. Abhängig von der Phase des Prozesses, in der der Straverfolgte sich befindet, wird er als Verdächtiger (indiciado), Beschuldigter (imputado) oder Angeklagter

${ }^{360}$ Reyes Medina, 2009, S. 62 ff. Für die Rolle der Disziplinarstaatsanwaltschaft im Strafverfahren s. KVerfG, Entsch. T-293 v. 2013, Abschn. „Consideraciones de la Corte“. 
(acusado) bezeichnet. ${ }^{361}$ In jedem Fall müssen die Durchführung des Ermittlungsverfahrens und die entsprechende Verknüpfung des Strafverfolgten durch die Identifizierung und Individualisierung desselben vorausgegangen sein (Art. 128 CPP). Die Identifizierung unterscheidet sich von der Individualisierung, denn die Bestimmung der Identität setzt die Übereinstimmung zwischen der Person und dem zivilrechtlich eingetragenen Namen voraus. Im Gegensatz dazu ist die Individualisierung eine Spezifikation des Individuums aus den Eigenschaften, die es von anderen unterscheiden. Daher ist es möglich, eine Person durch ihre morphologischen und psychologischen Eigenschaften absolut zu individualisieren, obwohl ihr Name nicht bekannt ist. ${ }^{362}$ Nach der Erfüllung dieser Bedingungen ist es möglich, die Beschuldigung zu erheben, dann wird der Verdächtige als Beschuldigter bezeichnet (Art. 126 und 286 CPP). Die Beziehung zwischen dem Beschuldigten als Prozesspartei und der Verteidigung wird als ein komplexer Begriff der Verteidigung (concepto complejo de defensa) verstanden. Dieses Konzept beinhaltet die Ausübung der Verteidigungsrechte des Beschuldigten und die Befugnisse und Pflichten der Verteidigung (Art. 130 CPP). ${ }^{363}$ Das Recht auf Verteidigung als Teil des Rechts auf einen fairen Prozess enthält alle notwendigen Elemente, um die Befugnisse des Beschuldigten im Strafverfahren zu bestimmen (Art. 8 und 130 CPP).

\section{Verteidiger}

\section{Konzept}

Die kolumbianische Verfassung schreibt die Beteiligung des Strafverteidigers am Strafverfahren vor und bestimmt: „,...] Wer verdächtigt wird, hat das Recht auf Verteidigung und die Beratung durch einen Rechtsanwalt [...]“ (Art. 29 Abs. 3 CN). ${ }^{364}$ In dieser Vorschrift liegt nicht nur die schlichte Wiederholung der Voraussetzung, dass bei dem Strafverfahren ein Verteidiger anwesend ist, sondern sie bedeutet auch, dass ein strafrechtlich Verfolgter aktiv am Verfahren teilnehmen darf, und sie garantiert, dass der Beschuldigte in dem Rechtsstreit selbst intervenieren (,Selbstverteidigung“) kann sowie

\footnotetext{
${ }^{361}$ Vgl. KVerfG, Entsch. C-033 v. 2003, T-611 v. 2003, Abschn. „Consideraciones de la Corte“.

${ }^{362}$ Vgl. Oberster Gerichtshof, Rad. 45753, Entsch. von 29.04.2015; Rad. 42755, Entsch. von 11.12.2013; Rad. 40849, Entsch. von 24.04.2013.

363 Art. 130 CPP: ,[...] el imputado o procesado, según el caso, dispondrá de las mismas atribuciones asignadas a la defensa que resultan compatibles con su condición. [...].“ (,der Beschuldigte oder Angeklagte, je nach Fall, verfügt über die gleichen Befugnisse der Verteidigung, die mit seinem Status kompatibel sind.“ dt. Übersetzung d. Verf.-).

364 Art. 29 Abs. 3 CN.: "[...] Quien sea sindicado tiene derecho a la defensa y a la asistencia de un abogado escogido por él, [...]." (dt. Übersetzung d. Verf.).
} 
fachkundig verteidigt werden kann. ${ }^{365}$ Diese Form der verfassungsmäßig verbürgten aktiven Beteiligung des Beschuldigten wird konkret umgesetzt durch die Aktivitäten eines zur Wahrnehmung seiner Aufgaben ausreichend befähigten Rechtsanwalts. In Art. 125 CPP sind zudem einige besondere Aufgaben und Pflichten des Strafverteidigers aufgeführt:

„1. Den strafrechtlich Verfolgten persönlich zu beraten und auch nach dessen Festnahme unüberwacht mit diesem zu kommunizieren;

2. Dem Strafverteidiger sind ausreichend Zeit und Mittel zur Vorbereitung der Verteidigung einzuräumen, auch wenn dies ausnahmsweise bedeutet, dass in gerechtfertigten Fällen eine Fristverlängerung und eine hiermit einhergehende Verschiebung der mündlichen Verhandlung gewährt werden muss.

3. Im Falle einer Anklage ist der Verteidiger über alle physischen Nachweise und materiellen Beweismittel, die der FGN zur Verfügung stehen, in Kenntnis zu setzen, auch wenn diese für den Verfolgten günstig sind.

4. Die Verwertbarkeit und Brauchbarkeit der Beweismittel dürfen bereits vor Beginn der mündlichen Verhandlung von dem Strafverteidiger in Frage gestellt werden;

5. Der Strafverteidiger darf die Zeugen und Sachverständigen befragen und ins Kreuzverhör nehmen;

6. Der Strafverteidiger darf die gerichtliche Ladung von Zeugen und Sachverständigen beantragen und gegebenenfalls die Anordnung von Zwangsmaßnahmen, um deren Erscheinen zu gewährleisten;

7. Beschlüsse und Urteile mit Rechtsbehelfen und Rechtsmitteln angreifen;

8. Der Strafverteidiger darf auch nicht verpflichtet werden, einen Entlastungsbeweis oder Gegenbeweis präsentieren zu müssen oder sich am Verfahren aktiv zu beteiligen;

9. Suche, Identifizierung, Sammeln und Verwahren von physischen Nachweisen und materiellen Beweismitteln; Befragungen durchführen und Gutachten von gesetzlich hierzu ermächtigten Ermittlern und technischen Sachverständigen einholen; Dabei sind öffentliche und private Einrichtungen und Privatpersonen verpflichtet, die von dem Strafverteidiger angeforderte Mitarbeit vorbehaltlos zu leisten, sofern dieser glaubhaft macht, dass die Informationen zu gerichtlichen Zwecken eingeholt und genutzt werden

${ }^{365}$ Dazu KVerfG, Entsch. T-549 v. 2010; T-654 v. 1998, Abschn. „Consideraciones de la Corte“. 
10. Ferner muss der Strafverteidiger keine Informationen über den Prozess und seinen Mandanten offenlegen. “366

Um jedermann den vollen Zugang zur Justizverwaltung im Bereich des Strafrechts zu garantieren, wurde im Gesetz 941 von 2005 ferner ein Nationales Netz von Ombudsstellen (Sistema Nacional de Defensoría Pública - SNDP) geschaffen, welches der Ombudsstelle für Bürgerrechte (Defensoría del Pueblo) untersteht. Diese Einrichtungen sind damit betraut, denjenigen fachlichen Rat zu erteilen, die aufgrund ihrer schwachen sozioökonomischen Stellung nicht in der Lage sind, einen Rechtsanwalt zu ihrer Verteidigung zu mandatieren. ${ }^{367}$

\section{Aufgaben der Strafverteidigung}

Aus fachlicher Hinsicht ist es die Aufgabe der Verteidigung, die Rechte und Garantien des Beschuldigten geltend $\mathrm{zu}$ machen und an dem Rechtsstreit mitzuwirken, um einen Freispruch für den Mandanten zu erwirken. Der Begriff der fachlichen Verteidigung (defensa técnica) bezieht sich dabei darauf, dass es sich bei dem Verteidiger um einen im Rechtswesen ausgebildeten Berufsträger handelt, der befähigt ist, einen Sachverhalt auf seine strafrechtliche Relevanz zu prüfen und dementsprechend einzuordnen, Anträge bei Gericht zu stellen, gerichtliche Entscheidungen anzufechten, Beweis zu führen, den strafrechtlich Verfolgten über die Einzelheiten der richterlichen Verfahrenshandlungen zu

\footnotetext{
366 Art. 125 CPP: „Deberes y atribuciones especiales. En especial la defensa tendrá los siguientes deberes y atribuciones: 1. Asistir personalmente al imputado desde su captura, a partir de la cual deberá garantizársele la oportunidad de mantener comunicación privada con él; 2. Disponer de tiempo y medios razonables para la preparación de la defensa, incluida la posibilidad excepcional de obtener prórrogas justificadas para la celebración del juicio oral; 3 . En el evento de una acusación, conocer en su oportunidad todos los elementos probatorios, evidencia física e informaciones de que tenga noticia la Fiscalía General de la Nación, incluidos los que sean favorables al procesado; 4 . Controvertir las pruebas, aunque sean practicadas en forma anticipada al juicio oral; 5. Interrogar y contrainterrogar en audiencia pública a los testigos y peritos; 6. Solicitar al juez la comparecencia, aun por medios coercitivos, de los testigos y peritos que puedan arrojar luz sobre los hechos materia de debate en el juicio oral; 7. Interponer y sustentar, si lo estimare conveniente, las nulidades, los recursos ordinarios y extraordinarios y la acción de revisión; 8. No ser obligado a presentar prueba de descargo o contraprueba, ni a intervenir activamente durante el juicio oral; 9. Buscar, identificar empíricamente, recoger y embalar elementos materiales probatorios y evidencia física; realizar entrevistas y valoraciones que requieran conocimientos especializados por medio de los técnicos e investigadores autorizados por la ley. Para tales efectos las entidades públicas y privadas, además de los particulares, prestarán la colaboración que requieran, sin que puedan oponer reserva, siempre que se acredite por parte del defensor certificado por la Fiscalía General de la Nación, que la información será utilizada para efectos judiciales; 10. Abstenerse de revelar información relacionada con el proceso y su cliente, conforme a la ley." (dt. Übersetzung d. Verf.). ${ }^{367}$ Es handelt sich hierbei um eine öffentliche Leistung, die vom Ombudsmann für Bürgerrechte organisiert, dirigiert und kontrolliert wird, zu Gunsten derjenigen Personen, die dies benötigen, um rechtlich beraten und vertreten zu werden. Für die Rolle der Verteidigung s. Bernal Cuellar/Montealegre Lynett, 2013 T. II, S 195 ff.; Reyes Medina, 2009, S. 56 f.
} 
informieren, den betreffenden Fall zu beurteilen und seinen Mandanten entsprechend zu beraten sowie seinen Mandanten im Rahmen ethischer Grundsätze und unter Wahrung der präzisen rechtlichen Anforderungen zur Wirksamkeit von Verfahrenshandlungen zu vertreten. ${ }^{368}$

Die Führung der Verteidigung steht dabei demjenigen Anwalt zu, den der Beschuldigte nach seinem freien Willen bestimmt oder den gegebenenfalls das Nationale Netz von Ombudsstellen benennt. ${ }^{369}$ Die Benennung des Verteidigers des Beschuldigten ist im Moment der Festnahme des Beschuldigten oder, falls eine solche nicht erfolgt, im Moment der förmlichen Erhebung der Beschuldigung vorzunehmen. In jedem Fall muss spätestens im Moment einer Anhörung, zu der der Beschuldigte geladen ist, ein Verteidiger benannt worden sein (Art. 119 CPP). Ist der Verteidiger einmal bestimmt, kann er in dem Strafverfahren agieren, ohne dass es weiterer Formalien bedarf (Art. 120 CPP). Der Verteidiger, der die Verteidigung leitet, „bestimmt die Verteidigungsstrategie und kann mit Zustimmung seines Mandanten und nach vorheriger Unterrichtung des Richters einen weiteren, begleitenden Verteidiger bestimmen. Letzterer handelt sodann unter Anleitung des leitenden Verteidigers und kann im Verfahren jederzeit von seinen Aufgaben wieder entbunden werden“" (Art. $121 \mathrm{CPP}){ }^{370}$

\section{Opfer}

Unter dem Begriff „Opfer“ im Sinne der kolumbianischen Strafprozessordnung versteht man diejenigen natürlichen oder juristischen Personen und sonstigen Rechtssubjekte, die aufgrund der rechtswidrigen Tat einen individuellen oder kollektiven Schaden erlitten haben. Die Eigenschaft des Opfers wird dabei unabhängig davon erlangt, ob der Täter der Straftat ermittelt, gefasst, verurteilt oder bestraft wird oder eine familiäre Beziehung zu diesem besteht (Art. 132 CPP). Das Opfer ist der Inhaber des durch die Straftat verletzten oder gefährdeten Rechtsguts.

\footnotetext{
${ }^{368}$ Siehe dazu KVerfG, Entsch. T-549 v. 2010; T-654 v. 1998, Abschn. „Consideraciones de la Corte“; Oberster Gerichtshof, Rad. 27.283, Entsch. von 1.08.2007.

${ }^{369}$ Art. 118 CPP: „Integración y designación. La defensa estará a cargo del abogado principal que libremente designe el imputado o, en su defecto, por el que le sea asignado por el Sistema Nacional de Defensoría Pública.“ („Integration und Verteidigerbestellung. Die Verteidigung wird vom Hauptanwalt, der freiwillig vom Beschuldigten oder alternativ von dem nationalen Netz von Ombudsstellen benannt wird, übernommen." -dt. Übersetzung d. Verf.-).

370 Art. 121 CPP: „Dirección de la defensa. El defensor que haya sido designado como principal dirigirá la defensa, pudiendo incluso seleccionar otro abogado que lo acompañe como defensor suplente, previa información al juez y autorización del imputado. [...].“ (dt Übersetzung d. Verf.).
} 


\section{Opferrechte}

Sowohl auf verfassungsrechtlicher und gesetzlicher Ebene als auch in der Rechtsprechung und Rechtslehre ist ein Recht des Opfers auf Wahrheit, Gerechtigkeit und Reparation anerkannt. Diese Schutzrechte finden sich in der kolumbianischen Strafprozessordnung in den Artikeln 11, 133, 134, 135 und 136 wieder. Nach den geltenden gesetzlichen Bestimmungen hat der Staat die Pflicht, eine effiziente Untersuchung durchzuführen, die zur Identifizierung, Festnahme und Bestrafung derjenigen Personen führt, die für die Verbrechen verantwortlich sind. ${ }^{371}$ Die Gesellschaft und insbesondere die Opfer haben das unabdingbare Recht, die Wahrheit zu erfahren. ${ }^{372}$ Das Recht der Opfer auf Wiedergutmachung umfasst Handlungen, die auf Wiederherstellung, Entschädigung, Rehabilitation, Genugtuung und die Garantien für die Vermeidung der Wiederholung der Taten abzielen. ${ }^{373}$ Konkret hat das Opfer beispielsweise das Recht, von der Staatsanwaltschaft von der Straftat in Kenntnis gesetzt und gehört zu werden. ${ }^{374}$ Zudem hat das Opfer das Recht, von einem Rechtsanwalt während des Ermittlungsverfahrens, des Hauptverfahrens und des Entschädigungsverfahrens (Incidente de Reparación Integral) beraten zu werden. Diese Rechte gehen mit der spezifischen Funktion des Staatsanwalts einher, der, wie bereits genannt, im Strafprozess auch dafür zuständig ist, die Interessen der Opfer geltend zu machen, und der somit zur „Stimme des Opfers“ im Strafverfahren wird.

\section{Beteiligungsrecht}

Dem Opfer steht auf Grundlage der CN die Stellung eines an dem Strafverfahren Beteiligten zu. Allerdings ist es keine Partei des Verfahrens, da ihm hierfür die Rechte und Ermächtigungen fehlen, die Urteilsfindung voranzubringen, wie sie die Staatsanwaltschaft und die Verteidigung haben. ${ }^{375}$ Jedoch basiert die Rolle des Opfers im Strafverfahren auf dem Grundgedanken, dass es zwecks Gewährung eines effektiven Rechtsschutzes die gleichen Rechte und Möglichkeiten wie der Beschuldigte haben soll u.a. deshalb, weil beide Seiten an der Lösung des durch die Straftat hervorgerufenen Konflikts beteiligt werden sollen. Um das Recht des Opfers auf Wahrheit, Gerechtigkeit und Reparation zu

\footnotetext{
${ }^{371}$ KVerfG, Entsch. C-095 v. 2007; T-489 v. 2008; T-439 v. 2014, Abschn. „Consideraciones de la Corte“.

${ }^{372}$ Siehe ausführlich KVerfG, Entsch. C-370 v. 2006, Abschn. „Consideraciones de la Corte“.

${ }^{373}$ Siehe ausführlich KVerfG, Entsch. C-409 v. 2009, Abschn. „Consideraciones de la Corte“.

${ }^{374}$ Dem Opfer ist die Möglichkeit einzuräumen, eigene Beweise einzubringen. Ihm ist eine würdige Behandlung zukommen zu lassen, seine Sicherheit ist zu gewährleisten und die Interessen des Opfers sind von der Staatsanwaltschaft zu berücksichtigen. Vgl. Bernal Cuellar/Montealegre Lynett, 2013 T. I, S. 693 ff.

${ }^{375}$ KVerfG, Entsch. C-209 v. 2007, Abschn. „Consideraciones de la Corte“; Bernal Cuellar/Montealegre Lynett, 2013 T. II, S. 218 ff.
} 
gewährleisten, hat das Opfer daher gemäß Art. 137 CPP das Recht, in jeder Phase des Verfahrens nach den folgenden Regeln zu intervenieren:

„1. Das Opfer kann in jeder Phase des Verfahrens von der Staatsanwaltschaft Maßnahmen zum Schutz vor möglichen Drohungen oder Straftaten gegen sich oder seine Familie beantragen;

2. Bei der Befragung des Opfers sind dessen persönliche Umstände, Rechte und Würde zu respektieren;

3. Die Opfer sind nicht gezwungen, ihre spezifischen Rechte über einen Rechtsanwalt wahrzunehmen; Ab der vorbereitenden Anhörung können sie sich allerdings nur über einen Rechtsanwalt oder einen bei einer Rechsberatungsstelle einer juristischen Fakultät beschäftigten Studenten aktiv am Prozess beteiligen;

4. Dieser Teil wurde in der Entscheidung C-516 von 2007 für verfassungswidrig erklärt;

5. Der Richter kann im Ausnahmefall anordnen, dass zum Schutz des Opfers dessen Beteiligung an der Hauptverhandlung unter Ausschluss der Öffentlichkeit stattfindet;

6. Sobald die strafrechtliche Verantwortlichkeit des Täters im Strafverfahren festgestellt worden ist, hat das Opfer das Recht, die Eröffnung eines besonderen Entschädigungsverfahrens zu beantragen.“376

\section{Zusammenfassung}

Sowohl der Kompetenzrahmen der Staatsanwaltschaft und der Kriminalpolizei im Ermittlungsverfahren als auch die Grundlagen für das Einholen und Aufbewahren von Beweismitteln sind verfassungsrechtlich vorgegeben und in der aktuellen Strafprozessordnung (Gesetz 906 von 2004) näher ausgestaltet. Das Sammeln von Beweisen und andere Ermittlungsmaßnahmen müssen in Übereinstimmung mit den verfassungsmäßig und menschenrechtlich verbürgten Rechten und Prinzipien interpretiert und ausgeübt werden. Die Ziele des Gesetzesaktes 03 von 2002 und die entsprechenden Änderungen von Art. 116, 250 und $251 \mathrm{CN}$ können nach zwei Gesichtspunkten klassifiziert werden: einerseits nach den insti-

\footnotetext{
376 Art. 137 CPP: „1. Las víctimas podrán solicitar al fiscal en cualquier momento de la actuación medidas de protección frente a probables hostigamientos, amenazas o atentados en su contra o de sus familiares; 2. El interrogatorio de las víctimas debe realizarse con respeto de su situación personal, derechos y dignidad; 3 . Para el ejercicio de sus derechos no es obligatorio que las víctimas estén representadas por un abogado; sin embargo, a partir de la audiencia preparatoria y para intervenir tendrán que ser asistidas por un profesional del derecho o estudiante de consultorio jurídico de facultad de derecho debidamente aprobada; 4. [...]; 5. Si la víctima no contare con medios suficientes para contratar un abogado a fin de intervenir, previa solicitud y comprobación sumaria de la necesidad, la Fiscalía General de la Nación le designará uno de oficio; 6 . El juez podrá en forma excepcional, y con el fin de proteger a las víctimas, decretar que durante su intervención el juicio se celebre a puerta cerrada; 7. Las víctimas podrán formular ante el juez de conocimiento el incidente de reparación integral, una vez establecida la responsabilidad penal del imputado.“(dt. Übersetzung d. Verf.) 116
} 
tutionellen Zwecken, d.h. die Stärkung der Ermittlungsfunktion der Staatsanwaltschaft und Entlastung der Gerichte. Andererseits nach strafprozessualen Zwecken, d.h. die Einführung des Richters zur Kontrolle der Verfahrensgarantien, des Anklagegrundsatzes, des öffentlichen, mündlichen, kontradiktorischen und konzentrierten Hauptverfahrens, die Modifizierung des Beweisrechts und die Einführung des Opportunitätsprinzips. Zur Umsetzung des Akkusationsprinzips und der grundsätzlichen Prinzipien des Hauptverfahrens hat die Verfassungsreform auch die Kompetenzen der am Prozess teilnehmenden Akteure modifiziert. Die Kompetenz zur Einleitung des Ermittlungsverfahrens und das Anklagemonopol liegen bei der Staatsanwaltschaft, nicht allerdings die Disposition zur Einstellung des Ermittlungsverfahrens, über die nach der Verfassungsreform nur der Erkenntnisrichter verfügen kann. Zur Beibringung von Beweisen sind sowohl die Staatsanwaltschaft als auch der Angeklagte und der Richter ermächtigt. Die Ermächtigung zur Anordnung von Zwangsmitteln liegt beim JCG. Die Art des Strafprozesssystems basiert auf der Trennung von Ermittlungs- und Hauptverfahren und dem Vorrang des Grundsatzes des Richtervorbehalts. Der Strafprozess unterteilt sich grundlegend in drei Etappen: das Ermittlungsverfahren, das Zwischenverfahren und das Hauptverfahren. Das Ermittlungsverfahren ist durch die Unterwerfung unter das Legalitätsprinzip und unter die richterliche Kontrolle der Ermittlungsmaßnahmen gekennzeichnet. Der Ablauf der Ermittlungsphase gliedert sich in Vorermittlung und Ermittlung im engeren Sinn. Die Ermittlungsphase beginnt formell mit der Erhebung der Beschuldigung (Art. 286 CPP) und endet mit der Erhebung der Anklage (Art. 336 CPP), der Einstellung des Ermittlungsverfahrens (Art. 331 CPP) oder der Anwendung des Opportunitätsprinzips (Art. $321 \mathrm{CPP}$ ). Prozesssubjekte des kolumbianischen Strafprozesses (Art. 113 ff. CPP) sind der Richter, der Staatsanwalt, die Kriminalpolizei, die Verteidigung, der Prozessierte (Verdächtige, Beschuldigte, Angeklagte oder Verurteilte), das Opfer und die schadenersatzpflichtigen Dritten. 


\section{§ 4. Der Richter zur Kontrolle der Garantien (Juez de Control de Garantías)}

\section{A. Begriff und Organisation}

In Kolumbien muss über die Rechtmäßigkeit jeder Beeinträchtigung der Grundrechte eines vor der Staatsanwaltschaft oder von anderen Ermittlungsbehörden Verdächtigen von einem Gericht entschieden werden, sei es durch eine vorherige oder nachträgliche Überprüfung. Der Justizbeamte, der über die Einhaltung der Grundrechte der Personen wacht, gegen die ein strafrechtliches Ermittlungsverfahren eingeleitet wird, ist der sog. Richter zur Kontrolle der Garantien (JCG). Laut Verfassung und Gesetzgebung ist er für die Förderung der Verwirklichung materiellen Rechts, insbesondere für die Sicherstellung der Einhaltung der Grundrechte zuständig. ${ }^{377}$ Der Gesetzesakt 03 von 2002 wies dem JCG Kompetenzen im Bereich der gerichtlichen Überprüfung von Eingriffen in die Grundrechte während der strafrechtlichen Ermittlung zu. ${ }^{378} \mathrm{Zu}$ der Überwachung der Ermittlungstätigkeiten durch den JCG gehört nicht nur die Ausübung der (i) vorherigen Überprüfung der Maßnahmen zur Freiheitsbeschränkung, zur körperlichen Untersuchung, Durchsuchungen von Personen und Probenahmen, die den Beschuldigten betreffen (Art. 246 bis $250 \mathrm{CPP}$ ), sondern auch (ii) eine nachträgliche Überprüfung der Maßnahmen bei einer Hausdurchsuchung und Überwachung der Kommunikation (Art. 213 bis 245 CPP). Der Handlungsbereich des JCG konzentriert sich auf die Überprüfung der Handlungen, die die Ausübung der Gerichtshoheit voraussetzen, da sie eine Einschränkung der Rechte beinhalten. Die wichtigen, von der Verfassung dem JCG zugeschriebenen Aufgaben beinhalten weder Bereiche der Arbeit des befassten Erkenntnisrichters, noch führen sie zu einer Beeinflussung derselben. Dieser Richter muss zudem gemäß Gesetzesakt 03 von 2002 ein anderer Beamter sein. Der JCG bezieht seine Rechtsgrundlage direkt aus der Verfassung und übt folglich eine Aufgabe aus, die durch die höchste Norm in der Normenhierarchie festgelegt wird. Er kann daher auch nicht als dem Obersten Gerichtshof untergeordnet oder von ihm abhängig betrachtet werden.

\footnotetext{
377 Das ist eine ständige Rechtsprechung des KVerfG. Vgl. KVerfG, Entsch. C-025 v. 2009; C-185 v. 2008; C-186 v. 2008 ; C-740 v. 2008 ; A-089 v. 2007; C-336 v. 2007; C-396 v. 2007, C-789 v. 2006; C-673 v. 2005; C-822 v. 2005 ; C-1260 v. 2005; C-1092 v. 2003, Abschn. „Consideraciones de la Corte“.

${ }^{378}$ Siehe u.a. Aponte Cardona, 2006, S. 23; Guerrero Peralta, 2006, S. 30; Guerrero Peralta, 2004, S. 188; CSJ, 2005, S. 21; Urbano Martínez, 2011, S. 135 ff.; Rivera Loaiza, RDP 40, S. 121-160.
} 
In Ausübung dieser Zuständigkeit werden die Folgen der richterlichen Entscheidung danach bestimmt, wie der JCG die Rechtmäßigkeit der Handlungen der FGN bewertet. ${ }^{379}$ So gibt es zwei grundsätzliche Bedingungen zu berücksichtigen: Zum einen, im Falle der Feststellung, dass die Handlung der Staatsanwaltschaft die Grundrechte und verfassungsrechtlichen Garantien des Verdächtigen und des Verfahrens verletzt hat, stellt der Richter die Rechtswidrigkeit der bewerteten Handlungen fest. Das erbrachte Beweismaterial gilt damit als nichtig und wird daher weder als Beweis zugelassen noch verwertet. Eine schlüssige Entscheidung über die Rechtswidrigkeit einer Ermittlungstätigkeit oder einer Zwangsmaßnahme gegen den Verdächtigen oder Beschuldigten führt zum Abbruch des strafrechtlichen Ermittlungsverfahrens sowie der mündlichen Verhandlung über Begründung der Anklage vor dem Erkenntnisrichter. ${ }^{380}$ In Fällen, in denen der JCG feststellt, dass die Staatsanwaltschaft in Ausübung ihrer Befugnisse innerhalb der verfassungs- und gesetzmäßig vorgegebenen Grenzen gehandelt hat, bestätigt er deren Amtshandlungen. Somit können die Ermittler ihre Ermittlungshandlungen fortsetzen, Beschuldigung oder Anklage erheben und einen Strafbefehl erwirken. In diesen Fällen sagt die Entscheidung des JCG jedoch nichts über die strafrechtliche Verantworlichkeit des Verdächtigen aus. Die Frage, ob diese gegeben ist, wird in der mündlichen und öffentlichen Hauptverhandlung im Rahmen der Urteilsfindung erörtert. ${ }^{381}$

Die Rechtmäßigkeit der Handlungen der FGN im Rahmen des Ermittlungsverfahrens setzt die verfassungsgemäße Durchführung des Strafverfahrens voraus. Mit dieser Zielsetzung und aus den Gründen, die in der Gesetzesbegründung dargestellt sind, kann festgestellt werden, dass die Kontrollaufgabe des JCG besteht, um die Überprüfung der Gründe, die das Vorziehen der Amtshandlungen veranlassten, ihre Zulässigkeit und insbesondere deren Überprüfung auf die Achtung der Grundrechte ${ }^{382}$ vorzunehmen. Die Gegenwart des JCG

\footnotetext{
${ }^{379}$ KVerfG, Entsch. C-1092 v. 2003, Abschn. „Consideraciones de la Corte“.

${ }^{380}$ Dieses Ergebnis entspricht dem in Art. $29 \mathrm{CN}$ Vorgesehenen; danach ist jedes Beweismittel, das unter Verletzung des rechtmäßigen Verfahrens gewonnen wurde, nichtig; dazu Rodríguez Chocontá, 2012, S. 50 f., 393 ff.; Defensoría del Pueblo, 2008, S. 77 ff.

${ }^{381}$ Vgl. Oberster Gerichtshof, Rad. 29904, Entsch. von 12.06.2008; dazu Guerrero Peralta, 2006, S. 67 f.; Bernal Cuellar/Montealegre Lynett, 2013 T. I, S. 317 ff.

${ }^{382}$ KVerfG, Entsch. C-1093 v. 2003, Abschn. „Consideraciones de la Corte“; Bernal Cuellar/Montealegre Lynett, 2013 T. I, S. 293 f. 
ergänzt die Aufgabe der Staatsanwaltschaft in Bezug auf den Schutz der Grundrechte, die während eines Ermittlungsverfahrens beeinträchtigt werden könnten. ${ }^{383}$

Entsprechend Art. 39 CPP kann die Aufgabe der Kontrolle der Garantien von jedem Strafrichter am Bezirksgericht ausgeübt werden. Dem Richter, dem die Kontrolle der Garantien obliegt, wird die sachlich-rechtliche Beurteilung desselben Falles untersagt. Wenn ein Vorgang, den dieser Richter kontrollieren soll, zu einem Fall gehört, der in den Zuständigkeitsbereich des Strafrichters am Gerichtsbezirk fällt oder wenn ein Hinderungs- oder Ablehnungsgrund vorliegt und es nur einen Strafrichter in dem jeweiligen Gerichtsbezirk gibt, muss die Aufgabe der Kontrolle der Garantien von einem anderen Richter desselben Gerichtsbezirks wahrgenommen werden unabhängig von seinem Fachbereich oder, in Ermangelung eines solchen, derjenige der nächstliegenden Gemeinde. Art. 39 Paragraph 1 CPP legt fest, dass in den Fällen, die das Oberste Gericht zu entscheiden hat, die Rolle des JCG von einem Einzelrichter der Strafkammer des Obersten Gerichtshofs (Tribunal Superior) von Bogotá ausgeübt wird. In Paragraph 2 wird zudem bestimmt, dass, wenn der Tatort zu einem Gerichtsbezirk mit vier oder mehr Richtern der Gemeinde gehört, eine bestimmte und im Verhältnis stehende Anzahl der Richter ausschließlich die Aufgabe der Kontrolle der Garantien ausüben soll. Dies geschieht nach der Überprüfung der Umstände, die für die Angelegenheit in Betracht gezogen werden müssen, und in Übereinstimmung mit der Verteilung und Organisation, die von der Verwaltungskammer des Obersten Rates der Justiz (Consejo Superior de la Judicatura) oder der Räte der Justiz der jeweiligen Ebene angeordnet wurden. ${ }^{384}$

\section{B. Funktion und Aufgaben des Richters zur Kontrolle der Garantien}

Wie schon erwähnt, hat der JCG die Aufgabe festzustellen, ob die ausgeübten Befugnisse der Staatsanwaltschaft und der Ermittlungsbehörde - abgesehen von den Ausnahmen (Art. $32 \mathrm{CN}$ ) - in Übereinstimmung mit den verfassungsmäßigen und gesetzlichen Vorgaben für strafrechtliche Eingriffe wahrgenommen werden. Die Ausübung dieser Aufgaben richtet sich nach dem Grundsatz der Verfügbarkeit, nach dem tatsächlich jederzeit mit dem

\footnotetext{
${ }^{383}$ Siehe u.a. KVerfG, Entsch. C-210 v. 2007; C-591 v. 2005 und C-873 v. 2003, Abschn. „Consideraciones de la Corte".

${ }^{384}$ Art. 39 Parag. 2 CPP: „Cuando el lugar donde se cometió el hecho pertenezca a un circuito en el que haya cuatro o más jueces municipales, un número determinado y proporcional de jueces ejercerán exclusivamente la función de control de garantías, de acuerdo con la distribución y organización dispuesta por la Sala Administrativa del Consejo Superior de la Judicatura o de los respectivos Consejos Seccionales de la Judicatura, previo estudio de los factores que para el asunto se deban tener en cuenta.“ (dt. Übersetzung d. Verf.).
} 
Eingriff eines JCG gerechnet werden muss, um die erwähnten Aufgaben wahrzunehmen. ${ }^{385}$ Im CPP von 2004 wurde festgelegt, dass es dem JCG obliegt, während einer vorbereitenden Anhörung die Angelegenheiten zu bestimmen, die während der Anklageerhebung, der Vorbereitungsanhörung oder der mündlichen Hauptverhandlung nicht angeordnet, entschieden oder getroffen werden dürfen, beispielsweise:

(i) Die Überprüfung der Rechtmäßigkeit der Gegenstände und Daten, die während einer von der Staatsanwaltschaft veranlassten Hausdurchsuchung oder Überwachung der Kommunikation erhoben wurden;

(ii) Die Verfahrensweise einer vorzeitigen Beweisaufnahme;

(iii) Die Anordnungen von notwendigen Maßnahmen für den Schutz der Opfer und Zeugen;

(iv) Der Antrag der Staatsanwaltschaft auf eine Sicherungsmaßnahme sowie ihre Aufhebung auf Antrag von einer Partei oder der Disziplinarstaatsanwaltschaft;

(v) Der Antrag auf Sicherungsmaßnahmen über Sachen;

(vi) Die Erhebung der Beschuldigung;

(vii) Die gerichtliche Überprüfung der Rechtmäßigkeit bei der Umsetzung des Opportunitätsprinzips gleich welcher Ausprägung;

(viii) Die Anträge auf Freilassung, die vor der Ankündigung des Urteils in der Sache gestellt werden. ${ }^{386}$

Grundsätzlich müssen die Beeinträchtigungen der Grundrechte innerhalb einer strafrechtlichen Ermittlung von einem JCG vorher angeordnet werden. Jedoch, auf Grundlage verschiedener gerichtlicher und für die Ermittlung typischer Befugnisse, die zur verfassungsmäßigen Ermittlungstätigkeit der Staatsanwaltschaft gehören, erfolgt diese Kontrolle nach-

\footnotetext{
385 Oberster Gerichtshof, Rad. 30363, Entsch. von 04.02.2009, Abschn. 2.1.1. Jueces de control de garantías. 386 Art. 154 CPP, verändert durch Art. 12 des Gesetzes 1142 von 2007: „Modalidades. Se tramitará en audiencia preliminar: 1. El acto de poner a disposición del juez de control de garantías los elementos recogidos en registros, allanamientos e interceptación de comunicaciones ordenadas por la Fiscalía, para su control de legalidad dentro de las treinta y seis (36) horas siguientes; 2. La práctica de una prueba anticipada; 3. La que ordena la adopción de medidas necesarias para la protección de víctimas y testigos; 4 . La que resuelve sobre la petición de medida de aseguramiento; 5 . La que resuelve sobre la petición de medidas cautelares reales; 6 . La formulación de la imputación; 7. El control de legalidad sobre la aplicación del principio de oportunidad; 8. Las peticiones de libertad que se presenten con anterioridad al anuncio del sentido del fallo; 9. Las que resuelvan asuntos similares a los anteriores." (dt. Übersetzung d. Verf.).
} 
träglich innerhalb einer Frist von 36 Stunden. ${ }^{387}$ Die Handlung des JCG erfolgt nicht von Amts wegen, sondern wird beantragt. Das bedeutet, dass die von ihm durchgeführten Anhörungen nach Anforderung einer der Parteien oder der Disziplinarstaatsanwaltschaft ausgeführt werden. Es obliegt dem Antragsteller, dem Richter die sachliche und rechtliche Grundlage des Antrags mit den ihn fundierenden Erkenntnismitteln vorzulegen. Um über den Antrag zu entscheiden, muss der Richter nicht nur die Rechtmäßigkeit der Handlung überprüfen, sondern auch die Achtung der Grundrechte und der grundlegenden Garantien. ${ }^{388}$

Wenn es sich um nachträgliche Zustimmungen oder Überprüfungen der Ermittlungstätigkeit handelt, darf der Richter nicht die Erforderlichkeit oder Geeignetheit der Durchführung der Amtshandlungen für den Erfolg des Ermittlungsverfahrens bewerten, sondern die Zulässigkeit und die sachliche und rechtliche Grundlage für die Beeinträchtigung des Grundrechts und, wenn die Amtshandlungen bereits ausgeführt wurden, die Beachtung der grundrechtlichen und verfassungsmäßigen Garantien. Die negative Beurteilung durch den Richter hat keine materielle, sondern eine formelle Rechtswirkung. Folglich ist es möglich, vor demselben wiederholt oder vor einem anderen JCG den Antrag zu stellen, wenn sich die auf Tatsachen beruhende Grundlage verändert hat. Die Überprüfung durch den JCG betrifft die Rechtmäßigkeit der Ermittlungstätigkeit und nicht die Zulässigkeit oder Unzulässigkeit der Beweismittel, da dies der Strafrichter während der Vorbereitungsanhörung festlegt. Damit Gegenstände als Beweismittel zugelassen werden können, muss ein Prüfungsschema durchlaufen worden sein und bestimmte Bedingungen erfüllt werden: (I) Fundgegenstand, (II) Nutzen - Zulässigkeit -, (III) Rechtmäßigkeit - Verfahren bei der Beschaffung -, (IV) Echtheit, (V) Einführung in der mündlichen Hauptverhandlung und (VI) Beweiswürdigung. ${ }^{389}$

\footnotetext{
${ }^{387}$ Diese Frist beginnt mit der Anordnung der Staatsanwaltschaft oder mit dem Zeitpunkt, zu dem der Zweck der Anordnung erfüllt worden ist. Vgl. KVerfG, Entsch. C-163 v. 2008 und C-239 v. 2012, Abschn. „Consideraciones de la Corte“; dazu ausführlich infra § 5. Nachträglicher Rechtsschutz gegen Maßnahmen zur Beschränkung der Intimität und § 6. Nachträglicher Rechtsschutz gegen Maßnahmen zur Beschränkung der Unverletzlichkeit der Kommunikation und der Freiheit.

${ }^{388}$ KVerfG, Entsch. C-1093 v. 2003, Abschn. „Consideraciones de la Corte“; Bernal Cuellar/Montealegre Lynett, 2013 T. I, S. 293 f.; s. infra § 5. A. II. Überprüfung der Achtung der Grundrecht; B. II. Gerichtliche Überprüfungsanhörung; C. IV. Überprüfungsanhörung und § 6. B. IV. Nachträgliche gerichtliche Überprüfungsanhörung.

${ }^{389}$ Bedoya Sierra, 2008, S. 195 ff.
} 


\section{Annahme von Maßnahmen}

Der JCG muss zu verschiedenen Zeitpunkten während der Ermittlungsphase handeln, um Amtshandlungen der Staatsanwaltschaft, die ein Grundrecht zu beschränken beabsichtigt, vorher zu erlauben. So überprüft er die formale und materielle Rechtmäßigkeit der Ermittlungshandlungen der Staatsanwaltschaft bei der Ausübung ihrer Befugnisse während des Ermittlungsverfahrens und entscheidet über die Anträge der Parteien zu Verfahrensfragen in Bezug auf die Erfüllung bestimmter Bedingungen von Prozesshandlungen. Die Amtshandlungen des JCG werden in folgenden Anhörungen durchgeführt:

(i) Erhebung der Beschuldigung (Art. 154 Nr. 6, 286 und 294 CPP);

(ii) Antrag und Anordnung von Sicherungsmaßnahmen (Art. 154 Nr. 4, 306 und $320 \mathrm{CPP})$;

(iii) Antrag und Anordnung von Sicherungsmaßnahmen über Sachen (Art. 92 und 154 Nr. 5 CPP);

(iv) Antrag auf Aufhebung oder Ersatz der Sicherungsmaßnahme (Art. 314 und 318 CPP);

(v) Anwendung des Opportunitätsprinzips (Art. 154 Nr. 7 und 327 CPP);

(vi) Vorzeitige Beweisaufnahme (Art. 154 Nr. 2, 284 und 285 CPP) und

(vii) Antrag und Annahme der notwendigen Maßnahmen zum Schutz der Opfer und Zeugen (Art. 154 Nr. 3 und 342 CPP).

Entsprechend Art. 250 Nr. 1 CN ist der JCG dafür zuständig, die Sicherungs- und Schutzmaßnahmen für die Gemeinschaft und Opfer zu treffen. Zu diesem Punkt ist anzumerken, dass die Sicherungsmaßnahmen, die das Erscheinen des Beschuldigten vor Gericht sicherstellen sollen, zu den ordentlichen Aufgaben des JCG gehören, da die Verfassung den Sondercharakter der gesetzlich geregelten Befugnis der Staatsanwaltschaft festlegt, Festnahmen anzuordnen und durchzuführen. ${ }^{390}$ Andererseits steht fest, dass, sobald die betreffenden Befugnisse ausgeübt werden und diese eine Einschränkung der Grundrechte zur Folge haben, der JCG in Bezug auf die Möglichkeit, dass die Staatsanwaltschaft einen grundrechtsrelevanten Eingriff durchführt, der Abwägung der Verhältnismäßigkeit unterliegt, d. h., dass sich die Maßnahmen auf die Erreichung der Ziele, die diese Verordnung enthält, richten und immer auch erforderlich sein müssen.

${ }^{390}$ Vgl. Bernal Cuellar/Montealegre Lynett, 2013 T. II, S. 464; dazu ausführlich infra § 6. C. I. Festnahme mit Ausnahmekompetenzen. 


\section{Anordnungen und Verhältnismäßigkeitsgrundsatz}

An zweiter Stelle steht die Aufgabe, Maßnahmen zu genehmigen. Es handelt sich um den Fall, der in Art. 250 Nr. 3 CN behandelt wird: Die Staatsanwaltschaft benötigt eine Genehmigung für Anordnungen, die materielle Beweismittel sichern sollen und eine Beeinträchtigung oder Einschränkung der Grundrechte zur Folge haben. Die vorausgehende Überprüfung der Garantien erfolgt in vorbereitenden Anhörungen, in denen über Folgendes entschieden wird:

(i) Haftbefehl gegen den Beschuldigten (Art. 297 CPP);

(ii) Probenahmen, die den Beschuldigten mit einschließen, wenn dieser sich weigert, sie zur Verfügung zu stellen (Art. 249 CPP) und

(iii) Vorgehen im Falle von Verletzten oder Opfern sexueller Gewalt (Inaugenscheinnahme und ärztliche Untersuchung ${ }^{391}$, (Art. 250 CPP); körperliche Untersuchung (Art. 247 CPP) und Durchsuchung von Personen (Art. 248 CPP)).

In Bezug auf die Handlungen, die einer vorherigen richterlichen Genehmigung bedürfen, führt der CPP durch den Art. 246 eine Generalklausel ein. Jede andere als die vorgesehene Maßnahme, die der Staatsanwalt eigenständig ergreifen möchte und die ein Grundrecht oder eine solche Garantie beeinträchtigt, muss vom JCG auf Antrag des betreffenden Staatsanwaltes genehmigt werden. ${ }^{392}$ In Übereinstimmung mit dem eben Erwähnten ist es die erste Aufgabe des Staatsanwalts, zu bestimmen oder festzulegen, ob mit der beabsichtigten Handlung ein Grundrecht des Befragten oder Beschuldigten derart gefährdet wird, dass eine vorhergehende richterliche Zustimmung zum Handeln notwendig ist. Der zentrale Aspekt für die Entscheidung über die Notwendigkeit der Zustimmung durch den JCG besteht in der Überprüfung der verfassungsmäßigen Begründung, die sich nach den Prinzipien Erforderlichkeit, Zweckmäßigkeit und Angemessenheit richtet. Der Richter muss also immer den Grundsatz der Verhältnismäßigkeit anwenden. ${ }^{393}$

\footnotetext{
${ }^{391}$ Vgl. KVerfG, Entsch, C-822 v. 2005, Abschn. „Consideraciones de la Corte“.

${ }^{392}$ Vgl. KVerfG, Entsch. C-336 v. 2007, Abschn. (i) Como regla general, las medidas que afectan derechos fundamentales requieren autorización previa del juez de control de garantías.

${ }^{393}$ In Übereinstimmung mit dem letzten Satz in Art. 246 CPP kann die Ermittlungsbehörde unter außergewöhnlichen Umständen höchster Dringlichkeit die vorherige Zustimmung direkt vor dem Richter beantragen. In diesem Fall muss der Staatsanwalt unverzüglich darüber informiert werden.
} 
Unbestritten ist die Einschränkung der Grundrechte, die nicht im engsten Sinne erforderlich ist, um die Beweismittel zu sichern, verboten. Genauso wenig sind Maßnahmen zulässig, die ausdrücklich in der Verfassung geregelte Verbote ignorieren, wie beispielsweise die Einschränkungen der Meinungsfreiheit oder Meinungsäußerungsfreiheit, die zu einer Zensur führen würden. Grundsätzlich muss auch sichergestellt werden, dass das rechtmäßige Verfahren nicht eingeschränkt wird. Das rechtmäßige Verfahren muss bei allen Handlungen beachtet werden und muss gesetzeskonform durchgeführt werden. Das Legalitätsprinzip Grundlage eines Rechtsstaates - ist demnach Teil des rechtmäßigen Verfahrens. Eine Einschränkung dieses Grundsatzes würde prima facie die Einschränkung eines grundlegenden Bestandteils des Normengefüges bedeuten.

Anders als die Einschränkungen, die ausdrücklich in der Verfassung festgelegt sind - Festnahme, Hausdurchsuchung, Abhören bzw. Abfangen von Nachrichten und Beschlagnahme -, bei denen Zweck und Reichweite der betreffenden Anordnung bekannt sind (da sie in der Verfassung vorgesehen sind), handelt es sich hier um den Antrag auf Maßnahmen, die nicht verfassungsmäßig geregelt sind. ${ }^{394}$ Da es sich um die Einschränkung der Grundrechte handelt - die Bedingung für die Notwendigkeit einer Zustimmung -, müssen die Maßnahmen nicht nur ein legitimes Ziel verfolgen (z. B. das Sichern materieller Beweismittel), geeignet und erforderlich sein, es erscheint vielmehr unerlässlich, das Ausmaß der Beeinträchtigung des Grundrechtes ins Verhältnis mit dem erreichten Nutzen zu setzen, insbesondere muss der Schutz des Grundrechtskerns gewährleistet werden. Wenn die FGN direkt eine Maßnahme anordnet, muss sie auch nach dem Grundsatz der Verhältnismäßigkeit handeln.

Mit dieser Überprüfung wird festgestellt, ob diese differenzierte Behandlung nicht wichtigere verfassungsmäßige Werte verletzt als die, die durch die beeinträchtigende Maßnahme geschützt werden. Aus dieser Erwägung muss geschlussfolgert werden, dass die Zwecke überragend sein müssen, die Mittel nicht nur geeignet, sondern auch erforderlich sein müssen, um den angestrebten Zweck zu erreichen, und dass die Maßnahmen nicht eine in Bezug auf die gesuchten Zwecke unverhältnismäßige Einschränkung der Rechte des Beschuldigten zur Folge haben. ${ }^{395}$ Mit dem strengen Grundsatz der Verhältnismäßigkeit wird mit

\footnotetext{
${ }^{394}$ Es handelt sich nicht um Mittel, die ausdrücklich von der Verfassung gestattet werden. Solche Maßnahmen sind in Art. 213 ff. normiert. S. dazu Bernal Cuellar/Montealegre Lynett, 2013 T. II, S. 227 ff.

395 Vgl. KVerfG, Entsch. C-838 v. 2013; C-258 v. 2013; C-822 v. 2005, Abschn. „Consideraciones de la Corte“; Bernal Cuellar/Montealegre Lynett, 2013 T. I, S. 385 ff.
} 
anderen Worten sichergestellt, dass die Einschränkungen durch den Nutzen, der aus der Geltung anderer Rechte hervorgeht, gerechtfertigt wird, wobei es unerlässlich erscheint, dass die Maßnahme als zielführend, berechtigt, angemessen und auch zwingend oder strikt unerlässlich bezeichnet werden kann, sodass der gesetzmäßige und wichtige Zweck berechtigterweise mit keinem weniger einschränkenden Mittel erreicht werden kann.

\section{Bestätigungen}

Schließlich hat der JCG die Aufgabe, die von der FGN getroffenen Entscheidungen zu überprüfen: Hausdurchsuchungen, Überwachung der Kommunikation, Beschlagnahme, Festnahmen und die Beachtung des Opportunitätsprinzips. ${ }^{396}$ In Bezug auf die Überprüfung solcher Entscheidungen muss bedacht werden, dass es sich um ein Urteil über die von der Staatsanwaltschaft hervorgebrachten Gründe handelt. Daher handelt es sich um eine tatsächliche Überprüfung der Verfassungs- und Rechtmäßigkeit der Maßnahme. In diesem Sinne muss der JCG in Bezug auf die Überprüfung der Verfassungsmäßigkeit feststellen, ob der Staatsanwalt die genauen verfassungsmäßigen Vorgaben bei der Ausübung seiner gerichtlichen Befugnisse gewahrt hat. ${ }^{397}$

Die nachträgliche Kontrolle der Garantien wird in einleitenden Anhörungen nahezu immer öffentlich ${ }^{398}$ durchgeführt. In diesen wird über die Rechtmäßigkeit von folgenden Maßnahmen entschieden:

(i) Festnahme auf frischer Tat (Art. 300 und $301 \mathrm{CPP}$ );

(ii) Hausdurchsuchung (Art. 219 und 237 CCP);

(iii) Überwachung der Kommunikation (Art. 235 und 237 CPP);

(iv) Verfahren zur Wiederherstellung der Information unter Verwendung technologischer Hilfsmittel - Internet - (Art. 236 und 237 CPP);

(v) Maßnahmen, die beschlagnahmungsfähige Sachen und Anträge zur Aufhebung des Verfügungsrechts über die Sachen betreffen (Art. 84 CPP);

(vi) Überwachung und Observierung von Personen (Art. 239 CPP);

\footnotetext{
${ }^{396}$ Dazu Guerrero Peralta, 2007, S. 335 ff.; Guerrero Peralta, 2006, S. 91 ff.

${ }^{397}$ Eben Gesagtes ergibt sich nämlich aus seiner Funktion als Schützer der Grundrechte, als Garant des richterlichen Vorbehalts bzgl. der Einschränkung desselben. S. dazu Zuluaga, Co-Herencia Vol. 4 Nr. 6 (2007), S. 133-165.

${ }^{398}$ Vgl. Art. 155 und 237 CPP, die eine Beschränkung der Öffentlichkeit einführen.
} 
(vii) Überwachungsmaßnahmen von Sachen (Art. 240 CPP);

(viii) Analyse und Infiltrierung krimineller Organisationen (Art. 241 CPP);

(ix) Vorgehen verdeckter Ermittler (Art. 242 CPP) und

(x) Verdeckte Überwachung von Transport und Verkauf von Waffen, Sprengstoff, Munition, Falschgeld und Drogen (Art. 243 CPP).

Aus den hier aufgeführten Punkten kann ohne Schwierigkeit gefolgert werden, dass es sich um streitentscheidende und dringende Maßnahmen handelt, die zum unmittelbaren Schutz der Grundrechte der Verdächtigen führen, wie z. B. persönliche Freiheit, die Rechtmäßigkeit der Handlungen bei der Ermittlung und der Beweismittel, das Recht auf Intimsphäre und auf ein rechtmäßiges Verfahren. ${ }^{399}$

\section{Der Aushilfsrichter zur Kontrolle der Garantien}

Art. 48 des Gesetzes 1453 von 2011 änderte den Art. 39 des CPP und führte in seinem Paragraphen 3 das Rechtsgebilde des Aushilfsrichters zur Kontrolle der Garantien oder des ambulanten JCG (juez de control de garantías ambulante) ein. Entsprechend dieser Verfahrensbestimmung ,wird es Aushilfsrichter zur Kontrolle der Garantien geben, die an Orten tätig sein werden, in denen es nur einen Bezirksrichter gibt oder dort, wo die Überführung der Parteien und der Beteiligten aus Transport- oder Entfernungsgründen oder durch höhere Gewalt erschwert ist oder in den Fällen, die bereits von der Nationalen Einheit für Menschenrechte der Generalstaatsanwaltschaft übernommen worden sind, oder wenn Gefahren für die Sicherheit der Beamten bestehen. ${ }^{“ 400}$ So ersetzt die Rechtsfigur des Aushilfsrichters den JCG bei dessen Abwesenheit in jenen Gebieten, wo die öffentliche Ordnung wegen der kolumbianischen bewaffneten Auseinandersetzungen vollständig infrage gestellt wird. ${ }^{401}$ Die Änderung des Art. 39 des Gesetzes 906 von 2004 versucht, diese allgemeine Möglichkeit eines Eingriffes flexibler zu gestalten.

\footnotetext{
${ }^{399}$ Dazu Bernal Cuellar/Montealegre Lynett, 2013 T. II, S. 241 ff.; Guerrero Peralta, 2007, S. 335 ff.

${ }^{400}$ Art. 39 Parag. 3 CPP: „Habrá jueces de garantías ambulantes que actúen en los sitios donde sólo existe un juez municipal o cuando se trate de un lugar en el que el traslado de las partes e intervinientes se dificulte por razones de transporte, distancia, fuerza mayor o en casos adelantados por la Unidad Nacional de Derechos Humanos de la Fiscalía General de la Nación o en los que exista problemas de seguridad de los funcionarios." (dt. Übersetzung d. Verf.).

${ }^{401} \mathrm{Vgl}$. dazu Zuluaga, Boletin GLIPGö 5 (2013), S. 34.

128
} 
Der erwähnte Artikel gibt eine allgemeine Richtung an mit dem Zweck, in möglichst kurzer Zeit den Eingriff zu ermöglichen und dabei die vielen Hindernisse zu überwinden, die sich aus dem Mangel an Richtern und Staatsanwälten, den geographischen Umständen und den Sicherheitsumständen ergeben, die die konkrete Möglichkeit, die Verdächtigen in allen Fällen unverzüglich vor den JCG zu bringen, sehr erschweren. Dieses Vorgehen richtet sich nach vernünftigen Kriterien, die im Falle schnellen Handelns zur Kontrolle und zum Schutz der Grundrechte beim Eingriff des JCG überwiegen müssen. ${ }^{402}$ Dieser Eingriff dient nicht nur zur Feststellung der Rechtmäßigkeit und Achtung der Grundrechte und Garantien, sondern auch zur Feststellung mit Bindungswirkung, dass die ermittelten Beweismittel nicht als Beweise von der Anklageseite verwendet werden dürfen und auch nicht von Gerichtsbeamten gewürdigt werden dürfen, wenn sie für entsprechend rechtswidrig gehalten werden. Dies ergibt sich aus dem Art. 29 CN, der Beweise, die auf einer Verletzung des rechtmäßigen Verfahrens beruhen, als nichtig einstuft.

\section{Grundrechtseingriffe mit nachträglicher Überprüfung}

\section{Anhörungen zur nachträglichen Überprüfung der Rechtmäßigkeit}

Art. 153 CPP bestimmt hinsichtlich der einleitenden Anhörungen (audiencias preliminares): „Handlungen, Anträge und Entscheidungen, die nicht in der Anhörung zur Erhebung der Anklage, bei der vorbereitenden Anhörung oder der mündlichen Hauptverhandlung angeordnet, beschlossen oder angenommen werden müssen, werden in einer Anhörung vor dem JCG vorbereitet, beschlossen oder entschieden. “403 Der CPP enthält in Art. 154 in enumerativer Form eine Liste von Gegenständen, die in einer einleitenden Anhörung beschlossen werden. Es werden u. a. die nachträgliche Überprüfung bei Hausdurchsuchungen, Überwachung der Kommunikation, der Antrag auf vorzeitige Beweisaufnahme, das Einleiten von Schutzmaßnahmen für Opfer und Zeugen, der Antrag auf Sicherungsmaßnahmen oder einstweilige Verfügungen, die Erhebung der Beschuldigung, die Überprüfung der Anwendung des Opportunitätsprinzips, die Anträge auf Freilassung, die vor der Ankündigung des Urteils gestellt werden, erwähnt ${ }^{404}$. Schließlich lässt Nr. 9 eine Vielfalt an Möglichkeiten für andere einleitende Anhörungen zu, indem bestimmt wird,

${ }^{402}$ Vgl. Oberster Gerichtshof, Rad. 29904, Entsch. von 12.06.2008, Abschn. „Consideraciones de la Corte“; Guerrero Peralta, 2006, S. 52.

${ }^{403}$ Art. 153 CPP: „Noción. Las actuaciones, peticiones y decisiones que no deban ordenarse, resolverse o adoptarse en audiencia de formulación de acusación, preparatoria o del juicio oral, se adelantarán, resolverán o decidirán en audiencia preliminar, ante el juez de control de garantías.“ (dt. Übersetzung d. Verf.).

${ }^{404}$ Siehe supra Fn. 386, dazu Bernal Cuellar/Montealegre Lynett, 2013 T. II, S. 181 ff. 
dass „Angelegenheiten, die den oben genannten Fällen entsprechen, während Anhörungen

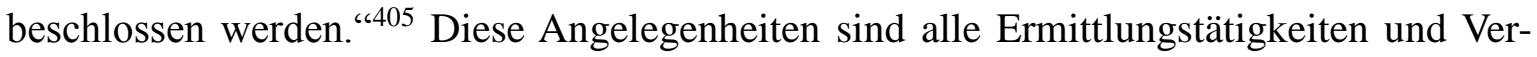
fahrensabschnitte, die im Laufe des CPP erwähnt werden, insbesondere unter dem Abschnitt der Vorermittlung und Ermittlung, wie die Kontrolle der Überwachungen, die selektive Suche in Datenbanken, die Aufhebung der Sicherungsmaßnahmen, u. a. Angelegenheiten, die in einleitenden Anhörungen überprüft werden und nicht in Art. 154 CPP aufgeführt sind.

Die Ziele der gerichtlichen Kontrolle sind i) die Sicherstellung der formellen und materiellen Rechtmäßigkeit der Handlung; ii) der Schutz der Grundrechte derjeniger, die aktiv oder passiv vom Verfahren betroffen sind und iii) die Überprüfung der Rechtmäßigkeit der rechtlichen Tätigkeit der Staatsanwaltschaft im Rahmen der angeordneten und wahrgenommenen Maßnahmen zur Sicherstellung der Beweismittel, der Strafverfolgung und im Rahmen des Versuchs, den Opfern Schadenersatz zu leisten und das Vertrauen der Gemeinschaft in die Rechtsordnung wiederherzustellen. ${ }^{406}$ Diese Umstände müssen vom JCG in Betracht gezogen werden, sowohl wenn eine Hausdurchsuchung, Beschlagnahme oder Überwachung der Kommunikation durchführt wurde als auch wenn geprüft wird, ob eine andere Beeinträchtigung der Grundrechte, die aus der Ermittlung hervorgehen könnte, erlaubt wird oder nicht.

In jeder Anhörung hat der Staatsanwalt die Darlegungslast bzgl. der Berechtigung der Maßnahmen wie z. B. zur Durchführung einer Hausdurchsuchung, zur Überwachung der Kommunikation, für die Anordnung einer Beschlagnahme oder Einziehung einer Sache u. a. unabhängig davon, ob die gerichtliche Überprüfung vor oder nach der Maßnahme stattfindet. Die Grundregel aus Art. 250 CN lautet, dass die Kontrolle vorausgehen solle, daher beschränken sich die Angelegenheiten, in denen dies nachträglich geschieht, auf die Fälle, die ausdrücklich in Nr. 2 dieser Verfassungsnorm festgelegt sind. Im Gegensatz dazu hat eine nachträgliche Überprüfung zur Folge, dass der Richter untersucht, ob ein schon stattgefundener Vorgang verfassungsmäßig und den gesetzlichen Normen entsprechend abgelaufen ist. Folglich muss der Richter im zweiten Fall feststellen: (i) ob es möglich war, den Vorgang ohne vorherige Überprüfung durchzuführen; (ii) ob die Anordnung von jemandem erlassen wurde, der dazu befugt war (Staatsanwalt); (iii) ob die Anordnung eine

\footnotetext{
${ }^{405}$ Art. 154 Nr. 9 CPP: „Las que resuelvan asuntos similares a los anteriores.“ (dt. Übersetzung d. Verf.).

${ }^{406}$ Vgl. KVerfG, Entsch. C-186 v. 2008; C-131 v. 2009; C-025 v. 2009, Abschn. „Consideraciones de la Corte“.
} 
ausreichende Begründung enthält einschließlich der Anwendung des Verhältnismäßigkeitsgrundsatzes oder des Exzessverbotes; (iv) ob der Ablauf gesetzeskonform war; (v) ob der Pflicht, die Grundrechte im geringstmöglichen Maß zu beeinträchtigen, nachgekommen wurde und (vi) ob die Kontrolle wie im Gesetz beschrieben erfolgte. ${ }^{407}$

Die Aufgabe der nachträglichen Kontrolle besteht darin, die formelle und materielle Gültigkeit der Handlung der FGN zu prüfen, d. h. zu überprüfen, ob die durch sie erfolgten oder beantragten Eingriffe in die Grundrechte gesetzmäßig (formelle Aspekte) stattgefunden haben und ob sie geeignet, notwendig und angemessen (materielle Aspekte) waren, was bedeutet: War der Eingriff in das Grundrecht (i) geeignet, dazu beizutragen, ein verfassungsmäßig legitimes Ziel zu erreichen; (ii) notwendig, da er das mildeste oder das minder schädlichste unter anderen möglichen Mitteln darstellte, um das Ziel zu erreichen und (iii) auf das Ziel orientiert, durch den Eingriff das erbrachte Opfer der Rechtsträger und der Gesellschaft auszugleichen. Der JCG trifft eine Entscheidung über die RechtmäBigkeit oder Rechtswidrigkeit der Maßnahme. Ihre Wirkungen wurden durch das Verfassungsgericht im Urteil C-591 von 2005 festgelegt. ${ }^{408}$ Wenn ein Rechtsmangel in der Handlung festgestellt wird und der zuständige JCG diese Handlung aufgrund dessen für rechtswidrig erklärt, wird das erhobene Beweismaterial als nicht existent betrachtet und damit nicht als Beweismittel zugelassen und schon gar nicht als solches gewürdigt.

Zudem spielen bei der nachträglichen gerichtlichen Kontrolle, die eine Ausnahme darstellt und nur bei den Maßnahmen erfolgen darf, die in Art. 250 Nr. 2 CN enthalten sind, nicht nur die formellen, sondern auch die materiellen Aspekte eine Rolle. Diese stehen in Bezug zu den betroffenen Grundrechten und zu einer bereits ausgeübten Amtshandlung, durch die schon Grundrechte beeinträchtigt worden sind. In diesem Sinne beugt die gerichtliche Handlung einem unrechtmäßigen Eingriff in Grundrechte nicht vor, wie es bei der vorherigen Kontrolle geschieht. Im Fall der tatsächlichen Feststellung, dass die Staatsanwaltschaft und/oder die Ermittlungsbehörde unter Nichtbeachtung der maßgebenden Regeln und Prinzipien gehandelt haben, dient die Rechtsschutzgarantie dazu, die übermäßig eingeschränkten Rechte wiederherzustellen. Dies erfolgt im Rahmen eines Verfahrens, d. h. mit dem Ausschluss derjenigen Beweismittel aus der Akte, die unter Verletzung von Protokoll,

\footnotetext{
${ }^{407} \mathrm{Zu}$ der nachträglichen Kontrolle von Ermittlungshandlungen s. Guerrero Peralta, 2006. S. $91 \mathrm{ff}$.

${ }^{408}$ KVerfG, Entsch. C-591 v. 2005, Abschn. „Consideraciones de la Corte“ (In dem es sein Präzedenzurteil (C-1092 von 2003) wiedergibt).
} 
Garantien und Verfahren erhoben wurden. ${ }^{409}$ Ermittlungstätigkeiten, die die Ermittlungsbehörde ohne richterliche Anordnung durchführt, sondern mit Anordnung des Staatsanwaltes, liegt zugrunde, dass diese Handlungen eine Beeinträchtigung der Grundrechte beinhalten, die laut Verfassung der vorherigen Kontrolle der Staatsanwaltschaft überlassen wurden. In diesem Sinne muss die Staatsanwaltschaft als Herrin des Verfahrens überprüfen, ob die Bedingungen für die Anordnung erfüllt sind, und in ihrer Prüfung des Eingriffes müssen das Exzessverbot und der Verhältnismäßigkeitsgrundsatz miteinbezogen werden, damit sie vor dem JCG ihre Entscheidung mit denselben Prinzipien rechtfertigen kann, mit denen der Richter in seiner Rolle als formelle und materielle Aufsichtsbehörde die Beachtung der Verfahrensgarantien und der Grundrechte überprüfen wird. ${ }^{410}$

\section{Nachträgliche Kontrolle („Controles posteriores“) der Ermittlungshandlun- gen}

Der Gesetzesakt 03 von 2002 (Art. 2 II) und die kolumbianische Strafprozessordnung (Art. 213 ff. CPP) bestimmen, dass Hausdurchsuchungen und weitere grundrechtsrelevante Ermittlungsmaßnahmen durch die Polizei lediglich der Zustimmung der Staatsanwaltschaft bedürfen und durch den JCG erst im Nachhinein auf ihre Rechtmäßigkeit überprüft werden. Der JCG nimmt in einer Anhörung ausgehend von den Gründen, die die Staatsanwaltschaft für die Vornahme und Autorisierung der Ermittlungsmaßnahme anführt, eine umfangreiche Untersuchung und Bewertung der rechtlichen und tatsächlichen Grundlagen sowie der konkreten Ausführung der jeweiligen Ermittlungsmaßnahme vor. ${ }^{411}$ Die Anhörung soll kontradiktorischen Charakter haben - in ihr sollen sowohl die Staatsanwaltschaft als auch die Eingriffsopfer angehört werden. Für den Fall, dass das Eingriffsopfer, i. d. R. der Straftatverdächtige, gegen den sich die Ermittlungsmaßnahme richtete, bei dieser Anhörung nicht anwesend ist, besteht die Möglichkeit, dass dessen Anhörung im Strafprozess

\footnotetext{
${ }^{409}$ Vgl. KVerfG, Entsch. C-334 v. 2010, Abschn. 87; auch C-131 v. 2009, Abschn. „Consideraciones de la Corte".

${ }^{410}$ Vgl. KVerfG, Entsch. C-822 v. 2005; C-059 v. 2010, Abschn. „Consideraciones de la Corte“; Guerrero Peralta, 2006, S. 138.

${ }^{411}$ Bernal Cuellar/Montealegre Lynett, 2013 T. I, S. 273, 293; Aponte Cardona, 2006, S. 76 ff.; CSJ, 2005, S. 21. 
nachgeholt wird, um festzustellen, ob die durch die fragliche Ermittlungsmaßnahme erlangten Beweise verwertet werden dürfen. ${ }^{412}$

Aus der Liste der Anordnungen des CPP in Bezug auf die Handlungen, die keine vorausgehende Anordnung benötigen, ergibt sich, dass diese zu einem großen Teil der Regelung des Art. 250 Nr. 2 CN darstellen. Es ist erforderlich hervorzuheben, wie im Ganzen Handlungen beschrieben werden, die dazu tendieren, Bereiche oder Güter zu betreffen, die direkt mit der strafbaren Handlung und mit dem Beschuldigten oder Verdächtigen in Zusammenhang stehen. Diejenigen Handlungen, bei denen die gerichtliche Kontrolle nach dem Agieren der Staatsanwaltschaft durchgeführt wird, betreffen im Allgemeinen Vermögenswerte oder Sachen, beweglich oder unbeweglich, einziehbar auf materielle oder informationstechnische Weise. Das eben Genannte wird insbesondere mit Blick auf Art. 219 CPP deutlich, der bestimmt, dass die Durchsuchung ,mit dem Zweck durchgeführt wird, sachliches Beweismaterial und Spuren zu sichern oder den Verdächtigen, Beschuldigten oder Verurteilten festzunehmen. ${ }^{\text {“413 }}$ Ebenso wird in Art. 220 CPP bestimmt, dass

„eine Hausdurchsuchungsanordnung nur dann erlassen werden kann, wenn es in Übereinstimmung mit den in diesem Gesetz vorgesehenen Erkenntnismitteln berechtigte Gründe gibt, festzustellen, dass der vermutete Täter oder Mittäter der ermittelten begangenen strafbaren Handlung der Eigentümer, Besitzer oder der vorübergehende Gewahrsamsinhaber des zu durchsuchenden Gutes ist. Anderenfalls müssen sich im Inneren der Räumlichkeiten die Mittel befinden, mit denen die strafbare Handlung begangen wurde oder die Gegenstände, die sich aus derselben ergaben. ${ }^{\text {" }}{ }^{14}$

Bzgl. der Überwachung der Kommunikation wird in Art. 235 CPP, geändert durch Art. 15 des Gesetzes 1142 von 2007, festgelegt, dass der Staatsanwalt (diese) „mit dem Ziel anordnen kann, sachliches Beweismaterial zu erheben, Spuren zu sichern, Beschuldigte oder

\footnotetext{
412 Art. 155 Abs. 2 CPP; Die Anhörungen vor dem JCG sind in der Regel öffentlich, aber der Öffentlichkeitsgrundsatz kommt nicht zur Anwendung bei Anhörungen vor dem JCG, die wegen Hausdurchsuchungen, Personendurchsuchungen oder Kommunikationsüberwachungen stattfinden (Art. 237 CPP).

${ }^{413}$ Art. 219 CPP: ,[...]con el fin de obtener elementos materiales probatorios y evidencia física o realizar la captura del indiciado, imputado o condenado [...].“(dt. Übersetzung d. Verf.).

${ }^{414}$ Art. 220 CPP: „Fundamento para la orden de registro y allanamiento. Sólo podrá expedirse una orden de registro y allanamiento cuando existan motivos razonablemente fundados, de acuerdo con los medios cognoscitivos previstos en este código, para concluir que la ocurrencia del delito investigado tiene como probable autor o partícipe al propietario, al simple tenedor del bien por registrar, al que transitoriamente se encontrare en él; o que en su interior se hallan los instrumentos con los que se ha cometido la infracción, o los objetos producto del ilícito." (dt. Übersetzung d. Verf.).
} 
Verdächtige zu suchen und zu orten.“415 Diese Überwachung darf mittels Tonaufnahme für die Ermittlung nur in Bezug auf beweiserhebliche Informationen erfolgen. Die Handlung muss trotzdem schriftlich begründet werden. Demnach muss der Eingriff der Staatsanwaltschaft und der Ermittlungsbehörde mittels Hausdurchsuchung, Beschlagnahme von unbeweglichen und beweglichen Sachen sowie die Überwachung der Kommunikation in unmittelbarem Bezug zu den Gütern stehen, deren Eigentümer oder Besitzer der Verdächtige oder Beschuldigte ist. Diese Rechtsfigur bezieht andere Orte nicht mit ein, eine Ausnahme stellt die frische Tat dar. In diesem Fall (Art. 229 CPP) darf die Ermittlungsbehörde die Hausdurchsuchung des Grundstückes, Schiffes oder Flugzeuges des Verdächtigen durchführen. Wenn dieser aber ,,in einem fremden, nicht öffentlichen Grundstück [Zuflucht sucht], ist die Zustimmung des Eigentümers oder Besitzers oder, in Ermangelung derselben, die entsprechende Anordnung der Generalstaatsanwaltschaft erforderlich. “416

\section{Ablauf des Kontrollverfahrens}

Im Allgemeinen muss in Bezug auf die nachträglich zu überprüfenden Maßnahmen neben den Hausdurchsuchungen sowie den Beschlagnahmen und der Überwachung der Kommunikation klargestellt werden, dass das KVerfG die Reichweite der veränderten Verfassungsnorm, die auf diese Maßnahmen verweist, festgelegt hat. Der Art. 250 Nr. 2 CN legt fest, dass dem JCG die Kontrolle der von der Staatsanwaltschaft getroffenen Maßnahmen obliegt, ohne dass dafür eine vorherige richterliche Zustimmung erforderlich sei. Diese ausdrücklich in der Verfassung erwähnten Maßnahmen sind Hausdurchsuchungen, Beschlagnahmen und die Überwachung der Kommunikation. Ursprünglich bestimmte das Gesetz, dass sich die Aufgabe des JCG auf die Feststellung der Gültigkeit der erwähnten Handlungen beschränkte. ${ }^{417}$ Den Äußerungen des Gerichtes zufolge ,erscheint es eindeutig, dass das Wort Gültigkeit in Art. 250 Nr. 2 CN einen juristisch unbestimmten Inhalt im Verfassungstext aufweist, da die abgeleitete verfassungsändernde Gewalt nicht die Möglichkeit hatte, sich ausführlich mit den Folgen der Einfügung in der untersuchten Norm auseinanderzusetzen. Daraus folgt ein anderer Sinn dieses Rechtssatzes, der sich von dem

\footnotetext{
415 Art. 235 CPP: ,[...] podrá ordenar, con el objeto de buscar elementos materiales probatorios, evidencia física, búsqueda y ubicación de imputados o indiciados [...].“ (dt. Übersetzung d. Verf.).

416 Art. 229 CPP: ,[...] ]en un bien inmueble ajeno, no abierto al público, se solicitará el consentimiento del propietario o tenedor o en su defecto se obtendrá la orden correspondiente de la Fiscalía General de la Nación.[...].“ (dt. Übersetzung d. Verf.).

${ }^{417}$ Das KVerfG erklärte dennoch den letzten Teil der Bestimmung für undurchführbar. Damit hat sich der Handlungsbereich des JCG erweitert. Siehe KVerfG, Entsch. C-1092 v. 2003, Abschn. „Consideraciones de la Corte". 
der Erstfassung der juristischen Institution des JCG unterscheidet.“" ${ }^{418}$ Zudem wird in der Entscheidung ausgeführt: „Ebenso kann mit den in den Gutachten der Berichterstatter zur Norm dargestellten Gründen festgestellt werden, dass die Kontrollaufgabe des JCG umfangreich und umfassend gestaltet wurde mit dem Ziel, die Gründe für das Vorziehen der Amtshandlungen, ihre Zulässigkeit und besonders die Beachtung der Grundrechte zu überprüfen. ${ }^{\text {"419 }}$

Auf diese Weise und der Logik folgend, die sich aus der dem Richteramt im Allgemeinen zugeordneten Kontrollfunktion herleitet, erschöpft sich seine Tätigkeit nicht bloß in der formellen Kontrolle der ergriffenen Maßnahmen und Handlungen, sondern besteht besonders auch auf materieller Ebene. Der Richter wird demnach nicht nur die lediglich formelle Gültigkeit der Maßnahme - ihr Bestehen in der Welt des Rechtes - überprüfen, sondern er muss auch die rechtliche Auswirkung der Maßnahme kontrollieren, insbesondere in Beziehung auf die Grundrechte, die von der Anwendung derselben betroffen sind. Es handelt sich außerdem um eine logische und offensichtliche Handlungsdynamik, wenn bedacht wird, dass die Anwendung von Maßnahmen wie Hausdurchsuchungen häufig in Widerspruch zu den Grundrechten und Garantien steht. ${ }^{420}$

In den eben genannten Fällen untersucht der JCG, ob es einen hinreichenden Rechtfertigungsgrund für den Grundrechtseingriff gab. Zu Beginn der Anhörung stellt der JCG die Anwesenheit der Disziplinarstaatsanwaltschaft, des Verdächtigen, der Staatsanwaltschaft und der weiteren Beteiligten fest und übergibt der Staatsanwaltschaft das Wort. Diese hat dem Richter die Notwendigkeit und Zweckmäßigkeit der Ermittlungsmaßnahme hinreichend begründet darzulegen, insbesondere diese mit Beweismitteln zu stützen, wie zum Beispiel mit Polizeiberichten, Zeugenaussagen und sonstigen Beweismitteln wie Fotogra-

\footnotetext{
${ }^{418}$ KVerfG, Entsch. C-1092 v. 2003, Abschn. „Consideraciones de la Corte“: „Es claro que la expresión validez inserta en el numeral 2 de artículo 250 superior, es de un valor jurídico incierto en el texto constitucional, como quiera que el Constituyente derivado no tuvo oportunidad de discutir con amplitud cuáles serían los efectos de su inclusión en la norma bajo examen, lo que comporta en el precepto un sentido restrictivo esencialmente distinto a como en primera vuelta se había estructurado la institución jurídica del control de garantías." (dt. Übersetzung d. Verf.).

${ }^{419}$ KVerfG, Entsch. C-1092 v. 2003, Abschn. „Consideraciones de la Corte“: „Así mismo, de las razones expuestas en los informes de ponencia respecto de la norma, se observa que el control a cargo de los jueces se configuró de manera amplia e integral y tendría por objeto el examen de las razones que motivaron el adelantamiento de la diligencia, su pertinencia y, en especial, la verificación sobre el respeto de los derechos fundamentales." (dt. Übersetzung d. Verf.).

${ }^{420}$ Im Allgemeinen kann gesagt werden, dass die Kontrolle durch den Richter nicht nur in Bezug auf diese Art von Maßnahmen neben formeller auch materieller Natur ist.
} 
fien, Videos, technische Aufzeichnungen. ${ }^{421}$ Wenn sich die Staatsanwaltschaft auf die beeidigte Aussage eines Informanten stützt, hat sie ebenfalls dessen Ausweisnummer und sonstige persönliche Daten beizubringen und dessen Vertrauenswürdigkeit zu belegen. ${ }^{422}$ Falls der JCG es verlangt, hat die Staatsanwaltschaft den entsprechenden Zeugen in der Anhörung nochmals zu befragen, um die Vertraulichkeit der Aussage zu beweisen.

Die Verteidigung des Verdächtigen hat das Recht, jeweils zu den von der Staatsanwaltschaft vorgebrachten Beweisen angehört zu werden und beispielsweise ebenfalls die geladenen Zeugen zu befragen. Wenn der JCG die fragliche Ermittlungsmaßnahme nach umfänglicher Prüfung aller Umstände für verfassungs- und rechtmäßig hält, da er den Grundrechtseingriff für gerechtfertigt und die Ausführung der Ermittlungsmaßnahme für im höchstmöglichen Maße grundrechtschonend erachtet, erklärt er die formelle und materielle Rechtmäßigkeit sowie die Wirksamkeit der Maßnahme. Sollte dies dagegen nicht der Fall sein, erklärt er die Ermittlungsmaßnahme für rechtswidrig und nichtig oder nur für rechtswidrig, wenn die Ermittlungsmaßnahme lediglich mit einem formellen Fehler behaftet ist. $^{423}$

Ist eine Ermittlungsmaßnahme nichtig, können die durch sie erlangten Beweise nicht zur Grundlage des späteren Urteils werden, sondern dürfen lediglich für die Anfechtung verwendet werden. ${ }^{424}$ Die Wirksamkeit der Ermittlungsmaßnahme hat hingegen nicht zur Folge, dass hiermit gleichzeitig die durch sie erlangten Beweise notwendigerweise auch für den Strafprozess verwendet werden dürfen. Die Zulässigkeit dieser Beweise ist vielmehr Gegenstand eines dem Hauptverfahren vorgelagerten, gesonderten Vorverfahrens.

\section{Zusammenfassung}

Die Rechtmäßigkeitskontrolle aller Grundrechtseingriffe im Ermittlungsverfahren erfolgt vor dem JCG durch eine vorherige oder nachträgliche Überprüfung der Maßnahmen. Die Kontrollaufgabe des JCG wurde umfangreich, vollständig und mit den Zielen gestaltet, die Überprüfung der Gründe, die das Vorziehen der Amtshandlungen veranlassten, ihre Zuläs-

\footnotetext{
${ }^{421}$ Vgl. Art. 221 CPP; dazu Guerrero Peralta, 2007, S. 198 f.

${ }^{422}$ Das KVerfG erklärte Art. 221 des CPP für verfassungsgemäß unter der Bedingung, dass Informantendaten nicht dem JCG vorenthalten werden dürfen (KVerfG, Entsch. C-673 v. 2005); dazu infra § 10. A. II. Die Beweisgrundlageproblematik gemäß Art. $221 \mathrm{CPP}$.

${ }^{423} \mathrm{Vgl}$. Aponte Cardona, 2006, S. 94 f. Im letztgenannten Fall kann die formelle Fehlerhaftigkeit der Ermittlungsmaßnahme korrigiert werden.

${ }^{424}$ Ausgenommen ist der Fall, dass die Staatsanwaltschaft das Vorliegen eines der in Art. 455 CPP beschriebenen Umstände belegen kann. 
sigkeit und insbesondere deren Überprüfung auf Achtung der Grundrechte zu überwachen. Die Aufgabe zur Kontrolle der Garantien kann von jedem Strafrichter am Bezirksgericht wahrgenommen werden. In den Fällen, in denen das Oberste Gericht zu entscheiden hat, wird die Rolle des JCG von einem Einzelrichter der Strafkammer des Obersten Gerichtshofs von Bogotá ausgeübt. Die Handlung des JCG erfolgt nicht von Amts wegen, sondern wird beantragt. Die Rechtmäßigkeitskontrolle der Ermittlungsmaßnahmen erfolgt in vorbereitenden Anhörungen, welche in Art. 154 CPP festgelegt sind. Der Richter darf nicht nur die Erforderlichkeit oder Geeignetheit der Durchführung der Amtshandlungen für den Erfolg des Ermittlungsverfahrens bewerten (Abwägung der Verhältnismäßigkeit), sondern ebenfalls die Zulässigkeit und die sachliche und rechtliche Grundlage für die Beeinträchtigung des Grundrechts. Die gerichtliche Kontrolle muss nicht nur formell, sondern auch materiell die Rechtmäßigkeit der Handlung sicherstellen. Die negative Beurteilung durch den Richter hat keine materielle, sondern eine formelle Rechtswirkung. Folglich ist es möglich, vor demselben wiederholt oder vor einem anderen JCG den Antrag zu stellen, wenn sich die auf Tatsachen beruhende Grundlage verändert hat. Die Maßnahmen, die Gegenstand der vorherigen Kontrolle sind, befinden sich in Art. 250 Nr. 3 CN und erfolgen bei Freiheitsbeschränkungen, Probenahmen, die den Beschuldigten mit einschließen, beim Vorgehen im Falle von Verletzten oder Opfern sexueller Gewalt, bei körperlichen Untersuchungen und Durchsuchung von Personen (Art. 246-250 CPP). Die nachträgliche Kontrolle erfolgt bei Hausdurchsuchungen, Überwachung der Kommunikation und Beschlagnahmen (Art. 213-245 CPP). Parallel zur Zuständigkeit der Strafrichter am Bezirksgericht zur Kontrolle der Garantien führte Art. 48 des Gesetzes 1453 von 2011 in seinem Paragraphen 3 das Rechtsgebilde des Aushilfs-JCG oder ambulanten JCG ein, wenn es sich um einen Ort handelt, bei dem die Überführung der Parteien und der Beteiligten aus Transportoder Entfernungsgründen oder wegen höherer Gewalt erschwert ist. 


\section{§ 5. Nachträglicher Rechtsschutz gegen Maßnahmen zur Beschränkung der Intimität}

\section{A. Die Hausdurchsuchungen (Art. 219-232 CPP)}

Art. 219 CPP regelt das Verfahren bzgl. der Hausdurchsuchungen. Demnach können die Staatsanwälte „die Durchsuchung einer Immobilie, eines Schiffs oder eines Flugzeugs durch die Kriminalpolizei anordnen, um Beweismittel zu erlangen oder die Festnahme des Verdächtigen, Beschuldigten oder Verurteilten vorzunehmen.“ Ebenso legt die Vorschrift fest, dass , in Fällen, in denen die Hausdurchsuchung einzig die Festnahme des Verdächtigen, Beschuldigten oder Verurteilten zum Ziel hat, diese nur bei Delikten angeordnet werden darf, die für eine Sicherungsmaßnahme in Form des Präventivgewahrsams tauglich sind. “425

Das durch die Hausdurchsuchung beeinträchtigte Grundrecht ist das Recht auf Intimität. In Kolumbien gilt auch mit Wirkung für die Strafverfolgung, dass der verfassungsrechtliche Schutz der Wohnung sich nicht nur auf den bloßen Schutz des Eigentums und Besitzes beschränkt. Der Schutz der Wohnung geht vielmehr über die eigentumsrechtliche Komponente hinaus und schließt den Schutz der Privats- und Intimsphäre mit ein. ${ }^{426}$ Aus diesem Grund fällt die Verletzung des physisch geschützten Raums durch eine Strafverfolgungsmaßnahme nicht notwendigerweise mit den zivilrechtlichen und handelsrechtlichen Parametern (Schutz des Eigentums) zusammen. Daher sind in Kolumbien Hausdurchsuchungen definiert als Eingriffe „,in einen Raum, den eine Person bewohnt, ohne dort den sozialen Gebräuchen und Konventionen unterworfen zu sein, und der ihr zur Ausübung ihrer intimsten Freiheit zur Verfügung steht. Geschützt ist nicht nur der physische Raum als solcher, sondern auch die Privatsphäre, die sich in ihm entfaltet. “427

\footnotetext{
${ }^{425}$ Art. 219 CPP: „Procedencia de los registros y allanamientos. El fiscal encargado de la dirección de la investigación, según lo establecido en los artículos siguientes y con el fin de obtener elementos materiales probatorios y evidencia física o realizar la captura del indiciado, imputado o condenado, podrá ordenar el registro y allanamiento de un inmueble, nave o aeronave, el cual será realizado por la policía judicial. Si el registro y allanamiento tiene como finalidad única la captura del indiciado, imputado o condenado, sólo podrá ordenarse en relación con delitos susceptibles de medida de aseguramiento de detención preventiva." (dt. Übersetzung d. Verf.).

${ }^{426}$ Vgl. KVerfG, Entsch. C-024 v. 1994; C-181 v. 1997, Abschn. „Consideraciones de la Corte“; Guerrero Peralta, DPC 92 (2011), S. 55 ff.; Bernal Cuellar/Montealegre Lynett, 2013 T. II, S. 241 ff.

${ }^{427}$ Guerrero Peralta, 2006, S. 92: „una injerencia en un espacio en el cual el individuo habita sin sujeción a los usos o convenciones sociales y que está dispuesto para el ejercicio de su libertad más íntima. No sólo se
} 
Indem Art. 219 CPP auch die Durchsuchung von Schiffen und Flugzeugen den gleichen Anforderungen unterwirft, die für die Durchsuchung von Wohnungen gelten, erstreckt sich die Privatsphäre auch auf jene Bereiche. Diese Ausweitung ist in der kolumbianischen Rechtslehre umstritten, da im Unterschied zu Wohnräumen Schiffe und Flugzeuge nicht grundsätzlich Räume sind, in denen Personen normalerweise ihre Intimität frei entfalten können. Es wird ferner kritisiert, dass eine solche Ausdehnung des Gegenstands der Hausdurchsuchung im Sinne von Art. 219 CPP zu der Konsequenz führt, dass sich der diesem innewohnende Schutz sogar auf juristische Personen erstrecken könnte. ${ }^{428}$ Die Frage ist, ob gleichsam auch Geschäfts- und Büroräume durch Art. 219 CPP geschützt sein könnten. Die herrschende Ansicht sagt hierzu, dass nicht jeder umschlossene Raum einem Wohnraum gleichgestellt werden könne, und keine Grundlage dafür gegeben sei, bei Durchsuchungen von Räumen, die ihrer Art nach mit der Idee der Privatsphäre nicht kompatibel seien, einen Eingriff in das Recht auf Intimität einer Person anzunehmen. ${ }^{429}$ Dies hat wichtige Auswirkungen für die Rechtmäßigkeit der Ausführung der Durchsuchung solcher Räume, denn wenn insoweit kein Eingriff in die Intimität einer Person gegeben ist, ist anders als bei der Durchsuchung eines Wohnraumes auch die Frage, ob der Eigentümer mit der Durchsuchung einverstanden ist, unbeachtlich. ${ }^{430}$

\section{Gründe der Maßnahmen und Relevanzüberprüfung}

Bei Hausdurchsuchungen sind zwei Grundrechte betroffen: die Unverletzlichkeit der Wohnung und das Recht auf Intimität. Das Recht auf Intimität als Leitnorm des gesamten CPP ist in Art. 14 geregelt, wonach

„niemand in seinem Privatleben gestört werden darf. Es dürfen keine Durchsuchungen von Personen und Wohnräumen und keine Beschlagnahmen in Wohnhäusern, gewöhnlichen Aufenthaltsorten oder Arbeitsplätzen erfolgen, außer aufgrund einer schriftlichen Anordnung des Generalstaatsanwalts oder seines Beauftragten. Diese hat den in diesem

ampara un espacio físico considerado en sí mismo, sino también la esfera privada que se desarrolla en él.“ (dt. Übersetzung d. Verf.).

${ }^{428}$ Guerrero Peralta, 2007, S. 336; Guerrero Peralta, 2006, S. 92.

${ }^{429}$ Vgl. KVerfG, Entsch. C-881 v. 2014; T-220 v. 2004, Abschn. „Consideraciones de la Corte“; Guerrero Peralta, 2006, S. 93; Bernal Cuellar/Montealegre Lynett, 2013 T. II, S. 245 f.; Pineda Estrada, 2004, S. 51 ff.; Ramírez Jaramillo, 2010, S. 66 ff.

${ }^{430}$ Guerrero Peralta, 2006, S. 93. 
Gesetz geregelten Formalitäten und Gründen zu entsprechen. Dies gilt nicht bei auf frischer Tat betroffen und sonstigen, gesetzlich festgelegten Ausnahmen.“431

Die Norm hat bedeutende Auswirkungen auf die Rechtskontrolle durch den JCG, insbesondere auf die nachträgliche Kontrolle. Die Begründung einer Maßnahme erfordert eine Überprüfung, ob eine ausreichende Indizienlage vorliegt, um einen Eingriff in Grundrechte vorzunehmen, welcher die Privatsphäre im Wohnraum (Art. $28 \mathrm{CN}$ für Fälle von Hausdurchsuchungen), die Kommunikationsfreiheit (Art. $15 \mathrm{CN}$ für Fälle der Kommunikationsüberwachung) und das Privateigentum (Art. $58 \mathrm{CN}$ ) betrifft. Außerdem ist genauso wie bei Maßnahmen, die eine vorherige richterliche Anordnung voraussetzen, auch hier eine Verhältnismäßigkeitskontrolle durchzuführen. ${ }^{432}$ In diesem Sinne bedarf es einer Angemessenheitsprüfung, um zu verifizieren, ob die von der FGN angeordnete Hausdurchsuchung für die Beweiserhebung relevant ist und kein anderes Mittel zur Verfügung steht, um zu dem gleichen Ergebnis zu gelangen (Erfoderlichkeit).

\section{II. Überprüfung der Achtung der Grundrechte}

Bei Hausdurchsuchungen ist eine doppelte Kontrolle durchzuführen. Auf der einen Seite in formaler Hinsicht dahingehend, ob die staatsanwaltliche Anordnung der Maßnahme ausreichend präzise den Ort/die Orte beschreibt, an dem/denen die Maßnahme durchzuführen ist, und ob die Anordnung gerechtfertigt war. Auf der anderen Seite ist eine materielle Rechtmäßigkeitskontrolle der Durchführung der Maßnahme als solche notwendig. Bei letzterer spielen bedeutende Aspekte wie die Menschenwürde, grausame und erniedrigende Behandlungen und andere Formen des Exzesses bei der Durchführung der Maßnahme eine Rolle. Der Begriff der materiellen Kontrolle bezieht sich direkt auf die Prüfung des Ausmaßes der Grundrechtsbeeinträchtigung. ${ }^{433}$ Bei der Kontrolle sind daher die folgenden Parameter zu beachten:

\footnotetext{
${ }^{431}$ Art. 14 CPP: „Intimidad. Toda persona tiene derecho al respeto de su intimidad. Nadie podrá ser molestado en su vida privada. No podrán hacerse registros, allanamientos ni incautaciones en domicilio, residencia, o lugar de trabajo, sino en virtud de orden escrita del Fiscal General de la Nación o su delegado, con arreglo de las formalidades y motivos previamente definidos en este código. Se entienden excluidas las situaciones de flagrancia y demás contempladas por la ley.“(dt. Übersetzung d. Verf.).

${ }^{432}$ Vgl. Bernal Cuellar/Montealegre Lynett, 2013 T. II, S. 251 ff.; Guerrero Peralta, 2007, S. 340 ff.

${ }^{433}$ Vgl. KVerfG, Entsch. C-1093 v. 2003, Abschn. „Consideraciones de la Corte“; Guerrero Peralta, 2006, S. $116,152$.
} 


\section{Angemessenheit der Maßnahme}

Wie bereits oben angesprochen, ist das Recht auf Intimsphäre durch Art. 14 CPP besonders geschützt. Hieraus ergeben sich die grundlegenden Parameter für die Bewertung, ob eine Durchsuchung einer Person oder eine Hausdurchsuchung angemessen ist. Die vorher genannte Vorschrift legt fest, dass derartige Maßnahmen nur durchgeführt werden dürfen, wenn ein gesetzlich vorgeschriebener Grund für sie vorliegt. Es handelt sich insoweit um einen direkten Verweis auf Art. 219 CPP, welcher als tauglichen Zweck für die Durchsuchung einer Person oder eine Hausdurchsuchung „das Erlangen von Beweismitteln oder die Durchführung der Festnahme des Verdächtigen, Beschuldigten oder Verurteilten“ vorsieht. ${ }^{434}$ Eine Anordnung der Maßnahme durch die Staatsanwaltschaft, die gegen eine der gesetzlichen Voraussetzungen verstößt, führt dazu, dass die Maßnahme unwirksam ist und folglich die durch sie erlangten Beweismittel und physischen Nachweise nicht verwertbar sind (Art. 232 CPP). Auf der anderen Seite ist auch hervorzuheben, dass die Festnahme als Zweck der Maßnahme zudem voraussetzt, dass fundierte Anhaltspunkte bestehen, die vernünftigerweise darauf schließen lassen, dass die festzunehmende Person Täter oder Teilnehmer des Delikts ist, wegen dem ermittelt wird. Bloße Indizien reichen daher nicht aus. ${ }^{435}$

\section{Die Anordnung}

Der CPP systematisiert nicht die Voraussetzungen der Anordnung, die die FGN erlassen muss, um eine Hausdurchsuchung durchzuführen. Einzig durch die Rechtsprechung sind die diesbezüglich notwendigen Formalien systematisch aufgestellt worden. Das KVerfG hat in seinem Urteil C-591 vom 9. Juni 2005 einen von der FGN zu beachtenden Anforderungskatalog entworfen. Demnach ist bei der Anordnung einer Hausdurchsuchung das Folgende zu beachten:

„i. Das Ziel der Maßnahme darf ausschließlich sein, Beweismittel oder physische Nachweise zu erlangen oder eine Festnahme vorzunehmen, und es muss sich daher auch um ein Delikt handeln, für welches die Sicherungsmaßnahme einer präventiven Festnahme überhaupt zugelassen ist;

\footnotetext{
${ }^{434}$ Erfolgt eine dieser Maßnahmen aus einem anderen Grund, ist sie rechtwidrig. Vgl. KVerfG, Entsch. C591 v. 2005, Abschn. „Consideraciones de la Corte“.

435 Vgl. dazu Bernal Cuellar/Montealegre Lynett, 2013 T. II, S. 457 f.; Aponte Cardona, 2006a, S. 121; zu der Schlußfolgerung bzgl. der Täterschaft oder Teilnahme an einer Straftat s. infra § 10. B. III. 1. Inkulpationsgrad als Ausgangspunkt. 
ii. Es müssen fundierte Anhaltspunkte dafür vorliegen, dass der mögliche Täter oder Teilnehmer des zugrunde liegenden Delikts diejenige Person ist, die Eigentümer oder Besitzer des durchsuchten Objekts ist oder die sich in diesem zumindest vorübergehend aufhält, oder dass sich in diesem Objekt Gegenstände befinden, mit denen ein Delikt verwirklicht wurde oder die aus einem Delikt hervorgegangen sind.

iii. Die Anhaltspunkte müssen sich zumindest auf einen entsprechenden Polizeibericht, beeidigte Erklärungen eines Zeugen oder Informanten oder auf Beweismittel oder physische Nachweise stützen, die eine wahrscheinliche Verbindung zwischen dem zu durchsuchenden Objekt und dem zu ermittelnden Delikt belegen;

iv. Die Anordnung des Staatsanwalts muss präzise den Ort der Durchsuchung festlegen;

v. Es gibt bestimmte Objekte, die nicht durchsucht werden dürfen;

vi. Das Gesetz sieht Fristen für die Durchführung der Hausdurchsuchung vor;

vii. Die Durchführung muss unter Achtung der hierfür gesetzlich festgelegten Maßstäbe erfolgen;

viii. Es sind Sonderregeln zu beachten, wenn es sich um eine besondere Hausdurchsuchung handelt;

ix. Die Durchsuchung kann bei Ertappen auf frischer Tat erfolgen;

x. Es ist ein entsprechendes Protokoll zu erstellen, das bzgl. des Inhalts und der Genauigkeit den gesetzlichen Maßstäben entspricht, in dem ebenfalls die von den Beteiligten angeforderten Nachweise enthalten sind und welches in Kopie dem Eigentümer, Besitzer oder Gewahrsamsinhaber auf Antrag auszuhändigen ist.“436

\footnotetext{
${ }^{436}$ KVerfG, Entsch. C-591 v. 2005, Abschn. „Consideraciones de la Corte“: „i. Con los únicos fines de obtener elementos materiales probatorios y evidencia física o realizar la captura del indiciado, imputado o condenado, caso éste que sólo procederá en relación con delitos susceptibles de medida de aseguramiento de detención preventiva; ii. Deben existir motivos razonablemente fundados para concluir que la ocurrencia del delito investigado tiene como posible autor o partícipe al propietario o al simple tenedor del bien que se registra o quien transitoriamente se encontrare en él, o que en su interior se hallan los instrumentos con lo que se ha cometido el delito u objetos producto del mismo; iii. Los motivos fundados deberán ser respaldados, al menos, por un informe de policía judicial, declaración jurada de testigo o informante o en elementos materiales probatorios y evidencia física que establezcan con verosimilitud la vinculación del bien por registrar con el delito investigado; iv. La orden expedida por el fiscal deberá determinar con precisión los lugares que se van a registrar, no pudiendo ser indiscriminados; v. Existen unos objetos no susceptibles de registro; vi. La ley establece unos plazos de diligenciamiento de la orden de registro y allanamiento; vii. La diligencia debe realizarse guardando las reglas particulares para tales efectos señaladas en la ley; viii. Se debe tener en cuenta la regla particular si se trata de un allanamiento especial; ix. Procede en caso de flagrancia bajo las reglas establecidas en la ley; $x$. Se debe levantar el acta correspondiente con las precisiones e indicaciones exigidas por la ley, en las que se dejarán igualmente las constancias que soliciten las personas que en ella intervengan, de la cual se expedirá una copia para los propietarios, poseedores o tenedores, si la solicitan." (dt. Übersetzung d. Verf.); bzgl. der Grenzen der Durchsuchung im deutschen Strafprozessrecht siehe Park, 2015, S. 47 ff.; zur Rechtsmäßigkeit des mündlichen Durchsuchungsbeschluss Harms, DriZ, 2004, S. 25-29; zu Ver-
} 
Art. 220 CPP legt fest, dass die Anordnung einer Hausdurchsuchung nur erfolgen darf, wenn vernünftig begründete Anhaltspunkte vorliegen, nach denen anhand der in diesem Gesetz vorgesehenen Erkenntnismittel darauf zu schließen ist, dass „der mögliche Täter oder Teilnehmer des zugrunde liegenden Delikts diejenige Person ist, die Eigentümer oder Besitzer des durchsuchten Objekts ist oder die sich in diesem zumindest vorübergehend aufhält, oder dass sich in diesem Objekt Gegenstände befinden, mit denen ein Delikt verwirklicht wurde oder die aus einem Delikt hervorgegangen sind.“437 Art. 220 CPP bezieht sich dabei auf zwei Kategorien: Einerseits auf den Eigentümer oder Besitzer und andererseits auf denjenigen, der sich vorübergehend in dem Objekt aufhält.

\section{Ausnahmen des Anordnungserfodernisses}

Auf der einen Seite sieht Art. 229 CPP vor, dass „die Kriminalpolizei bei Ertappen auf frischer Tat die Durchsuchung der Immobilie, des Schiffs oder des Flugzeugs vornehmen darf.“ Im Fall einer Flucht in ein nicht öffentliches, fremdes Gebäude „,ist zunächst die Einwilligung des Eigentümers oder Besitzers einzuholen, oder im Falle des Fehlens einer solchen Einwilligung die entsprechende Anordnung durch die FGN, es sei denn, Hilferufe lassen auf die Notwendigkeit eines sofortigen Einschreitens schließen oder der Verdächtige übt Zwang auf den Eigentümer oder Besitzer aus. “438

Die Kontrolle der Maßnahmen durch den JCG hat sich in Fällen, in denen das Vorliegen eines solchen Ausnahmefalls geltend gemacht wurde, als sehr problematisch erwiesen, da der JCG hier anders als bei einer staatsanwaltschaftlichen Anordnung nicht über die von der Staatsanwaltschaft eingeholten Informationen und Dokumentationen hinsichtlich der

pflichtungen des im Rahmen von Wohnungsdurchsuchungen eingeschalteten Ermittlungsrichters siehe Krehl, NStZ 2003, S. 461 ff.

${ }^{437}$ Art. 220 CPP: „Fundamento para la orden de registro y allanamiento. Sólo podrá expedirse una orden de registro y allanamiento cuando existan motivos razonablemente fundados, de acuerdo con los medios cognoscitivos previstos en este código, para concluir que la ocurrencia del delito investigado tiene como probable autor o partícipe al propietario, al simple tenedor del bien por registrar, al que transitoriamente se encontrare en él; o que en su interior se hallan los instrumentos con los que se ha cometido la infracción, o los objetos producto del ilícito."(dt. Übersetzung d. Verf.).

${ }^{438}$ Art. 229 CPP: „Procedimiento en caso de flagrancia. En las situaciones de flagrancia, la policía judicial podrá proceder al registro y allanamiento del inmueble, nave o aeronave del indiciado. En caso de refugiarse en un bien inmueble ajeno, no abierto al público, se solicitará el consentimiento del propietario o tenedor o en su defecto se obtendrá la orden correspondiente de la Fiscalía General de la Nación, salvo que por voces de auxilio resulte necesaria la intervención inmediata o se establezca coacción del indiciado en contra del propietario o tenedor.“" (dt. Übersetzung d. Verf.) 
Ziele der Durchsuchung verfügt. ${ }^{439}$ Auf der anderen Seite sieht auch Art. 230 CPP drei Fälle vor, in denen es einer Anordnung der Durchsuchung durch den Staatsanwalt nicht bedarf:

\section{a. Das Einverständnis des Rechtsinhabers des beeinträchtigten Guts oder desjenigen, der ein durch die Durchführung der Maßnahme beein- trächtigtes Interesse hat (Art. 230 Nr. 1 CPP)}

Art. 230 Nr. 1 CPP sieht vor, dass es der Einholung einer schriftlichen Anordnung durch die FGN zur Durchführung einer Hausdurchsuchung nicht bedarf, wenn „ein ausdrückliches Einverständnis des Eigentümers oder Besitzers des zu durchsuchenden Objekts vorliegt oder das Einverständnis desjenigen, der durch die Durchführung der Maßnahme in seinen Interessen beeinträchtig wird. Hierbei reicht nicht aus, dass lediglich ein Widerspruch des Rechtsinhabers fehlt, es muss vielmehr eine dessen freien Willen ausdrückende Genehmigung der Durchsuchung vorliegen.“440 Dementsprechend ist es notwendig $\mathrm{zu}$ verifizieren, ob es sich um eine freie Willensäußerung handelt. Das verfassungsrechtliche Problem, das bei der Auslegung der Norm auftaucht, ist, dass Grundrechte aufgrund ihres subjektiven Charakters unverzichtbar sind. Die Frage ist somit, ob das Einverständnis des Betroffenen es rechtfertigt, von den gesetzlich vorgesehenen Formalien abzusehen. Entgegen der Regelung des Art. 230 Nr. 1 CPP ist die h.M. der Auffassung, dass dies nicht gerechtfertigt sei, und begründet dies damit, dass es dem Einverständnis an rechtfertigender Wirkung fehle. ${ }^{441}$ Es könne nicht gehen, von dem Betroffenen eine Erlaubnis einzufordern, um einer richterlichen Entscheidung und Anordnung auszuweichen, sondern grunsätzlich sei zunächst eine Genehmigung einzuholen, bevor ein Individuum aufgesucht und gestört würde. ${ }^{442}$

\section{b. Die vernünftige Erwartung eines Eingriffs in die Intimitätsphäre} (Art. 230 Nr. 2 CPP)

Nach Art. 230 Nr. 2 CPP bedarf es einer Anordnung der FGN auch dann nicht, wenn „keine begründete Erwartung eines Eingriffs in die Intimsphäre besteht, die das Erfordernis

\footnotetext{
${ }^{439}$ Dazu KVerfG, Entsch. 806 v. 2009, Abschn. „Consideraciones de la Corte“.

${ }^{440}$ Art. 230 Nr. 1 CPP: „Medie consentimiento expreso del propietario o simple tenedor del bien objeto del registro, o de quien tenga interés por ser afectado durante el procedimiento. En esta eventualidad, no se considerará como suficiente la mera ausencia de objeciones por parte del interesado, sino que deberá acreditarse la libertad del afectado al manifestar la autorización para el registro.“(dt. Übersetzung d. Verf.).

${ }^{441}$ Guerrero Peralta, 2007, S. 347 f.; Guerrero Peralta, 2006, S. 98; Maier, 2004, S. 687.

${ }^{442}$ Vgl. Maier, 2004, S. 686.
} 
einer Anordnung begründet. Hierbei existiert eine solche Erwartung dann nicht, wenn sich das Objekt im offenen Feld oder in freier Sicht befindet oder es verlassen ist. “443 Dieser Ausnahmetatbestand inkorporiert die „open-field-Doktrin“ in das kolumbianische Strafprozessrecht, mit der das U.S.-amerikanische Supreme Court den durch den vierten Zusatzartikel der amerikanischen Verfassung gewährten Schutzbereich beschränkt hat. ${ }^{444}$ Die Übernahme der „open-field-Doktrin“ ist auf große Kritik gestoßen, da sie nicht mit den Vorgaben der kolumbianischen Verfassung vereinbar ist, aus denen sich keine Grundlage dafür ergibt, dass der Schutz des persönlichen Bereichs, des Eigentums und der Wohnung von den vernünftigen Erwartungen anderer abhängt. ${ }^{445}$ Die kolumbianische Verfassung und auch die Rechtsprechung des KVerfG betonen vielmehr, dass es einen unantastbaren Kern der Grundrechte gebe, in den die Strafverfolgung nicht eingreifen dürfe. ${ }^{446}$

Die Spannung zwischen der vernünftigen Erwartung hinsichtlich der Intimsphäre und der Idee von einem unantastbaren Kerngehalt der Grundrechte hat wichtige Auswirkungen auf die Rechtmäßigkeitskontrolle durch den JCG. Zum einen macht sie eine restriktive Auslegung der Reichweite des Art. 230 Nr. 2 CPP erforderlich, da die bloße Lage (im offenen Feld) des betroffenen Objekts und die Abwesenheit des Eigentümers oder Besitzers es nicht entbehrlich machen, die verfassungsrechtlichen Voraussetzungen für einen Grundrechtseingriff zu erfüllen. ${ }^{447}$ Denn die Verfassung sieht ebenfalls nicht vor, dass hinsichtlich des persönlichen Bereichs, des Eigentums und der Wohnung lediglich Schutzerwartungen anstelle von verfassungsmäßig garantierten Schutzrechten bestehen. Dies wäre so, als würde man annehmen, der Schutz der Wohnung sei einzig gegeben, wenn es sich um einen abgeschlossenen Ort handeln würde. Zum anderen muss der JCG prüfen, ob die betroffene Person selbst nicht davon ausgehen konnte, dass der Schutzbereich der Intimsphäre betroffen ist, weil sie freiwillig die Sicht von außen auf das erlaubt hat, was sich im Inneren des betroffenen Objekts befindet. Dies ist zum Beispiel der Fall, wenn der Täter eines Autodiebstahls das gestohlene Fahrzeug so in seiner geöffneten Garage abstellt,

\footnotetext{
${ }^{443}$ Art. 230 Nr. 2 CPP: „No exista una expectativa razonable de intimidad que justifique el requisito de la orden. En esta eventualidad, se considera que no existe dicha expectativa cuando el objeto se encuentra en campo abierto, a plena vista, o cuando se encuentra abandonado." (dt. Übersetzung d. Verf.).

${ }^{444}$ Vgl. Guerrero Peralta, DPC 92 (2011), S. 55 ff.; Guerrero Peralta, 2006, S. 99. Für die Rechtsprechung bzgl. der „Open field“-Doktrin in USA und die Unterscheidung zwischen dem unmittelbaren Nahbereich und sonstigem Gelände s. Wittmann, 2014, $168 \mathrm{ff}$.

${ }^{445}$ Aponte Cardona, 2006, S. 80.

${ }^{446}$ I.d.S Guerrero Peralta, 2007, S. 349 ff.; Aponte Cardona, 2006, S. 80 m.w.N.

${ }^{447}$ Aponte Cardona, 2006, S. 80.

146
} 
dass man ohne in die Garage zu gehen das Nummernschild des Fahrzeugs erkennen kann. ${ }^{448}$

Nach Art. 231 CPP „kann nur derjenige vor dem Richter zur Kontrolle der Garantien oder vor dem Erkenntnisrichter eine Verletzung seiner Verfahrensrechte rügen, sodass während einer Hausdurchsuchung unrechtmäßig erlangte Beweismittel nicht verwertet werden dürfen, der Verdächtiger oder Beschuldigter ist oder als Eigentümer oder Besitzer eine Rechtsposition hinsichtlich des von der Maßnahme betroffenen Objekts besitzt." Ebenso stellt fest, dass „dieses Recht sich ausnahmsweise auch auf einen Besucher [des Objekts] erstreckt, der in seiner Eigenschaft als Gast beweisen kann, dass er vernünftigerweise die Wahrung seiner Intimsphäre erwarten durfte in dem Moment, in dem die Maßnahme durchgeführt wurde.“449 Kann er eine solche Erwartungshaltung nicht beweisen, ist es möglich, dass eine Person, die sich mit Einverständnis des Eigentümers in dessen Wohnung aufhält, gleichwohl vom Schutz der Wohnung ausgeschlossen ist.

Allerdings argumentiert diesbezüglich ein Teil der Rechtslehre, dass nicht nur die Personen, die in ihren Rechten verletzt wurden, die Verwertbarkeit eines Beweismittels rügen dürfen, sondern auch Dritte. ${ }^{450}$ Nach dieser Ansicht gebietet die Reichweite des Grundrechts auf Schutz der Intimitätsphäre dem Richter im Falle einer Hausdurchsuchung nicht nur die materielle Rechtsposition des Eigentums oder des Besitzes zu berücksichtigen, sondern auch die Betroffenheit anderer Anwesender. ${ }^{451}$ Denn auch Grundrechte eines Dritten können durch die Maßnahme betroffenen sein: Wie verhält es sich beispielsweise, wenn die Polizei unrechtmäßig eine Hausdurchsuchung durchführt, und hierbei Besitztümer einer dritten Person an sich nimmt. Der Eigentümer des durchsuchten Objekts kann in diesem Fall die Rechtswidrigkeit der Maßnahme auch in Bezug auf den Dritten rügen mit dem Argument, dass die Maßnahme gegen diesen im Rahmen der gegen sein Eigentum gerichteten illegalen Hausdurchsuchung erfolgte.

\footnotetext{
448 Guerrero Peralta, 2006, S. 100.

449 Art. 231 CPP: „Únicamente podrá alegar la violación del debido proceso ante el juez de control de garantías o ante el juez de conocimiento, según sea el caso, con el fin de la exclusión de la evidencia ilegalmente obtenida durante el procedimiento de registro y allanamiento, quien haya sido considerado como indiciado o imputado o sea titular de un derecho de dominio, posesión o mera tenencia del bien objeto de la diligencia. Por excepción, se extenderá esta legitimación cuando se trate de un visitante que en su calidad de huésped pueda acreditar, como requisito de umbral, que tenía una expectativa razonable de intimidad al momento de la realización del registro.“(dt. Übersetzung d. Verf.).

${ }^{450}$ Vgl. Guerrero Peralta, 2006, S. 101.

${ }^{451}$ Vgl. Guerrero Peralta, 2006, S. 101.
} 
Insofern muss es aber auch für den Dritten möglich sein, die Verwertbarkeit der Maßnahme zu rügen, da er bei seiner Anwesenheit im fremden Eigentum, mit der der Eigentümer einverstanden war, vernünftigerweise die Wahrung seiner Intimsphäre erwarten durfte. ${ }^{452}$

\section{c. Notfallsituationen (Art. 230 Nr. 3 CPP)}

Art. 230 Nr. 3 CPP nimmt Bezug auf „Notfallsituationen, wie zum Beispiel Feuer, Explosionen, Überschwemmungen oder andere Risikoszenarien, die das Leben oder Eigentum gefährden oder eine drohende Gefahr für die Gesundheit, das Leben oder die körperliche oder sexuelle Unversehrtheit eines Minderjährigen darstellen. “453 Es handelt sich hierbei um gerade die Situationen, die in der deutschen StPO unter dem Begriff Gefahr im Verzug behandelt werden. ${ }^{454}$ Bei der Überprüfung, ob eine solche Notfallsituation vorliegt, hat der JCG zu beachten, dass eine Gefahr im Verzug insoweit vorliegt, wenn objektiv keine Möglichkeit vorlag, eine Anordnung der Maßnahme zu beantragen, ohne dass in der Folge die Möglichkeit zur Beweiserhebung verloren gegangen wäre. Der JCG hat also die Schwere des Schadenfalls und die Notwendigkeit der Beweisbeschaffung zu bewerten. ${ }^{455}$

Die Rechtmäßigkeitsprüfung bei drohenden Gefahren für die Gesundheit, das Leben, die körperliche oder sexuelle Unversehrtheit eines Minderjährigen ist ebenfalls komplex. Die Regelung ist so weit gefasst, dass ihr zufolge in einer Vielzahl der Fälle bei einer Hausdurchsuchung eine Anordnung entbehrlich wäre. Die Ausnahmeregelung wurde durch das Gesetz 1453 von 2011 eingeführt, welches in seinem Art. 53 den Begriff der drohenden Gefahr einführte. Nach dem KVerfG handelt es sich hierbei „um extreme Situationen, die ein Einschreiten der Behörden dringend und zwingend erforderlich machen, um die bedrohten Rechte und Interessen zu schützen.“456 Die Figur der Hausdurchsuchung zur Sicherung eines Minderjährigen ist demgegenüber im Jugendgesetz (Código del Menor) vorgesehen sowie in Art. 86 Nr. 6 und 106 des Gesetzes 1098 von 2006. Das KVerfG hat hierzu befunden, dass die Voraussetzungen dafür, dass diese Art von Hausdurchsuchungen

\footnotetext{
452 Guerrero Peralta, 2006, S. 101.

${ }^{453}$ Art. 230 Nr. 3 CPP: „Se trate de situaciones de emergencia tales como incendio, explosión, inundación u otra clase de estragos que pongan en peligro la vida o la propiedad, o en situaciones de riesgo inminente de la salud, la vida o integridad personal o sexual de un menor de edad."(dt. Übersetzung d. Verf.).

${ }^{454}$ I.d.S. Guerrero Peralta, 2006, S. 101.

455 Guerrero Peralta, 2007, S. 352 ff.; Guerrero Peralta, 2006, S. 102.

${ }^{456} \mathrm{KVerfG}$, Entsch. C-256 v. 2008, Abschn. 38: „situaciones extremas que requieren la intervención urgente y obligatoria de aquellas autoridades para preservar los derechos o intereses que se encuentran en grave riesgo de afectarse.“ 
verfassungsgemäß sind, darin bestehen, ,(i) dass eine drohende und schwerwiegende Gefahr besteht, (ii) das Leben, die Unversehrtheit, die Sicherheit oder die Gesundheit von Personen gefährdet ist und (iii) die diesen Maßnahmen zugrunde liegende Regelung den Entscheidungsrahmen der Verwaltungsbehörden vorschreiben muss und die nachträgliche richterliche Kontrolle in Fällen eines Exzesses oder von Willkür erfolgen muss. “‘57

\section{Begründung der Anordnung}

Der Begriff der vernünftig fundierten Anhaltspunkte ist nach Art. $220 \mathrm{CPP}^{458}$ das Resultat einer Wertung auf Grundlage bestimmter Erkenntnismittel. D.h., dass eine Analyse vorzunehmen ist, aus der sich eine „Gesamtheit empirisch und objektiv verifizierbarer Informationen, Beweise und rechtmäßig erlangter Elemente ergibt, die die Möglichkeit des Vorliegens eines Delikts indizieren sowie die wahrscheinliche Beteiligung des Bürgers,

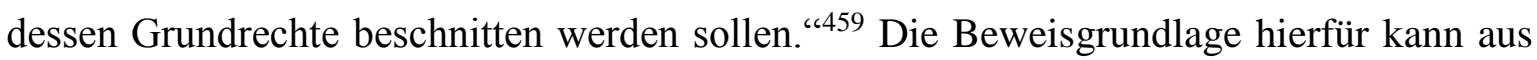
den Präventivmaßnahmen der FGN am Tatort, den Ermittlungsergebnissen eines verdeckten Ermittlers, der Vernehmung der vorgezogenen Beweisaufnahme etc. stammen. ${ }^{460}$

Ferner ist $\mathrm{zu}$ beachten, dass die Motive durch eine Beweisgrundlage im engeren Sinn gestützt sein müssen, d.h., es müssen Beweismittel vorliegen, die auch zur Verwendung in der mündlichen Hauptverhandlung bestimmt sind. Nach der kolumbianischen Strafprozessrechtsdoktrin reichen daher die bloße Verweisung auf die Ermittlungen der Kriminalpolizei am Tatort, der vage Verweis auf Angaben eines Informanten ohne Vorliegen weiterer Angaben oder die einfache Behauptung des Vorliegens von Beweisen gegen die betroffene Person nicht aus. ${ }^{461}$ Darüber hinaus bestimmt Art. $221 \mathrm{CPP}$, dass sich

\footnotetext{
${ }^{457}$ KVerfG, Entsch. C-256 v. 2008, Abschn. 40 und C-519 v. 2007, Abschn. 4.7.: „(i) la existencia de un peligro inminente y grave; (ii) que amenaza la vida, la integridad, la seguridad o la salubridad de las personas; y (iii) la existencia de elementos en la regulación demandada que circunscriben el margen decisorio de la autoridad administrativa y permiten un control posterior efectivo ante una autoridad judicial en caso de presentarse excesos o arbitrariedades.“

${ }^{458}$ Für den Wortlaut des Art. 220 CPP vgl. supra Fn. 437.

${ }^{459}$ KVerfG, Entsch. C-226 v. 2008, Abschn. 40 und C-519 v. 2007, Abschn. 4.7 „conjunto de razones empírica y objetivamente verificables en información, evidencia o elementos ma-teriales lícitamente recabados que indiquen la posible ocurrencia de un delito y probable participación en el mismo del ciudadano al que se le pretenden restringir sus derechos fundamentales.“ Dazu s. ausführlich infra § 7. Die sog. „,motivos fundados" als Voraussetzung von Ermittlungsmaßnahmen.

${ }^{460}$ Die sämtlichen zulässigen Quellen sind in Titel II, Buch 2 des CPP, Art. 275 bis 285 aufgezählt.

${ }^{461}$ Guerrero Peralta, 2006, S. 96; s. auch KVerfG, Entsch. 673 v. 2005, Abschn. „Consideraciones de la Corte“.
} 
die in Art. 220 thematisierten Anhaltspunke „mindestens aus einem Bericht der Kriminalpolizei, einer beeidigten Zeugenaussage oder aus materiellen Beweismitteln oder physischen Nachweisen ergeben müssen, die die Verbindung zwischen dem zu durchsuchenden Objekt und dem zu ermittelnden Delikt wahrscheinlich erscheinen lassen“. 462 Daher bedarf es bei der Bewertung, ob vernünftig begründete Anhaltspunkte vorliegen, einer doppelten Prüfung: Zum einen ist es notwendig, eine Verbindung zwischen dem zu durchsuchenden Objekt und dessen Eigentümer oder Besitzer zu überprüfen. Zum anderen ist zu kontrollieren, ob die Prüfung durch die FGN vor der Durchführung der Maßnahme auf einem Mindestmaß an Beweismitteln basierte, was die FGN vor dem JCG beweisen muss (Artikel $237 \mathrm{CPP}$ ). ${ }^{463}$ Das KVerfG hat diese Voraussetzungen bekräftigt, indem es betonte, dass ,der Erlass einer Anordnung einer Hausdurchsuchung nicht der Willkür des Staatsanwalts, der sie anordnet, überlassen sein soll. Vielmehr muss eine Grundlage vorliegen, zumindest in Form eines Berichts, einer beeidigten Aussage oder aufgrund materieller Beweismittel oder physischer Nachweise, sodass der Richter zu Kontrolle der Garantien Informationen hat, anhand derer er eine effektive Rechtmäßigkeitskontrolle durchführen kann. ${ }^{\text {‘464 }}$

\section{Ortsbestimmung}

Art. 222 CPP setzt voraus, „dass die Anordnung der Staatsanwaltschaft den zu durchsuchenden Ort zu bestimmen hat. Handelt es sich um Gebäude, Schiffe oder Flugzeuge, die über mehrere Zimmer bzw. Abteile verfügen, so sind auch diese genau zu bezeichnen.““465 Absatz 2 dieser Norm sieht vor, dass ,,in den Fällen, in denen eine exakte Beschreibung des zu durchsuchenden Ortes nicht möglich ist, die Staatsanwaltschaft in der Anordnung die Argumente darzulegen hat, weshalb eine Durchsuchung trotzdem

\footnotetext{
462 Art. 221 CPP: „Respaldo probatorio para los motivos fundados. Los motivos fundados de que trata el artículo anterior deberán ser respaldados, al menos, en informe de policía judicial, declaración jurada de testigo o informante, o en elementos materiales probatorios y evidencia física que establezcan con verosimilitud la vinculación del bien por registrar con el delito investigado.“ (dt. Übersetzung d. Verf.). Dazu infra § 10. A. II. Die Beweisgrundlageproblematik gemäß Art. 221 CPP.

${ }^{463}$ Guerrero Peralta, 2006, S. 97; dazu infra § 7. B. I. 2. Rechtmäßigkeitskontrolle des JCG.

${ }^{464}$ KVerfG, Entsch. C-673 v. 2005, Abschn. „Consideraciones de la Corte“: „la expedición de una orden de registro y allanamiento no queda al arbitrio del Fiscal que la ordena, sino que deberá tener un soporte o respaldo al menos en un informe, declaración jurada o elementos materiales probatorios y evidencia física, como garantía de la viabilidad de la diligencia (...) a fin de que el juez pueda acceder a una información que le permita realizar un efectivo control de legalidad." (dt. Übersetzung d. Verf.).

${ }^{465}$ Art. 222 Abs. 1 CPP: ,la orden expedida por el fiscal deberá determinar los lugares que se van a registrar. $\mathrm{Si}$ se trata de edifi-caciones, naves o aeronaves que dispongan de varias habitaciones o compartimentos, se indicará ex-presamente cuáles se encuentran comprendidos en la diligencia“ (dt. Übersetzung d. Verf.). 
stattfinden soll.“ Es wir fesgestellt, dass ,auf keinen Fall von der Generalstaatsanwaltschaft unbestimmte Durchsuchungen angeordnet werden dürfen oder Anordnungen ergehen, die pauschal das $\mathrm{zu}$ durchsuchende Objekt beschreiben."466 Insofern ist neben der Individualisierung der von der Durchsuchung betroffenen Personen erforderlich, das zu durchsuchende Objekt zu individualisieren. Hinsichtlich der Durchführung der so spezifizierten Maßnahme schreibt Art. 225 CPP einige besondere Regeln vor:

„1. Die Durchsuchung wird ausschließlich an den Orten durchgeführt, für die die Anordnung gilt, und für den Fall, dass neue Beweise für das ermittelte Delikt gefunden werden, kann sie auf andere Orte ausgedehnt werden einschließlich derjenigen, die bei Ertappen auf frischer Tat durchsucht werden können.

2. Es ist bei der Durchsuchung die geringstmögliche Beeinträchtigung der betroffenen Personen zu gewährleisten, weshalb die beschlagnahmbaren Güter auf die in der Anordnung ausgewiesenen beschränkt werden, es sei denn, es liegt ein Ertappen auf frischer Tat vor oder es tauchen Beweismittel oder physische Nachweise auf, die mit einem weiteren Delikt in Zusammenhang stehen.

3. Es ist ein Protokoll anzufertigen, dass die Durchführung der Maßnahme zusammenfasst, die durchsuchten Orte ausdrücklich bezeichnet sowie die beschlagnahmten Objekte oder Güter und die festgenommenen Personen. Es ist außerdem anzugeben, ob es Widerstand seitens der Betroffenen gab, und falls polizeiliche Präventivmaßnahmen ergriffen wurden, sind deren Art sowie deren Folgen zu benennen.

4. Das Protokoll ist den Personen vorzulesen, die angeben, von der Durchsuchung betroffen gewesen zu sein, und die aufzufordern sind, das Protokoll zu unterzeichnen, wenn sie mit dessen Inhalt einverstanden sind.“467

\footnotetext{
${ }^{466}$ Art. 222 Abs. 2 CPP: „De no ser posible la descripción exacta del lugar o lugares por registrar, el fiscal deberá indicar en la orden los argumentos para que, a pesar de ello, deba procederse al operativo. En ninguna circunstancia podrá autorizarse por la Fiscalía General de la Nación el diligenciamiento de órdenes de registro y allanamiento indiscriminados, o en donde de manera global se señale el bien por registrar." (dt. Übersetzung d. Verf.).

${ }^{467}$ Art. 225 CPP: ,Reglas particulares para el diligenciamiento de la orden de registro y allanamiento. Durante la diligencia de registro y allanamiento la Policía Judicial deberá: 1. El registro se adelantará exclusivamente en los lugares autorizados y, en el evento de encontrar nuevas evidencias de la comisión de los delitos investigados, podrá extenderse a otros lugares, incluidos los que puedan encuadrarse en las situaciones de flagrancia; 2. Se garantizará la menor restricción posible de los derechos de las personas afectadas con el registro y allanamiento, por lo que los bienes incautados se limitarán a los señalados en la orden, salvo que medien circunstancias de flagrancia o que aparezcan elementos materiales probatorios y evidencia física relacionados con otro delito; 3 . Se levantará un acta que resuma la diligencia en la que se hará indicación expresa de los lugares registrados, de los objetos ocupados o incautados y de las personas capturadas. Ade-
} 
Eine unzureichende Individualisierung des zu durchsuchenden Objekts wird als Verfahrensverletzung erachtet. ${ }^{468}$ Die Folge ist somit die Nichtigkeit der Maßnahme. Damit kann sie im Verfahren auch nicht verwertet werden (Art. 232 CPP). ${ }^{469}$ Die Durchführung einer Durchsuchung ohne vorherige genaue Bestimmung des zu durchsuchenden Ortes muss ausreichend und objektiv begründet werden. Beispielsweise könnte ihr der von Art. 221 CPP vorausgesetzte Beweisstandard zu Grunde liegen. In jedem Fall sind diejenigen Maßnahmen für unrechtmäßig zu erklären, bei denen unbegrenzt durchsucht worden ist, obwohl die Staatsanwaltschaft ausreichend Anhaltspunkte hatte, um das zu durchsuchende Objekt konkret zu bestimmen. ${ }^{470}$

\section{Nachträgliche gerichtliche Überprüfungsanhörung}

Die Kontrolle der Durchführung einer Hausdurchsuchung ist in Art. 224, 225 und 266 CPP geregelt. Der JCG kontrolliert die fristgemäße Durchführung, ob die Maßnahme zur richtigen Zeit am richtigen Ort und am richtigen Objekt (wie in der Anordnung ausgewiesen) durchgeführt wurde. Diese Einzelheiten müssen auch im Protokoll der Hausdurchsuchung niedergeschrieben werden. In dem Protokoll sind ferner ,alle untersuchten und beschlagnahmten Gegenstände sowie der Ort, an dem sie gefunden wurden, zu vermerken und zu beschreiben sowie die Erklärungen derjenigen Personen aufzunehmen, die an der Maßnahme mitgewirkt haben. Die Eigentümer oder Besitzer haben das Recht, eine Kopie des Protokolls zu erhalten“ (Art. 227 CPP). ${ }^{471}$ Über die Kontrolle formaler Aspekte (Vorliegen einer Anordnung, Begründung, Beweisgrundlage, Bestimmung der Reichweite etc.) hinaus hat der JCG auch eine materielle Rechtmäßigkeitskontrolle durchzuführen. D.h., der JCG bewertet die Durchführung der

más, se deberá señalar si hubo oposición por parte de los afectados y, en el evento de existir medidas preventivas policivas, se hará mención detallada de la naturaleza de la reacción y las consecuencias de ella; 4. El acta será leída a las personas que aleguen haber sido afectadas por el registro y allanamiento y se les solicitará que firmen si están de acuerdo con su contenido. En caso de existir discrepancias con lo anotado, deberán dejarse todas las precisiones solicitadas por los interesados y, si después de esto, se negaren a firmar, el funcionario de la policía judicial responsable del operativo, bajo juramento, dejará expresa constancia de ello.“ (dt. Übersetzung d. Verf.).

${ }^{468}$ KVerfG, Entsch. C-131 v. 2009, Abschn. „Consideraciones de la Corte“.

469 Aponte Cardona, 2006, S. 82. Auch die Beschlagnahmen, die sich außerhalb des von der Anordnung erfassten Rahmens bewegen, verletzen die Verfahrensregeln.

${ }^{470}$ Dazu Guerrero Peralta, 2007, S. 353 ff.

${ }^{471}$ Art. 227 CPP: „Acta de la diligencia. En el acta de la diligencia de allanamiento y registro deben identificarse y describirse todas las cosas que hayan sido examinadas o incautadas, el lugar donde fueron encontradas y se dejarán las constancias que soliciten las personas que en ella intervengan. Los propietarios, poseedores o tenedores tendrán derecho a que se les expida copia del acta, si la solicitan.“" (dt. Übersetzung d. Verf.). 
Maßnahme, prüft die Gründe der Hausdurchsuchung und gleicht sie mit deren Ergebnissen ab.

\section{Ablauf der Überprüfungsanhörung}

Nach Art. 237 CPP (geändert durch Gesetz 1142 von 2007, Art. 16; dieser wiederum modifiziert durch Gesetz 1453 von 2011, Art. 68) „hat der Staatsanwalt innerhalb von 24 Stunden nach Erhalt des Berichts der Kriminalpolizei über die Durchführung einer Durchsuchung, Kommunikationsüberwachung [etc.] vor dem JCG zu erscheinen, damit die Anhörung zur Überprüfung der Rechtmäßigkeit der Maßnahme durchgeführt werden kann.“472 An der Anhörung können neben dem Staatsanwalt auch Beamte der Kriminalpolizei sowie Zeugen und Sachverständige, die zwecks Erlass der Anordnung eine beeidigte Erklärung abgegeben haben oder an der Durchführung der Maßnahme mitgewirkt haben, teilnehmen. Wenn der Richter es für notwendig erachtet, kann er nach Art. 237 Abs. 3 CPP ,die Beteiligten direkt befragen und entscheidet nach Anhörung der Argumente des Staatsanwalts über die Wirksamkeit der Maßnahme insgesamt. “473

Im Rahmen der Anhörung prüft der JCG zunächst die Anwesenheit der Parteien, der Disziplinarstaatsanwaltschaft (Procuraduría) und gegebenenfalls weiterer Beteiligter, bevor er das Wort der FGN übergibt, damit diese die Gründe der von ihr erlassenen Anordnung darlegen und die ihr zugrunde liegenden Beweise, Berichte und Aussagen präsentieren kann. Auf Anordnung des Richters wird die Befragung der betreffenden Ermittler, des Sachverständigen oder des angebotenen Zeugen durchgeführt. Der Richter stellt das Vorliegen der erforderlichen Anordnung fest und verifiziert die Erfüllung der formalen Voraussetzungen. Gleiches gilt hinsichtlich des Protokolls der Hausdurchsuchung. Dann erteilt der Richter der Verteidigung das Wort, soweit diese an der Anhörung teilnimmt, damit sie die von der FGN dargelegten Gründe widerlegen und Gründe anführen kann, aus denen sich die Rechtswidrigkeit und Nichtigkeit der Hausdurchsuchung ergibt. Sollte die Verteidigung nicht an der Überprüfungsanhörung teilnehmen, kann sie gleichwohl noch später in der vorbereitenden Anhörung (audiencia

\footnotetext{
472 Art. 237 Abs. 1 CPP: „Dentro de las veinticuatro (24) horas siguientes al recibimiento del informe de Policía Judicial sobre las diligencias de las órdenes de registro y allanamiento, retención de correspondencia[...], el fiscal comparecerá ante el Juez de Control de Garantías, para que realice la audiencia de revisión de legalidad sobre lo actuado." (dt. Übersetzung d. Verf.).

473 Art. 237 Abs. 3 CPP: „El juez podrá, si lo estima conveniente, interrogar directamente a los comparecientes y, después de escuchar los argumentos del fiscal, decidirá de plano sobre la validez del procedimiento.“ (dt. Übersetzung d. Verf.).
} 
preparatoria) den Ausschluss der in der Hausdurchsuchung erlangten Beweise aus dem Verfahren beantragen (Art. $238 \mathrm{CPP}$ ).

Kommt der Richter zu dem Ergebnis, dass die Anordnung verfassungs- und rechtmäßig war, fundierte Anhaltspunkte bestanden, um das Recht auf Intimsphäre zu beschränken und die Hausdurchsuchung unter Achtung der Grundrechte und der Verfahrensgarantien im Rahmen der im CPP vorgeschriebenen Fristen durchgeführt wurde, erklärt er die Maßnahme für formell und materiell rechtmäßig. Sollte die Durchsuchung ein Grundrecht verletzt haben, ist sie für nichtig, bei Verstößen gegen das einfache Recht für rechtswidrig zu erklären. ${ }^{474}$ Die Entscheidung ist somit in drei Varianten denkbar: 1. Wirksamkeit der Maßnahme; 2. Nichtigkeit der Maßnahme und daher Ausschluss aus dem Prozess (Unverwertbarkeit); 3. Korrektur der rechtswidrigen, aber nicht nichtigen Handlungen. Wird eine Maßnahme für unwirksam erklärt, so sind die durch sie erlangten Beweismittel und physischen Nachweise nicht im Hauptverfahren verwertbar. Wird die Maßnahme hingegen für wirksam erklärt, heißt dies nicht notwendigerweise, dass die Beweismittel zur Verwertung im Hauptverfahren zugelassen werden. Diese Frage ist in der vorbereitenden Anhörung (audiencia preparatoria) zu erörtern und zu entscheiden. ${ }^{475}$

\section{Hauptproblem der materiellen und formellen Überprüfung (Art. 237 CPP)}

Die ursprüngliche Fassung dieser Norm wurde vielfach kritisiert in der kolumbianischen Strafprozessrechtsdoktrin. Die h.M. vertrat hierzu, dass die in der Anhörung nach Art. 237 CPP durchgeführte Kontrolle keine rein formelle Rechtmäßigkeitskontrolle sein dürfe, sondern auch eine materielle Rechtmäßigkeitskontrolle beinhalten müsse. ${ }^{476}$ Diese Ansicht spiegelt sich in der Rechtsprechung des KVerfG wieder, welche eindeutig bestimmt, dass der JCG die Grundrechte umfassend zu schützen hat. Daher muss der JCG auch die Durchführung der Maßnahme in materieller Hinsicht prüfen und bewerten können. ${ }^{477}$ Dies hat das KVerfG in mehreren Entscheidungen betont, in denen es ausführt, dass ,die Anhörung zur Überprüfung der Rechtmäßigkeit [nach Art. 237 CPP] dem besonderen Ziel dient, eine formelle und substantielle Prüfung der Durchführung von Maßnahmen wie

\footnotetext{
${ }^{474}$ CSJ, 2005, S. 37; Aponte Cardona, 2006, S. 95 ff.

475 Guerrero Peralta, 2006, S. 116.

476 Vgl. Guerrero Peralta, 2007, S. 114 ff.; Calle Calderón, NFP 67 (2005), S. 167, 169; Zuluaga, CoHerencia Vol. 4 Nr. 6 (2007), S. 140.

${ }^{477}$ KVerfG, Entsch. C-1092 v. 2003, Abschn. „Consideraciones de la Corte“. 
Durchsuchungen, Beschlagnahmen und Telefonüberwachungen zu gewährleisten. Es soll kontrolliert werden, ob die für die Anhörung und Durchführung dieser Maßnahmen geltenden gesetzlichen und verfassungsrechtlichen Parameter eingehalten wurden, und sichergestellt werden, dass keine Grundrechte verletzt wurden. “478

\section{B. Die Personenüberwachung (Art. 239 CPP)}

Gemäß Art. 239 CPP kann der Staatsanwalt ,die zeitlich begrenzte Überwachung einer Person durch die Kriminalpolizei anordnen, wenn er fundierte Anhaltspunkte dafür hat, [...] dass der Verdächtige oder Beschuldigte ihn zu ermittlungsrelevanten Informationen führen kann. “479 Unter Überwachung der Person ist dabei die feste oder mobile Beobachtung einer bestimmten Person zu verstehen, ohne deren begründete Erwartung auf Achtung der Intimitätsphäre zu verletzen. ${ }^{480}$ Der Staatsanwalt benötigt hierfür eine Genehmigung des nationalen Leiters oder Abteilungsleiters der FGN. Die Maßnahme darf für maximal ein Jahr angeordnet werden. Nach Ablauf dieses Zeitraums kann sie erneut angeordnet werden, wenn die Voraussetzungen für deren Anordnung immer noch vorliegen (Art. 239 CPP).

\section{Rechtliche Voraussetzungen}

\section{Anordnung des Staatsanwalts aufgrund von fundierten Anhaltspunk-} ten

Auch wenn die zuständigen Behörden Maßnahmen zur Prävention von Delikten durchführen müssen, darf dies nicht zur Folge haben, dass diese Maßnahmen der Willkür der kriminalpolizeilichen Organe unterliegen, denn das würde die persönliche Freiheit ernstlich gefährden. Daher ist es die FGN bzw. der zuständige Staatsanwalt, der die Überwachung einer Person durch die Kriminalpolizei anordnen muss. Dabei ist nicht

\footnotetext{
${ }^{478}$ KVerfG, Entsch. C-025 v. 2009, Abschn. 6.2: ,la audiencia de control de legalidad tiene como propósito específico llevar a cabo la revisión formal y sustancial del procedimiento utilizado en la práctica de las diligencias sobre medidas de registro, allanamiento, incautación e interceptación de comunicaciones, esto es, verificar que se hayan respetado los parámetros constitucionales y legales establecidos para su autorización y realización, e igualmente, que la medida de intervención no haya desconocido garantías fundamentales." (dt. Übersetzung d. Verf.); i.d.S. auch Entsch. C-131 v. 2009 und C-334 v. 2010.

${ }^{479}$ Art. 239 CPP: ,Vigilancia y seguimiento de personas. Sin perjuicio de los procedimientos preventivos que adelanta la fuerza pública, en cumplimiento de su deber constitucional, el fiscal que tuviere motivos razonablemente fundados, de acuerdo con los medios cognoscitivos previstos en este código, para inferir que el indiciado o el imputado pudiere conducirlo a conseguir información útil para la investigación que se adelanta [...].“ (dt. Übersetzung d. Verf.).

${ }^{480}$ FGN, 2005, S. 37 und Fn. 62.
} 
ausreichend, dass die betroffene Person lediglich verdächtigt wird. Es ist vielmehr notwendig, dass konkrete Indizien auf Grundlage objektiver Umstände bzgl. der betroffenen Person vorliegen. Die FGN muss daher die Anordnung einer Personenüberwachung auf begründete Anhaltspunkte stützen, die sich aus den im CPP zugelassenen Erkenntnismitteln ergeben. ${ }^{481}$ Daraus folgt, dass ein schlichter Rückschluss hier nicht ausreicht. Das Erfordernis der konkreten Indizien auf der Grundlage objektiver Umstände bedeutet, dass insoweit erhöhte Anforderungen zu erfüllen sind. So muss der Staatsanwalt auf Grundlage der zuvor durchgeführten Ermittlungen (Befragungen, Informanten, Telekommunikationsüberwachung etc.) zu dem Schluss gekommen sein, dass ihn der Verdächtige oder Beschuldigte zu ermittlungsrelevanten Informationen führen kann. ${ }^{482}$

\section{Zielperson der Überwachung}

Art. 239 CPP sieht als taugliche Zielpersonen einer Personenüberwachung den Verdächtigen oder Beschuldigten vor. Allerdings ist es wie auch bei Maßnahmen der Postoder Telekommunikationsüberwachung, dass durch die Personenüberwachung Dritte in ihren Grundrechten verletzt werden, gegen die sich die strafrechtlichen Ermittlungen nicht richten. Auch wenn der soeben genannte Artikel ausführt, dass die vernünftige Erwartung des Verdächtigen, Beschuldigten oder eines Dritten auf Wahrung seine Intimsphäre nicht beeinträchtigt werden darf, so ist es doch offensichtlich, dass Dritte, die mit dem Beschuldigten oder Verdächtigen in Berührung kommen, hierdurch ebenfalls in Verruf geraten. Die Fassung des Art. 239 wird daher wegen ihrer Ungenauigkeit kritisiert, da sie auch die Überwachung von Orten und Personen erlaubt, die der Verdächtige oder Beschuldigte aufgesucht hat. Die Norm ist insofern nicht geeignet, unangemessene Auswirkungen der Überwachung zu begrenzen. ${ }^{483}$ Dies hat wichtige Auswirkungen auf die Art und Weise der Durchführung der nachträglichen Rechtmäßigkeitskontrolle der Personenüberwachung durch den JCG. So wird dem JCG eine detaillierte Überprüfung der

\footnotetext{
${ }^{481}$ Vgl. KVerfG, Entsch. C-431 v. 2003, Abschn. „Consideraciones de la Corte“.

482 Guerrero Peralta, 2006, S. 137; Zuluaga NFP 83 (2015), S. 191, 195 ff.

${ }^{483}$ Dazu KVerfG, Entsch. C-881 v. 2014, Abschn. 3.8.; s. auch Guerrero Peralta, 2006, S. 138; Bernal Cuellar/Montealegre Lynett, 2013 T. II, S. 271 f. 
durchgeführten Maßnahme abverlangt sowie eine Verhältnismäßigkeitsprüfung im strengen Sinn, in deren Rahmen das Exzessverbot zu berücksichtigen ist. ${ }^{484}$

Die Personenüberwachung darf nicht permanent oder auf unbegrenzte Zeit erfolgen, vielmehr ist ein zeitlicher Rahmen festzulegen. Nach Art. 239 CPP darf die Dauer der Überwachung 1 Jahr nicht überschreiten. Daraus folgt, dass die Überwachung gegebenenfalls auch schon vorher zu beenden ist, falls die von ihr verfolgten Ziele bereits erreicht wurden. ${ }^{485}$

Als Ziel der Überwachung benennt Art. 239 CPP zum einen, dass die Personenüberwachung der Erlangung von Informationen dienen soll. Insofern ist für die Genehmigung der Maßnahme durch den Staatsanwalt notwenig, dass durch die Personenüberwachung relevante Erkenntnisse zu erwarten sind. Auf der anderen Seite ist es der Zweck der Personenüberwachung, „Informationen $\mathrm{zu}$ sammeln, die für die Identifizierung und Individualisierung von Tätern und Teilnehmern relevant sind sowie für die Personen, die sie frequentieren, die Orte, an denen sich aufhalten und Ähnliches“ (Art. 239 Abs. 2). ${ }^{486}$

\section{Gerichtliche Überprüfungsanhörung}

Art. 239 Abs. 3 CPP sieht vor, dass ,innerhalb von 36 Stunden nach der Anordnung durch die FGN die Genehmigung des Richters zur Kontrolle der Garantien hinsichtlich der formellen und materiellen Rechtmäßigkeit der Maßnahme einzuholen ist.“ Ebenso stellt Art. 239 CPP fest, dass „nach Ablauf der in der Anordnung für die Überwachung bestimmten Zeit oder nach Erlangung der weiterführenden Informationen der Staatsanwalt vor dem JCG erscheinen muss, damit dieser die Anhörung zur Überprüfung der

\footnotetext{
${ }^{484}$ Die Strafprozessrechtsdoktrin betont insbesondere die Notwendigkeit einer engen Auslegung des Begriffs der vernünftig begründeten Erwartung auf Achtung der Intimsphäre und zwar dahingehend, dass die Behörden beispielsweise keine Mikrofone oder Videokameras in einem privaten Wohnraum anbringen dürfen.; bzgl. des Exzessverbotes Aponte Cardona, 2006, S. 57 f.; Guerrero Peralta, 2006, S. 137.

${ }^{485}$ Dazu Guerrero Peralta, 2007, S. 388; Guerrero Peralta, 2006, S. 139.

${ }^{486}$ Art. 239 Abs. 2 CPP: „En la ejecución de la vigilancia se empleará cualquier medio que la técnica aconseje. En consecuencia, se podrán tomar fotografías, filmar videos y, en general, realizar todas las actividades relacionadas que permitan recaudar información relevante a fin de identificar o individualizar los autores o partícipes, las personas que lo frecuentan, los lugares adonde asiste y aspectos similares, cuidando de no afectar la expectativa razonable de la intimidad del indiciado o imputado o de terceros.“ (dt. Übersetzung d. Verf.).
} 
Rechtmäßigkeit der durchgeführten Maßnahmen durchführt. “487 Es ist zu prüfen, ob vernünftig fundierte Anhaltspunkte und Indizien gegen den Verdächtigen oder Beschuldigten vorlagen und die mit der Maßnahme gesuchten Informationen gemessen am Stand der Ermittlungen relevant sind. Werden diese Voraussetzungen nicht erfüllt, führt dies zur Verweigerung der Genehmigung der Maßnahme. Auf der zweiten Kontrollstufe prüft der JCG, ob der nach der Prüfung der Anordnung genehmigte Rahmen der Maßnahme bei deren Durchführung eingehalten wurde. D.h., der JCG prüft hier beispielsweise, ob die gesuchte Person durch die Staatsanwaltschaft individualisiert werden konnte oder ob durch die Überwachung die Vollendung eines Delikts verhindert werden konnte. ${ }^{488}$

Die Prüfung der Maßnahme anhand des Verhältnismäßigkeitsprinzips ist bei der Genehmigung der Überwachung von besonderer Bedeutung. Zur Bestimmung der Notwendigkeit der Maßnahme sind einerseits die Schwere des Delikts und andererseits der voraussichtliche Erfolg der Maßnahme zu beachten. An zweiter Stelle ist die Geeignetheit der Maßnahme mit dem Nutzen in Verhältnis zu setzen, wobei neben der Aufklärung des begangenen Delikts auch die Aussicht auf Festnahme der Täter und die Erlangung von Materialien und Daten für andere Ermittlungen zu berücksichtigen sind. In Bezug auf die Verhältnismäßigkeit im engeren Sinne (Angemessenheit) ist die Schwere des Delikts, wegen dem ermittelt wird, mit dem Ausmaß des Eingriffs in das Grundrecht auf Intimsphäre abzuwägen. ${ }^{489}$

\section{Die Überwachungsmaßnahmen an Sachen (Art. 240 CPP)}

Zur Erlangung ermittlungsrelevanter Informationen können auch Sachen (bewegliche oder unbewegliche) observiert werden. Dies kann ebenfalls von dem Staatsanwalt angeordnet werden, „wenn dieser vernünftig fundierte Anhaltspunkte hat, dass die Immobilie, das Schiff, das Flugzeug, irgendein anderes Fahrzeug oder irgendein beweglicher Gegenstand zum Verkauf von Drogen genutzt wird, der Herstellung von Drogen dient oder zum Verstecken von Sprengstoff, Waffen, Munition, zur Begehung eines Delikts im

487 Art. 239 Abs. 3 CPP: „En todo caso se surtirá la autorización del Juez de Control de Garantías para la determinación de su legalidad formal y material, dentro de las treinta y seis (36) horas siguientes a la expedición de la orden por parte de la Fiscalía General. Vencido el término de la orden de vigilancia u obtenida la información útil para la investigación el fiscal comparecerá ante el Juez de Control de Garantías, para que realice la audiencia de revisión de legalidad sobre lo actuado.“(dt. Übersetzung d. Verf.).

488 Guerrero Peralta, 2006, S. 140. Unabhängig hiervon wird immer eine nachträgliche Kontrolle durchgeführt, nachdem relevante Erkenntnisse erlangt worden sind oder die von der FGN angeordnete Dauer der Überwachung abgelaufen ist. Dazu $F G N, 2005$, S. 47.

489 Bernal Cuellar/Montealegre Lynett, 2013 T. II , S. 278; Guerrero Peralta, 2006, S. 141. 
Allgemeinen dient oder aus einem solchen stammt“ (Art. 240 CPP). ${ }^{490}$ Die Anordnung der Maßnahme ist maximal ein Jahr wirksam, kann aber erneut erlassen werden, wenn neue Erkenntnisse existieren, die den Erlass rechtfertigen. In der Anordnung kann jedes Mittel gewährt werden, das nicht die vernünftige Erwartung auf Wahrung der Intimsphäre des Verdächtigen, des Beschuldigten oder eines Dritten beeinträchtigt. Nach Erlass der Anordnung hat der Staatsanwalt innerhalb von 36 Stunden die Rechtmäßigkeitskontrolle durch den JCG zu beantragen.

\section{Verdeckte Ermittlungen (Art. 241-243 CPP)}

In den Art. 241-243 CPP wird der Einsatz verdeckter Ermittler geregelt. Im Einzelnen regelt Art. 241 die Analyse und Infiltrierung einer kriminellen Vereinigung, Art. 242 den eigentlichen Einsatz eines verdeckten Ermittlers, Art. 242 A (ergänzt durch Art. 36 des Gesetzes 1474 von 2011) verdeckte Operationen zur Bekämpfung der Korruption und Art. 243 die verdeckte Überwachung des Transports bzw. der Übergabe von verbotenen Gegenständen. Es geht hierbei prinzipiell um Fälle, in denen es zum Erfolg der Ermittlungen notwendig ist, in das Umfeld des Verdächtigen oder Beschuldigten unentdeckt einzudringen.

\section{Analyse und Infiltrierung einer kriminellen Organisation (Art. 241 CPP)}

Nach Art. 241 CPP kann der Staatsanwalt, wenn er aufgrund der in diesem Gesetz zugelassenen Erkenntnismittel vernünftig fundierte Anhaltspunkte hat, „dass der Beschuldigte oder Verdächtige einer kriminellen Organisation angehört oder mit einer solchen in Verbindung steht, anordnen, dass die Kriminalpolizei diese analysiert mit dem Ziel, ihre Organisationsstruktur, die Aggressivität ihrer Mitglieder und ihre Schwachstellen zu ermitteln.“ Danach kann er „die Planung, Vorbereitung und Durchführung einer Operation anordnen, in der ein oder mehrere Beamte in der Organisation verdeckt Ermittlungen anstellen, um für die Ermittlungen nützliche Informationen zu erlangen.“491

\footnotetext{
${ }^{490}$ Art. 240 CPP: „Vigilancia de cosas. El fiscal que dirija la investigación, que tuviere motivos razonablemente fundados, de acuerdo con los medios cognoscitivos previstos en este código, para inferir que un inmueble, nave, aeronave o cualquier otro vehículo o mueble se usa para almacenar droga que produzca dependencia, elemento que sirva para el procesamiento de dicha droga, o para ocultar explosivos, armas, municiones, sustancias para producir explosivos y, en general, los instrumentos de comisión de un delito o los bienes y efectos provenientes de su ejecución, ordenará a la policía judicial vigilar esos lugares y esas cosas, con el fin de conseguir información útil para la investigación que se adelanta. [...]“ (dt. Übersetzung d. Verf.).

${ }^{491}$ Art. 241 CPP: „Análisis e infiltración de organización criminal. Cuando el fiscal tuviere motivos razonablemente fundados, de acuerdo con los medios cognoscitivos previstos en este código, para inferir que el indi-
} 
Der Staatsanwalt prüft die Informationen, von denen er Kenntnis erlangt und die darauf hindeuten, dass der Verdächtige oder Beschuldigte einer kriminellen Organisation angehört oder mit einer solchen in Verbindung steht. ${ }^{492}$ Ziel ist es, die Identität der Mitglieder und ihre Aufgaben, primäre und sekundäre Aktivitäten der Gruppe, ihre Vorgehensweise, ihre Kontakte im legalen und illegalen Umfeld, Einsatz von Gewalt, die Interaktion mit anderen kriminellen Gruppen und ihre Finanzierung aufzudecken. Somit soll die Möglichkeit geschaffen werden, den Gruppierungen Einhalt zu gebieten und deren Vermögensgegenstände festzustellen. ${ }^{493}$

Um dies umzusetzen, kann der Staatsanwalt eine erste Anordnung dahingehend erlassen, dass die kriminelle Organisation analysiert wird. Die zweite Anordnung erlässt er erst, wenn sich aus der Analyse ergibt, dass eine verdeckte Ermittlung notwendig ist, um die Ermittlungsziele zu erreichen. Gehen die notwendigen Maßnahmen über den nationalen Raum hinaus, finden die internationalen Vereinbarungen und Instrumente für eine effektive internationale Ermittlungszusammenarbeit Anwendung. Ist eine verdeckte Operation erfolgt, ist innerhalb von 36 Stunden nach deren Beendigung die Angelegenheit dem JCG zur Rechtmäßigkeitsprüfung vorzulegen. ${ }^{494}$

\section{Einsatz verdeckter Ermittler (Art. 242 CPP)}

Nach Art. 242 CPP „kann der Staatsanwalt, wenn er aufgrund der in diesem Gesetz zugelassenen Erkenntnismittel vernünftig fundierte Anhaltspunkte hat, dass der Beschuldigte oder Verdächtige weiterhin kriminelle Handlungen vornimmt, nach vorheriger Genehmigung durch die Nationale Leitung oder Abteilungsleitung der Staatsanwaltschaft den Einsatz verdeckter Ermittler anordnen, sofern dieser für den Erfolg der Ermittlungen unerlässlich ist. ${ }^{\text {‘495 }}$ Nach dem CPP kann ein Mitglied der Kriminalpolizei

\footnotetext{
ciado o el imputado, en la indagación o investigación que se adelanta, pertenece o está relacionado con alguna organización criminal, ordenará a la policía judicial la realización del análisis de aquella con el fin de conocer su estructura organizativa, la agresividad de sus integrantes y los puntos débiles de la misma. Después, ordenará la planificación, preparación y manejo de una operación, para que agente o agentes encubiertos la infiltren con el fin de obtener información útil a la investigación que se adelanta, de conformidad con lo establecido en el artículo siguiente." (dt. Übersetzung d. Verf.).

${ }^{492}$ FGN, 2005, S. 47; dazu KVerfG, Entsch. C-156 v. 2016, Abschn. VI. Abs. 13 f.

${ }^{493}$ KVerfG, C-156 v. 2016, Abschn. VI. Abs. 14 f.; FGN, 2005a, S. 38.

${ }^{494}$ In Analogie zu den Art. 240 und 242 CPP: für die zeitliche Abgrenzung zur richterlichen Kontrolle siehe KVerfG, Entsch, C-239 v. 2012 und C-163 v. 2008, Abschn. „Consideraciones de la Corte“.

495 Art. 242 CPP: „Actuación de agentes encubiertos. Cuando el fiscal tuviere motivos razonablemente fundados, de acuerdo con los medios cognoscitivos previstos en este código, para inferir que el indiciado o el imputado en la investigación que se adelanta, continúa desarrollando una actividad criminal, previa autoriza160
} 
oder sogar eine Privatperson ein verdeckter Ermittler sein. Der verdeckte Ermittler darf unrechtmäßige, aber nicht strafbare Handlungen begehen, Geschäfte ausüben, Verpflichtungen übernehmen, an Treffen mit dem Beschuldigten teilnehmen und mit ihm gemeinsam Geschäfte machen, sofern dies notwendig ist. Verboten ist dem verdeckten Ermittler hingegen Folgendes: eine Straftat begehen, zu provozieren oder anzustiften; Rechtsgüter zu verletzen; das Leben oder die Unversehrtheit einer Person anzugreifen. ${ }^{496}$

Dementsprechend ist das Konzept des verdeckten Ermittlers im CPP ein anderes als das sog. „Agent Provocateur“. Der verdeckte Ermittler ist vielmehr ein außergewöhnliches Kontrollmittel zur Bekämpfung der organisierten Kriminalität. Der Einsatz eines verdeckten Ermittlers hat zwei Voraussetzungen: 1. Es ist zunächst eine „Machbarkeitsstudie“ vorzunehmen, um festzustellen, ob der Einsatz des verdeckten Ermittlers Aussicht auf Erfolg hat; 2. der Befund, dass es sich um einen Fall organisierter Kriminalität handelt und der Beschuldigte oder Verdächtige mit der Organisation in Verbindung steht bzw. dieser angehört, muss sich auf vernünftig fundierte Anhaltspunkte stützen. ${ }^{497}$

\section{Fundierte Anhaltspunkte}

Der Maßnahme müssen vernünftig fundierte Anhaltspunkte (motivos razonablemente fundados) in doppelter Hinsicht zugrunde liegen: 1. Dahingehend, dass der Beschuldigte oder Verdächtige der organisierten Kriminalität angehört oder mit dieser in Verbindung steht; 2. dahingehend, dass der Verdächtige oder Beschuldigte weiterhin kriminelle Handlungen betreibt. Indem das Gesetz darauf Bezug nimmt, dass der Beschuldigte oder Verdächtige ,weiterhin kriminelle Handlungen betreibt“ („,continúa desarrollando una actividad criminal ${ }^{\circ}$ ), soll ausgedrückt werden, dass diese Handlungen zeitlich weiterlaufen und dies hingenommen wird, damit die strafrechtlichen Ermittlungen Erfolg haben können. Diesbezüglich ist klarzustellen, dass Art. 242 CPP einzig darauf abstellt, dass das Ziel des Einsatzes des verdeckten Ermittlers der Erfolg der strafrechtlichen Ermittlungen ist. Der Erfolg der strafrechtlichen Ermittlungen, das Sammeln von Beweisen zwecks Erhebung einer Anklage, ist allerdings der Bereich, auf den der Einsatz der verdeckten Ermittler eher nachrangige Wirkung hat, da tatsächlich das mit dem Einsatz verdeckter Ermittler verfolgte

ción del Director Nacional o Seccional de Fiscalías, podrá ordenar la utilización de agentes encubiertos, siempre que resulte indispensable para el éxito de las tareas investigativas. [...]“ (dt. Übersetzung d. Verf.).

${ }^{496} F G N$, 2005a, S. 38; FGN, 2005, S. 39.

497 Guerrero Peralta, 2007, S. 393; Guerrero Peralta, 2006, S. 143. 
Ziel die Zerschlagung der kriminellen Gruppe ist ${ }^{498}$; 3. die Maßnahme muss unerlässlich sein und die Rechtfertigung ist ferner an der Schwere des aufzuklärenden Delikts zu messen. ${ }^{499}$

\section{Person des verdeckten Ermittlers}

Verdeckte Ermittler können wie schon erwähnt neben den Beamten der Kriminalpolizei auch Privatleute sein. Insoweit ist vor allem für die letzteren relevant, dass Art. 242 Abs. 2 CPP vorsieht, „dass als verdeckter Ermittler auch derjenige handeln kann, der ohne seine Identität zu verschleiern mit dem Verdächtigen oder Beschuldigten vertraut ist bzw. vertraut wird, um relevante Informationen, Beweismittel und physische Nachweise zu

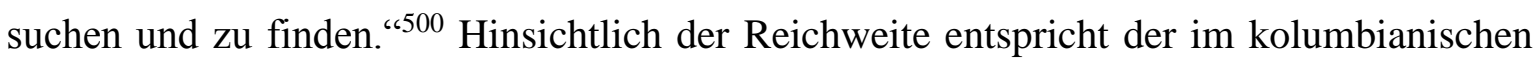
Recht vorgesehene verdeckte Ermittler der deutschen Figur des sog. „V-Manns.“501 Die Vereinbarkeit mit der Verfassung ist dabei auch in Kolumbien umstritten. Nach einer Ansicht ist die Einbeziehung privater Sicherheitskräfte als Infiltranten ein direkter Verstoß gegen Art. 250 CN, welcher der FGN die Aufgabe der Durchführung der Ermittlungen von Straftaten zuteilt. Auch erlaubt Art. $116 \mathrm{CN}$ nicht einmal die Übertragung der Ermittlungstätigkeit auf die Verwaltungsbehörden, woraus man schließen kann, dass es sich um einen Verstoß gegen das Verfassungsrecht handelt, wenn Privatleute in die strafrechtliche Ermittlung einbezogen werden. ${ }^{502}$ Ähnliche Bedenken hat auch das KVerfG geäußert, jedoch ausgeführt:

„(i) Angesichts des erhöhten Risikos, das Privatleute bei der Durchführung der Maßnahme zu tragen haben, ist der Staat verpflichtet, jene nicht nur zu bezahlen, sondern auch zu beschützen; (ii) dieser Schutz darf sich nicht auf Täter oder Teilnehmer von Straftaten erstrecken; (iii) die von diesen [Tätern/Teilnehmern an Delikten] erteilten Informationen sind hinsichtlich des Beschuldigten ohne Beweiswert und (iv) der Staat kann Zivilpersonen nicht zwingen, als Informanten zu dienen. “503

\footnotetext{
${ }^{498}$ Ramírez Jaramillo, 2010, S. 45 f.; krit. Escalante Barreto, 2011, S. 137 ff.

${ }^{499}$ Ramírez Jaramillo, 2010, S. 46; Guerrero Peralta, 2006, S. 143.

500 Art. 242 Abs. 2: „Así mismo, podrá disponerse que actúe como agente encubierto el particular que, sin modificar su identidad, sea de la confianza del indiciado o imputado o la adquiera para los efectos de la búsqueda y obtención de información relevante y de elementos materiales probatorios y evidencia física." (dt. Übersetzung d. Verf.).

${ }^{501}$ I.d.S. Guerrero Peralta, 2007, S. 396; Guerrero Peralta, 2006, S. 143.

502 Guerrero Peralta, 2007, S. 397; Guerrero Peralta, 2006, S. 147.

${ }^{503}$ KVerfG, Entsch. C-673 v. 2005, Abschn. „Consideraciones de la Corte“: „, i ), dado el elevado riesgo que éstos corren, el Estado está en la obligación no sólo de remunerarlos económicamente sino de protegerlos; ( ii 162
} 
Der somit aber grundsätzlich mögliche Einsatz von Privatpersonen als verdeckte Ermittler stellt erhöhte Anforderungen an die Kontrolle durch den JCG. Bei der Bewertung der Infiltrierung ist zum Beispiel auch zu berücksichtigen, dass eine Identitätsänderung des Ermittlers bestimmte Parameter einhalten muss, da der Ermittler mit dieser Identität einerseits im Rahmen der Ermittlungen zu handeln legitimiert ist, andererseits aber auch im rechtlichen und sozialen Umfeld. Insoweit er befähigt ist, Grundrechte von Dritten zu beeinträchtigen, Informationen aus der Intimsphäre von nicht strafrechtlich verfolgten Personen zu erlangen, Geschäfte unter fremder Identität vorzunehmen und vertragliche Verpflichtungen $\mathrm{zu}$ übernehmen etc., muss die Rechtmäßigkeitskontrolle mögliche Exzesse, Willkürhandlungen und Missbräuche der fiktiven Identität mit Wirkungen innerhalb und außerhalb der strafrechtlichen Ermittlung berücksichtigen. ${ }^{504}$

Art. 242 CPP sieht vor, dass der Einsatz verdeckter Ermittler die Dauer von einem Jahr nicht überschreiten darf, wobei der Einsatz um ein weiteres Jahr verlängert werden darf, soweit die Voraussetzungen für den Einsatz eines verdeckten Ermittlers nach wie vor gegeben sind. Wie bei der Personenüberwachung kann der Staatsanwalt aber auch einen Zeitraum von weniger als einem Jahr anordnen. Im Unterschied zur Personenüberwachung sieht die Regelung bei verdeckten Ermittlern eine Notwendigkeit einer nachträglichen Kontrolle durch den JCG auch vor, wenn diese keine Ergebnisse erbracht haben. ${ }^{505}$

In Übereinstimmung mit Art. 241 und 242 CPP wurde Art. 242 A CPP durch das Gesetz 1474 von 2011 eingeführt. Demnach können die in Art. 241 und 242 vorgesehenen Befugnisse genutzt werden, wenn möglicherweise in einer öffentlichen Einrichtung Delikte gegen die öffentliche Verwaltung vorgenommen werden würden. „Wenn ein verdeckter Ermittler bei der Ermittlung von Korruption Delikte gegen die öffentliche Verwaltung mit der Person begeht, gegen die ermittelt wird, ist er von der Strafbarkeit ausgenommen,

\footnotetext{
) dicho amparo no puede extenderse a autores o partícipes de delitos; ( iii ) las versiones suministradas por aquéllos carecen de valor probatorio en cuanto a la responsabilidad del imputado; y ( iv ) el Estado no puede obligar a los miembros de la población civil a convertirse en informantes, so pena de vulnerar el principio de distinción del derecho internacional humanitario." (dt. Übersetzung d. Verf.); i.d.S auch Entsch. C- 392 v. 2000; C- 251 v. 2002.

${ }^{504}$ Ramírez Jaramillo, 2010, S. 50; Guerrero Peralta, 2006, S. 159 ff.

505 Art. 242 Abs. 5 CPP: „En todo caso, el uso de agentes encubiertos no podrá extenderse por un período superior a un (1) año, prorrogable por un (1) año más mediante debida justificación. Si vencido el plazo señalado no se hubiere obtenido ningún resultado, esta se cancelará, sin perjuicio de la realización del control de legalidad correspondiente." (dt. Übersetzung d. Verf.).
} 
außer es existiert eine Absprache zur Begehung der Straftat fernab der verdeckten Ermittlung. "506

\section{III. Überwachung von Übergaben/Lieferungen (entrega vigilada) (Art. 243 CPP)}

Bei der in Art. 243 CPP geregelten Überwachung von Übergaben/Lieferungen geht es um die Überwachung von Überbringungshandlungen bezogen auf Sachen, die Produkte einer Straftat darstellen oder an sich bereits verboten sind. Die Norm ermöglicht die Übergabe/Lieferung innerhalb und sogar außerhalb des Landes, um die Straftat und die Identität des Täters/der Täter aufzudecken (Art. 243 CPP). Für den verdeckten Ermittler oder Infiltranten ist es demgegenüber verboten, bei dem Beschuldigten oder Verdächtigen die Idee der Deliktsbegehung zu „wecken“ (Art. 243 Abs. 2 CPP). ${ }^{507}$ Neben dem Beobachten der Übergabe/Lieferung darf er den betreffenden Gegenstand selbst übergeben oder als Mittelsmann dienen. ${ }^{508}$

Zur Durchführung dieser Ermittlungsmaßnahme können sämtliche technisch verfügbaren und zur Ermittlung geeigneten Mittel verwendet werden, wie zum Beispiel Radargeräte, Bewegungsdetektoren, Nacht- und Infrarotsichtgeräte und Mikrofone zur Überwachung von Konversation, solange sie im offenen Raum verwendet werden und hierdurch nicht die vernünftige Erwartung auf Wahrung der Intimsphäre verletzt wird. Der Staatsanwalt kann dabei besondere Überwachungsmaßnahmen anordnen, wenn es sich um Operationen handelt, die ihren Ursprung im Ausland haben (Art. 243 Abs. 3 CPP).

\section{IV. Überprüfungsanhörung}

Der Art. 243 Abs. 5 CPP verlangt, dass ,innerhalb von 36 Stunden nach Durchführung der Lieferung/Übergabe [...] die gewonnenen Resultate von dem Staatsanwalt dem Richter zur

\footnotetext{
506 Art. 242 A Abs. 2 CPP: „Cuando en investigaciones de corrupción, el agente encubierto, en desarrollo de la operación, cometa delitos contra la Administración Pública en coparticipación con la persona investigada, quedará exonerado de responsabilidad, salvo que exista un verdadero acuerdo criminal ajeno a la operación encubierta, mientras que el indiciado o imputado responderá por el delito correspondiente." (dt. Übersetzung d. Verf.).

${ }^{507}$ Art. 243 Abs. 2 CPP: „En estos eventos, está prohibido al agente encubierto sembrar la idea de la comisión del delito en el indiciado o imputado. Así, sólo está facultado para entregar por sí, o por interpuesta persona, o facilitar la entrega del objeto de la transacción ilegal, a instancia o por iniciativa del indiciado o imputado." (dt. Übersetzung d. Verf.).

${ }^{508} F G N, 2005$ a, S. 38; FGN, 2005, S. 40. 
Kontrolle der formellen und materiellen Rechtmäßigkeit vorzulegen [sind]. ${ }^{* 509}$ Da es sich hier um eine Maßnahme handelt, die den in Art. 237, 242 und 244 CPP geregelten Maßnahmen ähnelt, ergibt die analoge und systematische Auslegung, dass die Regeln für Hausdurchsuchungen auch hier anzuwenden sind. Insoweit keine besonderen Regeln für den Ablauf der Anhörung zur Kontrolle der Rechtmäßigkeit der Überwachung von Lieferungen/Übergaben bestehen, kann auf die diesbezüglichen Regelungen des Art. 237 CPP zurückgegriffen werden. ${ }^{510}$

Daher führt der JCG zunächst eine formelle Kontrolle durch, in der die Gründe der Staatsanwaltschaft zur Durchführung der Maßnahme, die Durchführung einer Vorabprüfung, die die Durchführung der Maßnahme rechtfertigt, und die Erteilung der Genehmigung durch die nationale Leitung oder Abteilungsleitung der FGN geprüft werden. Vor allem soll aber auch geprüft werden, ob die Maßnahme absolut unerlässlich für den Erfolg der Ermittlungen war. Im zweiten Schritt ist eine materielle Kontrolle vorzunehmen, in deren Rahmen der Staatsanwalt die bei der Operation erlangten Ergebnisse vorzulegen hat. Auf dieser Grundlage überprüft der JCG die Art und Weise, wie diese Ergebnisse erlangt wurden. Selbstverständlich sind an dieser Stelle die Schranken der im Rahmen der Überwachung erlaubten Handlungen zu berücksichtigen (geschäftliche Handlungen, Teilnahme an Treffen mit dem Beschuldigten, Anfertigen von Fotoaufnahmen etc.) und insbesondere, ob alle vorgenommenen Handlungen vom Umfang der Anordnung gedeckt waren oder auch Handlungen vorgenommen wurden, die nicht autorisiert waren. ${ }^{511}$

Ein vor dem KVerfG stark umstrittener Aspekt ist, ob auch bei dieser Art von Anhörung das Recht des Beschuldigten auf Verteidigung zu wahren ist. Für das KVerfG ,ist es keinesfalls gerechtfertigt, dass die Person, gegen die ermittelt wird, erst in dem Moment bei der Anhörung zur Kontrolle der Garantien teilnehmen darf, wenn sie bereits beschuldigt ist, d.h., wenn die betreffenden Maßnahmen im Ermittlungsverfahren

\footnotetext{
${ }^{509}$ Art. 243 Abs. 5 CPP: „En todo caso, una vez concluida la entrega vigilada, los resultados de la misma y, en especial, los elementos materiales probatorios y evidencia física, deberán ser objeto de revisión por parte del juez de control de garantías, lo cual cumplirá dentro de las treinta y seis (36) horas siguientes con el fin de establecer su legalidad formal y material.“ (dt. Übersetzung d. Verf.). Dazu Bernal Cuellar/Montealegre Lynett, 2013 T. II, S. 272; Guerrero Peralta, 2006, S. 152; krit. bzgl. der Regeln zur Überwachung von Übergaben/Lieferungen Morales Támara, 2009, S. $249 \mathrm{ff}$.

${ }^{510}$ KVerfG, Entsch. C-025 v. 2009, Abschn. 6.5.

${ }^{511}$ Guerrero Peralta, 2006, S. 152; krit. dazu Morales Támara, 2009, S. 252.
} 
durchgeführt werden, und dies dagegen nicht der Fall ist, wenn die gleichen Maßnahmen bereits im Rahmen des Vorermittlungsverfahrens durchgeführt wurden. “5512

Des Weiteren ist das KVerfG der Auffassung, dass das Recht auf Verteidigung bei diesem Anhörungstyp nicht bereits durch die Kontrolle durch den JCG gewährleistet ist, der die von der FGN im Rahmen der verdeckten Ermittlungen erlangten Beweismittel prüft. Denn die Verteidigung des Verdächtigen kann nicht durch die Arbeit des JCG ersetzt werden, da es dessen Funktion ist, Willkür der Ermittlungsbehörden zu vermeiden. Die Aufgabe der Verteidigung geht darüber hinaus, da sie ab Beginn des Verfahrens die Verwertbarkeit der Beweise anzweifelt, die den Verdächtigen auf vorläufiger Basis mit dem Delikt, wegen dem ermittelt wird, in Zusammenhang bringen. ${ }^{513}$

\section{Zusammenfassung}

In der ersten Gruppe von Maßnahmen, die intensive Grundrechtsbeeinträchtigungen bewirken, sind diejenigen enthalten, die das Recht auf Privatsphäre beschränken, namentlich die Hausdurchsuchungen (Art. 219-232 CPP), die Personenüberwachung (Art. 239 CPP) und die verdeckten Ermittlungen (Art. 241-243 CPP). Bei den Hausdurchsuchungen ist nicht nur der physische Raum als solcher, sondern auch die Privatsphäre, die sich in ihm entfaltet, geschützt. Für die Anordnung der Maßnahme muss eine ausreichende Indizienlage vorliegen (zumutbare fundierte Anhaltspunkte) und bei der Rechtmäßigkeitskontrolle erfolgt eine formelle (Anordnung der Maßnahme) und materielle (Ausmaß der Grundrechtsbeeinträchtigung) Überprüfung der Maßnahme. Der Verstoß der gesetzlichen Voraussetzungen führt dazu, dass die Maßnahme unwirksam ist und folglich die durch sie erlangten Beweismittel und physischen Nachweise nicht verwertbar sind (Art. 232 CPP). Der CPP systematisiert nicht die Voraussetzungen der Anordnung einer Hausdurchsuchung, aber dieselbe wurde von dem KVerfG (Entsch. C-591 v. 2005) bestimmt. In dem subjektiven Schutzrahmen bezieht sich Art. 220 CPP auf zwei Kategorien: einerseits auf den Eigentümer oder Besitzer und andererseits auf denjenigen, der sich vorübergehend in dem Objekt aufhält. Ausnahmsweise erlaubt der CPP die Durchführung dieser Maßnahme ohne Anordnung (Art. 230 CPP) unter den folgenden Umständen: beim Einverständnis des

\footnotetext{
512 KVerfG, Entsch. C-025 v. 2009, Abschn. 6.10.: „,carece de la más mínima justificación que sólo se permita la presencia del investigado en la audiencia de control de garantías a partir del hecho de haber adquirido la calidad de imputado, es decir, cuando las diligencias se han llevado a cabo durante la etapa de investigación, y no ocurra la mismo cuando las diligencias se practican en la etapa de indagación, teniendo el investigado la condición de indagado." (dt Übersetzung des Verf.).

${ }^{513}$ KVerfG, Entsch. C-025 v. 2009, Abschn. 6.11. 
Rechtsinhabers des beeinträchtigten Guts oder desjenigen, der ein durch die Durchführung der Maßnahme beeinträchtigtes Interesse hat; beim fehlenden Vorliegen einer vernünftigen Erwartung eines Eingriffs in die Intimitätssphäre und bei Notfallsituationen. Die Entscheidung vom JCG ist somit in drei Varianten denkbar: 1. Wirksamkeit der Maßnahme; 2. Nichtigkeit der Maßnahme und daher Ausschluss aus dem Prozess (Unverwertbarkeit); 3. Korrektur der rechtswidrigen, aber nicht mit Nichtigkeit sanktionierten Handlungen.

Diesen Voraussetzungen unterliegen auch Maßnahmen wie die Personenüberwachung (Art. 239 CPP) und die Überwachung von Sachen (Art. 240 CPP). Aus den vernünftig fundierten Anhaltspunkten muss sich ergeben, dass der Verdächtige oder Beschuldigte zu ermittlungsrelevanten Informationen führen kann. Bei der Rechtmäßigkeitskontrolle ist zu prüfen, ob vernünftig fundierte Anhaltspunkte und Indizien gegen den Verdächtigen oder Beschuldigten vorlagen und die mit der Maßnahme gesuchten Informationen gemessen am Stand der Ermittlungen relevant sind und ob der nach der Prüfung der Anordnung genehmigte Rahmen der Maßnahme bei ihrer Durchführung eingehalten wurde. Für die Anordnung des Einsatzes eines verdeckten Ermittlers (Art. 241-243 CPP) muss aus den fundierten Anhaltspunkten das Verhältnis des Verdächtigen oder Beschuldigten mit der organisierten Kriminalität und die Begehung einer kriminellen Aktivität in der Ausführung hergeleitet werden. Obwohl die Anhörung zur Kontrolle der Garantien reserviert werden könnte, ist die h.M. der Auffassung, dass das Recht auf Verteidigung nicht durch den JCG ersetzt werden dürfe und der Verdächtige die Möglichkeit haben müsse, dieses Recht so schnell wie möglich auszuüben. 


\section{§ 6. Nachträglicher Rechtsschutz gegen Maßnahmen zur Beschränkung der Unverletzlichkeit der Kommunikation und der Freiheit}

\section{A. Eingriff in die postalische Kommunikation (Art. 233 CPP)}

\section{Grundlagen}

Art. 233 CPP erlaubt es der FGN, der Kriminalpolizei anzuordnen, private postalische, telegrafische oder sonstige Korrespondenz, die der Beschuldigte oder Verdächtige erhalten soll, zurückzuhalten. Nach Art. 233 Abs. 2 sind die gleichen Regeln wie bei der Hausdurchsuchung zu beachten. ${ }^{514}$

\section{Rechtmäßigkeit des Gegenstandes der Maßnahme}

Die kolumbianische Starfprozessrechtsdoktrin geht davon aus, dass die postalische Überwachung über Briefe hinausgeht und alle Formen postalischer Kommunikation erfasst, wie zum Beispiel verschlossene Pakete, die Träger persönlicher oder geschäftlicher Nachrichten sein können. In diesem Sinne unterscheidet man die durch das Kommunikationsgeheimnis geschützte und nicht geschützte Korrespondenz. ${ }^{515}$ Unter geschützte Korrespondenz fallen Briefe und verschlossene Pakete. Offene Pakete dagegen dürfen auf Grundlage der vertraglichen Beziehung zu dem mit der Zustellung beauftragten Dienstleister von diesem eingesehen werden mit dem Ziel der Überprüfung, ob sich das darin Befindliche im Rahmen des Zulässigen bewegt. ${ }^{516}$

Die Grenzen des Kommunikationsgeheimnisses sind dabei allerdings sehr umstritten. Es wird dabei vertreten, dass jede Schutzbereichseinschränkung diesbezüglich in Übereinstimmung mit der allgemeinen Grundrechtstheorie eng auszulegen ist. ${ }^{517}$ Auseinandersetzungen hat auch die permanente und intensive Kontrolle von Koffern und Taschen beim Transport hervorgerufen. Der fehlende Schutz dieses Gepäcktyps wird damit gerechtfertigt, dass man anführt, es handele sich dabei nicht um postalische Kommunikation. Dagegen kann hier aber genauso das Recht auf Wahrung der Intimsphäre verletzt werden, da auch Koffer und Taschen schützenswerte Dinge, wie zum Beispiel

\footnotetext{
514 Art. 233 Abs. 2 CPP: „En estos casos se aplicarán analógicamente, según la naturaleza del acto, los criterios establecidos para los registros y allanamientos.“ („In diesen Fällen werden je nach der Rechtsnatur der Handlung die Kriterien für die Durchsuchungen analog angewendet") (Übersetzung d. Verf.).

515 Guerrero Peralta, 2007, S. 364; Guerrero Peralta, 2006, S. 109.

516 Guerrero Peralta, 2007, S. 364; Guerrero Peralta, 2006, S. 110.

517 Guerrero Peralta, 2007, S. 365; Guerrero Peralta, 2006, S. 110.
} 
geheime Dokumente, enthalten können. Für diese Fälle wird daher von anderer Seite vertreten, dass die Regeln der Hausdurchsuchung einzuhalten sind, sodass pauschal ausforschende Untersuchungen nicht möglich sind und die Grundrechte verletzen. ${ }^{518}$ Ferner ist auch zwischen dem Zurückhalten von Korrespondenz und der Überwachung einer Übergabe/Lieferung im Sinne des Art. 243 CPP zu unterscheiden. Nach der UN Drogenkonvention von 1988, die von Kolumbien ebenfalls unterzeichnet wurde, kann der Begriff „Zurückhaltung von Korrespondenz“ (retención de correspondencia) nicht angewendet werden, wenn die Überwachung der Lieferung/Übergabe die physische Beobachtung des postalischen Verlaufs einer Sendung ist, die keine für die Strafverfolgungsbehörden bekannte Person zum Empfänger hat. ${ }^{519}$

\section{Gegenstand des Eingriffs in die postalische Kommunikation (Art. 233 CPP)}

Art. 233 Abs. 3 CPP sieht vor, dass ,von den entsprechenden Büros Kopien der Nachrichten verlangt werden dürfen, die an den Beschuldigten oder Verdächtigen versandt wurden“. ${ }^{520}$ Indem hier auf Kopien der versendeten/empfangenen Nachrichten Bezug genommen wird, liegt keine Zurückhaltung im eigentlichen Sinne vor, sondern ein Eingriff in eine tatsächlich zugegangene Korrespondenz, deren Inhalt offenbart wird. ${ }^{521}$ Wenn demzufolge die Art dieses Vorgehens anstelle von Zurückhaltung von postalischer Kommunikation als Kommunikationsüberwachung (Art. 235 CPP) einzuordnen ist, dann reicht eine einfache Anordnung, die Korrespondenz zurückzuhalten, nicht aus. Vielmehr ist diese den Postdiensten zuzustellen, die dann verpflichtet sind, eine Kopie auszustellen, wie es in Art. 235 CPP vorgesehen ist.

Art. 233 Abs. 4 CPP sieht vor, „dass mit dem gleichen Verfahren auch angeordnet werden kann, dass Botendienste einen Bericht über die Sendungen liefern, die von dem

\footnotetext{
${ }^{518}$ Aponte Cardona, 2006, S. 84; FGN, 2005, S. 36.

519 Wiener Übereinkommen von 1988, Art. 1 g): „der Ausdruck „kontrollierte Lieferung“ bezeichnet die Methode, aufgrund derer unerlaubte oder verdächtigte Sendungen von Suchtstoffen, psychotropen Stoffen, in Tabelle I und Tabelle II zu diesem Übereinkommen aufgeführten Stoffen oder Austauschstoffen mit Wissen und unter Aufsicht der zuständigen Behörden aus dem Hoheitsgebiet eines oder mehrerer Staaten verbracht, durch dasselbe durchgeführt oder in dasselbe verbracht werden dürfen mit dem Ziel, Personen zu ermitteln, die an der Begehung von in Übereinstimmung mit Artikel 3 Absatz 1 umschriebenen Straftaten beteiligt sind; [...]“

${ }^{520}$ Art. 233 Abs. 3 CPP: „Así mismo, podrá solicitarse a las oficinas correspondientes copia de los mensajes transmitidos o recibidos por el indiciado o imputado.“(dt. Übersetzung d. Verf.).

${ }^{521}$ I.d.S. Guerrero Peralta, 2007, S. 366; Guerrero Peralta, 2006, S. 111, für den die Kommunikationsüberwachungsbestimmungen zur Rechtmäßigkeitskontrolle gehören sollen. 
Verdächtigen oder Beschuldigten gemacht wurden. ${ }^{\text {(522 }}$ Die Kenntnis der Existenz postalischer Kommunikation, ohne in diese einzugreifen, ist im Hinblick auf den Schutz der Intimsphäre und das Kommunikationsgeheimnis umstritten, vor allem in den Fällen sog. ,comptage“ oder ,pen register“. Hierbei handelt es sich um den Einsatz technischer Geräte, die die angewählte Nummer sowie den Zeitpunkt und die Dauer des Anrufs festhalten, ohne dabei den Inhalt des Gesprächs aufzuzeichnen. ${ }^{523}$ So geben beispielsweise die Telekommunikationsunternehmen den Nutzern die Möglichkeit, ihrer Telefonrechnung Tag, Uhrzeit, Dauer und Nummer des Gesprächspartners zu entnehmen. Auch in diesen Fällen sind Identität, Adresse und sonstige Informationen der an der Kommunikation beteiligten Personen nur solange geschützt, bis die FGN ausreichend fundierte Anhaltspunkte hat anzunehmen, dass für die Ermittlungen nützliche Informationen enthalten sind (Art. 233 Abs. 1 CPP). Nur auf Grundlage einer ausreichend begründeten Erwartung, etwas Ermittlungsrelevantes zu finden, ist es erlaubt, über Art. 233 CPP in Grundrechte einzugreifen.

\section{Ausführung des Eingriffs in die postalische Kommunikation}

Ziel der Zurückhaltung der Korrespondenz ist es $\mathrm{zu}$ verhindern, dass diese ihren Empfänger erreicht, wenn begründete Anhaltspunkte existieren, dass der Inhalt ermittlungsrelevant ist. Nach Art. 234 Abs. 1 CPP „untersucht die Kriminalpolizei die zurückgehaltene Korrespondenz und unterrichtet innerhalb von 12 Stunden den Staatsanwalt, der die Anordnung erlassen hat, falls sie Beweismaterial findet, welches sich für die Ermittlungen als relevant erweist.“524 Art. 234 Abs. 2 CPP sieht vor, „dass, wenn es sich um eine Code-Schrift oder Schrift in fremder Sprache handelt, unverzüglich die Enkodierung durch einen Gutachter bzw. die Übersetzung anzuordnen ist. “525 Nach Absatz 3 ist „im Falle, dass durch diese Überprüfung Informationen über ein anderes Delikt erlangt werden, eine Ermittlung einzuleiten oder die Post unter Bewachung an denjenigen

\footnotetext{
522 Art. 233 Abs. 4 CPP: „Similar procedimiento podrá autorizarse para que las empresas de mensajería especializada suministren la relación de envíos hechos por solicitud del indiciado o imputado o dirigidos a él.“ (dt. Übersetzung d. Verf.).

${ }^{523}$ Guerrero Peralta, 2006, S. 111. Für eine rechtsvergleichende Anaylse der staatlichen Abhörmaßnahmen bei Voice over IP (insb. Pen Register) zwischen Deutschland und den USA s. Gorgass, 2011, S. $148 \mathrm{ff}$.

${ }^{524}$ Art. 234 Abs. 1 CPP: „Examen y devolución de la correspondencia. La policía judicial examinará la correspondencia retenida y si encuentra elementos materiales probatorios y evidencia física que resulten relevantes a los fines de la investigación, en un plazo máximo de doce (12) horas, informará de ello al fiscal que expidió la orden." (dt. Übersetzung d. Verf.).

${ }^{525}$ Art. 234 Abs. 2 CPP: „Si se tratare de escritura en clave o en otro idioma, inmediatamente ordenará el desciframiento por peritos en criptografía, o su traducción.“( (dt. Übersetzung d. Verf.).
} 
weiterzuleiten, der die Ermittlungen vornimmt. ${ }^{\text {“526 }}$ Schließlich ordnet die Regelung an, „dass die zurückgehaltene und für die Ermittlungen nicht mehr relevante Korrespondenz zurückzugeben ist, sobald die Beschuldigung erhoben wurde. “527

Die Kenntnisnahme des Inhalts der Sendung zur Erlangung einer Ermittlungsquelle oder eines Beweises stellt die Grenzen des Eingriffs dar. D.h., der verfassungsrechtliche Schutz des Grundrechts des Kommunikationsgeheimnisses und der Intimsphäre erlaubt den Eingriff nur, insoweit er dazu dient, die Beweislage für eine Beschuldigung bzw. Anklage zu stützen. ${ }^{528}$ Die vernünftig fundierten Anhaltspunkte zur Anordnung des Eingriffs müssen sich dabei aus den im CPP vorgesehenen Erkenntnismitteln ergeben. Zulässige Erkenntnismittel sind beispielsweise diejenigen Beweismittel und physischen Nachweise, die in der Vorermittlung gesammelt wurden (Art. 275 CPP), die Ergebnisse der Ermittlungen eines verdeckten Ermittlers (Art. 279 CPP), die sich aus der Überwachung einer Übergabe/Lieferung ergeben oder die Erkenntnisse aus der Vernehmung des Verdächtigen. Der JCG muss bei der Prüfung der Rechtmäßigkeit der Maßnahme diese zwei Komponenten berücksichtigen, d.h. erstens prüfen, ob vernünftig fundierte Anhaltspunkte auf Grundlage zulässiger Erkenntnismittel vorliegen und zweitens, ob zu erwarten war, dass mit der Durchführung der Maßnahme ermittlungsrelevante Ergebnisse erlangt werden.

\section{B. Telefonüberwachung}

\section{Verfassungsproblematik}

Die Telefonüberwachung ist in Art. 235 CPP geregelt und wurde durch das Dekret 1704 von 2012 weiter ausgestaltet. Nach Art. 1 des Dekrets 1704 von 2012 ,ist die Kommunikationsüberwachung, gleich welchen technischen Ursprungs sie ist, ein Mechanismus der öffentlichen Sicherheit, welcher darauf abzielt, die Ermittlungsarbeit der Behörden und zuständigen Organe im gesetzlichen und verfassungsrechtlichen Rahmen zu

\footnotetext{
${ }^{526}$ Art. 234 Abs. 3 CPP: „Si por este examen se descubriere información sobre otro delito, iniciará la indagación correspondiente o bajo custodia la enviará a quien la adelanta.“ (dt. Übersetzung d. Verf.).

${ }^{527}$ Art. 234 Abs. 4 CPP: „Una vez formulada la imputación, o vencido el término fijado en el artículo anterior, la policía judicial devolverá la correspondencia retenida que no resulte de interés para los fines de la investigación.“ (dt. Übersetzung d. Verf.).

${ }^{528}$ Vgl. Guerrero Peralta, 2006, S. 112; dazu Bernal Cuellar/Montealegre Lynett, 2013 T. II, S. 254 ff. m.w.N. 
optimieren. ${ }^{\text {"529 }}$ Es handelt sich bei der Telefonüberwachung um ein Verfahren, in dem per Funk oder Telefon übertragene Gesprächsinhalte aufgenommen werden, um ermittlungsrelevante Informationen zu erhalten. ${ }^{530}$

Dabei handelt es sich um einen Eingriff in die durch Art. $15 \mathrm{CN}$ geschützte Kommunikationsfreiheit. Jedoch wird durch die Telefonüberwachung zusätzlich auch das Recht auf Wahrung der Intimsphäre berührt. Die Rechtslehre erkennt einen Unterschied zwischen Recht auf Wahrung der Intimsphäre und dem Kommunikationsgeheimnis dahingehend an, dass ersteres materiellen Charakters ist und den vertraulichsten Bereich des Individuums schützt. Das Kommunikationsgeheimnis ist demgegenüber formeller Art, da es die Kommunikation unabhängig davon schützt, ob ihr Inhalt geheimer Art ist oder nicht. $^{531}$

Indem die Verfassung in Art. 15 Abs. 3 anerkennt, dass „die Korrespondenz und andere Formen der Kommunikation unverletzlich sind“ (La correspondencia y demás formas de comunicación privada son inviolables), legt sie zugleich fest, dass es keine unterschiedlichen Voraussetzungen abhängig von der Art der Kommunikation geben darf. ${ }^{532}$ Unabhängig davon, welche Art der Kommunikation vorliegt und welche Technik daher $\mathrm{zu}$ ihrer Überwachung verwendet wird, müssen die für den Eingriff in das Kommunikationsgeheimnis gemäß Art. 235 CPP geltenden Voraussetzungen gewahrt werden. Allerdings wird Art. 235 CPP dahingehend kritisiert, dass die Eingriffe in das Kommunikationsgeheimnis nur unzureichend ausgestaltet sind. Zum einen gibt die Norm nämlich keine Einschränkungen hinsichtlich der Personen vor, die von dem Eingriff erfasst werden dürfen, was impliziert, dass die FGN ungehindert abhören darf, gleich wer an der Kommunikation beteiligt ist. ${ }^{533}$ Zum anderen sieht die Regelung - im Unterschied zum

\footnotetext{
${ }^{529}$ Art. 1 des Dekrets 1704 von 2012: „Definición de interceptación legal de comunicaciones. La interceptación de las comunicaciones, cualquiera que sea su origen o tecnología, es un mecanismo de seguridad pública que busca optimizar la labor de investigación de los delitos que adelantan las autoridades y organismos competentes, [...].“ (dt. Übersetzung d. Verf.).

${ }^{530}$ Für eine Begriffsbestimmung der Telekommunikationsüberwachung im kolumbianischen Strafverfahrensrecht vgl. KVerfG, Entsch. C-594 v. 2014, Abschn. 3.6.; Bernal Cuellar/Montealegre Lynett, 2013 T. II, S. 279 ff.; Escalante Barreto, 2011, S. 147, 174; FGN, 2005a, S. 36; i.d.S. siehe die Legaldefinition des $\$ 3 \mathrm{Nr}$. 2222 i.V.m. Nr. 23 TKG.

531 Vgl. KVerfG, Entsch. SU-056 v. 1995 ; T-340 v. 1993 ; T-729 v. 2002; T-220 v. 2004; T-453 v. 2005; T158 A v. 2008; C-053 v. 2001, Abschn. „Consideraciones de la Corte“.

${ }^{532}$ Vgl. KVerfG, Entsch. C-131 v. 2009, Abschn. „Consideraciones de la Corte“ und C-594 v. 2014, Abschn. 3.6.3. La necesidad de control de las interceptaciones.

${ }^{533}$ Guerrero Peralta, 2006, S. 120.
} 
Eingriff in das Postgeheimnis, für welchen fundierte Anhaltspunkte vorliegen müssen keine vergleichbaren Eingriffsvoraussetzungen vor. Daraus könnte geschlossen werden, dass die FGN intuitiv, ohne konkrete Anhaltspunkte zu haben, private Kommunikation aufnehmen darf. ${ }^{534}$ Darüber hinaus gestaltet die Norm auch nicht die Durchführung der Maßnahme aus, sodass die Grundrechte von Dritten, gegen die nicht ermittelt wird, nicht ausreichend geschützt sind. ${ }^{535}$

\section{Voraussetzungen}

\section{Zweck und Gegenstand der Überwachung}

Art. 235 CPP bestimmt, dass eine Anordnung zur Telekommunikationsüberwachung nur zu dem Zweck erlassen werden darf, Beweismittel und physische Nachweise zu erlangen sowie den Verdächtigen, Beschuldigten oder Verurteilten zu lokalisieren. An der Norm wird kritisiert, dass sie zu unbestimmt hinsichtlich des Zwecks der Überwachung sei. Wenn die Überwachung mit dem Ziel, physische Nachweise oder Beweismittel zu erlangen, vorgenommen wird, dann hat die Norm allerdings ein sehr begrenztes Ziel. ${ }^{536}$ Auf dieser Grundlage wird gefordert, dass dann die Anordnung der Maßnahme das spezifizieren muss, was mit ihr erreicht werden soll, beispielsweise ob es darum geht, den Ort eines Drogenverstecks aufzudecken oder eine Mordwaffe zu finden. Somit würde die Überwachung also weiter eingegrenzt werden. Schließlich bestimmt die Norm auch, dass nur die Kommunikation überwacht werden darf, die von Interesse für die Ermittlungen ist. Folglich müssen dem Staatsanwalt begründete Anhaltspunkte dafür vorliegen, dass die Überwachung ermittlungsrelevante Informationen liefert, beispielsweise ob der vermeintliche Täter des Delikts eine bestimmte Nummer oft anruft. Nur wenn man die Norm so interpretiert, dass das Ziel der Überwachung begrenzt sein muss und der Staatsanwalt Anhaltspunkte haben muss, dass das Ziel der Überwachung auch erreicht werden kann, ist es möglich, eine ausufernde Überwachung zu vermeiden. ${ }^{537}$

\footnotetext{
${ }^{534}$ Guerrero Peralta, 2006, S. 120.

${ }^{535}$ Guerrero Peralta, 2006, S. 120.

${ }^{536}$ Welches in der Absicht besteht, an die auf die Begehung des Delikts schließenden Beweismaterialien zu gelangen, wie sie in Art. 275 CPP ausdrücklich aufgezählt sind. Vgl. Guerrero Peralta, 2007, S. 373; dazu Escalante Barreto, 2011, S. $175 \mathrm{ff}$.

${ }^{537}$ Guerrero Peralta, 2007, S. 374; gegen unbegrenzte Überwachungen hat die Rechtsprechung des KVerfG eine klare Stellung eingenommen. Vgl. Entsch. SU-159 v. 2002, Abschn. „Consideraciones de la Corte“. 


\section{Subjektiver Anwendungsbereich der Maßnahme}

Auch wenn Art. 235 CPP nicht genau festlegt, in wessen Kommunikation mit der Überwachung eingegriffen werden darf, ist für die h.M. klar, dass diese Person nur diejenige sein könne, gegen die das Ermittlungsverfahren gerichtet sei. ${ }^{538}$ Umstritten ist deshalb die Überwachung von Kommunikationen dritter Personen, gegen die nicht ermittelt wird, die aber mit dem Beschuldigten, ohne von dem Ermittlungsverfahren zu wissen, ein Gespräch führen. Ebenso hoch umstritten ist die Überwachung der Personen, die der strafrechtlichen Ermittlung im konkreten Fall völlig fremd sind, wie es zum Beispiel bei der Überwachung eines Telefonanschlusses vorkommen kann, von dem aus nicht nur der Beschuldigte Anrufe tätigt, sondern auch andere Personen, sodass unter anderem Gespräche abgehört werden, an denen der Verdächtige/Beschuldigte überhaupt nicht beteiligt ist. Die h.M. schlägt hier als einzige Lösung vor, dass ausreichend qualitative und quantitative Gründe vorliegen müssen, damit die FGN die Maßnahme durchführen darf. ${ }^{539}$ Außerdem wird von demjenigen, der die Maßnahme durchführt, verlangt, dass er eine Relevanzprüfung hinsichtlich des abgehörten Inhalts vornimmt. Denn das Abhören privater Kommunikation, die ohne Relevanz für die Ermittlungen ist, überschreitet die Grenzen des rechtlich Zulässigen und würde die Überwachung rechtswidrig machen. Ebenfalls rechts- und verfassungswidrig ist es, die Kommunikation eines Zeugen abzuhören. ${ }^{540}$

Art. 235 CPP lässt offen, mit welchen Mitteln die Überwachung durchgeführt werden darf, indem er besagt: durch Tonbandaufnahmen oder Ähnliches (grabación magnetofónica o similares). Ferner darf nach Art. 235 CPP einzig Telekommunikation überwacht werden, d.h. lediglich Kommunikation auf elektromagnetischem Wege wie Telefongespräche, Gespräche über Funk etc., wohingegen es nicht von Art. 235 CPP gedeckt ist, ein Gespräch zwischen anwesenden Personen aufzunehmen. ${ }^{541}$ Die Norm sieht eine zulässige Dauer von 3 Monaten vor, welche verlängert werden darf, falls die Voraussetzungen, die die anfängliche Überwachung gerechtfertigt haben, weiterhin vorliegen.

\footnotetext{
538 Vgl. Guerrero Peralta, 2007, S. 374; Bernal Cuellar/Montealegre Lynett, 2013 T. II, S. 281; Aponte Cardona, 2006, S. 87.

539 Guerrero Peralta, 2007, S. 374; Aponte Cardona, 2006, S. 86; FGN, 2005, S. 36; KVerfG, Entsch. C-131 v. 2009, Abschn. 6.6; C-594 v. 2014, Abschn. 3.6.4.11.

${ }^{540}$ So wäre es zu Beispiel rechtswidrig, wenn man die Richtigkeit der Angaben eines Informanten dadurch zu bestätigen versuchen würde, indem man seine Telefongespräche abhören würde. Guerrero Peralta, 2007, S. 375; dazu KVerfG, Entsch. C-1024 v. 2002, Abschn. 3.4.

${ }^{541}$ Guerrero Peralta, 2007, S. 375; dazu Bernal Cuellar/Montealegre Lynett, 2013 T. II, S. 284.
} 


\section{Dekret 1704 von 2012}

Die Regelungen zur Kommunikationsüberwachung werden durch Dekret 1704 von 2012 komplementiert. Wie bereits erwähnt ist gem. Art. 1 „die Kommunikationsüberwachung, gleich welchen technischen Ursprungs sie ist, ein Mechanismus der öffentlichen Sicherheit, welcher darauf abzielt, die Ermittlungsarbeit der Behörden und zuständigen Organe im gesetzlichen und verfassungsrechtlichen Rahmen zu optimieren. “542 Art. 4 des Dekrets sieht vor, dass die Anbieter von Telekommunikationsnetzen und -diensten verpflichtet sind, der Staatsanwaltschaft die Daten ihrer Nutzer wie deren Identität, Rechnungsadresse und die Art der Telekommunikationsverbindung zur Verfügung zu stellen. ${ }^{543}$ Die Anbieter sind dabei ebenfalls verpflichtet, diese Daten aktuell zu halten und 5 Jahre lang aufzubewahren. Ferner haben die Anbieter gemäß Art. 5 des Dekrets „der FGN die Daten zu übermitteln, die zur Lokalisierung des Standorts der an der Telekommunikation beteiligten Endgeräte notwendig sind, d.h. geographische Daten, Signalstärke etc." ${ }^{\text {5 } 44}$

\section{Nachträgliche gerichtliche Überprüfungsanhörung}

Bei der nachträglichen Kontrolle der Telefonüberwachung und des Eingriffs in die postalische Kommunikation ist die Prüfung des Vorliegens vernünftig fundierter Anhaltspunkte wesentlich, d.h. die Prognose, etwas zu finden, und der Nutzen der gewählten Maßnahme aufgrund der Vorermittlungen durch den Staatsanwalt. In dieser Hinsicht muss der Staatsanwalt wie auch bei einer Hausdurchsuchung (Art. 221 CPP) mit den zulässigen Erkenntnismitteln seinen Befund stützen, d.h. zum Beispiel mit dem Polizeibericht oder einer Zeugen- oder Informantenaussage. Stützt er sich auf die Angaben eines Informanten, muss er die Identität des Informanten kennen und die Gründe, aus

\footnotetext{
${ }^{542}$ Art. 1 Dekret 1704 von 2012: „[...] la interceptación de las comunicaciones, cualquiera que sea su origen o tecnología, es un mecanismo de seguridad pública que busca optimizar la labor de investigación de los delitos que adelantan las autoridades y organismos competentes, en el marco de la Constitución y la Ley.“ (dt. Übersetzung d. Verf.). Für die gesetzliche Ausgestaltung der Telekommunikationsüberwachung in Deutschland vgl. Bratke, 2013, S. 104 ff.; bzgl. Ermittlungsmaßnahmen über das Internet Schön, 2013, S. 83 ff.; zum Zugriff auf Emails Meininghaus, 2007, S. 5 ff.

${ }^{543}$ Art. 4 Dekret 1704 von 2012: ,[...] Los proveedores de redes y servicios de telecomunicaciones, [...], deberán suministrar a la Fiscalía General de la Nación o demás autoridades competentes, [...], los datos del suscriptor, tales como identidad, dirección de facturación y tipo de conexión. [...]“ (dt. Übersetzung d. Verf.).

544 Art. 5 Dekret 1704 von 2012: „[...] Los proveedores de redes y servicios de telecomunicaciones, [...], deberán suministrar a la Fiscalía General de la Nación, [...], la información específica contenida en sus bases de datos, tal como sectores, coordenadas geográficas y potencia, entre otras, [...].“(dt. Übersetzung d. Verf.). 176
} 
denen sich dessen Vertraulichkeit ergibt. ${ }^{545}$ Die Prüfung der fundierten Anhaltspunkte ist Teil der materiellen Kontrolle über die Ausführung der Maßnahme, bei der das, was bei der Durchführung der Maßnahme tatsächlich geschehen ist, anhand des Protokolls und der Befragung der Beteiligten zu prüfen ist. Zusätzlich zur materiellen Prüfung der Ausführung der Maßnahme hat der JCG auch eine Verhältnismäßigkeitsprüfung vorzunehmen.

Die Bedeutung der Verhältnismäßigkeitsprüfung liegt vor allem darin, dass mit der Durchführung der Maßnahme auch Grundrechte (hier: Intimsphäre; Kommunikationsgeheimnis) von Personen verletzt werden können, ohne dass hierfür ein Rechtfertigungsgrund vorliegt. Der JCG prüft daher die teleologische Rechtfertigung und das Subprinzip der Angemessenheit. ${ }^{546}$ Diejenigen Maßnahmen, die zu Informationen führen, welche für die Ermittlungen aber nicht für die Anklage relevant sind - wie zum Beispiel die Information, dass der Betroffene nicht Täter oder Teilnehmer des Delikts ist aber Empfänger von Kommunikation des Verdächtigen oder Beschuldigten - sind nicht verhältnismäßig und daher nicht gerechtfertigt. In diesem Beispiel ergibt die Anwendung des Verhältnismäßigkeitsprinzips, dass keine Aussicht auf Erlangung eines ermittlungsrelevanten Fundes vorlag (Element der teleologischen Rechtfertigung und der Angemessenheit), die die Maßnahme rechtfertigen würde, sodass auch die Erlangung inkriminierenden Materials auf diesem Wege als Beweis unverwertbar sein kann. ${ }^{547}$

Umstritten ist die Anwendung des Verhältnismäßigkeitsprinzips vor dem Hintergrund des Art. 234 Abs. 3 CPP, der bestimmt, dass ,bei im Rahmen einer Untersuchung von Korrespondenz entdeckten Informationen über ein anderes Delikt [als über jenes, wegen dem ermittelt wird] entsprechende Ermittlungen einzuleiten sind. ${ }^{\circ 548}$ Ein Teil der Lehre vertritt hier die Auffassung, dass jeder Fund, der den Gesprächspartner des Beschuldigten betrifft, nicht als Beweis gegen diesen verwendet werden dürfe, da die Maßnahme nur gegen den Verdächtigen/Beschuldigten gerichtet gewesen sei und der Gesprächspartner nicht als Zielperson in der Anordnung der Staatsanwaltschaft konkretisiert worden sei.

\footnotetext{
545 Vgl. KVerfG, Entsch. C-673 v. 2005, Abschn. „Consideraciones de la Corte“; dazu infra § 7. B. I. 2. Rechtmäßigkeitskontrolle des JCG.

${ }^{546}$ Ein Eingriff in das Kommunikationsgeheimnis und die Intimsphäre ist nicht gerechtfertigt, wenn der Eingriff nicht notwendig war, um das Ermittlungsziel zu erreichen. Vgl. Bernal Cuellar/Montealegre Lynett, 2013 T. II, S. 288.

${ }^{547}$ Vgl. Bernal Cuellar/Montealegre Lynett, 2013 T. II, S. 288; Guerrero Peralta, 2007, S. 378 ff.; KVerfG, Entsch. C-594 v. 2014, Abschn. 3.5.2.

${ }^{548}$ Art. 234 Abs. 3 CPP: ,[[...] se descubriere información sobre otro delito, iniciará la indagación correspondiente o bajo custodia la enviará a quien la adelanta[...].“ (dt. Übersetzung d. Verf.).
} 
Gleichwohl sollen die Erkenntnisse ein neues Ermittlungsverfahren gegen den betreffenden Gesprächspartner stützen können. ${ }^{549}$ Eine andere Ansicht vertritt hingegen, dass ein Eingriff in die postalische Kommunikation, bei der weder der Absender noch der Empfänger die Voraussetzungen zur Durchführung der Maßnahme erfüllen, nicht rechtmäßig sei, selbst wenn es sich um Personen handle, die eine enge Beziehung zu dem Beschuldigten haben, außer es bestehe der Verdacht, dass sie selbst Beteiligte an den Straftaten sein könnten, wegen denen ermittelt wird. ${ }^{550}$

\section{Nachträglicher Rechtsschutz gegen Maßnahmen zur Beschränkung der Freiheit}

\section{Festnahme mit Ausnahmekompetenzen}

Die Festnahme in Form des physischen Festhaltens einer Person ist in zwei verschiedenen Szenarien zulässig: Wenn jemand auf frischer Tat betroffen wird oder wenn ein Festnahmebeschluss des JCG vorliegt. Ausnahmsweise räumt der CPP darüber hinaus die Möglichkeit zur Anordnung der Festnahme durch die FGN ohne vorherige richterliche Anordnung ein. Konkret ist dies in Art. 300 CPP festgelegt, in einer Vorschrift, die mehrfach reformiert und in ihrer Reichweite modifiziert worden ist. Die ursprüngliche Fassung der Vorschrift zur Festnahme ohne richterliche Anordnung sah vor, dass die FGN ausnahmsweise die Festnahme anordnen darf, „wenn sich im Verlauf der Ermittlungen fundierte Anhaltspunkte dafür ergeben, dass die betroffene Person an dem Verhalten, welches Gegenstand der Ermittlungen darstellt, beteiligt war, es nicht möglich ist, unverzüglich eine richterliche Anordnung zu erlangen und 1) die Gefahr besteht, dass die betroffene Person sich nicht für das Strafverfahren zur Verfügung halten wird oder 2) eine Gefahr für die Gesellschaft darstellt oder die Ermittlungen behindern wird. “551 Ebenso verlangte diese Vorschrift, dass der Festgenommene unverzüglich, in jedem Fall aber innerhalb von 36 Stunden, dem JCG vorzuführen ist, der die Rechtmäßigkeit der

\footnotetext{
${ }^{549}$ Guerrero Peralta, 2006, S. 114.

${ }^{550}$ Andernfalls läge eine Verletzung ihres Grundrechts auf Wahrung des Kommunikationsgeheimnisses vor. Vgl. Assalit Vives, Manual de formación continuada 12 (2000), S. $210 \mathrm{ff}$.

${ }^{551}$ Ursprüngliche Fassung von Art. 300 CPP: „Captura sin orden judicial. En los eventos en que proceda la detención preventiva, el Fiscal General de la Nación o su delegado podrá proferir excepcionalmente órdenes de captura cuando en desarrollo de la investigación tenga motivos fundados para inferir que determinada persona ha participado en la conducta investigada, no sea posible obtener inmediatamente orden judicial, y concurra al menos una de las siguientes causales: 1. Cuando exista riesgo de que la persona evada la acción de la justicia; 2. Cuando represente peligro para la comunidad u obstruya la investigación; [...]“ (dt. Übersetzung d. Verf.). 
Festnahme überprüft. ${ }^{552}$ Die Ausnahmebefugnis zur Festnahme ohne richterliche Anordnung existierte auch bereits zuvor in Kolumbien und war unter der Bezeichnung behördliche Festnahme oder behördlicher Präventiv-Gewahrsam (retención preventiva administrativa) bekannt. ${ }^{553}$ Jene konnte erfolgen, wenn die Notwendigkeit bestand, kurzfristig die Identität der betroffenen Person oder Sachverhalte zu prüfen, die mit den fundierten Anhaltspunkten für eine Festnahme in Zusammenhang stehen mit dem Ziel, die betroffene Person bei entsprechendem Ergebnis der Überprüfung der zuständigen Stelle zu übergeben und ein Ermittlungsverfahren zu eröffnen. ${ }^{554}$

Die in Art. 300 des Gesetzes 906 von 2004 vorgesehene Festnahme ohne richterliche Anordnung war Gegenstand von Klagen vor dem KVerfG wegen vermeintlicher Verstöße gegen drei Verfassungsnormen. Zum einen gegen Art. $28 \mathrm{CN}$, der als Bedingung für eine Festnahme vorschreibt, dass eine förmliche schriftliche Anordnung durch ein richterliches Organ vorliegen muss und nur aus gesetzlich festgelegten Gründen erfolgen darf. Die Kläger argumentierten damit, dass die Autonomie und Unabhängigkeit richterlicher Organe dem Festgenommenen ein erhöhtes Maß an Unparteilichkeit in der Entscheidung über seine Festnahme garantieren sollen, welches sie durch eine Übertragung der Entscheidungskompetenz an die FGN verletzt sahen. Auf der anderen Seite sahen die Kläger in einer weiteren Verfassungsklage Art. $250 \mathrm{Nr}$. $1 \mathrm{CN}$ verletzt. Sie vertraten die Ansicht, die Voraussetzungen, unter denen eine Festnahme ausnahmsweise durch die FGN angeordnet werden kann, seien nur „generell und abstrakt“ festgelegt und damit zu unbestimmt. Schließlich brachte eine weitere Verfassungsklage vor, die Norm verletze Art. $93 \mathrm{CN}$, da ,in von Kolumbien ratifizierten internationalen Verträgen zum Schutz der Menschenrechte, die durch die Figur des Verfassungsblocks (bloque de constitucionalidad) Teil der kolumbianischen Rechtsordnung sind, festgelegt sei, dass eine Festnahme nur auf richterliche Anordnung erfolgen darf mit Ausnahme gesetzlich ausgewiesener Fälle. “555

\footnotetext{
552 Art. 300 letzter Abs. CPP: „,...] En estos casos el capturado será puesto a disposición del juez de control de garantías inmedia-tamente a más tardar dentro de las treinta y seis (36) horas, para que en audiencia resuelva lo pertinente.“( dt. Übersetzung d. Verf.).

${ }^{553}$ Dort war für die Festnahme die Nationalpolizei zuständig. Vgl. Art. 56 lit. a, 58, 62 Abs. 2, und Art. 83 des Dekrets 1355 von 1970; dazu Bernal Cuellar/Montealegre Lynett, 2013 T. II, S. 491 ff.

${ }^{554}$ Es handelte sich somit um eine freiheitsbeschränkende Maßnahme zur Feststellung, ob ein strafrechtliches Ermittlungsverfahren angezeigt ist. Vgl. Sánchez Martínez, 2003, S. 7 ff.

555 Art. $93 \mathrm{CN}$ : „Los tratados y convenios internacionales ratificados por el Congreso, que reconocen los derechos humanos y que prohíben su limitación en los estados de excepción, prevalecen en el orden interno.
} 


\section{Das erste Urteil des KVerfG}

Auf die Verfassungsklagen hin hat das KVerfG die Möglichkeiten zur Festnahme ohne richterliche Anordnung auf ein Minimum beschränkt und dem Richtervorbehalt den Vorrang gegeben. Nach Auffassung des Gerichts ist der JCG dafür zuständig, über freiheitsbeschränkende Maßnahmen zu entscheiden. Diesbezüglich führte das Gericht aus, dass, „da es sich um eine Einschränkung der persönlichen Freiheit handelt, es unerlässlich ist, dass die Umstände und Bedingungen, unter denen ein [Freitheits]entzug zulässig ist, ausdrücklich und spezifisch vorgeschrieben sind und nicht dem Ermessen desjenigen unterliegen dürfen, der die Festnahme anordnet. “556 Nach Ansicht des Gerichts öffne die ursprüngliche Fassung des Art. 300 CPP dem Ermessen der FGN „Tür und Tor“, da die von dieser Vorschrift beschriebenen Voraussetzungen für eine Festnahme unbestimmt seien, und daher weder eine Beschränkung für die FGN darstellten, noch zur nur ausnahmsweisen Anwendung der Vorschrift anregten. Daher erklärte das KVerfG den Art. 300 CPP für verfassungswidrig. ${ }^{557}$

Die hier von dem KVerfG präsentierte Argumentation zum verfassungsrechtlich gebotenen Vorrang des Richtervorbehalts bei freiheitsbeschränkenden Maßnahmen geht auf den Beschluss des Gerichts im Juni 2005 zurück. ${ }^{558}$ In diesem hatte das Gericht im Rahmen der verfassungsrechtlichen Überprüfung des Art. 302 Abs. 4 CPP betont, dass es der Staatsanwaltschaft nicht zustehe, die Voraussetzungen für die Freilassung einer Person materiell zu überprüfen, wenn nicht die Voraussetzungen erfüllt seien, die eine vorläufige Festnahme erlauben würden. Die FGN dürfe nur eine streng objektive Prüfung der Voraussetzungen vornehmen, eine materiell rechtliche Überprüfung dagegen dürfe ausschließlich vom JCG vorgenommen werden. Das Gericht befand daher Art. 302 Abs. 4 CPP - welcher die nachträgliche Prüfung einer Vorschrift durch den JCG vorschreibt - für verfassungsgemäß und stärkte damit die rechtliche Kontrolle des Richters zur Kontrolle der Garantien. In diese Richtung ging ebenfalls die Entscheidung, in der das KVerfG ausführte, die Funktionsverteilung im neuen akkusatorischen Strafprozesssystem sei

\footnotetext{
Los derechos y deberes consagrados en esta Carta, se interpretarán de conformidad con los tratados internacionales sobre derechos humanos ratificados por Colombia.“(dt. Übersetzung d. Verf.). Vgl. dazu KVerfG, Entsch. C-802 v. 2002, C-070 v. 2009, C-751 v. 2015, Abschn. „Consideraciones de la Corte“.

${ }^{556}$ KVerfG, Entsch. C-1001 v. 2005, Abschn. 4.2.3.: ,por tratarse de la restricción de la libertad personal, es indispensable que los eventos y condiciones para proceder a su privación estén previstos de manera expresa y específica y no pueden quedar a discreción de quien ordene la captura." (dt. Übersetzung d. Verf.).

${ }^{557}$ KVerfG, Entsch. C-1001 v. 2005, Abschn. „Consideraciones de la Corte“.

${ }^{558}$ KVerfG, Entsch. C-591 v. 2005, Abschn. „Consideraciones de la Corte“.
}

180 
eindeutig und der Staatsanwaltschaft stehe es demnach nicht zu, unmittelbar Festnahmen anzuordnen. ${ }^{559}$

\section{Rechtliche Wiedereinführung der Ausnahmekompetenz zur Fest- nahme}

Trotz der Entscheidungen des KVerfG zur Verfassungswidrigkeit der Festnahme ohne richterliche Anordnung ergriff die FGN die Initiative und regte Diskussionen zur gesetzlichen Wiedereinführung ihrer Festnahmeermächtigung an. Als Rechtfertigung hierfür führte der dem Senat zur Diskussion vorgelegte Vorschlag an, dass die neue Vorschrift „einer ausnahmsweise von der Staatsanwaltschaft angeordneten Festnahme höhere Schranken auferlege u.a. dadurch, dass sie als Voraussetzung beinhalte, dass schwerwiegende und außerhalb der Kontrolle [der FGN] liegende Gründe vorliegen müssen, die eine richterliche Anordnung unmöglich machen.“ Hinzu komme, dass „der neue Gesetzesvorschlag die Wirksamkeit der Anordnung der Festnahme zeitlich beschränke und eine Frist vorschreibe, innerhalb derer der Festgenomme einem Richter vorzuführen sei.“560 Eine gesetzliche Regelung, die diese neuen Voraussetzungen beinhaltet, wurde in der Folge vom kolumbianischen Kongress im Gesetz 1142 von 2007 verabschiedet und auf diese Weise wurde die Ermächtigung der FGN zur Anordnung einer Festnahme in Ausnahmefällen gesetzlich wieder eingeführt. ${ }^{561}$ Diese neue Norm ermächtigte die FGN in Art. 21 des Gesetzes 1142 von 2007

„ausnahmsweise eine schriftliche Anordnung einer Festnahme zu erteilen, wenn die Umstände einer vorläufigen Festnahme vorliegen und aus schwerwiegenden und unkontrollierbaren Gründen kein Richter verfügbar ist, der sie anordnen könnte, und außerdem Beweise, physische Nachweise oder Informationen vorliegen, die vernünftigerweise darauf schließen lassen, dass der Verdächtige Täter oder Teilnehmer des Delikts ist, das den Gegenstand der Ermittlungen darstellt, und eine der folgenden Voraussetzungen erfüllt ist: 1. Die drohende Gefahr, dass die betreffende Person sich versteckt, flieht oder den Ort, an dem die Ermittlungen durchgeführt werden, verlässt; 2. die begründete Wahrscheinlichkeit, dass Beweismittel verändert werden; 3. eine Gefahr für

\footnotetext{
${ }^{559}$ KVerfG, Entsch. C-1001 v. 2005, Abschn. „Consideraciones de la Corte“.

${ }^{560}$ Gesetzblatt 124 von 19.04.2007: ,impondría mayores cargas para que se decretara la captura excepcional por la Fiscalía, entre ellas, la referente a que existan motivos serios y de fuerza mayor acerca de la imposibilidad dicha medida por parte del juez. A esta "nueva" exigencia se sumaba la vigencia de la orden de captura y el término para poner al capturado a disposición del juez." (dt. Übersetzung d. Verf.).

${ }^{561}$ Vgl. KVerfG, Entsch. C-1001 v. 2005, Abschn. „Consideraciones de la Corte“.
} 
die Sicherheit der Gemeinschaft oder der Opfer dahingehend, dass beim Ausbleiben der Festnahme der Verdächtige wieder eine Straftat verübt. “562

Hinsichtlich der Modifizierungen, die das Gesetz 1142 von 2007 im Vergleich zu Art. 300 CPP einführte, sind die Folgenden hervorzuheben:

i. Die Einführung der Voraussetzung einer schriftlichen und begründeten Anordnung durch den Staatsanwalt.

ii. Die Anordnung der Festnahme ist nur zulässig unter der Voraussetzung, dass schwerwiegende und unkontrollierbare Gründe vorliegen, aufgrund derer es nicht möglich ist, dass der Richter zur Kontrolle der Garantien sie anordnet.

iii. Die Bewertung durch die FGN muss durch Beweise, physiche Nachweise oder Informationen gestützt sein, die auf die Beteiligung des Festzunehmenden an einer Straftat schließen lassen.

iv. Der Zugang zum Richter zur Kontrolle der Garantien wird zu einer Wirksamkeitsvoraussetzung der Festnahmeanordnung dergestalt, dass nach dem Vollzug der Festnahme die festgenommene Person unverzüglich, spätestens aber innerhalb von 36 Stunden diesem vorzuführen ist. Der Richter zu Kontrolle der Garantien prüft sodann in einer Anhörung die Rechtmäßigkeit der Anordnung und Durchführung der Festnahme.

v. Für die Festnahme muss eine der drei folgenden Voraussetzungen vorliegen: a) Die drohende Gefahr, dass die betreffende Person sich versteckt, flieht oder den Ort, an dem die Ermittlungen durchgeführt werden, verlässt (Art. 300 Abs. 1); b) die begründete Wahrscheinlichkeit, dass Beweismittel verändert werden (Art. 300 Abs. 2); c) eine Gefahr für die Sicherheit der Gemeinschaft oder der Opfer dahingehend besteht, dass beim Ausbleiben der Festnahme der Verdächtige wieder eine Straftat

\footnotetext{
562 Art. 21 Gesetz 1142 von 2007: „El Fiscal General de la Nación o su delegado podrá proferir excepcionalmente orden de captura escrita y motivada en los eventos en los que proceda la detención preventiva, cuando por motivos serios y de fuerza mayor no se encuentre disponible un juez que pueda ordenarla, siempre que existan elementos materiales probatorios, evidencia física o información que permitan inferir razonablemente que el indiciado es autor o partícipe de la conducta investigada, y concurra cualquiera de las siguientes causales: 1. Riesgo inminente de que la persona se oculte, se fugue o se ausente del lugar donde se lleva a cabo la investigación; 2. Probabilidad fundada de alterar los medios probatorios; 3. Peligro para la seguridad de la comunidad o de la víctima en cuanto a que, si no es realizada la captura, el indiciado realice en contra de ellas una conducta punible.“ (dt. Übersetzung d. Verf.). 
verübt (Art. 300 Abs. 3). ${ }^{563}$

\section{Das zweite Urteil des KVerfG}

Die Wiedereinführung der Möglichkeit zur ausnahmsweisen Anordnung einer Festnahme durch die FGN durch Art. 21 des Gesetzes 1142 von 2007 eröffnete erneut die Debatte über deren Verfassungsmäßigkeit. Diese drehte sich vor allem um die Frage, ob durch die Modifizierungen die vom Verfassungsgericht bzgl. des ursprünglichen Art. 300 CPP herausgearbeiteten Verfassungsmängel überwunden wurden und die Neufassung nunmehr verhindere, dass die FGN faktisch den JCG bei der Entscheidung der Festnahme ersetzt. ${ }^{564}$ Gegenstand von Diskussionen war hierbei insbesondere, ob der durch Art. 21 des Gesetzes 1142 eingeführte Einschub, dass ,,aus schwerwiegenden und unkontrollierbaren Gründen kein Richter verfügbar ist, der sie anordnen könnte“"565, ausreichend konkret, präzise und bestimmt sei und dadurch einer fehlerhaften Auslegung ebenso vorbeuge wie dem Missbrauch und der damit einhergehenden Verletzung von Grundrechten. Diesbezüglich wurden verschiedene Ansichten vertreten unter denen diejenige der Disziplinarstaatsanwaltschaft vorherrschend war, nach der Art. 21 des Gesetzes 1142 von 2007 wieder das Legalitätsprinzip und das Prinzip des Richtervorbehalts bei freiheitsbeschränkenden Maßnahmen verletzte, da der eingeführte Begriff „unkontrollierbare Gründe“ als solcher vage sei und die Anforderungen des Bestimmtheitsgebots nicht erfülle. ${ }^{566}$

Darüber hinaus sah die Mehrheit auch eine Verletzung des Art. $28 \mathrm{CN}$ gegeben. ${ }^{567}$ Das vorherrschende Argument war hier, dass die Beschränkung der in Art. $210 \mathrm{Nr}$. $1 \mathrm{CN}$ verbürgten Freiheit nicht durch Normen geregelt werden könne, die doppeldeutig, ambivalent und sprachlich ungenau seien, wie dies bei Art. 21 des Gesetzes 1142 von 2007 der Fall sei. Denn die darin enthaltene Neuregelung der vormals durch Art. 300 CPP

\footnotetext{
${ }^{563}$ KVerfG, Entsch. C-185 v. 2008, Abschn. 3. „Los cambios introducidos por el artículo 21 de la Ley 1142 de 2007 a la figura de la captura excepcional por parte de FGN.“ Bzgl. der Gesetzänderung vgl. Uribe García, Ratio Juris 12 (2011), S. 87-117; Martínez Sánchez, DPC 20 (2010), S. 69-117; Suarez López, Temas de Derecho Penal 2008, S. 331-370; Monroy Cabra, FP 70 (2008), S. 29-52.

${ }^{564}$ Krit. zu der Ermächtigung der FGN Vélez Osorio, 2012, S. 109 ff.; Calle Calderón, NFP 67 (2005), S. 166 ff.; Aponte Cardona, 2006a, S. 53 ff.

565 Art. 21 Gesetz 1142 von 2007: ,[...] cuando por motivos serios y de fuerza mayor no se encuentre disponible un juez que pueda ordenarla [...].“

${ }^{566}$ KVerfG, Entsch. C-185 v. 2008, Abschn. „V. Concepto del Procurador General de la Nación.“

${ }^{567}$ KVerfG, Entsch. C-185 v. 2008, Abschn. „VI. 5. La regulación de la facultad de la FGN.
} 
normierten Materie erlaube einen hohen Interpretationsspielraum und sei daher nicht geeignet, freheitsbeschränkenden Maßnahmen die erforderlichen Grenzen zu setzen.

Das KVerfG befand die Regelung gleichwohl für verfassungsgemäß, wobei die Herleitung dieser Entscheidung paradox erscheint. So führte das Gericht in seiner Entscheidung C-185 von 2008 zwar einerseits aus, dass die vom Gesetzgeber gefundene Lösung nicht das Legalitätsprinzip erfülle, da sowohl die Begriffe „schwerwiegende und unkontrollierbare Gründe“ (,motivos serios y de fuerza mayor") als auch die Voraussetzung, dass keine Richter ,verfügbar“ seien, der Staatsanwaltschaft zu viel Ermessen bei der Bewertung, ob diese Umstände gegeben seien, lasse. ${ }^{568}$ Wie das Gericht ausdrücklich befand, könne die Staatsanwaltschaft bei den so formulierten Voraussetzungen willkürlich festlegen, dass ein ausreichend schwerwiegender Grund vorlag, aufgrund dessen sie einen Richter nicht erreichen konnte. Dem Urteil zufolge erfüllen daher die Voraussetzungen in keinster Weise die in Art. $29 \mathrm{CN}$ und die in der verfassungerichtlichen Rechtsprechung ausgewiesenen Parameter des Legalitätsprinzips, die besagen, dass „die Gründe und Bedingungen einer freiheitsbeschränkenden Maßnahme klar in dem betreffenden Gesetz niedergelegt sein müssen und demjenigen, der die Festnahme anordnet, kein Ermessen eingeräumt werden darf.“569 Nach Ansicht des KVerfG erlegen die Begriffe „schwerwiegende und unkontrollierbare Gründe“ (motivos serios y de fuerza mayor) als Voraussetzungen für eine Festnahme der Staatsanwaltschaft außerdem eine Beweis- und Argumentationslast auf, die flexibler sei als diejenige, der sich selbst ein JCG bei der Anordnung einer Festnahme ausgesetzt sieht. In Anbetracht der Vagheit der vorgenannten Begriffe, die dem Staatsanwalt eine subjektive Entscheidung ermöglichen würden und daher geeignet seien, die Anordnung der Festnahme durch die Staatsanwaltschaft ohne vorherige richterliche Anordnung praktisch zum Regelfall zu machen, entschied das Gericht, dass die Tatbestandsvoraussetzungen ,aus schwerwiegende und unkontrollierbaren Gründen“ verfassungswidrig seien. ${ }^{570}$

\footnotetext{
${ }^{568}$ KVerfG, Entsch. C-185 v. 2008, Abschn. VI. 5. „La regulación de la facultad de la FGN.“

${ }^{569} \mathrm{KVerfG}$, Entsch. C-185 v. 2008, Abschn. VI. 5. „La regulación de la facultad de la FGN“: „esos calificativos no cumplen en manera alguna los parámetros del principio de legalidad consagrado por la Constitución en su artículo 29 ni por los lineamientos señalados en la jurisprudencia constitucional, pues los motivos y las condiciones para restringir la libertad deben ser plasmados claramente en la ley y no pueden quedar a discreción de quien ordene la captura." (dt. Übersetzung d. Verf.).

${ }^{570}$ KVerfG, Entsch. C-185 v. 2008, Abschn. VI. 5. „La regulación de la facultad de la FGN.“ 
Andererseits kam das KVerfG aber - in einer unerwarteten und widersprüchlichen Wendung - zu dem Ergebnis, dass der Rest der Vorschrift, wenn auch mit weiteren Einschränkungen mit der Verfassung vereinbar sei. In der Entscheidung heißt es hierzu zunächst, dass nach der Rechtsprechung des Verfassungsgerichts

„die Ermächtigung der FGN oder ihres Delegierten, eine Festnahme eines Straftäters anzuordnen, klar ausgewiesener Voraussetzungen und Anforderungen in ihrer Ausübung bedarf, die aus dieser Ermächtigung tatsächlich eine Ausnahmekompetenz machen, und die keinesfalls geringer sein dürfen als diejenigen, denen ein Richter zur Kontrolle der Garantien unterliegt. Weiterhin darf diese das in Art. 29 der Verfassung niedergelegte Legalitätsprinzip nicht verletzen. ${ }^{\text {(571 }}$

Weiter führt das Gericht aus:

„Hinsichtlich der Voraussetzungen für den Erlass einer Festnahmeanordnung durch den Richter zur Kontrolle der Garantien verlangt Art. 19 des Gesetztes 1142 von 2007, dass „vernünftig fundierte Anhaltspunkte“ vorliegen müssen, welche sich gemäß Art. 221 des Gesetzes 906 von 2004 [CPP] auf einen Polizeibericht, eine beeidigte Aussage von Zeugen oder Informanten oder auf Beweismittel bzw. physische Nachweise stützen müssen. Für die ausnahmsweise mögliche Anordnung einer Festnahme durch die FGN oder dessen Delegierten setzt Art. 21 des Gesetzes 1142 von 2007 dagegen voraus, dass die Anordnung aus ernsten und unkontrollierbaren Gründen, aufgrund derer kein Richter verfügbar ist, der sie anordnen könnte, resultieren muss. “572

Die Argumentation des KVerfG im Sinne der Verfassungsmäßigkeit des Art. 300 CPP wird dahingehend kritisiert, dass das Gericht nicht zwischen den Gründen, die die Anordnung

\footnotetext{
${ }^{571}$ KVerfG, Entsch. C-185 v. 2008, Abschn. VI. 5. „La regulación de la facultad de la FGN““: ,el ejercicio de la facultad del Fiscal General de la Nación o su delegado para ordenar la captura de un infractor de la ley penal, requiere del señalamiento por el legislador de presupuestos y requisitos claramente definidos que hagan de dicha facultad algo verdaderamente excepcional, los cuales no pueden ser en ningún caso menores de los que se exijan al juez de control de garantías, ni pueden desconocer el principio de legalidad señalado en el artículo 29 de la Constitución."(dt. Übersetzung d. Verf.).

${ }^{572}$ KVerfG, Entsch. C-185 v. 2008, Abschn. VI. 5. La regulación de la facultad de la FGN: „En cuanto al fundamento que justifica la expedición de la orden de captura, en la captura ordenada por el juez de control de garantías, el artículo 19 de la Ley 1142 de 2007, exige la existencia de "motivos razonablemente fundados", los cuales, según lo que establece el artículo 221 de la Ley 906 de 2004, deben estar sustentados en informes de la policía judicial, en declaraciones juradas de testigos o informantes, o en elementos materiales probatorios y evidencia física. Por su parte, el artículo 21 de la Ley 1142 de 2007 señala que la orden de captura excepcional dictada por el Fiscal General o su delegado debe estar fundada en motivos serios y de fuerza mayor, que muestren que no se encuentra disponible un juez que pueda proferir la medida.“ (dt. Übersetzung d. Verf.).
} 
der Festnahme und deren Verfahren (Umsetzung des Legalitätsprinzips) regeln, und den Gründen, die im Einzelnen die Ausübung der Ermächtigung zur Anordnung einer Festnahme durch den Staatsanwalt rechtfertigen, unterscheide. Des Weiteren führen die Kritiker aus, dass das KVerfG die Kompetenz zur Anordnung einer Maßnahme (Anordnung der Festnahme) mit den Gründen rechtfertigt, die die Maßnahme an sich (Freiheitsbeschränkung) begründen. Außerdem gebe das Gericht das Prinzip des Richtervorbehalts in dem Glauben auf, dass der Ausnahmecharakter der Norm einzig in der Achtung des Legalitätsprinzips bestehe. ${ }^{573}$ Aus Sicht des KVerfG allerdings führe die neue Fassung des Art. 300 CPP wichtige Änderungen ein, aus denen die Verfassungskonformität resultiere. Im Unterschied zur vorherigen Fassung beinhalte die durch Gesetz 1142 eingeführte modifizierte Version erstens Beweisanforderungen, die den Staatsanwalt bei der Anordnung der Festnahme beschränken und verhindern, dass er diese grundlos treffe. Zweitens verlange die neue Version, dass die Anordnung der Maßnahme nicht durch den JCG erfolgen könne. Außerdem sei durch die Anforderung, dass der Festgenommene unverzüglich, aber spätestens innerhalb von 36 Stunden nach der Festnahme, dem JCG vorgeführt werden müsse, der Staatsanwaltschaft eine weitere Schranke auferlegt worden. ${ }^{574}$ Auch diese Ausführungen sind vielfach auf Widerspruch gestoßen. Laut der Kritiker sei das Gericht von seinem Standpunkt bzgl. der Notwendigkeit, dass der Gesetzgeber die Voraussetzungen für freiheitsbeschränkende Eingriffe eindeutig bezeichne und dadurch den Ausnahmecharakter derartiger Eingriffe gewährleiste, abgewichen. ${ }^{575}$

\section{Rechtsgrundlage}

Art. 297 CPP sieht vor, dass sich die Rechtmäßigkeitskontrolle nach erfolgter Festnahme der Person nicht nur auf die Prüfung beschränken darf, ob die Festnahme gemäß der Anordnung der FGN durchgeführt wurde, sondern sich auch auf die Frage erstrecken muss, ob sie in Übereinstimmung mit den in Art. 303 CPP niedergelegten Rechten des Verdächtigen vorgenommen wurde. ${ }^{576} \mathrm{Im}$ Falle einer Festnahme auf frischer Tat ist zudem zu prüfen, ob eine der fünf in Art. 301 CPP vorgeschriebenen Situationen vorlag:

\footnotetext{
${ }^{573}$ Vélez Osorio, 2012, S. 128.

${ }^{574}$ KVerfG, Entsch. C-185 v.de 2008, Abschn. VI. 5. La regulación de la facultad de la FGN

${ }^{575}$ Vélez Osorio, 2012, S. 130; Zuluaga, Boletin GLIPGö 5 (2013), S. 27 f.

${ }^{576}$ Art. 297 Abs. 2 CPP: „Capturada la persona será puesta a disposición de un juez de control de garantías en el plazo máximo de treinta y seis (36) horas para que efectúe la audiencia de control de legalidad, ordene la 186
} 
„1. Eine Person wurde bei der Begehung eines Delikts ertappt und gefasst; 2. eine Person wurde bei der Begehung eines Delikts ertappt oder individualisiert und unmittelbar danach verfolgt und gefasst oder sie wurde von dem Opfer oder einer anderen Person als Täter oder Teilnehmer eines Delikts identifiziert und unmittelbar nach dessen Begehung gefasst; 3. eine Person wurde ertappt und festgenommen mit Gegenständen, Instrumenten oder Spuren, aus denen ersichtlich ist, dass sie gerade ein Delikt begangen oder an einem solchen teilgenommen hat; 4. eine Person wird bei der Begehung eines Delikts in der Öffentlichkeit mittels einer Videoaufnahme identifiziert oder individualisiert und unmittelbar danach gefasst; 5. eine Person befindet sich in einem Fahrzeug, welches kurz vorher benutzt wurde, um von einem Tatort zu fliehen, außer es ist fundiert ersichtlich, dass die Person keine Kenntnis von dem Delikt hat.“577

Abgesehen davon ist in jedem Fall auch zu prüfen, ob der Festgenommene im Moment der Festnahme über seine Rechte belehrt wurde, er gut behandelt wurde und die Frist zur Vorführung des Festgenommenen vor dem JCG eingehalten wurde. ${ }^{578}$

Hinsichtlich der Kontrolle der Einhaltung der Rechte des Festgenommenen behandelt die Rechtslehre diesen Aspekt als maximale Ausdehnung des Freiheitsrechts mit den folgenden Inhalten: 1. Rechte vor der Festnahme betreffen die an die Begründetheit der Festnahme durch Verfassung und Gesetz gestellten Voraussetzungen. Hier geht es um den vor der Festnahme liegenden Sachverhalt; 2. Rechte nach der Festnahme beinhalten die Rechte auf Inanspruchnahme eines Übersetzers, auf Informationen hinsichtlich des Grundes der Festnahme sowie die allgemeinen, für Inhaftierte geltenden Rechte. Die Richter prüfen an

cancelación de la orden de captura y disponga lo pertinente con relación al aprehendido.“ („Wenn die Person festgenommen wird, wird ihr innerhalb eines Zeitraums von höchstens sechsunddreißig (36) Stunden ein Richter zur Kontrolle der Garantien zur Verfügung gestellt, um die Rechtmäßigkeitskontrolle durchzuführen, die Aufhebung des Haftbefehls anzuordnen und um das, was einschlägig in Bezug auf den Festgenommenen ist, anzuordnen.") (dt. Übersetzung d. Verf.).

577 Art. 301 CPP: „Flagrancia. Se entiende que hay flagrancia cuando: 1. La persona es sorprendida y aprehendida durante la comisión del delito. 2. La persona es sorprendida o individualizada durante la comisión del delito y aprehendida inmediatamente después por persecución o cuando fuere señalado por la víctima u otra persona como autor o cómplice del delito inmediatamente después de su perpetración. 3. La persona es sorprendida y capturada con objetos, instrumentos o huellas, de los cuales aparezca fundadamente que acaba de cometer un delito o de haber participado en él. 4. La persona es sorprendida o individualizada en la comisión de un delito en un sitio abierto al público a través de la grabación de un dispositivo de video y aprehendida inmediatamente después. La misma regla operará si la grabación del dispositivo de video se realiza en un lugar privado con consentimiento de la persona o personas que residan en el mismo. 5. La persona se encuentre en un vehículo utilizado momentos antes para huir del lugar de la comisión de un delito, salvo que aparezca fundadamente que el sujeto no tenga conocimiento de la conducta punible." (dt. Übersetzung d. Verf.).

${ }^{578}$ Vgl. u.a. Aponte Cardona, 2006a, S. 67; Bernal Cuellar/Montealegre Lynett, 2013 T. II, S. 489. 
dieser Stelle, auf welche Weise die Festnahme durchgeführt wurde und insbesondere, wie der Festgenommene im Gewahrsam der Polizei behandelt wurde; 3. Rechte während der Festnahme beinhalten die Rechte, sich selbst nicht belasten zu müssen, rechtlichen Beistand zu erhalten, auf Kommunikation, auf medizinischen Beistand, auf Belehrung über mögliche Rechtsbehelfe und darauf, dass die Frist zur Vorführung vor dem JCG eingehalten wird. Auch an dieser Stelle wird vor allem geprüft, ob die Polizeibeamten bei der Ausübung ihrer Gewalt die Grenzen des rechtlich Zulässigen überschritten haben. ${ }^{579}$

Hinsichtlich der Rechtskontrolle der Festnahme durch den JCG ist umstritten, ob der Richter nur die ihm berichteten Umstände zu Grunde zu legen hat, die unmittelbar im Moment der Festnahme vorlagen, oder ob es notwendig ist, auch die Gesamtumstände vor der Festnahme zu würdigen. ${ }^{580}$ Eine Ansicht löst die Fragestellung dahingehend, dass sie es für ausreichend erachtet, wenn die Festnahme an sich rechtmäßig war, da ihr eine formal rechtmäßige richterliche Anordnung zu Grunde liege und ein Festnahmegrund im Sinne des Art. 297 CPP vorliege oder die Festnahme wegen eines Ertappen des Täters auf frischer Tat gemäß Art. 301 CPP oder ausnahmsweise auf Anordnung der Staatsanwaltschaft ohne vorherige richterliche Anordnung gemäß Art. 301 CPP rechtmäßig war. Die weiteren Umstände, die der Festnahme zugrunde lagen und die über die vorgenannten Normen hinausgehen, seien nach dieser Ansicht nur disziplinarrechtlich in einem Verfahren gegen diejenigen, die im Vorfeld der Festnahme diese Verfahrensvorschriften verletzt haben, zu beachten. ${ }^{581}$

Eine andere Ansicht hingegen vertritt, dass die Verletzung der weiteren Verfahrensvorschriften ebenfalls geeignet sei, die Rechtmäßigkeit der Festnahme zu beeinträchtigen. Dies begründet sie wie folgt: 1. Sämtliche Regelungen, die den Freiheitsentzug begrenzen oder ausgestalten, dienen dem Grundrechtsschutz, wie er durch internationale Normen anerkannt ist. So sei beispielsweise das Recht eines jeden Festgenommenen auf unverzügliche Vorführung vor einen Richter ein durch den Internationalen Pakt über bürgerliche und politische Rechte verbürgtes Menschenrecht; 2.

\footnotetext{
${ }^{579}$ Hierbei reicht es nicht aus, dass der Festgenommene eine Erklärung über seine Behandlung während der Festnahme unterzeichnet, sondern es ist im Detail zu prüfen, auf welche Art und Weise der Eingriff in die persönliche Integrität erfolgt ist. Vgl. KVerfG. Entsch. C-425 v. 2008, Abschn. „Consideraciones de la Corte"; Aponte Cardona, 2006a, S. 69 f.

${ }^{580}$ Diese Frage ist zum Beispiel in Fällen relevant, in denen vor dem Auffinden des Verdächtigen eine unrechtmäßige Hausdurchsuchung erfolgt ist. Vgl. Aponte Cardona, 2006a, S. 67.

${ }^{581} \mathrm{Vgl}$. CSJ, Bericht von 9.08.2005, S. 3. 
die Festnahme sei ein komplexer Sachverhalt, der sich nicht in dem physischen Festhalten einer Person erschöpfe. ${ }^{582}$

Im Ergebnis ist die letztgenannte Auffassung auch in der Praxis vorherrschend. Die Rechtskontrolle durch den JCG erstreckt sich daher auf die folgenden Aspekte:

1. Prüfung der Verbindung zwischen den Tatsachen und Tatbeständen, in denen eine Sicherungsmaßnahme zulässig ist.

2. Prüfung der Rechtmäßigkeit der Festnahmeanordnung einschließlich der Motive, aus denen die Staatsanwaltschaft diese Anordnung erlassen hat und der Gründe, aus denen eine Einholung einer richterlichen Anordnung nicht möglich gewesen sein soll. Auch die Festnahmegründe Flucht, Verdunklungsgefahr, Gefahr für die Gesellschaft etc. werden an dieser Stelle geprüft.

3. Prüfung der maximalen Festnahmezeit und der Bedingungen, unter denen die Maßnahme ausgeführt wurde. ${ }^{583}$

\section{Freilassungsgründe}

Die Gründe, aus denen ein Festgenommener wieder freizulassen ist, sind in Art. 317 CPP geregelt. Die Norm sieht vor, dass Sicherungsmaßnahmen gemäß CPP ,während des gesamten Verfahrens gültig bleiben $[\ldots]^{6 / 584}$, d.h., sie bestehen während des Ermittlungsverfahrens und des Hauptverfahrens. Art. 317 CPP bestimmt für die Festnahme insbesondere, dass der Beschuldigte oder Angeklagte unverzüglich freizulassen ist, sobald einer der folgenden Sachverhalte eintritt.

\footnotetext{
${ }^{582}$ Daher gehen auch die Rechte des Festgenommenen und die zu seinen Gunsten verbürgten Garantien über den Moment des physischen Festhaltens hinaus und sind im gesamten Verlauf der Festnahme präsent, sodass sie auch in diesem Umfang einer richterlichen Kontrolle unterliegen müssen. Vgl. Aponte Cardona, 2006a, S. 68.

${ }^{583}$ KVerfG, Entsch. C-025 v. 2009, Abschn. „Consideraciones de la Corte“; Bernal Cuellar/Montealegre Lynett, 2013 T. II, S. 487 f.; Aponte Cardona, 2006a, S. 68 ff. Zu den vorgenannten Gründen kommt auch stets eine Prüfung der Gründe für eine Festnahme bei Ertappen auf frischer Tat (Art. 301 CPP), eine Prüfung des Festnahmeverfahrens einschließlich der Dauer der Festnahme und des Delikts, wegen dem die Festnahme durchgeführt wurde (Art. 302 CPP) und des Vorlesens der Rechte bei der Festnahme gemäß Art. 303 CPP. ${ }^{584}$ Art. 317 Abs. 1 CPP: ,[...] tendrán vigencia durante toda la actuación [...]“(dt. Übersetzung d. Verf.).
} 
„1. Wenn der Festgenommene einen Teil der Strafe, wie sie vorher festgelegt wurde, erfüllt hat, die Einstellung beschlossen wurde oder der Beschuldigte freigesprochen wurde. “585

Der Zweck dieses Freilassungsgrundes ist, ein Wiederaufkommen der Freilassungsgründe zu vermeiden, die eine präventive Festnahme mit unbegrenzter Dauer zuließen, wie es in Kolumbien vor der Verfassung von 1991 möglich war. Daher betont die jetzige Fassung, dass der Verurteilte freizulassen ist, sobald er die Strafe in der Höhe erfüllt hat, in der sie vorher festgesetzt worden ist, er freigesprochen oder das Verfahren eingestellt wird. Die Norm geht dabei von der Differenzierung zwischen präventiver Festnahme und Strafe aus. Dabei darf Erstere keine vorgezogene Strafe sein. Gleichwohl wird die Fassung dieser Regelung wegen ihrer Mehrdeutigkeit kritisiert, die es nicht ermöglicht, ihre Reichweite klar abzugrenzen. Als ein für die Interpretation maßgeblicher Gesichtspunkt hat sich das Angemessenheitsprinzip etabliert neben den Kriterien, die sich aus den Regelungen für eine vorzeitige Freilassung gemessen an der Ober- und Untergrenze des Strafrahmens ergeben. ${ }^{586}$ In keinem Fall darf daher der vorläufig Festgenommene die Zeit in Haft verbleiben, die der für das betreffende Delikt vorgesehen Dauer der Freiheitsstrafe entspricht.

Hinsichtlich des Kriteriums „der vorherigen Festsetzung der Höhe der Strafe“ sind die umstrittenen Fragen bzgl. seiner Anwendung und Auslegung vor allem die Folgenden: Zum einen wird diskutiert, ob die vorherige Festlegung nur auf Antrag oder von Amts wegen erfolgt, d.h., ob zuerst der Anwalt um eine Festlegung ersuchen muss. Für den Fall, dass ein Antrag erforderlich ist, stellt sich zum anderen die Frage, wie in Fällen zu verfahren ist, in denen dieser Antrag von der Verteidigung nicht gestellt wird, wenn es also mangels Antrags nicht zu einer vorherigen Festlegung gemäß den komplexen Vorgaben des Art. 60 CPP kommt. ${ }^{587}$ Die Fassung dieses Freilassungsgrundes hat viele Fragen aufgeworfen, die einem angemessenen Schutz der persönlichen Freiheit entgegenstehen.

\footnotetext{
585 Art. 317 Nr. 1 CPP: „1. Cuando se haya cumplido la pena según la determinación anticipada que para este efecto se haga, o se haya decretado la preclusión, o se haya absuelto al acusado." (dt. Übersetzung d. Verf.).

${ }^{586}$ Aponte Cardona, 2006a, S. 180; Bernal Cuellar/Montealegre Lynett, 2013 T. II, S. 608 f.

${ }^{587}$ Fraglich ist dann, ob und wie lange eine Person weiter in Haft bleiben darf. Vgl. Aponte Cardona, 2006a, S. $180 \mathrm{f}$. 
2. „In Folge einer Anwendung des Opportunitätsprinzips. “588

Nummer 2 des Art. 317 CPP betrifft die Wiedererlangung der Freiheit „,[i]n Folge der Anwendung des Opportunitätsprinzips“. Ausreichend ist, dass das Verfahren wegen irgendeines in Art. 324 CPP vorgesehenen Tatbestandes zur Anwendung des Opportunitätsprinzips endet. ${ }^{589}$

3. „Aufgrund eine im Rahmen einer Absprache getroffenen Regelung, die von dem Erkenntisrichter genehmigt wurde. “590

Verhandlungen und Absprachen können auch Klauseln betreffen, die mittelbar oder unmittelbar die Freilassung des Beschuldigten zum Gegenstand haben. Dies hat auch der höchste Gerichtshof Kolumbiens (Corte Suprema de Justicia) mehrfach bestätigt. ${ }^{591}$ So können zum Beispiel eine vorzeitige Entlassung unter Auflagen, die Verhängung eines Hausarrests oder andere auf die Vollstreckung der Strafe bezogenen Vergünstigungen vereinbart werden. Auch die FGN hat in ihrer Direktive vom 28. September 2006 die „Leitlinien für Absprachen und Verhandlungen zwischen der Staatsanwaltschaft und dem Beschuldigten oder Angeklagten“ festgesetzt und das Thema infolge von Absprachen gewährter Vergünstigungen näher ausgestaltet.

Die Direktive bezweckt damit unter anderem, dem Ermessensspielraum der Staatsanwälte durch Verbote und ausdrückliche Regelungen Grenzen zu setzen. Nach Ziffer b) dieser Direktive „können die Anerkennung sowie das Geständnis der Anklagepunkte und die Vergünstigungen, die diese mit sich bringen, Gegenstand von Verhandlungen in der Anhörung zur Erhebung der Beschuldigung sein, sobald der Staatsanwalt den Verdächtigen über seine Rechte aus Art. 288 Nr. 3 CPP informiert hat.“ Ebenso stellt sie fest, dass auch diese Verhandlungen in dem zwischen der Erhebung der Beschuldigung und der schriftlichen Erhebung der Anklage liegenden Zeitraum erfolgen können sowie zwischen

\footnotetext{
${ }^{588}$ Art. 317 Nr. 2 CPP: „Como consecuencia de la aplicación del Principio de Oportunidad.“ (dt. Übersetzung d. Verf.).

589 Vgl. dazu Bernal Cuellar/Montealegre Lynett, 2013 T. II, S. 612 f.; KVerfG, Entsch. C-390 v. 2014 , Abschn. „Consideraciones de la Corte“.

${ }^{590}$ Art. 317 Nr. 3 CPP: „Como consecuencia de las cláusulas del acuerdo cuando haya sido aceptado por el Juez de Conocimiento.“ (dt. Übersetzung d. Verf.).

${ }^{591}$ Oberster Gerichtshof, Rad. 24.531, Entsch. von 4.05.2006; Rad. 24.764, Entsch, von 1.06.2006, Abschn. „Consideraciones de la Corte“.
} 
der Erhebung der Anklage und der Vernehmung des Angeklagten in der mündlichen Verhandlung. "592

4. „Wenn 60 Tage nach der Erhebung der Beschuldigung die schriftliche Erhebung der Anklage noch nicht erfolgt oder die Einstellung des Verfahrens gemäß Art. 294 noch nicht beantragt ist. Die Frist beträgt 90 Tage, wenn Tatmehrheit vorliegt oder sich das Ermittlungsverfahren gegen drei oder mehr Beschuldigte richtet.“"593

Die Ziffer 4 (so wie Z. 5, s. infra Fn. 593) bezieht sich spezifisch auf die prozessualen Fristen. In Bezug auf die Anwendung von Ziffer 4 sind insbesondere die folgenden Punkte umstritten:

a. Zum einen ist fraglich, ob die von der Regelung genannten Tage Werk- oder Kalendertage sind. Eine Ansicht meint, dass stets, wenn eine Rechtsnorm Tage nenne, Werktage gemeint seien. Dagegen sei der Kalender maßgeblich, wenn auf Monate und Jahre Bezug genommen würde. ${ }^{594}$ Eine andere Ansicht vertritt, dass es sich bei Art. $317 \mathrm{Nr}$. 4 CPP um Kalendertage handle. ${ }^{595}$

b. Umstritten ist ferner der Begriff „Erhebung der Anklage“. Die Frage ist hier, ob sich die Regelung auf die Einreichung der Anklageschrift bezieht oder auf deren Verlesung im

${ }^{592}$ FGN Leitlinie (Directiva) von 28.09.2006 Lit. b) 1 : „El allanamiento o aceptación de los cargos imputados y los beneficios que comporta podrán ser objeto de negociación en la audiencia de formulación de imputación, después de que el fiscal informe al investigado del derecho a que se refiere el numeral $3^{\circ}$ del artículo 288 de la Ley 906. Asimismo, podrán realizarse estas negociaciones en el interregno comprendido entre la audiencia de formulación de imputación y hasta antes de la presentación del escrito de acusación o a partir de la presentación de la acusación y hasta el momento en que sea interrogado el acusado en el juicio oral.“ (dt. Übersetzung d. Verf.).

${ }^{593}$ Art. 317 Nr. 4 CPP: „Cuando transcurridos sesenta (60) días contados a partir de la fecha de la formulación de imputación no se hubiere presentado el escrito de acusación o solicitado la preclusión, conforme a lo dispuesto en el artículo 294. El término será de noventa (90) días cuando se presente concurso de delitos, o cuando sean tres o más los imputados.“(dt. Übersetzung d. Verf.).

${ }^{594}$ Dies ist eine Interpretation, die dem kolumbianischen Zivilrecht entnommen ist. Art. 67 des kolumbianischen Bürgerlichen Gesetzbuchs: „Todos los plazos de días, meses o años de que se haga mención legal, se entenderá que terminan a la media noche del último día del plazo. Por año y por mes se entienden los del calendario común, por día el espacio de veinticuatro horas; pero en la ejecución de las penas se estará a lo que disponga la ley penal.“ (Alle Fristen von Tagen, Monaten oder Jahren, die gesetzlich erwähnt werden, enden um Mitternacht am letzten Tag der Frist. Jahre und Monate richten sich nach dem ordentlichen Kalender, unter einem Tag sind 24 Stunden zu verstehen; aber bei dem Vollzug von Strafen muss es geregelt werden, wie es im Strafrecht vorgesehen wird. -dt. Übersetzung d. Verf.-).

${ }^{595}$ Diese Auslegung wird aus Art. 157 Abs. 2 abgeleitet. Art. 157 Abs 2 CPP: „Las actuaciones que se desarrollen ante los jueces que cumplan la función de control de garantías serán concentradas. Todos los días y horas son hábiles para el ejercicio de esta función.“ („Die Handlungen vor dem JCG werden konzentriert. Alle Tage und Stunden sind gültig für die Ausübung dieser Funktion.“"-dt. Übersetzung d. Verf.-). 
Rahmen der mündlichen Anhörung zur Anklageerhebung. Nach einer Auffassung werde die Frist eingehalten, wenn die FGN vor ihrem Ablauf die Anklageschrift einreiche, denn ab diesem Zeitpunkt beginne der gerichtliche Teil des Verfahrens (Zwischen- und Hauptverfahren), sodass von der Staatsanwaltschaft nicht die Kontrolle über einen Verfahrensabschnitt verlangt werden könne, für den der Erkenntnisrichter zuständig sei. ${ }^{596}$ Die entgegengesetzte Auffassung bringt vor, dass weder in Art. 175 noch in Art. 294 und auch nicht in Art. 317 CPP die Einreichung der Anklageschrift gemeint sei, sondern die Verlesung der Anklage (formulación de la acusación). Dies folge daraus, dass die Erhebung der Anklage erst wirksam sei, wenn die Anklage in der hierzu bestimmten Anhörung verlesen sei.

Die letztgenannte Ansicht ist hierbei zu Recht vorherrschend, denn die Einreichung der Anklageschrift ist eine reine Formalie, wohingegen nur mit der Verlesung der Anklage in der hierzu bestimmten mündlichen Verhandlung der eigentliche Gegenstand des Rechtsstreits wirksam festgelegt wird. Ferner dürfen dem Beschuldigten Verzögerungen und Funktionsmängel des Strafjustizsystems nicht zur Last fallen. ${ }^{597}$

5. „Wenn nach 120 Tagen ab dem Datum der Verlesung der Anklage die mündliche Verhandlung des Hauptverfahrens noch nicht begonnen hat. “6598

Auch bzgl. der Auslegung dieses Freilassungsgrundes bestehen Diskussionen, vergleichbar mit den oben Dargestellten zu Ziffer 4.:

a. Wie bei Ziffer 4 wird auch hinsichtlich Ziffer 3 diskutiert, ob sich die „Tage“ auf Werkoder Kalendertage beziehen. Zieht man Art. 157 Abs. 3 CPP heran, ist zunächst festzustellen, dass „für vor dem Erkenntnisrichter vorzunehmende Handlungen in Übereinstimmung mit den offiziell festgelegten Gerichtszeiten Werktage und -stunden maßgeblich sind. “599 Insofern könnte man annehmen, es komme auch bei der Regelung des Art. 317 Nr. 5 CPP auf Werktage an. Der Oberste Gerichtshof jedoch stellt auf die schützende Funktion der Norm zugunsten des Angeklagten ab, für den es keinen

\footnotetext{
${ }^{596}$ Aponte Cardona, 2006a, S. 175 ff.; dazu Oberster Gerichtshof, Rad. 30363, Entsch. von 4.02.2009.

${ }^{597}$ Aponte Cardona, 2006a, S. 176.

598 Art. 317 Nr. 5. CPP: „Cuando transcurridos ciento veinte (120) días contados a partir de la fecha de la formulación de la acusación, no se haya dado inicio a la audiencia de juzgamiento.“ (dt. Übersetzung d. Verf.).

599 Art. 157 Abs. 3 CPP: „Las actuaciones que se surtan ante el juez de conocimiento se adelantarán en días y horas hábiles, de acuerdo con el horario judicial establecido oficialmente.“(dt. Übersetzung d. Verf.).
} 
Unterschied macht, ob die Gerichte an den Tagen, an denen er sich in Haft befindet, arbeiten oder nicht. ${ }^{600}$ Es wäre insofern unangemessen und auch mit dem internationalen Recht nicht vereinbar, wenn ein noch nicht verurteilter Angeklagter, der sich präventiv in Gewahrsam befindet, länger auf das Voranschreiten des Verfahrens warten und damit länger in Haft bleiben müsste, obwohl für ihn weiterhin die Unschuldsvermutung gelte. Dies aber wäre der Fall, wenn es sich bei dem maßgeblichen Zeitraum um Werktage handeln würde. ${ }^{601}$

b. Eine weitere Frage bzgl. Ziffer 5 ist, welcher Richter zuständig ist, um nach Verlesung der Anklage und damit nach Beginn des Hauptverfahrens über einen Antrag auf Freilassung $\mathrm{zu}$ entscheiden. Denn es existiert im CPP keine Norm, die dem Erkenntnisrichter die Zuständigkeit hierfür zuschreibt, obwohl dieser tatsächlich bei einigen Gerichten über derartige Anträge entscheidet. ${ }^{602}$ Verschiedene Normen und Prinzipien allerdings deuten darauf hin, dass einzig der JCG zuständig sein kann:

Erstens implizieren das Unmittelbarkeitsprinzip, das Kontradiktionsprinzip und die Konzentrationsmaxime, dass der Erkenntnisrichter von seinen eigentlichen Funktionen, namentlich der Vorbereitung und Durchführung der mündlichen Verhandlungen vor und während des Hauptverfahrens, nicht abgelenkt werden soll. Eine Befassung des Erkenntnisrichters mit anderen Angelegenheiten würde dazu führen, dass er sich möglicherweise nicht mehr unparteilich und unmittelbar mit dem Sachverhalt im Rahmen der mündlichen Verhandlung befassen und über diesen entscheiden könnte, so wie es eigentlich angebracht wäre. Zweitens ist es die ureigene Funktion des Richters zur Kontrolle der Garantien, über Fragen zu entscheiden, die mit der Einhaltung von Verfahrensrechten des Beschuldigten/Angeklagten in Zusammenhang stehen, und zu denen vor allem das Recht auf Freiheit gemäß Art. 2 CPP zählt. Drittens lässt sich ein Antrag auf Freilassung seiner Art nach ohne Weiteres unter die in Art. 154 Nr. 8 CPP genannten „ähnlichen Angelegenheiten“ subsumieren, für welche die Entscheidungskompetenz allein beim JCG liegt.

\footnotetext{
${ }^{600}$ Vgl. Oberster Gerichtshof, Rad. 65256 von 20.02.2013, Berichterstatter Fernando Alberto Castro; auch. KVerfG, Entsch. C-774 v. 2001, Abschn. 5.5.

${ }^{601}$ Vgl. Oberster Gerichtshof, Rad. 65256 von 20.02.2013, Berichterstatter Fernando Alberto Castro; auch. KVerfG, Entsch. C-774 v. 2001, Abschn. 5.5. ${ }^{602} \mathrm{Vgl}$. Aponte Cardona, 2006a, S. 178. 
Im Hinblick auf den Ausnahmecharakter freiheitsbeschränkender Maßnahmen und darauf, dass Sicherungsmaßnahmen stets angemessen sein müssen (Art. 250 Nr. 1 CN und 295 CPP), sind die Regelungen des CPP zum Freiheitsentzug zudem „restriktiv auszulegen, und ihre Anwendung muss notwendig, angemessen, proportional und vernünftig bzgl. der Inhalte der Verfassung sein“ (Art. 295 CPP) ${ }^{603}$ D.h., dass eine Beschränkung der Freiheit nicht aus anderen Gründen und Zielen erfolgen darf als den im CPP Festgelegten (Art. 296 CPP) und dass diese, sobald die Voraussetzungen für eine Freilassung gegeben sind, unverzüglich zu veranlassen ist. ${ }^{604}$

Das KVerfG hat hinsichtlich des zeitlich unbegrenzten Ausmaßes, den die präventive Inhaftierung in zahlreichen Fällen angenommen hat, Richtlinien festgelegt, an denen sich die verantwortlichen Strafverfolgungsorgane bei der Festlegung des angemessenen, gerechten und verhältnismäßigen Zeitrahmens orientieren können. So hat es in dem Urteil C-774 von 2001 befunden, dass sich die Strafverfolgungsorgane stets an den folgenden Kriterien orientieren müssen: $:^{605}$

1. Die Auswirkungen der Dauer der Inhaftierungen (Entsprechung zwischen Inhaftierung und ihren Zielen);

2. Die bereits in Haft verbrachte Zeit;

3. Dauer der Haft im Verhältnis zu der vorgeworfenen Straftat;

4. Die Auswirkung der (konkret vorgeworfenen) Straftat;

5. Die materiellen und moralischen Wirkungen der Maßnahme auf den Verdächtigen;

6. Das Verhalten der Strafverfolgungsorgane bei der Festnahme;

\footnotetext{
${ }^{603}$ Art. 295 CPP: „Afirmación de la libertad. Las disposiciones de este código que autorizan preventivamente la privación o restricción de la libertad del imputado tienen carácter excepcional; solo podrán ser interpretadas restrictivamente y su aplicación debe ser necesaria, adecuada, proporcional y razonable frente a los contenidos constitucionales.“ (dt. Übersetzung d. Verf.).

${ }^{604}$ In Anbetracht der mehrdeutigen und problematischen Fassung des Artikels sind die für das Konzept der „angemessenen Frist" geltenden Maßstäbe zu berücksichtigen. Vgl. Aponte Cardona, 2006a, S. 178 ff.; Bernal Cuellar/Montealegre Lynett, 2013 T. II, S. 618 f.

${ }^{605}$ KVerfG, Entsch. C-774 v. 2001, Abschn. VI. „Consideraciones de la Corte“, Nr. 5.5.: „1. La efectividad de la duración (amoldar la detención a sus objetivos); 2. El tiempo actual de detención; 3. Duración de la detención en relación con la ofensa producida; 4 . Los efectos de la conducta punible; 5 . Los efectos materiales y morales que para el sindicado comporta la medida; 6 . La conducta de las autoridades judiciales; 7. Podría agregarse, más aún en el caso colombiano, la consideración sobre las condiciones objetivas del sistema carcelario y su impacto sobre la dignidad de las personas.“(dt. Übersetzung d. Verf.).
} 
7. Die Berücksichtigung der Haftbedingungen und deren Auswirkungen auf die Menschenwürde.

\section{Das Gesetz über die öffentliche Sicherheit}

Durch das Gesetz 1453 von $2011^{606}$ wurden das kolumbianische Strafgesetzbuch (CP), die Strafprozessordnung (CPP) und das Gesetz für Kinder und Heranwachsende (Código de Infancia y Adolescencia) reformiert, die Regelungen über den Verlust des Eigentums geändert und weitere sicherheitsrelevante Vorschriften erlassen; Außerdem wurden mit dem Argument, die Opfer von Straftaten besser schützen zu wollen, verschiedene Mechanismen zum „Kampf gegen das Verbrechen“ eingeführt. Diese Vorschriften führten dazu, dass die Dauer und die Bedingungen für einen Freiheitsentzug wie folgt erweitert wurden:

Die Fristen, die einzuhalten sind, da andernfalls eine Freilassung zu erfolgen hat, wurden verlängert. So wurde die Frist von 60 Tagen, innerhalb derer nach Verlesung der Beschuldigung die Verlesung der Anklage oder ein Antrag auf Einstellung zu erfolgen hat, auf 90 Tage ausgedehnt für Fälle, in denen Tatmehrheit vorliegt oder drei oder mehr Beschuldigte verfolgt werden (Art. 317 Nr. 4 CPP). ${ }^{607}$ Die nach der Verlesung der Anklage bis zum Beginn der mündlichen Hauptverhandlung geltende Frist ist sogar auf bis zu 120 Tage erweitert worden (Art. 317 Nr. 5 CPP) für Fälle, in denen die mündliche Hauptverhandlung aufgrund von dem Angeklagten vorgenommener „Verschleppungshandlungen“ nicht beginnen konnte oder die mündliche Hauptverhandlung aus anderen nachvollziehbaren Gründen nicht beginnen konnte. Zudem wurde die Dauer der Geltung einer Festnahmeanordnung verlängert und zwar dahingehend, dass die FGN, die vorher eine Frist von 6 Monaten einhalten musste, die sie einmalig um 6 Monate verlängern konnte, nunmehr 1 Jahr zur Verfügung hat und um 1 Jahr zusätzlich verlängern kann (Art. 298 CPP). Darüber hinaus wurde dem Opfer oder dessen Vertretern die Möglichkeit eingeräumt, selbst unmittelbar Sicherungsmaßnahmen zu beantragen, sofern die Staatsanwaltschaft dies nicht bereits getan hat (Art. 306 CPP). Insofern wird eine gewisse Tendenz des Gesetzgebers deutlich, sogar die unverdächtigsten Verhaltensweisen durch Strafverfahren zu kriminalisieren, ${ }^{608}$ was den Beschränkungen der

${ }^{606}$ Dieses Gesetz wurde auch durch Gesetz 1760 von 2015 geändert. Vgl. dazu Zuluaga, Boletín GLIPGö 5 (2013), S. 29.

${ }^{607}$ Dazu Oberster Gerichtshof, Rad. 37877, Entsch. von 18.11.2011, Abschn. „Consideraciones de la Corte“. ${ }^{608} \mathrm{Vgl}$. Sotomayor Acosta, NFP 71 (2007), S. 41 ff.; Calle Calderón, NFP 67 (2005), S. 158. 
Strafgewalt widerspricht, die dem Gesetzgeber durch Verfassung und Gesetz auferlegt sind. Zu diesem Zweck nimmt er den Ausschluss von strafrechtlichen Vergünstigungen und die Freiheitsstrafe ersetzenden Maßnahmen zu Hilfe sowie Verbote von Zugeständnissen wegen des Geständnisses der Anklagepunkte, von Absprachen zwischen Verteidigung und FGN (Art. 68 A CP), das Verbot einer Aussetzung der Strafe zur Bewährung (libertad provisional) und die Erweiterung der Gründe zur präventiven Festnahme in Form der Unterbringung in einem Gefängnis (Art. 313 CPP).

\section{Zusammenfassung}

In der zweiten Gruppe von Maßnahmen, die intensive Grundrechtsbeeinträchtigungen zur Folge haben, befinden sich diejenigen, die das Recht auf die Unverletzlichkeit der Kommunikation beschränken, namentlich der Eingriff in die postalische Kommunikation (Art. $233 \mathrm{CPP}$ ) und die Telefonüberwachung (Art. $235 \mathrm{CPP}$ ). Beim Eingriff in die postalische Kommunikation wird bezweckt, die Existenz und den Inhalt der von den Verdächtigen oder Beschuldigten übermittelten Informationen zu erhalten, die für die Ermittlung nützlich sein können. Das Objekt der postalischen Überwachung geht über Briefe hinaus und erfasst alle Formen postalischer Kommunikation, wie zum Beispiel verschlossene Pakete, die Träger persönlicher oder geschäftlicher Nachrichten sein können. Indem hier Bezug auf Kopien der versendeten/empfangenen Nachrichten genommen wird, liegt kein Zurückhalten im eigentlichen Sinne vor, sondern ein Eingriff in eine tatsächlich zugegangene Korrespondenz, deren Inhalt erlangt wird. Die Kenntnisnahme des Inhalts der Sendung zur Erlangung einer Ermittlungsquelle oder eines Beweises ist die Grenze des Eingriffs. Bei der Telefonüberwachung handelt es sich um ein Verfahren, in dem per Funk oder Telefon übertragene Gesprächsinhalte aufgenommen werden. Für die h.M. muss das Objekt ein Gespräch zwischen zwei Gesprächspartnern sein zu dem Zweck, Informationen zu erhalten, die für die Ermittlung nützlich sind, und diese Person kann nur diejenige sein, gegen die das Ermittlungsverfahren gerichtet ist. Bei der nachträglichen Kontrolle der Telefonüberwachung und des Eingriffs in die postalische Kommunikation ist die Prüfung des Vorliegens vernünftig fundierter Anhaltspunkte wesentlich, d.h. die Prognose, etwas zu finden, und der Nutzen der gewählten Maßnahme aufgrund der Vorermittlungen durch die Staatsanwaltschaft.

Der intensivste Grundrechtseingriff im Ermittlungsverfahren ist die Einschränkung der Freiheit, die in zwei verschiedenen Szenarien zulässig ist: Wenn jemand auf frischer Tat 
betroffen wird oder wenn ein Festnahmebeschluss des Richters zur Kontrolle der Garantien vorliegt. Ausnahmsweise räumt der CPP darüber hinaus die Möglichkeit zur Anordnung der Festnahme durch die Staatsanwaltschaft ohne vorherige richterliche Anordnung ein (Art. 300 CPP). Die Rechtskontrolle durch den JCG erstreckt sich daher auf die folgenden Aspekte: 1. Prüfung der Verbindung zwischen der Tatsache und den Tatbeständen, bei der eine Sicherungsmaßnahme zulässig ist; 2. Prüfung der Rechtmäßigkeit der Festnahmeanordnung; 3. Prüfung der maximalen Festnahmezeit; 4. Weitere Aspekte wie die Prüfung des Festnahmeverfahrens. Die Gründe, aus denen ein Festgenommener wieder freizulassen ist, sind in Art. 317 CPP geregelt. Durch das Gesetz 1453 von 2011 wurden die Fristen der Festnahme und die Dauer der Geltung einer Festnahmeanordnung verlängert. Darüber hinaus wurde dem Opfer oder dessen Vertreter die Möglichkeit eingeräumt, selbst Sicherungsmaßnahmen unmittelbar $\mathrm{zu}$ beantragen, sofern die Staatsanwaltschaft dies nicht bereits getan hat (Art. 306 CPP). 


\section{Zweiter Teil: Probleme bei der Feststellung der Rechtswidrigkeit eines Ermittlungseingriffes}

\section{§ 7. Die sog. „motivos fundados“ als Voraussetzung von Ermittlungsmaßnahmen}

\section{A. Der Begriff ,motivos fundados“6}

\section{Verfassungsrechtliche Bedeutung}

Die sog. „fundierten Anhaltspunkte“ (,motivos fundados“) stellen eine der wichtigsten Voraussetzungen für die Anordnungen von Grundrechtseingriffen in der Ermittlungsphase des kolumbianischen Strafverfahrens dar. Einerseits beschreiben sie einen Grund der Anordnung auf Seiten der FGN, um jegliche Ermittlungshandlungen auszuführen, wobei es hierbei um jene Maßnahmen geht, die keine vorherige richterliche Anordnung verlangen (Art. 213-245 CPP). In den Fällen, in welchen es sich um Maßnahmen mit nachträglichen Kontrollen handelt, ist der fundierte Anhaltspunkt gleichzeitig ein Objekt der richterlichen Prüfung durch den JCG. Sowohl dessen Beweisunterstützung als auch die Schlussfolgerung, welche sich aus dem fundierten Anhaltspunkt ergibt und die Basis der staatsanwaltschaftlichen Entscheidungen bildet, werden durch den $\mathrm{JCG}^{609}$ überprüft. Andererseits sollte sich der JCG stets auf die Existenz von fundierten Anhaltspunkten beziehen, um den Grundrechtseingriff anzuordnen, soweit es sich um andere Maßnahmen als die oben Beschriebenen (Artikel 213-245 CPP) handelt, also alle Ermittlungsmaßnahmen, die eine vorherige richterliche Anordnung verlangen. ${ }^{610}$ In diesem Sinne stellen die fundierten Anhaltspunkte für die FGN einen Grund zur Anordnung einer Ermittlungsmaßnahme dar bzw. bilden in jedem anderen Fall für den JCG das Fundament seiner Entscheidungen (Art. 246 CPP). Zugleich stellen die fundierten Anhaltspunkte einen Grund zur Bestätigung im Rahmen der

\footnotetext{
${ }^{609}$ Vgl. dazu supra § 4. B. III. Bestätigungen; s. auch u.a. Zapata Betancur, 2007, S. 133 ff.; Aponte Cardona, 2006, S. 64 ff.; Guerrero Peralta, 2006, S. 91 ff.; Guerrero Peralta, 2007, S. 191 ff.; CSJ, 2005, S. 31 ff.; Bernal Cuellar/Montealegre Lynett, 2013 T. I, S. 273 ff., 292. und T. II, S. 107, 203.

${ }^{610} \mathrm{Vgl}$. dazu supra § 4. B. II. Anordnungen; s. auch u.a. Aponte Cardona, 2006, S. 23; Bernal Cuellar/Montealegre Lynett, 2013 T. I, S. 291 f. und T. II, S. 204; CSJ, 2005, S. 21; Guerrero Peralta, 2006, S. 30; Guerrero Peralta, 2007, S. 187 f., 199 ff.
} 
nachträglichen Kontrollen der Ermittlungsmaßnahmen dar, die keiner vorherigen richterlichen Genehmigung bedürfen. ${ }^{611}$

Die Notwendigkeit der fundierten Anhaltspunkte als Basis der staatsanwaltschaftlichen Anordnung von Ermittlungsmaßnahmen wurde im Rahmen der Debatten zur Verfassungsänderung, welche das sog. akkusatorische System in Kolumbien einführte, berücksichtigt. Durch den Gesetzesakt 03 von 2002 wurde der Art. $250 \mathrm{CN}^{612}$ reformiert, der in Abs. 1 die Forderung nach „hinreichenden Hinweisen oder Motiven“ auf eine Straftat ${ }^{613}$ als Voraussetzung zur Einleitung des Ermittlungsverfahrens konstituiert. So steht in der Gesetzesbegründung des Art. 250 - insbesondere in den betreffenden Diskussionen um Nr. 2 des genannten Artikels -, dass der Staatsanwalt Hausdurchsuchungen, Beschlagnahmen und Überwachung und Aufzeichnung von Kommunikation ohne richterliche Genehmigung vornehmen kann. Der Gesetzgeber beabsichtigte mit dieser Verfassungsänderung, dass „die Gründe für die Staatsanwaltschaft, um eine dieser Maßnahmen im Rahmen der Ermittlung vorzunehmen, auf vernünftigen Motiven und nicht auf bloßem Verdacht basieren müssen. “614 An dieser Stelle wird Art. 250 Nr. 2 CN nicht nur zur Grundlage einer richterlich nicht angeordneten Ermittlungshandlung seitens der FGN, sondern auch zum Fundament der nachträglichen Kontrollen durch den JCG. In beiden Fällen, sei es die staatsanwaltschaftliche Entscheidung oder die richterliche Bestätigung, gilt die Überprüfung der fundierten Anhaltspunkte oder ,,motivos fundados“ als essentiell.

Der Wortlaut des Art. $250 \mathrm{CN}$ wurde als zweideutig und somit unbestimmt kritisiert. Es heißt, er erlaube keine deutliche Interpretation darüber, was als Beweisschwelle bezeichnet

611 S. dazu ausführlich supra § 5. Nachträglicher Rechtsschutz gegen Maßnahmen zur Beschränkung der Intimität und $\S 6$. Nachträglicher Rechtsschutz gegen Maßnahmen zur Beschränkung der Unverletzlichkeit der Kommunikation und der Freiheit.

${ }^{612}$ Vgl. supra § 3. A. I. 1. Gesetzesakt 03 von 2002; s. dazu García Valencia, 2003, S. 19 ff.; Bzgl. der Entstehungsgeschichte der Verfassungsänderung s. CEJ, 2003, S. 133 ff.; s. auch KVerfG Entsch. C-1092 v. 2003, Nr. 4.1.1.1.

613 Art. 250 Abs. 1: ,adelantar el ejercicio de la acción penal y realizar la investigación de los hechos que revistan las características de un delito que lleguen a su conocimiento [...], siempre y cuando medien suficientes motivos y circunstancias fácticas que indiquen la posible existencia del mismo“. („die Strafsache einzuleiten und die Ermittlung des zu ihrer Kenntnis, möglicherweise die Merkmale einer Straftat erfüllenden Verhaltens vorzunehmen [...], wenn ausreichende Gründe und faktische Umstände vorliegen, die das Vorliegen einer solchen möglich erscheinen lassen." -dt. Übersetzung d. Verf.-); s. dazu supra § 3. A. I. 1. C. i. Einleitung des Ermittlungsverfahrens und Fn. 286.

${ }^{614}$ Vgl. Gaceta del Congreso 134 (2002), V. D). 3.: „las razones que motivaron al fiscal para adoptar alguna de estas medidas durante la investigación, se encuentren apoyadas por motivos razonables, y no simples sospechas.“ (dt. Übersetzung d. Verf.). 
werden könne, wann also ein Grundrechtseingriff ${ }^{615}$ angeordnet werden dürfe. Dennoch im Speziellen durch die Verfassungsmäßigkeitskontrolle des Gesetzesaktes 03 von $2002^{616}$ - legte die Rechtsprechung des KVerfG die Transzendenz der Begründung für die Ermittlungen von Tatsachen fest. Deutlich wird dies in der Kontrolle der Verfassungskonformität von Art. 250 Nr. 2, welche in dem Urteil C-1092 von 2003 enthalten ist, in welchem das KVerfG feststellt, dass die Überprüfung der Gründe, welche die Ermittlungsmaßnahmen stützen, einen Teil der umfassenden und integralen Kontrolle des JCG bildet. ${ }^{617}$ Diese Beurteilung des KVerfG basiert auf einer teleologischen Auslegung, durch welche deutlich wird, dass der vom Gesetzgeber verfolgte Zweck sich darauf bezieht, dass alle Handlungen der FGN bzw. Einleitung, Ablauf und Abschluss des Ermittlungsverfahrens durch ausreichende Motive begründet sind. ${ }^{618}$ Diese Ansicht des KVerfG bzgl. des Art. 250 Nr. 2 CN hat als unmittelbares Präzedenzurteil die Entscheidung C-805 von 2002 zitiert $^{619}$, bei welcher die Verfassungsmäßigkeit des Art. 392 des Gesetzes 600 von 2002 (vorheriger $\mathrm{CPP}^{620}$ ) bzgl. der Rechtmäßigkeit von Sicherungsmaßnahmen der FGN überprüft wurde. Für das KVerfG folgt aus dem Art. 28 Abs. $1 \mathrm{CN}^{621}$, dass die Grundrechtseingriffe in einer strafrechtlichen Ermittlung nur aus einem materiellen Beweiskriterium (,criterio material de orden probatorio" $)^{622}$ hervorgehen dürfen. Diese Rechtsprechung, durch welche ein eigener Beweisstandard für Ermittlungsmaßnahmen entsteht, wurde in dem Urteil C-024 von 1994 (Meilenstein-Urteil) etabliert. In diesem Urteil wurde eine Verfassungsbeschwerde gegen das Dekret 1355 von 1970 (Código Nacional de Policía) geklärt, welches den sog. behördlichen Präventiv-Gewahrsam (captura administrativa) ${ }^{623}$ erlaubte. Bei dem

\footnotetext{
${ }^{615}$ Vgl. Guerrero Peralta, 2007, S. 166 f.; Bzgl. der Beweisordnung von CPP s. Bernal Cuellar/Montealegre Lynett, 2013 T. I, S. 255 f.

616 Der Gesetzesakt 03 v. 2002 wurde von KVerfG ausführlich überprüft. Vgl. u. a. Entsch. C-1039 v. 2004 , C-1092 v. 2003, C-970 v. 2004, C-334 v. 2005 und C-013 v. 2004.

${ }^{617}$ KVerfG, Entsch. C-1092 v. 2003, Abschn. 5.1.

${ }^{618}$ KVerfG, Entsch. C-1092 v. 2003, Abschn. 4.1.1.1.

${ }^{619}$ KVerfG, Entsch. C-805 v. 2002, Abschn. VI. Consideraciones y Fundamentos.

${ }^{620} \mathrm{Vgl}$. dazu supra $§ 2$. C. II. Die Strafprozessordnung von 2000.

${ }^{621}$ Art. 28 Abs. $1 \mathrm{CN}$ : „Nadie puede ser molestado en su persona o familia, ni reducido a prisión o arresto, ni detenido, ni su domicilio registrado, sino en virtud de mandamiento escrito de autoridad judicial competente, con las formalidades legales y por motivo previamente definido en la ley. (Herv. d. Verf.). („Niemand darf in seiner Person oder Familie belästigt, inhaftiert, festgenommen oder in der Wohnung durgesucht werden, außer aufgrund einer förmlichen schriftlichen Anordnung, die durch ein richterliches Organ ausgestellt wird, und nur aus gesetzlich festgelegten Gründen.“-dt. Übersetzung d. Verf.-).

${ }^{622}$ KVerfG, Etnsch. C-805 v. 2002, Abschn. VI. 17.

${ }^{623}$ KVerfG, Entsch. C-024 v. 1994, Abschn. II. Fundamento Jurídico. Für die sog. "Captura administrativa" vgl. Bernal Cuellar/Montealegre Lynett, 2013 T. II, S. 493 ff.; Prieto Vera, 2006, S. 47f.; Martínez Rave,
} 
Versuch, die Motive der Festnahme zu definieren und zu verdeutlichen, schuf das KVerfG eine erste Annäherung, durch welche sich der Kerngehalt der fundierten Anhaltspunkte verstehen ließe. In diesem Sinne bekräftigte es, dass hierfür Folgendes verstanden werden müsse:

„Tatsachen, Sachverhalte, die nicht die Unmittelbarkeit der Fälle auf frischer Tat betroffen, sondern eine mittelbare Beziehung zu der Festnahme aufweisen, müssen deutlich und dringlich für die Rechtfertigung der Festnahme sein. Der fundierte Anhaltspunkt, mit dem die Festnahme begründet wird, ist eine Gesamtheit von artikulierten Tatsachen, die objektiv darauf schließen lassen, dass die festzunehmende Person wahrscheinlich Täter oder Teilnehmer einer Straftat ist. Daher wird der bloße Verdacht oder die einfache Wahrnehmung des Polizisten nicht als fundierter Anhaltspunkt gelten. “624

Diese Definition beinhaltet eine doppelte Verfassungsgrundlage. Erstens fordert der Art. 28 Abs. $1 \mathrm{CN}$ eine besondere Begründung zur Anordnung von Grundrechtseingriffen in die persönliche Freiheit. ${ }^{625}$ Zweitens wird im Art. 29 als Grundrecht das Recht auf ein faires Verfahren konstituiert. Deutlich wird dies im Abs. 3, der das Verteidigungsrecht festlegt und im Abs. 4, welcher das Beweisverwertungsverbot ${ }^{626}$ definiert. Zusätzlich ist diese Position des KVerfG, welche in mehreren vorherigen Urteilen ${ }^{627}$ bestätigt wurde, in der Verfassungsmäßigkeitskontrolle der Reform des Art. $250 \mathrm{CN}$ enthalten. In der Analyse des Abs. 1 Nr. 2 des genannten Artikels bekräftigt das KVerfG die in der Gesetzesbegründung

2002, S. 447 f.; Sánchez Martínez, 2003, S. 7; Aponte Cardona, 2006a, S. 53 ff.; s. dazu auch supra § 6. C. I. Festnahme mit Ausnahmekompetenzen.

${ }^{624}$ KVerfG, Entsch. C-024 v. 1994, Abschn. II. 7.2.: „hechos, situaciones fácticas, que si bien no tienen la inmediatez de los casos de flagrancia sino una relación mediata con el momento de la aprehensión material, deben ser suficientemente claros y urgentes para justificar la detención. El motivo fundado que justifica una aprehensión material es entonces un conjunto articulado de hechos que permitan inferir de manera objetiva que la persona que va a ser aprehendida es probablemente autora de una infracción o partícipe de ella. Por consiguiente, la mera sospecha o la simple convicción del agente policial no constituye motivo fundado." (dt. Übersetzung d. Verf.)

${ }^{625}$ KVerfG, Entsch. C-024 v- 1994, Abschn. II. 6; Entsch. C-580 v. 2002, Abschn. 3.2. Artículo 7; Entsch. C805 v. 2002 , Abschn. VI. 6 ff.

${ }^{626}$ KVerfG, Entsch. C-805 v. 2002, Abschn. VI. 30; s. auch KVerfG, Entsch. T-508 v. 2011, C-592 v. 2005 ; Bzgl. der "Fairness" (Debido proceso) im kolumbianischen Strafprozessrecht s. Bernal Cuellar/Montealegre Lynett, 2013 T. I, S. 911 ff.; Calle Calderón, NFP 63 (2000), S. 3 ff.; Camargo, 2002, S. 105 ff.; Molina Arrubla, 2002, S. 295 ff.; Suárez Sánchez, 2001, S. 220 ff.; Bzgl. der Nichtigkeit der Beweise, deren Erhebung das faire Verfahren nicht beachtete, s. Molina López, 2012, S. 370.

${ }^{627}$ Diese Meinung wurde mehrmals in der Rechtsprechung des KVerfG bestätigt. Vgl. u.a. KVerfG, Entsch. C-179 v. 1994; Entsch. C-270 v. 1994; Entsch. C-327 v. 1997; C-251 v. 2002; C-580 v. 2002, Abschn. 3.2. C-025 v. 2009 und C-127 v. 2011. Dennoch ist in der Entsch. C-176 v. 2007, in der die Verfassungsmäßigkeit des Dekrets 1355 v. 1970 und des behördlichen Präventiv-Gewahrsam geprüft wurde, eine Gegenmeinung zu sehen. Dazu s. Bernal Cuellar/Montealegre Lynett, 2013 T. II, S. 493 ff.

202 
des Gesetzesakts 03 von 2002 präsentierten Argumente, durch welche die Notwendigkeit fundierter Anhaltspunkte - im Gegensatz zum bloßen Verdacht - zum Zeitpunkt der Ergreifung von Ermittlungsmaßnahmen festgelegt wurde. ${ }^{628}$ Auf diese Weise wird zudem eine extensive Verständlichkeit der Schlüsselinhalte des aktuellen Strafverfahrensmodells ermöglicht. ${ }^{629}$

Aufgrund der verfassungsrechtlichen Fundamente und der durch die Entscheidung C-024 von 1994 eingenommenen Position des KVerfG lässt sich folgern, dass ein fundierter Anhaltspunkt 1) eine Gesamtheit von artikulierten Tatsachen ist (objektive Situation), 2) die durch Beweismittel unterstützt werden (Beweisunterstützung), 3) aus denen objektiv geschlossen wird (Schlussfolgerung), 4) ob eine Wahrscheinlichkeit von Täterschaft oder Teilnahme an strafbaren Handlungen besteht. ${ }^{630}$ Er kann nicht als äquivalent zum bloßen Verdacht oder als einfache Überzeugung des polizeilichen Vertreters angesehen werden (hohe Anforderungen an die Angemessenheit). ${ }^{631}$ Zusätzlich zu den Kriterien, welche sich aus der Definition des KVerfG ergeben, begründet der Gesetzesakt 03 von 2002 die Kontrolle ex ante bzw. ex post durch den JCG zur Feststellung von fundierten Anhaltspunkten (richterliche Kontrolle). ${ }^{632}$

\section{Systematische Lage im aktuellen CPP}

Bei der Entwicklung des Gesetzesakts 03 von 2002 hat das Gesetz 906 von 2004 den Begriff ,fundierter Anhaltspunkt“ an verschiedenen Stellen eingeführt: als Fundament der Beschlagnahmen (Art. 83 Abs. 2); als Basis für die Aufhebung und Außerkraftsetzung der Rechtspersönlichkeit oder die temporäre Schließung von Lokalen und öffentlichen Einrichtungen (Art. 91 Abs. 1); als Fundament der Aufhebung und Streichung aus dem Güterrechtsregister, dessen Eigentumstitel durch Betrug erlangt wurde (Art. 101 Abs. 1); als Grund für Ermittlungsmaßnahmen mit oder ohne richterliche Anordnung (Art. 213-250); als Fundament, um Vernehmungen in der Vorermittlung voranzutreiben (Art. 282); als Ba-

\footnotetext{
${ }^{628}$ Vgl. KVerfG, Entsch. C-1092 v. 2003, Abschn. 4.1.1.1.

${ }^{629}$ Für eine Beschreibung des kolumbianischen Ermittlungsverfahren s. ausführlich supra § 3. Das strafrechtliche Ermittlungsverfahren in Kolumbien.

${ }^{630}$ Dies ist eine der im CPP dargestellten Schlussfolgerungen. Vgl. dazu Prieto Vera, 2006, S. 54 ff.; darüber hinaus gibt es eine Vielzahl von Schlussfolgerungen, die nachher analysiert werden. s. infra $\S 10$. B. II. Streitfälle.

${ }^{631}$ Für einen Vergleich der Begriffe in der Strafprozessordnungen von Spanien, Chile, Venezuela und Peru s. Pava Lugo, 2009, S. 6 f.

${ }^{632}$ Vgl. dazu ausführlich supra § 4. Der Richter zur Kontrolle der Garantien (Juez de Control de Garantías), mit Bezug auf ihre richterliche Kompetenz.
} 
sis der vorgezogenen Beweisaufnahme (Art. 284 Nr. 3); als Basis zur Anordnung eines Haftbefehls durch den JCG (Art. 297); als Fundament zur Anordnung von Sicherheitsmaßnahmen (Art. 308-311) und als Fundament zur Vernehmung von Zeugen unter 12 Jahren (Art. 383 Abs. 2). In all diesen Maßnahmen werden zudem die Schlussfolgerung und der Zweck, an welchen sich die Anforderungen der Begründung mit Bezug auf die fundierten Anhaltspunkte orientieren, genannt, welche im Folgenden behandelt werden:

\section{Fundament, um Präventivmaßnahmen anzuordnen (Art. 83 Abs. 2,}

\section{Abs. 1 und 101 Abs. 1 CPP)}

Die erste Gruppe von Maßnahmen ist mit der Beschlagnahme von beweglichem und unbeweglichem Vermögen verwandt. Der CPP fordert fundierte Anhaltspunkte als Fundament für drei spezifische Maßnahmen: erstens zur Beschlagnahme von Vermögen, welches mit strafbaren Handlungen in Verbindung steht (Art. 83 Abs. 2 CPP); zweitens für die Aufhebung oder vorübergehende Schließung von Lokalen und öffentlichen Einrichtungen (Art. 91 Abs. 1 CPP); drittens für die Aufhebung einer Verfügungsbefugnis (Eigentumstitel) über unbewegliche Gegenstände (Art. 101 CPP). Der CPP verlangt, dass aus den fundierten Anhaltspunkten, welche diese Maßnahmen legitimieren, eine Verbindung des Vermögens oder der Verfügungsmacht mit der Straftat hervorgeht. ${ }^{633}$

Einerseits beschreibt Art. 83 Abs. 2 CPP, welcher sich mit der Beschlagnahme von Gütern befasst, dass die fundierten Anhaltspunkte drei spezifische Schlussfolgerungen hervorbringen müssen: a) Das Vermögen oder Geld ist ein direktes oder indirektes Produkt einer vorsätzlichen Straftat; b) der Wert ist äquivalent zu den beschlagnahmten Einnahmen; c) das Objekt wurde benutzt oder war für die Benutzung für vorsätzliche Straftaten vorgesehen bzw. sollte das materielle Objekt des Verbrechens ${ }^{634}$ ersetzen. Es ist zu verdeutlichen, dass die Beschlagnahme im CPP nur erfolgt, wenn die strafrechtliche Verantwortlichkeit des Beschuldigten bzw. Angeklagten bestimmt wurde (Art. 82 CPP). Aus diesem Grund unterscheidet sie sich von anderen Figuren, welche auch das Eigentumsrecht einschränken v.gr.

\footnotetext{
${ }^{633}$ Vgl. dazu Pava Lugo 2009, S. 33, nach denen ist die Entscheidung über die Einschränkung des Rechts auf Eigentum gerechtfertigt, wenn Gründe vorliegen, die auf Erkenntnismittel, die als Beweis in der Hauptverhandlung dienen, unterstützt werden und Grundlage für die abschließende richterliche Entscheidung darstellen. (dt. Übersetzung d. Verf.) ("cuando existan motivos fundados en medios cognoscitivos que tengan la capacidad de ser pruebas y la vocación de ser parte del fundamento demostrativo de la decisión judicial definitiva." - Herv. i. Orig. -).

${ }^{634}$ Bzgl. der Beschlagnahme vgl. Bernal Cuellar/Montealegre Lynnet, 2013, T. II, S. 373; Aponte Cardona, 2006, S. 71; Restrepo Medina 2007, S. 73; CSJ, 2005, S. 38.
} 
das Erlöschen des Eigentumsrechts, die Enteignung und die administrative Beschlagnah$m e .{ }^{635}$ Ebenso etabliert der CPP eine Voraussetzung bzgl. des Vorgehens bei der Beschlagnahme, welche nur bei vorsätzlichen Straftaten angeordnet wird. Problematisch ist, dass keine Klarheit darüber besteht, ob die in Art. 83 Abs. 2 CPP aufgezeigten Schlussfolgerungen kumulativ oder disjunktiv vorliegen müssen. ${ }^{636}$ Eine strenge Interpretation des Art. 83 Abs. 2 bezweckt, das Eigentum weitläufig gegenüber willkürlichen Eingriffen zu schützen. Auch wenn der Art. 83 Abs. 2 CPP aufgrund seiner Mehrdeutigkeit bzgl. seiner Aussagen viel Konfusion bewirkt, kann nur eine strikte Interpretation - also eine kumulative - auf Interventionen in die Eigentumsrechte einschränkend wirken.

Im Rahmen der Art. 82-91 CPP mit Bezug auf die Beschlagnahme Art. 91 CPP wird die Möglichkeit geschaffen, die Rechtsfähigkeit zu suspendieren bzw. aufzuheben oder lokale und öffentliche Einrichtungen vorübergehend zu schließen. ${ }^{637}$ Die Aufhebung oder Suspension der Rechtsfähigkeit bedeutet den dauerhaften oder temporären Verlust der Anerkennung einer Organisation bzw. eines Unternehmens oder anderer Typen des Geschäftswesen, welche die Befähigung für Vertragspflichten und Aktivitäten, die eine rechtliche Verantwortung sich selbst oder anderen gegenüber generieren, mit sich bringen. Die genannten Maßnahmen können zu jedem Zeitpunkt vor der Anklage verordnet werden und die Basis der fundierten Anhaltspunkte schaffen, aus welchen hervorgehen kann, dass die betroffenen Güter vollständig ,ganz oder teilweise der Entwicklung von Straftaten gewidmet"“(Art. 91 Abs. 1 CPP) ${ }^{638}$ sind.

Die Suspension oder Streichung aus dem Eigentumsregister ist auch eine gegen betrügerisch erworbene Eigentumstitel vorgesehene Maßnahme. So werden sie von dem Art. 101 CPP berücksichtigt, welcher den JCG dazu autorisiert, Eigentumstitel auf der Basis von fundierten Anhaltspunkten zu suspendieren oder zu streichen, wenn diese auf illegale Wei-

\footnotetext{
${ }^{635}$ Für eine Unterscheidung zwischen Beschlagnahme und diesen anderen Maßnahmen im CPP vgl. ausführlich Restrepo Medina 2007, S. 30 ff.. Für die Einordnung der Maßnahmen, die das Recht auf Eigentum in Strafverfahren beeinträchtigen, s. Bernal Cuellar/Montealegre Lynnet, 2013, T. II, S. 371 ff.

${ }^{636} \mathrm{Vgl}$. Aponte Cardona, 2006, S. 71 f.; Guerrero Peralta, 2004, S. 185. Für eine Kritik an der Systematik der Vorschriften über die Beschlagnahme in Kolumbien s. Restrepo Medina Rev. Estud. Socio-Juríd. 8 (2) 2006, S. 151-170.

${ }^{637}$ Vgl. dazu Aponte Cardona, 2006, S. 76; Guerrero Peralta, 2004, S. 186 f.

${ }^{638} \mathrm{Vgl}$. dazu Guerrero Peralta, 2004, S. 186, dem „es dafür genügt, dass die fundierten Anhaltspunkte den Indizien nach der Bestimmung des Geschäftes oder der juristischen Person für kriminelle Zwecke entsprechen." („basta con que los motivos fundados correspondan a elementos indiciarios sobre la destinación del establecimiento o la persona jurídica a actividades delictivas.”) (dt. Übersetzung d. Verf.).
} 
se erworben worden sind. Diese Maßnahmen sind erst seit kurzer Zeit Tradition in Kolumbien. Erstmalig sind sie im Dekret 050 von 1987 erschienen, erweitert durch das Dekret 2700 von 1991 und das Gesetz 600 von 2000. Im neuen CPP (Gesetz 906 von 2004) fungieren diese Maßnahmen als ein Instrument zur Wahrung der Rechte der Opfer, indem eine Rückgabe der Objekte erfolgt, welche Gegenstände des Delikts waren, um weitere Schädigungen zu verhindern. ${ }^{639}$ Das Ziel dieser Maßnahmen ist es, die Wirksamkeit der eventuellen strafrechtlichen Verurteilung zu sichern, welche eine Entschädigung des Opfers mit sich bringt. ${ }^{640}$

2. Grundlage für weitere Ermittlungsmaßnahmen (Art. 213-250, 383 Abs. 2 CPP)

Die Begründung aller Ermittlungshandlungen ist ein Prinzip, das die Grundlage der Ermittlungstätigkeiten nach dem CPP bildet. ${ }^{641}$ Dies ergibt sich aus Art. $250 \mathrm{CN}$, demzufolge Ermittlungen in Strafsachen das Vorliegen ausreichender Gründe und Tatumstände erfordern, die auf ein mögliches Vorliegen einer Straftat schließen lassen. Alle Maßnahmen, die im Laufe der strafrechtlichen Ermittlungen angeordnet werden, wie bereits erwähnt, unterliegen zudem dem Verhältnismäßigkeitsgrundsatz, ${ }^{642}$ die Ausführung derselben hängt somit von einer positiven Bewertung ihrer Zweckmäßigkeit, Erforderlichkeit und Angemessenheit ab. Die Zweckmäßigkeit bestimmt sich danach, ob die Maßnahme geeignet ist, das von der FGN gewünschte Ergebnis zu erreichen. Bei der Erforderlichkeit wird beurteilt, ob es andere geeignete - gleich wirksame - Maßnahmen für das vorgegebene Ziel gibt. Die Angemessenheit setzt eine hinreichende Begründung der vorhergehenden Kriterien voraus. ${ }^{643}$

Der CPP sieht in den Artikeln 213 bis 250 die Zwangsmaßnahmen während der Ermittlungsphase des kolumbianischen Strafprozesses vor. Zu den wichtigsten Maßnahmen zählen die Inspektion des Tatorts (Art. 213), die Leicheninspektion (Art. 214), Exhumierung

\footnotetext{
${ }^{639}$ KVerfG, Entsch. C-839 v. 2013 Abschn. 3.7.1.7. In dieser Entscheidung wird umfassend die Gesetzesbegründung in Bezug auf Art. $101 \mathrm{CPP}$ und die Meinungsentwicklung sowohl vom KVerfG als auch vom obersten Gerichthof erörtet; s. ausführlich Abschn. 3.7. ff.

${ }^{640}$ KVerfG, Entsch. C-210 v. 2007, Abschn. II. 3 ff. u. C-839 v. 2013, Abschn. 3.6.6.

${ }^{641} \mathrm{Vgl}$. supra § 3. A II. 2. Grundzüge des Ermittlungsverfahrens; ausführlich Guerrero Peralta, 2007, S. 168.

${ }^{642}$ Bzgl. des Verhaltnismäßigkeitsprinzips im kolumbianischen Strafprozessrecht s. ausführlich Bernal Cuellar/Montealegre Lynnet, 2013, T. I. S. 385 ff.; In Bezug auf die Freiheitsbeschränkung vgl. u.a. Prieto Vera, 2006, S. 30-103; Aponte Cardona, 2006 a, S. 135 ff.

${ }^{643}$ Guerrero Peralta, 2007, S. 177; dazu supra § 4. B. II. Anordnungen und Verhältnismäßigkeitsgrundsatz. 
(Art. 217), Hausdurchsuchungen (Art. 219-232), Beschlagnahme von Briefen, Ladungen und Telegrammen - Korrespondenz (Art. 233-234), Überwachung und Aufzeichnung von Kommunikation (Art. 235), Wiederbeschaffung von Informationen (Art. 236), Personenüberwachung (Art. 239), Überwachungsmaßnahmen an Sachen (Art. 240), Analyse und Infiltrierung krimineller Organisationen (Art. 241), Einsatz verdeckter Ermittler (Art. 242), verdeckte Maßnahmen gegen Korruption (Art. 242A), verdeckte Überwachung von Transport, Verkauf, Vermietung von Waffen, Sprengstoff, Munition, Falschgeld und Drogen (Art. 243), selektive Suche in Datensammlungen (Art. 244), die Entnahme und Auswertung von DNA-Proben (Art. 245), körperliche Untersuchung (Art. 247), Durchsuchungen von Personen (Art. 248) und Maßnahmen zur Beweissicherung (Untersuchung auf Spermaspuren, Blutentnahme) bei Sexualdelikten oder Delikten gegen die körperliche Unversehrtheit, die eine körperliche Untersuchung des Opfers erfordern (Art. 249-250). ${ }^{644}$

In Bezug auf die nachträgliche Kontrolle durch den JCG können vier grundlegende Probleme hervorgehoben werden, die umfassend in der kolumbianischen Prozessrechtslehre diskutiert werden. ${ }^{645} \mathrm{Im}$ Rahmen der Hausdurchsuchung ${ }^{646}$ sind vor allem zwei Aspekte Gegenstand der Debatte. Zum einen wird kritisiert, dass Art. 220 CPP die Einbeziehung eines besonderen persönlichen Merkmals des Subjekts (Eigentümer oder Besitzer) verlangt, das die Schlussfolgerungen begründet, auf denen eine Hausdurchsuchung beruht. Die h.M. verlangt zudem, dass der vom CPP geforderte Schutz jedem zusteht, der sich auf einem Grundstück befindet, auf dem sich Privatleben entwickeln kann, unabhängig davon, ob er Eigentümer oder nur Besitzer ist. ${ }^{647}$ Andererseits herrscht auch überwiegend die Ansicht, dass die Qualität der Beweismittel, auf die sich der fundierte Anhaltspunkt für die Anordnung einer Hausdurchsuchung stützt, eng auszulegen ist bzw. besonders hoch sein muss. Es muss sich also um Beweise handeln, die in der Hauptverhandlung Beweisqualität haben können. ${ }^{648}$

\footnotetext{
${ }^{644}$ Für eine Liste aller Ermittlungsmaßnahmen vgl. dazu ausführlich infra Anlage 2: Übersicht über den Ermittlungsmaßnahmen im kolumbianischen Strafverfahren.

${ }^{645} \mathrm{Bzgl}$. des nachträglichen Rechtsschutzes im kolumbianischen Ermittlungsverfahren s. ausführlich supra $\S \S 5$. u. 6.

${ }^{646}$ Vgl. supra § 5. A. Die Hausdurchsuchungen (Art. 219-232 CPP).

${ }^{647}$ Vgl. Guerrero Peralta, 2007, S. 342 f.; Guerrero Peralta, 2006, S. 95 f., in Übereinstimmung mit der Entsch. C-591 v. 2005, die die Voraussetzungen der Hausdurchsuchungen darstellt.

${ }^{648}$ Eine extensive Auslegung des von einer Hausdurchsuchung Betroffenen und eine enge Auslegung in Bezug auf die Beweisunterlagen sind damit zwei Bedingungen, die in der kolumbianischen Strafprozessrechtslehre als einschränkende Gründe für die Hausdurchsuchung aufgenommen worden sind; vgl. Bernal
} 
Der zweite Punkt bezieht sich auf die in Art. $235 \mathrm{CPP}^{649}$ geregelte Überwachung der Kommunikation. Einerseits wird in Art. 235 Abs. 1 CPP eine Begründung der Ermittlungsmaßnahme durch einen fundierten Anhaltspunkt nicht ausdrücklich gefordert. Das Problem dieser Unterlassung besteht darin, dass sie so ausgelegt werden könnte, dass der Staatsanwalt ohne das Vorliegen von Gründen und ausschließlich aus eigenem Ermessen die Überwachung der Kommunikation anordnen könnte. Diese Auslegung lässt aber die Systematik im Strafverfahren außer Betracht und insbesondere diejenige, die dem CPP innewohnt, da - wie schon erwähnt wurde - die Begründung der Ermittlungshandlungen ein Grundsatz ist, dem sich alle Ermittlungsmaßnahmen unterzuordnen haben. ${ }^{650}$ Diese Auslegung wurde außerdem aufgrund der Bestimmungen in den Abs. 2 und 4 dieses Artikels abgelehnt. Abs. 2 verlangt eine schriftliche Begründung der Überwachungsanordnung, was die fehlende Erwähnung des fundierten Anhaltspunkts als Erfordernis in Abs. 1 irrelevant erscheinen lässt. Abs. 4 bestätigt, dass die Verlängerung einer Ermittlungsmaßnahme mit dem Weiterbestehen des fundierten Anhaltspunkts begründet werden muss, der sie ursprünglich veranlasst hat. Die Überwachungsanordnung muss somit auf fundierten Anhaltspunkten beruhen. Diese Auslegung wurde 2009 vom KVerfG in seinem Urteil C-131 bestätigt. ${ }^{651}$ Demnach muss die Anordnung des Staatsanwalts zur Verlängerung der Überwachung der Kommunikation einer vorangehenden Rechtmäßigkeitskontrolle durch den JCG unterzogen werden. ${ }^{652}$ Zudem wurde festgestellt, dass die in Art. 221 CPP festgelegten Vorgaben, die die Beweiskraft für die fundierten Anhaltspunkte verlangen, beachtet werden müssen. Davon ausgehend ist jede Überwachungsanordnung ohne fundierte Anhaltspunkte ausgeschlossen.

Des Weiteren ist die in Art. 239 CPP geregelte Personenüberwachung stark umstritten. Die h.M. stimmt darin überein, dass der Begründungsstandard sensu stricto verstanden werden

Cuellar/Montealegre Lynnet, 2013, T. II, S. 259; Guerrero Peralta, 2007, S. 343 f.; s. dazu infra § 10. A. II. Die Beweisgrundlageproblematik gemäß Art. 221 CPP.

${ }^{649}$ Vgl. dazu ausführlich supra § 6. A. Nachträglicher Rechtsschutz gegen Maßnahmen zur Beschränkung der Unverletzlichkeit der Kommunikation.

${ }^{650}$ Vgl. dazu supra Fn. 641 m.w.N.

${ }^{651}$ KVerfG, Entsch. C-131 v. 2009, in der bestimmt wird, dass die Verlängerung nicht von dem „Ermessen des Staatsanwalts“ abhängig ist, sofern ,es um eine zusätzliche Maßnahme mit Beeinträchtigung von Grundrechten durch die Überwachung der Kommunikation geht und das Prinzip des Richtervorbehalts für den Schutz der Intimität verletzt wird.“ (dt. Übersetzung d. Verf.) (,la prorroga no puede depender del 'juicio del fiscal' en tanto que por tratarse de una medida adicional que implica la afectación de derechos fundamentales con la prolongación de la interceptación de comunicaciones telefónicas y similares, se conculca el principio de reserva judicial en la protección del derecho a la intimidad.“) (Abschn. 6.5.).

${ }^{652}$ KVerfG Entsch. C-131 v. 2009 Abschn. 6.5.

208 
muss. ${ }^{653}$ Die auf fundierte Anhaltspunkte gestützte Begründung muss auf objektiven, externen Umständen beruhen, die konkrete Indizien erkennen lassen. Eine einfache Schlussfolgerung ist nicht ausreichend. Es muss eine zumutbare Schlussfolgerung ausgehend von konkreten Indizien oder objektiven und externen Umständen gestützt auf die grundlegenden Beweisprinzipien vorhanden sein. Die Schlussfolgerung muss zum Ergebnis kommen, dass die Überwachung einer Person zur Sicherung anderer, notwendiger und relevanter Erkenntnisse für die strafrechtliche Ermittlung führt (Art. 239 Abs. 1 CPP).

Der vierte Punkt bezieht sich auf die Analyse und Infiltrierung krimineller Organisationen. Nach Art. 241 CPP kann die FGN die Infiltrierung in eine kriminelle Organisation anordnen, wenn fundierte Anhaltspunkte Anlass dazu geben, dass der Verdächtige zu derselben gehört oder mit ihr in Verbindung steht. ${ }^{654}$ Die überwiegende Lehrmeinung fordert, dass die FGN zwei Aspekte begründen muss: Zum einen muss die Verbindung des Verdächtigen zum organisierten Verbrechen festgestellt werden, zum anderen muss sich aus den fundierten Anhaltspunkten schließen lassen, dass die kriminelle Handlung fortgesetzt wird. ${ }^{655}$ An dieser Stelle hat sich eine Frage zur Auslegung der Rechtfertigung hinsichtlich der Infiltrierung einer Organisation in den Fällen ergeben, in denen der Beschuldigte eine Straftat schon begangen hat oder noch als bestehendes Mitglied der kriminellen Organisation andere Straftaten vorbereitet hat. Hier wird vertreten, dass unter diesen Umständen die Festnahme, die Beschuldigung und der Antrag auf Sicherungsmaßnahmen angebracht seien. ${ }^{656}$ Zusätzlich zu den Begrenzungen durch die Begründung der Maßnahme wird die Anordnung der FGN besonderen materiellen Einschränkungen unterworfen. Einerseits darf diese Maßnahme dem Verhältnismäßikeitsgrundsatz entsprechend nicht bei Straftaten mit geringen sozialen Auswirkungen eingesetzt werden. Die Beweismittel müssen andererseits nicht nur die Bewertung der Zweckmäßigkeit, Erforderlichkeit und Angemessenheit ermöglichen, sondern auch geeignet sein, das Vorliegen einer Straftat nachzuweisen und in der

\footnotetext{
${ }^{653}$ Bernal Cuellar/Montealegre Lynnet, 2013, T. II, S. 271 ff.; Guerrero Peralta, 2007, S. 381, 386 ff.; vgl. dazu ausführlich supra § 5. B. Die Personenüberwachung (Art. 239 CPP).

${ }^{654}$ Vgl. dazu supra § 5. C. Einsatz eines verdeckten Ermittlers (Art. 241-243 CPP).

655 Morales Támara, 2009, S. 239 ff.; Bernal Cuellar/Montealegre Lynnet, 2013, T. II, S. 276; Guerrero Peralta, 2006, S. 144 f.

${ }^{656}$ Guerrero Peralta, 2006, S. 144, der dieser Interpretation widerspricht, ,der Zweck der Maßnahme ist der Erfolg der Ermittlung im Sinne der Zerschlagung von organisierter Kriminalität, was ihre Unerlässlichkeit bestimmt.“ (dt. Übersetzung d. Verf.) (,el objeto de la medida es el éxito de la investigación en el sentido de desarticulación de bandas de criminalidad organizada, lo que define su carácter imprescindible.") (S. 145).
} 
Folge die strafrechtliche Verantwortlichkeit begründen. ${ }^{657}$ Bzgl. verdeckter Ermittler hat der Gesetzgeber außerdem ihren Einsatz in kriminellen Organisationen auf Fälle einer Fortsetzung der strafbaren Handlungen und auf klagebegründende Tatsachen bei Straftaten gegen die öffentliche Verwaltung (Art. 242A) beschränkt.

\section{Begründung der Freiheitsbeschränkung (Art. 297, 308-311 CPP)}

Der Art. 297 CPP fordert für die Festnahme eine schriftliche Anordnung des JCG, die - in Übereinstimmung mit Art. 221 CPP - der gesetzlich verlangten Form entspricht und sich auf fundierte Anhaltspunkte ${ }^{658}$ stützt, die die Schlussfolgerung zulassen, dass der Betroffene Täter oder Teilnehmer der ermittelten Straftat ist. Die auf fundierte Anhaltspunkte gestützte Schlussfolgerung der Täterschaft oder Teilnahme ist auch Grundlage anderer Strafprozesshandlungen während der Ermittlungsphase, so zum Beispiel bei der Vernehmung des Tatverdächtigen im Verlauf der Vorermittlung (Art. 282 CPP), bei der Erhebung der Beschuldigungen (Art. 287 CPP ${ }^{659}$ und bei der Anordnung der vorläufigen Festnahme als Sicherungsmaßnahme (Art. 308-312 CPP). Obwohl die Anordnung des Haftbefehls in einer früheren Phase des Ermittlungsverfahrens erfolgt als die Erhebung der Beschuldigung, erfordert die Voraussetzung der Schlussfolgerung der Täterschaft und Teilnahme ein bereits fortgeschrittenes Ermittlungsniveau. Diese fortgeschrittene Phase im Ermittlungsverfahren sollte nicht nur ein Mindestmaß der Schuld feststellen, sondern muss auch die Erforderlichkeit und Wahrscheinlichkeit einer späteren Sicherungsmaßnahme begründen. Eine Festnahme ist somit auch vor der Erhebung der Beschuldigung möglich, wenn es Anhaltspunkte gibt, die darauf schließen lassen, dass im Nachhinein die Anordnung der Untersuchungshaft als Sicherungsmaßnahme berechtigt ist (Art. 306 ff). ${ }^{660}$

Nach einer wörtlichen Auslegung dieser Art von Schlussfolgerung - bezogen auf Art. 297 CPP - wird festgestellt, dass die berechtigte Schlussfolgerung bzgl. Täterschaft und Teil-

\footnotetext{
${ }^{657}$ Bzgl. des Verhältnismäßigkeitsprinzips und die Eignung der Beweise als materielle Grenze vgl. Bernal Cuellar/Montealegre Lynnet, 2013, T. II, S. 273 u. 274.

${ }^{658}$ Bzgl. der Systematik der Regelung der Freiheit im CPP vgl. Bernal Cuellar/Montealegre Lynnet, 2013, T. II, S. 523 f.; Prieto Vera, 2006, S. 54 ff.

${ }^{659} \mathrm{Vgl}$. dazu supra § 3. A. II. 3. b. Die Beschuldigung (Formulación de imputación).

${ }^{660}$ I.d.S. Bernal Cuellar/Montealegre Lynnet, 2013, T. II, S. 458: „in der Regel darf die Festnahme zum Zweck der Beschuldigungerhebung nicht durchgefuhrt werden“ („la regla general es que la captura no es procedente para realizar únicamente la audiencia de imputación"), obwohl eine Beschränkung der Freiheit aufgrund von Notwendigkeitsgründen und in den Fällen der Festnahme auf frischer Tat in der Vorermittlung bzw. vor der Erhebung der Beschuldigung angenommen wird. (-S. 459- dt. Übersetzung d. Verf.). 
nahme zur Bestimmung eines Mindestmaßes an Schuld führen muss. ${ }^{661}$ Sie muss also einen Kausalzusammenhang zwischen zwei Aspekten herstellen: zwischen der Handlung oder dem Unterlassen des Beschuldigten und dem rechtlich relevanten Ergebnis. ${ }^{662}$ Ein Teil der Lehre ist sogar der Auffassung, dass für die Auswertung ,alle Faktoren, die das Strafgesetz im Kontext von Handlung und Unterlassen, unmittelbarer oder mittelbarer Ausführung einer Straftat, von vorbereitenden Absprachen, von der Bedeutung des Beitrags in Bezug auf ein rechtlich zurechenbares Ergebnis und die Beiträge zu einem rechtswidrigen Verhalten“" vorsieht, relevant sind. Dies schließe die Anwendbarkeit der erweiternden Verwirklichungsstufen der Straftat in den Art. 27 und 31 CP (Versuch und Konkurrenz) ein. ${ }^{663}$

Die fundierten Anhaltspunkte, die zu dieser Schlussfolgerung führen, müssen sich auf das Beweismaterial stützen. In diesem Sinne verweist Art. 297 auf Art. 221 CPP, der die Anforderung einer strengen Beweisführung ${ }^{664}$ formuliert. Auf diese Weise werden bei der Begründung des Haftbefehls oder der Anordnung der vorläufigen Festnahme lediglich einfache Schlussfolgerungen ausgeschlossen. Die fundierten Anhaltspunkte müssen sich strikt auf Beweismaterial stützen, das Beweisqualität im Sinne des CPP hat und dessen Beweiskraft für eine Hauptverhandlung ausreicht. Diese Beweismittelgrundlage muss zu einer berechtigten Schlussfolgerung über die Handlung (im objektiven Sinne) und über die Täterschaft oder Teilnahme (im subjektiven Sinne) der ermittelten Straftat führen. Dieser Grundsatz wurde auch durch den Kolumbianischen Obersten Gerichtshof bestätigt, indem er erklärt: „Obwohl es in diesem Moment nicht notwendig ist, die materiellen Beweiselemente oder die sachlichen Beweismittel vorzuweisen, ist es jedoch notwendig, dem JCG entscheidungsrelevante Unterlagen vorzulegen mit dem Ziel, den strafrechtlichen Charakter der Handlung und den Zusammenhang des Beschuldigten mit derselben zu belegen.

\footnotetext{
${ }^{661}$ Guerrero Peralta, 2007, S. 260, der die Auffasung vertritt, dass „die zumutbare Schlussfolgerung aus den subjektiven Tatbestandsmerkmalen geschlossen werden muss.“ („la inferencia razonable se debe hacer sobre los elementos jurídicos de atribución subjetiva de la conducta punible investigada.") (dt. Übersetzung d. Verf.).

${ }^{662}$ Guerrero Peralta, 2007, S. 265, für den „die zumutbare Schlussfolgerung ein logisches Kriterium ist, damit der Staatsanwalt eine objektive und subjektive Mindest-Überzeugung bzgl. der Täterschaft oder Teilnahme des Verdächtigen erreichen kann.") (,la inferencia razonable es un criterio lógico que pretende que el fiscal llegue a una mínima convicción objetiva y subjetiva sobre la autoría o participación del investigado en un delito.") (dt. Übersetzung d. Verf.).

${ }^{663}$ Bernal Cuellar/Montealegre Lynett, 2013, T. II. S. 127, die vertreten, dass „dies ein weiterer Grund ist, warum eine Beschuldigung sich an rechtlichen Formulierungen und nicht an einfachen tatsächlichen Sachverhalten orientieren muss.“ („esta es otra de las razones por las que debe hablarse de una imputación más cercana a las formulaciones jurídicas que a los simples supuestos fácticos.") (dt. Übersetzung d. Verf.).

${ }^{664} \mathrm{Vgl}$. dazu supra § 6. C. II. Rechtsgrundlage und infra § 10. A. II. Die Beweisgrundlageproblematik gemäß Art. 221 CPP.
} 
Nur auf diese Weise wird eine, berechtigte Schlussfolgerung bzgl. der Täterschaft oder Teilnahme des Beschuldigten in der ermittelten Straftat' erlangt.“665

\section{Grundlage für die Beweissicherung (Art. 284 Nr. 3 CPP)}

Im Titel über die Erkenntnismittel im Vorermittlungs- und Ermittlungsverfahren (Buch II, Titel II, einziger Abschnitt), konkret Art. 284 CPP, wird beschrieben, dass jede zulässige Beweiserhebung während des Ermittlungsverfahrens bis zur Hauptverhandlung bereits vorab möglich ist. Diese vorzeitige Beweisaufnahme stellt eine Ausnahme des Unmittelbarkeitsgrundsatzes dar, da sie vor der Hauptverhandlung und vor dem JCG und nicht vor dem Strafrichter stattfindet. Unter anderem werden zur Berechtigung dieser Beweismittel „fundierte Anhaltspunkte und eine unbedingte Notwendigkeit, um den Verlust oder die Manipulation der Beweismittel zu vermeiden“ gefordert. ${ }^{666}$ Das Erfordernis der fundierten Anhaltspunkte kann nicht durch die einfache Aussage des Antragstellers ersetzt werden. Ein Teil der Strafrechtslehre meint, dass es zur Sicherung bei Dringlichkeit oder zwingender Notwendigkeit unerlässlich sei, dem JCG alle Ermittlungshandlungen oder sachlichen Beweismittel zur Kenntnis vorzulegen, aus denen sich die zwingende Notwendigkeit ergebe und auf die sich die Beweisaufnahme vor der Hauptverhandlung stütze. ${ }^{667}$ In diesem Sinne ist auch der Beweisstandard, der in Art. 221 CPP vorgesehen ist, anwendbar. Es handelt sich folglich um einen strengen Beweis, der sich auf die im CPP festgelegten Beweiselemente stützt.

Diese Praxis der Beweissicherung wurde durch die kolumbianische Rechtsprechung bestätigt. Einerseits wird anerkannt, dass der außergewöhnliche Charakter dieser Beweiserhebung und mit ihr die Aufweichung des Unmittelbarkeitsgrundsatzes der Beweisaufnahme

\footnotetext{
${ }^{665}$ Oberster Gerichtshof, Rad. 31280, Entsch. von 8.07.2009, Abschn. „Consideraciones de la Corte“, Abschn. 1: „si bien en este momento no es menester descubrir los elementos materiales probatorios ni la evidencia física, si es necesario ofrecer al juez de control de garantías elementos de juicio tendientes a acreditar la índole penal del comportamiento y la relación del imputado con el mismo, no de otro modo se logra ínferir razonablemente que el imputado es autor o partícipe del delito que se investiga.'“ (dt. Übersetzung d. Verf.). ${ }^{666}$ Art. 284 Nr. 3 CPP: ,Que sea por motivos fundados y de extrema necesidad y para evitar la pérdida o alteración del medio probatorio.“ (dt. Übersetzung d. Verf.).

${ }^{667}$ Defensoría del Pueblo, 2008, S. 72, die behauptet, dass ,der Verlust oder die Veränderung von Beweisen auch geprüft werden sollte, beispielsweise die besonderen Bedingungen des Zeugen in Bezug auf die Bedrohung seines Lebens durch Krankheit oder offensichtliche Gefahr, Verschlechterung der physikalischen Beweise oder des Tatorts durch Umweltfaktoren oder die öffentliche Sicherheit.“ („La perdida o alteración del medio probatorio, también debe comprobarse como por ejemplo las condiciones especiales del testigo en relación con su vida amenazada por enfermedad o peligro evidente, el deterioro de la evidencia física o de la escena del delito por factores ambientales o de seguridad pública.") (dt. Übersetzung d. Verf.).
} 
während der Hauptverhandlung verfassungsrechtlich gerechtfertigt sind. ${ }^{668}$ Andererseits wird die Beweisaufnahme im Sinne eines Gültigkeitserfordernisses der Überprüfung durch den JCG unterworfen. ${ }^{69}$ Der JCG muss dabei überprüfen, ob tatsächlich eine außergewöhnliche und dringende Lage besteht, die zu einer vorzeitigen Beweisaufnahme berechtigt und die - wenn möglich - während der Hauptverhandlung wiederholt werden soll. Wenn diese Voraussetzungen nicht vorliegen, wird der Antrag vom Richter abgelehnt werden müssen. Die Zulässigkeit der Beweismittel wird ebenfalls hinsichtlich ihrer Entscheidungserheblichkeit nach dem Grundsatz der Verhältnismäßigkeit überprüft.

\section{B. Auslegung des Begriffes „motivos fundados“ in der Rechtsprechung}

Die Behandlung der „fundierten Anhaltspunkte“ (,motivos fundados“) der Rechtsprechung ist bezogen auf die Anordnung von Ermittlungsmaßnahmen durch die FGN ohne vorangehende richterliche Zustimmung nicht ohne Widerspruch hingenommen worden. Nach der Annahme des Gesetzesakts 03 von 2002 und der Entwicklung des neuen CPP (Gesetz 906 von 2004) bestand kein gemeinsames Verständnis der „fundierten Anhaltspunkte“, das dem Ethos des Akkusationsprinzips entspricht. Die Rechtsprechung der obersten kolumbianischen Gerichtshöfe hat versucht, viele Mehrdeutigkeiten zu klären, sowohl die des Art. 250 $\mathrm{CN}^{670}$ als auch die der systematischen Entwicklung des CPP bzgl. der Grundlage der genannten Maßnahmen, also die ausschließlich von der FGN angeordneten Ermittlungstätigkeiten. Vor allem einige Urteile des KVerfG helfen dabei, den Rechtsbegriff „motivos fundados $^{\text {“ }}$ zu verstehen und zu klären, wie diese durch Beweismittel begründet werden müssen. ${ }^{671}$ Dennoch fehlt immer noch eine Auslegung der Reichweite der im CPP definierten Abstufung der Begründung; die Reichweite von Grundsätzen wie das kontradiktorische Prinzip, der Öffentlichkeitsgrundsatz, das Mündlichkeitsprinzip und der Unmittelbarkeitsgrundsatz sowie eine systematische Auslegung der Zwecke einer berechtigten Schlussfol-

\footnotetext{
${ }^{668}$ Vgl. KVerfG, Entsch. C-591 v. 2005, C-1154 v. 2005; auch Oberster Gerichtshof, Rad. 25920, Entsch. von 21.02.2007.

${ }^{669}$ KVerfG, Entsch. C-1092 v. 2003, Abschn. 5.1., in der fesgestellt wird, dass „der Beweisantritt nicht nur bei Einhaltung der formellen Voraussetzungen bedingt wird, (...) sondern auch von der Einhaltung der materiellen Bedingungen, die eine Beweiserhebung mit uneingeschränkter Achtung der Verfahrensregeln und anderen materiellen Bestimmungen fordert und deren Prüfung den JCG betrifft.“ (,que la prueba no solo se encuentra condicionada al cumplimiento de los requisitos de carácter formal para su aducción, (...), sino además al cumplimiento de requisitos materiales que exigen que la prueba sea obtenida con pleno respeto de normas procesales y sustanciales de todo rango, examen inherente al control garantías.") (dt. Übersetzung d. Verf.).

${ }^{670}$ Vgl. Guerrero Peralta, 2007, S. 166 f. Für eine Allgemeinkritik des Gesetzesaktes 03 von 2002 vgl. Calle Calderón, NFP 67 (2005), S. 153 ff.

${ }^{671}$ Für eine allgemeine Annäherung an diesen Aspekt s. Pava Lugo 2009, S. 27.
} 
gerung, zu der die „fundierten Anhaltspunkte“ führen sollen. ${ }^{672}$ So kann festgestellt werden, dass es immer noch keine strengen Kriterien gibt, die alle Aspekte der Beweggründe für die Maßnahmen ohne richterliche Anordnung beinhalten. Daraus folgt eine Ausweitung des Ermessens der FGN bei der Begründung und Durchführung der Ermittlungsmaßnahmen, die keine vorangehende richterliche Bewilligung erfordern. Dies wird durch die Aufweichung des richterlichen Vorbehalts bei Grundrechtseinschränkungen und durch die Legitimierung des geheimen Ermittlungsverfahrenes bei Anhörungen zur Überprüfung der Maßnahmen, die keine vorausgehende richterliche Genehmigung benötigen, gefördert. ${ }^{673}$

\section{Entscheidung C-673 von 2005 KVerfG}

Das Verfassungsgericht untersuchte in dieser Entscheidung zwei Aspekte, die gegen Art. 221 CPP sprechen. Einerseits, ob es sich bereits um einen Verstoß gegen das faire Verfahren im Sinne des kontradiktorischen Prinzips handle, wenn Aussagen, die eine Person vor der Ermittlungsbehörde macht, obwohl nur der Staatsanwalt anwesend ist, als zulässige Beweisaussagen angesehen werden können. Andererseits wird erörtert, ob die Geheimhaltung der Angaben zum Informanten, auf dessen Aussage sich eine Durchsuchungs- und Hausdurchsuchungsanordnung stützt, gegenüber dem JCG die verfassungsrechtlichen Befugnisse beschneidet. ${ }^{674}$ Dieses Urteil ist relevant, weil die Notwendigkeit einer strengen Beweisführung bei „fundierten Anhaltspunkten“ für eine Durchsuchungs- und Hausdurchsuchungsanordnung bestätigt wird. In diesem Gedankenschema bestimmt das Gericht die Kriterien der Rechtmäßigkeitskontrolle der Maßnahme seitens des JCG. Umstritten ist dabei die Legitimation des Art. 155 Abs. 2 CPP, der die Vertraulichkeit der Kontrollanhörungen festlegt. Im Folgenden werden die entscheidenden Aspekte beschrieben und besprochen:

\section{Reichweite des Art. 221 CPP}

Das KVerfG bestätigt zunächst die Forderung des Art. 221 Abs. 1 CPP nach Beweismaterial für die „fundierten Anhaltspunkte“, um eine Durchsuchungs- und Hausdurchsuchungsanordnung zu erlassen, und das Verbot von willkürlichen Durchsuchungen und Hausdurchsuchungen nach freiem Ermessen des Staatsanwalts. Deswegen wird in Übereinstimmung

\footnotetext{
${ }^{672}$ Diese Probleme werden nachfolgend diskutiert, vgl. infra § 10. B. Ziele der zumutbaren Schlussfolgerungen.

${ }^{673}$ I.d.S. Zuluaga, Boletin GLIPGö 5 (2013) S. 23 ff.; Zuluaga, Co-Herencia Vol. 4 Nr. 6 (2007), S. 133 ff.

${ }^{674}$ Vgl. KVerfG, Entsch. C-637 v. 2005, Abschn. VI. 3. Análisis de los cargos propuestos contra el artículo 221 de la ley 906 de 2004. 
mit Art. 221 CPP die Verpflichtung wiederholt, dass für die Anordnung des Staatsanwaltes mindestens ein Bericht, eine beeidete Aussage oder materielle Beweismittel vorliegen müssen. Für das Gericht ist dies eine Garantie der Durchführbarkeit der Ermittlungshandlung, ,sodass der Richter auf die Informationen Zugriff hat, die ihm erlauben, eine wirksame Rechtmäßigkeitskontrolle vorzunehmen. “675

Danach wird Art. 221 Abs. 2 CPP untersucht, der darauf hinweist, dass sich die beeidete Zeugen- oder Informantenaussage als Beweismittel eignet. Laut Art. 221 CPP muss der Staatsanwalt - mit Blick auf eine etwaige spätere Vernehmung - bei einer beeideten Zeugenaussage anwesend sein. Bei einer Informantenaussage wird darauf hingewiesen, dass die Ermittlungsbehörde nur gegenüber dem Staatsanwalt Angaben zur Person des Informanten preisgeben muss. ${ }^{676}$ Damit wird in diesem Artikel eine absolute Vertraulichkeit über Angaben zur Person des Informanten gegenüber anderen Parteien und Beteiligten im Verfahren angeordnet. Außerdem, obwohl der Zeuge oder der Informant eine eidesstattliche Erklärung vor dem Staatsanwalt ablegen musste, durfte dieser den Informanten nicht weiter vernehmen, um seine Glaubwürdigkeit zu überprüfen.

Diese Einschränkung des Zuganges zum Informanten wurde für verfassungswidrig erklärt. Das Gericht hält es nicht für verfassungsgemäß, dass der Staatsanwalt nicht befugt sei, den Informanten im Hinblick auf seine Glaubwürdigkeit zu vernehmen. Das Gericht hält die Glaubhaftigkeitsbeurteilung des Zeugen nur aufgrund der Informationen der Ermittlungsbehörde über die Identität des Informanten und eine einfache Erklärung über die Gründe, auf denen das Vertrauen der Ermittlungsbehörde beruht, für unzureichend. Aus diesem Grund bestimmte das Gericht, dass ,im Falle des Informanten auch die Möglichkeit einer etwaigen Vernehmung durch den mit dem Fall befassten Staatsanwalt angebracht ist. “677

Für das Gericht ist die Förmlichkeit beider Aussagen unter Eid der Grund, der die Glaubwürdigkeit derselben belegt, und daher auch die Wahrscheinlichkeit einer Verbindung zwi-

\footnotetext{
${ }^{675}$ KVerfG, Entsch. C-637 v. 2005, Abschn. VI. 3: „,a fin de que el juez pueda acceder a una información que le permita realizar un efectivo control de legalidad." (dt. Übersetzung d. Verf.).

${ }^{676} \mathrm{Vgl}$. dazu supra § 6. B. I. 1. Begründete Anordnung des Staatsanwalts; Krit. der ursprünglichen Fassung vom Art. 221 CPP Fernández León, 2005, S. 61.

${ }^{677}$ KVerfG, Entsch. C-637 v. 2005, Abschn. VI. 3: „en el caso del informante, también deberá proceder la posibilidad de que eventualmente el Fiscal que dirige la investigación pueda interrogarlo“ (dt. Übersetzung d. Verf.); über die Ausdehnung der richterlichen Kontrolle der Erkenntnismittel, die die Nodwendigkeit eines Eingriffes unterstützen, s. auch KVerfG, Entsch. C-806 v. 2009, Abschn. VI. 5.; vgl. dazu Bernal Cuellar/Montealegre Lynnet, 2013, T. II. S. 259; Guerrero Peralta, 2007, S. 344.
} 
schen dem zu durchsuchenden Grundbesitz und der ermittelten Straftat. Die Bestimmung dieser Wahrscheinlichkeit erfordert, dass der Staatsanwalt die Personen vernehmen kann, die eine Aussage erstatten, seien sie Zeugen oder Informanten. Die eidesstattliche Zeugenoder Informantenaussage erfüllt bei Durchsuchungs- und Hausdurchsuchungsanordnungen einzig die Aufgabe, die Wahrscheinlichkeit zu bestimmen, dass „fundierte Anhaltspunkte“ vorliegen, um eine das Recht auf Intimsphäre einschränkende Maßnahme anzuordnen. ${ }^{678}$

Nach den Worten des KVerfG sind „die eidesstattliche Zeugen- oder Informantenaussage sowie die anderen materiellen Beweismittel nur Mittel, die der staatlichen Ermittlungshandlung die Richtung vorgeben und sie weiterführen.“679 Diese extensive Überprüfung der Aussagen erlaubt dem Staatsanwalt das Treffen einer ,tatsächlichen Beurteilung bezogen auf die Würdigung der materiellen Beweismittel, die eine Vorverlegung für ratsam erscheinen lassen, und das Treffen einer rechtlichen Beurteilung, die sich auf die Abwägung der sich gegenüberstehenden Interessen stützt, so das Recht auf die Unverletzlichkeit der Wohnung einerseits und das allgemeine Recht auf die Aufklärung einer Straftat andererseits. “680

\section{Rechtmäßigkeitskontrolle seitens des JCG}

Das KVerfG weist nicht nur darauf hin, dass der Staatsanwalt die Möglichkeit haben muss, sowohl den Zeugen als auch den Informanten zu verhören, sondern es bestimmt auch, dass der JCG über alle Mittel verfügen muss, um die Rechtmäßigkeit der Maßnahme zu überprüfen. Für das Gericht „,muss der JCG über die nötigen Möglichkeiten verfügen, um zu überprüfen, ob ein gravierender Eingriff in das Grundrecht auf die Privatsphäre wie bei der Hausdurchsuchung, die ohne vorangehende Anordnung der FGN stattfindet, der Verfassung und den gesetzlichen Vorgaben entsprach.“681

\footnotetext{
${ }^{678}$ KVerfG, Entsch. C-637 v. 2005, Abschn. VI. 3.; dazu Vanegas Villa, 2007, S. 102.

${ }^{679}$ KVerfG, Entsch. C-637 v. 2005, Abschn. VI. 3: „la declaración jurada de testigo o informante, al igual que los demás elementos materiales probatorios y la evidencia física, constituyen tan solo instrumentos para direccionar y encausar la actividad investigativa del Estado." (dt. Übersetzung d. Verf.).

${ }^{680}$ KVerfG, Entsch. C-637 v. 2005, Abschn. VI. 3: ,juicio fáctico, referido a la apreciación de los elementos materiales probatorios que hacen aconsejable adelantarlo, y un juicio jurídico, centrado en la ponderación de los intereses confrontados, y que son, el respeto por el derecho a la inviolabilidad del domicilio, y por otro, el interés general por la persecución del delito.“(dt. Übersetzung d. Verf.).

${ }^{681}$ KVerfG, Entsch. C-637 v. 2005, Abschn. VI. 3: „el juez de control de garantías debe contar con los medios necesarios para verificar si una severa medida de intervención en el derecho fundamental a la intimidad, como lo es la práctica de un registro y allanamiento, llevada a cabo sin orden judicial previa por la Fiscalía General de la Nación, se ajustó a la Constitución y a la ley.“(dt. Übersetzung d. Verf.).
} 
Daher erklärt es auch, dass die Vertraulichkeit der persönlichen Daten des Informanten aus Art. 221 Abs. 2 CPP so verstanden werden müsse, dass sie nicht für den JCG gelte. Das Gericht weist darauf hin, dass eine solche Geheimhaltung eine wirksame Überprüfung der fundierten Anhaltspunkte verhindern würde. Einerseits würde diese Geheimhaltung die Möglichkeit einer formalen und sachlichen Überprüfung der Ermittlungsmaßnahme einschränken. Andererseits würde es eine Bewertung der Angemessenheit der Maßnahme verhindern, d. h. ein Verhältnismäßigkeitsurteil würde sich als unmöglich erweisen ,in dem Sinne, ob sich mit der Maßnahme ein im Rahmen der Verfassung zulässiges Ziel erreichen lässt, ob der Zweck nicht durch ein weniger das Grundrecht belastendes Mittel erreicht werden konnte und schließlich, ob die durch den Eingriff erreichten Vorteile die erbrachten Opfer der Grundrechtsträger ausgleichen. “682 Sonst würde das Beweisverwertungsverbot die materiellen Beweismittel, die während der Ermittlungsphase durch Verstoß gegen Grundrechte gesammelt wurden, außer Kraft setzen. ${ }^{683}$ Auf diese Weise bestärkt das Gericht die Notwendigkeit eines umfassenden Zugangs zum Beweismaterial, welches die fundierten Anhaltspunkte stützt, und verlangt die Notwendigkeit einer Überprüfung der Begründung der Hausdurchsuchungsanordnung seitens des Staatsanwaltes und des JCG.

\section{Vertraulichkeit der Anhörungen}

Auch wenn das KVerfG dem Staatsanwalt und dem JCG einen umfassenden Zugang zu den Beweismitteln einräumt, erkennt es auch ein gewisses Maß an Vertraulichkeit der persönlichen Daten des Informanten an. Zum Schutz der Sicherheit des Informanten muss es möglich sein, dass die Daten desselben nicht allgemein zugänglich sind. Nach der Meinung des Gerichts würde die Offenlegung der persönlichen Angaben des Informanten „dessen Sicherheit stark gefährden und außerdem verhindern, dass auch zukünftig Bürger den zuständigen Behörden wertvolle Information liefern könnten.“684 Andererseits - mit Blick auf Art. 155 CPP - wird dargelegt, dass die persönlichen Daten des Informanten während der

\footnotetext{
${ }^{682}$ KVerfG, Entsch. C-637 v. 2005, Abschn. VI. 3: „en el sentido de que si con ésta se perseguía un fin constitucionalmente válido; si el propósito no podía ser alcanzado por otro medio menos gravoso para el derecho fundamental, y si finalmente, las ventajas obtenidas mediante la intervención compensan los sacrificios que ésta implica para sus titulares."(dt. Überssetzung d. Verf.).

${ }^{683}$ KVerfG, Entsch. C-637 v. 2005, Abschn. VI. 3.

${ }^{684}$ KVerfG, Entsch. C-637 v. 2005, Abschn. VI. 3: „poner en grave peligro la seguridad de éste, y además, impediría que en el futuro el ciudadano pudiese seguir suministrando valiosa información a las autoridades competentes." (dt. Übersetzung d. Verf.).
} 
Anhörung zur Rechtmäßigkeitskontrolle nicht veröffentlicht werden dürfen, auch wenn der JCG Zugang zu den Angaben hat. ${ }^{685}$

Das Gericht erklärt außerdem, dass die Durchsuchungs- und Hausdurchsuchungsanordnungen, die vor Erhebung der Beschuldigung erlassen worden sind, nicht dem kontradiktorischen Prinzip unterworfen werden können. Es meint sogar, dass die verfassungsrechtlichen Ziele der Ermittlung nicht erreicht werden könnten, wenn dies so wäre. Erst wenn die Beschuldigung erhoben worden ist, muss der Beschuldigte oder sein Verteidiger vorgeladen werden, um die Möglichkeit zu bekommen Widerspruch einzulegen, falls er es wünscht. ${ }^{686}$ Das Gericht meint, der Widerspruch gegen die beeidete Zeugenaussage vor der Erhebung der Beschuldigung würde verhindern, dass die Ziele der Ermittlung erreicht werden, „da diese Beweishandlung nicht vollzogen werden könnte, wenn es noch keinen Beschuldigten gäbe oder der Verteidiger bevollmächtigt wäre, der vertraulichen Aussage eines Informanten zu widersprechen, während gerade solche Ermittlungshandlungen zur Suche nach materiellen Beweismitteln oder zu der Festnahme des Verdächtigen, Beschuldigten, Angeklagten oder Verurteilten führen. “687

\section{Anmerkung zur Entscheidung}

Die analysierte Entscheidung hat in zweierlei Hinsicht Relevanz. Einerseits bestätigt sie die Bedeutung der Unterstützung der ,fundierten Anhaltspunkte“ durch materielle Beweismittel. Die Beweisunterstützung wird als eine Grenze betrachtet, die jede Möglichkeit zum willkürlichen Handeln des Staatsanwaltes ausschließt und die die Durchführbarkeit der Durchsuchung und Hausdurchsuchung absichert. Andererseits bestimmt das Verfassungsgericht zwei Richtungen der Überprüfung der „fundierten Anhaltspunkte“. Eine erste Richtung besteht in der Konfrontation des Staatsanwaltes mit dem Beweismittel, auf das sich die „fundierten Anhaltspunkte“ stützen; im Falle des Art. 221 CPP erfolgt dies durch die Möglichkeit, sowohl die Zeugen als auch die Informanten zu vernehmen. Zweitens wird dies gewährleistet, indem jede Möglichkeit der Geheimhaltung jener Beweismittel

\footnotetext{
${ }^{685}$ Die Vertraulichkeit gilt also mit anderen Worten gegenüber dem Beschuldigten, der Verteidigung und der Disziplinarstaatsanwaltschaft. KVerfG, Entsch. C-637 v. 2005, Abschn. VI. 3.

${ }^{686} \mathrm{KVerfG}$, Entsch. C-637 v. 2005, Abschn. VI. 3.

${ }^{687}$ KVerfG, Entsch. C-637 v. 2005, Abschn. VI. 3: „por cuanto esta diligencia no podría practicarse si no existe imputado o se estaría habilitando al defensor para controvertir el dicho de un informante que tiene carácter reservado, cuando tales diligencias se orientan justamente a la búsqueda de elementos materiales probatorios y evidencias físicas o realizar la captura del indiciado, imputado o condenado." (dt. Übersetzung d. Verf.). 
gegenüber dem JCG ausgeschlossen wird. In diesem Sinne wird eine zweigleisige Strategie der Überprüfung der „,fundierten Anhaltspunkte“ und ihrer Beweisgrundlage postuliert: zum einen durch den Staatsanwalt, sobald er den Eingriff in die Grundrechte anordnet. Die bloße Behauptung von „fundierten Anhaltspunkten“ reicht dabei nicht aus. Es ist notwendig, die Beweismittel, die sie stützen, gegenüberzustellen. Auf diese Weise erfolgt auch die Anhörung zur Rechtmäßigkeitsprüfung durch den JCG. So wird dem Staatsanwalt auferlegt, alle verfügbaren Beweismittel vorzulegen, mit denen die Begründung der Maßnahme überprüft werden kann. Die Beweismittel müssen dabei nicht nur der Überprüfung der „fundierten Anhaltspunkte“ (formale Rechtmäßigkeitskontrolle) standhalten, sondern auch die materielle Rechtmäßigkeitskontrolle der Ermittlungsmaßnahme stützen. ${ }^{68}$

Umstritten sind dabei jedoch zwei Aspekte. Einer ist die Rechtfertigung der fehlenden Widerspruchsmöglichkeit vor der Erhebung der Beschuldigung. Mit dieser Ansicht des KVerfG widerspricht er einer gefestigten Rechtsprechung. Sowohl im Rahmen des Dekretes 2700 von $1991^{689}$ als auch des Gesetzes 600 von $2000^{690}$ hatte das KVerfG festgestellt, dass das Recht auf Verteidigung während der Vorermittlung nicht eingeschränkt werden dürfe, der Widerspruch gegen die Beweismittel also während dieser Phase nicht begrenzt werden könne. ${ }^{691}$ Diese Meinung ist auch in dem Strafverfahren nach Gesetz 906 von 2004 zum Ausdruck gekommen. In späteren Beschlüssen hat das KVerfG wiederholt erklärt: „Die korrekte Auslegung des Rechts auf Verteidigung im Prozess setzt voraus, dass dieses vor der Erhebung der Beschuldigung ausgeübt werden kann“692. Diese Meinung diente sogar als Grundlage, den Art. $237 \mathrm{CPP}^{693}$ für verfassungswidrig zu erklären, der - genauso wie Art. 155 CPP - die Teilnahme der Verteidigung an den Anhörungen zur nachträglichen Rechtmäßigkeitskontrolle einschränkte. Zusammenfassend kann gesagt werden, dass die Ansicht des KVerfG beinhaltet hat, dass a) das Recht auf Verteidigung in jedem Verfahrensabschnitt gewährleistet werden muss, dass b) das Recht auf Verteidigung mit der Kenntnisnahme von der Einleitung eines Verfahrens gegen eine Person entsteht und mit

\footnotetext{
${ }^{688}$ KVerfG, Entsch. C-637 v. 2005, Abschn. VI. 3.

${ }^{689} \mathrm{Vgl}$. dazu supra § 2. C. I. 1. Dekret 2700 von 1991.

${ }^{690} \mathrm{Vgl}$. dazu supra $\$ 2$. C. II. Die Strafprozessordnung von 2000.

${ }^{691}$ Vgl. KVerfG, Entsch. C-150 v. 1993, C-412 v. 1993, C-475 v. 1997, T-181 v. 1999, C-1711 v. 2000 , C033 v. 2003.

${ }^{692}$ KVerfG, Entsch. C-799 v. 2005, Abschn. „Consideraciones de la Corte“ - „Interpretación sistemática en concordancia con los Arts. 8 y 267 CPP“: „la correcta interpretación del derecho de defensa implica que se pueda ejercer desde antes de la imputación.“(dt. Übersetzung d. Verf.).

${ }^{693}$ KVerfG, Entsch. C-025 v. 2009 Abschn. 6.10.
} 
demselben endet ${ }^{694}$ und dass c) das Recht auf Verteidigung vor der Erhebung der Beschuldigung ausgeübt werden kann. ${ }^{695}$

Der zweite Aspekt ist die Anerkennung des Art. 155 Abs. 2 CPP über die Vertraulichkeit der Anhörungen während des Ermittlungsverfahrens. ${ }^{696}$ Die anfängliche Auslegung des KVerfG führt zu gravierenden Einschränkungen des Verteidigungsrechtes. Trotz dieser ersten Meinung über den Art. 155 Abs. 2 CPP führt eine systematische Auslegung zu einer anderen Schlussfolgerung. Im Wesentlichen führen die Erörterungen über den Art. 237 $\mathrm{CPP}^{697}$ dazu, die anfängliche Auslegung des Art. 155 Abs. 2 CPP zu korrigieren. Das KVerfG vertritt zu dem Art. 237 CPP $^{698}$ eine andere Position, die folgendermaßen zusammengefasst werden kann: a) Es sei unerlässlich, dass der Verdächtige während der Anhörung anwesend sei und somit sein Recht auf Verteidigung wahrnehmen könne; b) eine unterschiedliche Behandlung des Verdächtigen in den verschiedenen Verfahrensabschnitten sei nicht zulässig, d. h., das Recht auf Verteidigung müsse in allen Abschnitten gewährleistet sein; c) eine Beschränkung des Rechtes auf Verteidigung könne eine negative Auswirkung auf die folgenden Abschnitte des Verfahrens haben; d) die Vertraulichkeit würde dabei nicht infrage gestellt, da das Gericht anerkenne, dass aus kriminalpolitischen Gründen und der Wirksamkeit der Justiz die notwendigen, angemessenen und ausreichenden technischen Mittel zur Verfügung stehen müssten, um schnell und wirkungsvoll das Verbrechen zu bekämpfen. In diesem Sinne könnten die Einschränkungen der Öffentlichkeit des Verfahrens, die der Art. 155 Abs. 2 CPP für die Rechtmäßigkeitskontrolle der Ermittlungshandlungen vorsehe, keine Einschränkung des Rechts auf Verteidigung einschließen. ${ }^{69}$

Zusammenfassend kann gesagt werden, dass die Entscheidung C-673 von 2005 einen wichtigen Beitrag zum Verständnis der „fundierten Anhaltspunkte“ leistet. Zum einen durch die Bestätigung der Forderung nach einer strengen Beweisführung basierend auf einer extensiven Auslegung des Art. 221 CPP und gleichzeitig durch die Forderung nach einer doppelten Überprüfung der „fundierten Anhaltspunkte“ sowohl durch den Staatsan-

\footnotetext{
${ }^{694}$ KVerfG, Entsch. C-1154 v. 2005, Abschn. 2.6.3. La audiencia de imputación.

${ }^{695}$ KVerfG, Entsch. C-1194 v. 2005 und C-210 v. 2007, Abschn. „Consideraciones de la Corte“.

${ }^{696}$ Vgl. dazu infra IV. Vertraulichkeit der Anhörungen zur Legalitätskontrolle (Art. 155 Abs. 2 CPP).

${ }^{697}$ Krit. der ursprünglichen Fassung von Art. 237 CPP Guerro Peralta, 2007, S. 375 ff., der eine grundlegende Überprüfung durch den JCG fordert.

${ }^{698}$ KVerfG, Entsch. C-025 v. 2009, Abschn. 6.4 ff.

${ }^{699}$ Kritiker der Einschränkungen der Öffentlichkeit Zuluaga, Co-Herencia Vol. 4 Nr. 6 (2007), S. 140 f. Für eine Rechtfertigung der Vertraulichkeit in der Anhörung s. Morales Támara, 2009, S. 248 f.
} 
walt als auch durch den JCG. Aufgrund einer systematischen Auslegung des Art. 155 Abs. 2 CPP müsste andererseits die Überprüfung der „fundierten Anhaltspunkte“ als verstärkt verstanden werden, nachdem die Beweismittel bestritten werden können und Widerspruch möglich ist, wie es sich aus der Rechtsprechung des KVerfG zu der Ausübung des Rechts auf Verteidigung während des Ermittlungsverfahrens ergibt.

\section{Entscheidung C-822 von 2005 KVerfG}

In dieser Entscheidung wurde eine Klage behandelt, die die Artikel zur körperlichen Untersuchung (Art. 247 CPP), zur Durchsuchung von Personen (Art. 248 CPP), zur Entnahme und Auswertung von DNA-Proben beim Beschuldigten (Art. 249 CPP) und zu Maßnahmen der Beweissicherung bei Sexualdelikten, die eine körperliche Untersuchung des Opfers erfordern (Art. 250 CPP), betraf. Dies sind solche Maßnahmen, die vor der Durchführung einer vorausgehenden richterlichen Anordnung unterliegen. ${ }^{700}$ Dabei stellte sich die Frage, ob diese Maßnahmen gegen die Menschenwürde (Art. $1 \mathrm{CN}$ ), gegen das Recht, keiner grausamen, unmenschlichen oder herabwürdigenden Behandlung unterworfen zu sein (Art. $12 \mathrm{CN}$ ), gegen das Recht auf Intimsphäre (Art. $15 \mathrm{CN}$ ), gegen die Unschuldsvermutung (Art. $29 \mathrm{CN}$ ) und gegen das Recht, sich nicht selbst zu beschuldigen (Art. $33 \mathrm{CN}$ ), verstoßen. In Bezug auf die Verletzung der Menschenwürde erklärten die Kläger, dass „der fundamentale Kern dieser Verletzung, die Entziehung des Rechtes, sein Einverständnis zu verweigern, ist die Freiheit, über sich selbst zu entscheiden.“701 Was das Recht auf Intimsphäre betrifft, wurde argumentiert, dass diese Grundrechtseinschränkung nur durch eine richterliche Anordnung und nicht durch einen Staatsanwalt erfolgen dürfe, wie es die beklagten Normen beschreiben. ${ }^{702}$ Bzgl. des rechtmäßigen Verfahrens wurde die Verletzung der Unschuldsvermutung angeführt, da die Maßnahmen der Ermittler am Körper der Person als eine Behandlung eines bereits Schuldigen angesehen werden könnten. ${ }^{703}$ Das KVerfG erklärte die Artikel unter bestimmten Bedingungen für anwendbar. Zu den hervorstechenden Aspekten soll die Forderung nach richterlichem Vorbehalt (vorausgehende richterliche Anordnung) bei diesen Maßnahmen genannt werden und die Auslegung der verschiedenen Anforderungen an die fundierten Anhaltspunkte bzgl. möglicher Konflikte mit

\footnotetext{
${ }^{700} \mathrm{Vgl}$. dazu supra § 4. B. II. Anordnungen und Verhältnismäßigkeitsgrundsatz u. infra Anlage 2: Übersicht über den Ermittlungsmaßnahmen im kolumbianischen Strafverfahren

${ }^{701}$ KVerfG, Entsch. C-822 v. 2005, Abschn. III. Demanda: „el núcleo fundamental de esta violación es la privación del consentimiento, de la voluntad de decidir sobre si mismo." (dt. Übersetzung d. Verf.).

702 KVerfG, Entsch. C-822 v. 2005, Abschn. III. Demanda.

${ }^{703}$ KVerfG, Entsch. C-822 v. 2005, Abschn. III. Demanda.
} 
der Unschuldsvermutung. Es werden nun im Folgenden die wesentlichen Aspekte der Entscheidung vorgestellt und besprochen.

\section{Grundlage für die vorausgehende richterliche Anordnung}

Das KVerfG beschreibt zunächst die normative Grundlage, aus der sich die Beweiserhebungsfälle ergeben, die eine Betroffenheit der Grundrechte einschließen und damit einer richterlichen Genehmigung bedürfen. Das Gericht bezieht sich genauer auf Art. 250 Nr. 3 $\mathrm{CN}$, aus dem es die Verpflichtung ableitet, eine vorausgehende richterliche Genehmigung einzufordern, die sich aus der Betroffenheit der Grundrechte ergibt. Demnach ,ist es der ,Eingriff in die Grundrechte', der den Staatsanwalt ausdrücklich für diesen Fall verpflichtet, eine vorausgehende richterliche Genehmigung zu erwirken. [...].“704 Diese Beschränkung oder Begrenzung muss „(i) gesetzlich vorgesehen sein (Prinzip des Gesetzesvorbehalts) und erfordert zudem (ii) die Mitwirkung des Gerichts (Prinzip des richterlichen Vorbehalts), um festzustellen, ob die Maßnahme unangemessen oder unverhältnismäßig ist.“705

Das KVerfG sieht in den Maßnahmen aus den Art. 247-250 eine Betroffenheit der Grundrechte und formuliert zwei Ebenen der Grundrechtsbetroffenheit: mittel und hoch. ${ }^{706} \mathrm{Zu}$ dem erklärt es, dass bei diesen beiden Ebenen der Eingriffe immer das Prinzip des richterlichen Vorbehalts beachtet werden müsse. Die Stärke der Betroffenheit „hänge demnach von der Art des körperlichen Eingriffs, den Umständen, unter denen er stattfindet, den beteiligten Interessen und den konkreten Auswirkung, die die Maßnahmen auf die Grundrechte des Individuums haben“707 ab.

Die Wirksamkeit des Prinzips des richterlichen Vorbehalts führt dem Gericht zufolge zu zwei Ergebnissen: Einerseits hat sich der Staatsanwalt an den JCG zu wenden und die Genehmigung zu beantragen. Ein Eingriff, der die Grundrechte beschränkt, fällt damit aus-

\footnotetext{
${ }^{704}$ KVerfG, Entsch. C-822 v. 2005, Abschn. VIII. 5.1.: es la 'afectación de derechos fundamentales' la que obliga al Fiscal a solicitar de manera expresa y específica la autorización judicial previa. [...]. (dt. Übersetzung d. Verf./Herv. i. Orig.).

${ }^{705}$ KVerfG, Entsch. C-822 v. 2005, Abschn. VIII. 5.1.: „Dicha limitación o restricción (i) debe estar prevista en una ley (principio de reserva legal) y requiere, además, (ii) de la intervención judicial (principio de reserva judicial), para determinar si resulta irrazonable o desproporcionada.“ (dt. Übersetzung d. Verf.). Bzgl. des Begriffs „Grundrechtseingriff“ in dem kolumbianischen Strafverfahren vgl. Bernal Cuellar/Montealegre Lynnet, 2013, T. II., S. $371 \mathrm{ff}$.

${ }^{706}$ KVerfG, Entsch. C-822 v. 2005, Abschn. VIII. 5.1.

${ }^{707}$ KVerfG, Entsch. C-822 v. 2005, Abschn. VIII. 5.1: „depende “del tipo de intervención corporal, de las condiciones en que ésta se realice, de los intereses específicos en juego y del impacto concreto que tal medida tenga en el ejercicio y goce de los derechos fundamentales del individuo." (dt. Übersetzung d. Verf.).
} 
schließlich in die Kompetenz des JCG. Mit den Worten des Gerichts „,erfordert der richterliche Vorbehalt (i) den ausdrücklichen Antrag des Staatsanwaltes oder ausnahmsweise der Kriminalpolizei im Fall der, außerordentlichen Dringlichkeit ${ }^{\star}$ und (ii) die vorausgehende richterliche Entscheidung des JCG, damit die Maßnahme durchgeführt werden kann.“708 Zudem formuliert es besondere Auflagen für den JCG hinsichtlich der Bewertung der Möglichkeit, über einen Grundrechtseingriff zu entscheiden. Es handelt sich grundsätzlich um eine Erwägung auf Grundlage des Verhältnismäßigkeitsprinzips bzgl. des Antrags des Staatsanwalts. $^{709}$

\section{Zweck der ,motivos fundados“}

Das KVerfG bestätigt das Erfordernis der „fundierten Anhaltspunkte“ als Teil der materiellen Voraussetzungen, um eine der in den Art. 247-250 CPP vorgesehenen Maßnahmen zu genehmigen. Außerdem legt es die Notwendigkeit eines konkreten Zweckes fest, der als Orientierung für die Begründung der Maßnahme notwendig ist. Bezogen auf körperliche Untersuchungen (Art. 247 CPP) fordert es, ,(iii) dass diese Gründe ,die Staatsanwaltschaft oder den Staatsanwalt ${ }^{\star}$ - also die FGN oder ihren Vertreter - überzeugen, dass sich der gesuchte Beweisgegenstand oder der physische Beweis im Körper des Beschuldigten befindet. ${ }^{\text {"710 }}$ So verhält es sich auch bei der Leibesvisitation (Art. 248 CPP). Dort fordert es, „dass die Gründe den ,Generalstaatsanwalt oder seinen Vertreter ' darauf schließen lassen,

\footnotetext{
${ }^{708}$ KVerfG, Entsch. C-822 v. 2005, Abschn. VIII. 5.1.: „esta reserva judicial exige (i) la solicitud expresa del fiscal, o excepcionalmente de la policía judicial en circunstancias de "extrema urgencia" y, por supuesto, (ii) la decisión judicial previa, proferida por el juez de control de garantías, para que las medidas puedan ser practicadas.“(dt. Übersetzung d. Verf./Herv. i. Orig.).

${ }^{709}$ KVerfG, Entsch. C-822 v. 2005, Abschn. VIII. 5.1.: „el JCG debe examinar si la medida es o no pertinente, y de serlo, si la medida solicitada es idónea para alcanzar dicho fin; si además de idónea, es necesaria porque no existe otro medio alternativo menos restrictivo de los derechos con eficacia semejante para obtener los elementos materiales probatorios y evidencias materiales dentro del programa de investigación; y si al ponderar los derechos y las finalidades buscadas la medida en concreto no resulta desproporcionada.“ („Dem Gericht zufolge soll der JCG ermitteln, ob die Maßnahme erforderlich ist oder nicht, und wenn sie erforderlich ist, ob die beantragte Maßnahme zweckdienlich ist, ob sie außer geeignet auch notwendig ist, da keine andere Maßnahme bereitsteht, die einen geringeren Rechtseingriff bewirkt, aber genauso geeignet ist, die materiellen Beweisgegenstände und Beweismittel im Rahmen des Ermittlungsverfahrens zu sichern und außerdem, dass bei der Abwägung der Rechte und gewünschten Ziele die konkrete Maßnahme nicht außer Verhältnis steht.“" -dt. Übersetzung d. Verf.-).

${ }^{710}$ KVerfG, Entsch. C-822 v. 2005, Abschn. VIII. 5.2.1.5.: „“(iii) que tales motivos lleven al 'Fiscal o fiscal'-esto es al Fiscal General de la Nación o a su delegado- a creer que el elemento material probatorio o la evidencia física buscada se encuentra en el cuerpo del imputado.“(dt. Überetzung d. Verf./Herv. i. Orig.).
} 
dass der gesuchte Beweisgegenstand oder der gesuchte physische Beweis im Besitz einer Person ist, die mit der Ermittlung in Zusammenhang steht." ${ }^{711}$

Zusätzlich zu dem gerade Gesagten, fordert das KVerfG die Prüfung der Erforderlichkeit der „fundierten Anhaltspunkte“, wenn es sich um einen Antrag auf eine körperliche Untersuchung handelt, d. h., es verneint die Möglichkeit der Genehmigung der Maßnahme bei der Suche nach irrelevanten Elementen. Für das Gericht „müssen objektive Elemente und Gründe vorliegen, die dem JCG eine Entscheidung über die Anordnung einer vom Staatsanwalt beantragten körperlichen Untersuchung ermöglichen. Dieser muss außerdem angeben, was das gesuchte Beweismaterial ist, und begründen, warum er davon ausgeht, dass dieses sich am Körper des Beschuldigten befindet. “712

Bei der Durchsuchung von Personen fordert das Gericht, dass der Beweisgegenstand oder der gesuchte physische Beweis innerhalb des methodologischen Rahmens ${ }^{713}$ liegt, dass er also ein nützlicher Teil des Ermittlungsplans ist, den der Staatsanwalt erarbeitet, um seine Ermittlungsmaßnahmen zu planen. ${ }^{714}$ Zudem stellt das Gericht fest, dass „Durchsuchungen bei unbestimmten Personen nicht zulässig sind, sondern dass die Verbindung nachvollziehbar begründet werden muss, die zwischen der Person, die durchsucht werden soll, und der Ermittlung, die durchgeführt wird, besteht." ${ }^{\text {"715 }}$ Für das Gericht soll die Beziehung zwischen den materiellen Beweismitteln und den physischen Beweisen und der Ermittlung ausgehend von den berechtigten fundierten Anhaltspunkten hergestellt werden, d. h., es handelt sich nicht um eine willkürliche Suche. Zudem „soll das materielle Beweismittel oder der physische Beweis, wenn er schon nicht von essentieller Bedeutung ist, für die Ermittlung eine gewisse Relevanz innerhalb des Plans der Ermittlung haben. Der JCG

\footnotetext{
${ }^{711}$ KVerfG, Entsch. C-822 v. 2005, Abschn. VIII. 5.3.1.7.: „que tales motivos lleven al 'Fiscal General o su delegado' a inferir que el elemento material probatorio o la evidencia física buscada está en posesión de una persona relacionada con la investigación.“ (dt. Übersetzung d. Verf./Herv. i. Orig.).

${ }^{712}$ KVerfG, Entsch. C-822 v. 2005, Abschn. VIII. 5.3.1.5.: „deben existir elementos objetivos y razones que permitan al juez de control de garantías decidir sobre la autorización de la inspección corporal a solicitud del fiscal, el cual también habrá de señalar, cuál es el material probatorio buscado y explicar por qué cree que éste se encuentra en el cuerpo del imputado."(dt. Übersetzung d. Verf.).

${ }^{713}$ KVerfG, Entsch. C-822 v. 2005, Abschn. VIII. 5.3.1.2.

${ }^{714}$ Bzgl. des methodischen Ermittlungsprogramms vgl. dazu supra § 3. A. II. 3. und infra $§ 9$. B. II. 1. Das sog. „programa metodológico“(Art. $207 \mathrm{CPP}$ ).

${ }^{715}$ KVerfG, Entsch. C-822 v. 2005, Abschn. VIII. 5.3.1.7.: „no están permitidos los registros de personas indeterminadas, sino que se debe establecer razonablemente la relación que existe entre la persona sobre la que recaerá el registro y la investigación que se realiza." (dt. Übersetzung d. Verf.).
} 
überprüft, ob die durch den Staatsanwalt gegebene Begründung Teil der , berechtigten fundierten Anhaltspunkte ‘ im Rahmen des Falles ist. “716

\section{3. „Motivos fundados“" vs. Unschuldsvermutung}

Das Gericht beginnt mit der Lösung der Frage, ob die Schlussfolgerung der Täterschaft oder Teilnahme, zu der die „fundierten Anhaltspunkte“ führen sollen, das Prinzip der Unschuldsvermutung anerkennt. Für das Gericht liege keine Verletzung der Unschuldsvermutung vor, wenn es nicht um die Verantwortlichkeit des Beschuldigten gehe. Zudem können die materiellen Beweismittel nur dann als Beweise angesehen werden, wenn sie Teil der Hauptverhandlung werden und dort auch widerspruchsfähig sind. Ein Verfahren gegen den Beschuldigten wird daher nicht nur durch fundierte Anhaltspunkte eröffnet. Im Gegenteil wird nur über „die objektiven Kriterien“ diskutiert, „die eine Grundlage darstellen könnten, um anzunehmen, dass im/am Körper des Beschuldigten ein materielles Beweismittel gefunden werden könnte, das für die Ermittlung von Relevanz ist. Solche Ziele können nicht beim Staatsanwalt liegen. ${ }^{\text {“717 }}$ Für das Gericht müsse sich die Diskussion über die Anordnung der Maßnahme nicht notwendigerweise auf Aspekte der strafrechtlichen Verantwortlichkeit beziehen. Diese Zuständigkeit liege beim Strafrichter. ${ }^{718}$ Darüber hinaus „stellen die Ergebnisse der körperlichen Untersuchung keinen Beweis gegen den Beschuldigten dar, solange sie nicht in der Hauptverhandlung eingeführt worden und dem Widerspruch zugänglich sind.“719

\section{Anmerkung zur Entscheidung}

Das Urteil des KVerfG ist ein Meilenstein in der verfassungsrechtlichen Beurteilung von Ermittlungsmaßnahmen geregelt in den Art. 247-250 CPP, die eine vorausgehende richterliche Anordnung für ihre Ausführung benötigen. Auf der Grundlage der verfassungsmäßi-

\footnotetext{
${ }^{716}$ KVerfG, Entsch. C-822 v. 2005, Abschn. VIII. 5.3.1.7.: „el elemento material probatorio o la evidencia física si bien no tienen que ser esenciales para la investigación, si deben tener alguna relevancia dentro del programa de investigación. El juez de control de garantías analizará si la justificación expuesta por el fiscal efectivamente parte de "motivos razonablemente fundados" en el contexto del caso." (dt. Übersetzung d. Verf.).

${ }^{717}$ KVerfG, Entsch. C-822 v. 2005, Abschn. VIII. 5.2.2.5.: „los criterios objetivos con base en los cuales existiría fundamento para creer que en el cuerpo del imputado se encuentra algún elemento material probatorio necesario para la investigación. Tales motivos no pueden ser subjetivos del fiscal.“ (dt. Übersetzung d. Verf.).

${ }^{718}$ KVerfG, Entsch. C-822 v. 2005, Abschn. VIII. 5.2.2.5.

${ }^{719}$ KVerfG, Entsch. C-822 v. 2005, Abschn. VIII. 5.2.2.5.: „los resultados de la inspección corporal no constituyen prueba en contra del imputado mientras no sean presentados y sometidos a contradicción en la etapa del juicio.“(dt. Übersetzung d. Verf.).
} 
gen Reform des Gesetzesakts 03 von 2002 und der weiteren Entwicklung des Gesetzes 906 von 2004 ist dieses Urteil das Erste, das Maßnahmen analysiert, die sich auf Durchsuchungen von Personen, körperliche Untersuchungen, Probenahmen bei Beschuldigten und Maßnahmen zur Beweissicherung bei Sexualdelikten beziehen. ${ }^{720}$ Die Entscheidung formuliert eine Definition für jede der Maßnahmen und postuliert zudem die Unterschiede, die zwischen den Einzelnen existieren. Sie bietet zudem eine Auslegung über die Art und Weise, wie die Maßnahmen ausgehend vom Verhältnismäßigkeitsprinzip durch den JCG überprüft werden sollen. Damit bestimmte die Entscheidung die formalen wie auch die materiellen Voraussetzungen jeder Maßnahme. Bezogen auf den letzten Aspekt ist die Analyse der Unterprinzipien wie die Zweckmäßigkeit, Erforderlichkeit und Angemessenheit im engeren Sinne mit Blick auf jede Ermittlungshandlung hervorzuheben. ${ }^{721}$

Essenziell ist die Art und Weise, wie das KVerfG die Grundlage für die Verpflichtung des Staatsanwalts zur vorausgehenden richterlichen Anordnung bestimmt. Basierend auf Art. 250 Nr. 3 CN interpretiert das Gericht, dass die Betroffenheit von Grundrechten die Grundlage für diese Verpflichtung sei. ${ }^{722}$ Damit gibt es zu verstehen, dass die Verpflichtung zur richterlichen Genehmigung in allen Fällen Anwendung findet, in denen Grundrechte durch Ermittlungsmaßnahmen betroffen sind. Einerseits präsentiert es eine weite Auslegung des Problems der Betroffenheit der Grundrechte durch strafrechtliche Ermittlungsmaßnahmen. Andererseits wird - indirekt - der Wirkungskreis des Prinzips des richterlichen Vorbehalts erweitert. Werden diese Ergebnisse des Gerichts konsequent angewendet, erfordern alle die Grundrechte einschränkenden Maßnahmen im CPP eine vorausgehende Anordnung des JCG. ${ }^{723}$ Problematisch erscheint, dass das Gericht in dieser Entscheidung nicht zwischen einer Ausnahme von dieser Verpflichtung zur richterlichen Genehmigung unterscheidet. Damit ergibt sich eine Auslegung, die die Gültigkeit des Art. 250 Nr. 2 CN darauf beschränkt, Ermittlungshandlungen zu normieren, die keine vorausgehende richterliche An-

\footnotetext{
${ }^{720}$ Für eine Auflistung der Voraussetzungen für die Durchführung einer körperlichen Untersuchung vgl. Bernal Cuellar/Montealegre Lynnet, 2013, T. II, S. 320 ff.; Bzgl. der Ermittlungsmaßnahmen, die eine vorherige richterliche Anordnung benötigen, vgl. u.a. Guerrero Peralta, 2006, S. 155 ff.; Aponte Cardona, 2006, S. 87.

${ }^{721}$ KVerfG Entsch. C-822 v. 2005 Abschn. 5.2.2.5.; Bzgl. der Verhältnismäßigkeitsprüfung s. supra Fn. 657 m.w.N.

${ }^{722}$ KVerfG Entsch. C-822 v. 2005 Abschn. 5.1., in der als Beeinträchtigung (afectación) auch Einschränkung (limitación) verstanden wird.

${ }^{723}$ Zugunsten einer vorherigen Anordnung der Maßnahmen, die mittlere oder intensive Eingriffe in Grundrechte durchführen und nicht von Art. $250 \mathrm{Nr}$. $2 \mathrm{CN}$ berücksichtigt werden, vgl. Bernal Cuellar/Montealegre Lynnet, 2013, T. I, S. 383; s. auch KVerfG, Entsch. C-156 v. 2016, Abschn. VI Abs. 33 ff.
} 
ordnung benötigen. Dieses Problem wurde in der Entscheidung C-336 von 2007 angesprochen. In diesem Urteil wurde als generelle Regel die vorausgehende richterliche Genehmigung bestimmt und auf Grundlage des Art. 250 Nr. 2 CN die nachträgliche Kontrolle als eine Ausnahme. ${ }^{724}$ Trotzdem bleibt, wie im Weiteren ${ }^{725}$ noch $\mathrm{zu}$ sehen sein wird, die Grundlage der Ausnahme fraglich.

Bezugnehmend auf körperliche Untersuchungen und Durchsuchungen von Personen erscheint die Einbeziehung der Erheblichkeit als Element von Bedeutung, welche das Gericht bei der Bewertung der einzelnen materiellen Beweismittel fordert. Dies schlägt in zweierlei Hinsicht auf die Forderung der fundierten Anhaltspunkte durch. Zunächst wird jegliche Möglichkeit ausgeschlossen, unbestimmte oder abstrakte Begründungen zu liefern. Die berechtigten fundierten Anhaltspukte müssen einen hohen Grad an Konkretheit ${ }^{726}$ haben. Dann muss die Begründung der Maßnahme die Tauglichkeit des erhobenen Beweisgegenstandes für die Ermittlung erkennen lassen. Mit dieser Ansicht wird die frühere Praxis von Massendurchsuchungen der Polizei oder des Militärs ausgeschlossen. ${ }^{727}$ Besonders fraglich sind diese Art Ermittlungsmaßnahmen in der Phase der Vorermittlung. Da das Gericht feststellt, dass das Subjekt der Maßnahme der Beschuldigte sei ${ }^{728}$, kommt man zu dem Schluss, dass diese Handlungen gegenüber dem Verdächtigen in einer strafrechtlichen Vorermittlung unzulässig sind. Da aber gerade viele andere Maßnahmen mit dem Ziel, materielle Beweismittel zu beschaffen, in der Vorermittlung durchgeführt werden können ${ }^{729}$, scheint die Beschränkung durch das Gericht dysfunktional bzgl. der Struktur des Strafprozesses und der Kompetenzen der FGN in der Phase der Vorermittlung. Ein Teil der Lehre ist daher zur Auffassung gelangt vorzuschlagen, dass das Recht auf Verteidigung bereits vor der Beeinträchtigung der Grundrechte durch Ermittlungshandlungen ansetzen solle. ${ }^{730}$

\footnotetext{
${ }^{724}$ KVerfG, Entsch. C-336 v. 2007 Abschn. 10.

${ }^{725}$ Vgl. infra § 7. B. III. Entsch. C-336 v. 2007 KVerfG.

${ }^{726}$ Vgl. dazu auch Entsch. C-185 v. 2008 KVerfG, s. infra § 7. B. IV. 1. Forderung nach Konkretheit der „motivos fundados“.

${ }^{727}$ Für eine Zusammenfassung der Rechtsprechung diesbezüglich s. KVerfG, Entsch. C-879 v. 2011 Abschn. II. $4 \mathrm{ff}$.

${ }^{728}$ KVerfG, Entsch. C-822 v. 2005, Abschn. 5.2.1.2.

${ }^{729}$ Vgl. dazu Guerrero Peralta, 2007, S. 230. 236; Fernández León, 2005, S. 24 ff.; s. auch supra § 3. A. II. 3. Ablauf des Ermittlungsverfahrens u. Anlage 2: Übersicht über den Ermittlungsmaßnahmen im kolumbianischen Strafverfahren

${ }^{730}$ Mit dem Verlangen nach einer doppelten Kontrolle aufgrund einer weiten Auslegung des Art. 237 CPP Guerrero Peralta, 2007, S. 377 f.; vgl. dazu supra Fn. 722 m.w.N.
} 
Dies würde helfen, die Fragestellungen, die sich aus der Beschränkung der Öffentlichkeit und dem Recht auf Verteidigung des Verdächtigen ergeben, zu reduzieren.

Problembehaftet ist auch die Analyse des Umfangs der Verletzung der Unschuldsvermutung. Grundsätzlich vermeidet das KVerfG die Auswirkungen der Forderung nach einer Schlussfolgerung der Täterschaft oder Teilnahme im Rahmen der anderen Maßnahmen. Es ergibt sich die Frage, ob die sog. „Miniurteile über die Schuld“ (minijuicios de culpabili$d a d)$, die sich aus der Begründung der Schlussfolgerung der Täterschaft oder Teilnahme ergeben, eine Verletzung der Unschuldsvermutung ergeben könnten. Dazu existiert keine Rechtsprechung, die diese Frage klärt. Dennoch, wenn man teilweise davon ausgeht, dass die strafrechtliche Verantwortlichkeit in der Hauptverhandlung bestimmt wird, bleibt das der Moment, die Mutmaßung zu beseitigen. Daraus ergibt sich, dass das Ergebnis des Gerichts bzgl. der Verletzung der Vermutung korrekt sein könnte, die Analyse jedoch erscheint mangelhaft.

\section{Entscheidung C-336 von 2007 KVerfG}

Dieses Urteil hatte eine Klage gegen Art. 4 und 244 CPP zum Gegenstand. Nach Ansicht der Kläger erlaubten diese Artikel eine gezielte Suche in vertraulichen Datenbanken ohne eine vorausgehende richterliche Anordnung des JCG. Ihrer Meinung nach wäre dies verfassungswidrig, weil diese Maßnahme nicht in den Ausnahmen für vorausgehende richterliche Genehmigungen des Art. 250 Nr. 2 CN aufgeführt sei. ${ }^{731}$ Dieses Urteil ist dahingehend bedeutsam, dass es sich auf die Rechtsprechung über die - grundsätzlich notwendige vorausgehende richterliche Anordnung für die Ermittlungsmaßnahmen bezieht, die einen Eingriff in die Grundrechte darstellen. Außerdem legt es das Wesen der Maßnahmen fest, die ohne vorausgehende richterliche Genehmigung und mit nachfolgender Überprüfung durch den JCG erfolgen. Im Folgenden werden die bedeutendsten Aspekte vorgestellt und untersucht.

\footnotetext{
${ }^{731}$ Art. 250 Nr. 2 CN: ,2. Durchführung von Hausdurchsuchungen, Beschlagnahmen und Überwachung und Aufzeichnung von Kommunikation. In diesen Fälle erfolgt eine nachträgliche Überprüfung durch den JCG innerhalb der folgenden 36 Stunden." (,Adelantar registros, allanamientos, incautaciones e interceptaciones de comunicaciones. En estos eventos el juez que ejerza las funciones de control de garantías efectuará el control posterior respectivo, a más tardar dentro de las treinta y seis (36) horas siguientes.") (dt. Übersetzung d. Verf.). 


\section{Grundlage für die Ausnahme von der vorausgehenden richterlichen}

\section{Anordnung}

Das KVerfG bestätigt zunächst die Notwendigkeit einer vorausgehenden richterlichen Anordnung im Falle eines Grundrechtseingriffs während des Ermittlungsverfahrens. Für das Gericht „leitet sich die vorherige richterliche Rechtmäßigkeitskontrolle - als Grundsatz aus der Verstärkung der strafrechtlichen Ermittlung nach dem Akkusationsprinzip ab, die sich im richterlichen Vorbehalt bei Grundrechtseingriffen niederschlägt ${ }^{\text {“732 }}$. Bzgl. der Notwendigkeit der vorausgehenden richterlichen Genehmigung berief sich das Gericht auf das Urteil C-822 von $2005^{733}$, in dem - im Sinne einer allgemeine Regel - festgelegt wurde, dass eine vorausgehende richterliche Genehmigung in allen Fällen erforderlich sei, in denen ein Grundrecht betroffen sei. Das Gericht folgert also, dass ,als generelle Regel alle Ermittlungsmaßnahmen, die eine Belastung der Grundrechte vorsehen, grundsätzlich einer vorherigen richterlichen Genehmigung des JCG bedürfen. “" 734

In diesem Sinne erfolgt danach die Erläuterung der Grundlage für Ausnahmen der vorausgehenden richterlichen Anordnung durch das Gericht. Die in Art. 250 Nr. 2 CN eingeführte Flexibilisierung dieses Prinzips „kann durch die Notwendigkeit und Gelegenheit der Erhebung von Informationen erklärt werden, insofern es sich um Ermittlungshandlungen bezogen auf tatsächliche Sachverhalte handelt, die plötzlichen Veränderungen unterliegen können oder die unter Umständen zum Nachteil des staatlichen Interesses an der Ermittlung verändert werden könnten. “735 Für das Gericht ist die Auflistung in Art. 250 Nr. 2 CN beschränkend und restriktiv auszulegen, daher können andere als die in Art. 250 Nr. 2 CN genannten Ausnahmen nicht als verfassungsgemäß gelten. ${ }^{736}$ Unter dieser Voraussetzung bewertet das Gericht einige Maßnahmen, die nicht mithilfe dieser Grundlage gerechtfertigt

\footnotetext{
${ }^{732}$ KVerfG, Entsch. C-336 v. 2007, Abschn. VI. 6.: „el carácter previo del control judicial, como regla, deriva del reforzamiento que en el sistema de investigación penal de tendencia acusatoria se imprimió al principio de reserva judicial de las intervenciones que afectan derechos fundamentales." (dt. Übersetzung d. Verf./Herv. i. Orig.); i.d.S. auch KVerfG, Entsch. C-1092 v. 2003.

${ }^{733}$ Vgl. supra 2. Entsch. C-822 v. 2005 KVerfG zitiert auch in der Entsch. C-336 v. 2007, Abschn. VI. 9.

${ }^{734}$ KVerfG, Entsch. C-336 v. 2007, Abschn. VI. 10.: „,como principio general, toda medida de investigación que implique afectación de derechos fundamentales debe estar precedida de autorización del juez de control de garantías." (dt. Übersetzung d. Verf./Herv. i. Orig.).

${ }^{735}$ KVerfG, Entsch. C-336 v. 2007, Abschn. VI. 14: ,puede explicarse en la necesidad y oportunidad del recaudo de la información, en cuanto se trata de diligencias que generalmente están referidas a realidades fácticas que pueden estar propensas a cambios repentinos, o que podrían eventualmente ser alteradas en desmedro del interés estatal de proteger la investigación.“ (dt. Übersetzung d. Verf.); i.d.S. auch Entsch. C-156 v. 2016, Abschn. VI Abs. 43.

${ }^{736}$ KVerfG, Entsch. C-336 v. 2007, Abschn. VI. 17.
} 
werden können. Aus den Maßnahmen mit nachträglicher Überprüfung schließt es i. d. S. die selektive Suche nach vertraulicher Information in Datenbanken i. S. d. Art. 14 und 244 CPP aus. ${ }^{737}$

\section{Anmerkung zur Entscheidung}

Dieses Urteil ergänzt die Auslegung des KVerfG zum Art. 250 Nr. 3 CN in Bezug auf die Notwendigkeit der vorausgehenden richterlichen Anordnung im Falle eines Grundrechtseingriffes während des Ermittlungsverfahrens. ${ }^{738}$ Dennoch relativiert es diese Anforderung ausgehend von zwei Ansatzpunkten. Einerseits bestimmt es, dass nur die in Art. 250 Nr. 2 $\mathrm{CN}$ angegebenen Maßnahmen als eine Ausnahme von der vorausgehenden richterlichen Anordnung betrachtet werden könnten. Andererseits wird als Grundlage für eine Ausnahme von der vorausgehenden richterlichen Genehmigung die „Notwendigkeit und Gelegenheit" der Erhebung der Information genannt. Diese Auslegung ist in zweierlei Hinsicht problematisch. Erstens: Maßnahmen wie die Infiltrierung krimineller Organisationen (Art. 241 und 242 CPP), die Personenüberwachung (Art. 239 CPP), der Zugriff auf Datenbanken (Art. 236 CPP) oder die körperliche Untersuchung (Art. 247 CPP) würden eine vorhergehende richterliche Anordnung erfordern, da sie nicht in Art. 250 Nr. 2 CN aufgezählt werden, ${ }^{739}$ obwohl sie im CPP im Kapitel über die Maßnahmen, die keine vorgehende richterliche Genehmigung brauchen, geregelt werden. Zweitens: Wenn die Grundlage der Verpflichtung zu einer vorhergehenden richterlichen Anordnung die Betroffenheit der Grundrechte ist, ist es nicht verständlich, wie eine vorhergehende richterliche Genehmigung eine angebrachte Erhebung der Information unwirksam machen kann. Es wird mit anderen Worten nicht deutlich, aus welchem Grund es bei der angebrachten Erhebung der sachlichen Beweismittel eine Ausnahme von der vorausgehenden richterlichen Anordnung geben muss. Das KVerfG legt den Art. 250 Nr. 2 CN streng aus, da die Tatsache, dass eine vorausgehende richterliche Genehmigung die angebrachte Erhebung von sachlichen Beweis-

\footnotetext{
${ }^{737}$ KVerfG, Entsch. C-336 v. 2007, Abschn. VI. 24.

${ }^{738} \mathrm{Vgl}$. supra $§ 7$ B. II. Entsch. C-822 v. 2005 KVerfG.

${ }^{739}$ I.d.S. Bernal Cuellar/Montealegre Lynnet, 2013, T. I, S. 384, die davor warnen, dass eine bedingte Entscheidung des Verfassungsgerichts in Bezug auf diese Artikel erforderlich sei, um diese Vorschriften in einer Weise auszulegen, sodass der Richtervorbehalt gewährleistet wird.“ („se requiere una sentencia condicionada de la Corte Constitucional en relación con estos artículos, que interprete las disposiciones citadas en un sentido que respete la reserva judicial.") (dt. Übersetzung d. Verf.). 
mitteln ausschließen würde, nicht als eine unbeschränkte Voraussetzung betrachtet werden könne. ${ }^{740}$

Zusätzlich zu dem Vorangehenden hat die Auslegung des Gerichtes zur Beantragung der Ausnahme der Verpflichtung einer vorausgehenden richterlichen Genehmigung Auswirkungen auf die Problematik der „fundierten Anhaltspunkte.“ Die Auffassung der Flexibilisierung des Prinzips des richterlichen Vorbehalts führt dazu, dass der Staatsanwalt die Dringlichkeit der Erhebung der Beweismittel bewertet. Die „fundierten Anhaltspunkte“ müssen also dazu führen, gleichzeitig die Gründe für die Notwendigkeit darzulegen, die eine Ausnahme von der vorausgehenden richterlichen Genehmigung des JCG rechtfertigen. Dies könnte zur Auffassung führen, dass die in Art. 250 Nr. 2 CN angegebenen Maßnahmen (mit nachträglicher Kontrolle) nur dann ohne vorausgehende richterliche Anordnung des JCG durchgeführt werden können, wenn zusätzlich „fundierte Anhaltspunkte“ vorliegen, die die Dringlichkeit der Erhebung der Informationen untermauern. In anderen Fällen würde die Überprüfung zweimal stattfinden, ${ }^{741} e x$ - ante und ex - post. Fraglich ist, warum das KVerfG keine systematische Bewertung anderer Maßnahmen vornimmt, die sich wegen ihrer mittleren oder hohen Belastung der Grundrechte nach dem Prinzip des richterlichen Vorbehaltes richten müssten, aber nach Art. 250 Nr. 2 CN nachträglich überprüft werden müssen, z. B. Hausdurchsuchungen, Beschlagnahmen und Überwachung der Kommunikation. Diese Unbestimmtheit besteht weiterhin, obwohl diese Problematik im Urteil C131 von 2009 behandelt wurde, d. h., es wurde die Gültigkeit des Prinzips des richterlichen Vorbehalts für die Hausdurchsuchung erörtert. ${ }^{742}$

\section{Entscheidung C-185 von 2008 KVerfG}

Dieses Urteil betraf eine Klage gegen Art. 21 des Gesetzes 1142 von 2007. ${ }^{743}$ Mit diesem Gesetz wurde der Art. 300 CPP wieder aufgenommen, der zuvor durch das Verfassungsgericht mit der Entscheidung C-1001 von $2005^{744}$ für verfassungswidrig und damit für nicht mehr anwendbar erklärt worden war. Die Entscheidung aus dem Jahr 2005 erklärte diesen

\footnotetext{
${ }^{740}$ Vgl. Guerrero Peralta, 2007, S. 377, für den die vorherige Kontrolle auf die Begründung der Anordnung und die nachträgliche Kontrolle auf die Duchführung der Maßnahme ausgeübt werden muss.

${ }^{741}$ Vgl. Guerrero Peralta, 2007, S. 377; Bzgl. verdeckter Ermittlungen Morales Tamara, 2009, S. 239.

${ }^{742}$ KVerfG, Entsch. C-131 v. 2009, Abschn. VI. 5.

${ }^{743}$ Für eine Analyse dieser Reform vgl. Vélez Osorio 2012, S. 109 ff.; s. auch Uribe García in Ratio Juris 12 (2011), S. 87-117; Martínez Sánchez DPC 20 (2010), S. 69-117; Suarez López Temas de Derecho Penal 2008, S. 331-370; Monroy Cabra, FP 70 (2008), S. 29-52.

${ }^{744}$ KVerfG, Entsch. C-1001 v. 2005, Abschn. VII. Decisión.
} 
Artikel für verfassungswidrig, weil er vage war und allgemeine Kriterien für die Erlaubnis eines behördlichen vorbeugenden Gewahrsams ${ }^{745}$ festlegte. Dieser Beschluss ist insofern wichtig, als dass er eine Bewertung der Grenzen beim Vorgehen im Sonderfall einer vorbeugenden Gewahrsamsnahme nach Anordnung des Staatsanwalts für die FGN vornimmt. Bezogen auf die Forderung nach „fundierten Anhaltspunkten“, die einen Eingriff in die Bewegungsfreiheit unterstützen, bewertet das Gericht die Anpassung des Art. 21 des Gesetzes 1142 von 2007 an die wiederholten Forderungen der Rechtsprechung des KVerfG nach Konkretheit. Im Folgenden werden die bedeutenden Aspekte beschrieben und erläutert.

\section{Forderung nach Konkretisierung der ,motivos fundados“}

Das Gericht bewertet in der Entscheidung die in Art. 21 des Gesetzes 1142 von 2007 vorgesehene und in Art. 300 CPP abgeänderte Forderung nach „fundierten Anhaltspunkten“. Für die Rechtfertigung des vorbeugenden Gewahrsams erklärt dieser Artikel, dass die Anordnung des Staatsanwalts durch wichtige Gründe und höhere Gewalt begründet werden muss, aus denen gefolgert werden kann, dass kein JCG erreichbar ist, der die Maßnahme erlassen kann. Das Gericht verglich dies mit den Voraussetzungen für den Erlass eines Haftbefehls durch den JCG (Art. 297 CPP) und stellte fest, dass der Art. 21 des Gesetzes 1142 von 2007 „nicht ausdrücklich verlangt, dass jene Gründe durch Beweismittel gestützt werden, noch dass sich die Begründung auf eine tatsächliche Feststellung der Unmöglichkeit, sich an einen JCG zu wenden, der die Anordnung erlässt, stützen muss.“746

Das KVerfG weist darauf hin, dass die in diesem Artikel geforderte Begründung, die Forderungen nach Konkretheit, Exaktheit und Bestimmtheit, nicht erfüllt werde, die sich aus Art. $250 \mathrm{CN}$ für den Grundrechtseingriff - insbesondere aus Art. 250 Nr. 1, der genaue Begrenzungen für die Befugnis für einen vorübergehenden Gewahrsam verlangt ergibt. ${ }^{747}$ Für das Gericht lassen die „Formulierungen von ,schwerwiegenden und unkontrollierbaren Gründen' und das Kriterium der fehlenden ,Verfügbarkeit' des JCG mannig-

\footnotetext{
${ }^{745}$ Vgl. dazu Bernal Cuellar/Montealegre Lynnet, 2013, T. II, S. 491 f.; Bzgl. der behördlichen Festnahme von Art. 69 Código Nacional de Policía vgl. Bernal Cuellar/Montealegre Lynett, 2013 T. II, S. 493 f.; Aponte Cardona, 2006a, S. 53 ff.; Sánchez Martínez, 2003, S. 7; Martínez Rave, 2002, S. 447 f.

${ }^{746}$ KVerfG, Entsch. C-185 v. 2008, Abschn. V. 5.: „,no exige expresamente que tales motivos estén fundados en elementos probatorios, ni que la motivación deba basarse en una constatación fáctica de la imposibilidad de acudir a un juez de control de garantías para que expida la orden.“ (dt. Übersetzung d. Verf.).

${ }^{747}$ Vgl. dazu supra $§$ 6. C. I. Festnahme mit Ausnahmekompetenzen.

232
} 
faltige Hypothesen und Annahmen zu, die die Bestimmung dieser Umstände dem Ermessen eben dieses Staatsanwaltes überlassen, der die Festnahme anordnen wird.“748

Das Gericht weist darauf hin, dass die Bezeichnung „schwerwiegend“ des Art. 300 Abs. 1 CPP mehrdeutig und unbestimmt sei. Auch die Forderung nach unkontrollierbaren Gründen wurde als inhaltlich unbestimmt beschrieben. Diese Formulierungen führen zu willkürlichen Entscheidungen, weil sie die Definition eines schwerwiegenden und unkontrollierbaren Grundes dem Ermessen des Staatsanwaltes überlassen, erklärte das Gericht. Insofern entfernt sich die Anordnung eines vorbeugenden Gewahrsams von einer objektiven Begründung. Mit den Worten des Gerichts: „Diese Formulierungen erfüllen in keinerlei Hinsicht die Vorgaben des in Art. 29 der Verfassung gewährleisteten Legalitätsprinzips noch die in der Verfassungsrechtsprechung vorgegebenen Leitlinien, da die Begründungen und Bedingungen einer Freiheitseinschränkung deutlich im Gesetz geregelt werden müssen und nicht dem Ermessen desjenigen überlassen werden können, der die Festnahme anordnet. “749 Es wiederholt, dass die Entscheidung über eine Freiheitseinschränkung mittels eines Haftbefehls nicht aufgrund von vagen und unbestimmten Kriterien getroffen werden könne.

In der Konkretheit, Genauigkeit, Bestimmtheit der Begründungen, die als Grundlage für den Haftbefehl des Staatsanwaltes verlangt werden, liegt die Beschränkung, die einen beliebigen Gebrauch dieser Maßnahme seitens der Staatsanwaltschaft verhindert. Für das Gericht bleibe der Ausnahmecharakter der Maßnahme erhalten, indem vom Staatsanwalt verlangt wird, dass er ,,seine Schritte nachweist, die er unternommen hat, um tatsächlich einen JCG zu finden, und die Umstände darlegt, die seine Suche erfolglos machten. Der Ausnahmecharakter dieser Rechtsfigur erfordert eine Entscheidung nach objektiver Notwendigkeit, die dem Staatsanwalt im Einzelfall auferlegt, die verfassungsrechtlichen und

\footnotetext{
${ }^{748}$ KVerfG, Entsch. C-185 v. 2008, Abschn. V. 5. la expresión "motivos serios y de fuerza mayor" y el criterio de la falta de "disponibilidad" del juez de control de garantías, dan lugar a las más variadas hipótesis y supuestos que dejan a la discrecionalidad del propio fiscal que ha de efectuar la captura, la determinación de esas circunstancias.“ (dt. Übersetzung d. Verf./Herv. i. Orig.).

${ }^{749}$ KVerfG, Entsch. C-185 v. 2008, Abschn. V. 5.: „esos calificativos no cumplen en manera alguna, los parámetros del principio de legalidad consagrado por la Constitución en su artículo 29 ni por los lineamientos señalados en la jurisprudencia constitucional, pues los motivos y las condiciones para restringir la libertad deben ser plasmados claramente en la ley y no pueden quedar a discreción de quien ordene la captura." (dt. Übersetzung d. Verf.).
} 
gesetzlichen Voraussetzungen dieser Maßnahme nachzuweisen.“750 Als Konsequenz der vorangehenden Erläuterungen hat das Gericht die hier erwähnten Formulierungen, die „schwerwiegenden und unkontrollierbaren Gründe“, für verfassungswidrig erklärt. ${ }^{751} \mathrm{Au}$ ßerdem verlangte es eine strenge Beweisführung, die sich auf sachliche Beweismittel in Übereinstimmung mit Art. 221 CPP stützt.

\section{Anmerkung zur Entscheidung}

Das Urteil C-185 von 2007 festigt die Rechtsprechung über die Grenzen des vorbeugenden Gewahrsams. Die Argumente, die zur partiellen Verfassungswidrigkeit des Art. 21 des Gesetzes 1142 von 2007 führen, finden sich bereits in einigen vorangehenden Entscheidungen bzgl. der Festnahme ohne richterliche Anordnung. ${ }^{752}$ Die erste zu erwähnende Entscheidung ist die C-730 von 2005, die Art. 2 CPP für teilweise verfassungswidrig erklärte. Mit dieser Entscheidung wurde vom Gericht klargestellt, dass sich die Möglichkeit der weiten Auslegung der Bestimmungen, die die Anordnung eines Haftbefehls seitens des Staatsanwaltes (nicht richterlich) erlauben, nicht mit dem Ausnahmecharakter der Befugnis für Festnahmen des JCG decken. ${ }^{753}$ Auch die Entscheidung C-1001 von $2005^{754}$, in welcher bestimmt wurde, dass die Begründungen und Voraussetzungen einer Freiheitseinschränkung durch einen vorbeugenden Gewahrsam gesetzlich festgelegt werden müssen und nicht dem Ermessen desjenigen unterliegen dürfen, der die Festnahme anordnet, führt diese Argumentation fort. ${ }^{755}$ Dennoch entschied das KVerfG im Unterschied zu den erwähnten Entscheidungen im Urteil C-185 von 2008, dass der Art. 21 des Gesetzes 1142 von 2007 nicht die Wiedergabe des Art. 300 CPP darstelle - der für verfassungswidrig und für nicht anwendbar erklärt worden war. Diese Meinung wurde in den Entscheidungen C-226 von $2008^{756}$ und C-336 von $2014^{757}$ bekräftigt.

\footnotetext{
${ }^{750}$ KVerfG, Entsch. C-185 v. 2008, Abschn. V. $5 .:$ „mostrar todo lo que hizo para encontrar fácticamente un juez de control de garantías y las circunstancias que impidieron que lo encontrara. La excepcionalidad de la figura exige un juicio de necesidad objetiva, que impone al Fiscal la obligación de demostrar en el caso concreto el cumplimiento de los requisitos constitucionales y legales de esta figura." (dt. Übersetzung d. Verf.).

${ }^{751}$ KVerfG, Entsch. C-185 v. 2008, Abschn. 2. Decisión.

${ }^{752}$ Vgl. dazu Bernal Cuellar/Montealegre Lynnet, 2013, T. II, S. 491 f.; Martínez Sánchez DPC 20 (2010), S.

94 ff.; Prieto Vera, 2006, S. 34 f.

${ }^{753} \mathrm{KVerfG}$, Entsch. C-730 v. 2005, Abschn. VI. 3.1. ff.

${ }^{754}$ KVerfG, Entsch. C-1001 v. 2005, Abschn. VI. 3.3. ff.

${ }^{755}$ KVerfG, Entsch. C-1001 v. 2005, Abschn. VI. 4.2.3.

${ }^{756}$ KVerfG, Entsch. C-226 v. 2008, Abschn. 15 ff.

${ }^{757}$ KVerfG, Entsch. C-366 v. 2014, Abschn. 6.7. ff. 
Die Forderung nach Konkretheit, Genauigkeit und Bestimmtheit für die Begründung der Anordnungen durch den Staatsanwalt, die Grundrechte belasten, stimmt mit dem Verbot von willkürlichen Eingriffen, d. h. dem Verbot eines freien Ermessens des Staatsanwaltes (i. V. m. Art. $28 \mathrm{CN}$ ), überein. Dennoch ist die Argumentation des Gerichtes infrage gestellt worden vor allem, weil sie das Prinzip des richterlichen Vorbehalts bzgl. der Freiheitseinschränkung relativiert, das in vorangehenden Beschlüssen konsequent verteidigt worden war. ${ }^{758}$ Die Entscheidung des Verfassungsgerichts, die Begründung für den Ausnahmecharakter der Bestimmung von einigen zusätzlichen Voraussetzungen abzuleiten, die das Gesetz 1142 von 2007 einführte, z. B. die Frist für die Rechtmäßigkeitskontrolle bei der Festnahme oder die geringe Geltungsdauer der Anordnung, ist kritisiert worden. Im Ergebnis der Argumentation verwechsele das Gericht „die Forderung nach Begründungen, die den Haftbefehl und seine Durchführung stützen - Entfaltung des Legalitätsprinzips - mit der Gewährleistung der genauen Begründungen zur Ausübung der Befugnis der Staatsanwaltschaft eine Festnahme anzuordnen, was nichts anderes ist, als die Regelung der Ausnahme vom Prinzip des richterlichen Vorbehalts, die Beschränkung der Freizügigkeit betreffend. “759 In diesem Sinne führt die fehlende Unterscheidung zwischen den Begründungen für die Befugnis der FGN zur Festnahme einerseits und den Begründungen eines Haftbefehls andererseits zu einer ungerechtfertigten Einschränkung des Prinzips des richterlichen Vorbehalts bei Freiheitseinschränkungen.

Zudem können noch zwei Aspekte problematisch erscheinen. Erstens: Das KVerfG stellt keine Forderung nach der Ausfüllung der Gesetzeslücke bzgl. der Forderung nach beschränkenden Kriterien für die Voraussetzungen und Begründungen, unter denen der Staatsanwalt zur Freiheitseinschränkung befugt wäre. Zweitens: In Anbetracht dieser Gesetzeslücke erweisen sich die partielle Verfassungswidrigkeit und die Nichtanwendbarkeit des Art. 21 des Gesetzes 1142 von 2007 als problematisch. Wenn aus dieser Norm nur die Ausdrücke „schwerwiegende und unkontrollierbare Gründe“ und „,keine Verfügbarkeit des

\footnotetext{
${ }^{758}$ Vélez Osorio, 2012, S. 123 ff.; Zugunsten der Wiedereinführung der behördlichen Festnahme Martínez Sánchez DPC 20 (2010), S. 98.

${ }^{759}$ Vélez Osorio, 2012, S. 128. Nach Vélez's Meinung das KVerfG „beschloss, den Ausnahmecharakter der Regelung in der Tatsache zu finden, dass das neue Gesetz formale und beweisrechtliche Voraussetzungen für die Festnahme erfordert oder dafür die anspruchsvollsten Bedingungen beschließt, wie die Frist für die Rechtmäßigkeitskontrolle der Festnahme oder die Rechtskraft der Anordnung“(,decidió buscar la excepcionalidad de la norma en el hecho de que la nueva ley exigiera requisitos formales y probatorios para la captura, o impusiera aspectos más exigentes, como el término para el control de legalidad de la captura o la vigencia de la orden.") (dt. Übersetzung d. Verf.).
} 
Richters“ ausgeschlossen werden, sind die Begründungen, auf welche sich die Sonderbefugnis zum Gewahrsam seitens des Staatsanwalts stützen sollte, nicht deutlich zu erkennen. ${ }^{760}$ Diese Lücke würde zunächst zu zwei Auslegungen führen. Einerseits müsste sich der Haftbefehl mit Blick auf Art. 297 CPP in Übereinstimmung mit Art. 221 auf berechtigte fundierte Anhaltspunkte stützen, um folgern zu können, dass der Betroffene Täter oder Teilnehmer der ermittelten Straftat ist. Diese Ansicht ist fraglich, da sie die Begründung der Freiheitseinschränkung mit jedem anderen möglichen Eingriff in die Grundrechte gleichsetzen würde, d. h., sie hebt die Forderung nach ausdrücklich genannten Gründen auf (Gründe, die zuvor gesetzlich definiert wurden). Andererseits könnte eine Lösung vorgeschlagen werden, die mit den Forderungen des Art. $28 \mathrm{CN}$ übereinstimmt und mit den Forderungen der Entscheidungen C-739 von 2005 und C-1001 von 2005 in Einklang steht. Mit dieser Begründung müsste die Befugnis des Staatsanwalts zum vorbeugenden Gewahrsam in Übereinstimmung mit Art. $4 \mathrm{CN}$ wegen Verfassungswidrigkeit nicht anwendbar sein, bis die Gesetzeslücke ausgefüllt wird und im Gesetz vorbestimmte Begründungen aufgenommen werden. ${ }^{761}$

\section{Systematischer Überblick der ausgewählten Rechtsprechung}

Die Auswertung der Rechtsprechung des kolumbianischen Verfassungsgerichtes zum Begriff der „fundierten Anhaltspunkte“ zeigt die Tragweite dieser Rechtsfigur im kolumbianischen Strafprozess. In einem ersten Schritt führt der Art. 250 Abs. $1 \mathrm{CN}$ die Forderung nach der Begründung der Ermittlungsmaßnahmen ein. In einem zweiten führt der CPP diese Forderung für alle Fälle aus, in denen die Grundrechte betroffen sind, und zusätzlich für andere strafprozessuale Maßnahmen. Eine grundsätzliche Bestimmung des Begriffs fundierte Anhaltspunkte oder „motivos fundados “ wurde von dem KVerfG in seiner Entscheidung C-024 von 1994 ausgeführt. Dennoch, durch die Verabschiedung des Gesetzesakts 03 von 2002 und seiner Weiterentwicklung durch das Gesetz 906 von 2004 wird eine eingehendere Bewertung der Begründung und Grenzen dieses Begriffes erreicht. Die Rechtsprechung zum neuen Strafprozess hat den in der Entscheidung C-024 von 1994 vorgesehenen anfänglichen Begriff wieder aufgenommen, ihn dabei aber in wesentlichen Aspekten wie Zweck und Notwendigkeit der Konkretisierung, Genauigkeit und Bestimmtheit, Beweis-

\footnotetext{
${ }^{760}$ Vélez Osorio, 2012, S. 130.

${ }^{761} \mathrm{Bzgl}$. der Ausnahme der Verfassungswidrigkeit (excepción de inconstitucionalidad) in Kolumbien vgl. Bernal Cano, 2002, S. 87 ff.; Blanco Zuñiga, RDUN 16 (2001), S. 268 - 279; Bernal Cuellar/Montealegre Lynnet, 2013, T. I, S. 163 f.; KVerfG, Entsch. C-122 v. 2011, Abschn.VI. 2 ff.; C-067 v. 2008, Abschn. „Consideraciones de la Corte“. 
führung und Rechtmäßigkeitskontrolle durch den JCG zu den „fundierte Anhaltspunkte“ weiterentwickelt. Im Anschluss werden die wesentlichen Erläuterungen jeder dieser Aspekte zusammengefasst.

\section{Grundlage des richterlichen Vorbehalts}

Die Analyse der Rechtsprechung des richterlichen Vorbehalts lässt zwei Argumentationsebenen des KVerfG erkennen. Die erste Ebene ist theoretisch-verfassungsrechtlicher Art und setzt voraus, dass bei Beeinträchtigung der Grundrechte immer eine vorangehende richterliche Anordnung notwendig ist. Diese Erwägung des Verfassungsgerichts wird von der gesetzlichen Regelung in Art. 250 Nr. 3 CN und seinen Ausführungsbestimmungen in Art. 246-250 CPP gestützt. Auf einer zweiten Argumentationsebene zu diesen Maßnahmen (mit vorausgehender richterlicher Genehmigung) stellt das Verfassungsgericht fest, dass sie zwei Grade der Grundrechtsbetroffenheit enthalten. Zur Bestimmung des Grades der Betroffenheit etabliert das Gericht offene Voraussetzungen, die zu einer Einzelfallprüfung führen. So hängt die Festlegung des Grades der Einschränkung von der Maßnahme selbst, den Umständen der Durchführung, den betroffenen Interessen und den Auswirkungen auf die Grundrechte ab. Auch wenn die Auffassung zur „Betroffenheit der Grundrechte“ auf der ersten Ebene eine allgemeine Gültigkeit unabhängig der Natur der Maßnahme für sich beanspruchen kann, relativiert das Verfassungsgericht auf der zweiten Argumentationsebene diese Gültigkeit, indem es einige Urteilskriterien zur Bestimmung des Belastungsgrades einführt.

Die allgemeine Gültigkeit des Prinzips des richterlichen Vorbehalts wird auch durch zwei zusätzliche Thesen relativiert. Einerseits können ausgehend von der wörtlichen Auslegung des Art. 250 Nr. 2 CN nur die dort aufgezählten Maßnahmen (Hausdurchsuchung, Beschlagnahme und Überwachung der Kommunikation) von einem Antrag auf eine vorausgehende richterliche Anordnung ausgeschlossen werden. Andererseits wird mit Blick auf die Analyse der Natur dieser Maßnahmen erwogen, dass die „Notwendigkeit und Gelegenheit“ zur Erhebung der Informationen diese Ausnahme von der vorangehenden Genehmi-

gung des JCG, um diese Maßnahmen zu erlauben, rechtfertigen. In der Analyse der Rechtsprechung zur Graduierung der Betroffenheit ist nicht deutlich zu erkennen, was unter einer „geringen“ Belastung verstanden werden kann oder wie eine mittlere oder hohe Belastung bestimmt werden könnte. Ebenso bleibt die Begründung undeutlich, warum ein Eingriff des JCG vor der Durchführung der Maßnahme die Gelegenheit zur Erhebung der In- 
formationen einschränken könne. Außerdem macht das Gericht keine systematische Bewertung anderer Maßnahmen, die sich wegen ihrer mittleren oder hohen Belastung der Grundrechte nach dem Prinzip des richterlichen Vorbehalts richten müssten, die aber durch Art. $250 \mathrm{Nr}$. $2 \mathrm{CN}$ an eine nachträgliche Kontrolle gebunden werden.

\section{Zweck der ,motivos fundados“6}

Die Möglichkeit einer von vagen und unbestimmten Kriterien ausgehenden Begründung für eine Einschränkung der Grundrechte wird vom KVerfG verwehrt. Obwohl keine spezifische Lehrmeinung zur Bestimmbarkeit der „fundierten Anhaltspunkte“ oder zur Begründung einer Anordnung, die zur Einschränkung von Grundrechten führt, erkennbar ist, missbilligt das KVerfG wiederholt die polizeiliche Praxis „ohne Begründung und konkretes Ziel““. Dem Gericht zufolge muss in der Anordnung einer Ermittlungsmaßnahme von fundierten Anhaltspunkten ausgehend die Bedeutung der Ermittlungshandlung innerhalb des Ermittlungsverfahrens oder sogar des methodologischen Rahmens der Staatsanwaltschaft angegeben werden. So werden die Ermittlungsmaßnahmen mit unbestimmten oder abstrakten Begründungen beanstandet.

Das KVerfG ist deutlich genauer bei der Auswertung der Begründung, die sich aus Art. 300 CPP bzgl. der Befugnis zum vorbeugenden Gewahrsam ergibt. Die Formulierung von „schwerwiegenden und unkontrollierbaren Gründen“ wurden mit dem Argument, dass sie zu vielfältigen Annahmen und Vermutungen veranlassen würden, die die Bestimmungen der Umstände und Begründung der Festnahme dem Ermessen des Staatsanwalts überlassen würden, für verfassungswidrig erklärt. Das Gericht stellt einen direkten Zusammenhang zwischen der Einschränkung des staatsanwaltlichen Ermessens, dem Ausnahmecharakter der Maßnahme und der Konkretheit, Genauigkeit, Bestimmtheit der zur Unterstützung der Anordnung zur Festnahme verlangten Anhaltspunkte her. In diesem Sinne findet das KVerfG in der Beurteilung der objektiven Erforderlichkeit der Maßnahme die Begründung des Ausnahmecharakters dieser Rechtsfigur. Die objektive Beurteilung der Notwendigkeit basiert auf der Auseinandersetzung mit den konkreten, genauen und bestimmten Gründen.

\section{Beweisunterstützung für ,motivos fundados"6}

Bei der Analyse des Art. 221 CPP, der für das Verständnis der Beweismittelsituation für „fundierte Anhaltspunkte“ relevant ist, führt das KVerfG einige notwendige Erwägungen zur Auslegung desselben ein. Das Gericht entwickelt eine doppelte Interpretation der Be- 
weismittel für die „fundierten Anhaltspunkte“. Einerseits besteht eine Verpflichtung zur Begründung der Anordnung des Staatsanwalts mit mindestens einem Bericht, einer eidesstatlichen Erklärung oder sachlichen Beweismitteln. Andererseits ist aus inhaltlicher Sicht ein uneingeschränkter Zugang des Staatsanwaltes und des JCG zu den Beweismitteln, auf die sich die „fundierten Anhaltspunkte“ stützen, notwendig. Dieser umfassende Zugang muss zu einer zweifachen Beurteilung (sachlichen und rechtlichen) führen, aus der die Entscheidung oder Bestätigung der Belastung der Grundrechte hervorgeht. Fraglich ist die Einschränkung des Verteidigungsrechts vor der Erhebung der Beschuldigung durch das Abschneiden des Widerspruchsrechts gegen die Ermittlungshandlungen des Staatsanwalts während der Vorermittlungsphase.

\section{Vertraulichkeit der Anhörungen zur Legalitätskontrolle}

Das KVerfG erklärt, dass die Vertraulichkeit der persönlichen Angaben des Informanten aus Art. 221 Abs. 2 CPP nicht für den JCG gelte. Das Gericht weist darauf hin, dass eine solche Vertraulichkeit eine wirksame Überprüfung der „fundierten Anhaltspunkte“ verhindern würde. Einerseits würde diese Vertraulichkeit die Möglichkeit einer formalen und sachlichen Überprüfung der Ermittlungsmaßnahme beschränken. Andererseits würde es eine Überprüfung der Verhältnismäßigkeit der Maßnahme verhindern. Das KVerfG erkennt dennoch ein gewisses Maß an Vertraulichkeit der persönlichen Daten des Informanten an. Die Sicherheit des Informanten rechtfertigt, dass dessen Daten nicht allgemein zugänglich sind. Andererseits wird i. S. d. Art. 155 CPP erklärt, dass die persönlichen Daten des Informanten während der Anhörungen zur Rechtmäßigkeitskontrolle nicht veröffentlicht werden können, der JCG aber Zugang zu den Daten hat.

Die Anerkennung des Art. 155 Abs. 2 CPP über die Vertraulichkeit der Vorermittlungen führt zu einer gravierenden Einschränkung des Verteidigungsrechtes. Eine systematische Auslegung würde zu einer anderen Schlussfolgerung führen. Im Wesentlichen führen die Erörterungen zum Art. 237 CPP dazu, die anfängliche Auslegung des Art. 155 Abs. 2 zu verändern. Konsequenterweise dürfen die in Art. 155 Abs. 2 eingeführten Einschränkungen zur Rechtmäßigkeitskontrolle der Ermittlungshandlungen weder eine Einschränkung des Verteidigungsrechtes noch eine besondere Behandlung der anderen Partei und der anderen Beteiligten zur Folge haben. 


\section{Zusammenfassung}

Die sog. „fundierten Anhaltspunkte“ (,motivos fundados“) stellen eine der wichtigsten Voraussetzungen für die Anordnungen und einen Grund der Bestätigung im Rahmen der nachträglichen Kontrollen von Grundrechtseingriffen durch den JCG in der Ermittlungsphase dar. Als fundierter Anhaltspunkt versteht sich eine Gesamtheit von artikulierten Tatsachen, die durch Beweismittel unterstützt werden, aus denen objektiv geschlossen wird, dass eine Wahrscheinlichkeit von Täterschaft oder Teilnahme an strafbaren Handlungen besteht und nicht das Äquivalent zum bloßen Verdacht oder zur einfachen Überzeugung des polizeilichen Vertreters ist. Der CPP führte den fundierten Anhaltspunkt als Fundament der Beschlagmaßnahmen (Art. 83 Abs. 2) ein; als Basis für die Aufhebung und Außerkraftsetzung der Rechtspersönlichkeit oder die temporäre Schließung von Lokalen und öffentlichen Einrichtungen (Art. 91 Abs. 1); als Fundament der Aufhebung und Streichung aus dem Güterrechtsregister, dessen Eigentumstitel durch Betrug erlangt wurde (Art. 101 Abs. 1); als Grund für Ermittlungsmaßnahmen mit oder ohne richterliche Anordnung (Art. 213-250); als Fundament, um Vernehmungen in der Vorermittlung voranzutreiben (Art. 282); als Fundament der vorgezogenen Beweisaufnahme (Art. 284 Nr. 3); als Basis zur Anordnung eines Haftbefehls durch den JCG (Art. 297); als Fundament zur Anordnung von Sicherheitsmaßnahmen (Art. 308-311) und als Fundament zur Beweisaufnahme von Zeugen unter 12 Jahren (Art. 383 Abs. 2). Dennoch fehlt eine Auslegung über die Reichweite der im CPP definierten Abstufung der Begründung; die Reichweite von Grundsätzen wie das kontradiktorische Prinzip, der Öffentlichkeitsgrundsatz, das Mündlichkeitsprinzip und der Unmittelbarkeitsgrundsatz sowie eine systematische Auslegung über die Zwecke einer berechtigten Schlussfolgerung, zu der die „fundierten Anhaltspunkte“ führen sollen. Die Rechtsprechung zum neuen Strafprozess hat die wesentlichen Aspekte wie Zweck, Notwendigkeit der Konkretisierung, Genauigkeit und Bestimmtheit, Beweisführung und Rechtmäßigkeitskontrolle durch den JCG zu den „,fundierten Anhaltspunkten“ weiterentwickelt. Beispielsweise stellt das KVerfG fest, dass bei Beeinträchtigung der Grundrechte immer eine vorangehende richterliche Anordnung notwendig sei. Ausgehend von der wörtlichen Auslegung des Art. 250 Nr. 2 CN wird jedoch die allgemeine Gültigkeit des Prinzips des richterlichen Vorbehalts relativiert. Als Ergebnis dieser Auslegung könnten nur die dort aufgezählten Maßnahmen (Hausdurchsuchung, Beschlagnahme und Überwachung der Kommunikation) von einem Antrag auf eine vorausgehende richterliche Anordnung ausgeschlossen werden. Zur Beweisunterstützung führt das KVerfG eine Verpflichtung zur 
Begründung der Anordnung des Staatsanwalts mit mindestens einem Bericht, einer eidesstattlichen Erklärung oder sachlichen Beweismitteln ein. Das KVerfG erkennt dennoch ein gewisses Maß an Vertraulichkeit der persönlichen Daten des Informanten an. Die Sicherheit des Informanten rechtfertigt, dass dessen Daten nicht allgemein zugänglich sind. 


\section{§ 8. Die Lehre des Tatverdachts als rechtsvergleichender Parameter}

\section{A. Vorbemerkung}

Wie schon erwähnt wurde, wird das Erfordernis einer Begründung für Entscheidungen als zentrales Thema im Strafverfahren betrachtet, die bzgl. der Zwangsmaßnahmen dazu tendieren, die Grundrechte des Tatverdächtigen zu beeinflussen. Bei einer strafprozessrechtlichen Vergleichung wird deutlich, dass die Auflage einer Begründung in verschiedenen Strafprozessordnungen durch Begriffe ausgedrückt wird, die den fundierten Anhaltspunkten (motivos fundados) des kolumbianischen CPP gleichkommen. Innerhalb des gesamten spanischsprachigen Sprachraums wird zum Beispiel im spanischen Ley de Enjuiciamiento Criminal von motivos racionalmente bastantes (hinreichend vernünftige Gründe) ${ }^{762}$ gesprochen, der chilenische Código Procesal Penal befasst sich mit antecedentes que permitieren presumir fundadamente (Gründe, die bzgl. ihres Hintergrunds vermuten lassen), ${ }^{763}$ der peruanische Código de Procedimientos Penales beruft sich auf indicios suficientes o elementos de juicio reveladores (hinreichende Anhaltspunkte oder aufschlussreiche Beurteilungselemente), ${ }^{764}$ der venezolanische Código Orgánico Procesal Penal stützt sich auf den Begriff fundados elementos de convicción (begründete Beweiselemente) ${ }^{765}$ und der argentinische Código Procesal Penal benutzt Ausdrücke wie motivos bastantes (genügend Gründe), ${ }^{766}$ motivos suficientes (hinreichende Gründe) ${ }^{767}$ oder einfach motivo (Grund). ${ }^{768}$ Über den Bereich der spanischsprachigen Strafprozessordnungen hinaus besteht auch ein

\footnotetext{
${ }^{762}$ Art. 492 Nr. 4.1: „Que la Autoridad o agente tenga motivos racionalmente bastantes para creer en la existencia de un hecho que presente los caracteres de delito." (Herv. d. Verf.).

${ }^{763}$ Art. 140 b): „Que existen antecedentes que permitieren presumir fundadamente que el imputado ha tenido participación en el delito como autor, cómplice o encubridor, “(Herv. d. Verf.).

${ }^{764}$ Art. 75 Nr. 2: „Recibido el informe pericial, previa audiencia, con intervención de las partes y del perito, si el Juez considera que existen indicios suficientes para estimar acreditado el estado de inimputabilidad del procesado, dictará la resolución correspondiente instando la incoación del procedimiento de seguridad según lo dispuesto en el presente Código." (Herv. d. Verf.).

${ }^{765}$ Art. 236 Nr. 2: „Fundados elementos de convicción para estimar que el imputado o imputada ha sido autor o autora, o partícipe en la comisión de un hecho punible.“(Herv. d. Verf.).

766 Art. 212 bis: „No obstante lo establecido en el artículo 213 inciso a), cuando hubiese motivo bastante para sospechar que una persona ha participado en la comisión de alguno de los delitos previstos por los artículos 142 bis y 170 del Código Penal de la Nación, o en alguna otra infracción penal cuya investigación resulte conexa con aquéllas, el Fiscal procederá a recibirle declaración, salvo que el imputado manifestase su voluntad de declarar ante el Juez“(Herv. d. Verf.).

767 Art. 230: „El juez ordenará la requisa de una persona, mediante decreto fundado, siempre que haya motivos suficientes para presumir que oculta en su cuerpo cosas relacionadas con un delito." (Herv. d. Verf.).

768 Art. 224: „Si hubiere motivo para presumir que en determinado lugar existen cosas vinculadas a la investigación del delito, o que allí puede efectuarse la detención del imputado o de alguna persona evadida o sospechada de criminalidad, el juez ordenará por auto fundado el registro de ese lugar“(Herv. d. Verf.).
} 
wichtiger Ansatz für den Vergleichsrahmen in der deutschen Strafprozessordnung (StPO). In Deutschland stellt der Begriff Tatverdacht ${ }^{769}$ den Ausgangspunkt für die Diskussion bzgl. der Begründung einer möglichen Anordnung einer Ermittlungsmaßnahme dar. Der Begriff des Tatverdachts wird auch als zentraler Begriff des Strafverfahrens angesehen und weist in der StPO drei verschiedene Grade auf: „Anfangsverdacht“, „,hinreichender Tatverdacht“ und „dringender Tatverdacht.“"770 Außerdem wird auch in anderen nicht kontinentaleuropäischen Modellen auf die Notwendigkeit einer Begründung zurückgegriffen. Dies trifft für die USA und ihr common law zu, das aufgrund der IV. Verfassungsänderung eine rechtsprechende Linie anhand des Begriffs Probable Cause ${ }^{771}$ entwickelt. Auch in Puerto Rico wurde der Begriff der motivos fundados in die Verordnungen 4, 11 und 12 des Strafverfahrens (procedimiento criminal) aufgenommen. ${ }^{772}$

Trotz der verschiedenen Begriffe und Prozessmodelle, die ersteren zu Grunde liegen, und der systematischen Behandlung der Ausdrücke, die dem Begriff motivos fundados gleichkommen, ergibt der Vergleich der verschiedenen juristischen Strafprozessordnungen, dass das Erfordernis einer Begründung bindend und unumgänglich ist, um eine Ermittlungsmaßnahme zu bewilligen. Besonders relevant für eine Analyse der Problematik der fundierten Anhaltspunkte (motivos fundados) in Kolumbien ist der Vergleich mit dem Tatverdacht in der deutschen StPO. Wie es schon am Beispiel Deutschlands aufgezeigt wurde, muss jegliche Ermittlungsmaßnahme, die die Grundrechte des Tatverdächtigen in der Ermittlung beeinträchtigen könnte, begründet und auf gerichtlichem Wege genehmigt oder bestätigt werden. Die Begründung einer Maßnahme wird auf einer minimalen Grundlage, die im Tatverdacht verankert ist, festgelegt. Damit bezieht sich die StPO auf eine anzustre-

\footnotetext{
${ }^{769} \mathrm{Im}$ Allgemeinen s. Volk/Engländer, 2013, § 8 Rn. 3 (ebd. in der span. Fassung, s. Volk, 2015); Roxin/Schünemann, 2014, § 39 Rn. 15 ff.; Kühne, 2015, Rn. 322 ff.; zur Geschichte des Verdachts als Rechtsfigur Schulz, 2001, S. 23 ff. Für einen Überblick über die rechtliche Ausgestaltung und den Tatnachweis im Strafbefehlsverfahren s. Ebert, 2000, S. 17 ff.; bzgl. der praktischen Handhabung und Kontrolle am Beispiel der polizeilichen Verdachtsfeststellung s. Lohner, 1994, S. 125 ff.; Vgl. dazu infra § 8. B. Der Tatverdacht in der StPO.

${ }^{770} \mathrm{Vgl}$. dazu infra § 8. B. II. Verdachtsgrade; zu den Verdachtsgraden siehe u.a. Steinberg JZ 21 (2006), S. 1048 f.; Ebert, 2000, S. 101 ff.; Lohner, 1994, S. 61 ff.; Fincke ZStW 95 (1983), S. 924 ff.; Kühne NJW 1979 , S. 618 ff.; Hindte, 1973, S. 32 ff.;

${ }^{771}$ Amendment IV: „The right of the people to be secure in their persons, houses, papers, and effects, against unreasonable searches and seizures, shall not be violated, and no warrants shall issue, but upon probable cause, supported by oath or affirmation, and particularly describing the place to be searched, and the persons or things to be seized“(Hervorh. d. Verf.). Bzgl der Bedeutung, Rechtsnatur und Voraussetzungen vom „Probable Cause" s. ausführlich LaFave, Vol. 2: Sections 3.1 through 4.13 S. 4 ff. m.w.N.

${ }^{772}$ Für eine Differenzierung zwischen „Probable Cause“ und „Motivos fundados“ in der strafprozessualen Rechtslage von Puerto Rico s. Canals Torres RJ UPR (2014), S. $141 \mathrm{ff}$.
} 
bende Beweisgrundlage, damit die Staatsanwaltschaft beginnen kann, Zwangsmaßnahmen in der Ermittlungsphase durchzuführen, was gleichzeitig zum Schutz des Bürgers gegenüber staatlichen Eingriffen dient. ${ }^{773}$

Die kontrastierende Untersuchung der fundierten Anhaltspunkte und der Doktrin bzgl. des Begriffs des Tatverdachts im deutschen Strafprozess steuert dazu bei, die Handhabung und die Problematik der Begründung der Ermittlungsmaßnahmen in Kolumbien besser zu verstehen. Einerseits vermag die vergleichende Analyse einige wichtige Unterschiede für das Verständnis des Begriffs fundierte Anhaltspunkte herauszustellen, die vom kolumbianischen Strafprozessrecht nicht in Betracht gezogen werden. Wie sich im Weiteren herausstellen wird, beinhaltet die Festlegung eines Tatverdachts die Durchführung eines Wahrscheinlichkeitsverfahrens (juicio de probabilidad) bzgl. der Täterschaft oder Teilnahme an einer Straftat. Diese Prognose über die Art der Bindung und der Schuld einer Person bzgl. der Straftat stellt eine der wichtigsten Entscheidungen beim Tatverdacht dar. In dieser Hinsicht wird die Konkretisierung der Wahrscheinlichkeit der Täterschaft oder Teilnahme in den Mittelpunkt der Definition eines Tatverdachts gestellt, wie es auch bei den fundierten Anhaltspunkten weitgehend der Fall ist.

Andererseits erlaubt die Unterscheidung, die im deutschen Strafprozessrecht durch drei verschiedene Tatverdachtsgrade vorgenommen wird, von vornherein die Feststellung des Fehlens einer derartige Differenzierung in den fundierten Anhaltspunkten im kolumbianischen CPP. Der Begriff Tatverdacht der StPO erläutert einleuchtend, wie die Begründungsgrade im Bereich des Begriffs fundierte Anhaltspunkte zu systematisieren sind. Der Begriff des CPP führt dazu, verschiedene Wertungsgrade in demselben aufzuzeigen, nicht nur aufgrund der terminologischen Varietät, mit der er im $\mathrm{CPP}^{774}$ angegangen wird, sondern auch wenn dieser Begriff in Konkordanz mit den Intensitätsgraden interpretiert wird, die die verschiedenen prozessualen Eingriffe und die verschiedenen Ziele jeder Ermittlungsmaßnahme des CPP beinhalten.

\footnotetext{
${ }^{773}$ I.d.S. wird es von der h.M. dargestellt. Siehe u.a. Zabel ZIS 7-8/2014, S. 340, der die Schematisierung der Verdachtsgrade als „Reziprozität von Eingriffsschwere und Verdachtsschwelle“ versteht; Ebert, 2000, S. 70, der den Tatverdacht als „Grundlage hoheitlicher Inanspruchnahme“ beschreibt; Lohner, 1994, S. 17, für den die Verdachtsgrade eine Art „Zauberschlüssel“ für Eingriffe in Rechte Dritter darstellen; zu der Rechtsschutzfunktion des Tatverdachts s. Schulz, 2001, S. 251 f. und 476 f.; s. auch Kühne, 2015, Rn. 321.

${ }^{774}$ Einige Vorüberlegungen zu der Einstufung von „motivos fundados“ finden sich schon in Zuluaga, NFP 83 (2015), S. $169 \mathrm{ff}$.
} 
Obwohl nicht auf die Wurzeln und Traditionen der zu vergleichenden Modelle eingegangen wird, trägt doch schließlich der Vergleich zwischen den fundierten Anhaltspunkten des CPP und dem Begriff des Tatverdachts der $\mathrm{StPO}^{775}$ dazu bei, einige Strafprozessbegrenzungen in den fundierten Anhaltspunkten als Grundlage für Anordnungen für Eingriffe in die Grundrechte durch Zwangsmaßnahmen zu bestimmen. Ausgehend von der Identifizierung und der Gegenüberstellung können auch die Implikationen verstanden werden, die ein solches Begründungsmodell für die Überprüfung der Justiz der fundierten Anhaltspunkte, d.h. für den Schutz der Grundrechte des Tatverdächtigen, beinhalten.

\section{B. Der Tatverdacht in der StPO}

Der Tatverdacht wird als Grundlage für die Strafverfolgung während der Ermittlungspha$\mathrm{se}^{776}$ betrachtet und gilt im deutschen Strafprozessrecht als zentraler Begriff. ${ }^{777}$ Einerseits stellt er die Grenze oder ein Mindesterfordernis dar, um die Durchführung von Zwangsmaßnahmen in der strafrechtlichen Ermittlung anzuordnen. Diese Grenze wird gleichzeitig als Schutzmauer für den Bürger vor staatlichen Eingriffen betrachtet. ${ }^{778}$ Andererseits stellt diese Regelung einen Ausgangspunkt für die Wahrheitsfindung im Strafprozess dar und damit für jegliche Entscheidung über Freispruch oder Verurteilung. Die StPO bedient sich des Begriffes Tatverdacht, indem sie verschiedene Formulierungen benutzt und verschiedene Niveaus oder Verdachtsgrade aufführt. ${ }^{779}$ Ein erster Hinweis findet sich in $\S 160$ Abs. $1 \mathrm{StPO}$, wo auf den „Verdacht einer Straftat“ hingewiesen wird und von dem der Beginn der Ermittlung der Staatsanwaltschaft abhängt. § 100a Abs. 1 bezieht sich auf die Möglichkeit der Telekommunikationsüberwachung, ,wenn bestimmte Tatsachen den Verdacht begründen“. $§ 112$ Abs. 1 autorisiert die Untersuchungshaft bei dringendem Tatverdacht gegen eine Person, bei der eine derartige Maßnahme angewendet werden muss. Gemäß $\S$ 203 wird das Hauptverfahren eröffnet, nachdem die Ergebnisse der Ermittlungen einen

\footnotetext{
775 Eine solche Differenzierung von ,motivos fundados“ wird aufgrund der Schematisierung der Verdachtsgrade unten vorgestellt. S. infra § 9. Die sog. ,,motivos fundados“ i.V.m. dem Tatverdacht.

${ }^{776}$ I.d.S Kühne, 2015, Rn. 321; ,trotz aller Schwierigkeiten ihn prognostisch zu objektivieren, ist der Verdachtsbegriff Dreh- und Angelpunkt des Ermittlungsverfahrens “.

777 Vgl. Zabel ZIS 7-8/2014, S. 340, „Ohne Verdacht keine Ermittlungen und Keine Wahrheitsforschung“; Volk/Engländer, 2013, § 8 Rn. 3 (ebd. in der span. Fassung, s. Volk, 2015), der den Tatvedacht als einen Grund von „Sicherheit, Gewissheit und 'Wahrheit' bezeichnet; Schulz, 2001, S. 475, „Der Verdacht ist Anlass und prozessbezogener Grund des Verfahrens“; Ebert, 2000, S. 101, „Die verfahrensrechtliche Bedeutung des Tatverdachts durchzieht den gesamten Strafprozeß.“

${ }^{778}$ Kühne, 2015, Rn. 321 hebt hervor, dass ,,in dieser Doppelfunktion entspricht der Verdacht dem Terminus der Gefahr im Polizeirecht“; dazu Paeffgen, GA 2014, S. 639 ff.

${ }^{779} \mathrm{Vgl}$. Volk/Engländer, 2013, § 8 Rn. 3 (ebd. in der span. Fassung, s. Volk, 2015); Kohlmann, 2012, S. 161; Roxin/Schünemann, 2014, § 39 Rn. 15 ff.; Kühne, 2015, Rn. 322; Bernsmann/Jansen, StV 1998, S. 219 f. 
„hinreichenden Tatverdacht“ für eine Straftat begründen. ${ }^{780}$ Sogar über diese drei Verdachtsgrade hinaus enthält die StPO Formulierungen, die nicht ausdrücklich auf den Verdacht anspielen, die jedoch einen gewissen Verdachtsgrad darstellen. ${ }^{781}$ Parallel dazu bedient sich die StPO einiger äquivalenter Begriffe, wie z.B. „Gefahr“, ein Begriff, der auf ein Verhalten hinweist, von dem angenommen wird, dass es sich konkretisiert. Die Hypothese, dass ein besagtes Verhalten eintritt, beruht auf dem Verdacht. ${ }^{782}$

Obwohl die StPO ausdrücklich verschiedene Verdachtsgrade aufführt, existiert keine rechtliche Definition dieses Begriffs. Gleichwohl wird allgemein eine Hierarchie innerhalb der Verdachtsgrade anerkannt. In diesem Sinne versteht sich der „einfache Tatverdacht“ ( 160 Abs. 1) als die niedrigste Stufe, darüber befinden sich der ,hinreichende Tatverdacht“ (§ 203) und der „,dringende Tatverdacht“ (§ 112 Abs. 1). ${ }^{783}$ Hiermit übereinstimmend steht außer Diskussion, dass die terminologische Varietät der StPO bzgl. des Begriffs Tatverdacht verschiedene rechtliche Verdachtsgrade aufzeigt. So ist zum Beispiel eindeutig, dass der „hinreichende Tatverdacht“, der für die Einleitung des Prozesses notwendig ist ( $§ 203)$, nicht die Intensität des „dringenden Tatverdachts“, der die Maßnahme der Untersuchungshaft ermöglicht, aufweist. Diese Maßnahme kann ohne die Beendigung einer formalen Strafermittlung angeordnet werden, während die Feststellung eines „hinreichenden Tatverdachts“ erst aufgrund des Endergebnisses der Ermittlung festgestellt werden kann, was die Notwendigkeit einer umfassenderen faktischen Grundlage für die Feststellung oder die Diskussion über einen weniger schweren Verdachtsgrad wie den des „hinreichenden Tatverdachts" beinhaltet. ${ }^{784}$

\footnotetext{
${ }^{780}$ Laut Kühne, 2015, Rn. 322 Fn 29, „§ 138a I stellt den dringenden Verdacht sogar alternativ neben den hinreichenden".

${ }^{781}$ Vgl. Kühne, 2015, Rn. 322; Kohlmann, 2012, S. 161; zu nennen sind beispielweise §§ 99, 111a, 138c, 160 Abs. 1 StPO.

${ }^{782}$ Beispielweise bei den Haftgründen der Fluchtgefahr ( $§ 112$ Abs. 2 Nr. 2), der Verdunkelungsgefahr ( $\S$ 112 Abs. 2 Nr. 3) und der Wiederholungsgefahr (§ 112a Abs. 1); Vgl. dazu Kühne, 2015, Rn. 323; LR/Hilger $\S 112$ Rn. 25 m.w.N.

${ }^{783}$ Roxin/Schünemann, 2014, § 39 Rn. 16; Volk/Engländer, 2013, § 8 Rn. 3 (ebd. in der span. Fassung, s. Volk, 2015); Kühne, 2015, Rn. 324; Steinberg JZ 21 (2006), S. 1048; ausführlich Schulz, 2001, S. 567 ff. m.W.N.

${ }^{784}$ Kühne, 2015, Rn. 324 und Fn. 31 m.w.N.; Schulz nennt der Sauers Konzeption als Grund der Verdachtslinie; bzgl. Sauers Konzeption und die Rezeption in anderen Lehrbüchern s. Schulz, 2001, S. 583 und Fn. 561 m.w.N.
} 
Ungeachtet des Konsenses über die Klassifizierung der Verdachtsgrade der $\mathrm{StPO}^{785}$ wurde das Bedeutungsvakuum dieses Begriffs kritisiert. Mit der Unklarheit des Begriffs geht auch die der Definitionen der verschiedenen Verdachtsgrade einher. Der Grund des Begriffsvakuums bzgl. der Bezeichnung „Tatverdacht“ in der deutschen StPO beruht grundsätzlich auf der nicht ausreichend analytischen Reflektion des Begriffs „Wahrscheinlichkeit“ und dessen Anwendung auf den jeweiligen Verdachtsgrad. Es wird kritisiert, dass die Lehrmeinung des Strafprozesses die Diskussion über die Ungewissheit als implizierten Teil des Verdachtsbegriffs eingeengt habe und sie eher dahingehend tendiere, die Entwicklung des Verständnisses dieses Begriffs zu fördern ungeachtet dessen, dass derselbe wenige sichere

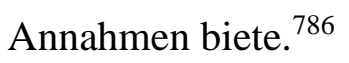

\section{Voraussetzung eines Verdachtsverständnisses}

Im überwiegenden Teil der deutschen StPO wird der Begriff der Wahrscheinlichkeit gebraucht, um die Bedeutung des Verdachtsbegriffs einzugrenzen. ${ }^{787}$ Um einen Verdacht festzustellen, wird zur Erklärung hauptsächlich auf das Wahrscheinlichkeitsverfahren zurückgegriffen. Dieses Verfahren verläuft über die Wertung der Umstände und mögliche an der Straftat beteiligte Täter oder Teilnehmer. In diesem Sinne, und indem ein Wahrscheinlichkeitsverfahren verfolgt wird, stellt die Feststellung eines Verdachts bestimmte Tatsachen und Umstände infrage, d.h., sie antwortet auf die Frage, ob und wie eine bestimmte Straftat, so wie sie stattfand, möglich ist. Die Gleichläufigkeit der Begriffe Verdacht und Wahrscheinlichkeit verändert sich je nach Art des Verdachts. Die StPO stellt mit anderen Worten aufgrund verschiedener Verdachtsgrade unterschiedliche Wahrscheinlichkeitsgrade fest. Dies ist zum Beispiel in $\S 152$ Abs. 2 StPO der Fall, in dem ,zureichende Anhalts-

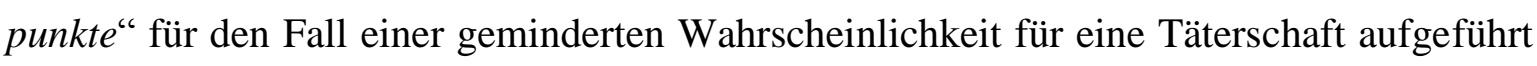
werden. ${ }^{788}$ Ebenso begrenzen sowohl $\S 170$ Abs. 1 als auch $\S 203$ StPO den hinreichenden

\footnotetext{
${ }^{785}$ Vgl. Zabel, ZIS 7-8/2014, S. 340: „,iese Schematisierung der Verdachtsgrade versteht die herrschende Dogmatik als 'typisierte Verhältnismäßigkeit von Ermittlungseingriffe'“; i.d.S. Schulz, 2001, S. 567 f.: „die Verdachtsgrade optimieren die Verhältnismäßigkeit durch Rahmensetzung.“

${ }^{786} \mathrm{Vgl}$. Kühne, 2015, Rn. 325, für den die Unbestimmtheit des Begriffs zu Willkürmaßnahmen führen kann und die Definitionsversuche „Leerformeln, die die Ungewissheit paraphrasieren“, sind (Herv. i. Orig.); auch Zabel, ZIS 7-8/2014, S. 340: „freilich ist diese Schematisierung noch wenig ausagekräftig“; s. dazu auch Eisenberg/Conen, NJW 1998, S. 2241.

${ }^{787}$ Bzgl. des Verdachts als Wahrscheinlichkeitsebene s. Ebert, S. 16; zu der Wahrscheinlichkeit als Voraussetzung der Verdachtsdefinition Kühne, 2015, Rn. 327 ff. und für die Feststellung des Tatverdachts Lohner, 1994, S. 39; s. auch Kohlmann, 2012, S. 162 und Fn. 725 m.w.N.

788 Über die Voraussetzungen des Anfangsverdachts s. infra § 8. C I. Anfangsverdacht; ausführlich und mit zahlreichen weiteren Nachweisen LR/Beulke, § 152 Rn. $21 \mathrm{ff}$.
} 
Tatverdacht im Falle einer Verurteilungswahrscheinlichkeit. Auch wird ein dringender Tatverdacht festgestellt, wenn ein hoher Wahrscheinlichkeitsgrad besteht, dass der Beschuldigte die Tat begangen hat und alle Voraussetzungen für eine „Strafbarkeit“ und die „Verfolgbarkeit“ bestehen. ${ }^{789}$ Die verschiedenen Verdachtsgrade enthalten vornehmlich Wahrscheinlichkeitserfordernisse, von denen aus jeweils bestimmte Zwangsmaßnahmen oder der Anstoß oder die Veranlassung einer Prozesshandlung (z.B. Eröffnungsentscheidung) erfolgen.

Die Wahrscheinlichkeit, die von den Verdachtsgraden der StPO ausgeht, besteht in einer Deduktion, die auf einer Tatbestandswertung beruht, die es erlaubt, auf das Geschehen eines Vorfalls zu schließen. Die Analyse der Umstände und der Modalitäten, die in einem Wahrscheinlichkeitsverfahren bzgl. einer als Straftat angenommenen Tatsache durchgeführt wird, gibt die Struktur einer Prognose wieder. Diese für die Prognose typische Art von Verfahren ist im deutschen Strafrecht nicht selten. Als Beispiele seien $\S 56$ Abs. 1 und 2 StGB genannt für den Fall, in dem das zukünftige Verhalten einer Person beurteilt werden muss, um über eine Strafaussetzung zu entscheiden. Ebenso seien auch $§ 68$ Abs. 1 StGB, der als eine der Voraussetzungen für die „Führungsaufsicht“ die Voraussage erfordert, ob der Verurteilte weitere Straftaten begehen könnte, sowie auch § 111a Abs. 1 StPO anzuführen, wo die Wahrscheinlichkeitsanalyse in Aussicht gestellt wird, die zur „Entziehung der Fahrerlaubnis“ führt. Was diese Art von Prognosen ausmacht, ist die Tatsache, dass aufgrund von bekannten faktischen und normativen Annahmen ein unbekannter Sachverhalt abgeleitet werden muss. ${ }^{790}$

Die Prognose, die jedoch mit der Determinierung des Verdachts einhergeht, konkretisiert sich auf andere Art und Weise. In diesem Fall wird keine logisch voraussehende Überlegung durchgeführt, sondern es wird anfänglich darüber diskutiert, ob ein bestimmter Vorgang in der Vergangenheit stattgefunden hat. Um zu einem Verdacht zu gelangen, wird nicht erwartet, dass ein Ermittlungsverfahren in Strafsachen erfolgreich abgeschlossen ist, sondern dass es im Gegenteil parallel zu den Ergebnissen des Verfahrens verläuft. Die dem Verdacht immanente Prognose ist mit anderen Worten keine Voraussage, sondern vielmehr eine Deduktion, die von verschiedenen Fakten ausgeht. Der Charakter der eigentlichen Verdachtsprognose entspricht keiner Voraussage über einen bestimmten Vorfall, sondern

${ }^{789}$ Vgl. infra § 8. C. II. Dringender Tatverdacht; zum dringenden Tatverdacht als ein täterbezogener Verdacht Ebert, 2000, S. 138 ff.; ausführlich LR/Hilger, § 112 Rn. 16 ff.; Paeffgen, 1986, S. 183 jeweils m.w.N. ${ }^{790}$ Kühne, 2015, Rn. 327; zur abduktiven Logik des Verdachts s. ausführlich Schulz, 2001, S. $273 \mathrm{ff}$. 
ist vielmehr ein Ausdruck der Wahrscheinlichkeit eines Geschehnisses oder Umstandes in der Vergangenheit. Aus diesem Grund stellt die Bestimmung der Wahrscheinlichkeit eine „retrospektive Prognose“ dar. ${ }^{791}$

Die h.M. erkennt die Anbindung dieser Prognose an eine faktische Grundlage bzw. konkrete Tatsachen an, die von denjenigen Normen der StPO begrenzt wird, die den Verdacht als eine Voraussetzung einer Prozesshandlung ansehen. ${ }^{792}$ Allgemein gilt, dass der Verdacht immer ein tat- und täterbezogener Verdacht sein muss, was prinzipiell impliziert, einen Verdacht gegen eine unbestimmte Person auszusprechen. Diese Bedingung der Verdachtsbestimmung bedeutet nicht, dass eine strafrechtliche Ermittlung sich nicht gegen unbekannte Täter richten kann. ${ }^{793}$ Diese Tatsache wird auch im einfachen Verdacht des $\S$ 152 StPO anerkannt, in dem nur zureichende tatsächliche Anhaltspunkte erwähnt werden und die Verdachtsbestimmung nicht mit einer spezifischen Person verbunden ist. In diesem Fall verbietet die Verbindung mit einer konkreten Person (Täter oder Teilnehmer) nicht die Verbindung mit einer konkreten Tat. Diese Anbindung an einen subjektiven und/oder sachlichen Bereich wird allgemein für die Verdachtsfindung hergestellt. Ausnahmsweise ist in der StPO die Möglichkeit verankert, Eingriffe in die Rechte von unbekannten Dritten vorzunehmen, auch wenn kein konkreter Verdacht bzgl. einer bestimmten Person besteht. Dies ist der Fall in $\S 103$ Abs. 1 StPO, der die Durchsuchung Dritter gestattet, wenn aufgrund dieser Maßnahme Hinweise zur untersuchten Straftat erwartet werden können. Äquivalente Vorschriften befinden sich in $\S 100$ c Abs. 2 S. 3 und 163e Abs. 1 S. 3 StPO. Diese Variante bezieht sich nicht auf die Anbindung des Tatverdachts an einen Täter, sondern an eine Tat. D.h., dass es sich hier um Fälle handelt, in denen es keinen konkreten Strafverdächtigen gibt. ${ }^{794}$

Zusammenfassend kann gesagt werden, dass das Verständnis des Verdachtsbegriffs auf drei konkreten Voraussetzungen beruht. Einerseits handelt es sich um ein Wahrscheinlich-

\footnotetext{
${ }^{791}$ Bzgl. des Verdachts als retrospektive Prognose s. Ebert, 2000, S. 17; Lohner, 1994, S. 69 ff.; Die Feststellung des Tatverdachts bedarf auch einer prospektiven Prognose über den Verfahrensgang und anderer juristischer Wertungen, s. dazu Lohner, 1994, S. 109 ff.

792 Vgl. u.a. Schulz, 2001, S. 408 ff.; Ebert, 2000, S. 17, 19; Lohner, 1994, S. 69; v. Hindte, 1973, S. 34; LR/Beulke, § 152 Rn. 25 m.w.N.

${ }^{793}$ Vgl. Zabel ZIS 7-8/2014, S. 341; LR/Beulke, § 152 Rn. 23; Haas, 2003, S. 16 u. Fn. 20 m.w.N.; Ebert, 2000, S. 18 u. Fn. 17 m.w.N.

${ }^{794}$ Bzgl. der Durchsuchung bei Dritten s. LR/Tsambikakis, § 103 Rn. 9 ff.; Krit. Ebert, 2000, S. 19, der die Erwähnung des Beschuldigten in $\S 103$ die Voraussetzung des Inkulpationsverdachts suggeriert; zur Problematik der Ermittlungen zu Lasten Dritter vgl. ausführlich Eckstein, 2013, S. 75 ff.
} 
keitsverfahren, das auf die Frage antwortet, ob es möglich ist, dass eine bestimmte Straftat auf eine bestimmte Art und Weise begangen wurde. Andererseits spiegelt der umstandsbedingte und modale Ansatz, der in einem Wahrscheinlichkeitsverfahren über eine bestimmte angeblich verübte Straftat eingebunden ist, die Struktur einer Prognose wider. Im Grunde genommen wird die Verdachtsfindung durch eine retrospektive Prognose durchgeführt, d.h., sie ist der Wahrscheinlichkeitsausdruck eines in der Vergangenheit liegenden Geschehnisses oder Umstandes. Letztendlich handelt es sich um einen Prozess, der an einen bestimmten subjektiven Bereich gebunden ist und/oder an einen konkreten tat- und täterbezogenen Verdacht. I.d.S. kann der Verdachtsbegriff im Allgemeinen als eine retrospektive Prognose über die Wahrscheinlichkeit einer Täterschaft oder Teilnahme an einer Straftat bezeichnet werden. ${ }^{795}$

Die Feststellung eines Verdachts im Rahmen eines Ansatzes eines Wahrscheinlichkeitsverfahrens ist von den Kritikpunkten umgeben, die diese Art von Prozess angreifen, d.h., dass diese Kritikpunkte sich auf die methodologische Struktur der Verdachtsfindung beziehen. Dem Wahrscheinlichkeitsbegriff werden nicht nur viele Arten von Definitions- und logischem Bestimmungsvakuum angelastet, sondern auch das Nichtvorhandensein einer Gesetzesentwicklung, die seine Struktur und rechtliche Umsetzung begrenzt. ${ }^{796}$ Mit der Wahrscheinlichkeitsfindung im Bereich der Existenz eines Sachverhaltes, die zu einer Verdachtskonkretisierung führen sollte, wird ebenfalls nicht klar, welche Faktoren zur Bestimmung derselben analysiert werden müssen, d.h., welche Konzepte zur Verdachtsbestimung in die Wahrscheinlichkeit integriert werden können. ${ }^{797}$ Es wird kritisiert, dass aufgrund der Bedeutung des Begriffs Tatverdacht anscheinend ausgeschlossen wird, dass die Unsicherheit eine grundlegende Komponente seiner Struktur ist. ${ }^{798}$ Diese Problematik besteht nicht ausschließlich im Wahrscheinlichkeitsverfahren, sondern zeigt sich z.B. in einem Gerichtsbeschluss, den ein Richter im Rahmen der Bewertung der Tatsachen trifft mit dem Ziel, Verurteilung oder Freispruch zu beschließen. In diesen Fällen handelt es sich

\footnotetext{
${ }^{795}$ I.d.S. Ebert, 2000, S. 22, wobei er zusätzlich von „Vorbehaltlichkeit“ als ein weiteres Merkmal des Tatverdachts spricht; dazu s. auch Nell, 1983, S. 85; Bzgl. der Definition des Verdachts siehe u.a. Kühne, 2015, Rn. 335-339.

${ }^{796}$ Kritisch bzgl. der fehlenden Aussagekraft der üblichen Schematisierung der Verdachtsgrade Zabel ZIS 78/2014, S. 340; i.d.S. auch Ebert, 2000, S. 16; jeweils m.w.N.

${ }^{797}$ Für die Ansätze, die den Begriff der Wahrscheinlichkeit fassen, vgl. Nell, 1983, S. 21 ff.; s. auch Kohlmann, 2012, S. 163 und Fn. 728.

${ }^{798}$ I.d.S. Kühne, 2015, Rn. 326: „der Grund für die auffällige argumentative Abstinenz bei der Definition von Verdacht ist wohl die Scheu vor exakt analystischem Umgang mit dem Begriff der Wahrscheinlichkeit“; s. auch Köhlmann, 2012, S. 165.
} 
auch um eine retrospektive Prognose im Bereich des Dilemmas, ob der Angeklagte wirklich die ihm angehängten Taten begangen hat. ${ }^{799}$

\section{Bestimmungsansätze eines Begriffes}

In Anbetracht der oben genannten Bedingungen werden in der deutschen strafprozessrechtlichen Doktrin fünf Methoden aufgeführt, mittels derer versucht wird, ein abstraktes Verständnis des Begriffs Tatverdacht zu etablieren. An erster Stelle wird von der kasuistischen Methode gesprochen, die auf kriminalistischer Basis versucht, einen Katalog von Fällen aufzustellen, die als Tatverdacht zu identifizieren sind. ${ }^{800}$ An zweiter Stelle steht die statistische Methode, die sich dem Verständnis von Tatverdacht über Wahrscheinlichkeitsberechnungen nähert. ${ }^{801}$ An dritter Stelle wird das Erfolgsprognoseverfahren beschrieben, das den Tatverdacht unter dem Gesichtspunkt der Effizienz definiert. ${ }^{802}$ Viertens wird der prima facie Verdacht erwähnt, der eine Definition des Tatverdachts aufgrund von Parallelen zu der Methode herzustellen versucht, die auf das Ergebnis eines Urteils des Zivilrechts durch prima facie Beweise auf der Basis von Erfahrungssätzen hinausläuft. ${ }^{803}$ Fünftens werden andere Gesichtspunkte erwähnt, die als Schemata angesehen werden können, die als Intersektionen oder Mischung von den oben genannten Methoden angesehen werden können. ${ }^{804}$

Die allgemeine Kritik stellt die Fähigkeit dieser Methoden, den Verdachtsbegriff zu bestimmen und Anweisungen festzulegen, die die Bildung dieses Begriffs ermöglichen können, infrage. ${ }^{805}$ Dennoch ergibt eine allgemeine Annäherung an die allgemeinen Thesen Sinn und vor allem an die Kritik derselben. An der kasuistischen Methode wird kritisiert, dass sie ein sehr kompliziertes Register oder einen Katalog der Annahmen des Verdachts aufstelle. Die Verdachtsbeispiele, die gleichzeitig Erfahrungssätze darstellen, finden bei vielen konkreten Beispielen keine Anwendung. Die Tatsache, dass es sich um Regelbei-

\footnotetext{
799 Vgl. Kühne, 2015, Rn. 327: ,aus einer bekannten Tatasache, einem bekannten Gesetz, wird eine unbekannte Tatsache abgeleitet.“

${ }^{800}$ Vgl. Ebert, 2000, S. 39; Lohner, 1994, S. 39; Fincke, ZStW 95 (1983), S. 932.

${ }^{801}$ Vgl. Lohner, 1994, S. 40; s. Ebert, 2000, S. 40 ff., der von mathematischen Methode spricht.

${ }^{802}$ Dazu Lohner, 1994, S. 41, der zwischen Erfolgsaussicht und einem gewissen Maß an Überführungsaussicht als Voraussetzung des Tatverdachts unterscheidet.

${ }^{803} \mathrm{Vgl}$. Kühne, 2015, Rn. 328, der den prima-facie-Beweis als eine Erfahrungsstufe beschreibt; der., NJW 1979, S. 620; Lohner, 1994, S. 42.

${ }^{804}$ I.d.S. Lohner, 1994, S. 44: ,beim Verdacht handelt es sich viel mehr um ein Urteil im Einzelfall, das derjenige zu treffen hat, der die Entscheidung über das Vorliegen oder Nichtvorliegen eines Verdachts vornehmen muss".

${ }^{805}$ Für eine Zusammenfassung aller Einwände vgl. Kohlmann, 2012, S. 166; im Einzelnen Lohner, S. 39 ff. 
spiele handle, erlaube es nicht, Logik und Unterschiede der Einzelheiten der konkreten Fälle in Einklang zu bringen. Die Anwendung eines Regelbeispiels auf einen bestimmten Fall impliziere einen Handlungsspielraum, der die Deduktion eines Verdachts von verschiedenen individuellen und nicht juristischen Kriterien abhängig mache. ${ }^{806}$ Noch dazu würden die Regelbeispiele von zeitlichen und sozialen Entwicklungen abhängen, was zu dem Schluss führe, dass der Verdachtsbegriff nicht spezifischen Regelbeispielen zuzuordnen sei. Kritiker verweisen darauf, dass Mängel zugegeben werden müssten, damit ein Katalog von Regelbeispielen wenigstens die Entscheidung eines Anfangsverdachtsgrades stützen könne, was bedeuten würde, dass eine hohe Wahrscheinlichkeit in den Verdachtsformen zu fordern sei ${ }^{807}$ Der Verdacht stellt ein Kontinuum denkbarer Verdachtsgrade dar, mit anderen Worten ein evolutives Konzept mit einer breiten Skala von möglichen Bedeutungen. ${ }^{808}$

Bzgl. der statistischen Methode verhalten sich die Kritiken ähnlich wie bei der kasuistischen Methode. Bzgl. des statistischen Ansatzes erlauben bestimmte Indizien, eine bestimmte Gruppe von Personen einer Gesellschaft als Täter zu identifizieren. Der Teil der Gruppe, der mehrere Indizien aufweist, kann als verdächtig betrachtet werden. Aufgrund einer Anzahl von Indizien kann es zu einer Wahrscheinlichkeit des Verdachts kommen. ${ }^{809}$ Gegenüber diesem Ansatz wird von den Kritikern darauf verwiesen, dass es unmöglich sei, ausgehend von einem Kollektiv, das durch zufällige bestimmte gemeinsame Charakteristiken einiger Elemente definiert wurde, Konsequenzen für die Konstellation von spezifischen Fällen abzuleiten. ${ }^{810}$ Innerhalb derselben Logik werde man, falls die Analyse sich innerhalb einer anderen Bevölkerungsgruppe vollziehe, zu anderen Wahrscheinlichkeitswerten gelangen. ${ }^{811}$ Auf der anderen Seite wird kritisiert, dass eine empirisch-statistische Wahrscheinlichkeitswertung unberücksichtigt lasse, dass sich im Strafprozess die Entscheidung, ob eine Person eine Straftat begangen habe oder nicht, auf einen konkreten Fall beschränke. ${ }^{812}$ Zusätzlich zu der Schwierigkeit, die Wahrscheinlichkeit eines bestimmten Falles einzuschätzen, wird darauf hingewiesen, dass es weitaus schwieriger sei, einen mi-

\footnotetext{
${ }^{806}$ Vgl. Kohlmann, 2012, S. 166; i.d.S unter Berufung auf Walder s. auch Lohner, 1994, S. 39 f.

${ }^{807}$ Lohner, 1994, S. 40.

${ }^{808}$ Vgl. Lohner, 1994, S. 40; Dölling, 1987, S. 268.

${ }^{809}$ Vgl. Kohlmann, 2012, S. 166; mit Beispielsfällen Ebert, 2000, S. 40 ff. und mit Rechenbeispielen zu möglichen Wahrscheinlichkeiten Lohner, 1994, S. 41.

${ }^{810}$ Kohlmann, 2012, S. 166; Lohner, 1994, S. 40; s. auch Walder, ZStW 95 (1983), S. 880.

${ }^{811}$ Lohner, 1994, S. 40; bzgl. des Einzelfalls als Element eines Kollektivs s. Nell, 1983, S. 24 ff.

${ }^{812}$ Lohner, 1994, S. 41 und Fn. 112 m.w.N.
} 
nimalen Wahrscheinlichkeitsgrad festzulegen, der für die verschiedenen Gesichtspunkte des Verdachts richtungsweisend sei. In diesen Fällen könnten auch die Erfahrungssätze keine Sicherheit bieten, die sich aus der Logik ableiten. ${ }^{813}$

$\mathrm{Zu}$ den oben genannten Ansätzen kommen jene Versuche hinzu, die ein Verständnis des Tatverdachts über eine Erfolgsprognose nahelegen. Diese Methode beleuchtet die Frage nach dem Tatverdacht von der Seite des Erfolgs. Im Falle des anfänglichen Tatverdachts wird angenommen, dass dieser existiere, wenn die Ermittlung Erfolg verspreche. ${ }^{814}$ Die Antwort auf die Frage nach der Erfolgsprognose wird als unmittelbare Bedingung des Tatverdachts angesehen. Auch kann zum Beispiel gemäß $§ 152$ Abs. 2 von zureichenden tatsächlichen Anhaltspunkten gesprochen werden, wenn bestimmte grundlegende faktische Bedingungen für ein erfolgreiches Eingreifen der Polizei vorliegen. ${ }^{815}$ An diesem Ansatz wird kritisiert, dass er keinerlei Ansatzpunkte für die Definition des Tatverdachts liefere. ${ }^{816}$ Zusätzlich wird behauptet, dass eine Erfolgsprognose keine unmittelbare Bedingung für den Tatverdacht darstellen könne, denn gerade der Beginn einer Ermittlung würde vereitelt werden, wenn eine solche Bedingung existiere. ${ }^{817}$

Ein von den statistischen und quantitativen Ansätzen weit entfernter, aber nicht weniger polemischer Ansatz ist derjenige, der auf der Wertung der prima-facie-Beweise basiert. Dieser Ansatz vergleicht den Entstehungsprozess eines Verdachts mit der bekannten Methode der Urteilsfindung mittels des prima-facie-Beweises im Zivilrecht, insoweit es sich um Erfahrungssätze handelt, deren Genauigkeit nicht mit der wissenschaftlichen Genauigkeit zu vergleichen ist, die jedoch einen Wahrscheinlichkeitsgrad aufgreift, der die Dimension der Zufälligkeit mit einer entfernt vergleichbaren Art der statistischen Genauigkeit verändert. ${ }^{818}$ Kühne beschreibt den prima-facie-Beweis als ein Erfahrungsniveau, das zwischen den Erfahrungssätzen Platz finde, die absoluten, einfachen oder mittleren Charakter

\footnotetext{
${ }^{813}$ Vgl. Ebert, 2000, S. 43: „die statistiche Methode verfehlt damit ihr Ziel, sie vermag in Einzelfällen aber dennoch das Gefühl subjektiver Ungewißheit zu unterdrücken, indem sie die Operation der Verdächtigung 'wenigstens teilweise bewußt macht und Fehler entdecken läßt'“; s. auch Lohner, 1994, S. 41;

${ }^{814}$ Lohner, 1994, S. 41. Für eine Zusammenfassung der Einwände gegen die Effektivitätsgesichtspunkte vgl. Kohlmann, 2012, S. 167.

${ }^{815}$ I.d.S. Weigend, 1978, S. 61: der Wirkungsbereich des Legalitätsprinzips beginnt erst dort, ,[,..] wo irgendwelche, wenn auch spärliche Anknüpfungspunkte für erfolgversprechende Ermittlungen vorhanden sind."

${ }^{816}$ Lohner, 1994, S. 42; i.d.S. auch Dölling, 1987, S. 270: Bei der Kenntniserlangung einer Straftat „läßt sich häufig noch gar nicht abschätzen, ob die Ermittlungen Aussicht auf Erfolg haben.“

${ }^{817}$ Kohlmann, 2012, S. 167 und bzgl. der Gewinnung des Verdachts S. $170 \mathrm{ff}$.

${ }^{818}$ Kühne, 2015, Rn. 330 ff.; Hainmüller, 1966, S. 87-148; 
haben können. ${ }^{819}$ Diese Methode wird kritisiert, weil sie keine objektiven oder substantiellen Kriterien für die Wahrscheinlichkeitsfindung aufweise. Dieser Ansatz erlaube es nicht, eine anwendbare Methode für die Verdachtsdeterminierung zu bestimmen. ${ }^{820}$ Die Meinung von Kühne wird nicht in Frage gestellt, insofern er darauf hinweist, dass ein Tatverdacht nur auf der Basis eines juristisch argumentativen Prozesses bestimmt werden könne, der die Rechtsgrundlage des Tatverdachts durch eine mögliche spätere und/oder übergeordnete Kontrollinstanz überwache. Allerdings wird darauf hingewiesen, dass eine derartige Argumentation und Rechtskontrolle im Idealfall der Strafprozesspraxis nicht angewendet werde. In der Praxis halten sich die Prozesse zur Bestimmung eines Tatverdachts grundsätzlich an die Regeln und Instanzen der Polizeibeamten. ${ }^{821}$

Trotz der Kritik, die bzgl. der jeweiligen Methoden geäußert wird, können einige Übereinstimmungen unter ihnen festgestellt werden. Alle Ansätze berufen sich auf die Erfahrungssätze oder grundlegenden statistischen Prinzipien als Leitfäden ihrer Vorschläge, von denen aus ein gewisser Wahrscheinlichkeitsgrad abgeleitet werden könne. Der gesuchte Wahrscheinlichkeitsgrad werde direkt mit dem Tatverdacht in Verbindung gebracht, der von der Analyse des Falls abgeleitet werde. Es wird darauf verwiesen, dass sich der Wahrscheinlichkeitsbegriff innerhalb von Ermessensentscheidungen bewege, die im Strafprozess mittels der Beweisprognose an Bedeutung gewinnen würden, ${ }^{822}$ wie unsichere Voraussagen über den Prozessverlauf, die Ergebnisse der Beweisermittlung, etc. Ein Wahrscheinlichkeitsverfahren, von dem aus auf einen Tatverdacht geschlossen wird, verlangt nach Tatsachen, die die Wahrscheinlichkeitsprognose unterstützen. Daher reicht die einfache Annahme einer Straftat nicht aus, um einen Tatverdacht zu begründen. ${ }^{823}$ In diesem Sinne wird anerkannt, dass die Ableitung eines Tatverdachts eine Wertung von rechtlichen

\footnotetext{
819 Kühne, 2015, Rn. 331, der vor allem daran interessiert ist, wie diese Sätze erkennbar und überprüfbar sind; s. auch Hainmüller, 1966, S. 29 f.

${ }^{820}$ Kohlmann, 2010, S. 167, die die Festellung des Verdachts durch die Auseinandersetzung von Erfahrungssätzen als nicht praktikabel bezeichnet; i.d.S. auch Lohner, 1994, S. 43: „Bei dem von Kühne vorgezeichneten Weg zur Verdachtsfindung handelt es sich um eine bei den meisten Fällen in der praktischen Anwendung so nicht stattfindende Methode. “; bzgl. des Ansatzes Kühnes und der Problematik von inferentiellen Kontexten im Ermittlungsverfahren s. ausführlich Kotsoglou, 2015, S. 302 ff.

${ }^{821}$ Lohner, 1994, S. 43, der erstreckt seine Kritik auf Helgert's Ansatz, der gleiche Eigenschaften wie Kühne darstellt.

822 Vgl. Kohlmann, 2010, S. 168; Ebert, 2000, S. 17 mit Prognosebeispielen im Strafrecht.

${ }^{823}$ Das erklärt teilweise, warum nach der h.M. die bloße Vermutung einer Straftat nicht als Verdacht anerkannt wird; s. LR/Beulke § 152 Rn. 25 m.w.N.
} 
und faktischen Gesichtspunkten des anerkannten Sachverhalts verlangt. ${ }^{824}$ Daher wird darauf hingewiesen, dass bei der Methode der Tatverdachtsdeduktion im Allgemeinen zunächst vom Richter eine anfängliche Diagnose durchgeführt wird. Daraufhin wird nach der Wahrnehmung der Tatsachen ein retrospektives Schema einer unvollständigen Sequenz von Fakten erfolgen. Als Drittes führt der Richter eine retrospektive Prognose durch, um festzustellen, ob eine logische Tatsachensequenz aus dem zu untersuchenden Sachverhalt aufgestellt werden kann. Schließlich wird ein Subsumtionsverfahren verfolgt, das zur Aufklärung dient, ob der untersuchte Fall strafprozessrechtlich relevant ist. ${ }^{825}$

Diese Beobachtung hat zwei allgemeine Folgen für das Verständnis des Begriffes. Erstens müssen die Regeln, durch die ein Tatverdacht vonseiten der Wahrscheinlichkeit von unvollständigen Tatsachen aufgestellt werden kann, als Erfahrungsgrundsatz identifiziert werden. ${ }^{826}$ Jedoch basiert diese Verbindung zu Begründungen oder Lebenserfahrungssätzen, so wie oben schon festgestellt wurde, wiederum auf der Wahrscheinlichkeit, dass diese Maxime in einem bestimmten Fall bestätigt wird. Sofern keine absolute Sicherheit besteht, wird mit jeder Maxime die Gefahr eingegangen, dass sie in einem konkreten Fall zu einer Fehlbeurteilung führt, wobei zugestanden wird, dass subjektive Wertungen von der Person, die den Prozess führt, vorgenommen werden. ${ }^{827}$ Trotzdem wird darauf hingewiesen, dass dies nicht einer Ermessensentscheidung gleichkomme, denn der Verdacht sei in sich ein unbestimmter Begriff in den einzelnen Schritten, die zur Determinierung desselben führen würden. ${ }^{828}$ Außerdem kann ein Verdacht nur mit Begründung in einer retrospektiven Prognose aufgrund von Tatsachen abgeleitet werden. Ohne faktisch nachweisbare Tatsachen kann kein Tatverdacht bestehen. ${ }^{829}$

\footnotetext{
${ }^{824}$ Zabel ZIS 7-8/2014, S. 341; Hellmann, 2006, Rn. 59; Haas, 2003, S. 34 m.w.N.; andere Ansicht: LR/Beulke § 152 Rn. 25: „Es ist nicht erforderlich, dass die Tatsachen bereits sie Subsumtion unter einen bestimmtem Tatbestand ermöglichen.“

${ }^{825}$ Für diese Aufstellung der Verdachtsgewinnung s. Kohlmann, 2010, S. 170; Ebert, 2000, S. 44; i.d.S. Zabel ZIS 7-8/2014, S. 341 mit der Präzisierung des Anfangverdachts nach drei Seiten; auch Schulz, 2001, S. 581 ff. mit der Differenzierung von Tatsachenbasis, Schlusselement und Zeitfaktor jedes Verdachtsgrads.

${ }^{826}$ Kühne, 2015, Rn. 335; Kühne, NJW 1979, S. 620 ff.; Kohlmann, 2010, S. 171; Ebert, $2000,44$.

${ }^{827}$ Vgl. u.a. Kotsoglou, 2015, S. 309 ff.; Steinberg, JZ 21 (2006), S. 1046 f.; Ebert, 2000, S. 45; Fincke ZStW 95 (1983), S. 927.

828 i.d.S. Schulz, 2001, S. 619 ff.; bzgl. des Tatverdachts als unbestimmter Begriff vgl. Zabel ZIS 7-8/2014, S. 341 und Fn. 29 m.w.N.; Jahn, 2007, S. 563; Deiters, 2006, S. 115 ff.; Lohner, 1994, S. 46 ff.

${ }^{829}$ Kühne, 2015, Rn. 336; bzgl. der Tatbezogenheit vgl. LR/Beulke, § 152 Rn. 25; Schulz, 2001, S. 593 ff.; Ebert, 2000, S. 18, 104 ff.; Steinberg, JZ 21 (2006), S. 1048.
} 
Trotzdem wird in der h.M. weiterhin eine alleinige Definition des Begriffes Tatverdacht vermisst, auch wenn die Anerkennung der Transzendenz der objektiven Umstände (Tatsachen) und die Wertung derselben mittels retrospektiver Prognosen unter den Parametern der Wahrscheinlichkeitssätze bestehen. Es wird behauptet, dass es unmöglich sei, eine objektive Verdachtsdefinition aufzustellen, solange Subjektivität und persönliche Erfahrungen die Bestimmung derselben beeinflussen würden. ${ }^{830}$ Es wurde dennoch versucht, eine Deduktion des besagten Begriffs und das Vorgehen mit demselben auf verschiedene Art und Weise zu ermöglichen, aber es wurde wohlweislich in Betracht gezogen, dass die subjektiven Elemente auf abstraktem Weg nicht objektiv verständlich gemacht werden können. Zusätzlich hierzu wird auch ein objektives Verständnis ausgeschlossen, da die StPO verschiedene Verdachtsgrade anerkennt, die eine einzige Bestimmung unmöglich machen. Im Gegensatz hierzu führen die Verdachtsgrade zu Differenzierungen sowohl der faktischen und juristischen Begründungen als auch der Regeln für ihre spezifische Determinierung. In diesem Sinne, und obwohl es sich um keinen objektiven Begriff handelt, können eine Bestimmung und ein konkretes Verständnis besser aufgrund der Analyse der verschiedenen in der StPO aufgeführten Verdachtsgrade erreicht werden.

\section{Verdachtsgrade}

Die Bestimmung eines Verdachts stellt wie gesehen ein vorläufiges Prognoseurteil bzgl. der Wahrscheinlichkeit der Schuld eines Täters dar. Vor jeder gerichtlichen Entscheidung bzgl. Freispruch oder Verurteilung besteht nur ein Verdacht, der die Wahrscheinlichkeit der Schuld dimensioniert. Das Ausmaß eines Verdachts umfasst verschiedene Grade, die von einem niedrigen Grad bis zur Grenze der bewiesenen Schuld reichen. Die Verdachtsgrade, die die StPO erwähnt, stellen lediglich Mindestvoraussetzungen dar, um eine bestimmte Ermittlungsmaßahme oder Verfahrenshandlung vorzunehmen. Die Verdachtsgrade haben ihrerseits als Ausgangspunkte für die Entscheidung einer Ermittlungsmaßnahme Grenzen, die sich zwischen der Vermutung und der erwiesenen Schuld bewegen. In diesem Sinne kann behauptet werden, dass der Verdacht ein Begriff ist, der von der Vermutung bis zur ausreichenden Überzeugung reicht. Die Punkte, die die Verdachtsskala abgrenzen, sind

${ }^{830}$ Vgl. Ackermann, FS Riklin (2007), S. 315; bzgl. der Subjektivität des Verdachts vgl. Fincke ZStW 95 (1983), S. 923 ff.; s. auch Köhlmann, 2010, S. 180; bzgl. des Beurteilungsspielraums bei der Tatverdachtsfindung Ebert, 2000, S. 47 ff.; mit Abl. Schulz, 2001, S. 623 ff.; zu der kognitiven und normativen Basis des Verdachtsbegriffs Zabel, ZIS 7-8/2014, S. 346. 
wie oben erwähnt der Anfangsverdacht, der dringende Tatverdacht und der hinreichende Tatverdacht. ${ }^{831}$

Als Mindesterfordernisse für eine Ermittlungsmaßnahme oder Verfahrenshandlung werden die Verdachtsgrade, die sich aus der StPO ableiten, anerkannt und stellen gleichzeitig Parameter für die Konkretisierung des Verhältnismäßigkeitsprinzips dar. ${ }^{832}$ Jeder Verdachtsgrad stellt einen Rahmen als Ausgangspunkt für die Wertung der Verhältnismäßigkeit dar, die das staatliche Eingreifen aus der Perspektive der Sachgerechtigkeit, Geeignetheit, Erforderlichkeit und Angemessenheit bestimmt. Die Verdachtsgrade tragen zur Entscheidung über die Durchführung einer Ermittlungsmaßnahme als Rahmen mit Maßstabscharakter bei. Was die Grundlage für die Entscheidung bzgl. einer Eingriffsmaßnahme in der Ermittlungsphase betrifft, sei es im Rahmen einer Genehmigung oder Bestätigung, werden sie als ein Ausgangsparameter betrachtet, der den Rahmen der Verhältnismäßigkeit optimiert und zu besserer Rechtssicherheit und demnach zu einem besseren Schutz des Verdächtigen oder Dritten führt. ${ }^{833}$ Je stärker der Intensitätsgrad einer Ermittlungsmaßnahme sich in diesem Sinne darbietet, desto höher muss auch der Verdachtsgrad sein. Die sog. Typifizierung des Verhältnismäßigkeitsverfahrens aufgrund von Verdachtsgraden untersteht der Tatsache, dass versucht wird, die normativen Räume auf den Ermessensspielraum innerhalb der Rechtsmäßigkeitsprüfung zu reduzieren. ${ }^{834}$

Obwohl die StPO konkrete Verdachtsgrade (einfacher, dringender und hinreichender Tatverdacht) aufstellt und diese Grade speziell als Filter gemeinsam mit der Analyse der Verhältnismäßigkeit anerkannt sind, um zu einer Entscheidung einer Zwangsmaßnahme in der Phase der Ermittlung zu gelangen, wird in der Literatur eine abstrakte Analyse ausgeschlossen, die die Bedeutung der verschiedenen Verdachtsniveaus vereinheitlichen könnte. Jeder Verdachtsgrad wird von sehr spezifischen Bedingungen in jedem konkreten Fall umgeben je nach Ermittlungsmaßnahme, die eine allgemein gültige Theoretisierung derselben

\footnotetext{
${ }^{831} \mathrm{Zu}$ den verschiedenen Verdachtsgraden s. etwa Zabel, ZIS 7-8/2014, S. 340 und Fn. 7; Steinberg, JZ 21 (2006), S. 1048; Schulz, 2001, S. 566 ff.; Ebert, 2000, S. 101 ff.; Lohner, 1994, S. 61; Kühne, NJW 1979, S. $618 \mathrm{f}$.

832 Als „typisierte Verhältnismäßigkeit“ Schulz, 2001, S. 567; ,als Reziprozität von Eingriffsschwere und Verdachtsschwelle“ Zabel, ZIS 7-8/2014, S. 340; bzgl. der Verhältnismäßigkeit und Grundrechtsschutz im Präventionsstrafrecht vgl. ausführlich Kaspar, 2014, S. 124 ff.

${ }^{833}$ Schulz, 2001, S. 568: „durch Typisierung über den Weg von Verdachtsgraden - entspricht der Umstand, dass für die Zweckmäßigkeit innerhalb der Rechtmäßigkeit normativ Freiräume ausscheiden.“

${ }^{834}$ Ackermann, FS Riklin (2007), S. 322; Schulz, 2001, S. 568 und Fn. 488 m.w.N. 
ausschließen. ${ }^{835}$ Obwohl allgemein angenommen wird, dass eine abstrakte Diskussion nicht zu befriedigenden Ergebnissen führt, kann aus der Literatur auf zwei Analysevarianten geschlossen werden, um den Unterschied zwischen den Verdachtsgraden zu verstehen. Zum einen ist die Eingriffstheorie ${ }^{836} \mathrm{zu}$ nennen, die davon ausgeht, dass der Verdachtsgrad mithilfe der Eingriffsintensität einer Ermittlungsmaßnahme bestimmt werden kann. Eine Konstante kann in Bezug auf die Eingriffsintensiät mittels einer Wertung der vorliegenden Tatsachen sowohl vonseiten der Verhältnismäßigkeit als auch vonseiten des Wahrscheinlichkeitsverfahrens bzgl. der Ergebnisse der Wertung einer Straftat erlangt werden. Die Feststellung des jeweiligen Verdachtsgrades würde demnach von der jeweiligen Dynamik des Ermittlungsverfahrens mittels der Veränderung oder Erweiterung der untersuchten Sachverhaltsgrundlage abhängen. ${ }^{837}$

Andererseits besteht neben dem Verständnis bzgl. der Eingriffsintensität als indikatives Kriterium des Verdachtsgrades ein teleologisch-funktionaler Ansatz. Diese Perspektive wird von der h.M. aufgenommen. Darin wird die Ansicht vertreten, dass für die Anordnung einer Ermittlungsmaßnahme der Verdachtsgrad und die Eingriffsintensität im Einklang mit dem Zweck der spezifischen Ermittlungsmaßnahme und der Funktion der respektiven Prozessphase sein müssen, in der dieselbe durchgeführt wird (Zwecktheorie). ${ }^{838}$ Diese Erweiterung des Verständnisses der Eingriffsintensität geht auf einen Beschluss des BVerfG aus dem Jahre $2004^{839}$ zurück, in dem diskutiert wurde, ob eine Erweiterung des Verdachtsgrades in den Fällen der akustischen Wohnraumüberwachung ohne Kenntnis des Überwachten nötig sei (§ 100c Abs. 1 (3) StPO). Ausgehend vom Verhältnismäßigkeitsprinzip war es für das BVerfG nicht notwendig, den Verdachtsgrad anzuheben, d.h., im Falle des $\S 100$ c Abs. 1 (3) StPO waren nur zureichende tatsächliche Anhaltspunkte notwendig. Die Schwere der Tatsache und das Ausmaß des Verdachts sind auch für die Entscheidung ausschlaggebend, ob eine Ermittlungsmaßnahme im Verhältnis zu einem respektiven Eingriff in Grundrechte steht. Dem BVerfG zufolge sei es nicht notwendig, eine akustische Wohnraumüberwachung von einem bestimmten Verdachtsgrad abhängig zu machen. Falls nur ein dringender Verdacht erforderlich wäre, erübrige sich die Diskussion

\footnotetext{
${ }^{835}$ Lohner, 1994, S. 63, für den dieses Problem unter anderem aus dem Verhältnis der retrospektiven Diagnose zur prospektiven Prognose resultiert.

${ }^{836}$ Zabel, ZIS 7-8/2014, S. 341; Steinberg JZ 21 (2006), S. 1048 f.

${ }^{837}$ Fincke, ZStW 95 (1983) S. 927: ,der Verdachtsgrad ist von der Indizien- und damit von der Ermittlungsgrundlage zwar abhängig.“; i.d.S. Zabel, ZIS 7-8/2014, S. 341; Hellmann, FS Kühne (2013), S. 249.

${ }^{838}$ Zabel, ZIS 7-8/2014, S. 341; LR/Stuckenberg, § 203 Rn. 9 und Fn. 26 m.w.N.

${ }^{839}$ BVerfGE 109, 279 (351 f.) = NJW 2004, S. 1012.
} 
über die Tauglichkeit des Mittels. In diesem Sinne müssen die Erwägung über das Ziel der Maßnahme und die Funktion der respektiven Phase des Verfahrens dazu dienen, eine Abhängigkeit zwischen Verhältnismäßigkeit einer Ermittlungsmaßnahme und ihrer Tauglichkeit aufzustellen. ${ }^{840}$

Über diese beiden Szenarien hinaus, die in einem übergeordneten Rahmen Kriterien zu definieren versuchen, um zu einer abstrakten Klassifizierung und systematischen Bestimmung der Verdachtsgrade und den Bedingungen zur Konkretisierung derselben gegenüber bestimmten Ermittlungsmaßnahmen zu gelangen, orientiert sich die Diskussion an den von der StPO festgelegten Referenzen, unter denen es keine gesetzliche Vorgabe bzgl. ihrer Hierarchie gibt. Die Klassifizierung der verschiedenen Verdachtsgrade geht von dem Unterschied aus, der in der Eingriffsintensität besteht, die sie zu begründen versucht. ${ }^{841}$ In diesem Sinne ist die h.M., dass sich der Anfangs- oder der einfache Verdacht auf der niedrigsten Stufe der Hierarchie befindet. ${ }^{842}$ Es wird darüber diskutiert, ob eine hierarchische Ordnung zwischen dem hinreichenden und dem dringenden Tatverdacht bestehe. ${ }^{843}$ Die Mehrheit behauptet, dass der dringende Tatverdacht über dem hinreichenden Tatverdacht stehen müsse, da ersterer zu intensiveren Eingriffen führe. ${ }^{844}$ Andere Meinungen laufen jedoch darauf hinaus, dass im Gegenteil der hinreichende Tatverdacht an oberster Stelle der Hierarchie stehen müsse, denn er stelle die Bedingung für die Anklage und Eröffnung des Strafprozesses dar ( $\S 179$ (1), 203 StPO) und erfordere somit die Wahrscheinlichkeit einer Verurteilung. ${ }^{845}$ Für die Hierarchie der Verdachtsgrade wird prinzipiell die Eingriffsdimension als relevantes Kriterium betrachtet, da diese Dimension mit der Verdachtsintensität einhergehe.

\footnotetext{
${ }^{840}$ BVerfGE 109, 279 (351 f.) = NJW 2004, S. 1012.

${ }^{841}$ Ebert, 2000, S. 102: „die Abstufung verschiedener Verdachtsgrade setzt voraus, dass die maßgeblichen Wesensmerkmale der einzelnen Verdachtsarten miteinander vergleichbar sind und sich nur in ihrer Intensität voneinander abgrenzen.“

${ }^{842}$ Vgl. dazu Kühne, 2015, Rn. 341 ff.; LR/Beulke, § 152 Rn. 21 ff.; bzgl. der Verdachtsgrade s. supra Fn. 831 m.w.N.

${ }^{843}$ Für die Differenz von hinreichendem und dringendem Verdacht s. Schulz, 2001, S. 614.

${ }^{844}$ I.d.S. Ebert, 2000, S. 103, der diese Verdachtsgraduierung aufgrund der grundrechtsrelevanten Wirkung der Eingriffsmaßnahmen annimmt.

${ }^{845}$ Schulz, 2001, S. 616, nach dem der hinreichende Verdacht kein Zeitpunkt während des Ermittlungsverfahrens ist, sondern den Abschluss markiert; i.d.S. auch Fincke, ZStW 95 (1983), S. 924.
} 


\section{Anfangsverdacht}

\section{Die Bedeutung des Anfangsverdachts}

Gemäß der h.M. liegt ein Anfangsverdacht vor, wenn zureichende tatsächliche Anhaltspunkte für eine zu verfolgende Straftat vorliegen. ${ }^{846}$ Der Anfangsverdacht ist in der StPO als eines der Erfordernisse für den Beginn einer Ermittlung enthalten, so wie $\S 152$ Abs. 2 es vorsieht. Der Begriff ist auch im $§ 160$ Abs. 1 enthalten, obwohl in diesem Fall nur von Verdacht gesprochen wird. Der Anfangsverdacht aktiviert nicht nur die Erforschungspflicht, sondern grenzt die strafverfahrensrechtliche Befugnis zum Einschreiten ein. ${ }^{847}$ Der Aktivierung der Befugnis zum Einschreiten geht das Aufklärungsprinzip voraus, das sich in der Forderung nach zureichenden tatsächlichen Anhaltspunkten konkretisiert. ${ }^{848}$ Obwohl sich $\S \S 152$ Abs. 2 und $\S 160$ Abs. 1 einer anderen Terminologie bedienen, werden sowohl der Begriff zureichende tatsächliche Anhaltspunkte als auch der Begriff Verdacht im selben Sinne interpretiert, d.h., dass der Eingriffsverpflichtung die Evaluierung des Vorhandenseins des Verdachts vorausgeht, um ein Ermittlungsverfahren zu eröffnen. ${ }^{849}$ Bzgl. des Parameters, den $\S \S 152$ Abs. 2 und 160 Abs. 1 für den Beginn des Ermittlungsverfahrens aufstellen, ist es wichtig, den Anfangsverdacht von den bloßen Vermutungen und Möglichkeiten abzugrenzen, die keinerlei Art von Anfangsverdacht begründen. ${ }^{850}$ Der Beginn einer Ermittlung orientiert sich am Legalitätsprinzip und somit werden als Grundlage die Hypothesen ausgeschlossen, die auf einfachen Vermutungen über kriminelle Tatsachen basieren, die also nicht von konkreten faktischen Inhalten belegt werden. ${ }^{851}$ Dies erklärt auch, dass ohne faktische konkrete Inhalte keine Ermächtigung oder Verpflichtung zur Ermittlung abgeleitet wird. ${ }^{852}$ Unter einer kriminalistischen Annahme wird eine aus dem

\footnotetext{
${ }^{846}$ Vgl. Satzger, FS Beulke (2015), S. 1011, 1013 ff.; Zabel, ZIS 7-8/2014, S. 342; Beulke, 2012, Rn. 311; Kühne, 2015, Rn. 316; HK/Krehl, § 152 Rn. 7; Meyer-Goßner/Schmitt, § 152 Rn. 4; Schulz, 2001, S. 527 f.: LR/Beulke, § 152 Rn. 21 und Fn. 57 m.w.N.

${ }^{847}$ Vgl. Kühne, 2015, Rn. 341; Hellmann, FS Kühne (2013), S. 235; LR/Beulke, § 152 Rn. 22, 32 ff. und Fn. 59 m.w.N.; Forkert-Hosser, 2011, S. 53 ff.; Lohner, 1994, S. 140; Fincke, ZStW 95 (1983), S. 924.

${ }^{848}$ Meyer-Goßner/Schmitt, § 152 Rn. 4; LR/Beulke § 152 Rn. 22; Ebert, 2000, S. 104; Lohner, 1994, S. 65.

${ }^{849}$ Vgl. LR/Beulke, § 152 Rn. 22; Kohlmann, 2010, S. 173, Schulz, 2001. S. 527; v. Hindte, 1973, S. 23.

${ }^{850}$ Vgl. Haas, 2003, S. 24; Schulz, 2001, S. 530; Ebert, 2000, S. 37; Lohner, 1994, S. 38; s. auch MeyerGoßner/Schmitt, § 152 Rn. 4; LR/Beulke § 152 Rn. 22 und Fn. 61 m.w.N.

${ }^{851}$ Roxin/Schünemann, 2014, § 39 Rn. 15; Kühne, 2015, Rn. 341; LR/Beulke § 152 Rn. 22 Fn. 62; Jahn, 2007, S. 563 und Fn. 60 m.w.N; bzgl. der kriminalistischen Hypothese (Vermutung) s. Haas, 2003, S. 21 f., 24.

${ }^{852}$ Kühne, 2015, Rn. 341; Deiters, 2006, S. 115 ff.; LR/Beulke $§ 152$ Rn. 22 und Fn. 63 m.w.N.
} 
Leben oder der Erfahrung gegriffene Annahme verstanden, die ein strafbares Verhalten anzeigen kann, aber nicht durch konkrete Tatsachen dokumentiert ist. ${ }^{853}$

Als zureichende Anhaltspunkte werden solche betrachtet, die eine Ermittlung durch die Strafverfolgungsbehörden und gemäß dem Verdachtsgrad den Eingriff in die Bürgerrechte rechtfertigen, um festzustellen, ob eine Straftat vorliegt, und wer diese begangen hat. ${ }^{854}$ Es wird als gerechtfertigt angesehen, dass die zureichenden Anhaltspunkte zu einer gewissen, wenn auch noch geringen Wahrscheinlichkeit bzgl. des Vorliegens einer Straftat führen, jedoch wird verlangt, dass diese über eine theoretisch allgemeine Möglichkeit hinausgeht. ${ }^{855}$ Auf dieser Basis wird nicht angenommen, dass zureichende Anhaltspunkte bestehen, wenn die Umstände, die den Verdacht begründen, offensichtlich ohne Grundlage oder inkorrekt sind. ${ }^{856}$ Die Verpflichtung zur Ermittlung entsteht ebenso wenig, wenn aus den Umständen des Falls hervorgeht, dass der Verdacht zu dem Ergebnis führen kann, dass kein Strafverhalten angenommen werden kann, wenn also die Elemente eines objektiven Tatbestandes nicht gegeben sind, die subjektive Seite des strafbaren Verhaltens fehlt oder die ermittelte Straftat nicht als rechtswidrig oder schuldhaft bezeichnet werden kann. ${ }^{857}$

Es wird darüber hinaus diskutiert, wie weit die zureichenden Anhaltspunkte über eine bestimmte Person als Täter oder Teilnehmer an einer Straftat Auskunft geben dürfen. Nach der h.M. darf der Anfangsverdacht keine bestimmte Person bezeichnen, d.h. er individualisiert keinen bestimmten Täter oder Teilnehmer, da $\S 152$ Abs. 2 auch zu einer Ermittlung gegen Unbekannt verpflichtet. ${ }^{858}$ In diesem Sinne wird zwischen tat- und täterbezogenem Verdacht unterschieden. ${ }^{859}$ Diese Haltung geht davon aus, dass das Ziel der Strafermittlungsphase ist, festzustellen, ob ein bestimmtes Ereignis eine Straftat darstellt und im zutreffenden Fall, ob gegen eine Person als Täter ermittelt werden kann. Daher ist es mög-

\footnotetext{
${ }^{853}$ Haas, 2003, S. 21 und Fn. 53 m.w.N.; Schulz, 2001, S. 530; LR/Beulke § 152 Rn. 25; Lohner, 1994, S. 62; dazu auch Satzger, FS Beulke (2015), S. 1015 f.

${ }^{854}$ Vgl. dazu Haas, 2003, S. 13-16; Schulz, 2001, S 590 ff.; LR/Beulke § 152 Rn. 23; Meyer-Goßner/Schmitt, $\S 152$ Rn. 4.

${ }^{855}$ Dazu reichen dürftige, noch ungeprüfte Tatsachen, Gerüchte aus. Vgl. LR/Beulke $§ 152$ Rn. 23 und Fn. 65 m.w.N.; mit Darlegung von Beispielen Haas, 2003, S. 14.

${ }^{856}$ Beispielweise die Mitteilungen von bekannten Querulanten, s. LR/Beulke § 152 Rn. 24; zu den verdachtsbegründenden Tatsachen vgl. Haas, 2003, S. 17.

${ }^{857}$ Beispielweise die Fälle der Nothilfe bei einer Geiselnahme, s. LR/ Beulke $\S 152$ Rn. 24; MeyerGoßner/Schmitt, § 152 Rn. 4.

${ }^{858}$ Kühne, 2015, Rn. 319 f.; Haas, 2003, S. 16; KK/Pfeiffer, Einl. Rn. 33; LR/Beulke, § 152 Rn. 23; MeyerGoßner/Schmitt, § 152 Rn. 5.

${ }^{859}$ Vgl. Müller, 2009, S. 43; Haas, 2003, S. 16; Schulz, 2001, S. 546 ff. (Verdacht in/ad rem und in personam); Ebert, 2000, S. 18; Lohner, 1994, S. 65.
} 
lich, eine Strafermittlung einzuleiten, wenn ein Anfangsverdacht bzgl. einer Straftat besteht und der Täter unbekannt ist. Die Bestimmung eines Verdachts muss mit anderen Worten von einer Tat ausgehen und zum Täter führen. Die mit dem Täter verbundenen Aspekte, so wie z.B. die Verfolgung einer Person, der Beweis oder das Wahrscheinlichkeitsurteil, sind Aspekte, die nur in prospektiven Teilen der Prognose in Betracht gezogen werden. ${ }^{860}$ Der Anfangsverdacht der StPO ist ein Verdachtsbegriff, der an die Tatsachen anknüpft. Erst im Laufe der Ermittlung gewinnen die täterbezogenen Hinweise an Bedeutung. In diesem Sinne wird auch ein Unterscheidungskriterium zwischen den Verdachtsgraden geschaffen, denn je höher das Verdachtsniveau ist, desto genauer muss die Person bestimmt sein, gegen die eine Ermittlung durchgeführt wird. Nur hohe Verdachtsniveaus (dringender und hinreichender Tatverdacht) verlangen die Bestimmung der Person oder des Täters. ${ }^{861}$

Auf diese Weise kann behauptet werden, dass die zureichenden Anhaltspunkte, die den Anfangsverdacht stützen, notwendigerweise eine tatsächliche Grundlage aufweisen müssen. ${ }^{862}$ Dieser sachliche Anspruch wird z.B. durch hinweisende oder auffallende Tatsachen erfüllt, die konkrete Informationen über ein strafbares Verhalten liefern. Von diesen sachlich zutreffenden Gründen wird nicht verlangt, dass sie eine Subsumtion eines bestimmten Straftatbestandes darstellen. Die alleinige Wahrscheinlichkeit der Tatsache wird als zufriedenstellend angesehen, denn der Ermittlungsbeginn hat zum Ziel zu untersuchen, ob die besagten Tatsachen richtig sind. ${ }^{863}$ Es wird darüber diskutiert, ob ein Anfangsverdacht auf Tatsachen aufbauen kann, die mit einem Beweisverwertungsverbot verknüpft sind. ${ }^{864}$ Es besteht ein Bereich von bestimmten Interventionen, die nicht als Beweismittel geltend gemacht werden können. So können z.B. bei großen Lauschangriffen gemäß § 100c Abs. 4 Satz 1 StPO keine Aussagen aus dem Kernbereich privater Lebensgestaltung aufgenommen werden (Art. 13 Abs. 1 GG). ${ }^{865}$

\footnotetext{
${ }^{860}$ Zabel ZIS 7-8/2014, S. 342; Schulz, 2001, S. 529 f.; Ebert, 2000, S. 105; Lohner, 1994, S. 65.

${ }^{861}$ Zu dem täterbezogenen Verdacht vgl. Schulz, 2001, S. 46 ff.; Ebert, 2000, S. 119 ff.; bzgl. des Verdachts als Voraussetzung für Inkulpation s. Lohner, 1994, S. 18.

${ }^{862}$ Vgl. Satzger, FS Beulke (2015), S. 1013 f.; LR/Beulke, § 152 Rn. 25; Meyer-Goßner/Schmitt, § 152 Rn. 4; KK/Pfeiffer, Einl. Rn. 33 jeweils m.w.N.

${ }^{863}$ Vgl. Schulz, 2001, S. 528 ff.; Meyer-Goßner/Schmitt, § 152 Rn. 4; LR/Beulke, § 152 Rn. 25 und Fn. 74 m.w.N.

${ }^{864}$ Es geht um das Problem der Vorauswirkung von Verwertungsverboten, s. dazu LR/Beulke § 152 Rn. $26 \mathrm{f}$.

${ }^{865}$ Vgl. Böse, FS Amelung (2009), S. 572 ff.; dazu § 100c Abs. 5 Satz 1 StPO: „Das Abhören und Aufzeichnen ist unverzüglich zu unterbrechen, soweit sich während der Überwachung Anhaltspunkte dafür ergeben,
} 
Die obige Haltung, die auch von der Rechtsprechung des BVerfG ${ }^{866}$ vertreten wird, wird von der Doktrin der sog. Widerspruchslösung relativiert. Gemäß dieser Doktrin müssen die Angeklagten ausdrücklich der Beweiswürdigung widersprechen, denn andernfalls würden die Beweise angenommen und auch diejenigen, die ein Defizit bzgl. der Rechtmäßigkeit bei der Ermittlung aufweisen. ${ }^{867}$ Die Kritik an dieser Ansicht weist darauf hin, dass diese Doktrin zu der unangenehmen Konsequenz der Akzeptanz der antizipierten Effekte der Würdigung von unrechtmäßigen Beweisen im Moment der Entscheidung über das Vorliegen eines Anfangsverdachts führe. Der Ausschluss von illegal erhaltenem Beweismaterial muss auch auf die Feststellung des Anfangsverdachts angewendet werden unabhängig davon, ob später ein ausdrücklicher Widerspruch vonseiten der Verteidigung erfolgt. ${ }^{868}$ An diese Polemik reiht sich die Legitimierung der sog. Doktrin des Spurenansatzes, gemäß derer die illegal erhaltenen Beweisstücke nicht für Beweiszwecke benutzt werden können jedoch als Grundlage für Ermittlungen, ${ }^{869}$ woraus hervorgeht, dass diese Elemente auch einen Anfangsverdacht begründen können. Die h.M. weist diese Möglichkeit als Grundlage des Anfangsverdachts zurück, besonders mit dem sog. unselbständigen Beweisverwertungsverbot, d.h. jenem Beweisverwertungsverbot, das aus einer vorherigen und illegalen Sammlung von Beweisen hervorgeht. ${ }^{870}$ Jedoch ergibt sich aus den sog. selbständigen Beweisverwertungsverboten, d.h. aus denjenigen, die nicht aus einer illegalen vorherigen Beweissammlung hervorgehen, und aus der Diskussion über die Fernwirkung und auch über die Vorauswirkung in dem Ermittlungsverfahren (des Beweisverwertungsverbots) eine andere Antwort, die nur auf einer Gesamtabwägung beruht. ${ }^{871}$ Die h.M. schließt die Be-

dass Äußerungen, die dem Kernbereich privater Lebensgestaltung zuzurechnen sind, erfasst werden. Aufzeichnungen über solche Äußerungen sind unverzüglich zu löschen. Erkenntnisse über solche Äußerungen dürfen nicht verwertet werden. Die Tatsache der Erfassung der Daten und ihrer Löschung ist zu dokumentieren.“. Für einen Überblick der Rechtsgrundlage des Kernbereichs privater Lebensgestaltung Duttge, 1995, S. 174.

${ }^{866}$ BVerfGE 44, 383 = Knauth JuS 1979 S. 341; dazu LR/Beulke, § 152 Rn. 26.

${ }^{867}$ Vgl. ausführlich Lippe, 2001, S. 3 ff.; Dudel, 1999, S. 29 ff.; dazu auch LR/Beulke § 152 Rn. 26 f.

${ }^{868} \mathrm{Vgl}$. LR/Beulke $\S 152$ Rn. 26. Für ein Überblick über die Argumente gegen die Widerspruchslösung s. Lippe, 2001, S. 159 ff.

${ }^{869}$ Ausführlich zum Meinungsstand Lohberger FS Hanack (1999), S. 253 ff.; Roxin/Schünemann, $2014, \S 24$ Rn. 59 ff.; dazu LR/Beulke $§ 152$ Rn. 27 und Fn. 87 m.w.N.; mit Beispielen unselbständiger Beweisverwertungsverbote Ambos, 2010, S. $51 \mathrm{ff}$.

${ }^{870}$ Vgl. Roxin/Schünemann, 2014, § 24 Rn. 59 ff.; Beulke, 2012, Rn. 476; Lohberger FS Hanack (1999), S. 253 ff.; LR/Beulke $\S 152$ Rn. 27 und Fn. 88 m.w.N.; mit Beispielen unselbständiger Beweisverwertungsverbote Ambos, 2010, S. $51 \mathrm{ff}$.

${ }^{871}$ Vgl. Duttge, FS Heintschel-Heinegg (2015), S. 103 f.; Schulz, 2001, S. 648 ff.; Beulke, ZStW 103 1991, S. 657; LR/Beulke § 152 Rn. 27 Fn 89; mit Beispielen selbständiger Beweisverwertungsverbote Ambos, 2010, S. $70 \mathrm{ff}$. 
fürwortung oder Ablehnung des Anfangsverdachts von allgemeinen politisch-kriminellen Verwertungen aus und steht im Gegensatz dazu für eine Verwertung der Fernwirkung des Beweisverwertungsverbots ausgehend von einer Abwägung der Intensität des das Beweisverbot auslösenden Rechtsverstoßes und der Schwere der aufzuklärenden Tat. ${ }^{872}$

Die Tatsachen, die einen Anfangsverdacht begründen, müssen eine Straftat konstituieren, die eine Strafverfolgung impliziert, d.h., es handelt sich um tatbestandsmäßige, rechtswidrige und schuldhafte Handlungen. Wenn der Sachverhalt nicht denjenigen entspricht, die das Strafgesetz unter Strafe stellt, rechtfertigt den Anfangsverdacht nicht die Erforschungspflicht (Legalitätsprinzip). ${ }^{873}$ Eine Straftat wird als verfolgbar angesehen, wenn keine persönlichen Strafausschließungsgründe oder Verfahrenshindernisse bestehen. ${ }^{874}$ Der Begriff verfolgbare Straftat bedeutet nicht, dass die rechtliche Beurteilung, die während der Prüfung des Anfangsverdachts vorgenommen wird, definitiv sein muss, sondern dass die rechtliche Wertung der Tat vorläufig ist. Allerdings besteht zwischen tatsächlichen Anhaltspunkten und verfolgbarer Straftat eine direkte Beziehung, aufgrund derer immer untersucht wird, ob ein bestimmter Fall strafmäßig relevant ist oder ob er Anhaltspunkte enthält, aus denen andere Ermittlungen abgeleitet werden können. ${ }^{875}$ I.d.S spricht man von der doppelten Prüfung des Anfangsverdachts. Die Prüfung erfolgt einerseits durch die Tatfrage, d.h. durch die Wertung der zureichenden tatsächlichen Anhaltspunkte, und andererseits durch die Rechtsfrage, die klärt, ob sich diese Anhaltspunkte auf eine verfolgbare Straftat beziehen. ${ }^{876}$

Vonseiten der Methodologie beinhaltet die Bestimmung des Anfangsverdachts eine retrospektive Diagnose, d.h. eine Feststellung, ob eine tatbestandsmäßige, rechtswidrige und schuldhafte Handlung bestand. ${ }^{877}$ Es wird darüber diskutiert, ob der Prozess der Konkreti-

\footnotetext{
872 Vgl. LR/Beulke § 152 Rn. 27 und Fn. 90 m.w.N.; Zur Abwägungslehre s. Roxin/Schünemann, 2014, § 24 Rn. $30 \mathrm{ff}$.

${ }^{873}$ Vgl. u.a. KK/Schoreit § 152 Rn. 31; Meyer-Goßner/Schmitt, § 152 Rn. 4; LR/Beulke § 152 Rn. 29; mit einer Begrenzung des Ausgangspunktes des Anfangsverdachts Haas, 2003, S. 33: „Die Frage, ob der Betroffene rechtswidrig gehandelt hat, ist Teil des Ermittlungsverfahrens.“

${ }^{874} \mathrm{Vgl}$. KK/Schoreit, § 152 Rn. 27; LR/Beulke, § 152 Rn. 30; mit Auflistung der wesentlichen Verfahrensvoraussetzungen Haas, 2003, S. 35; Schulz, 2001, S. 528.

${ }^{875}$ Dazu Schulz, 2001, S. 528 f.; Fincke ZStW 95 (1983), S. 922; v. Hindte, 1973, S. 26 ff.

${ }^{876}$ Haas, 2003, S. 34; Eisenberg/Conen NJW 1998, 2244; a.A. LR/Hilger, § 112 Rn. 18: „für die Rechtsfrage gibt es keine Wahrscheinlichkeit.“

877 Vgl. Schulz, 2001, S. 529; Lohner, 1994, S. 69 ff.; Kühne NWJ 1979, S. 622.
} 
sierung des Anfangsverdachts auch prospektive Komponenten einführe. ${ }^{878}$ Ein großer Teil der Doktrin erkennt an, dass die Bestimmung des Anfangsverdachts die Hypothese für das Ermittlungsverfahren aufstellt und somit die Verfahrensperspektive den Anfangsverdacht konstituiert. Auf diese Art und Weise wird die Prognose als Komponente dieses Verdachtsgrades eingeführt. ${ }^{879}$ So wird davon gesprochen, dass das Wahrscheinlichkeitsverfahren, das die Bestimmung des Anfangsverdachts einschließt, eine doppelte Wahrscheinlichkeit darstellt, also gleichzeitig eine Diagnose und eine Wahrscheinlichkeitsprognose darstellt. ${ }^{880}$ Einerseits werden die Tatsachen bewertet und auf retrospektive Art wird der Geschehensablauf festgestellt. Auf der anderen Seite kann von der prospektiven Prognose, von der aus projiziert wird, auf logische Art ein Geschehensablauf entwickelt werden, sobald die strafrechtliche Ermittlung beendet ist.

\section{Anfangsverdacht und Vorermittlung}

Bei der Bestimmung eines Anfangsverdachts wird als Möglichkeit angenommen, dass Ermittlungen durchgeführt werden, die zur Aufklärung einiger vager Verdachtselemente führen. Diese Art von Aktivitäten wird allgemein als Vorermittlung bezeichnet ${ }^{881}$, die dann durchgeführt wird, wenn ein Verdacht vorliegt, aber keine zureichenden tatsächlichen Anhaltspunkte einer Straftat. Es handelt sich mit anderen Worten um eine Aufklärung, ob ein Anfangsverdacht besteht oder nicht, und damit um die Entscheidung für oder gegen die Einleitung eines Ermittlungsverfahrens. Auch wenn es sich hier um einen Begriff handelt, der nicht in der StPO enthalten ist, wird er doch mehrheitlich in der Strafprozessliteratur verwendet. Die normative Rechtfertigung dieser Art von Ermittlungen wurde in $§ 159$ StPO verankert, dessen Ziel es ist, der Staatsanwaltschaft die frühzeitige Entscheidung zu erleichtern, ob eine Ermittlung wegen eines nicht natürlichen Todes eingeleitet werden muss. ${ }^{882}$ Daraus geht das Kriterium der Stärke von Anhaltspunkten für die Straftat für die Unterscheidung dieser beiden Phasen hervor, welches weitgehend angenommen worden

\footnotetext{
${ }^{878}$ Bzw. ob es der Feststellung einer wenn auch >geringen Wahrscheinlichkeit $<$ des hinreichenden Verdachts bedarf, Schulz, 2001, S. 529.

${ }^{879}$ Schulz, 2001, S. 530; Zabel ZIS 7-8/2014, S. 342; Abl. v. Hindte, 1973, S. 32 ff.

${ }^{880}$ Vgl. Steinberg JZ 21 (2006), S. 1047; Schulz, 2001, S. 530; Lohner, 1994, S. 44 ff.; Nell, 1983, S. 80 ff.

881 Vgl. dazu Hellmann, FS Kühne (2013), S. 246 ff.; Schulz, 2001, S. 5381 ff.; Lohner, 1994, S. 125;

LR/Beulke § 152 Rn. 33. Für die Unterscheidung zwischen Initiativ-, Vor- und Strukturermittlungen s. Forkert-Hosser, 2011, S. 123 ff.; Jahn, 2007, S. 554 ff.; Haas, 2003, S. 38 ff.; Zabel ZIS 7-8/2014, S. 343 und Fn. 35 m.w.N.

${ }^{882}$ I.d.S. Ebert, 2000, S. 108; bzgl. der Vorermittlungen bei unnatürlichem Tod vgl. Haas, 2003, S. 47; Schulz, 2001, S. 539 ff.; Lohner, 1994, S 144 ff. jeweils m.w.N.
} 
ist. $^{883}$ Bzgl. der Rechtfertigung der Vorermittlung handelt es sich um eine abstrakttheoretische Annahme einer unsicheren Möglichkeit, die die Pflicht entstehen lässt, aufzuklären, ob hinter dem untersuchten Anhaltspunkt ein menschliches Vorgehen steht, das als Straftat bezeichnet werden kann. ${ }^{84}$ Allgemein werden in der Vorermittlung nicht diejenigen Elemente in Betracht gezogen, die abstrakt gesehen das Ergebnis einer Straftat darstellen, sondern die notwendigerweise konkrete Inhalte der Tat liefern. In dieser Phase wird die Ermittlung von neutralen Elementen ohne Strafbarkeitsrelevanz ausgeschlossen mit dem Ziel, das Strafpotential dieser Elemente zu untersuchen. Wenn jedoch im Gegensatz hierzu schon bekannt ist, dass die Gründe eines bestimmten Falls mit dem kriminellen Bereich verbunden sind, wird nicht nach strafbaren Handlungen und Verhalten gesucht, sondern nach der Bestätigung, ob das Verhalten oder der als strafbar bewertete Fall eine Rolle gespielt hat. ${ }^{885}$ Solange es sich um die Feststellung des Anfangsverdachts handelt, wird die Durchführung von Ermittlungsmaßnahmen ausgeschlossen, die das Einschreiten in die Rechte des Verdächtigen implizieren. ${ }^{886}$ Im Bereich der Vorermittlung werden Ermittlungshandlungen wie interne Abklärungen, Behördenanfragen und Akteneinsichtsgesuche (sog. informatorische Befragungen) in Betracht gezogen. ${ }^{887}$ Dies stellt einen anderen Grund dar, der die Tatsache erklärt, dass nicht von Verdachtsermittlung gesprochen wird, sondern von Verdachtsgewinnung oder Verdachtssteuerung. ${ }^{888}$

\section{Fazit}

Die Regulierung des Anfangsverdachts, die sich aus § 152 Abs. 2 StPO ergibt, erfüllt zwei grundlegende Funktionen: einerseits wird das Legalitätsprinzip konkretisiert und andererseits führt sie das Verbot ein, Ermittlungen verfrüht durchzuführen, die sich nicht auf zu-

\footnotetext{
${ }^{883}$ I.d.S. Ebert, 2000, S. 108: „weil das Gesetz vom ,Verdacht einer Straftat“ spricht (§ 160 Abs. 1 StPO), muss die Strafverfolgungsbehörde von ihrer Begehung nicht überzeugt sein.“

${ }^{884}$ I.d.S. Ebert, 2000, S. 109, der den Ausgangspunkt in der Ursachenforschung stellt.

${ }^{885}$ Ebert, 2000, S. 110, der die Grenzen zwischen Vorermittlung und Ermittlung als fließend betrachtet und die Beseitigung derselben in dem Verhältnis zur präventivpolizeilichen Gefahrenabwehr darstellt; bzgl. der tatsächlichen Definitionsmacht der Polizei über den Anfangsverdacht vgl. Ottow, 2014, S. 25 ff.

886 „Das folgt aus dem Verdacht in seiner Funktion, die Ausnahme vom Grundsatz der Unschuld zu begründen" (Schulz, 2001, S. 538); zur Problematik der Begrenzung antizipierter Strafverfolgung durch den Anfangsverdacht s. Rudolph, 2005, S. $168 \mathrm{ff}$.

${ }^{887}$ Für den Anwendungsbereich, Umfang, Ausgestaltung und Normierung strafprozessualer Voermittlungen vgl. ausführlich vgl. auch Forkert-Hosser, 2011, S. 161 ff.; s. auch Ebert, 2000, S. 110; LR/Beulke § 152 Rn. 34 und Fn. 117 m.w.N.; zu den Grundrechtseingriffen infolge der Annahme eines Anfangsverdachts vgl. Ottow, 2014, S. 29 ff.; Hass, 2003, S. 31 f.

${ }^{888}$ I.d.S. Schulz, 2001, S. 533 f., der auch zwischen Verdachtsschöpfung, Verdachtsgewinnung und Verdachtskonkretisierung unterscheidet.
} 
reichende tatsächliche Anhaltspunkte stützen. In diesem Sinne bildet sie den Ausgangspunkt für die Durchführung der Erforschungspflicht und einen Parameter, der die Kompetenzen und die Macht der staatlichen Eingriffe einschränkt. Paradoxerweise ist der Anfangsverdacht als abgrenzende Referenz für die Ermittlungen gleichzeitig Produkt und Objekt der Ermittlungen der Staatsanwaltschaft. Auf jeden Fall müssen die zureichenden tatsächlichen Anhaltspunkte durch Tatsachen begründet werden. Diese Tatsachen weisen auf einen Lebenssachverhalt hin, der auf der Grundlage einer kriminalistischen, kriminologischen und allgemeinen Wertung den Verdacht stützt. Dieses Tatmaterial ist nicht per se schon die entscheidende oder abschließende Voraussetzung bei der Bildung eines Verdachts, denn seine Qualifizierung als verfolgbare Straftat hängt von jedem konkreten Fall ab. In diesem Sinne begründen die Tatsachen nur dann einen Anfangsverdacht, wenn sie verfolgbare Straftaten wiedergeben. Es handelt sich weder um eine vorherige Determinierung aller Details einer Straftat noch um eine exakte Individualisierung des Täters, sondern um die Festlegung von tatbestandsmäßigen Handlungen. Zusätzlich zur Abgrenzung, die die Tatsachen bei der Aufstellung eines Anfangsverdachts darstellen, stützt sich die Bestimmung derselben auf einen Wahrscheinlichkeitsprozess, der zwei Varianten aufweist: eine retrospektive Diagnose und eine verfahrensbezogene Prognostik. Die retrospektive Diagnose bezieht sich auf eine Wahrscheinlichkeit bzgl. des Eintretens einer Straftat, die über den Zufall hinausgeht. Die verfahrensbezogene Prognostik bestimmt die Wahrscheinlichkeit eines zukünftigen Prozesses. In diesem Sinne wird von einer doppelten Wahrscheinlichkeit gesprochen. Diese Parameter für die Bestimmung des Anfangsverdachts führen zur Unterscheidung dieses Begriffes von der Vermutung oder der Spekulation. Der Anfangsverdacht als unbestimmter juristischer Begriff impliziert einen weiten und flexiblen Handlungsbereich, der methodologisch durch die Zulassung eines Ermessensspielraums abgesichert ist.

\section{Dringender Tatverdacht}

Für die Zwangsmaßnahmen, deren Eingriff in die Grundrechte als drastisch und durchgreifend bezeichnet werden kann, fordert die StPO das Vorliegen eines dringenden Tatverdachts als Bedingung, um diese Maßnahme zu rechtfertigen. Die wichtigste Regelung stellt $\S 112$ StPO bzgl. der Untersuchungshaft dar, aber auch $\S \S 81$ Abs. 2, 132 Abs. 1, 138a Abs. 1 StPO nehmen die Notwendigkeit des dringenden Tatverdachts auf. Ein dringender Tatverdacht liegt vor, wenn eine hohe Wahrscheinlichkeit besteht, dass der Beschuldigter 
Täter oder Teilnehmer einer Straftat ist (retrospektive Diagnose) ${ }^{889}$ Die hohe Wahrscheinlichkeit muss sich sowohl auf das Vorliegen bestimmter Umstände oder Tatsachen stützen sowie auch auf den Täter. Ein Teil der Meinungen fordert außerdem, dass sich aus den vorliegenden Beweisen ergeben müsse, dass die Verurteilung des Beschuldigten Wahrscheinlichkeitscharakter hat. ${ }^{890}$ Auf diese Weise wird die prospektive Prognose eingeführt, von der aus sich eine mögliche Entscheidung für die Verurteilung ableiten lässt. Diese verfahrensbezogene Prognostik kann auch in Frage gestellt zu werden, da es in der Ermittlungsphase nicht möglich ist, alle Umstände vorauszusehen, die in einem Urteil bewertet werden müssen. Es wird zugegeben, dass es im Moment der Entscheidung für das Aussprechen eines dringenden Tatverdachts unmöglich sei, vorauszusehen, wie die Entscheidung des Gerichts, das über Freispruch oder Verurteilung entscheiden muss, ausfallen wird. $^{891}$

Es besteht Einigkeit darüber, dass sich der dringende Tatverdacht auf erhebliche Verdachtsmomente gegen den Beschuldigten stützen muss. ${ }^{892}$ Die solide Grundlage des Verdachts führt nicht zur Sicherheit oder Überzeugung bzgl. der Täterschaft des Verdächtigen, sie bedeutet jedoch, dass keine wesentlichen Zweifel hinsichtlich der Anbindung desselben zu den untersuchten Tatsachen bestehen. ${ }^{893}$ Die Ergebnisse der Ermittlung bei der Entscheidung für einen dringenden Tatverdacht müssen gegeneinander abgewogen werden. Damit der Verdacht angenommen wird, dürfen die gesammelten Tatsachen oder das Beweismaterial, das für den Verdächtigen spricht, kein nennenswertes Gewicht gegenüber dem belastenden Material besitzen. ${ }^{894}$ Diese Bewertung des Gewichts des Verdachts berücksichtigt in jedem Fall, dass sich jenes im Verlauf des Prozesses verändern kann und die Möglichkeit besteht, dass der dringende Tatverdacht verändert werden oder in sich

\footnotetext{
${ }^{889}$ Roxin/Schünemann, 2014, § 30 Rn. 5; Volk/Engländer, 2013, § 8 Rn. 3 und $§ 10$ Rn. 7 (ebd. in der span. Fassung, s. Volk, 2015); Beulke, 2012, Rn. 114, 210; Kühne, 2015, Rn. 337; Schulz, 2001, S. 599 ff.; Ebert, 2000, S. 138 ff. (krit. des Begriffes ",hohe Wahrscheinlichkeit“ -S. 143-); Meyer-Goßner/Schmitt, § 112 Rn. 5; LR/Hilger, § 112 Rn. 16 ff. und. Fn. 21 m.w.N.

${ }^{890}$ Ebert, 2000, S. 146; Paeffgen, 1986, S. 183 ff.; v. Hindte, 1973, 167 ff.; AnwK-StPO/Lammer, § 112 Rn. 10; LR/Hilger, § 112 Rn. 17 und Fn 22 m.w.N.

${ }^{891}$ Ebert, 2000, S. 146; Beulke, 2012, Rn. 209; Meyer-Goßner/Schmitt, § 112 Rn. 5; LR/Hilger, § 112 Rn. 16.

${ }^{892}$ Vgl. Kohlmann, 2010, S. 178; Schulz, 2001, S. 603; Ebert, 2000, S. 141.

${ }^{893}$ Ebert, 2000, S. 140; Schulz, 2001, S. 603: „der zunächst dringende Verdacht hört auf, ein solcher zu sein, sobald feststeht, dass Lücken in der Kette eines Indizienbeweises auch durch weitere Ermittlungen nicht mehr gescholossen werden können.“

${ }^{894}$ Ebert, 2000, S. 144: „wenn ernstzunehmende Zweifel vorhanden sind, aber behoben werden können, darf einem Antrag auf Haftbefehl gleichwohl nicht stattgegeben werden.“
} 
zusammenfallen kann. Wenn die Möglichkeit besteht, dass das Vakuum in den Indizienbeweisen während der Ermittlung nicht überwunden wird, ist der Verdacht nicht mehr als dringender Tatverdacht einzustufen. Nach der h.M. entfällt die Dringlichkeit des Verdachts zum Beispiel, wenn die Ermittlungsbehörden nicht in der Lage sind, sich mit der notwendigen Eile den jeweiligen Ermittlungen zu widmen, die das Indizienvakuum überwinden sollen. ${ }^{895}$

Um sich für einen dringenden Tatverdacht zu entscheiden, orientiert sich der Ermittlungsrichter an einer freien Beweiswürdigung auf der Grundlage von konkreten Tatsachen. ${ }^{896} \mathrm{Im}$ Gegensatz zu dem, was bei einer Entscheidung für eine Verurteilung geschieht, geht der Bestätigung eines dringenden Tatverdachts keine volle richterliche Überzeugung - § 261 StPO - dahingehend voraus, dass der Angeklagte eine tatbestandsmäßige, rechtswidrige und schuldhafte Handlung begangen hat. Der Ermittlungsrichter, der über das Vorliegen eines dringenden Tatverdachts entscheidet, stützt seine Überzeugung nur auf das im Moment seiner Entscheidung bestehende Beweismaterial. ${ }^{897} \mathrm{Im}$ Falle einer Entscheidung für eine Verhaftung während oder am Ende der Hauptverhandlung wird sogar als möglich erachtet, dass das Vakuum der Begründung durch spätere ergänzende Ermittlungen beseitigt werden kann, die die Defekte der Beweisermittlung beheben können. ${ }^{898}$

Es gibt gewisse Bestimmungen, gemäß denen das Beschwerdegericht während der Hauptverhandlung einen Haftbefehl erwägen muss. In diesem Fall ist die Entscheidung, ob ein dringender Tatverdacht besteht, auch überprüfbar, jedoch ist das Ausmaß der Überprüfung begrenzt. Die Begrenzungen der besagten Überprüfung sind bemerkenswert, insbesondere dann, wenn die Beweisermittlung unmittelbar vor dem Abschluss der Ermittlung erfolgt und auch im Falle von Beweismaterial, dessen Beweisbedeutung aus den Akten nicht ersichtlich ist. ${ }^{899}$ Das Beschwerdegericht kann nicht erwägen, ob die Beweisergebnisse, die in der Hauptverhandlung für einen Haftbefehl erlangt wurden, richtig sind und ob die be-

\footnotetext{
${ }^{895}$ Vgl. Schulz, 2001, S. 603 f.; LR/Hilger, § 112 Rn. 19 und Fn. 34 m.w.N.; dazu Paeffgen, 1986, S. 189 ff.

${ }^{896} \mathrm{KK} /$ Boujong, $\S 112 \mathrm{Rn} .8 \mathrm{LR} /$ Hilger $\S 112 \mathrm{Rn}$. 21. Für die Parallele zwischen Beweiswürdigung und Verdachtsausspruch s. Paeffgen, 1986, S. $192 \mathrm{ff}$.

${ }^{897}$ KK/Boujong, § 112 Rn. 8; LR/Hilger, § 112 Rn. 21; Ebert, 2000, S. 143 m.w.N.

${ }^{898}$ LR/Hilger, § 112 Rn. 20; der dringende Tatverdacht kann entfallen, ,wenn die Strafverfolgungsbehörden die gebotenen weiteren Ermittlungen nicht unverzüglich vornehmen“ (Ebert, 2000, S. 144); Auf jeden Fall fällt der Ermittlungsrichter seine Entscheidung auf der Grundlage des neuesten Standes der Ermittlung und der Beweissituation (SK/Paeffgen, § 112 Rn. 7).

${ }^{899}$ LR/Hilger, § 112 Rn. 20: „die Beurteilung des dringenden Tatverdachts ist nur in beschränktem Umfang überprüfbar.“ 
sagten Ergebnisse korrekt in dem Haftbefehl vertreten sind, denn der Richter des Beschwerdegerichts hat nicht die notwendige Information über die Entwicklung der Beweisermittlung und kann sie auch nicht erlangen. ${ }^{900}$

\section{Hinreichender Tatverdacht}

Der hinreichende Tatverdacht ist in den $\S \S 170$ Abs. 1 und 203 StPO enthalten und stellt eine der Voraussetzungen zur Erhebung der Anklage dar. Allgemein wird er als die Wahrscheinlichkeit definiert, mit der der Beschuldigte eine Straftat begangen hat und verurteilt wird. ${ }^{901}$ Im Gegensatz zum Anfangsverdacht wird bei dem hinreichenden Tatverdacht nicht die Wahrscheinlichkeit der Täterschaft oder Teilnahme im retrospektiven Sinne und auf der Grundlage der Ergebnisse der Ermittlung diskutiert. Die Bestimmung des hinreichenden Tatverdachts geht darüber hinaus und verlangt, dass der Angeklagte mit hoher Wahrscheinlichkeit sofort nach der Hauptverhandlung verurteilt wird (prozessuale Prognose). ${ }^{902}$ Darüber hinaus gibt es sowohl im Schrifttum als auch in der Rechtsprechung keine Sicherheit bzgl. des terminologischen Verständnisses und in der substantiellen Würdigung des Konzepts des hinreichenden Verdachts. ${ }^{903}$ Einerseits ist nicht klar, ob die Voraussetzungen für den hinreichenden Tatverdacht, die in $\S 203$ genannt werden und auch für $\S$ 170 StPO gültig sind ${ }^{904}$, alle Wertungen und Überlegungen umfassen, die der Richter bei der Eröffnung der Hauptverhandlung in Betracht ziehen muss, d.h., es ist nicht eindeutig, ob tatsächlich ein Teil der Bewertung der Beweise durchgeführt werden muss. Ein Teil der Meinungen beinhaltet teilweise in der Bestimmung des Begriffs die Urteile und Entscheidungsbedingungen, die der Richter berücksichtigen muss, um die Verhandlung zu eröffnen. Der hinreichende Verdacht verlangt mit anderen Worten nur eine Richtigkeitsüberzeugung (etwa in Rechtsfragen). ${ }^{905}$ Die h.M. jedoch behauptet, dass $§ 203$ StPO nur auf

\footnotetext{
900 „Es hat z.B. zu untersuchen, ob alle entscheidungserheblichen Tatsachen in der angefochtenen Entscheidung widerspruchfrei berücksichtigt und gewürdigt worden sind“ (LR/Hilger, § 112 Rn. 20 und Fn. 48 m.w.N.).

${ }^{901}$ Roxin/Schünemann, 2014, § 40 Rn. 114; Volk/Engländer, 2013, § 8 Rn. 3 und § 16 Rn. 10 (ebd. in der span. Fassung, s. Volk, 2015); Beulke, 2012, Rn. 114, 319 ff.; Kühne, 2015, Rn. 339, 610; Schulz, 2001, S. 609 ff.; Ebert, 2000, S. 162 ff.; Meyer-Goßner/Schmitt, § 203 Rn. 2; LR/Stuckenberg, § 203 Rn. 6 ff.

902 Schulz, 2001, S. 613 f.; Ebert, 2000, S. 162 und Fn. 705 m.w.N, 166 ff.; Meyer-Goßner/Schmitt, § 203 Rn. 2; LR/Stuckenberg, § 203 Rn. 11 f. (definiert die Verurteilungswahrscheinlichkeit als eine Summe von Wahrscheinlichkeitsurteilen).

${ }^{903}$ Bzgl. der sachlichen und terminologischen Unklarheiten s. LR/Stuckenberg, § 203 Rn. 7 f.

${ }^{904}$ Dazu Schulz, 2001, S. 612; Als identisch betrachtet Ebert, 2000, S. 163 und Fn. 708 m.w.N; v. Hindte, 1973, S. 89 f.

905 Vgl. LR/Stuckenberg, § 203 Rn. 7.
} 
einen Teil der Bedingungen für die Eröffnungsentscheidung hinweise. ${ }^{906}$ In diesem letzteren Sinne wird der hinreichende Tatverdacht als eine Verurteilungsprognose verstanden, die auch die Prozessvoraussetzungen berücksichtigt.

Auf der anderen Seite wird darüber diskutiert, welcher der Wahrscheinlichkeitsgrad ist, der mit dem Wort „verdächtig” in $\S 203$ StPO angekündigt wird, und worauf dieser Begriff aufbaut. Die h.M. ist der Auffassung, dass eine Anklage nicht allein aufgrund einer bloßen Wahrscheinlichkeit ausgesprochen werden dürfe. Es müsse vielmehr eine Wahrscheinlichkeit bestehen, dass der Beschuldigte eine Straftat begangen habe und dass sich aus dem gesammelten Beweismaterial und den Möglichkeiten der Kenntnisnahme, die sich aus der Beweisaufdeckung in der Hauptverhandlung ergeben, eine Verurteilungswahrscheinlichkeit aufgrund einer Straftat ergebe. ${ }^{907}$ Jedoch gewährleistet der Ausdruck der Verurteilungswahrscheinlichkeit nicht genügend Klarheit bzgl. der Verdachtsstärke. Daher bleibt die Frage nach der Verdachtsstärke, die existieren sollte, damit eine Verurteilung wahrscheinlich erscheint, unbeantwortet. ${ }^{908}$

Eine erste Abgrenzung der Intensität des hinreichenden Tatverdachts ergibt sich aus dem Vergleich mit dem dringenden Tatverdacht. Es wird allgemein akzeptiert, dass der Verdachtsgrad aus $\S 203$ StPO nicht derselbe ist, den der dringende Tatverdacht verlangt. ${ }^{909}$ Der Grund, auf dem die Unterscheidung der Intensität beider Verdachtsgrade beruht, ist der Rahmen der rechtlichen Konsequenzen und die Art der Einflussnahme im Bereich der Grundrechte des Verdächtigen. Während der dringende Tatverdacht zu einem direkten Eingriff in die persönliche Freiheit führt, wird mit dem hinreichenden Tatverdacht und der Erhebung einer Anklage und der Hauptverfahrenseröffnung keine Freiheitseinschränkung gerechtfertigt. Die Einflussnahme, zu der der hinreichende Tatverdacht führt, ist mit der des dringenden Tatverdachts nicht zu vergleichen. ${ }^{910}$ Obwohl die Intensität des Verdachts mit der Einflussnahme auf Grundrechte wie die persönliche Freiheit nicht vergleichbar ist,

\footnotetext{
906 Vgl. dazu Meyer-Goßner/Schmitt, § 203 Rn. 2; LR/Stuckenberg, § 203 Rn. 7; dazu Ebert, 2000. S. 164 (Verdachtsstärke als Vorherrschen belastender Anhaltspunkte).

907 Kohlmann, 2010, S. 179; Ebert, 2000, S. 167; Meyer-Goßner/Schmitt, § 203 Rn. 2; LR/Stuckenberg, § 203 Rn. 9.

${ }^{908}$ Für eine abweichende Auffassung der h.M. vgl. Miehe, FS Grünwald (1999), S. 390 f., nach dem der Begriff des hinreichenden Tatverdachts nur die retrospektive Beurteilung der Wahrscheinlichkeit der Tatbegehung umfasst, nicht aber die prospektive Verurteilungswahrscheinlichkeit.

${ }^{909}$ Zum Verhältnis zwischen dringendem und hinreichendem Tatverdacht vgl. Schulz, 2000, S. 614 f.; Ebert, 2000, S. $171 \mathrm{ff}$.

${ }^{910}$ Ebert, 2000, S. 165; LR/Stuckenberg, § 203 Rn. 14.

272
} 
erkennt ein Teil der Meinungen doch an, dass mit dem hinreichenden Tatverdacht auf jeden Fall eine Verdachtsintensität existiert, in der sich die belastenden Anhaltspunkte mit den entlastenden Anhaltspunkten überschneiden, sodass die Wahrscheinlichkeit der Täterschaft wesentlich höher als die der Schuldlosigkeit ist. ${ }^{911}$

Der Vorrang der belastenden Anhaltspunkte ist ein Teil des Bestimmungsverfahrens bzgl. der Verurteilungswahrscheinlichkeit. Die Verurteilungswahrscheinlichkeit ist mit der Wahrscheinlichkeit der Täterschaft verbunden und letztere kann nicht angenommen werden, wenn es unwahrscheinlich ist, dass die Begehung der Tat mit Wahrscheinlichkeit bewiesen werden kann. ${ }^{912}$ Allerdings hängt die Verurteilungswahrscheinlichkeit nicht ausschließlich von einem hohen Verdachtsniveau ab, denn aus diesem ist kein möglicher Verfahrensausgang zu schließen. Der hinreichende Verdacht ist nicht mit Verurteilungswahrscheinlichkeit gleichzusetzen, er ist jedoch eines der Analyseelemente, um eine Verurteilungswahrscheinlichkeit zu bestimmen. Obwohl sich $§ 203$ StPO nur auf den hinreichenden Verdacht als Voraussetzung für die Anklage bezieht, wird eingeräumt, dass gleichzeitig Fragen bzgl. der Rechtswidrigkeit, Schuld und Strafausschließungsgründe sowie auch die Analyse der Prozesshindernisse Beachtung finden. An die Analyse dieser Komponenten reihen sich Aspekte wie die Beweisbarkeit des Tatvorwurfs. Der hinreichende Tatverdacht benötigt eine überwiegende Wahrscheinlichkeit, sowohl was die Täterschaft angeht als auch die Beweisbarkeit der Zurechnung der Straftat sowie auch das nicht Vorliegen von Verfahrenshindernissen. Gegenüber jedem dieser Analyseelemente und der Bestimmung des hinreichenden Verdachts muss eine überwiegend positive Wahrscheinlichkeit vorliegen. Sollte eine der Komponenten dieses Wahrscheinlichkeitsniveau nicht erreichen, liegt ein hinreichender Tatverdacht vor, der nicht die Wahrscheinlichkeitsdichte erreicht. ${ }^{913}$

Zusammenfassend kann festgestellt werden, dass ein hinreichender Tatverdacht vorliegt, wenn die Verurteilungswahrscheinlichkeit gegeben ist. Damit eine Verurteilung als wahrscheinlich betrachtet werden kann, sind außerdem mehrere Wahrscheinlichkeitsurteile notwendig. Erstens müssen die Ergebnisse der Ermittlung beweisbar sein und es muss wahrscheinlich sein, dass sich die Überzeugung des Richters aus der Kenntnisnahme dieser

\footnotetext{
911 Ebert, 2000, S. 166 und Fn. 719 m.w.N.; v. Hindte, 1973, S. 110.

912 Ebert, 2000, S. 167; dazu LR/Stuckenberg, § 203 Rn. 15 (hinreichender Tatverdacht ist als materieller Tatverdacht und prozessualer Verurteilungsverdacht zu interpretieren).

913 Ebert, 2000, S. 168 (bei Unverwertbarkeit der Belege besteht kein hinreichender Verdacht); LR/Stuckenberg, § 203 Rn. 11 Fn 29 m.w.N.
} 
Ergebnisse und gemäß den Beweisregeln der Hauptverhandlung ergibt. Das Wahrscheinlichkeitsurteil über die Überzeugung des Richters bzgl. der im Prozess zu beweisenden Straftat entwickelt sich angesichts des gesamten Akteninhalts. In diesem Bereich stellt der hinreichende Tatverdacht eine Prozessvoraussage dar, dass der Beweis der akzeptierten Prozessmittel zu der Überzeugung des Gerichtsvorsitzenden führt. In diesem Sinne wird zusätzlich zum retrospektiven Wahrscheinlichkeitsurteil eine vorläufige verfahrensbezogene Prognostik eingeführt. Die verfahrensbezogene Prognostik ergibt in allen Fällen, in denen ein Beweisverwertungsverbot oder die Möglichkeit unüberwindbarer Beweisschwierigkeiten besteht, ein negatives Resultat. ${ }^{914}$ Zweitens muss die Wahrscheinlichkeit bestehen, dass mit dem zu beweisenden Material eine Strafbarkeit des Beschuldigten begründet werden kann. Aus den Tatsachen, die bestimmt werden sollen, muss zweifelsfrei der objektive und subjektive Tatbestand geschlossen und begründet werden sowie auch der Mangel an Rechtfertigungsgründen oder persönlichen Strafausschließungsgründen. Drittens müssen die Prozessvoraussetzungen (Fehlen von Verfahrenshindernissen) von rechtlicher und sachlicher Seite gegeben sein. Alle Zweifel bzgl. möglicher Prozesshindernisse müssen vor der Entscheidung für die Hauptverhandlungseröffnung überwunden werden. Die einzige zu berücksichtigende Ausnahme gegenüber dieser Regelung besteht im Falle der Klärung von zweifelhaften Tatsachen, die die angeklagte Straftat betreffen und die in der Hauptverhandlung bewiesen werden müssen. In diesen Fällen wird als genügend angenommen, dass eine hinreichende Wahrscheinlichkeit besteht, dass die Beweisaufnahme in der Hauptverhandlung nicht zu dem Ergebnis führt, dass Verfahrenshindernisse bestehen.

\section{Zusammenfassung}

Besonders relevant für eine Analyse der Problematik der motivos fundados in Kolumbien ist der Vergleich mit dem Tatverdacht in der StPO. Damit bezieht sich die StPO auf eine anzustrebende Beweisgrundlage, damit die Staatsanwaltschaft beginnen kann, Zwangsmaßnahmen in der Ermittlungsphase durchzuführen. Der Vergleich ermöglicht ein besseres Verständnis des Wahrscheinlichkeitsurteils bzgl. der Täterschaft oder Teilnahme an einer Straftat als zentrale Voraussetzung der Definition des fundierten Anhaltpunktes. Der Begriff Tatverdacht der StPO erläutert einleuchtend, wie die Begründungsgrade im Bereich des Begriffs motivos fundados zu systematisieren sind. Obwohl die StPO keine rechtliche

\footnotetext{
${ }^{914}$ LR/Stuckenberg § 203 Rn. 15 (dies kann beispielweise in folgenden Fällen in Betracht kommen: bei Gebrauch des Zeugen vom Weigerungsrecht, nicht Einführung ihrer Aussagen, nicht ausreichende Überzeugungsbildung oder fehlende Verfügung eines V-Mann für die Hauptverhandlung). 
Definition des Verdachts enthält, erkennt die h.M. drei Verdachtsgrade an: Anfangsverdacht, dringender und hinreichender Tatverdacht. Um einen Verdacht festzustellen, wird zur Erklärung hauptsächlich auf das Wahrscheinlichkeitsverfahren zurückgegriffen. Die Analyse der Umstände und der Modalitäten, die in einem Wahrscheinlichkeitsverfahren bzgl. einer als Straftat angenommenen Tatsache durchgeführt wird, gibt die Struktur einer Prognose wider. Die Verdachtsgrade stellen lediglich Mindestvoraussetzungen dar, um eine bestimmte Ermittlungsmaßnahme oder Verfahrenshandlung zu verordnen. Der Anfangsverdacht liegt vor, wenn ,zureichende tatsächliche Anhaltspunkte“ für eine zu verfolgende Straftat vorliegen. Der Anfangsverdacht aktiviert nicht nur die Erforschungspflicht, sondern grenzt die „strafverfahrensrechtliche Befugnis zum Einschreiten“ ein. Es ist wichtig, den Anfangsverdacht von den bloßen Vermutungen und Möglichkeiten zu trennen, die keinerlei Art von Anfangsverdacht begründen. Der Anfangsverdacht setzt nicht die Individualisierung des Täters oder Teilnehmers voraus, aufgrund derer zwischen tat- und täterbezogenem Verdacht zu unterscheiden ist. Gegenüber den Zwangsmaßnahmen, deren Eingriff in die Grundrechte als drastisch und durchgreifend bezeichnet werden kann, fordert die StPO das Vorliegen eines dringenden Tatverdachts als Bedingung. Die wichtigste Regelung stellt § 112 StPO bzgl. der Untersuchungshaft dar. Ein dringender Tatverdacht liegt vor, wenn eine hohe Wahrscheinlichkeit besteht, dass der Angeklagte Täter oder Teilnehmer einer Straftat ist. Der hinreichende Tatverdacht ist in den $\S \S 170$ Abs. 1 und 203 StPO enthalten und stellt eine der Voraussetzungen zur Erhebung der Anklage dar. Allgemein wird er als die Wahrscheinlichkeit definiert, mit der der Beschuldigte eine Straftat begangen hat und verurteilt werden wird. Damit eine Verurteilung als wahrscheinlich betrachtet werden kann, sind außerdem mehrere Wahrscheinlichkeitsurteile notwendig. Die Ergebnisse der Ermittlung müssen beweisbar sein und es muss wahrscheinlich sein, dass sich die Überzeugung des Richters aus der Kenntnisnahme dieser Ergebnisse und gemäß den Beweisregeln der Hauptverhandlung ergibt. Es muss die Wahrscheinlichkeit bestehen, dass mit dem zu beweisenden Material eine Strafbarkeit des Angeschuldigten begründet werden kann. Die Prozessvoraussetzungen (das Fehlen von Verfahrenshindernissen) müssen von rechtlicher und sachlicher Seite gegeben sein. 


\section{§ 9. Die sog. „,motivos fundados“ im Vergleich mit dem Tatverdacht}

Die Lehre des Tatverdachts, die auf den Regelungen der StPO, besonders auf $\S \S 152$ Abs. 2, 112 und 203 aufbaut, ist ein Vergleichsmaßstab, der eine Analyse verschiedener Probleme bzgl. des Konzepts und der Regelung der fundierten Anhaltspunkte (motivos fundados) erlaubt. Mit dem Verdachtsbegriff der StPO können drei spezifische thematische Niveaus verglichen werden, von denen aus es möglich ist, konkrete Aspekte der fundierten Anhaltspunkte in Kolumbien zu beleuchten, besonders die der Einordnung, Bestimmung und der Funktion im Ermittlungsverfahren. Obwohl keine Methode besteht, den Verdacht und seine Grade zu bestimmen, ist auf einem ersten Niveau die Diskussion über die Verdachtsstufen relevant vor der undifferenzierten (nicht graduierten) Behandlung der fundierten Anhaltspunkte gegenüber verschiedenen Ermittlungsmaßnahmen und zu den verschiedenen Zeitpunkten des Ermittlungsverfahrens im CPP. Auf einem zweiten Niveau ist die Wahrscheinlichkeit als Bedingung zur Festlegung des Verdachts ein Kriterium, das im Bereich der fundierten Anhaltspunkte angewendet wird. Relevant ist die Rolle, die sowohl die retrospektive tatbezogene Diagnose als auch die prospektive täterbezogene Prognose für die Bestimmung dieses Konzepts spielen. Auf einem dritten Niveau ist dadurch, dass auch der CPP eine Vorermittlungs- und eine Ermittlungsphase im strikten Sinne vorsieht, eine Unterscheidung zwischen anfänglichen fundierten Anhaltspunkten (motivos fundados iniciales) und zumutbaren fundierten Anhaltspunkten (motivos razonablemente fundados) angebracht, in Analogie zu der Funktion des Anfangsverdachts und des dringenden Tatverdachts der StPO.

Bzgl. dieser Vergleichsbereiche zwischen dem Tatverdacht in der StPO und dem Konzept der fundierten Anhaltspunkte im CPP werden drei Stufen oder Grade bei den fundierten Anhaltspunkten geschaffen. In erster Linie wird versucht, die Grundlagen für die Festlegung der anfänglichen fundierten Anhaltspunkten zu legen, vornehmlich auf der Basis des Art. 205 CPP. Zweitens wird auf der Grundlage der im vorherigen Kapitel erlangten Konzeptualisierung des Begriffs des dringenden Tatverdachts eine Analyse des Konzepts der zumutbaren fundierten Anhaltspunkte (motivos razonablemente fundados) im Bereich der Ermittlungsmaßnahmen durchgeführt. Da es sich um eine Bedingung für die Durchführung von Maßnahmen handelt, die einen intensiven Eingriff in Grundrechte darstellen, ist dieses Konzept mit dem des dringenden Tatverdachts vergleichbar. In diesem Sinne wird disku- 
tiert, ob die Analyseelemente für die Bestimmung des dringenden Tatverdachts anwendbar auf die Bestimmung von zumutbaren fundierten Anhaltspunkten sind. Drittens wird versucht, ausgehend vom Art. 336 CPP und der Forderung nach Wahrheitswahrscheinlichkeit (probabilidad de verdad) in der die Anklageschrift begründenden Schlussfolgerung, eine dritte Qualifikation der fundierten Anhaltspunkte aufzustellen, die mit dem hinreichenden Tatverdacht vergleichbar ist.

\section{A. Vorbemerkung}

Die Behandlung der Forderung nach Begründung für die Durchführung von Ermittlungsmaßnahmen im CPP ist nicht einheitlich. Der CPP erfasst verschiedene Formulierungen und Ausdrücke, die sich auf die Forderung nach fundierten Anhaltspunkten beziehen. So wird zum Beispiel in Art. 2 Abs. 1 und 14 Abs. 2 CPP auf,,motivos previamente definidos en la Ley“ (Gründe, die gesetzlich definiert wurden) eingegangen, in Anspielung auf die Gründe, die die Beschränkung der Freiheit ${ }^{915}$ und des Rechts auf Schutz der Privatsphä$\mathrm{re}^{916}$ angehen. In anderen Absätzen, jedoch mit demselben Ansinnen, die Begründung der Maßnahmen abzusichern, gebraucht der CPP den Begriff motivos fundados konkreter. Besonders für die Vorsorgemaßnahmen bzgl. einzuziehender Vermögensgegenstände (Art. 83 Abs. 2), der Aufhebung und Außerkraftsetzung der Rechtspersönlichkeit (Art. 91 Abs. 1), der Aufhebung und Streichung des Güterrechtsregisters, dessen Eigentumstitel durch Betrug erlangt wurde (Art. 101 Abs. 1), bzgl. der Beweisunterstützung der motivos fundados (Art. 221 Abs. 1 und 3), der Verlängerung der Maßnahme des Lauschangriffs (Art. 235 Abs. 3), der Durchführung der Telekommunikationsüberwachung (Art. 282), der vorgezogenen Beweisaufnahme (Art. 284) und der Feststellung von Gefahr für das Opfer als Vo-

\footnotetext{
915 Art. 2 Abs. 1 CPP: „Libertad. [...]. Nadie podrá ser molestado en su persona ni privado de su libertad sino en virtud de mandamiento escrito de autoridad judicial competente, emitido con las formalidades legales y por motivos previamente definidos en la ley.“ („Freiheit. [...]. Niemand darf in seiner Person belästigt oder seiner Freiheit beraubt werden, außer durch von einer zuständigen Justizbehörde schriftlich ausgestellten Haftbefehl mit den rechtlichen Formalitäten und aus zuvor durch Gesetz festgelegten Gründen."-dt. Übersetzung d. Verf./Herv. d. Verf.-). Vgl. dazu supra § 6. C. Maßnahmen zur Beschränkung der Freiheit.

916 Art. 14 Abs. 2 CPP: „No podrán hacerse registros, allanamientos ni incautaciones en domicilio, residencia, o lugar de trabajo, sino en virtud de orden escrita del Fiscal General de la Nación o su delegado, con arreglo de las formalidades y motivos previamente definidos en este código.“ („In Wohnsitz oder Arbeitsplatz dürfen keine Durchsuchungen oder Beschlagnahmen durchgeführt werden, außer durch schriftliche Anordnung der Generalstaatsanwaltschaft oder ihrer Vertretung, in Übereinstimmung mit den Formalitäten und Gründen, die zuvor in diese Strafprozessordnung festgelegt sind." -dt. Übersetzung d. Verf./Herv. d. Verf.-). Vgl. dazu supra § 5. A. Maßnahmen zur Beschränkung der Intimität. 
raussetzung für die Anordnung einer Sicherheitsmaßnahme (Art. 311). ${ }^{917}$ Im selben Sinn, aber unter Hinzufügung eines Modaladverbs, gebraucht der CPP den Ausdruck motivos razonablemente fundados (zumutbare fundierte Anhaltspunkte), sowohl bzgl. der Ermittlungsmaßnahmen, die keine vorherige richterliche Anordnung verlangen als auch bzgl. jener, die diese Genehmigung benötigen. ${ }^{918}$ Neben den erwähnten gibt es auch Formulierungen, die nicht den Begriff ,fundados “ enthalten, die jedoch unter der Bezeichnung motivos razonables (zumutbare Gründe) (Art. 298 Parag. 2 CPP) darauf anspielen. ${ }^{919}$ In anderen Fällen wird sich einfach auf motivos graves (schwere Gründe) (Art. $309 \mathrm{CPP})^{920}$ oder motivos serios (schwerwiegende Gründe) bezogen (Art. 300 CPP). ${ }^{921}$ Schließlich wird in Art. 205, 287 und 308 CPP eine Formulierung gebraucht, die nicht ausdrücklich den Begriff motivos fundados (fundierte Anhaltspunkte) erwähnt, jedoch die Forderung nach Be-

917 Bzgl. der Behandlung von motivos fundados im CPP vgl. supra § 7. A. II. Systematische Lage im aktuellen CPP; zusammenfassend Zuluaga, NFP 83 (2015), S. 173.

${ }^{918}$ Insbesondere als Grundlage für Anordnung von Hausdurchsuchungen (Art. 220), Eingriff in die postalische Kommunikation (Art. 233), Wiederbeschaffung von Informationen (Art. 236 Abs. 1), Personenüberwachung (Art. 239 Abs. 1), Überwachungsmaßnahmen an Sachen (Art. 240 Abs. 1), Analyse und Infiltrierung von kriminellen Organisationen (Art. 241 Abs. 1), Einsatz verdeckter Ermittler (Art. 242), Verdeckte Überwachung von Transport, Verkauf, Vermietung von Waffen, Sprengstoff, Munition, Falschgeld und Drogen (Art. 243), Körperliche Untersuchungen (Art. 247), Durchsuchungen von Personen (Art. 248 Abs. 1) und Haftbefehl (Art. 297 Abs. 1); vgl. dazu s. supra § 7. A. II. Systematische Lage im aktuellen CPP.

${ }^{919}$ Vgl. Art. 298 parag. 2 CPP: „Cuando existan motivos razonables para sospechar que una nave está siendo utilizada para el tráfico ilícito de estupefacientes y sustancias sicotrópicas.“ („Wenn vernünftige Gründe vorliegen zu verdächtigen, dass ein Schiff für den illegalen Handel mit Betäubungsmitteln und psychotropen Stoffen verwendet wird“ -dt. Übersetzung d. Verf.-); auch im Art. 383 Abs. 2: „El juez, con fundamento en motivos razonables, podrá practicar el testimonio del menor fuera de la sala de audiencia, de acuerdo con lo previsto en el numeral $5^{\circ}$ del artículo 146 de este código.“ („Der Richter kann, basierend auf vernünftigen Gründen, die Zeugenaussage eines Minderjährigen außerhalb des Gerichtssaals nach den Bestimmungen von Absatz 5 des Artikels 146 dieser Strafprozessordnung durchzuführen.“ -dt. Übersetzung d. Verf./Herv. d. Verf.-)

${ }^{920}$ Art. 309 CPP: „Obstrucción de la justicia. Se entenderá que la imposición de la medida de aseguramiento es indispensable para evitar la obstrucción de la justicia, cuando existan motivos graves y fundados que permitan inferir que el imputado podrá destruir, modificar, dirigir, impedir, ocultar o falsificar elementos de prueba; $[\ldots]$ “. („Behinderung der Justiz. Es versteht sich, dass die Einführung der Sicherheitsmaßnahme notwendig ist, um Behinderung der Justiz zu verhindern, wenn schwere und berechtigte Gründe vorliegen zu folgern, dass der Beschuldigte die Beweise zerstören, modifizieren, verwalten, verhindern, unterdrücken oder verfälschen könnte; [...]“-dt. Übersetzung d. Verf./Herv. d. Verf-).

${ }^{921}$ Art. 300 CPP: „Captura excepcional por orden de la Fiscalía. El Fiscal General de la Nación o su delegado podrá proferir excepcionalmente orden de captura escrita y motivada en los eventos en los que proceda la detención preventiva, cuando por motivos serios y de fuerza mayor no se encuentre disponible un juez que pueda ordenarla [...].“ („Festnahme ohne richterliche Anordnung. Der FGN darf ausnahmsweise die Festnahme anordnen, wenn sich im Verlauf der Ermittlungen fundierte Anhaltspunkte dafür ergeben, dass die betroffene Person an dem Verhalten, welches Gegenstand der Ermittlungen darstellt, beteiligt war und es auf Grund schwerwiegender und unkontrollierbarer Gründe nicht möglich ist, unverzüglich eine richterliche Anordnung zu erlangen [...].“ -dt. Übersetzung d. Verf./Herv. d. Verf.-). Vgl. dazu supra § 6. C. I. Festnahme mit Ausnahmekompetenzen. 
gründung enthält, und sogar den Begriff inferencia razonable (zumutbare Schlussfolgerung) gebraucht, der aus dieser Begründung hervorgehen muss. ${ }^{922}$

Dieser ungleiche Gebrauch der fundierten Anhaltspunkte im Hinblick auf die Forderung der Begründung von Ermittlungsmaßnahmen ist einerseits Ausdruck der vom CPP vorgegebenen Einführung der Forderung nach einer Begründungsschwelle oder Gründen, die von Art. $250 \mathrm{CN}$ vorgegeben sind, um über die Ermittlungsmaßnahmen zu entscheiden, die in vielen Fällen eine Einschränkung der Grundrechte des Verdächtigen bedeuten. ${ }^{923}$ Andererseits scheint der Gebrauch der verschiedenen Ausdrücke bzgl. der Begründungsforderung darauf hinzuweisen, dass das Vorgehen des CPP verschiedene Niveaus im Bereich der Maßnahmenbegründung umfasst. Jedoch enthält der CPP in keinem Absatz einen ausdrücklichen Hinweis auf Abstufungen der fundierten Anhaltspunkte. Diese Frage ist noch nicht einmal in der wenig umfangreichen Literatur des kolumbianischen Strafprozessrechts angeschnitten oder diskutiert worden, von der aus jeglicher deskriptiver Versuch ein immenses Vakuum bzgl. eines möglichen Rahmens von Graden der fundierten Anhaltspunkte offenbaren würde.

Trotzdem kann behauptet werden, dass vergleichbar zum Tatverdacht der StPO bzgl. der terminologisch differenzierten Behandlung der fundierten Anhaltspunkten im CPP es möglich ist, Stufen oder Niveaus aufzustellen. Es finden sich drei Szenarien im CPP, die Forderungen nach Begründungen entwickeln, die dem Anfangs-, dringenden und hinreichenden Verdacht der StPO vergleichbar sind. Erstens wird in Art. 205 CPP ein Begriff der fundierten Anhaltspunkte eingeführt, der dem $§ 152$ Abs. 2 StPO ähnelt. Art. 205 CPP geht von der Vorermittlung (indagación) aus, wenn die Ermittlungsbehörde Anzeigen, Klagen oder andere Arten von Informationen erhält, aus denen sich die Möglichkeit der Begehung einer Straftat ableiten lässt. Es handelt sich um einen Begriff des fundierten Anhaltspunktes, der, vergleichbar dem Anfangsverdacht in der StPO, die Ermittlung aktiviert und das Einschreiten der Ermittlungsbehörde begrenzt. Ebenso führt der CPP in Art. 287 die Bedingung der

\footnotetext{
${ }^{222}$ Art. 308 CPP: „Requisitos. El juez de control de garantías, a petición del Fiscal General de la Nación o de su delegado, decretará la medida de aseguramiento cuando de los elementos materiales probatorios y evidencia física recogidos y asegurados o de la información obtenidos legalmente, se pueda inferir razonablemente que el imputado puede ser autor o partícipe de la conducta delictiva que se investiga, [...].“ („,Voraussetzungen. Der Richter zur Kontrolle der Garantien, auf Antrag der Generalstaatsanwaltschaft oder ihrer Vertretung, wird die Sicherheitsmaßnahme anordnen, wenn aus den materiellen Beweise und des Beweismaterials [...] vernünftigerweise folgt, dass der Beschuldigte Täter oder Teilnehmer an der ermittelten Straftat sein kann [...].“-dt. Übersetzung d. Verf./Herv. d. Verf.-).

${ }^{923}$ Vgl. dazu supra § 7. A. I. Verfassungsrechtliche Bedeutung; auch Zuluaga, NFP 83 (2015), S. 173 f.

280
} 
fundierten Anhaltspunkte für die Ermittlungseröffnung gegenüber einer bestimmten Person im strikten Sinn als Voraussetzung für die Erhebung einer Beschuldigung ein. Es ist ein mit dem Inkulpationsverdacht ${ }^{924}$ vergleichbarer Begriff, von dem aus eine zumutbare Schlussfolgerung zur Täterschaft oder Teilnahme gefordert wird. Zweitens stellt der CPP das Vorliegen der zumutbaren fundierten Anhaltspunkte als Bedingung der Zwangsmaßnahmen auf, deren Einschreiten in Grundrechte mittleren oder intensiven Charakters ist. Diese Art von fundierten Anhaltspunkten könnte dem dringenden Tatverdacht gleichgestellt werden, in dem Sinne, als zumindest ein zumutbarer Zusammenhang mit der Täterschaft oder Teilnahme gefordert wird. Drittens wird als Bedingung für die Vorlage der Anklageschrift in Art. 336 CPP ein Begriff der fundierten Anhaltspunkte gefordert, der dem hinreichenden Tatverdacht vergleichbar ist, in dem Sinne, als eine hohe Wahrscheinlichkeit bzgl. des Vorliegens der Straftat und der Verantwortlichkeit des Angeklagten als Täter oder Teilnehmer gefordert wird.

In diesen vier Dimensionen erweisen sich die fundierten Anhaltspunkten als ein statischer Parameter, von dem aus die Begründung einer Ermittlungsmaßnahme bestimmt wird. Sie unterstellen sich somit einem dynamischen Prozess innerhalb der richterlichen Kontrolle, deren Ergebnis die Bestätigung oder die Missbilligung ebenjener fundierten Anhaltspunkte ist. Die Evaluierung der fundierten Anhaltspunkte als dynamischer Prozess erlangt an Bedeutung während der richterlichen vorherigen oder nachträglichen Kontrolle und der Widersprüche der Parteien während der jeweiligen Anhörungen. Nach dem Ziel der Ermittlungsmaßnahme (Zwecktheorie) ist es auch möglich, zwischen diesen Niveaus oder Graden der fundierten Anhaltspunkte zu unterscheiden. Außerdem entwickelt der CPP eine Regelung von zumutbaren Schlussfolgerungen, in der es möglich ist, unter den fundierten Anhaltspunkten Wahrscheinlichkeitsurteile zu unterscheiden, die sich an einer spezifischen Art der retrospektiven Diagnose und prospektiven Prognose orientieren. ${ }^{925}$ Im Folgenden werden diese verschiedenen Dimensionen der fundierten Anhaltspunkte unter dem Blickwinkel der Lehre der Verdachtsgrade der StPO untersucht.

\footnotetext{
${ }^{924} \mathrm{Vgl}$. zum Inkulpationsverdacht in der StPO nicht als Verdachtsstufe sondern als Verdachtsintensität Ebert, 2000, S. 137: der Inkulpationsverdacht wird dadurch charakterisiert, „daß die Ermittlungen einen Stand erreicht haben, auf dem die Zweifel an der Täterschaft des Verdächtigen nicht mehr überwiegen, sondern sich mit den belastenden Indizien zumindest die Waage halten.“; s. dazu infra § 9. C. I. 2. Inkulpationsgrad.

925 Vgl. dazu ausführlich infra $§ 10$. B. Ziele der zumutbaren Schlussfolgerungen; bzgl. der abduktiven Logik des Verdachts vgl. Schulz, 2001, S. 273 ff. und 546 ff. (zu dem Verdacht in personam).
} 


\section{B. Tatbezogene, ,Motivos fundados“}

\section{I. „Motivo fundado inicial“ (Erste Qualifikation)}

\section{Funktion in dem Verfahrensabschnitt}

Um mit den Ermittlungen von Seiten der Polizeibehörde in der Ermittlungsphase zu beginnen, fordert Art. 205 CPP das Vorliegen von Informationen, von denen auf das mögliche Verüben der Straftat geschlossen wird. In diesem Sinne wird in diesem Artikel das Vorliegen eines fundierten Anhaltspunktes sichtbar, dessen sachlicher Bereich oder objektive Situation die notitia criminis ist, die zur Ermittlungsbehörde mittels Anzeigen, spezieller Gesuche, Klagen oder anderer Mittel (nicht formelle Quellen) gelangt (Art. 66 CPP). ${ }^{926}$ Der anfängliche fundierte Anhaltspunkt (motivo fundado inicial), der in Art. 205 CPP enthalten ist, muss zu einer tatbezogenen Schlussfolgerung im Grad der Möglichkeit über die Begehung einer Straftat führen, da in dieser Phase mit den anfänglichen Ermittlungen versucht wird, grundsätzlich zu überprüfen, ob die angezeigte Tatsache und ihre Umstände die Charakteristika einer Straftat aufweisen, und zu untersuchen, ob die Strafklage und die Identifizierung und Individualisierung der Täter oder Teilnehmer der untersuchten Handlung zutreffen. Das Ziel dieser Vorermittlungen besteht darin, den rechtlichen Rahmen des Ereignisses, das Gegenstand der Ermittlung und des Prozesses sein wird, zu definieren. ${ }^{927}$ Daraus ergibt sich, dass die Information, auf der die Schlussfolgerung für ein mögliches Begehen einer Straftat beruht, nicht daran gebunden ist, eine bestimmte Person anzugeben. ${ }^{928}$

Fraglich ist, ob diejenigen notitia criminis, die über nicht als strafbar zu betrachtende Umständen informieren oder die nicht als objektive oder subjektive Elemente eines Tatbestandes angesehen werden können, Ermittlungstätigkeiten auslösen, bzw. notwendigerweise die Entwicklung von Ermittlungstätigkeiten auslösen können. Gemäß dem CPP wird das Ermittlungsverfahren eingestellt, wenn festgestellt wird, dass keine Gründe oder tatsächlichen Umstände vorliegen, die eine Charakterisierung als Straftat oder die mögliche Exis-

\footnotetext{
${ }^{926} \mathrm{Vgl}$ supra § 3. 1. I. c. i. Einleitung des Ermittlungsverfahrens; dazu Guerrero Peralta, 2007, S. 230 ff.; Bernal Cuellar/Montealegre Lynett, 2013 T. II, S. 83 ff.; KVerfG, Entsch. C-1177 v. 2005, Abschn. VI. 1. (La naturaleza de la denuncia como acto procesal); C-873 v. 2003, Abschn. 3.4.4.3. b. (i).

927 Bzgl. der Vorermittlung im CPP s. Avella Franco, 2007a, S. 61 ff.; vgl. supra § 3. A. II. 3. Ablauf des Ermittlungsverfahrens.

${ }^{928}$ Vgl. Fernández León, 2005, S. 24 ff.; KVerfG, Entsch. C-127 v. 2011, Abschn. „Consideraciones de la Corte“; C-1194 v. 2005, Abschn. VI. 3. 
tenz einer solchen erlauben (Art. 79 CPP). Das bedeutet zumindest, dass eine Bestätigung vorgenommen wird, in der die Überprüfung der Staatsanwaltschaft obliegt, je nach höherer oder minderer Wahrscheinlichkeit des Begehens der Straftat. Um zur Einstellung des Ermittlungsverfahrens in der Vorermittlung (archivo de la investigación) zu gelangen, muss die Schlussfolgerung über das Nichtvorhandensein der Tat oder eines Tatbestandes gezogen werden. ${ }^{929}$

Bzgl. der Funktion in der Vorermittlungsphase sind Anfangsverdacht und was wir hier motivo fundado inicial nennen, vergleichbar. Einerseits haben sie eine hohe Relevanz für das Verfahren gemeinsam, denn sie bilden die Parameter für das Auslösen der Ermittlung. ${ }^{930}$ Sowohl der Anfangsverdacht als auch der anfängliche fundierte Anhaltspunkt aktivieren die Erforschungspflicht. Andererseits beschneiden sie, in Übereinstimmung mit ihrer Verfahrensbedeutung, das Einschreiten bei Ermittlungen von Seiten der Ermittlungsbehörde. Im Falle des anfänglichen fundierten Anhaltspunktes des Art. 205 CPP lösen sie die Durchführung der sog. actos urgentes (dringende Handlungen) aus, so wie z.B. die Überprüfung am Tatort, Leichenschau, Befragungen und Vernehmungen, ${ }^{931}$ d.h. Aktivitäten, die auf Eigeninitiative der Kriminalpolizei bei der Vorermittlung durchgeführt werden und die auf Grund ihrer Transzendenz und besonderen Umstände ein sofortiges Einschreiten derselben notwendig machen. In keinem Fall wird die Durchführung von intensivem oder mittlerem Einschreiten in Grundrechte in Betracht gezogen; es handelt sich nur um Tätigkeiten, die zum Ziel haben, Informationen zusammenzutragen. ${ }^{932}$

Unter diesem letzten Gesichtspunkt ist es möglich, einen wichtigen Unterschied zwischen dem anfänglichen fundierten Anhaltspunkt und dem Anfangsverdacht zu finden. Aus dem anfänglichen fundierten Anhaltspunkt werden nur Tätigkeiten abgeleitet, die das Sammeln

\footnotetext{
${ }^{929}$ Art. 79 CPP: „Archivo de las diligencias. Cuando la Fiscalía tenga conocimiento de un hecho respecto del cual constate que no existen motivos o circunstancias fácticas que permitan su caracterización como delito, o indiquen su posible existencia como tal, dispondrá el archivo de la actuación.“ („Einstellung des Ermittlungsverfahrens. Sobald die Staatsanwaltschaft tatsächliche Kenntnis davon erhält, dass keine Gründe oder tatsächlichen Verhältnisse vorliegen, die die Charakterisierung einer Tatsache als ein Verbrechen erlauben oder deren mögliche Existenz als solche geben, wird das Ermittlungsverfahrens eingestellt.“ -dt. Übersetzung d. Verf.-).

${ }^{930}$ Vgl. supra § 8. C. I. Anfangsverdacht; dazu Satzger, FS Beulke (2015), S. 1009 ff.; Kotsoglou, 2015, S. 312 ff.; Ottow, 2014, S. 19 ff.; Haas, 2003, S. 31 f.; Ebert, 2000, S. 104 ff.

${ }^{931} \mathrm{Gem}$. Art. 205 CPP werden als dringende Handlungen Inspektion des Tatorts und von Orten, an denen Beweismaterial vermutet wird, Leicheninspektion, Interviews mit mutmaßlichen Opfern oder Zeugen eines Verbrechens verstanden.

${ }^{932}$ Vgl. FGN, 2005a, S. 19 ff.; FGN, 2005, S. 32; Bernal Cuellar/Montealegre Lynett, 2013 T. II, S. 57; bzgl. der Inspektion des Tatorts gem. CPP vgl. López Calvo, 2008, S. 65 ff.
} 
von Informationen fördern und keine Zwangsmaßnahmen, die das Einschreiten in Grundrechte bedeuten. In diesem Punkt ist der anfängliche fundierte Anhaltspunkt vergleichbar mit dem von der deutschen StPO genannten Vorverdacht, ${ }^{933}$ von dem aus Tätigkeiten entwickelt werden können, die dazu dienen, vage Elemente des Anfangsverdachts aufzuklären (informatorische Befragungen). Zusammenfassend kann gesagt werden, dass der hier so genannte anfängliche fundierte Anhaltspunkt im CPP dem Anfangsverdacht aus der StPO einerseits vergleichbar ist, was seine Funktion betrifft, denn beide stellen Parameter dar, von denen aus die Ermittlungskompetenzen ausgelöst werden, wenn sich aus der Information die Möglichkeit einer Straftat ableitet. Andererseits sind die auf der Grundlage des anfänglichen fundierten Anhaltspunktes und des Anfangsverdachts zu entwickelnden Maßnahmen unterschiedlich. Der CPP ermächtigt die Durchführung von Maßnahmen von geringer Eingriffsintensität, d.h. informatorische Befragungen im Rahmen der Vorermittlungen. ${ }^{934}$

\section{Wahrscheinlichkeitsgrad}

Der anfängliche fundierte Anhaltspunkt von Art. 205 Abs. 1 S. 1 CPP befasst sich nur mit einem möglichen Begehen einer Straftat als Voraussetzung für die Durchführung von dringenden Handlungen (actos urgentes). Ebenso wie beim Anfangsverdacht ist die Analyse der Ermittlungsbehörde auf die Bestimmung des Wahrscheinlichkeitsgrades der Begehung einer Straftat gerichtet. ${ }^{935}$ Durch seinen Anfangscharakter und dadurch, dass er nur ein Parameter für die Aktivierung der Informationssammlung zur Bestimmung der Umstände einer Straftat darstellt, kann die Wahrscheinlichkeit gering sein, d.h. es können sogar die Zweifel bzgl. des Vorliegens einer Straftat überwiegen. Mit dem Ziel, informatorische Befragungen oder dringende Handlungen zu beginnen, können Erfolgsprognosen - d.h. Prognosen, die die Wahrscheinlichkeit betreffen, einen Täter oder die Verurteilung desselben zu bestimmen - ausgeschlossen werden. Dies erklärt auch, dass der Beginn der Ermittlungsphase nicht mit dem effektiven Vorliegen oder der Bestimmung des möglichen Täters

\footnotetext{
${ }^{933}$ Im Schrifttum ist auch die Rede von einem „Vor-Verdächtigen“. Für die Begrenzung von Vorermittlungen und Vorverdacht vgl. Forkert-Hosser, 2011, S. 177 ff.; dazu auch Haas, 2003, S. 25; Schulz, 2001, S. 531 ff. ${ }_{934} \mathrm{Vgl}$. dazu supra § 8. C. I. 2. Anfangsverdacht und Vorermittlung.

935 Art. 205 Abs. 1 S. 1: „Actividad de policía judicial en la indagación e investigación. Los servidores públicos que, en ejercicio de sus funciones de policía judicial, reciban denuncias, querellas o informes de otra clase, de los cuales se infiera la posible comisión de un delito [...].“ („Tätigkeit der Kriminalpolizei in der Vorermittlung und Ermittlung. Beamte, die in Ausübung ihrer gerichtlichen Kriminalpolizeifunktionen Anzeigen, Beschwerden oder Berichte anderer Art erhalten, aus denen die Begehung eines Verbrechens folgt [...].“ -dt. Übersetzung d. Verf.-); s. auch Bernal Cuellar/Montealegre Lynett, 2013 T. II, S. 85. 
einhergeht. Das Nichtbestehen einer Akzessorietät zwischen dem anfänglichen fundierten Anhaltspunkt und den Prozessvoraussetzungen für die Erhebung der Beschuldigung oder Anklage wird dadurch offensichtlich, als die zumutbare Schlussfolgerung des anfänglichen fundierten Anhaltspunktes sich von den Zielen der Vorermittlungsphase unterscheidet. ${ }^{936}$ Der anfängliche fundierte Anhaltspunkt öffnet nur die Tür dazu, einen Schluss zu ziehen, ob die Erhebung der Beschuldigung notwendig ist oder nicht, d.h., ob ein fundierter Anhaltspunkt mit Inkulpationsgrad (motivo fundado inculpatorio) besteht. ${ }^{937}$ Diese letztere Frage wird erst dann entschieden, wenn die gesamte Wertung der Beweise der Vorermittlungen abgeschlossen ist.

In diesem Sinne ist der anfängliche fundierte Anhaltspunkt in Art. 205 CPP nur an eine retrospektive Diagnose bzgl. einer eventuell begangenen Straftat gebunden. Im Gegensatz zum Anfangsverdacht wird die verfahrensbezogene Prognose ausgeschlossen. Die Schlussfolgerung bzgl. einer möglicherweise begangenen Straftat bedeutet nur eine Wertung der Strafrelevanz der Straftat. Die Subsumption derselben stellt keine Voraussetzung für dringende Handlungen dar, sondern nur ein Element des methodologischen Ermittlungsprogramms (Art. 207 CPP), das die Entscheidung bzgl. der Einstellung der Ermittlungen (Art. 79 CPP), der Anwendung des Opportunitätsgrundsatzes (Art. 321 CPP) oder der Erhebung der Beschuldigung (Art. 286 CPP) begrenzt. In diesem Sinne werden nur bei der Planung eines methodologischen Programms über die Analyse der Existenz von Verfahrensvoraussetzungen - d.h. das Nichtvorhandensein von Prozesshindernissen wie z.B. Verjährung das Fehlen von Zuständigkeit für die Ermittlungen oder andere Gründe für das Erlöschen des Strafanspruchs diskutiert und bei der Einstellung der Ermittlungen vor dem JCG (Art. 79 CPP) entschieden. ${ }^{938}$ Die retrospektive Diagnose zur Feststellung eines anfänglichen fundierten Anhaltspunktes, d.h. die Schlussfolgerung bzgl. des Begehens einer Straftat, wird durch Elemente der vorläufigen Kenntnisnahme bestimmt. Es handelt sich nicht um hinreichende tatsächliche Anhaltspunkte, sondern um eine abstrakt-theoretische Annahme einer ungesicherten Möglichkeit, von der aus die Existenz eines relevanten Sachverhalts für das Strafrecht gesucht wird.

\footnotetext{
936 Vgl. supra § 3. A. I. 3. a. Ermittlungsverfahren; auch Guerrero Peralta, 2007, S. 230 ff.

${ }^{937}$ Bzgl. der Beschuldigung im CPP s. Bernal Cuellar/Montealegre Lynett, 2013 T. II S. 113; zu den täterbezogenen ,motivos fundados“ und dem Inkulpationsgrad s. infra § 9 C. I. 2. Inkulpationsgrad. Für die Begründung der Beschuldigteneigenschaft und des Inkulpationsverdachts in der StPO s. Ebert, 2000, S. $136 \mathrm{ff}$.

938 Vgl. KVerfG, Entsch. T- 520A/09, Abschn. 6; C-591 v. 2005, Abschn. 6. J.; dazu auch Bernal Cuellar/Montealegre Lynett, 2013 T. II, 93 ff. Für den Art. 79 CPP s. supra Fn. 929.
} 


\section{Bewertung der einleitenden Ermittlungsergebnisse}

\section{Das sog. ,programa metodológico“(Art. $207 \mathrm{CPP})$}

Die Ergebnisse der Ermittlung, die sich aus den dringenden Handlungen der Kriminalpolizei ergeben, werden der Staatsanwaltschaft mittels eines offiziellen Berichts (informe ejecutivo) vorgelegt (Art. 205 Abs. 3 CPP). Gemäß der Analyse dieser Information entwirft die Staatsanwaltschaft ein methodologisches Programm (programa metodológico) (Art. 207 CPP), in dem er die Straftathypothesen aufstellt, von denen aus Antworten auf die Fragen gefunden werden, ob eine Straftat vorliegt, wer sie begangen hat, wer mitbeteiligt war und welches die kognitiven Mittel sind, dies zu beweisen. ${ }^{939}$ Die Ausarbeitung des methodologischen Programms stellt einerseits eine Überprüfung des anfänglichen fundierten Anhaltspunktes dar, andererseits ist es das Szenarium für die Durchführung der täterund teilnehmerbezogenen Prognose, sowie auch der Prognose bzgl. der Beweiswahrscheinlichkeit und der Verfahrensvoraussetzungen. ${ }^{940}$ Das entworfene Programm muss die Bestimmung der Ziele in Bezug auf die Eigenschaft der Straftathypothese, die Evaluierungskriterien für die Information, die funktionale Abgrenzung der zum Erreichen der gestellten Ziele erstellten Aufgaben, das Kontrollvorgehen in der Durchführung der Maßnahmen und die Mittel zur Verbesserung der erhaltenen Ergebnisse enthalten (Art. 207 Abs. 2 CPP). ${ }^{941}$ Mit anderen Worten, das Programm grenzt die Ermittlungen ab, mit deren Ergebnissen die Straftathypothese bewiesen werden kann, d.h. die strukturellen Elemente des abgeleiteten Tatbestandes und die Verantwortlichkeit des vermeintlichen Täters.

Das methodologische Programm leitet die auf Grund von anfänglichen fundierten Anhaltspunkten (Art. 205 CPP) durch die dringenden Handlungen gesammelten Information weiter. Genauer gesagt, bringt der anfängliche fundierte Anhaltspunkt die Bestimmung der bezugnehmenden Information (información de referencia) mit sich, die die Erarbeitung des methodologischen Programms begründet. Zusätzlich zur bezugnehmenden Information

\footnotetext{
${ }^{939}$ Vgl. ausführlich Avella Franco, 2007, S. 17 ff.; s. auch FGN, 2005, S. 15.

${ }^{940} \mathrm{Zu}$ den grundlegenden Fragen des methodologischen Programms vgl. Avella Franco, 2007, S. 29 f.

${ }^{941}$ Art. 207 Abs. 2 CPP: „La determinación de los objetivos en relación con la naturaleza de la hipótesis delictiva; los criterios para evaluar la información; la delimitación funcional de las tareas que se deban adelantar en procura de los objetivos trazados; los procedimientos de control en el desarrollo de las labores y los recursos de mejoramiento de los resultados obtenidos.“ („,Die Bestimmung der Ziele in Bezug auf die Art der kriminellen Hypothese; die Kriterien für die Bewertung der Information; die funktionale Abgrenzung der durchzuführenden Aufgaben zur Erreichung der festgelegten Ziele; die Kontrollverfahren bei der Durchführung der Arbeit und Ressourcen zur Verbesserung der Ergebnisse“ -dt. Übersetzung d. Verf.-); vgl. dazu Avella Franco, 2007, S. 37 ff.
} 
werden mit dem methodologischen Programm gleichzeitig prospektive Prognosen bzgl. sachlicher, rechtlicher und Beweiskomponenten bestimmt, die sich aus der Straftathypothese ableiten. Diese Prognosen stellen die Begründung für die Planung der Ermittlungen dar, die darauf hinauslaufen, die Umstände bzw. Modus, Zeit und Ort des Geschehens der Tat zu bestimmen, die respektiven rechtlichen Subsumptionen, die die Beschuldigung (Art. 286 CPP) und die Anklage (Art. 336 CPP) begründen, zu leiten und die Schlussfolgerung und die Begründung der fundierten Anhaltspunkte, die die Ermittlungshandlungen stützen und legitimieren, zu erleichtern, um so mehr, wenn diese Einschränkungen der Grundrechte mit sich führen.

Auf diese Weise teilt sich das Wahrscheinlichkeitsurteil in der Vorermittlung in zwei Linien auf: in erster Linie die Durchführung einer retrospektiven Diagnose bzgl. des möglichen Begehens einer Straftat, die gleichzeitig zwei Niveaus aufweist: erstens in der Schlussfolgerung bzgl. des möglichen Begehens der Straftat (Art. 205 CPP) und zweitens mit der Unterordnung eines Sachverhalts unter einen Tatbestand (Subsumption), der aus der Straftathypothese für die Entwicklung des methodologischen Programms des Art. 207 CPP hervorgeht. In zweiter Linie die verfahrensbezogene Prognostik oder prospektive Diagnose über die verfahrens- und beweisrechtliche Durchführbarkeit der Ermittlung einer Straftat und die Ermittlung möglicher Täter oder Teilnehmer derselben. In diesem Sinne könnte man über ein graduelles Wahrscheinlichkeitsurteil in der Vorermittlungsphase sprechen, in der die prozessuale Prognose die zweite Phase derselben darstellt und mittels der Subsumption der Handlung in der Entwicklung des methodologischen Programms auf der Überprüfung der Information bzgl. des Begehens der Straftat aufbaut.

Bzgl. der zweiten Qualifikation (der zumutbaren fundierten Anhaltspunkte - motivos razonablemente fundados) ${ }^{942}$ stellt das methodologische Programm eine programmatische Grundlage der Bestandteile dar, die dieselben konstituieren. Erstens grenzt es die Gesamtheit der Tatsachen ab, von denen aus die sachliche Grundlage bestimmt wird, die die Maßnahmen mit Eingriff in Grundrechte stützen. Dies findet nicht nur mit der Überprüfung des Vorliegens einer Straftat statt (phänomenologische Bestätigung), sondern auch mit der Subsumption der Tatsachen unter einen Tatbestand, der die Wahl einer Strafhypothese

\footnotetext{
942 Vgl. dazu infra § 9. C. I. Begründungsgrad für die Anordnung von Grundrechtseingriffen: die sog. ,motivos razonablemente fundados" (Zweite Qualifikation).
} 
fordert. ${ }^{943}$ Zweitens bestimmt es die Kenntnis der Elemente, die die sachliche Grundlage begründen und zumutbare Schlussfolgerungen, wie die der Täterschaft oder Teilnahme (Inkulpationsgrad) (inferencias razonables de autoría o participación), oder andere Schlussfolgerungen, die im CPP vorgesehen sind, stützen. ${ }^{944}$ In diesem Bereich muss das methodologische Programm die Bestimmung und Projektion der Ermittlungsmaßnahmen vorgeben, die darauf abzielen, beweisrechtlich das Vorhaben vor dem JCG oder dem Gerichtsvorsitzenden zu bestehen. Es ergibt Sinn, dass die Durchführung dieses Vorgehens in der Vorermittlungsphase vonstatten geht, wenn die folgenden Ermittlungsmaßnahmen zumindest einen fundierten Anhaltspunkt im Inkulpationsgrad fordern, d.h. dass die belastenden Indizien gegenüber den Zweifeln bzgl. der Täterschaft oder Teilnahme des Verdächtigen überwiegen. ${ }^{945}$

\section{Maßnahmen im Rahmen der Vorermittlung}

Gemäß Art. 207 Abs. 3 kann die Staatsanwaltschaft für die Durchführung des methodologischen Programms Maßnahmen anordnen, die keinen Eingriff in Grundrechte mit sich bringen. Derselbe Art. 207 Abs. 3 legt als Ziel dieser Maßnahmen die Aufklärung des Sachverhalts, das Finden der materiellen Beweiselemente und der physischen Evidenz fest, ebenso wie die Individualisierung der Täter und Teilnehmer der Straftat, die Evaluierung und Quantifizierung des verursachten Schadens und die Hilfe und den Schutz der Opfer. ${ }^{946}$ Dieser Artikel legt zwei Einschränkungen bzgl. der autonomen Kompetenzen der FGN in dem methodologischen Programm fest. Einerseits werden sie auf jene Maßnahmen beschränkt, die keine Eingriffe in die Grundrechte bedeuten. In diesem Bereich können die Entgegennahme von Beschwerden, Strafanträgen, Beantragungen oder Berichte über Straf-

\footnotetext{
${ }^{943}$ Zur Begrenzung und Darstellung des Ermittlungsproblems vgl. Avella Franco, 2007, S. 37 ff. ${ }^{944}$ Vgl. infra § 10. B. II. 2. Zumutbare Schlussfolgerungen über das Vorhandensein von tauglicher Information.

945 Dazu infra § 9. C. I. 2. Inkulpationsgrad; bzgl. der Beschuldigungseigenschaft s. Guerrero Peralta, 2007, S. $258 \mathrm{ff}$.

946 Art. 207 Abs. 3 CPP: „En desarrollo del programa metodológico de la investigación, el fiscal ordenará la realización de todas las actividades que no impliquen restricción a los derechos fundamentales y que sean conducentes al esclarecimiento de los hechos, al descubrimiento de los elementos materiales probatorios y evidencia física, a la individualización de los autores y partícipes del delito, a la evaluación y cuantificación de los daños causados y a la asistencia y protección de las víctimas.“ („Bei der Entwicklung des methodologischen Programms der Ermittlung ordnet die Staatsanwaltschaft die Ausführung aller Tätigkeiten an, die Grundrechte nicht einschränken und geeignet sind, den Sachverhalt zu klären, materielle und physische Beweise zu erlangen, die Täter und Teilnehmer an der Straftat zu individualisieren, den Schaden zu bewerten und zu quantifizieren und die Opfer zu schützen“ -dt. Übersetzung d. Verf.-); vgl. dazu infra § 10. A. II. 2. Kritische Überlegung zu Beweismitteln gem. Art. 221 CPP und Fn. 1017.
} 
taten, Begleitung oder Überführung des Opfers für gerichtsmedizinische Untersuchung, Maßnahmen zur gerichtsmedizinischen Untersuchung oder Identifizierung von Opfern, Interviews mit mutmaßlichen Opfern oder Zeugen eines Verbrechens, Leicheninspektion, Befragung der Angeklagten in Anwesenheit eines Anwalts, Inspektion des Tatorts und von Orten, an denen Beweismaterial vermutet wird, Identifizierung, Sammlung und Spurensicherung, Suche und Zusammenstellung von Daten auf magnetischer oder mechanischer Basis und Aufzeichnung öffentlich zugänglicher Informationen durchgeführt werden. ${ }^{947}$ Andererseits führt sie grundsätzlich zur Durchführung von Vorermittlungsmaßnahmen, die dazu tendieren, die sachliche und Beweisgrundlage einzuschränken, sowohl in der Erhebung der Beschuldigung als auch der Anklage und in der Hauptverhandlung und der Individualisierung von Tätern und Teilnehmern. ${ }^{948}$ Dieser erste Bereich von Maßnahmen bedeutet eine weit gesteckte Autonomie sowohl der Kriminalpolizei als auch der Staatsanwaltschaft, da sie nicht vom JCG kontrolliert werden.

Trotz der in Art. 203 Abs. 3 vorgesehenen Einschränkungen, sieht der CPP die Möglichkeit vor, Grundrechtseingriffe mittlerer oder höherer Intensität in der Ermittlungsphase vorzunehmen, d.h. die Durchführung der von Art. 219 bis 250 CPP vorgesehenen Ermittlungsmaßnahmen. Dieses zweite Niveau von Ermittlungshandlungen unterteilt sich, wie schon erwähnt, in jene mit vorheriger und nachträglicher Kontrolle durch den JCG. ${ }^{949} \mathrm{Ob}-$ wohl es sich um eine Vorermittlungsphase handelt - d.h. vor der Erhebung der Beschuldigung - fordert der CPP bei jeder dieser Arten von Maßnahmen zumutbare fundierte Anhaltspunkte (zweite Qualifikation). In diesen Fällen würde es sich um fundierte Anhaltspunkte handeln mit einer Schlussfolgerung im Inkulpationsgrad bzgl. der Täterschaft oder Teilnahme oder Beweisgewinnung (hallazgo probatorio). ${ }^{950}$ Diese Art Maßnahmen sind sowohl für die Vorermittlung als auch für die Ermittlung im strikten Sinne vorgesehen und werden stets einer (vorherigen oder nachträglichen) Überprüfung des JCG unterzogen. Allerdings bedeutet die Durchführung dieser Maßnahmen in der Vorermittlungsphase, ein antizipiertes Einschreiten und schafft genaue Voraussetzungen für die Durchführung des-

\footnotetext{
947 Vgl. dazu Bernal Cuellar/Montealegre Lynett, 2013 T. II, S. 85 ff. Für die Auflistung der Maßnahmen in der Vorermittlung s. infra Anlage 2: Übersicht über den Ermittlungsmaßnahmen im kolumbianischen Strafverfahren.

${ }^{948}$ Avella Franco, 2007, S. 83, 100; Bernal Cuellar/Montealegre Lynett, 2013 T. II, S. 85 ff., 123 ff.

949 Vgl. Guerrero Peralta, 2006, S. 91 ff.; dazu supra § 4. B. Funktion und Aufgaben des Richters zur Kontrolle der Garantien.

${ }^{950}$ Bzgl. der Beweisgewinnung als Schlussfolgerung vgl. Zuluaga, NFP 83 (2015), S. 194 ff.; dazu infra § 10. B. II. 2. Zumutbare Schlussfolgerungen über das Vorhandensein von tauglicher Information.
} 
selben. Erstens, basierend auf Art. 155 und 237 CPP, werden Hausdurchsuchungen, Beschlagnahme der Korrespondenz, Abhören der Kommunikation, das Wiedererlangen von Informationen aus der Datenübermittlung, sowie auch die Überwachung und Verfolgung von Personen und Sachen der Kontrolle des JCG unterstellt, die als vertraulich angesehen werden muss, d.h. ohne die pflichtmäßige Anwesenheit der Verteidigung. ${ }^{951}$ Zweitens wird die Feststellung der zumutbaren fundierten Anhaltspunkte vor der Erhebung der Beschuldigung mit durchlässigeren Parametern durchgeführt als diejenigen der Ermittlung im strikten Sinne.

Die sowohl sachliche als auch rechtliche Erhebung der Beschuldigung impliziert eine Aufstellung von konkreten Tatsachen und eine bestimmte Subsumption der ermittelten Handlung, von der aus es sogar möglich ist, das Ausmaß der möglichen Strafe zu ermessen, mit dem Ziel, das Verfahren schon vorzeitig auf Grund des Geständnisses der Anklagepunkte einzustellen. ${ }^{952}$ Dieses Konkretionsniveau wird in dem Aufbau der zumutbaren fundierten Anhaltspunkte begründet, sowohl in seiner sachlichen als auch in seiner Beweisgrundlage und auf dem Wahrscheinlichkeitsniveau der Schlussfolgerungen im Inkulpationsgrad bzgl. der Täterschaft oder Teilnahme. ${ }^{953}$ Diese zweite Qualifikation betreffs der fundierten Anhaltspunkte würde mit Wahrscheinlichkeit vermuten lassen, dass der Beschuldigte eine Straftat begangen hat, d.h. es besteht die objektive und subjektive Überzeugung der Staatsanwaltschaft bzgl. der Täterschaft oder Teilnahme des Untersuchten an einer Straftat. Diese Schlussfolgerung ist fundierter, insofern derselben ein strikter Widerspruch der Verteidigung und eine Überprüfung der Beweisgrundlage durch den JCG vorausgeht. Jedoch ist dies nicht der Fall bei der Bestimmung der zumutbaren fundierten Anhaltspunkte in der Vorermittlung, in der die Beteiligung der Verteidigung und der entsprechende Widerspruch derselben nicht vorhanden sind und, auf der Grundlage dringender Ermittlungshandlungen oder anderer Tätigkeiten, infolgedessen eine schwache Schlussfolgerung im Inkulpationsgrad bzgl. der Täterschaft und Teilnahme gezogen wird. In diesem Sinne bedeutet die Feststellung der zumutbaren fundierten Anhaltspunkte in der Vorermittlungsphase eine gewisse Befreiung oder Flexibilisierung von denjenigen strikten Parametern der

\footnotetext{
${ }^{951}$ Krit. dazu Zuluaga, Co-Herencia Vol. 4 Nr. 6 (2007), S. 133 ff.; Rivera Loaiza, RDP 40, S. 121 ff.

952 Bernal Cuellar/Montealegre Lynett, 2013 T. II, S. 113 ff.; Guerrero Peralta, 2007. S 258 ff.

953 Vgl. KVerfG, Entsch. C-303 v. 2013, Abschn. 4; Bernal Cuellar/Montealegre Lynett, 2013 T. II, S. 125; Guererro Peralta, 2007, S. 265; Guerrero Peralta, 2006, S. 65 ff.; s. supra § 3. A. II. 3. b. Die Beschuldigung (Formulación de imputación). 
Feststellung, die ab der Erhebung der Beschuldigung beachtet werden müssen. ${ }^{954}$ Auf diese Weise könnte man zwischen flexiblen und strikten zumutbaren fundierten Anhaltspunkten (motivos razonablemente fundados flexibles y estrictos) unterscheiden, je nachdem, ob sie vor oder nach der Erhebung der Beschuldigung festgestellt wurden.

\section{Die täterbezogenen ,motivos fundados“6}

\section{Begründungsgrad für die Anordnung von Grundrechtseingriffen: die sog. „motivos razonablemente fundados“ (Zweite Qualifikation)}

\section{Vorbemerkung}

Das Bestehen einer zweiten Qualifikation der fundierten Anhaltspunkte im kolumbianischen Strafprozesssystem gründet sich auf vier Gesichtspunkte: die Intensität der von ihnen begründeten Zwangsmaßnahmen, die Ermittlungsbasis, die sie unterstützt, die gerichtliche Kontrolle durch den JCG und die Täterbezogenheit, die bei der Schlussfolgerung bzgl. der Täterschaft oder Teilnahme aufgestellt wird. Was die Intensität der Ermittlungsmaßnahmen betrifft, die diese zweite Qualifikation benötigen, ist das Vorhandensein von zumutbaren fundierten Anhaltspunkten ein notwendiges Erfordernis für das mittlere und intensive Einschreiten in die Grundrechte. Diese Unterscheidung von niedrigem, mittlerem und intensivem Grad des Einschreitens wurde, wie oben aufgezeigt, durch das KVerfG in dem Urteil C-822 von 2005 bestätigt. ${ }^{955}$ Da es sich um mittlere und hohe Grade handelte, wies das KVerfG darauf hin, dass das Prinzip des Richtervorbehalts respektiert werden müsse, d.h. dass die vorherige Anordnung des JCG nötig sei, außer in den von Art. $250 \mathrm{Nr}$. $2 \mathrm{CN}$ vorgesehenen Fällen wie Hausdurchsuchungen, Beschlagnahmen und Überwachung der Telekommunikationen. ${ }^{956}$ Diese Unterscheidung der verschiedenen Niveaus beim Einschreiten in Grundrechte besagt nicht nur, dass das intensive Einschreiten eine strikte gerichtliche Kontrolle benötigt, sondern auch eine strikte Begründung. ${ }^{957}$ Dieses Begrün-

\footnotetext{
${ }^{954}$ Dazu Zuluaga, Co-Herencia Vol. 4 Nr. 6 (2007), S. 140.

955 Vgl. KVerfG, Entsch. C-822 v. 2005, Abschn. 5.1.; dazu supra § 7. B. II. Entscheidung C-822 de 2005 KVerfG.

${ }^{956}$ Art. 250 Nr. 2 CN: „Adelantar registros, allanamientos, incautaciones e interceptaciones de comunicaciones. En estos eventos el juez que ejerza las funciones de control de garantías efectuará el control posterior respectivo, a más tardar dentro de las treinta y seis (36) horas siguientes.“ („2. Durchführung von Hausdurchsuchungen, Beschlagnahmen und Überwachung und Aufzeichnung von Kommunikationen. In diesen Fälle erfolgt eine nachträgliche Überprüfung durch den JCG innerhalb der folgenden 36 Stunden.“ -dt. Übersetzung d. Verf.-).

957 Vgl. dazu supra § 7. B. III. Entscheidung C-336 von 2007 KVerfG; zugunsten einer vorherigen Anordnung der Maßnahmen, die eine mittlere oder intensive Eingriffe in Grundrechte durchführen vgl. Bernal
} 
dungsniveau ist sowohl das Ergebnis der Forderung nach zumutbaren fundierten Anhaltspunkten für die Anordnung der Maßnahmen als auch der Ausübung der Überprüfung und des Widerspruchs zwischen den Parteien in der Anhörung der Kontrollinstanz vor dem JCG. In diesem Sinne kann von einer Eingriffstheorie gesprochen werden, von der die Intensität des Einschreitens, die Dimension des fundierten Anhaltspunktes und das Niveau bzw. die Art und Weise der gerichtlichen Kontrolle der Maßnahmen bestimmt werden. Dies ergibt einen wichtigen Unterschied zu der Eingriffstheorie, die sich um das Konzept des Tatverdachts der StPO gebildet hat, wo die Intensität des Einschreitens oder der Zwangsmaßnahme einen wesentlichen Parameter zur Bestimmung des konkreten Verdachtsgrades darstellt. ${ }^{958}$

In dem von der Lehre entworfenen Schema bzgl. des mittleren und intensiven Einschreitens in Grundrechte sind die zumutbaren fundierten Anhaltspunkte feststehende Parameter. Die Begründung einer Maßnahme wäre ein dynamischer Prozess in der Anhörung der Kontrollinstanz, der darauf hinausliefe, den von der Staatsanwaltschaft im Antrag für die Genehmigung oder Bestätigung der als von mittlerer oder hoher Intensität verstandenen Ermittlungsmaßnahmen vorgetragenen fundierten Anhaltspunkt zu bestätigen bzw. zu überprüfen. Die Begründung der Forderung nach zumutbaren fundierten Anhaltspunkten befindet sich in den Artikeln des CPP, die die Ermittlungsmaßnahmen mit oder ohne vorherige Kontrolle des JCG regeln. ${ }^{959}$ Einerseits finden sich die Maßnahmen mit Anordnung der FGN und nachträglicher Kontrolle durch den JCG: Hausdurchsuchungen (Art. 220 CPP), Überwachung und Aufzeichnung von Kommunikationen (Art. 233 CPP), Wiederbeschaffung von Informationen (Art. 236 CPP), Personenüberwachung (Art. 239 CPP), Überwachungsmaßnahmen an Sachen (Art. 240 CPP), Analyse und Infiltrierung krimineller Organisationen (Art. 241 CPP), Einsatz verdeckter Ermittler (Art. 242 CPP) und verdeckte Überwachung von Transport, Verkauf, Vermietung von Waffen, Sprengstoff, Munition, Falschgeld und Drogen (Art. 243 CPP). Außerdem werden die Maßnahmen geregelt, welche der Anordnung durch den JCG bedürfen: Körperliche Untersuchungen (Art. 247 CPP) und Durchsuchungen von Personen (Art. 248 CPP). Auch das Vorliegen der zumutbaren fundierten Anhaltspunkte ist ein Erfordernis für die Anordnung der Untersuchungs-

Cuellar/Montealegre Lynnet, 2013, T. I, S. 383; s. auch KVerfG, Entsch. C-156 v. 2016, Abschn. VI Abs. 33 ff.

958 Vgl. Zabel ZIS 7-8/2014, S. 341; Steinberg JZ 21 (2006), S. 1048 f.; Fincke, ZStW 95 (1983), S. 927; dazu supra § 8. B. Tatverdacht in StPO.

${ }^{959}$ Vgl. infra Anlage 2: Übersicht über den Ermittlungsmaßnahmen im kolumbianischen Strafverfahren. 
haft (Art. 297 CPP). In all diesen Fällen handelt es sich um intensives Einschreiten in die Grundrechte des Verdächtigen.

Dieses Niveau der fundierten Anhaltspunkte muss, wie oben erwähnt, strikt durch Beweismaterial unterstützt werden. ${ }^{960}$ Diese Unterstützung geht zunächst aus vorhergehenden Tätigkeiten hervor, wie zum Beispiel präventive Ermittlungen oder dringende Maßnahmen. ${ }^{961}$ In diesem Sinne erfüllen der einfache Rückverweis auf Vorgehen der Kriminalpolizei am Tatort, die vagen Referenzen auf die Erklärung eines Informanten ohne jegliche andere Bestätigungsart, Anmerkungen, die sich auf die einfache Existenz von Elementen des Beweismaterials gegen den Verdächtigen beziehen, nicht die Anforderungen, die an die Unterstützung der fundierten Anhaltspunkte per Beweismaterial gestellt werden. ${ }^{962}$ Diese Forderung nach unterstützenden Beweisen der fundierten Anhaltspunkte bezieht sich auf einen objektiven Parameter in Art. 221 CPP, wo festgelegt wird, dass die fundierten Anhaltspunkte zumindest durch einen Bericht der Kriminalpolizei, eine beeidigte Erklärung eines Zeugen oder Informanten oder durch Beweismaterial und glaubhafte physische Evidenz unterstützt werden müssen. Die Forderung einer strikten Unterstuitzung durch Beweise ist der Grund dafür, dass der JCG bei der Anhörung durch die Kontrollinstanz keinerlei Restriktion beim Zugang zu den Quellen unterliegt, die die besagte Unterstützung darstellen, so wie es durch das KVerfG festgelegt ist. ${ }^{963}$

Ein hohes Begründungsniveau könnte durch einen strikten Widerspruch von den fundierten Anhaltspunkten ausgeübt werden, die eine Ermittlungsmaßnahme unterstützen. Nur auf diese Art und Weise könnte von einer strikten Begründung gesprochen werden, so wie sie bei schwerem Einschreiten in Grundrechte gefordert wird, das eine Anordnung in einer vorherigen Anhörung vor dem JCG für die Maßnahme erfordert. In diesen Fällen wird nach der h.M. eine zweifache Kontrolle gefordert ${ }^{964}$ : für die Anordnung der Maßnahme und die Überprüfung der Durchführung derselben. Somit erfordert ein schweres Einschreiten ein striktes Begründungsniveau. Andererseits könnte man von einer flexibleren Begründung sprechen, zu dem die Anhörungen zu einer nachträglichen Kontrolle führen, wie

\footnotetext{
960 Vgl. supra § 7. C. III. Beweisunterstützung für „,motivos fundados“.

961 Guerrero Peralta, 2007 S. 343; Bernal Cuellar/Montealegre Lynett, 2013, T. II, S. 124.

962 Vgl. dazu infra § 10. A. II. Die Beweisgrundlageproblematik gemäß Art. 221 CPP.

963 Vgl. supra § 7. B. I. Entscheidung C-673 von 2005 KVerfG. 2. Rechtmäßigkeitskontrolle seitens des JCG. 964 Vgl. Zuluaga, NFP 83 (2015), S. 186; Morales Támara, 2009, S. 239; Guerrero Peralta, 2007, S. 377 f. (Zugunsten einer doppelten Kontrolle als eine Lösung für die Abwesenheit der Verteidigung in der Vorermittlung).
} 
sie Art. 250 Nr. 2 CN für bestimmte Maßnahmen vorsieht, die schwere Eingriffe in Grundrechte sowie Hausdurchsuchungen, Beschlagnahme und Überwachung der Telekommunikationen implizieren. Insofern diese Maßnahmen weder die vorherige Kontrolle von Seiten des JCG bedeuten, noch die Möglichkeit des Widerspruchs gegen die Maßnahme durch die Verteidigung im Falle der Anhörungen von Art. 155 und 237 CPP, wäre das Anforderungsniveau der Begründung für die Anordnung der Maßnahme von Seiten der Staatsanwaltschaft als weit gefasst oder niedrig zu bezeichnen. Diese Begründung kann als Ergebnis der Kontrollausübung und des Widerspruchs in der nachträglichen Kontrollanhörung Änderungen unterliegen. Wie oben bemerkt, ist die Begründung einer Maßnahme ein $d y$ namischer Prozess, der von der Bestimmung des fundierten Anhaltspunktes (statischer Parameter) und der richterlichen Kontrollinstanz und dem Widerspruch derselben (dynamischer Parameter) abhängt. Das Begründungsniveau kann als Ergebnis der Kontrollinstanz und des Widerspruchs zwischen den Parteien abnehmen oder angehoben werden. In jedem Fall kann jedoch nur eine strikte Begründung zu einer Anordnung oder richterlichen Bestätigung einer Ermittlungsmaßnahme führen, da es sich um mittlere oder schwere Eingriffe in Grundrechte handelt. ${ }^{965}$

Eine strikte Begründung muss zumindest zu einer Schlussfolgerung im Inkulpationsgrad führen, d.h. zu einer angemessenen Schlussfolgerung bzgl. der Täterschaft oder Teilnahme in der ermittelten Straftat. Diese Schlussfolgerung wird bei der Anordnung von Ermittlungsmaßnahmen mit mittlerem oder intensivem Eingreifen in Grundrechte gefordert, wie z.B. Hausdurchsuchungen (Art. $220 \mathrm{CPP}$ ), so wie auch für Verfahrensmaßnahmen wie die Erhebung der Beschuldigung (Art. 287 CPP), als Voraussetzung für Festnahmen von Seiten des JCG (Art. 297 CPP), für außergewöhnliche Festnahmen auf Grund von Anordnung der FGN (Art. 300 CPP) und für die Anordnung von Sicherheitsmaßnahmen durch den JCG (Art. 308 CPP). Im Hinblick auf die Ziele der Ermittlungsmaßnahmen entwickelt der CPP eine Regelung von zumutbaren Schlussfolgerungen, d.h. der CPP definiert gegenüber jeder Maßnahme die Deduktion, zu der die fundierten Anhaltspunkte führen müssen, die jeden Antrag zur Anordnung oder Bestätigung von Ermittlungsmaßnahmen unterstützen. In einigen Fällen betreffen die geforderten Schlussfolgerungen die Täterschaft oder Teilnahme, in anderen Fällen fordert der CPP, dass diese zweite Qualifikation der fundierten Anhaltspunkte zu Schlussfolgerungen betreffs Gewinnung von Beweismaterial führt, d.h.

${ }^{965}$ Vgl. Zuluaga, NFP 83 (2015), S. 181; KVerfG, Entsch. C-822 v. 2005, Abschn. 5.1.; dazu infra § 10. A. III. 2. a. Diskussionsbasis eines restriktiven Ansatzes. 
nur zu der Schlussfolgerung zu gelangen, dass für die Ermittlung nützliche Information gefunden wird. ${ }^{966}$ Im Weiteren wird erläutert werden, dass z.B. in den Art. 233, 234, 235 , 239, 240 CPP gefordert wird, dass sich die Schlussfolgerung ergebe, dass nützliche und relevante Information für die Ermittlung vorliegt (,se infiera que existe información útil “). Auch Art. 236 CPP handelt davon, dass eine Schlussfolgerung auf einer sicheren Tatsache (,inferir un hecho cierto“) besteht, wie z.B. die Übermittlung von Daten. Als weiteres Beispiel sei Art. 241 CPP genannt, der fordert, dass die Schlussfolgerung zu ziehen ist, dass der Verdächtige oder Beschuldigte mit einer kriminellen Organisation in Verbindung steht. $^{967}$

\section{Inkulpationsgrad}

Als fundierte Anhaltspunkte im Inkulpationsgrad können diejenigen bezeichnet werden, in denen gefordert wird, dass die zumutbare Schlussfolgerung dazu führt, dass der Verdächtigte oder Beschuldigte Täter oder Teilnehmer der untersuchten Straftat ist. Im Bereich der Ermittlungsmaßnahmen mit mittleren oder schweren Eingriffen in Grundrechte beinhaltet nur Art. 220 diese Forderung der zumutbaren Schlussfolgerung. Gemäß Art. 220 kann nur dann eine Anordnung für eine Hausdurchsuchung erfolgen, wenn zumutbare fundierte Anhaltspunkte vorliegen, die darauf schließen lassen, dass der Eigentümer oder einfache Inhaber des zu registrierenden Gutes, der sich zeitweise darin aufhält, möglicher Täter oder Teilnehmer der Straftat ist. ${ }^{968}$ Nach der h.M. sucht der CPP mit der Schlussfolgerung bzgl. der Täterschaft und Teilnahme eine zumutbare Folgerung bzgl. des objektiven (Verhalten) und subjektiven Charakters (Täterschaft und Teilnahme) der ermittelten Straftat aufzuzeigen, d.h. eine Schlussfolgerung, in der die belastenden Anhaltspunkte sich über die Zweifel bzgl. einer kausalen Beziehung zwischen der Handlung oder dem Unterlassen des Verdächtigen oder Beschuldigten mit einem rechtlich relevanten Ergebnis erheben. ${ }^{969}$

Die zumutbare Schlussfolgerung, die dem fundierten Anhaltspunkt Beschuldigungsdichte verleiht, setzt ein normatives Element ein, und zwar die Bestimmung des Wahrscheinlichkeitsgrads der Täterschaft oder Teilnahme des Verdächtigen an einer Straftat. Ein Teil der Meinungen vertritt in Bezug auf die Bestimmung dieses Elements, dass ,,alle Faktoren herangezogen werden, die das Strafgesetz im Zusammenhang mit der Tat, dem Unterlassen

\footnotetext{
966 Vgl. dazu Zuluaga, NFP 83 (2015), S. 194 ff.

967 Vgl. infra $§ 10$. B. Ziele der zumutbaren Schlussfolgerungen.

${ }^{968}$ Für den Wortlaut des Art. 220 CPP vgl. supra Fn. 437.

${ }^{969}$ Bernal Cuellar/Montealegre Lynett, 2013, T. II, S. 125; Guerrero Peralta, 2007, S. 265.
} 
oder der direkten oder indirekten Durchführung einer Strafhandlung in Betracht zieht sowie vorherige Abkommen, die Relevanz des Beitrags zu einem strafrechtlich zurechenbaren Erfolg und der Beitrag zur rechtswidrigen Handlung. “970 Diese Haltung scheint idealistischen Charakter zu haben, wenn man bedenkt, dass diese Art Analyse unmöglich durchführbar ist, wenn z.B. eine Hausdurchsuchung während der Vorermittlung vollzogen wird. Wie oben erwähnt finden die fundierten Anhaltspunkte und ihre respektiven zumutbaren Schlussfolgerungen in dieser Phase grundsätzlich ihre Unterstützung in Elementen, die auf vorherige Kenntnisnahmen zurückgreifen, die oftmals das Ergebnis von dringenden Maßnahmen sind. Die Konsequenz wäre, dass eine Wertung all dieser normativen Komponenten überflüssig sein würde.

Als Beweisgrundlage dieser normativen Komponente findet der CPP, wie schon erwähnt, einen objektiven Parameter in Art. 221, d.h. in einem Bericht der Kriminalpolizei, beeidigter Aussage eines Zeugen oder Informanten, Beweismaterial und physischer Evidenz. ${ }^{971}$ Jedoch ist ein Teil der Doktrin der Meinung, dass die Beweisvoraussetzungen, um eine Schlussfolgerung der Täterschaft oder Teilnahme zuzurechnen auch mit Art. 207 CPP in Einklang gebracht werden müssen. Hierunter fallen alle Aktivitäten, die zur Durchführung des methodologischen Programms dienen. ${ }^{972}$ In diesem Sinne finden Ermittlungen statt, die keine (mittleren oder schweren) Einschränkungen der Grundrechte bedeuten, Maßnahmen, die keine vorherige richterliche Anordnung für die Durchführung benötigen und Eingriffe, die einer vorherigen Kontrolle durch den JCG bedürfen. Unter dieser Voraussetzung könnte die Schlussfolgerung im Inkulpationsgrad einen Rückhalt in intensiven Eingriffen finden, so wie z.B. alle diejenigen, die ex ante oder ex post vom JCG kontrolliert werden. Wie im nächsten Kapitel aufgezeigt werden wird, steht dieses Eingriffsniveau in der Vorermittlungsphase in vollkommenem Gegensatz zu den Zielen dieser Phase. ${ }^{973}$

Diese Haltung zeigt sich noch kontroverser, wenn die Schwierigkeit berücksichtigt wird, die besteht, um die Rechtmäßigkeit dringender Handlungen, wie z.B. die Interviews oder

\footnotetext{
970 Bernal Cuellar/Montealegre Lynett, 2013, T. II, S. 127: „todos los factores que considera la ley penal en el contexto de la acción, omisión, la realización directa o mediata de una conducta punible, los acuerdos previos, la importancia del aporte con respecto a un resultado jurídicamente imputable y las contribuciones a la conducta antijurídica." (dt. Übersetzung d. Verf.). Darüber hinaus wären die Erweiterungen des Tatbestandes nach den Art. 27 und 31 des kolumbianischen Strafgesetzbuchs anzuwenden.

${ }^{971}$ Vgl. dazu KVerfG, Entsch. C-673 v. 2005; Guerrero Peralta, 2007, S. 343 f.

972 Vgl. Bernal Cuellar/Montealegre Lynett, 2013, T. II, S. 126; s. infra § 10. A. II. 1. b. Auslegung i.V.m. Art. 207 CPP.

${ }^{973} \mathrm{Vgl}$. infra § 10. B. II. 3. Kritische Überlegung zu Schlussfolgerungen im CPP. 
Vernehmungen oder mittlere oder schwere Eingriffe mit nachträglicher Kontrolle des JCG in der Vorermittlung zu überprüfen. In vielen dieser Ermittlungshandlungen sieht der CPP nicht die Aufzeichnung schriftlicher Äußerungen vor, mit denen die Berücksichtigung der Grundrechte des Verdächtigen bestätigt werden könnte. ${ }^{974}$ Somit wären ohne Beweisunterstützung zur Überprüfung alle diejenigen Handlungen unverwertbar, in denen der Person ihr Recht auf Nichtaussage nicht übermittelt wurde oder die erhaltene Information durch einen Betrug erlangt wurde. In diesem Sinne wäre die Entwicklung der mittleren oder schweren Eingriffe zur Gewinnung von Beweismaterial, nur mit dem Ziel, diese Art von Schlussfolgerungen zu unterstützen, grundsätzlich unverhältnismäßig, auch wenn die Ermittlungen dazu dienen können, eine minimale objektive oder subjektive Überzeugung bzgl. der Täterschaft oder Teilnahme zu befriedigen.

\section{Wahrscheinlichkeitsgrad}

Die Bestimmung des Wahrscheinlichkeitsgrades (der Täterschaft, Teilnahme oder Beweisgewinnung), der der zweiten Qualifikation der fundierten Anhaltspunkten immanent ist, basiert auf verschiedenen Faktoren. Einerseits hängt sie von dem geforderten Typ der zumutbaren Schlussfolgerung (inferencia razonable) ab. Jede Ermittlungsmaßnahme beinhaltet spezifische zumutbare Schlussfolgerungen, die voneinander zu unterscheiden sind, um festzustellen, welcher Wahrscheinlichkeitsgrad sich mit jeder Schlussfolgerung verbindet. In diesem Sinn erscheint als relevant die Unterscheidung zwischen Schlussfolgerungen, die eine Inkulpation oder eine Beweisgewinnung zur Folge haben, die an diese zweite Qualifikation der fundierten Anhaltspunkte gebunden sind. ${ }^{975}$ Andererseits hängt die hohe Wahrscheinlichkeit in jeder Schlussfolgerung jeweils von dem Beweismaterial ab, auf das sich die fundierten Anhaltspunkte stützen, obwohl jede Maßnahme konkrete zumutbare Schlussfolgerungen beinhaltet. ${ }^{976}$ Aus diesem Grund kann sich die Durchführung eines Wahrscheinlichkeitsurteils auf unterschiedliche Weise gestalten, je nachdem, ob es sich um Maßnahmen in der Vorermittlungs- oder Ermittlungsphase handelt. In jedem Fall muss eine Überzeugung bzgl. des Vorliegens einer strafrechtlich relevanten Tatsache und die Charakterisierung derselben als Tatbestand vorliegen, d.h. der Wahrscheinlichkeitsgrad, der die Schlussfolgerung von Art. $205 \mathrm{CPP}^{977}$ beinhaltet, kann nicht derselbe sein, um die

\footnotetext{
974 Bernal Cuellar/Montealegre Lynett, 2013, T. II, S. 126.

975 Vgl. Zuluaga, NFP 83 (2015), S. 194 ff.; s. infra § 10. B. Ziele der zumutbaren Schlussfolgerungen.

976 Vgl. dazu Bernal Cuellar/Montealegre Lynett, 2013, T. II, S. 126 f.

977 Vgl. supra § 9. B. I. „Motivo fundado inicial“ (Erste Qualifikation).
} 
Maßnahmen, die diese zweite Qualifikation der fundierten Anhaltspunkte implizieren, zu rechtfertigen. Dies ist zu verstehen, solange die objektive Situation oder sachliche Grundlage der fundierten Anhaltspunkte für die Anordnung von mittleren oder schweren Eingriffen in Grundrechte einen höheren Wahrscheinlichkeitsgrad erreicht, um der Genehmigung dieser Eingriffe zumindest dringende Maßnahmen vorausgehen zu lassen, die eine bessere Konkretisierung oder Abgrenzung der sachlichen Grundlage schaffen. Bzgl. der fundierten Anhaltspunkte im Inkulpationsgrad bestätigt die h.M., dass diese sich im Bereich des Wahrscheinlichkeitsgrades bewegen und dass sie zu einer minimalen objektiven und subjektiven Überzeugung bzgl. der Täterschaft oder Teilnahme des Verdächtigen einer Straftat führen. ${ }^{978} \mathrm{Zu}$ dieser Anerkennung kommen ihre Vertreter durch die Analyse der zumutbaren Schlussfolgerung, die zur Erhebung der Beschuldigung führt (Art. 287 CPP). ${ }^{979}$ Jedoch wird nicht darüber diskutiert, ob derselbe oder ein anderer Überzeugungsgrad vorliegen muss, wenn es um die Schlussfolgerung betreffs des Art. 220 geht, der die Grundlagen für eine Hausdurchsuchung beinhaltet. Die Angelegenheit hat keine erhebliche Transzendenz, wenn diese Maßnahme während der Ermittlung im strikten Sinn durchgeführt wird, da diese Tatsache bedeutet, dass die Beschuldigung schon erhoben wurde. Das Problem besteht in der Anordnung der Hausdurchsuchung in der Vorermittlungsphase. Während der Anordnung der Maßnahme grundsätzlich nur dringende (vorherige) Maßnahmen vorausgehen, ist das Überzeugungsniveau oder die Inkulpationswahrscheinlichkeit geringer als in der Erhebung der Beschuldigung. In diesem Sinne kann behauptet werden, dass der CPP eine Unterscheidung in der Wahrscheinlichkeit der Schlussfolgerungen im Inkulpationsgrad vorsieht: ein niedriges Niveau für den Fall von Art. 220 CPP und ein gehobeneres Niveau für die Erhebung der Beschuldigung gemäß Art. 287 CPP.

Die Problematik stellt sich schwieriger dar, wenn sie vom Gesichtspunkt der fundierten Anhaltspunkte angegangen wird, von denen aus die Möglichkeit der Beweisgewinnung gefolgert werden muss. Diese Art von Schlussfolgerungen werden detailliert im nächsten Kapitel analysiert, ${ }^{980}$ es können jedoch schon von vornherein einige Ausgangspunkte der Analyse angekündigt werden. Die Möglichkeit der Entdeckung eines Beweises muss in-

\footnotetext{
978 Bernal Cuellar/Montealegre Lynett, 2013, T. II, S. 128 und Fn. 16 m.w.N.; Guerrero Peralta, 2007, S. 265 mit Abl. der Erfolgsprognosekriterien.

979 Vgl. dazu KVerfG, Enstch. C-1194 v. 2005, Abschn. 3; Vanegas Villa, 2007, S. 49 ff.; Guerrero Peralta, 2007, S. supra § 3. A. II. 3. b. Die Beschuldigung (Formulación de imputación).

${ }^{980} \mathrm{Vgl}$. infra § 10. B. II. 2. Zumutbare Schlussfolgerungen über das Vorhandensein von tauglicher Information. 
nerhalb der Grenzen eines Wahrscheinlichkeitsurteils geschehen, d.h. das Wahrscheinlichkeitsurteil muss auf der Analyse der Angemessenheit der Maßnahme aufbauen. Da es sich um fundierte Anhaltspunkte handelt, deren Schlussfolgerungen mittlere oder schwere Eingriffe in Grundrechte rechtfertigen, im Sinne des „dringenden Tatverdachts“, müssen die belastenden Anhaltspunkte überwiegen. In diesem Sinne muss die Anordnung der Maßnahme auch von einer Schlussfolgerung im Inkulpationsgrad unterstützt werden, wenn die Maßnahme in der Phase der Vorermittlung durchgeführt werden soll. Ebenso muss eine hohe Wahrscheinlichkeit im Bereich des dringenden Tatverdachts in der StPO aus der Tatsache abzuleiten sein, dass die untersuchte Straftat im Hauptverfahren bewiesen wird und dass der Verdächtigte verurteilt werden kann (prospektive Prognose).

\section{II. „Motivos fundados“ für die Erhebung der Anklage (Dritte Qualifikation)}

Eine dritte Qualifikation der fundierten Anhaltspunkte findet sich in Art. 336 CPP, in dem die Voraussetzungen für die Erhebung der Anklage aufgeführt sind. ${ }^{981}$ In diesem Artikel wird die zumutbare Schlussfolgerung der Täterschaft oder Teilnahme, die für die Erhebung der Beschuldigung notwendig ist, mit einer höheren Qualifikation eingeführt, d.h. einer strikteren deduktiven Schlussfolgerung, die vom CPP als Wahrheitswahrscheinlichkeit (probabilidad de verdad) bezeichnet wird. Dieser Erkenntnisgrad ist höher als das Überzeugungsniveau, das die Schlussfolgerung der Täterschaft oder Teilnahme für die Erhebung der Beschuldigung oder die Durchführung von Hausdurchsuchungen unterstellt, da keine zumutbare Schlussfolgerung, sondern eine Wahrheitswahrscheinlichkeit gefordert wird. So wie bei den anderen Qualifikationen der fundierten Anhaltspunkte muss die objektive Situation oder sachliche Grundlage dieses Wahrscheinlichkeitsurteils mittels Beweismaterial unterstützt werden, der rechtmäßig erlangten physischen oder informativen Evidenz. Gemäß Art. 337 CPP befindet sich unter den Voraussetzungen für die Erhebung der Anklage die konkrete Individualisierung der Angeklagten, die klare Aufzählung der rechtlich relevanten Tatsachen, sowie auch die Vorlage von Beweismitteln. Mit der Ankla-

\footnotetext{
981 Art. 336 CPP: „Presentación de la acusación. El fiscal presentará el escrito de acusación ante el juez competente para adelantar el juicio cuando de los elementos materiales probatorios, evidencia física o información legalmente obtenida, se pueda afirmar, con probabilidad de verdad, que la conducta delictiva existió y que el imputado es su autor o partícipe.“ („Erhebung der Anklage. Die Staatsanwaltschaft wird die Anklage vor dem zuständigen Gericht zur Durchführung der Hauptverhandlung erheben, wenn aus dem rechtmäßig erlangten Beweismaterial, den physischen Beweisen oder Informationen mit Wahrheitswahrscheinlichkeit gesagt werden kann, dass das kriminelle Verhalten existierte und dass der Beschuldigte Täter oder Teilnehmer ist.“ -dt. Übersetzung d. Verf.-)
} 
ge muss erreicht werden, mit Wahrheitswahrscheinlichkeit zu bestätigen, dass die Straftat durchgeführt wurde und dass der Angeklagte deren Täter oder Teilnehmer ist.

\section{Täter- und Tatbezogenheit}

Voraussetzung für die Erhebung der Anklage ist zum einen die konkrete Individualisierung der Angeklagten und zum anderen eine klare Auflistung der rechtlich relevanten Tatsachen. Was das erste Erfordernis betrifft, so wird darunter verstanden, dass die Angeklagten individuell aufgeführt werden, wenn in der Anklageschrift ihre Namen, alle Angaben zur Identität und die Anschrift für Zustellungen von Ladungen aufgeführt sind. ${ }^{982}$ Dies bedeutet, dass die Anklage grundsätzlich eine Bestätigung der Beschuldigung ist, aber mit einer strikteren Beweisgrundlage. Mit anderen Worten: die konkrete Individualisierung des Angeklagten ist eines der Kriterien, um die Wahrscheinlichkeit einer Verurteilung zu bestimmen. ${ }^{983}$ Was das zweite Erfordernis betrifft, so wird darunter eine klare Auflistung der rechtlich relevanten Tatsachen verstanden, wenn die sachliche und rechtliche Zurechnung des Verhaltens dem Angeklagten mitsamt einer Beschreibung der zeitlichen, modalen und örtlichen Umstände, unter denen die Tat verübt wurde, durchgeführt wird. ${ }^{984}$ Bzgl. der Auflistung der Tatsachen wird darüber diskutiert, welche die Implikationen der Beschreibung der Tatsachen sind, sowohl in der Festlegung des Verfahrensgegenstandes als auch in Bezug auf den Widerspruch gegen die Beweise. ${ }^{985}$

Bzgl. der rechtlich relevanten Tatsachen wird einerseits darauf hingewiesen, dass die FGN in der Durchführung der Anklage oftmals die Auflistung der rechtlich relevanten Tatsachen mit der Beschreibung der vor der Anklage stattgefundenen Ermittlungstätigkeit verwechselt. Nah der h.M. handelt es sich nicht um einen Bericht über die Art und Weise, wie die FGN die Information über die Straftat und die damit verbundenen Ermittlungsmaßnahmen erhielt, sondern es handelt sich vielmehr um eine Ausführung der Tatsachen, die

\footnotetext{
982 Art. 337 Nr. 1 CPP: „La individualización concreta de quiénes son acusados, incluyendo su nombre, los datos que sirvan para identificarlo y el domicilio de citaciones.“ (Die konkrete Identifizierung derjenigen, die beschuldigt werden, einschließlich ihrer Namen, die nützlichen Daten zur Identifizierung und die Anschrift für die Entgegennahme einer Ladung zu einer Gerichtsverhandlung“ “-dt. Übersetzung d. Verf.-); vgl. dazu Bernal Cuellar/Montealegre Lynett, 2013, T. II, S. 767.

${ }^{983}$ Bernal Cuellar/Montealegre Lynett, 2013, T. II, S.767; Guerrero Peralta, 2007, S. 291.

984 Art. 337 Nr. 2 CPP: „Una relación clara y sucinta de los hechos jurídicamente relevantes, en un lenguaje comprensible.“ („Eine klare und kurze Darstellung der rechtlich relevanten Fakten in verständlicher Sprache.“ -dt. Übersetzung d. Verf.-); vgl. Urbano Martínez, 2011, S. 2244 f.; Guerrero Peralta, 2007, S. 291. 985 Vgl. Avella Franco, 2007a, S. 127; Bernal Cuellar/Montealegre Lynett, 2013, T. II, S. 768 und Fn. 8 m.w.N. 
der Beschuldigungserhebung und der Beweisgrundlage, die dieselbe bestätigt und so zur Anklage führt, zugrunde liegen. ${ }^{986}$ Auf der anderen Seite wird auch darauf hingewiesen, dass es sich um Tatsachen handeln muss, mit denen die Voraussetzungen der strafrechtlichen Haftung gestützt werden. Dies würde bestätigen, dass die für die Grundlegung der Anklage sachlich unnötigen oder unzutreffenden Annahmen ausgeschlossen werden, jedoch verlangt ein Teil der Lehre, dass auch das für den Angeklagten entlastende Beweismaterial der Verteidigung zur Verfügung gestellt werden sollte. ${ }^{987}$

Die sachliche und subjektive Anbindung, die die Wahrscheinlichkeitsableitung unterstützt, ist mit einigen Wahrscheinlichkeitskomponenten vergleichbar, die mit dem hinreichenden Tatverdacht der StPO in Verbindung stehen. Aus den Tatsachen, die bestätigt werden sollen, muss ohne Zweifel die objektive und subjektive Tatbestandsmäßigkeit hervorgehen und begründet werden. Wie im Folgenden erläutert werden wird, muss die Auflistung der Tatsachen sowohl in der dritten Qualifikation der fundierten Anhaltspunkte als auch im hinreichenden Tatverdacht im Hauptverfahren beweisbar sein, d.h. es muss eine prädominante Wahrscheinlichkeit der Beweisbarkeit der Zurechnung vorliegen. ${ }^{988}$ Dies wird von dem Erfordernis von Art. 337 CPP unterstützt, eine Vorlage der Beweismittel durchzuführen, wodurch intendiert wird, nicht nur die Beweisdebatte abzugrenzen, sondern auch alle Beweismittel einzusetzen, mit denen die FGN ihren Anklageanspruch aufrecht erhalten und das Verteidigungsrecht gewährleistet werden kann.

\section{Wahrscheinlichkeitsgrad}

Die Wahrheitswahrscheinlichkeit (probablilidad de verdad) ist der in Art. 336 CPP enthaltene Ausdruck, um sich auf das Überzeugungsniveau zu beziehen, das bzgl. des Vorliegens der Straftat und der Täterschaft oder Teilnahme des Verdächtigen vorhanden sein muss. Die h.M. unterscheidet sie von dem Konzept der zumutbaren Schlussfolgerung und bezeichnet sie als einen höheren Kenntnisgrad, vergleichbar einem logischen Schlussfolgerungsurteil mit einem Grad der Zumutbarkeit, der ab der Beschuldigungserhebung entwickelt wird. ${ }^{989}$ Auch in Kolumbien ist die Wahrheitswahrscheinlichkeit verbunden mit der Wahrscheinlichkeit der Verurteilung (probabilidad de condena). Ein Teil der Meinungen

\footnotetext{
${ }^{986} \mathrm{Vgl}$. Urbano Martínez, 2011, S. 225; bzgl. der richterlichen Kontrolle der Anklage vgl. Urbano Martínez, 2013, S. $77 \mathrm{ff}$.

${ }^{987}$ Avella Franco, 2007a, S. 97; KVerfG, Entsch. C-1194 v 2005; zugunsten der Ablehnung undurchsichtiger Anklagen Bernal Cuellar/Montealegre Lynett, 2013, T. II, S. 768.

${ }^{988}$ Bernal Cuellar/Montealegre Lynett, 2013, T. II, S. 766; Pava Lugo, 2009, S. 32

989 Suarez, Principia Iuris 16 (2011), S. 312; Bustamante Rúa, Opin. jurid. vol. 9 no. 17 (2010), S. 71.
} 
erkennt an, dass die Staatsanwaltschaft zur Bestimmung dieser Wahrheitswahrscheinlichkeit überprüfen muss, ob die sachlichen Voraussetzungen alle Rechtserfordernisse in sich vereinen, damit sie als Straftat angeklagt werden können, um daraus ein hohes Überzeugungsniveau abzuleiten, dass am Ende des Verfahrens eine Verurteilung erzielt werden wird. In diesem Sinne wird behauptet, dass ein Übereinstimmen von Wahrscheinlichkeiten erforderlich ist, d.h. die Durchführung der Straftat beweisbar sein muss und die Überzeugung des Richters vorliegen bzgl. der Elemente, die die Strafbarkeit der Handlung begründen, so wie das Fehlen von Verfahrenshindernissen hoch wahrscheinlich sein müssen. ${ }^{990}$

Derselbe CPP fordert eine Diskussion dieser Erfordernisse für die Anklage. Gemäß Art. 339 CPP muss der Anhörung der Erhebung der Anklage die Diskussion über das Vorliegen von Unzuständigkeit des Gerichts, Prozesshindernisse, Ablehnung des Erkenntnisrichters, Nichtigkeit von Prozesshandlungen oder anderer Bemerkungen, die bzgl. der Anklageschrift bestehen, vorausgehen. Auch muss die Staatsanwaltschaft in dieser Anhörung das Beweismaterial, die physische Evidenz oder rechtmäßig erhaltene Information, die er im Hauptverfahren geltend machen will (Vorlage der Beweismittel - descubrimiento de prueba), bezeichnen. ${ }^{991}$ In diesem Sinne wird diese dritte Qualifikation in einem hohen Wahrscheinlichkeitsgrad gehalten, d.h. in einer Verurteilungswahrscheinlichkeit, einem Grad, der in der Anhörung der Anklageerhebung bestätigt wird. In dieser Anhörung wird überprüft, ob keine Prozesshindernisse bestehen und die Existenz des Beweismaterials bestätigt, das den Antrag der Staatsanwaltschaft begründet. Das Erfordernis eines strikten oder hohen Wahrscheinlichkeitsniveaus beschleunigt die Eröffnung des Hauptverfahrens und bestimmt den Gegenstand desselben. In diesem Sinne - ebenso wie beim hinreichenden Tatverdacht - wird, wenn eine der Komponenten des Wahrscheinlichkeitsurteils nicht das positive Übergewicht erlangt, auch das Wahrscheinlichkeitsniveau nicht erreicht bzw. nicht die Überprüfung in der Anhörung der Anklageerhebung bestanden.

\footnotetext{
990 Bernal Cuellar/Montealegre Lynett, 2013, T. II, S. 766, der feststellt, dass es eine Strecke zwischen der Überzeugung der Staatsanwaltschaft und der Wahrheitswahrscheinlichkeit gibt, die schwer zu befahren ist.

${ }^{991}$ Art. 339 CPP: „Abierta por el juez la audiencia, ordenará el traslado del escrito de acusación a las demás partes; [...] para que expresen oralmente las causales de incompetencia, impedimentos, recusaciones, nulidades, si las hubiere, y las observaciones sobre el escrito de acusación [...].“(„Bei der Eröffnung der Anhörung wird der Richter die Übertragung der Anklage an die anderen Parteien anordnen [...], damit sie mündlich mögliche Unzuständigkeitsgründe des Gerichts, Prozesshindernisse, Ablehnungsgründe des Erkenntnisrichters, Nichtigkeit von Prozesshandlungen oder andere Bemerkungen bzgl. der Anklageschrift ausdrückenvorbringen“ -dt. Übersetzung d. Verf.-); vgl. dazu KVerfG, Entsch. C-1194 v. 2005, Abschn. 5; CSJ, Rad. 25920, Entsch. v. 21.02.2007, Abschn. „Consideraciones de la Corte“.
} 


\section{Zusammenfassung}

Ausgehend vom Verdachtsbegriff der StPO können konkrete Aspekte der Doktrin der motivos fundados in Kolumbien beleuchtet werden, besonders die der Einordnung, Bestimmung und der Funktion im Ermittlungsverfahren. Es können drei Stufen oder Grade bei den motivos fundados im CPP unterschieden werden. Eine erste Qualifikation wird in Art. 205 CPP gefunden. Der anfängliche fundierte Anhaltspunkt (motivo fundado inicial) muss zu einer tatbezogenen Schlussfolgerung im Grad der Möglichkeit über die Begehung einer Straftat führen. Der anfängliche fundierte Anhaltspunkt aktiviert die Erforschungspflicht und löst die Durchführung der sog. actos urgentes (dringenden Handlungen) aus. Im Unterschied zum Anfangsverdacht werden aus dem anfänglichen fundierten Anhaltspunkt nur Tätigkeiten abgeleitet, die die Sammlung von Informationen fördern und keine Zwangsmaßnahmen, die das Einschreiten in Grundrechte bedeuten. In diesem Punkt ist der anfängliche fundierte Anhaltspunkt vergleichbar mit dem sog. Vorverdacht. Die Wahrscheinlichkeit kann gering sein, d.h. es können sogar die Zweifel bzgl. des Vorliegens einer Straftat überwiegen, weshalb Erfolgsprognosen ausgeschlossen werden können. Das Bestehen einer zweiten Qualifikation der fundierten Anhaltspunkte im kolumbianischen Strafprozesssystem gründet sich auf vier Gesichtspunkte: die Intensität der von ihnen begründeten Zwangsmaßnahmen, die Ermittlungsbasis (base probatoria), die sie unterstützt, die gerichtliche Kontrolle und die Täterbezogenheit. Diese Forderung nach unterstützenden Beweisen der fundierten Anhaltspunkte bezieht sich auf einen objektiven Parameter in Art. 221 CPP. In diesen Fällen wird nach h.M. eine zweifache Kontrolle gefordert: für die Anordnung der Maßnahme und die Überprüfung der Durchführung derselben. Eine strikte Begründung muss zumindest zu einer Schlussfolgerung im Inkulpationsgrad führen. Eine dritte Qualifikation der fundierten Anhaltspunkte befindet sich in Art. 336 CPP, in dem die Voraussetzungen für die Erhebung der Anklage aufgeführt sind. In diesem Artikel wird die zumutbare Schlussfolgerung der Täterschaft oder Teilnahme, die für die Erhebung der Beschuldigung notwendig ist, mit einer höheren Qualifikation eingeführt, d.h. einer strikteren deduktiven Schlussfolgerung, die vom CPP als Wahrheitswahrscheinlichkeit (probabilidad de verdad) bezeichnet wird. In diesem Sinne wird behauptet, dass ein Übereinstimmen von Wahrscheinlichkeiten erforderlich ist: die Durchführung der Straftat muss beweisbar sein und die Überzeugung des Richters bzgl. der Elemente, die die Strafbarkeit der Handlung begründen, vorliegen, des Weiteren muss das Fehlen von Verfahrenshindernissen hoch wahrscheinlich

sein. 


\section{$\S 10$. Probleme der Kontrolle von „,motivos fundados“ durch den JCG}

\section{A. Beweisgrundlage der ,motivos fundados“}

\section{Problemstellung}

Wie oben aufgeführt, beruht eine der Voraussetzungen für die Bestimmung eines fundierten Anhaltspunktes darin, dass die Tatsachenseite (base fáctica) oder objektive Situation, aus der sich eine zumutbare Schlussfolgerung ableiten lässt, über eine durch den CPP im Bereich zugelassener Erkenntnismittel vorgesehene Beweisgrundlage verfügt. ${ }^{992}$ Jedoch ist die vom CPP definierte und entwickelte Forderung nach einer Beweisgrundlage in mehrerer Hinsicht problematisch. In erster Hinsicht erscheint im CPP keine Generalklausel, die verständlich macht, mit welchen Erkenntnismitteln ein fundierter Anhaltspunkt mit Beweisgrundlage festgestellt werden soll und wie das Vorgehen bei der Feststellung desselben aussieht. Nur in Art. 221 CPP wird eine Vorschrift für die Beweisgrundlage (regla para el respaldo probatorio) der fundierten Anhaltspunkte eingeführt, die grundlegend für die von Art. 220 CPP geforderte Anordnung der Hausdurchsuchung ist. ${ }^{993}$ In diesem Sinne wird darüber diskutiert, ob die in Art. $221 \mathrm{CPP}$ aufgeführte Vorschrift Allgemeingültigkeit gegenüber anderen vom CPP vorgesehenen Ermittlungsmaßnahmen hat, d.h. ob Art. 221 CPP über eine extensive Anwendung auf andere Regelbeispiele verfügt, die die Forderung nach fundierten Anhaltspunkten beinhalten. Ein Teil der Doktrin richtet sich nach dieser Auslegung und erkennt Art. 221 CPP als objektiven Parameter für die Beweisgrundlage der fundierten Anhaltspunkte an. ${ }^{994}$ Bei der Infragestellung dieser Auffassung dreht es sich um die Frage, ob Art. 221 CPP als ausreichender Parameter für die Beweisgrundlage gegenüber anderen Zwangsmaßnahmen in dem Ermittlungsverfahren angesehen werden kann. D.h., es wird erörtert, ob der Bericht der Kriminalpolizei und die eidesstattliche Erklärung von Zeugen oder Informanten, die im Art. $221 \mathrm{CPP}$ als grundlegend für die Beweisgrundlage der fundierten Anhaltspunkte aufgeführt werden, als angemessene und effektive Erkenntnismittel für die Aufrechterhaltung der fundierten Anhaltspunkte angesehen werden können, die andere vom CPP vorgesehene Ermittlungsmaßnahmen stützen.

\footnotetext{
${ }^{992}$ Vgl. KVerfG, Entsch. C-637 v. 2005, Abschn. VI. 3; dazu supra § 7. C. III. Beweisunterstützung für „,motivos fundados".

993 Vgl. dazu supra § 7. B I. 1. Reichweite des Art. 221 CPP; krit. der Wortlaut von Art. 221 Fernández León, 2005, S. 61.

${ }^{994}$ Vgl. Pava Lugo 2009, S. 36 ff.; Guerrero Peralta, 2007, S. 343 ff.
} 
In zweiter Hinsicht wird das Verfahren für die Wertung von Seiten des JCG der Erkenntnismittel, die die Beweisgrundlage der fundierten Anhaltspunkte stützen, in Frage gestellt. Genauer gesagt, wird darüber diskutiert, ob der JCG eine Beweisprognose über die Eignung der Erkenntnismittel durchführen soll, damit diese als Beweis in der Hauptverhandlung dienen und eine Verurteilung stützen können. Teils wird die Notwendigkeit der Durchführung einer derartigen Beweisprognose abgestritten, und zwar mit dem Argument, dass die Ermittlungsmaßnahmen zu dem Zweck stattfinden, einen höheren Wahrscheinlichkeitsgrad in Bezug auf die Klärung von Sachverhalten und die Täterschaft oder Teilnahme des Verdächtigen zu erreichen. ${ }^{995}$ Trotz dieser bestehenden Meinung enthält der Art. 221 CPP doch eine bestimmte Wahrscheinlichkeitsstufe. So kann der Artikel derart verstanden werden, als darin verankert ist, dass die Erkenntnismittel mit Wahrscheinlichkeit (verosimilitud) eine zumutbare Schlussfolgerung festlegen müssen oder zumindest einige ihrer Elemente, was für den Fall von Art. 221 CPP die Forderung nach der Anbindung des zu durchsuchenden Gutes mit dem ermittelten Delikt wäre. Dieses Wahrscheinlichkeitserfordernis ist auch einer doppelten Überprüfung unterworfen ${ }^{996}$, sowohl durch den FGN, als auch in der Kontrollanhörung von Seiten des JCG. In diesem Sinne wird in Frage gestellt, was unter Wahrscheinlichkeit verstanden wird und ob Erkenntnismittel wie die eidesstattliche Erklärung von Zeugen und der Bericht der Kriminalpolizei zu dieser Wahrscheinlichkeitsstufe führen können.

Innerhalb der Diskussionen über die extensive Anwendung von Art. 221 CPP konzentrieren sich zweifellos und mit substantieller Gewichtigkeit die wichtigsten Probleme auf die Beweisgrundlage der fundierten Anhaltspunkte. Angesichts dieser Feststellung wird hier einerseits versucht die Grenzen der durch Art. 221 CPP festgelegten konstitutionell extensiven Anwendung abzustecken. Andererseits werden kritische Überlegungen angestellt, und zwar in Bezug auf die Fähigkeit der Erkenntnismittel, so wie die eidesstattliche Erklärung von Zeugen und der Bericht der Kriminalpolizei, um die zumutbaren fundierten Anhaltspunkte (zweite Qualifikation) zu stützen. In Verbindung mit diesen kritischen Anmerkungen werden Bedingungen erörtert, um die Forderung nach der in Art. 221 CPP verankerten Beweisgrundlage zu verstehen. Es wird also versucht zu begründen, warum die Beweis-

\footnotetext{
995 I.d.S. Pava Lugo, 2009, S. 37, mit Abl. der Wahrscheinlichkeitsprüfung von Erkenntnismitteln zur Anordnung von Ermittlungsmaßnahmen.

996 Vgl. Guerrero Peralta, 2007, S. 343 f.; dazu supra § 7. B I 2 Rechtmäßigkeitskontrolle des JCG. 
grundlage der zumutbaren fundierten Anhaltspunkte strikt sein und wie die Wahrscheinlichkeit auf einer Stufe mit Vorrang von Indizien bestimmt werden muss.

\section{Die Beweisgrundlageproblematik gemäß Art. 221 CPP}

\section{Meinungsstand zum Art. 221 CPP}

Artikel 221 CPP befindet sich im 2. Band des CPP, Titel I, Kapitel II, wo die Regelungen der Maßnahmen, die keine richterliche Anordnung vor ihrer Durchführung benötigen (Actuaciones que no requieren autorización judicial previa para su realización), enthalten sind, d.h. diejenigen, von denen Art. 250 Nr. 2 CN handelt, wie Hausdurchsuchungen, Beschlagnahmen und Überwachung und Aufzeichnung von Kommunikationen. ${ }^{997}$ Insbesondere regelt dieser Artikel die Beweisgrundlage der fundierten Anhaltspunkte für die Ausstellung eines Hausdurchsuchungsbefehls für Gebäude, Werk- oder Flugzeughallen, um Beweismaterial und physische Evidenz zu erlangen oder die Festnahme des Verdächtigen, Beschuldigten oder Verurteilten zu bewirken. Wie schon erwähnt, müssen die Erkenntnismittel im Sinne von Art. 221 CPP, die die fundierten Anhaltspunkte stützen, zu der Schlussfolgerung führen, dass der Besitzer oder der einfache Inhaber des zu durchsuchenden Gutes wahrscheinlich Täter oder Teilnehmer des betreffenden Delikts ist, der sich vorübergehend darin aufhalten könnte; oder dass sich in seinem Inneren die Instrumente befinden, mit denen die Straftat begangen worden ist oder die Produkte derselben. ${ }^{998}$

Im Rahmen der Erfordernisse für die Ausstellung des Hausdurchsuchungsbefehls erfüllt die Forderung der Beweisgrundlage der fundierten Anhaltspunkte eine doppelte Funktion. Einerseits ist sie das Scharnier, das die Verbindung zwischen dem zu durchsuchenden Gut und dem untersuchten Delikt herstellt. In diesem Sinne erfüllt sie eine hinweisende Funktion (función demostrativa), die in der Determinierung der Verbindung zwischen dem Gegenstand einer Ermittlungsmaßnahme und der zu ermittelnden Straftat besteht. Bei dieser

\footnotetext{
997 Vgl. ausführlich supra $§$ 5-6. Nachträglicher Rechtsschutz gegen Maßnahmen zur Beschränkung der Intimität, der Unverletzlichkeit der Kommunikation und der Freiheit; dazu auch Escalante Barreto, $2011, \mathrm{~S}$. 171 ff.; Bernal Cuellar/Montealegre Lynett, 2013 T. II, S. 254 ff.; FGN, 2005, S. 34.

998 Art. 221 CPP: „Los motivos fundados de que trata el artículo anterior deberán ser respaldados, al menos, en informe de policía judicial, declaración jurada de testigo o informante, o en elementos materiales probatorios y evidencia física que establezcan con verosimilitud la vinculación del bien por registrar con el delito investigado.“ („Die im vorherigen Artikel genannten fundierten Anhaltspunkten müssen mindestens durch einen Bericht der Kriminalpolizei, eine beeidigte Zeugenaussage oder materielle Beweismittel oder physische Nachweise, die die Verbindung zwischen dem zu durchsuchenden Objekt und dem zu ermittelnden Delikt wahrscheinlich machen, gestützt sein.“ -dt. Übersetzung d. Verf.-).
} 
Maßnahme muss die Beweisgrundlage der fundierten Anhaltspunkte dazu führen, den Maßnahmegegenstand mit der ermittelten Straftat zu verbinden. Andererseits wird durch die notwendige Beweisbarkeit der in Art. 221 CPP angesprochenen Verbindung eine spezifische (präventive) Schutzfunktion aufgebaut, mithilfe derer versucht wird, unnötige Hausdurchsuchungen zu verhindern. Mit anderen Worten, es wird erreicht, bestimmte rechtliche und faktische Bereiche, die keine Verbindung mit einer zu ermittelnden Straftat haben, vor willkürlichen Eingriffen zu schützen. ${ }^{999}$ Diese doppelte Funktion konkretisiert gleichzeitig die Schutzfunktion von Rechten, die den fundierten Anhaltspunkten inhärent sind, bzw. der Forderung nach der Begründung einer Ermittlungsmaßnahme.

Allerdings wurde die Diskussion über die Leistung bzgl. des Rechtsschutzes, die der Forderung einer Beweisgrundlage der fundierten Anhaltspunkte innewohnt, vornehmlich ausgehend von dem Kontrast mit dem Prinzip eines fairen Verfahrens geführt. Auf dieser Diskussionsbasis wurden die hauptsächlichen Interpretationen von Art. 221 CPP vorgenommen. Zunächst einmal auf Grund des Urteils C-673 von 2005, in dem das KVerfG Art. 221 CPP auf seine Verfassungsmäßigkeit hin analysiert. Zweitens ist man auf Grund der Frage nach der Gültigkeit bzw. Tauglichkeit der Erkenntnismittel, welche die fundierten Anhaltspunkte mit Beweisen stützen, zu einer zusätzlichen Interpretation von Art. 221 CPP gelangt. Im Folgenden werden beide Ansätze vorgestellt, auf deren Grundlage eine kritische Stellungnahme auf der Suche nach einer verfassungsrechtlich gültigen Interpretation des Art. 221 CPP erörtert wird.

\section{a. Ansatz des KVerfG}

Der Ansatz des KVerfG bzgl. Art. 221 CPP wurde, wie oben analysiert, im Urteil C-637 von 2005 aufgegriffen. ${ }^{1000}$ Einige Anmerkungen dieses Urteils sind für das Verständnis des Problems der Beweisgrundlage der fundierten Anhaltspunkte relevant. Erstens hält das KVerfG die Forderung nach der Beweisgrundlage für die fundierten Anhaltspunkte für einen Hausdurchsuchungsbefehl für verfassungsrechtlich vertretbar. Gemäß dem KVerfG ist die Beweisgrundlage eine Art Gegenpart oder hat abschreckenden Charakter gegenüber der staatsanwaltschaftlichen Willkür. Diesbezüglich setzt das Gericht die Beweisgrundlage mit einer Garantie für die Durchführbarkeit der Ermittlungsmaßnahme gleich. ${ }^{1001}$ Der Be-

\footnotetext{
${ }^{999}$ Vgl. Bernal Cuellar/Montealegre Lynett, 2013 T. II, S. 24, 54 f.; Guerrero Peralta, 2007, S. 344.

1000 Vgl. supra § 7. B I. Entscheidung C-673 von 2005 KVerfG. Für eine kritische Stellungnahme s. Fernández León, 2005, S. 61.

${ }^{1001}$ KVerfG, Entsch. C-637 v. 2005, Abschn. VI. 3.

308
} 
griff „Durchführbarkeit“ (viabilidad) kann sowohl als Substantiv verstanden werden, d.h. als Voraussetzung für die Rechtfertigung des Hausdurchsuchungsbefehls, als auch im prozessualen Sinn, sei es für die Durchführung der Ermittlungsmaßnahme als auch für Kontrollen von Seiten des JCG, „damit der Richter an eine Information gelangen kann, die es ihm erlaubt, eine effektive Rechtskontrolle auszuüben."1002 Zweitens befasst sich das KVerfG mit der Verfahrensbedeutung der Erkenntnismittel, mit denen die Beweisgrundlage eines fundierten Anhaltspunkts geschaffen wird. Hiermit wird wiederum die Funktionalität der Anhörung zur Kontrolle der Rechtmäßigkeit angesprochen, da festgelegt wird, dass für die Staatsanwaltschaft und den JCG kein eingeschränkter Zugang zu den Beweismitteln, mit denen die fundierten Anhaltspunkte gestützt werden, bestehen darf. ${ }^{1003}$ Dieser umfassende Zugang muss zu einem doppelten (faktischen und rechtlichen) Urteil führen, von dem aus bestimmt oder festgestellt werden muss, ob ein Eingriff in Grundrechte besteht.

Dieser Ansatz des KVerfG grenzt teilweise die Diskussion über den verfassungsrechtlichen Sinn und die Verfahrensentwicklung der Beweisgrundlage der fundierten Anhaltspunkte ein. Einerseits erkennt das KVerfG eine präventive Funktion bzgl. des Schutzes der Rechtssphäre an, die Gegenstand eines Eingriffs durch eine Hausdurchsuchung ist, insofern anerkannt wird, dass mit der Forderung nach der Beweisgrundlage das Ermessen der Staatsanwaltschaft eingeschränkt wird. Andererseits setzt das KVerfG die Art und Weise, wie in der ursprünglichen Fassung des Art. 221 CPP sowohl die Öffentlichkeitsgarantie als auch der Widerspruchsgrundsatz bzgl. der Erkenntnismittel, mit denen ein fundierter Anhaltspunkt gestützt wird, wiedergegeben wurden, in eine neue Dimension. Dieser Ansatz des KVerfG bzgl. Art. $221 \mathrm{CPP}$ lehnt sich teilweise an eine teleologische Auslegung an, von der aus das KVerfG anerkennt, dass es der Wille des Gesetzgebers war, die eidesstattliche Erklärung eines Zeugen oder Informanten mit einer gewissen Formalität zu umgeben, und er der Auffassung war, dass dies der Verfassung entsprach, da die Formalitäten „der durch den Zeugen oder Informanten vermittelten Information Ernsthaftigkeit und Glaubwürdigkeit verleihen, auf der Grundlage derselben die Staatsanwaltschaft ein Verfahren ausarbeitet, das auf der Hausdurchsuchung beruht, d.h. auf der Entscheidung, eine rest-

1002 Vgl. KVerfG, Entsch. C-637 v. 2005, Abschn. VI. 3. (,,a fin de que el juez pueda acceder a una información que le permita realizar un efectivo control de legalidad.“) (dt. Übersetzung d. Verf.).

${ }^{1003}$ KVerfG, Entsch. C-637 v. 2005, Abschn. VI. 3. 
riktive Maßnahme eines Grundrechts zu befehlen und durchzuführen." ${ }^{1004}$ In diesem Sinne wird in Übereinstimmung mit dem Willen des Gesetzgebers anerkannt, dass die Bedingung zur Erstellung eines von Art. 221 CPP geforderten Wahrscheinlichkeitsgrades in der Formalität der Erklärung oder Aussage liegt. Zusätzlich wurde die Möglichkeit der Zeugenvernehmung oder -erklärung zur Überprüfung der Glaubwürdigkeit der Erkenntnismittel eingeführt. ${ }^{1005}$

Obwohl mit dieser Interpretation die Wichtigkeit der Glaubwürdigkeit der Erkenntnismittel zur Feststellung des von Art. 221 CPP geforderten Wahrscheinlichkeitsgrades gestützt wird, entwickelt das KVerfG keine strikte Interpretation der Garantien bzgl. der Öffentlichkeit und des Widerspruchs, sondern macht Zugeständnisse zu gewissen Einschränkungen diesbezüglich. Das KVerfG betrachtet die Tatsache, dass „,eine eidesstattliche Erklärung von Zeugen bei der Erteilung eines Hausdurchsuchungsbefehls dem Widerspruchsprinzip unterstellt wird, ohne dass die Beschuldigung eines Verdächtigen oder des Informanten erhoben wurde“, ${ }^{1006}$ als eine Einschränkung der Effektivität der strafrechtlichen Verfolgung. Das KVerfG rechtfertigt den Vorbehalt des Zeugen und Informanten gegenüber der Verteidigung, wenn der Befehl zur Maßnahme vor der Erhebung der Beschuldigung stattfindet. Dieser letzte Teil der Betrachtungen des KVerfG scheint im Widerspruch zur ersten Stufe zu stehen, auf der der uneingeschränkte Zugriff der Staatsanwaltschaft und des JCG auf die Erklärung von Zeugen oder Informanten verteidigt wurde. Außerdem werden die Verteidigung und die Widerspruchsmöglichkeit in einen Risikofaktor für die Sicherheit der Zeugen oder Informanten verwandelt. In diesem Sinne wird nicht anerkannt, dass die Einschränkung des Rechts auf Verteidigung in der Vorermittlungsphase die Leistung des Verfahrens einschränkt, und zwar in Bezug auf die Verhältnismäßigkeit der Maßnahme und gleichzeitig der Analysen bzgl. des Beweisverwertungsverbots.

In diesem letzten Sinne relativiert das KVerfG die teleologische und systematische Interpretation des Art. 221 CPP, denn durch diese Auslegung wird nicht anerkannt, dass Art.

${ }^{1004}$ KVerfG, Entsch. C-637 v. 2005, Abschn. VI. 3.: „Seriedad y confiabilidad a la información suministrada por el testigo o informante, con base en la cual el fiscal elaborará un juicio sobre la procedencia de un registro y allanamiento, esto es, sobre la decisión de decretar y practicar una medida restrictiva del ejercicio de un derecho fundamental.." (dt. Übersetzung d. Verf.).; dazu auch KVerfG, Entsch. C-806 v. 2009, Abschn. VI. 5.; Bernal Cuellar/Montealegre Lynnet, 2013, T. II S. 259; Guerrero Peralta, 2007, S. 344.

1005 KVerfG, Entsch. C-637 v. 2005, Abschn. VI. 3.

${ }^{1006}$ KVerfG, Entsch. C-637 v. 2005, Abschn. VI. 3.: „someter al principio de contradicción una declaración jurada de testigo cuando se da la orden de allanamiento y registro sin haberse formulado la imputación, o la del informante." (dt. Übersetzung d. Verf.). 
221 CPP eine direkte Beziehung zu anderen Regelungen über die Beweisgrundlage der fundierten Anhaltspunkte hat. Außerdem widerspricht die Rechtfertigung des Nichtvorhandenseins des Widerspruchs vor der Beschuldigungserhebung einem konsolidierten Ansatz in der Rechtsprechung. In anderen Urteilen hatte das KVerfG sich dahingehend ausgesprochen, dass das Recht auf Verteidigung, bzw. dass die Beweiskontroverse während der Vorermittlung nicht eingeschränkt werden dürfe. ${ }^{1007}$ Das KVerfG hat wiederholt darauf verwiesen, dass „die korrekte Interpretation des Rechts auf Verteidigung beinhaltet, dass letztere schon vor der Beschuldigung ausgeübt werden kann.“1008 Wie schon oben aufgeführt, hat das KVerfG folgende Punkte herausgestellt: a) das Verteidigungsrecht muss zu jedem Zeitpunkt des Verfahrens garantiert sein, b) das Verteidigungsrecht besteht von dem Zeitpunkt an, in dem davon Kenntnis genommen wird, dass ein Strafverfahren gegen eine Person besteht, und endet, wenn dieses Verfahren zum Abschluss gebracht ist, ${ }^{1009} \mathrm{c}$ ) das Verteidigungsrecht kann schon vor der Erhebung der Beschuldigung in Anspruch genommen werden. ${ }^{1010}$

\section{b. Auslegung i.V.m. Art. 207 CPP}

Über den Ansatz des KVerfG bzgl. des Art. 221 CPP und die Problematik der Beweisgrundlage der fundierten Anhaltspunkte hinausgehend, ist es möglich, einen anderen Ansatz zu erkennen, von dem aus sich eine breitangelegte Interpretation der Erkenntnismittel für die in Art. $221 \mathrm{CPP}$ geforderte Beweisgrundlage festlegen lässt. Diese Interpretation beruht auf dem zweiten Teil von Art. 221 CPP, gemäß dem für die Beweisgrundlage der fundierten Anhaltspunkte auch andere materielle Beweiselemente und die physische Evidenz angenommen werden. Dieser zweite Teil von Art. 221 CPP legt einen offenen Rahmen für die Erkenntnismittel der Beweisgrundlage fest und führt hiermit zu einer breitangelegten Interpretation, die in Konkordanz zum Art. 207 CPP steht, d.h. der Norm, die das methodologische Ermittlungsprogramm regelt. ${ }^{1011}$ In diesem Sinn wären Maßnahmen für die Beweisgrundlage von fundierten Anhaltspunkten gültig, die keine Einschränkungen der

\footnotetext{
1007 Vgl. KVerfG, Entsch. C-150 v. 1993; C-412 v. 1993; C-475 v. 1997; T-181 v. 1999; C-1711 v. 2000; C033 v. 2003.

${ }^{1008}$ KVerfG, Entsch. C-799 v. 2005, Abschn. „Interpretación sistemática en concordancia con los Art. 8 y 267 CPР“: „la correcta interpretación del derecho de defensa implica que se pueda ejercer desde antes de la imputación" (dt. Übersetzung d. Verf.). Diese Stellungnahme des KVerfG wurde auch zur Grundlage für die Erklärung von Art. 237 CPP als verfassungswidrig. Siehe KVerfG, Entsch. C-025 v. 2009, Abschn. 6.10.

${ }^{1009}$ KVerfG, Entsch. C-1154 v. 2005, Abschn. 2.6.3.

${ }^{1010}$ KVerfG, Entsch. C-1194 v. 2005 und C-210 v. 2007, Abschn. „Consideraciones de la Corte“.

${ }^{1011}$ Vgl. dazu supra § 9. B. II. 1. Das sog. „programa metodológico“(Art. 207 CPP).
} 
Grundrechte beinhalten, Ergebnisse von Ermittlungen, die keiner vorherigen richterlichen Anordnung bedürfen und Maßnahmen, die im Vorhinein durch den JCG kontrolliert werden müssen. ${ }^{1012}$ Diese Auslegung von Art. 221 CPP in Übereinstimmung mit Art. 207 CPP übernimmt für diese Beweisgrundlage sowohl Ermittlungstätigkeiten als auch Beweismittel und Ermittlungsergebnisse. Mit anderen Worten verbindet sie zwei Stufen der Beweisgrundlage: Beweisquellen (fuentes probatorias) und -mittel (medios probatorios) im wahrsten Sinne des Wortes. Diese Haltung würde zur Festlegung eines weit gefassten Rahmens führen, von dem aus die Beweisgrundlage der fundierten Anhaltspunkte sich breiter und flexibler darstellt.

Diese Verbindung von Art. 207 CPP mit der Definition der Beweismittel für die Beweisgrundlage der fundierten Anhaltspunkte stammt aus den Diskussionen über die Beweisgrundlage der Erhebung der Beschuldigung. In diesem Szenarium wird auch beansprucht, wie oben schon erwähnt ${ }^{1013}$, dass die fundierten Anhaltspunkte, die zu einer Schlussfolgerung im Inkulpationsgrad führen, mit einer Beweisgrundlage abgesichert sind. Da es sich um eine zweite Qualifikation der fundierten Anhaltspunkte handelt, von der aus nach der Beschuldigungserhebung die Einleitung einer Ermittlung im engeren Sinn erfolgt, haben die meisten Schriften der Diskussion über das gesetzmäßige Erlangen von Informationen Vorrang verliehen, wobei diejenigen Diskussionen auf zweiter Ebene abgehandelt wurden, die sich mit den Grenzen der Maxime der freien Beweiserhebung (principio de libertad probatoria) für die Grundlage der fundierten Anhaltspunkte befassen. Obwohl dieser Ansatz eine laxe Auslegung dieser Maxime darstellt, könnten einige Einwände hierzu aufgeführt werden. Die freie Beweiserhebung weist während des Ermittlungsverfahrens Grenzen auf, d.h. die Sammlung von Erkenntnismitteln und Beweiselementen ist begrenzt und wird durch verfassungsmäßige und spezifisch strafrechtliche Prinzipien bestimmt. Konkreter ausgedrückt muss die Beweiserhebung, die der Grundlage der fundierten Anhaltspunkte dient, durch eine faktische (objektive Situation) und rechtliche (zumutbare Schlussfolgerung) Hypothese bestimmt sein. Keinesfalls darf die freie Beweiserhebung eine Nichtanerkennung des Verhältnismäßigkeitsprinzips für die Durchführung von Ermittlungstätigkeiten bedeuten. In diesem Sinne hat auch das Erlangen der Beweisgrundlage funktionale und

\footnotetext{
1012 Vgl. Bernal Cuellar/Montealegre Lynett, 2013 T. II, S. 126.

1013 Vgl. § 3. A II. 3. b. Die Beschuldigung (Formulación de imputación) und § 9. C. I. 2. Inkulpationsgrad. 
teleologische Grenzen, die grundlegend durch die Regelung jeglicher Ermittlungsmaßnahme und durch den axiologischen Rahmen des CPP bestimmt sind. ${ }^{1014}$

Bei der Behandlung der Ermittlungsmaßnahmen, die ihre Grundlage in einer zweiten Qualifikation der fundierten Anhaltspunkte erhalten, deren Schlussfolgerungen eine Inkulpation oder eine Beweisgewinnung zur Folge haben, weist die freie Beweiserhebung, die aus dem zweiten Teil von Art. 221 CPP hervorgeht, strengere Grenzen auf. Von Seiten des Verhältnismäßigkeitsprinzips muss das Erlangen der Beweisgrundlage der fundierten Anhaltspunkte einer strikten Würdigung unterliegen, d.h. einem weit gefassten Widerspruch der Parteien und Beteiligten bzgl. der Angemessenheit und Notwendigkeit der Maßnahme und ihrer Beweisgrundlage. Nicht nur, weil es sich auf dieser Stufe der fundierten Anhaltspunkte um mittlere und intensive Eingriffe in Grundrechte handelt, sondern auch, weil ein großer Teil dieser Maßnahmen keine vorherige Anordnung (Kontrolle) durch den JCG benötigt. Von Seiten der Tauglichkeit der Beweismittel, um derartig zumutbare Schlussfolgerungen zu rechtfertigen, werden diejenigen ausgeschlossen, die nicht dazu führen, eine Wahrscheinlichkeitsstufe zu bestimmen, die benötigt wird, um diese zweite Qualifikation der fundierten Anhaltspunkte festzulegen. ${ }^{1015}$ In diesem Sinne sollten die Maßnahmen, die keinem weit gefassten Widerspruch in der Kontrollanhörung durch den JCG unterworfen werden können, keine exklusive Beweisgrundlage sein, sondern komplementären und nachfolgenden Charakter haben. Aus diesem Grund sind sowohl die eidesstattliche Erklärung von Zeugen als auch der Bericht der Kriminalpolizei anzuzweifeln, mit deren kritischer Wertung wir uns im Folgenden beschäftigen werden.

\section{Kritische Überlegung zu Beweismitteln gem. Art. 221 CPP}

Die verschiedenen Interpretationen, die bzgl. Art. 221 CPP beschrieben wurden, stimmen dahingehend überein, dass sie den Artikel als Parameter für die Bestimmung der Beweisgrundlage der fundierten Anhaltspunkte verstehen. Mit dieser Haltung werden nicht nur die Kriterien für die Beweisgrundlage der fundierten Anhaltspunkte aufgestellt, auf denen ein Hausdurchsuchungsbefehl beruht, sondern auch für die gesamte Reihe der Ermittlungsmaßnahmen, die durch den CPP hinzugefügt wurden. Somit wird eine extensive Auslegung von Art. $221 \mathrm{CPP}$ angestrebt und Kriterien werden aufgestellt, um die Glaubwürdig-

1014 Bzgl. der normativen bzw. verfassungsrechtlichen Begrezung der ,,motivos fundados“ vgl. Zuluaga, NFP 83 (2015), S. 176 f.; dazu supra § 7. A. I. Verfassungsrechtliche Bedeutung.

${ }^{1015}$ Die Tauglichkeit von Erkenntnismittel wird nach den Kriterien von Art. 305 CPP bestimmt; vgl. dazu Bedoya Sierra, 2008, S. 205 f. 
keit der Erkenntnismittel zu unterstützen, mit denen die Beweisgrundlage eines fundierten Anhaltspunkts gestützt wird. Trotz der oben angeführten Beobachtungen über Art. 221 CPP lässt das Verständnis desselben als orientierender Parameter für die Beweisgrundlage einige Lücken offen.

Erstens: obgleich anscheinend keine Widersprüche gegen die extensive Anwendung dieses Artikels bestehen, so ist doch offensichtlich, dass jede Ermittlungsmaßnahme verschiedene Voraussetzungen für die Anordnung und Rechtmäßigkeitskontrolle vorschlägt, was zur Folge hat, dass die Kriterien für die Beweisgrundlage von Art. 221 CPP case by case Anwendung finden, denn damit die fundierten Anhaltspunkte als durch eine Beweisgrundlage gestützt angesehen werden, ist es notwendig, dass das Erkenntnismittel sachdienlich ist. ${ }^{1016}$ Die Forderung nach Sachdienlichkeit der Aktivitäten für die Beweissammlung und damit auch die Entscheidung für Quellen und Beweismittel zur Aufklärung des Sachverhalts wird durch Art. 207 Abs. 3 CPP geregelt, ein Artikel, der sich auf die Entwicklung des methodologischen Ermittlungsprogramms bezieht. ${ }^{1017}$ Dies muss in Übereinstimmung mit Art. 375 CPP verstanden werden, der von der Tauglichkeit des materiellen Beweiselements, der physischen Evidenz und den Beweismitteln spricht, d.h. von der Notwendigkeit, dass diese Beweismittel sich direkt oder indirekt auf den Sachverhalt oder Umstände beziehen, die mit der Begehung einer Straftat in Zusammenhang stehen, sowie auch mit der Identität oder der strafrechtlichen Verantwortung des Angeklagten. ${ }^{1018}$ In diesem Sinne muss eine extensive Interpretation von Art. $221 \mathrm{CPP}$ berücksichtigen, dass die in diesem Artikel erfassten Kriterien der Beweisgrundlage nur ein Ausgangspunkt sind, der immer in Zusammenhang mit den Erfordernissen für eine Anordnung jeder Ermittlungsmaßnahme und deren entsprechender Rechtskontrolle durch den JCG steht.

\footnotetext{
${ }^{1016}$ Zuluaga, NFP 83 (2015), S. 185; Bedoya Sierra, 2008, S. 205 f.; bzgl. der Relevanz von Erkenntnismitteln vgl. KVerfG, Entsch. C-185 v. 2008; dazu supra § 7. B. IV. 1. Forderung nach Konkretheit der „,motivos fundados".

${ }^{1017}$ Art. 207 Abs. 3 CPP: „En desarrollo del programa metodológico de la investigación, el fiscal ordenará la realización de todas las actividades que no impliquen restricción a los derechos fundamentales y que sean conducentes al esclarecimiento de los hechos, al descubrimiento de los elementos materiales probatorios y evidencia física, a la individualización de los autores y partícipes del delito, a la evaluación y cuantificación de los daños causados y a la asistencia y protección de las víctimas.“ (,während der Durchführung des methodologischen Programms wird die Staatsanwaltschaft alle Ermittlungstätigkeiten anordnen, die keinen Eingriff in Grundrechte einschließen und zur Aufklärung des Sachverhalts, Gewinnung von materiellen Beweiselementen und physischer Evidenz, ebenso zur Individualisierung der Täter und Teilnehmer der Straftat, Evaluierung und Quantifizierung des verursachten Schadens und Hilfe und Schutz der Opfer sachdienlich seien.“-dt. Übersetzung d. Verf.-).

${ }^{1018}$ Bedoya Sierra, 2008, S. 205; dazu infra § 10. B. III. 2. Bestimmbarkeit der Tauglichkeit von Informationen.
} 
Zweitens: Die extensiven Anwendungsbestrebungen von Art. 221 CPP berücksichtigen nicht, dass der Aufbau der fundierten Anhaltspunkte, die eine Ermittlungsmaßnahme begründen, verschiedene Stufen aufweist, je nach Verfahrensstufe und dem Widerspruchsgrad, in den sich die Parteien und Beteiligten verwickelt sehen. In diesem Sinne ist die Wahrscheinlichkeitsstufe (verosimilitud) der zumutbaren Schlussfolgerungen variabel und hängt von dem Fortschreiten der Ermittlungen ab. Da es sich um die zweite Qualifikation der fundierten Anhaltspunkte handelt, die bei der vorliegenden Forschung von Bedeutung ist, deren Wahrscheinlichkeitsgrad ein Überwiegen von inkriminierenden Elementen erforderlich macht, ${ }^{1019}$ bringt Art. 221 CPP zwei Erkenntnismittel ein, die zu Unzulänglichkeiten der Beweisgrundlage dieser Stufe der fundierten Anhaltspunkte führen. Sowohl der Bericht der Kriminalpolizei als auch die eidesstattliche Erklärung von Zeugen oder Informanten können als solche nicht für eine Wahrscheinlichkeitsdefinition dieser zweiten Qualifikation der fundierten Anhaltspunkte als sachdienlich angesehen werden. Im Folgenden wird jedes dieser Mittel analysiert.

\section{a. Die eidesstattliche Erklärung von Zeugen oder Informanten}

Wenn Art. 221 CPP eine eidesstattliche Erklärung erwähnt, ist damit die Aussage unter Eid gemeint, die die Person vor der Kriminalpolizei oder einer anderen Behörde macht. ${ }^{1020}$ Diese Art von Erklärungen kann zu jedem Zeitpunkt abgegeben werden, sogar bis vor dem Ablauf der durchzuführenden Beweisaufnahme in der Hauptverhandlung (Art. 393 (b) CPP). Art. 221 CPP verweist auf zwei konkrete Beweisquellen: den Zeugen und den Informanten. Einerseits kann die eidesstattliche Erklärung von Zeugen nicht nur mit dem Zweck durchgeführt werden, dass hiermit die Beweisgrundlage der fundierten Anhaltspunkte geschaffen wird, sondern auch zur eigentlichen Durchführung einer Zeugenaussage in der Hauptverhandlung. Wie oben erwähnt, fordert Art. 221 CPP für die Beweisgrundlage der fundierten Anhaltspunkte, dass die Staatsanwaltschaft bei der Erklärung anwesend ist, mit dem Ziel, dass eine eventuelle Befragung durchgeführt wird, die der Erklärung größere Glaubwürdigkeit verleiht. Diese Art Erklärung kann auch vom Beschuldigten oder seinem Verteidiger beantragt werden. Diese Möglichkeit wurde in Art. 272 CPP aufgenommen, gemäß dessen der Beschuldigte oder sein Verteidiger einen Bürgermeister, Poli-

\footnotetext{
${ }^{1019}$ Mit Bezug auf den täterbezogenen ,motivos fundados“ vgl. supra § 9. I. 2. Inkulpationsgrad.

${ }^{1020}$ Vgl. FGN, 2005a, S. 28, als andere Behörde im Rahmen der strafrechtlichen Ermittlung ist die $F G N \mathrm{zu}$ berücksichtigen; auch Rodríguez Chocontá, 2012, S. 69 f.
} 
zeiinspektor oder Notar bitten kann, diese eidesstattliche Erklärung, die „für die Ermittlung von besonderer Tauglichkeit sein kann“1021, von einer Person aufzunehmen.

Auf der anderen Seite betrachtet Art. 221 CPP die eidesstattliche Erklärung eines Informanten als angebracht für die Beweisgrundlage der fundierten Anhaltspunkte. Im Gegensatz zum Zeugen verfügt der Informant in seiner Erklärung über eine größere Vertraulichkeit, d.h., für seine Erklärung ist nicht die Anwesenheit der Staatsanwaltschaft notwendig, sondern es genügt die Beschreibung der Identifizierung des Informanten durch die Kriminalpolizei gegenüber der Staatsanwaltschaft und Angabe der Gründe, warum derselbe vertrauenswürdig ist (Art. 221 Abs. 2 CPP). Obwohl diese Art der Einschränkung durch das KVerfG durch das Urteil C-673 von $2005^{1022}$ verfassungsrechtlich bedingt wurde, kann doch festgestellt werden, dass weiterhin Zweifel bzgl. des Identitätsgeheimnisses der Informanten gegenüber der Verteidigung und anderen Beteiligten bestehen. So wie zurzeit der CPP die Frage der Informanten handhabt, kann ein großer Unterschied zu der vorherigen Handhabung des CPP (Gesetz 600 von 2000) der Beweiswürdigung der Informantenerklärungen beobachtet werden. Vor dem Gesetz 906 von 2004 erfreuten sich die Versionen der Informanten keinerlei Beweiskraft. So wurde in Art. 50 Gesetz 504 von 1994 festgelegt, dass ,in keinem Fall die Berichte der Kriminalpolizei und die Versionen der Informanten Beweiswert im Prozess erhalten.“1023 Wie oben erwähnt, existierte diese Einschränkung der Beweiskraft der Informanten auf Grund der vielen Willkürlichkeiten, denen sich viele Angeklagte wegen mehrfacher falscher Erklärungen und Prozessmanipulationen der FGN in Kolumbien ausgesetzt sahen. ${ }^{1024}$

Die eidesstattliche Erklärung, sei es von Seiten der Zeugen oder der Informanten, die Art. 221 CPP aufnimmt, bedeutet ein eingeschränktes Erkenntnismittel für die Beweisgrundlage der fundierten Anhaltspunkte und seine Beweisfähigkeit ist in mehrfachem Sinne eingeschränkt. Die geforderte „Vertraulichkeit“ der Beweisquellen (von Zeugen oder Informanten) legen der Beweiswürdigung der eidesstattlichen Erklärung eine Einschränkung auf.

${ }^{1021}$ Art. 272 CPP: „El imputado o su defensor podrán solicitar a un alcalde municipal, inspector de policía o notario público, que le reciba declaración jurada a la persona, cuya exposición pueda resultar de especial utilidad para la investigación." (dt. Übersetzung d. Verf./Herv. d. Verf.).

1022 Vgl. KVerfG, Entsch. C-673 v. 2005, Abschn. VI. 3.; dazu supra § 7. B. I. 2. Rechtmäßigkeitskontrolle seitens des JCG.

${ }^{1023}$ Art. 50 Gesetz 504 von 1994: ,en ningún caso los informes de la policía judicial y las versiones suministradas por informantes tendrán valor probatorio en el proceso." (dt. Übersetzung d. Verf.); dazu Pava Lugo, 2009, S. $37 \mathrm{f}$.

${ }^{1024}$ Vgl. Gonzalez Mongui, 2007, S. 219. 
Gerade dadurch, dass es sich um Beweismittel handelt, die nicht dem Widerspruch der Verteidigung oder anderer Beteiligter unterworfen sind, können diese auf Grund ebenjener „Vertraulichkeit“ in ihrer Essenz als geheime Zeugenaussagen bezeichnet werden und die

Möglichkeit zu verschiedenen Beweismanipulationen öffnen würde. ${ }^{1025}$ Die Glaubwürdigkeit dieser Beweisfindung kann nicht durch die Förmlichkeit (solemnidad) des Eides gesichert werden, den der Zeuge oder der Informant leistet. Diese Förmlichkeit erfüllt somit eine (unzureichende) Ersatzfunktion für Garantien wie die Unmittelbarkeit und den Widerspruch des JCG und die Verteidigung, die bessere Erklärungsinhalte sicherstellen könnten. In diesem Sinne macht Art. 221 CPP die Festlegung der Wahrscheinlichkeit von einer formellen Aufnahme der Erklärung der Zeugen oder Informanten abhängig, d.h. von einem formellen Verständnis der Beweisaufnahme (unter Eid), wobei die Gewährleistung von Garantien wie Widerspruch, Unmittelbarkeit und Öffentlichkeit unberücksichtigt gelassen wird. Wie wir im Folgenden auch für den Fall des Berichts der Kriminalpolizei sehen werden, handelt es sich um unilaterale Informationen, die für die Schaffung der Basis einer Wahrscheinlichkeit für zumutbare Schlussfolgerungen bzgl. der Täterschaft, Teilnahme oder Beweisgewinnung ungeeignet sind. ${ }^{1026}$

\section{b. Bericht der Kriminalpolizei}

Der Bericht der Kriminalpolizei ist ein anderes Beweismittel, das von Art. 221 CPP als geeignet angesehen wird, um eine Beweisgrundlage für die fundierten Anhaltspunkte zu schaffen. Dieser Bericht stellt im Wesentlichen ein Mitteilungsformat zwischen der Kriminalpolizei und der Staatsanwaltschaft dar, durch welches die Kriminalpolizei die Erkenntnisse einer Ermittlung proprio motu oder auf Grund eines Auftrags liefert. ${ }^{1027}$ Außer der Beschreibung der Ermittlungstätigkeiten und der jeweiligen Ergebnisse stellt der Bericht Hypothesen auf, um die Ermittlungsergebnisse auszulegen, d.h. Schlussfolgerungen, die sich auf Grund von Situationen oder Tätigkeiten innerhalb der Ermittlung ergeben. ${ }^{1028}$ Obwohl ihre Eigenschaft als Berichtsformat zwischen der Kriminalpolizei und der Staatsanwaltschaft nicht in Frage gestellt wird, wird die Anerkennung einer Beweiskraft breit

\footnotetext{
1025 Gonzalez Mongui, 2007, S. 220.

$1026 \mathrm{Vgl}$. infra § 10. C. I. Polizeiliche Vormachtstellung in der Bestimmung der „motivos fundados“.

${ }^{1027}$ Lozada Bustos, 2003, S. 105; Gonzalez Mongui, 2007, S. 399.

${ }^{1028}$ Lozada Bustos, 2003, S. 108; Avella Franco, 2007, S. 48.
} 
angelegt diskutiert. Das KVerfG selbst hat sich mittels verschiedener Urteile dahingehend geäußert, die Beweiskraft dieser Berichte abzulehnen. ${ }^{1029}$

Vor allem im Urteil C-392 von 2000 geht das KVerfG detailliert auf die Diskussion bzgl. des Beweiswerts der Berichte der Kriminalpolizei ein. Zunächst erkennt das KVerfG an, dass, „obwohl häufig objektive Situationen von der Kriminalpolizei aufgedeckt werden, handelt es sich jedoch in anderen Fällen um Ermittlungsergebnisse von Dritten, oftmals unbestimmten Charakters, die Vermutungen oder Wahrnehmungen strukturieren, die vom materiellen Standpunkt aus nicht dazu dienen können, einen Beweis zu erbringen; aber auf jeden Fall sind dabei nicht die Verdächtigen beteiligt, die davon betroffen sein könnten. “1030 Mit dieser Aussage warnt das KVerfG vor den Ungenauigkeiten, die bei den Berichten auftreten können, sei es auf Grund des Fehlens von Überprüfungen der übermittelten Information oder durch die Ungenauigkeit oder Verallgemeinerung ihrer Inhalte. Weiterhin, insofern es sich um eine Verfassungmäßigkeitsprüfung von Art. 50 Gesetz 504 von 1999 handelte, hat das KVerfG hervorgehoben, dass es sich für diese Zeitspanne um eine Entscheidung des Gesetzgebers handele, die Beweiskraft dieser Berichte zu verweigern. Diese Entscheidung wurde ,auf Grund von politischen Zweckmäßigkeiten getroffen, über die der Gesetzgeber frei entschieden hat, die die Unilateralität derselben betreffen könnten und diejenigen, die darauf anlegen zu verhindern, dass die Beamten, die richten sollen, sich nur an diese halten und keine anderen Beweise im Verfahren beibringen, mit dem Ziel, die Wahrheit zu verfolgen, in Unkenntnis der Rechte der Verdächtigen. “1031 Auf dieser Ebene hat das KVerfG anerkannt, dass die Praxis der Kriminalpolizei defizient sein kann, was im Weiteren unvereinbar mit dem strafprozessrechtlichen Mandat einer vollständigen Ermittlung (mandato de investigación integral) wäre.

\footnotetext{
${ }^{1029}$ Vgl. KVerfG, Entsch. C-392 v. 2000; C-793 v. 2000; C-1315 v. 2000, Abschn. „Consideraciones de la Corte".

${ }^{1030}$ KVerfG, Entsch. C-392 v. 2000, Abs. 2.2.19.: „si bien muchas veces revelan situaciones objetivas que han verificado sus agentes, en otras, son producto de indagaciones con terceros, muchas veces indeterminados, que estructuran conjeturas o apreciaciones que materialmente no son idóneas para fundar una prueba; pero en todo caso en su producción no intervienen las personas sindicadas que pueden verse afectadas por ellos.“(dt. Übersetzung d. Verf.).

${ }^{1031}$ KVerfG, Entsch. C-392 v. 2000, Abs. 2.2.19.: „sobre la base de conveniencias políticas, que él libremente ha apreciado, como podrían ser la unilateralidad de éstos, y la de evitar que los funcionarios que deban juzgar se atengan exclusivamente a éstos y no produzcan otras pruebas en el proceso, en aras de la búsqueda de la verdad real, con desconocimiento de los derechos de los sindicados.“(dt. Übersetzung d. Verf.). 
Anfänglich umfasst das KVerfG zwei Argumentationsebenen, um die Ablehnung der Beweiskraft der Berichte der Kriminalpolizei zu unterstützen. Zum einen sind es Gründe, die auf Ermittlungspraxis und der Methodologie zur Berichterstattung aufbauen, auf deren Basis anerkannt wird, dass diese Berichte offen für Verallgemeinerungen und unbestimmte Information sind, die für eine Beweisgrundlage ungeeignet sind. Zum anderen handelt es sich um strafprozessrechtlich politische Argumente (politische Zweckmäßigkeit), von denen behauptet werden kann, dass sie mit der Maxime der vollständigen Ermittlung in Verbindung stehen, gemäß derer eine freie und einseitige Annahme der Kriminalpolizei nicht ausreicht, d.h. die Gerichtsbeschlüsse müssen auf Wertungen eines umfassenderen und integralen Beweismaterials aufbauen. Diesbezüglich können analog zum KVerfG in der Literatur ähnliche Fragestellungen bzgl. der Anerkennung der Beweiskraft von Berichten der Kriminalpolizei gefunden werden. Es wird festgestellt, dass die Ausarbeitung von derartigen Berichten nicht auf der Praxis des Widerspruchsprinzips der Verteidigung aufbaue. Außerdem missachte die Anerkennung der Beweiskraft Art. 29 Nr. 3 CN, der garantiert, dass die Unschuldsvermutung nicht durch extraprozessuale Tätigkeiten außer Kraft gesetzt werden darf. ${ }^{1032}$

Da es sich um die Beweisgrundlage für die zweite Qualifikation der fundierten Anhaltspunkte handelt, würde der Bericht der Kriminalpolizei weder ein angemessenes Mittel für die retrospektive Prognose noch für die prozessuale Prognostik darstellen. ${ }^{1033}$ Einerseits könnte die Wahrscheinlichkeit für eine Feststellung der Täterschaft oder Teilnahme nicht einmal zu einem minimalen Überzeugungsgrad auf Grund eines unilateralen oder unbestimmten Berichts bestimmt werden. Mit weitaus schwerwiegenderem Argument wäre dieser Bericht unzureichend, wenn er nicht mit anderen Beweismitteln abgewogen wird, d.h. es wäre kein ausreichendes Material vorhanden, um festzustellen, dass das belastende Material vorrangig ist. Andererseits würden bei der Unmöglichkeit einer Gegenüberstellung des Berichts der Kriminalpolizei mit anderen Beweismitteln diejenigen prospektiven Prognosen unzureichend ausfallen, von denen aus in annähernder Weise der Verfahrensverlauf projiziert wird. Auch kann keine hohe Wahrscheinlichkeit für eine Verurteilung projiziert werden, die diese Entscheidung der zweiten Qualifikation der fundierten Anhaltspunkte begleiten muss und dementsprechend die mittleren oder intensiven Eingriffe in Grundrech-

1032 Vgl. Pava Lugo, 2009, S. 38 und Fn. 82 m.w.N.; Lozada Bustos, 2003, S. 106 f.

${ }^{1033}$ Vgl. dazu supra § 9. C. I. 3. 3. Wahrscheinlichkeitsgrad. Für die Wahrscheinlichkeit als Voraussetzung von „motivos fundados“" s. Zuluaga, NFP 83 (2015), S. 189 ff. 
te. Konkreter gesagt, ohne durch nachweisbare oder vergleichbare Tatsachenbefunde können keine fundierten Anhaltspunkte bestehen.

\section{Lösungsversuch}

\section{Vorbemerkung}

Das Nichtvorhandensein von spezifischen Parametern für die Beweisgrundlage der fundierten Anhaltspunkte gegenüber jeder der Ermittlungsmaßnahmen, die im CPP enthalten sind, hat dazu geführt, dass Art. $221 \mathrm{CPP}$ die vorrangige Referenz für die Diskussion über die Problematik der Beweisgrundlage darstellt. Trotz des Vorherrschens der Maxime der freien Beweiserhebung haben Art. 221 CPP und seine extensive Anwendung dazu geführt, den Bericht der Kriminalpolizei und die eidesstattliche Erklärung von Zeugen und Informanten als in Bezug zu nehmende Mittel für die fundierten Anhaltspunkte anzusehen. Die Diskussion dreht sich um die Geeignetheit zum Erreichen nicht nur der von Art. 221 CPP geforderten spezifischen Wahrscheinlichkeitsstufe, sondern auch der retrospektiven Diagnose und der prozessualen Prognostik, die mit den Inkulpations- oder Beweisgewinnungsschlussfolgerungen in der Regelung der verschiedenen Ermittlungsmaßnahmen vom CPP aufgeführt werden. Gegenüber dieser Problematik muss angeführt werden, dass die Geeignetheit des Mittels nicht allein durch die reine Formalität (eidesstattliche Erklärung), die Art. 221 CPP und das KVerfG fordern, garantiert wird. Vor dem Vorherrschen der formellen Interpretation, die in der Förmlichkeit der Beweiserhebung eine Garantie für die Geeignetheit des Mittels für die Beweisgrundlage sieht, muss eine stärkere Forderung nach Überprüfung der Erkenntnismittel von Seiten der FGN und dem Widerspruch der Verteidigung in Anwesenheit des JCG erfolgen.

Angesichts der Feststellung, dass die herrschende Auslegung von Art. 221 CPP die Rolle der Verteidigung und den Einfluss des Widerspruchsprinzips in der Definition der Beweismittel für die Beweisgrundlage der fundierten Anhaltspunkte relativiert hat, soll im Folgenden die beschriebene Auslegung von Art. 221 CPP diskutiert werden. Für diese Auslegung von Art. $221 \mathrm{CPP}$ ist es zunächst notwendig, die normativen Grundlagen zu bestimmen, von denen aus es möglich ist, den Widerspruch gegen die Beweismittel für die Beweisgrundlage der fundierten Anhaltspunkte zu belegen, und diesbezüglich sogar die eidesstattliche Erklärung von Informanten. Zweitens wird versucht, die Parameter festzulegen, die die Geeignetheit dieser Beweismittel abgrenzen. Wie oben angemerkt, wird die 
Bestimmung der Geeignetheit durch die Erfordernisse einer Anordnung bzw. richterlichen Kontrolle jeder Ermittlungsmaßnahme bedingt, jedoch werden auch einige Bedingungen allgemeinen Charakters aufgeführt, die den spezifischen Analysen der Geeignetheit gegenüber jeder Maßnahme vorausgehen und sie begründen müssen. Diese Neuinterpretation von Art. 221 CPP versucht, das Verständnis der Beweisgrundlage der fundierten Anhaltspunkte auf der Grundlage des Widerspruchsprinzips und einer strikten Bestimmung der Geeignetheit der Erkenntnismittel zu begrenzen. Diese beiden Parameter müssen gleichzeitig als Voraussetzungen für die Rechtskontrolle bei der Anhörung vor dem JCG gelten.

\section{Zum Verständnis von Art. 221 CPP}

\section{a. Diskussionsbasis eines restriktiven Ansatzes}

Für die Beweisgrundlage der fundierten Anhaltspunkte kann die FGN die objektive oder faktische Situation durch jegliches Beweismittel stützen (Maxime der freien Beweiserhebung). Jedoch ist die Annahme derselben verschiedenen Restriktionen unterworfen. Auf einem ersten Niveau bestehen normative Voraussetzungen, die sowohl von den Erfordernissen einer Anordnung für jede Ermittlungsmaßnahme aufgeworfen werden als auch durch die vom CPP definierten Bedingungen zur Rechtmäßigkeitskontrolle. Bzgl. dieses letzteren Aspekts sind sowohl die Verhältnismäßigkeitsforderung als auch die Geeignetheit des Mittels ausschlaggebend, um den jeweiligen Wahrscheinlichkeitsgrad zu stützen, sei es einer zur Inkulpation führenden Schlussfolgerung oder einer Beweisfindung. ${ }^{1034}$ Ein zweites abgrenzendes Niveau zeichnet sich im Bereich der Rechtmäßigkeitskontrolle ab, in dem die Sachdienlichkeit des Beweismittels der Überprüfung und dem Widerspruch unterworfen wird. Diese zweite Stufe wird grundsätzlich durch die Staatsanwaltschaft im Verlauf der Anordnung einer Ermittlungsmaßnahme und unter Kontrolle derselben durch den JCG vollzogen, und zwar in Übereinstimmung mit der Perspektive der strikten Begründung, wenn es sich um mittlere und intensive Eingriffe in Grundrechte handelt. ${ }^{1035}$ Diese Stufen der Bestimmung der Sachdienlichkeit des Beweismittels stellen a priori keine Restriktion der freien Beweiserhebung dar, sondern bestimmen die Bedingungen, von denen aus ein Beweismittel sachdienlich und annehmbar für die Beweisgrundlage der fundierten Anhaltspunkte ist.

\footnotetext{
${ }^{1034}$ Vgl. Zuluaga, NFP 83 (2015), S. 194 f.; dazu infra § 10. B. Ziele der zumutbaren Schlussfolgerungen. ${ }^{1035}$ Vgl. KVerfG, Entsch. C-185 v. 2008, Abschn. VI. 5.; dazu supra § 7. C. III. Beweisunterstützung für „motivos fundados“.
} 
Diese Parameter für die Abgrenzung der Sachdienlichkeit eines Beweismittels verfügen über eine doppelte Verfassungsgrundlage. Einerseits Art. $250 \mathrm{CN}$, wie oben schon analysiert. ${ }^{1036}$ Insbesondere die Doktrin des ausreichenden Beweisstandards (estándar probatorio suficiente), die an denselben gebunden ist und auf Grund derer die Eingriffe in Grundrechte während der Strafrechtsermittlung auf der Basis von einem materiellen Beweiskriterium ${ }^{1037}$ verlaufen und welche Beweisidentifizierung, -wert und -würdigung bestimmen. Andererseits Art. 29 Abs. 3 CN, der die Garantien regelt, die mit dem fairen Verfahren verbunden sind, insbesondere dem Recht, den Beweisen zu widersprechen, die gegen den Verdächtigen, Beschuldigten oder Angeklagten angeführt werden. ${ }^{1038}$ Diese normativen und Verfahrensfilter führen zu einer strikten Bestimmung der Geeignetheit des Beweismittels und sind demnach gleichzeitig Kontrollparameter für die Effizienz dieses Mittels, das der Richterüberzeugung dient.

In diesem Sinne ist die Rechtfertigung eines restriktiven Verständnisses von Art. 221 CPP, d.h. der Maxime der freien Beweiserhebung, verfassungs- und rechtmäßig gerechtfertigt. Einerseits würde es sich nicht um eine einfache extensive Anwendung von Art. 221 CPP handeln, sondern eher um eine Angleichung der Maxime der freien Beweiserhebung für die Grundlage der fundierten Anhaltspunkte. Diese Grundlage, die sich an der Beweisfreiheit orientiert, verfügt über eine Konkretisierung case by case je nach den Erfordernissen, die jede Ermittlungsmaßnahme erfordert. Grundsätzlich müssen die Beweismittel eine Eignung aufweisen, um den Wahrscheinlichkeitsgrad zu beweisen, der an jede zumutbare Schlussfolgerung gebunden ist oder von ihr erfordert wird. Andererseits muss gegenüber der Maxime der freien Beweiserhebung angeführt werden, dass die Aufnahme von Mitteln wie der Bericht der Kriminalpolizei und die eidesstattliche Erklärung von Zeugen und Informanten restriktiv interpretiert werden muss, mit anderen Worten, es handelt sich um Ausnahmen, die einer strikten Überprüfung ihrer Inhalte unterworfen werden müssen.

Die Wichtigkeit einer strikten Überprüfung und einer Gegenüberstellung von Beweismitteln, die intensive Eingriffe in Grundrechte begründen, wurde schon vom KVerfG diskutiert. Im Urteil C-805 von 2002 bzgl. der Kompetenz, die die Staatsanwaltschaft durch Ge-

\footnotetext{
${ }^{1036} \mathrm{Vgl}$. Zuluaga, NFP 83 (2015), S. 174; dazu supra § 7. A. I. Verfassungsrechtliche Bedeutung.

${ }^{1037}$ KVerfG, Entsch. C-805 v. 2002, Abschn. VI. 17 f.

1038 Bzgl. der "Fairness" (Debido proceso) im kolumbianischen Strafprozessrecht s. Bernal Cuellar/Montealegre Lynett, 2013 T. I, S. 911 ff.; Calle Calderón, NFP 63 (2000), S. 3 ff.; Camargo, 2002, S. 105 ff.; Molina Arrubla, 2002, S. 295 ff.; Suárez Sánchez, 2001, S. 220 ff.
} 
setz 600 von $2000^{1039}$ zur Anordnung von Sicherheitsmaßnahmen hatte, behauptete das KVerfG, dass für diese Entscheidungen, die von den fundierten Anhaltspunkten bestimmt seien, „mit der Beweissicherheit der Indizien vorzugehen sei, die auf objektive Tatsachen zurückgehen und mit hoher Wahrscheinlichkeit, die über den einfachen Verdacht oder die einfache Feststellung einer plausiblen Verbindung der Person mit den ermittelten Tatsachen hinausgeht, darauf verweist, dass die Person verantwortlich ist. “" ${ }^{1040}$ Für das KVerfG ist bei dieser Art von Eingriffen sehr wichtig, dass die Gesamtheit der Beweise und ihre Abwägung in ihrer Gesamtheit im Auge behalten wird, da „die Gesamtwertung verhindert, dass etwas, was als Tatsache erfasst wird, als eine Realität gleichgesetzt wird, wenn in Wirklichkeit eine andere Tatsache, die auch bewiesen ist, anfällt, die die Schlussfolgerung verändert, zu der man durch eine fragmentarische Beweiswürdigung gelangen würde.“1041

Zusammenfassend kann gesagt werden, dass der Ansatz einer extensiven Anwendung von Art. 221 CPP in dem Sinne verstanden werden muss, dass die Maxime der freien Beweiserhebung wie eine Generalklausel für die Beweisgrundlage der fundierten Anhaltspunkte betrachtet werden muss, eine Maxime, dass case by case konkretisiert werden muss. Die Beweisfreiheit muss die erwähnten normativen und Verfahrensfilter berücksichtigen, insbesondere muss sie zusichern, dass das Beweismittel die Eignung besitzt, um die zumutbare Schlussfolgerung zu unterstützen, die jede Ermittlungsmaßnahme mit sich bringt. Gegenüber der extensiven Anwendung von Art. 221 CPP, d.h. der Angleichung der Beweisfreiheit, muss ausnahmsweise der Bericht der Kriminalpolizei und die eidesstattliche Erklärung von Zeugen und Informanten Beachtung finden. Im Falle der Beweismittel, die auf Quellen mit einem hohen Vertraulichkeitsniveau basieren, müsste die Überprüfung strikt sein, d.h. sie müsste mit anderen Beweismitteln kontrastiert werden. Ohne die Möglichkeit der Gegenüberstellung kann die Eignung der besagten Mittel zur Schaffung der Beweis-

\footnotetext{
${ }^{1039}$ Vgl. Martínez Rave, 2002, S. 447 f.; dazu supra § 2. C. II. Die Strafprozessordnung von 2000 und $\S 6$. C. I. Festnahme mit Ausnahmekompetenzen.

1040 d.h sie hat eine tatbestandsmäßige, rechtswidrige und schuldhafte Handlung durchgeführt. KVerfG, Entsch. C-805 v. 2002, Abschn. VI. 18: „obrar en el acervo probatorio dos indicios relativos a hechos objetivos que indiquen con una alta probabilidad, más allá de la simple sospecha o de la mera constatación de una plausible vinculación de la persona con los hechos investigados, que la persona es responsable, es decir, que realizó una conducta típica, antijurídica y culpable.“(dt. Übersetzung d. Verf.).

1041 Sowie auch um zu unterstützen, dass das Hauptgewicht des Bewiesenen sich gegen den Verdächtigen richtet und nicht zu seinen Gunsten. KVerfG, C-805 v. 2002, Abschn. VI. 18: „la valoración integral evita que lo que indica un hecho se tome como cierto cuando en realidad obre otro, también probado, que desvirtúa la conclusión a la que se llegaría por un análisis fragmentado del acervo; así como para corroborar que el mayor peso de lo demostrado se inclina en contra del investigado, no a su favor.“ (dt. Übersetzung d. Verf.).
} 
grundlage der zumutbaren fundierten Anhaltspunkte (zweite Qualifikation) nicht zugesichert werden.

\section{b. Zur Beweisbegründung von „motivos fundados“6}

Der restriktive Charakter der Beweisfreiheit für die Beweisgrundlage der fundierten Anhaltspunkte würde durch die Eignungs- oder Sachdienlichkeitsbedingungen des Beweismittels bestimmt, die durch die Regelungen jeder Ermittlungsmaßnahme aufgestellt werden und case by case gewertet werden. Die Geeignetheit bzw. Sachdienlichkeit des Beweismittels bezieht sich auf die Geeignetheit, eine objektive Situation oder Tatsachenseite zu beweisen. ${ }^{1042}$ Die Forderung nach Geeignetheit ist von den ersten Momenten der Ermittlungsphase an bindend. So wird sie beispielsweise von Art. 207 Abs. 3 CPP aufgenommen, der das methodologische Ermittlungsprogramm regelt. ${ }^{1043}$ Auch handelt es sich hier um ein Orientierungsprinzip der Beweisaufnahme in der Hauptverhandlung (Art. 375 CPP). Im Bereich der Aufnahme von materiellen Elementen oder physischer Evidenz, die durch das methodologische Ermittlungsprogramm begrenzt wird, wird beansprucht, dass dieselben dazu führen, die Tatsachen aufzuklären, materielle Beweiselemente und physische Evidenz aufzudecken, Täter und Teilnehmer eines Delikts zu erkennen, die Evaluierung und Quantifizierung des entstandenen Schadens und die Assistenz und den Schutz der Opfer zu gewährleisten (Art. 207 Abs. 3 CPP).

Im Falle der Beweisgrundlage für die fundierten Anhaltspunkte würde die Bestimmung der Geeignetheit des Beweismittels eine Analyse auf verschiedenen Niveaus verlangen. Einerseits, zusätzlich zur Erfüllung der Zeit, Art- und Ortsformalitäten zur Beweisaufnahme, stellt die Bestätigung der erlangten Information einen notwendigen Schritt zur Bestimmung der Nützlichkeit des Beweismittels dar. Im Falle einer eidesstattlichen Erklärung von Zeugen und Informanten muss sie die Regeln der Wertung der Zeugenerklärung von Art. 404 CPP beachten. ${ }^{1044}$ Andererseits, sobald die Rechtmäßigkeit der Beweiserhebung und die

1042 Vgl. Devis Echandía, 2002, S. 125 f., für den die Sachdienlichkeit (conducencia) des Beweismittels die freie Beweiserhebung begrenzt.

1043 Vgl. supra A. II. 2. Kritische Überlegung zu Beweismitteln gemäß Art. 221 CPP und Fn. 1017.

1044 Art. 404 CPP: „Apreciación del testimonio. Para apreciar el testimonio, el juez tendrá en cuenta los principios técnico científicos sobre la percepción y la memoria y, especialmente, lo relativo a la naturaleza del objeto percibido, al estado de sanidad del sentido o sentidos por los cuales se tuvo la percepción, las circunstancias de lugar, tiempo y modo en que se percibió, los procesos de rememoración, el comportamiento del testigo durante el interrogatorio y el contrainterrogatorio, la forma de sus respuestas y su personalidad.“ (,Würdigung einer Zeugenaussage. Um die Zeugenaussage zu würdigen, wird der Richter die wissenschaftlich-technischen Grundlagen der Wahrnehmung und Erinnerung betrachten sowie insbesondere alles im 324 
Bestätigung der Information erfolgt ist, verlangt die Bestimmung der Beweisgrundlage der fundierten Anhaltspunkte die Durchführung eines Wahrscheinlichkeitsurteils, das die Eignung des Beweismittels für die Begründung der zumutbaren Schlussfolgerung zulässt, die aus der Wertung der fundierten Anhaltspunkte hervorgeht. Diese beiden Niveaus vervollständigen die Bedingungen der Beweisgrundlage der fundierten Anhaltspunkte von Art. 221 CPP. Mit der Forderung nach Überprüfung als Filter der Beweiserhebung wird dem formalistischen Verständnis bzgl. der Glaubwürdigkeit bzw. der Anerkennung der Inhalte der eidesstattlichen Erklärung von Zeugen und Informanten oder des von der Kriminalpolizei übergebenen Berichts Rechnung getragen. Gleichzeitig trägt die Doktrin des Wahrscheinlichkeitsurteils zu einer besseren Konkretisierung der Prognosen bei, die an die Bestimmung der zumutbaren Schlussfolgerung gebunden sind; ein Punkt, der durch Art. 221 CPP auf eine einfache Formel gebracht wurde: „mit Wahrscheinlichkeit feststellen“ (establecer con verosimilitud).

Auf einem ersten Niveau würde die Überprüfung der Information oder Inhalte der Beweismittel zwei Ziele bzgl. der Beweisgrundlage der fundierten Anhaltspunkte verfolgen. Erstens, in Bezug auf die Verfahrenseffizienz, erlaubt die Überprüfung die Feststellung, ob die Beweisgrundlage besteht, um die rechtlichen Kontrollschritte einzuleiten. Mit dieser Maßnahme können unnötige Schritte des JCG festgestellt werden. ${ }^{1045}$ Zweitens können bzgl. der Effizienz der Beweisgrundlage die Beweismittel und die physische Evidenz gefiltert werden, die die Eignung zur Beweisgrundlage haben. Gerade angesichts des Formalismus von Art. $221 \mathrm{CPP}$ in Bezug auf die Unterstützung der objektiven Situation oder Tatsachenseite, auf die sich die fundierten Anhaltspunkte stützen, tragen die Bestimmung der Eignung des Beweismittels und damit auch die Forderung der Überprüfung ihrer Inhalte nicht nur zu einer besseren Überprüfung der fundierten Anhaltspunkte bei, sondern auch zur materiellen Kontrolle der Ermittlungsmaßnahme von Seiten des JCG. ${ }^{1046}$ Die Wichtigkeit des Eignungsprinzips bzgl. der Beweismittel ist schon durch die Rechtsprechung des

\footnotetext{
Hinblick auf die Natur des wahrgenommenen Gegenstandes, den Gesundheitszustand des Sinnes oder der Sinne, durch welche die Wahrnehmung erlangt wurde, die zeitlichen und örtlichen Umstände und die Art und Weise, in der wahrgenommen wurde, die Prozesse der Erinnerung, das Verhalten des Zeugen während der Vernehmung und des Kreuzverhörs, die Form ihrer Antworten und Persönlichkeit.“ -dt. Übersetzung d. Verf.-).

1045 Bzgl. der Überprüfung von Zeugnisaussage vgl. Bedoya Sierra, 2008, S. 78 ff. Für die Sachdienlichkeit als Bedingung der Verfahrenseffizienz Devis Echandía, 2002, S. 125.

1046 Bzgl. der materiellen bzw. rechtlichen Rechtmäßigkeitskontrolle durch den Richter zur Kontrolle der Garantien vgl. KVerfG, Entsch. C-805 v. 2002 und C-1092 v. 2003.
} 
Obersten Gerichtshofs bestätigt worden, wo die Sachdienlichkeitsanalyse als Filter gewürdigt wird, der es erlaubt, unangemessene Verzögerungen und unnötige Anhörungen im Prozess zu unterbinden. ${ }^{1047}$

Die Meinungen bzgl. der Überprüfung der Information der Beweismittel verstehen die Erhärtung als eine Praxis, die auf der Gegenüberstellung des Beweismittels beruht. ${ }^{1048}$ Der Kontrast erlaubt es, nicht nur eine konkrete Tatsachenseite, sondern auch andere Versionen oder die Information in anderen Beweismitteln zu überprüfen. Die sog. „Bestätigungsevidenz" (evidencia de corroboración) ist als nützlich betrachtet worden, um begleitende Umstände zu überprüfen, Aspekte, die mit strafbarem Verhalten verbunden sind, die jedoch unter anderen zeitlichen und örtlichen Umständen stattfanden, Auswirkungen einer strafbaren Handlung, Aspekte des sozialen und familiären Umfeldes, wo die strafbare Handlung stattfindet, spezifische oder generische Umstände, die eine höhere oder geringere Strafbarkeit bestimmen, oder die Echtheit von Dokumenten oder physischen Evidenzen. ${ }^{1049}$ Die Ergebnisse der Bestätigung können verschiedene Niveaus erreichen (Mindest- oder höchstes Niveau) und würden bedeuten, dass die in dem Beweismittel enthaltene Information durch eine Tatsache, eine Angabe oder einen vom Beweismittel externen oder unabhängigen Umstand gestützt wird. ${ }^{1050}$ Im kolumbianischen Fall wäre auch die Forderung nach Bestätigung übereinstimmend mit der Forderung nach Objektivität, die von Art. 115 CPP erhoben wird, gemäß derer die FGN ihr Vorgehen objektiven und transparenten Kriterien angleichen muss. ${ }^{1051}$

Im spezifischen Fall der eidesstattlichen Erklärung des Zeugen oder Informanten (Art. 221 Abs. 1 CPP) muss die Überprüfung derselben in zweierlei Hinsicht ablaufen. Einerseits bzgl. der durch den Aussagenden verabreichten Information. Zu diesem Zwecke wäre eine Gegenüberstellung mit anderen Beweismitteln (Bestätigungsevidenz) nützlich und sogar

\footnotetext{
1047 Vgl. dazu Cuello Iriarte, 2008, S. 698; Devis Echandía, 2002, S. 321 f.

${ }^{1048}$ Bedoya Sierra, 2008, S. 78; Bedoya Sierra, 2007, S. 83.

${ }^{1049}$ Vgl. dazu ausführlich Bedoya Sierra, 2008, S. 78 ff.

${ }^{1050}$ So wird in vergleichbaren Strafverfahrensmodellen berücksichtigt, dass das zu erhärtende Element eine spezifische Angabe ist, die nicht mit der Quelle der Tatsache zusammenfällt. Für den spanischen Fall vgl. Fernández López, Cuadernos electrónicos de filosofía del derecho 15 (2007), S. 7.

${ }^{1051}$ Art. 115 CPP: „Principio de objetividad. La Fiscalía General de la Nación, con el apoyo de los organismos que ejerzan funciones de policía judicial, adecuará su actuación a un criterio objetivo y transparente, ajustado jurídicamente para la correcta aplicación de la Constitución Política y la ley.“ („Objektivitätsgrundsatz. Die Generalstaatsanwaltschaft, mit der Unterstützung der Behörden, die Befugnisse als Kriminalpolizei ausüben, wird das Vorgehen einem objektiven und transparenten Kriterium anpassen, das rechtlich für die korrekte Anwendung der Verfassung und des Gesetzes gesetzt wird.“ -dt. Übersetzung d. Verf.-).
} 
die sog. objektiven peripherischen Bestätigungen (corroboraciones periféricas objetivas), die von der Doktrin als Teil einer möglichen Bestätigungsevidenz betrachtet werden. ${ }^{1052}$ Die Folge der Bestätigungsevidenz muss gleichzeitig durch die FGN als Entwicklung des methodologischen Ermittlungsprogramms geplant werden. ${ }^{1053}$ Die Analysen bzgl. der Glaubwürdigkeit der Information dürfen nicht bis zur Hauptverhandlung hinausgeschoben werden, sondern müssen, wie oben erwähnt, Teil des Prozesses der Begründung jeglichen Eingriffs in Grundrechte des Verdächtigen in der Ermittlungsphase sein. ${ }^{1054}$ Andererseits muss die FGN die Leistungsfähigkeit der Zeugen und Informanten prüfen, um die Information der eidesstattlichen Erklärung zunehmen, zu sammeln und zu übergeben. Mit anderen Worten, zur Überprüfung der Glaubwürdigkeit des Aussagenden ist eine vorherige Analyse der Aussagekraft der Aussage und des Aussagenden notwendig, unabhängig von der Wertung, der sie in der Kontrollanhörung unterzogen wird. Unter den Kriterien, die für die Überprüfung dieser Erklärungen genannt werden, wird erwähnt, dass die FGN die Möglichkeit der Wahrnehmung, die Fähigkeit der Erinnerung und die der Übermittlung der erworbenen Erkenntnis bewerten muss. ${ }^{1055}$ Diese Kriterien werden von Art. 404 CPP eingeführt, der die Aufnahme der Zeugenaussage durch den Richter betrifft. ${ }^{1056}$

Auf einem zweiten Niveau erfordert die Eignung der Beweisgrundlage eine Bewertung des Beweismittels bzgl. der Fähigkeit desselben zur Bestätigung einiger wesentlicher Aspekte der zumutbaren Schlussfolgerung. Im Falle der Ermittlungsmaßnahmen, die eine zweite Qualifikation der fundierten Anhaltspunkte erfordern, definiert die zumutbare Inkulpationsschlussfolgerung die Parameter der Zurechnung als Täter oder Teilnehmer. Dafür müssen die Tatbestandsmerkmale bestätigt werden, welche die ermittelte Handlung konstituieren, ${ }^{1057}$ im dem Sinne, dass die Verdachtsindizien gegenüber den entlastenden eine Vorrangstellung einnehmen, so wie oben beschrieben. ${ }^{1058}$ So wie ein breiter Teil der Strafprozessdoktrin erkennt, ,ist die Kenntnis der Strafdogmatik eng mit der Bestimmung der Sachdienlichkeit der materiellen Beweiselemente verbunden, denn nur ausgehend von die-

1052 Bedoya Sierra, 2008, S. 108; Fernández López, Cuadernos electrónicos de filosofía del derecho 15 (2007), S. 7.

${ }^{1053}$ Bedoya Sierra, 2008, S. 108.

${ }^{1054}$ Vgl. Bedoya Sierra, 2008, S. 63; Rodríguez Chocontá, 2012, S. 133 ff.; KVerfG, Entsch. C-673 v. 2005, Abschn. „Consideraciones de la Corte“; dazu supra A. II. 1. Meinungsstand zum Art. 221 CPP.

${ }^{1055}$ Bedoya Sierra, 2008, S. 90; s. dazu Rodríguez Chocontá, 2012, S. $181 \mathrm{ff}$.

${ }^{1056}$ Für den Art. 404 CPP vgl. supra Fn. 1044; bzgl. der Würdigung der Zeugenaussage im CPP vgl. Rodríguez Chocontá, 2012, S. 319 ff.

${ }^{1057}$ Bedoya Sierra, 2008, S. 206.

${ }^{1058} \mathrm{Vgl}$ supra § 9. C. I. 2. Inkulpationsgrad. 
ser Kenntnisnahme kann mit Genauigkeit festgestellt werden, was bewiesen werden soll." ${ }^{1059}$ Für die Schlussfolgerung bzgl. einer Beweisentdeckung ist es notwendig, jede einzelne Maßnahme aufzufassen. Diese Art Schlussfolgerung würde grundsätzlich eine Prognose oder eine prospektive Diagnose erfordern, von der aus eine für die Ermittlung taugliche Information entdeckt wird. Im folgenden Abschnitt werden die Analyse der Zweckmäßigkeit der zumutbaren Schlussfolgerungen durchgeführt und die Schwierigkeiten für die Beweisgrundlage der fundierten Anhaltspunkte angesprochen, die die besagten Schlussfolgerungen stützen.

\section{Ergebnis}

Eine extensive Interpretation von Art. 221 CPP für die Beweisgrundlage der fundierten Anhaltspunkte muss einen restriktiven Ansatz der Maxime der freien Beweiserhebung in Betracht ziehen. Trotz der formellen Ausdrucksweise von Art. 221 CPP und des Ansatzes des KVerfG im Urteil C-673 von 2005, hat die Rechtfertigung einer Praxis, in der höhere Gegenüberstellungen angeregt werden, um zu dieser Beweisgrundlage zu gelangen, eine explizite Grundlage im CPP. Auf der Grundlage der Sachdienlichkeit, die der Möglichkeit der Annahme der Beweismittel innewohnt, die sowohl im Art. 207 Abs. 3 als auch in Art. 375 CPP festgelegt ist, kann ein Erfordernis nach Bestätigung der Beweismittel begründet werden, vor allem solcher, gegenüber denen eine gewisse Vertraulichkeit als berechtigt angesehen wird, wie die eidesstattliche Erklärung von Zeugen oder Informanten. Dies würde eine Analyse auf verschiedenen Niveaus erfordern. Einerseits ist die Bestätigung der gesammelten Information eine definitorische Praxis der Geeignetheit des Beweismittels. Im Falle der eidesstattlichen Erklärung von Zeugen und Informanten muss die in Art. 404 CPP beschriebene Regelung bzgl. der Wertung der Erklärung gelten. Andererseits erfordert die Feststellung der Beweisgrundlage der fundierten Anhaltspunkte die Durchführung eines Wahrscheinlichkeitsurteils, das die Feststellung der Fähigkeit des Beweismittels für die Begründung einer zumutbaren Schlussfolgerung zulässt.

\footnotetext{
1059 Bedoya Sierra, 2008, S. 206: „el conocimiento de la dogmática penal está íntimamente ligado a la determinación de la pertinencia de los elementos materiales probatorios, pues sólo a partir de dicho conocimiento puede establecer con precisión lo que se debe probar.“ (dt. Übersetzung d. Verf.). 


\section{B. Ziele der zumutbaren Schlussfolgerungen}

\section{Problemstellung}

Die zumutbare Schlussfolgerung ist eines der wesentlichen Komponenten der fundierten Anhaltspunkte. ${ }^{1060}$ Es ist nicht nur das abschließende Element im Verfahren zur Feststellung der fundierten Anhaltspunkte, sondern auch eine besondere Grundlage für eine richterliche Entscheidung, die dazu führt, eine Ermittlungsmaßnahme anzuordnen oder zu bestätigen. Als Verschlusselement steht die zumutbare Schlussfolgerung am Ende der (deduktiven oder induktiven) Analyse der objektiven Tatsachenseite, die mit der Beweisgrundlage durch eines der vom CPP bewilligten Erkenntnismittel unterstützt werden muss. Diese Art von abschließender Zusammenfassung gibt Aufschluss über verschiedene Wahrscheinlichkeitsgrade, ${ }^{1061}$ abhängig von der Verfahrensphase, in der sie durchgeführt werden, der Ermittlungsmaßnahme, die versucht wird anzuordnen oder zu bestätigen und der Intensität des Eingriffs in das Grundrecht, das hiervon beeinträchtigt wird. Als besondere Grundlage für einige richterliche Entscheidungen erfordert die zumutbare Schlussfolgerung besondere Entscheidungen, die davon abhängen, ob man versucht, eine Ermittlungsmaßnahme anzuordnen, eine Beschuldigung zu erheben oder die Grundlage für die Vorlage eines Anklageschreibens zu erlangen. Im Falle der Anordnung von Ermittlungsmaßnahmen ist die Regelung für zumutbare Schlussfolgerungen im CPP heterogen. Zusätzlich zur Täterschaft- oder Teilnahmeschlussfolgerung des Verdächtigen einer Straftat sieht der CPP eine andere Art von Schlussfolgerungen vor, die darauf hinauslaufen, die Entdeckung tauglicher Information oder sogar das einfache Einschreiten bzgl. einer Straftat zu begründen mit dem Ziel, dieselbe zu neutralisieren. ${ }^{1062}$

Diese drei Niveaus der zumutbaren Schlussfolgerungen, die im Rahmen der Begründung für die Anordnung oder Bestätigung der Ermittlungsmaßnahmen eingeführt werden, sind nicht nur heterogen, sondern auch vorausbestimmend für den Strafermittlungsapparat für außergerichtliche Ziele. Es handelt sich nicht nur um den Eingriff mittels Ermittlungsmaßnahmen in Grundrechte von vermutlichen Straftätern oder Teilnehmern, sondern auch um die Anwendung von Ermittlungsmaßnahmen mit eminent taktischem Charakter als Instru-

\footnotetext{
1060 Vgl. Zuluaga, NFP 83 (2015), S. 194 ff.; dazu supra § 7. A. I. Verfassungsrechtliche Bedeutung. 1061 Vgl. Suarez, Principia Iuris 16 (2011), S. 307 ff., mit der Unterscheidung zwischen Schlussfolgerung (inferencia), Wahrheitswahrscheinlichkeit (probabilidad de verdad) und Kenntnis über jeden vernünftigen Zweifel (Conocimiento más allá de duda razonable). 1062 Vgl. Zuluaga, NFP 83 (2015), S. 194 ff.; Guerrero Peralta, 2006, S. 144 f.
} 
mente zur strafrechtlichen Reaktion auf die Ausübung einer Straftat. Diese Durchführung der Ermittlungsmaßnahmen ist notorisch in verdeckten Ermittlungstätigkeiten, die vom CPP geregelt werden, wie z.B. die Überwachung von Personen (Art. 239), die Überwachung von Sachen (Art. 240), Analyse und Infiltrieren krimineller Organisationen (Art. 241), der Einsatz verdeckter Ermittler (Art. 242) und die verdeckte Überwachung von Transport, Verkauf, Vermietung von Waffen, Sprengstoff, Munition, Falschgeld und Drogen (Art. 243). Diese Maßnahmen verstehen sich als polizeiliche Intervention anteiudicium mit dem Ziel, die kriminellen Organisationen oder die Ausübung von Straftaten zu neutralisieren. ${ }^{1063}$

Die Tatsache, dass diese Ermittlungsmaßnahmen außergerichtlichen Zielen unterstellt werden, hat verschiedene Konsequenzen, sowohl in Bezug auf die Rolle der Kriminalpolizei als auch auf die der Ergebnisse des JCG bei der Kontrolle der Ermittlungsmaßnahmen. Einerseits handelt es sich um Szenarien, in denen die Polizei mit einem weit gesteckten Ermessen intervenieren kann, d.h., wo die Ermittlungsbehörde keinen genauen Regeln der Überwachung durch die FGN unterworfen ist. Andererseits, da es sich - in allen erwähnten Fällen - um Maßnahmen handelt, die einer nachträglichen Kontrolle durch den JCG und Kontrollanhörungen unterworfen sind, wo die Anwesenheit der Verteidigung nicht verpflichtend ist, hat die materielle Kontrolle der Ermittlungen die Tendenz, ungenügend zu sein. Das Problem dieser Art von Schlussfolgerungen wird z.B bei der Eröffnung von Kompetenzen ante oder extra-iudicium für die Kriminalpolizei deutlich und der Einschränkung des Kontrollsystems der Garantien für die Rechtfertigung von außergerichtlichen Ermittlungen, die nicht streng genommen auf einer Schlussfolgerung im Inkulpationsgrad bzgl. einer Täterschaft oder Teilnahme aufbauen. Im Folgenden werden diese Grade der zumutbaren Schlussfolgerungen beschrieben, wobei unterschieden werden soll zwischen denen, die zum Ziel das Einschreiten bei Straftaten und jenen, die das Vorhandensein von für die Ermittlung tauglicher Information haben.

\section{Streitfälle}

Im CPP findet sich keine Einordnung der zumutbaren Schlussfolgerungen, aber die Regelung jeder Ermittlungsmaßnahme beinhaltet einen ausdrücklichen Hinweis auf dieselben.

${ }^{1063}$ Zuluaga, Co-Herencia Vol. 4 Nr. 6 (2007), S. 142; Vgl. Guerrero Peralta, 2007, S. 360 ff.; Bernal Cuellar/Montealegre Lynett, 2013 T. II, S. 275 ff.; ausführlich supra § 5. und § 6. Nachträglicher Rechtsschutz gegen Maßnahmen zur Beschränkung der Intimität, der Unverletzlichkeit der Kommunikation und der Freiheit. 
Die vom CPP aufgenommene Begrifflichkeit bzgl. der zumutbaren Schlussfolgerungen ist vielseitig. Wie oben bemerkt, bezieht sie sich in einigen Fällen auf eine Schlussfolgerung zu Täterschaft oder Teilnahme bei einer Straftat (Inkulpationsschlussfolgerung). Diese Art Schlussfolgerung ist sowohl den Hausdurchsuchungen eigen (Art. 220 CPP) als auch den Voraussetzungen für die Erhebung der Beschuldigung (Art. 287 CPP). Eine konkrete Schlussfolgerung ist auch in der Regelung für das Zurückhalten von Korrespondenz (Art. $233 \mathrm{CPP}) \mathrm{zu}$ finden, wo direkt gefordert wird, dass taugliche Information für die Ermittlung vorhanden ist, sowie auch in der Regelung für die Überwachung von Personen (Art. 239 CPP); jedoch ist bei anderen Maßnahmen die Art der geforderten Schlussfolgerung unpräzise. Dies ist der Fall bei der Wiederbeschaffung von Informationen, die aus der Datenübermittlung hervorgehen (Art. 236 CPP), den Überwachungsmaßnahmen an Sachen (Art. 240 CPP), der Analyse und Infiltration krimineller Organisationen (Art. 241 CPP), dem Einsatz verdeckter Ermittler (Art. 242 CPP), der verdeckten Überwachung des Transports bzw. der Übergabe von verbotenen Gegenständen (Art. 243 CPP) und der selektiven Suche in Datenbanken (Art. 244 CPP). In allen diesen Fällen wird nicht schlussfolgernd verlangt, dass der Verdächtige Täter oder Teilnehmer einer Straftat ist oder dass taugliche Information für die Ermittlung existiert, sondern dass der CPP Schlussfolgerungen vorschlägt, wie z.B. die der Zugehörigkeit zu einer kriminellen Organisation, des Eingriffs in eine Straftat oder des Gebrauchs einiger Elemente zum Durchführen der Straftaten.

Über die Inkulpationsschlussfolgerung hinausgehend fordern die erwähnten Arten von Schlussfolgerungen eine Entscheidung bzgl. der Begehung der Straftat. Nur auf Grund dieser Entscheidung, d.h. der zumutbaren Schlussfolgerung, wird das Ziel jeder Maßnahme bestimmt, das in den meisten Fällen darin besteht, ,taugliche Information für die Ermittlung“ (información útil para la investigación) zu finden. In diesem Sinne wird die Beweisentdeckung durch eine Ermittlungsmaßnahme in einigen Fällen als Ergebnis der zumutbaren Schlussfolgerung ausgegeben, in anderen Fällen als das Ziel der Ermittlungsmaßnahme. Diese Art von Schlussfolgerungen führen zur Durchführung von Wahrscheinlichkeitsurteilen, nicht mehr mit retrospektivem Charakter wie bei der Inkulpationsschlussfolgerung, sondern hauptsächlich mit prospektivem Charakter. Der prospektive Charakter des Wahrscheinlichkeitsurteils wird wesentlich bzgl. der Tauglichkeit der Information deutlich, die als Ergebnis der Durchführung einer Ermittlungsmaßnahme zusammengestellt wird. Jedoch entspricht, wie wir im Folgenden sehen werden, die Grundlage dieses Wahrscheinlichkeitsurteils nicht der retrospektiven Diagnose der Täterschaft oder Teilnahme. 
Im Folgenden werden diese beiden Stufen der zumutbaren Schlussfolgerung analysiert, um danach eine kritische Stellungnahme über ihre Grundlage und Auswirkungen in der Strafermittlung anzustellen.

\section{Zumutbare Schlussfolgerungen bzgl. der Begehung von Straftaten}

Im CPP werden fünf Maßnahmen hervorgehoben, in denen Schlussfolgerungen enthalten sind, mit denen gefordert wird, die (gegenwärtige und fortgesetzte) Begehung einer Straftat festzustellen. Erstens fordert Art. 236 CPP bzgl. der Wiederbeschaffung von Information, die aus der Datenübermittlung über das Kommunikationsnetz hervorgegangen ist, dass mit der zumutbaren Schlussfolgerung festgelegt wird, dass ,der Verdächtigte Daten über das Telekommunikationsnetz übermittelt oder manipuliert.“"1064 Zweitens legt Art. 240 CPP bzgl. der Überwachungsmaßnahmen an Sachen fest, dass gefolgert werden muss, dass „,die Immobilie, das Schiff, Flugzeug, irgendein anderes Fahrzeug oder irgendein beweglicher Gegenstand zum Verkauf von Drogen genutzt wird, der Herstellung von Drogen dient, oder zum Verstecken von Sprengstoff, Waffen, Munition, bzw. zur Begehung eines Delikts im Allgemeinen dient oder aus einem solchen stammt.“1065 Drittens fordert Art. 241 CPP für die Analyse und Infiltration krimineller Organisationen die Schlussfolgerung, „dass aus der vorhergehenden Ermittlung hervorgeht, dass der Beschuldigte oder Verdächtigte einer kriminellen Organisation angehört oder mit einer solchen in Verbindung steht.“"1066 Viertens wird in Art. 242 CPP festgelegt, dass der Einsatz verdeckter Ermittler durch die FGN angeordnet wird, wenn die Schlussfolgerung der vorausgehenden Ermittlung darin besteht, „dass der Verdächtigte oder Beschuldigte weiterhin kriminelle Tätigkeiten durchführt.“1067 Fünftens fordert Art. 243 CPP für die Überwachung von Übergaben/Lieferungen die Schlussfolgerung, dass „,der Verdächtigte oder Beschuldigte Waffen- Sprengkörper-, Munitions-, Falschgeldtransport oder Transport von Drogen, die Abhängigkeit erzeugen, leitet

\footnotetext{
${ }^{1064}$ Art. 236 CPP: ,[...] el indiciado o imputado está transmitiendo o manipulando datos a través de las redes de telecomunicaciones [...].“ (dt. Übersetzung d. Verf.).

1065 Art. 240 CPP: ,[...] que un inmueble, nave, aeronave o cualquier otro vehículo o mueble se usa para almacenar droga que produzca dependencia, elemento que sirva para el procesamiento de dicha droga, o para ocultar explosivos, armas, municiones, sustancias para producir explosivos y, en general, los instrumentos de comisión de un delito o los bienes y efectos provenientes de su ejecución [...].“ (dt. Übersetzung d. Verf.); vgl. dazu supra § 5. B. III. Die Überwachungsmaßnahmen an Sachen (Art. 240 CPP).

1066 Art. 241 CPP: „[...] que el indiciado o el imputado, en la indagación o investigación que se adelanta, pertenece o está relacionado con alguna organización criminal [...].“ (dt. Übersetzung d. Verf.); vgl. dazu supra § 5. C. I. Analyse und Infiltrierung einer kriminellen Organisation (Art. 241 CPP).

${ }^{1067}$ Art. 242 CPP: , ,...] que el indiciado o el imputado en la investigación que se adelanta, continúa desarrollando una actividad criminal [...].“ (dt. Übersetzung d. Verf.); vgl. dazu supra § 5. C. II. Einsatz verdeckter Ermittler (Art. 242 CPP).
} 
oder daran in irgendeiner Art und Weise beteiligt ist oder auch, wenn er in irgendeiner Weise durch einen verdeckten oder vertraulichen Ermittler von der Tatsache unterrichtet wird, dass die Straftat weiterhin verübt wird.“1068

Wie oben schon erwähnt, diese Schlussfolgerungen gehen über die Wahrscheinlichkeit einer Täterschaft oder Teilnahme bei einer Straftat hinaus und fordern, dass die Schlüsse, die sich aus der Analyse der Gesamtheit der Tatsachen (objektive Situation) ergeben, dazu führen, dass der Verdächtigte oder Beschuldigte einer kriminellen Organisation angehört, an einer Straftat teilnimmt oder dass einige Elemente oder Materialien für die Ausübung einer Straftat verwendet werden. Diese sind die Schlussfolgerungen, von denen aus die intensivsten Eingriffe in Grundrechte durch eine verdeckte Ermittlung begründet werden. ${ }^{1069} \mathrm{Im}$ Gegensatz zu anderen Ermittlungsmaßnahmen wird von den zumutbaren Schlussfolgerungen für Maßnahmen, die die verdeckte Ermittlung regeln, nicht gefordert, ein bestimmtes Niveau der strafrechtlichen Verantwortung oder der Existenz von tauglicher Information ex ante zu bestimmen; wenigstens würde zu diesem Schluss die wörtliche Auslegung der betreffenden Artikel führen. Im Einklang mit dieser Interpretation wäre die Grundlage, um diese Art von Tätigkeiten zu rechtfertigen, der Schluss bzgl. der Zugehörigkeit zu einer kriminellen Organisation und der Eingriff bei der Begehung einer Straftat. Obwohl ein Teil der Doktrin der Meinung ist, dass eine Inkulpationsschlussfolgerung (der Täterschaft oder Teilnahme) eine materielle Grenze dieser Eingriffe darstellt, ${ }^{1070}$ besonders, wenn die Beschuldigung schon erhoben wurde, ist doch sicher, dass eine exegetische Interpretation der Vorschriften dieser Maßnahmen im CPP aus der zumutbaren Schlussfolgerung ein mögliches Wahrscheinlichkeitsurteil bzgl. der Täterschaft oder Teilnahme ausschließen würde. Das Ziel der Maßnahmen ist das Auffinden tauglicher Information, auch ohne eine vorherige Bestätigung der Existenz derselben. ${ }^{1071}$

Die zentrale Problemstellung der zumutbaren Schlussfolgerungen, die die Anordnung dieser Art von Maßnahmen begründen, ist der Schluss, ob der Verdächtigte oder Beschuldigte

\footnotetext{
1068 Art. 243 CPP: ,[...] el indiciado o el imputado dirige, o de cualquier forma interviene en el transporte de armas, explosivos, municiones, moneda falsificada, drogas que producen dependencia o también cuando sea informado por agente encubierto o de confianza de la existencia de una actividad criminal continua[...]." (dt. Übersetzung d. Verf.); vgl. dazu supra § 5. C. III. Überwachung von Übergaben/Lieferungen (Entrega vigilada) (Art. $243 \mathrm{CPP}$ ).

1069 Dazu Perdomo Torres, 2009, S. 204, für den die Rechtfertigung dieser Maßnahme sich in der Verstärkung der Ermittlungen gegen die organisierte Kriminalität findet.

${ }^{1070}$ Bzgl. der Grenzen von verdeckter Ermittlung s. Bernal Cuellar/Montealegre Lynett, 2013 T. II, S. 273.

${ }^{1071}$ I.d.S. Bernal Cuellar/Montealegre Lynett, 2013 T. II, S. 275 ff.; Guerrero Peralta, 2007, S. 394 f.
} 
eine kriminelle Tätigkeit weiterhin ausübt, oder, im Falle der Überwachungsmaßnahmen an Sachen, dass ein Element in dieser Tätigkeit benutzt wird. Diese Art Schluss wird kritisiert, denn von ihm ausgehend entsteht ein Interpretationsproblem bzgl. der Reaktion der FGN auf Grund der Kenntnisnahme der Begehung einer Straftat. Manche Meinungen laufen darauf hinaus, dass, wenn eine Straftat verübt worden ist oder eine neue vorbereitet wird, die logische Reaktion die der Festnahme, Beschuldigung und des Antrags auf eine Sicherungsmaßnahme und Anklage sein sollte. ${ }^{1072}$ Über diese Problematik hinausgehend ist ein Teil der Doktrin der Meinung, dass, wenn der CPP auf eine kriminelle Tätigkeit hinweist, dies bedeute, dass der Gesetzgeber den soeben erwähnten Schluss erlaube, denn das Ziel der Maßnahmen sei das Sammeln von für die Ermittlung tauglichen Informationen, d.h. der „Erfolg der Ermittlung. “" ${ }^{1073}$ Die Kritik gegenüber dieser Art von Ermittlungszielen weist darauf hin, dass der Erfolg der Ermittlung der des eingeschränktesten betreffenden Bereiches der verdeckten Ermittlung ist, denn das zentrale Ziel dieser Maßnahmen ist die Zerschlagung von kriminellen Organisationen und nicht das Beenden der Beteiligung des Verdächtigen oder Beschuldigten an dieser Organisation oder in der Durchführung einer bestimmten kriminellen Aktivität. ${ }^{1074}$

Insofern die zumutbaren Schlussfolgerungen, die in den die verdeckten Ermittlungsmaßnahmen regelnden Artikeln behandelt werden, insbesondere auf den Erfolg der Ermittlung hinweisen, dies aber tun, ohne ein Wahrscheinlichkeitsurteil über die Täterschaft oder Teilnahme des Verdächtigen damit zu verbinden, hat ein Teil der Doktrin versucht, materielle Grenzen gegenüber diesen Maßnahmen abzustecken. In diesem Sinn ist besonderer Wert auf das Verhältnismäßigkeitsprinzip als Grenzbereich dieser Maßnahmen gelegt worden, insbesondere um die Zumutbarkeit der Schlussfolgerung zu unterstützen, auch in der Bewertung der Tauglichkeit der Maßnahme. ${ }^{1075}$ In Fortführung dieses Gedankens besteht die Meinung, dass die Schlussfolgerung dazu führen sollte, nicht nur die Durchführung einer Straftat zu bestimmen, sondern auch dazu, festzustellen, dass die Maßnahme tauglich und angemessen ist, um das Ziel der Maßnahme zu erreichen, d.h. relevante Information zu erbringen. ${ }^{1076}$ Für die Tauglichkeitsanalysen müssen die Wahrscheinlichkeitsevaluationen

\footnotetext{
1072 Bernal Cuellar/Montealegre Lynett, 2013 T. II, S. 274; Guerrero Peralta, 2007, S. 344.

${ }^{1073}$ Guerrero Peralta, 2007, S. 395; Perdomo Torres, 2009, S. 204, 210.

1074 Guerrero Peralta, 2007, S. 395; Zuluaga, NFP 83 (2015), S. 196.

1075 Perdomo Torres, 2009, S. 208, 210 f.; Zuluaga, NFP 83 (2015), S. 195; Bernal Cuellar/Montealegre Lynett, 2013 T. II, S. 277 f.

1076 Guerrero Peralta, 2007, S. 395; Bernal Cuellar/Montealegre Lynett, 2013 T. II, S. 277. 
bzgl. des Erfolges der Maßnahme, d.h., die Analysen, die dazu führen, die Durchführbarkeit einer Maßnahme bei der Erlangung der tauglichen Information zu bestimmen, die Evaluation der Pläne zur Durchführung der Maßnahmen einbeziehen. ${ }^{1077}$ Bei der Entwicklung des methodologischen Ermittlungsprogramms muss die Planung dieser Schritte die Dauer der Durchführung, die Fähigkeiten der infiltrierten oder verdeckten Ermittler und die Intensität der Eingriffe, die bei ihrer Durchführung entwickelt werden, begründen. ${ }^{1078}$

Die Durchführbarkeit der Maßnahme ist außerdem durch das Einhalten der Regeln der Gewahrsamskette (cadena de custodia) bedingt, wodurch die Beweiskraft der durch verdeckte Ermittler erlangten Information bestimmt wird. Art. 279 CPP drückt es folgendermaßen aus:

„[...]das materielle Beweiselement und die physische Evidenz, die von einem verdeckten oder infiltrierten Agenten bei der Durchführung einer rechtmäßig programmierten Ermittlungshandlung erlangt wurden, können nur als Quelle einer Ermittlungstätigkeit benützt werden. Aber nach der Feststellung seiner Authentizität und nach Aufnahme in die Gewahrsamskette hat es den Wert jeglichen anderen materiellen Beweiselements und physischer Evidenz[...].“1079

Hieraus geht hervor, dass die während der verdeckten Ermittlung erlangte Information keine willkürliche Anwendung finden darf. Um es konkreter auszudrücken: ohne die Überprüfung der Authentizität und der Absicherung mittels einer Gewahrsamskette $e^{1080}$ kann diese Information nicht als in den Prozess aufgenommen gelten, d.h. dass sie kein Beweismittel darstellt. Es würde sich nur um eine Quelle einer Ermittlungstätigkeit handeln, d.h. eine extra-prozessuale Information, von der aus Ermittlungsmaßnahmen programmiert werden können, die jedoch weder mit einem materiellen Beweiselement gleichzusetzen sind noch mit physischer Evidenz, von der aus sogar die Existenz von fundierten Anhaltspunkten festgestellt werden könnte. Gemäß Art. 435 CPP „,sind die materiellen Beweiselemente und die physische Evidenz als authentisch zu bezeichnen, wenn sie entsprechend den Re-

\footnotetext{
1077 Perdomo Torres, 2009, S. 208; Bernal Cuellar/Montealegre Lynett, 2013 T. II, S. 276.

1078 Bernal Cuellar/Montealegre Lynett, 2013 T. II, S. 278; dazu auch Avella Franco, 2007, S. 83 ff.

1079 Art. 279 CPP: ,[...] el elemento material probatorio y evidencia física, recogidos por agente encubierto o agente infiltrado, en desarrollo de operación legalmente programada, sólo podrá ser utilizado como fuente de actividad investigativa. Pero establecida su autenticidad y sometido a cadena de custodia, tiene el valor de cualquier otro elemento material probatorio y evidencia física [...].“ (dt. Übersetzung d. Verf.).

${ }^{1080}$ Vgl. dazu ausführlich Mora Izquierdo/Sánchez Prada, 2007, Kap. 11. La cadena de custodia; Bedoya Sierra, 2008, S. 210 ff.; FGN, 2005a, S. 56.
} 
geln der Gewahrsamskette entdeckt, festgestellt, eingesammelt und technisch verpackt worden sind. “1081 In diesem Sinne haben die Beweiselemente, die aus den verdeckten Ermittlungen hervorgegangen sind, nur einen Beweiswert, wenn sie den Erfordernissen für die Aufnahme in ein Verfahren entsprechen, die in den Art. 254 - 266 CPP $^{1082}$ vorgesehen sind. Mit anderen Worten haben diese materiellen Beweiselemente oder die physische Evidenz nur Beweiswert in dem Maße, in dem die Sammlung und Aufnahme in das Verfahren den rechtlichen Erfordernissen entspricht und dies vom JCG überprüft worden ist.

Bzgl. der Entdeckung und der Sammlung von Information wurden verschiedene Kritikpunkte über die rechtlichen Grenzen der verdeckten Eingriffe aufgeführt. Insbesondere wird die Frage aufgeworfen, ob die Regelung dieser Maßnahmen nicht dazu führen könnte, dass die verdeckten Ermittler selbst Delikte verüben könnten oder in welchem Maße die Durchführung von unrechtmäßigen Aktivitäten bewilligt wird. ${ }^{1083}$ Diese Rechtslücke tritt in Art. 242 Abs. 1 CPP auf, gemäß dem ,ein oder mehrere Beamte der Kriminalpolizei oder auch natürliche Personen in dieser Eigenschaft handeln und strafrechtlich außergerichtliche Tätigkeiten mit rechtlicher Transzendenz durchführen können.“1084 Der Ausdruck ,außergerichtlich“ (extrapenal) wurde von einem Teil der Doktrin als ,authorisierte deliktive Tätigkeiten außerhalb des Strafrechts“ beschrieben. ${ }^{1085}$ Diese Definition geht aus demselben Art. 242 Abs. 1 CPP hervor, wo festgelegt wird, dass die „Beamten dazu befugt sind, in den Handelsverkehr einzugreifen, Verpflichtungen aufzunehmen, bei Versammlungen anwesend zu sein und im Arbeitsbereich des Verdächtigen oder Beschuldigten einzugreifen und, wenn es notwendig wäre, Transaktionen mit ihm durchführen können.“1086 Jedoch erlaubt die wörtliche Auslegung dieses Artikels nicht zu bestimmen, ob der Handelsverkehr und die Verpflichtungen, die sich aus der verdeckten Tätigkeit ableiten lassen,

\footnotetext{
${ }^{1081}$ Art. 435 CPP: , $[\ldots]$ los elementos materiales probatorios y la evidencia física son auténticos cuando han sido detectados, fijados, recogidos y embalados técnicamente, y sometidos a las reglas de cadena de custodia [...].“(dt. Übersetzung d. Verf.).

${ }^{1082}$ Vgl. Bernal Cuellar/Montealegre Lynett, 2013 T. II, S. 810 ff.; dazu krit. Urbano Martínez, 2011, S. 271 ff.

${ }^{1083}$ Für einen Überblick über die Einwände gegen die Vorschriften der verdeckten Ermittlung vgl. Morales Támara, 2009, S. 239 ff.

${ }^{1084}$ Art. 242 Abs. 1 CPP: ,[...] uno o varios funcionarios de la policía judicial o, incluso particulares, puedan actuar en esta condición y realizar actos extrapenales con trascendencia jurídica [...].“ (dt. Übersetzung d. Verf.).

${ }^{1085}$ Vgl. Morales Támara, 2009, S. 243: „conductas delictivas autorizadas porque quedan fuera de la Ley penal [...].“(dt. Übersetzung d. Verf.).

1086 Art. 242 Abs. 1 CPP: ,[...] agentes estarán facultados para intervenir en el tráfico comercial, asumir obligaciones, ingresar y participar en reuniones en el lugar de trabajo o domicilio del indiciado o imputado y, si fuere necesario, adelantar transacciones con él [...].“ (dt. Übersetzung d. Verf.).
} 
zulässig oder unzulässig sein müssen. ${ }^{1087}$ Wie noch auszuführen sein wird, stellt die ex ante-Wertung der Wahrscheinlichkeit einer nützlichen Information nur die Wiedergabe der Durchführung der Maßnahme dar, die durch das Ermessen des an der Durchführung der Maßnahme beteiligten Ermittlers bestimmt wird.

\section{Zumutbare Schlussfolgerungen über das Vorhandensein von taugli- cher Information}

Das Auffinden von tauglicher Information ist eine transversale Zielsetzung der Regelung der Ermittlungsmaßnahmen im CPP. Wie im vorherigen Abschnitt verdeutlicht, ist einerseits die Sammlung von tauglicher Information das Ziel selbst der Ermittlungsmaßnahmen. Sowohl bei Überwachung von Kommunikationen (Art. 235) so wie auch in der Wiederbeschaffung von Informationen, die aus der Datenübermittlung (Art. 236) und den verdeckten Ermittlungsmaßnahmen (Art. 239-243) hervorgeht, ist das Ziel der Maßnahme, ,materielle Beweismittel und physische Evidenz“ oder „taugliche Information für die Ermittlung zu erhalten“. Andererseits legt der CPP auf striktere Weise fest, dass für die Anordnung einiger Ermittlungsmaßnahmen die aus den fundierten Anhaltspunkten hervorgehende zumutbare Schlussfolgerung die Existenz von für die Ermittlung nützlicher Information sein muss. Dies ist der Fall von Art. 233 CPP, wo festgelegt wird, dass das Zurückhalten der Korrespondenz befohlen werden kann, wenn zumutbare fundierte Anhaltspunkte vorliegen, um zu folgern, dass taugliche Information für die Ermittlung vorliegt. Gleichzeitig legt Art. 239 CPP fest, dass die Staatsanwaltschaft eine Überwachung und Verfolgung von Personen anordnen kann, wenn fundierte Anhaltspunkte vorliegen, „um darauf zu schließen, dass der Verdächtigte oder Beschuldigte zum Erhalten von für die Ermittlung nützlicher Information hinführen könnte. “1088 Diese beiden Maßnahmen, d.h. das Zurückhalten der Korrespondenz und die Überwachung und das Verfolgen von Personen, binden das Vorhandensein der tauglichen Information ein - nicht als Ziel der Maßnahme, sondern als zumutbare Schlussfolgerung selbst, die aus den fundierten Anhaltspunkten hervorgehen muss. ${ }^{1089}$

${ }^{1087}$ Morales Támara, 2009, S. 243, für den allein betrachtet die Übernahme von Verpflichtungen nicht die Begehung von Straftaten impliziert.

${ }^{1088}$ Art. 239 CPP: , ,...] para inferir que el indiciado o el imputado pudiere conducirlo a conseguir información útil para la investigación que se adelanta [...].“ (dt. Übersetzung d. Verf.).

${ }^{1089}$ Vgl. Guerrero Peralta, 2007, S. 362 ff., 382 ff.; dazu supra § 5. B. Die Personenüberwachung (Art. 239 $\mathrm{CPP}$ ) und $\S 6$ A. Eingriff in die postalische Kommunikation (Art. $233 \mathrm{CPP}$ ). 
Allerdings ist, wie schon oben erwähnt, die Behandlung dieser Art von Schlussfolgerungen und allgemein des Ziels, für die Ermittlung taugliche Information zu erhalten, im CPP problematisch. Als zumutbare Schlussfolgerung wird die Existenz von tauglicher Information auf zwei verschiedenen Stufen behandelt. Erstens, wie es bei der Regelung des Zurückhaltens der Korrespondenz (Art. 233 CPP) der Fall ist, würde die zumutbare Schlussfolgerung zu einem retrospektiven Schluss führen, d.h. einer Bestätigung ex ante, dass diese Information existiert. Zweitens, wie es bei der Regelung der Überwachung und dem Verfolgen von Personen der Fall ist (Art. 239 CPP), verlangt die zumutbare Schlussfolgerung einen prospektiven Schluss bzgl. der Tatsache, dass der Verdächtigte oder Beschuldigte zur Erlangung von tauglicher Information führen könnte. ${ }^{1090}$ In diesem Fall ist es nicht die Bestätigung der Existenz tauglicher Information, sondern eine Projektion bzgl. der Information, die durch die Überwachung und das Verfolgen des Verdächtigen oder Beschuldigten erlangt werden könnte. Diese Stufen von zumutbaren Schlussfolgerungen legen zwei verschiedene Ansichten bzgl. der Sammlung von Informationen offen und lassen einige Schwierigkeiten für das Verständnis dieser Tätigkeit erkennen, sowohl von Seiten der zumutbaren Schlussfolgerung als auch von Seiten der Zielsetzung derselben.

Die relevantesten Kritiken sind gegenüber der Behandlung der Sammlung von Informationen als Ziel der Ermittlungsmaßnahmen im CPP ausgesprochen worden, besonders bzgl. der Probleme, die die wörtliche Interpretation von Art. 239 CPP hervorruft. Einige Meinungen laufen darauf hinaus, dass die Aufnahme der Suche nach materiellen Beweismitteln als Ziel der Maßnahme oder Schlussfolgerung, die aus dem fundierten Anhaltspunkt hervorgeht, ein eingeschränktes Ziel ist. ${ }^{1091}$ In diesem Sinne ist die Ermittlungsmaßnahme nur ein Mittel, um zu einem Beweismittel zu gelangen, jedoch sind die Regelungen für diese Maßnahmen nicht klar in Bezug auf die Beweisfähigkeit dieser Beweismittel. Außerdem beinhaltet der weit gefasste Ausdruck ,tauglich für die Ermittlung“ ein breites Spektrum von Möglichkeiten über den Gebrauch der materiellen Beweiselemente oder der physisch erbrachten Evidenz. Diese Elemente können in mehrerlei Hinsicht tauglich sein, wie z.B. zur Unterstuitzung der Grundlage für eine Beschuldigung oder Anklage oder sie können einfach eine andere notitia criminis belegen. Das zentrale Problem beruht darin, dass die Ambiguität des Begriffs „taugliche Information“ dahin führt, dass die Wertung der

1090 Vgl. Bernal Cuellar/Montealegre Lynett, 2013 T. II, S. 271, 273; dazu supra § 5. B I. 1. Anordnung des Staatsanwalts aufgrund von fundierten Anhaltspunkten.

1091 Vgl. Guerrero Peralta, 2007, S. 373. 
Tauglichkeit von der Kriminalpolizei selbst bei der Durchführung der Ermittlungsmaßnahme getroffen werden kann. Die Wertungen bzgl. der Eignung der Beweiselemente würden allein vom Sachverstand der Kriminalpolizei abhängen und in diesem Sinne von einem nicht eingeschränkten Ermessen. ${ }^{1092}$

Dieses zuletzt angesprochene Problem stand mit den verschiedenen Regelungen in $\mathrm{Zu}$ sammenhang, die Bezug nehmen auf das passive Verfolgen von Personen, wie es z.B. auch in Art. 243 Gesetz 600 von 2000 (vorheriger CPP) der Fall ist, der die Beweissicherung durch das passive Überwachen von verdächtigen Tätigkeiten regelte. Diesem Artikel wurde vorgeworfen, dass die Durchführung dieser Maßnahme sich am willkürlichen Vorgehen der Kriminalpolizei orientiert. Dies wurde sogar zum Gegenstand von unterschiedlichen Klagen vor dem KVerfG, die im Urteil C-431 von 2003 entschieden wurden. ${ }^{1093}$ Ausgehend von der strikten Auslegung des beklagten Artikels befand das KVerfG, dass diese Tätigkeiten nicht nach dem willkürlichen Ermessen von Seiten der Kriminalpolizei gehandhabt werden können, sondern dass „die Existenz von objektiven externen Umständen gefordert ist, die konkrete Indizien über die Angelegenheit oder wenigstens die Existenz eines Beweisprinzips geben." ${ }^{1094}$ Für einen Teil der Doktrin setzt diese Haltung des KVerfG eine Grenze für die Bewilligung der passiven Überwachung als versteckte Ermittlungsmaßnahme, insofern die Maßnahme mit der Existenz von fundierten Anhaltspunkten beginnt und endet, wenn diese fundierten Anhaltspunkte nicht mehr existieren. ${ }^{1095}$ In diesem Sinne ist die Auffassung des KVerfG relevant, insofern sie erfordert, dass der Schluss der passiven Überwachung dokumentiert wird, der die Parameter der Handlungen der Kriminalpolizei aufstellt. ${ }^{1096}$ Auf diese Weise wäre die Zulässigkeit der gesammelten Beweiselemente nicht nur durch die Tauglichkeit und ihre Eignung für die Ermittlung bestimmt, sondern genauer gesagt durch das Einhalten der Grenzen, die bei der Durchführung durch die Staatsanwaltschaft festgesetzt werden und die dokumentiert und ausdrücklich begründet sein müssen.

\footnotetext{
1092 I.d.S. Zuluaga, NFP 83 (2015), S. 196; dazu infra § 10. C. I. Polizeiliche Vormachtstellung in der Bestimmung der ,, motivos fundados “.

${ }^{1093}$ KVerfG, Entsch. C-431 v. 2003, Abschn. „Consideraciones de la Corte“; dazu Gonzalez Mongui, 2007, S. 24 f.; Martínez Rave, 2002, S. 329.

${ }^{1094}$ KVerfG, Entsch. C-431 v. 2003, Abschn. 3.3.: „[...].se requiere la existencia de circunstancias objetivas, externas, que constituyan indicios concretos sobre el particular o la existencia de a lo menos un principio de prueba. [...].“ (dt. Übersetzung d. Verf.).

${ }^{1095}$ Bernal Cuellar/Montealegre Lynett, 2013 T. II, S. 272.

${ }^{1096}$ KVerfG, Entsch. C-431 v. 2003, Abschn. 3.3.
} 


\section{Kritische Überlegung zu Schlussfolgerungen im CPP}

Die vom CPP vorgesehenen verdeckten Ermittlungsmaßnahmen haben für die Ermittlung vorbereitenden Charakter. Dies kann aus den verschiedenen Artikeln des CPP entnommen werden, die als Ziel der Maßnahmen das „Einsammeln tauglicher Information“ festlegen. Diese Maßnahmen sind grundsätzlich für den Einsatz in bestimmten Bereichen der Kriminalität, wie z.B. das organisierte Verbrechen, bestimmt. ${ }^{1097}$ So legt es z.B. Art. 241 CPP in Bezug auf die Analyse und Infiltration krimineller Organisationen fest, deren Grundsatzregeln in den folgenden versteckten Ermittlungsmaßnahmen wiederholt genannt werden. Der Akzent dieser Maßnahmen, die für die Anwendung in kriminellen Strukturen mit dem Ziel, taugliche Informationen zu finden, gedacht sind, legt spezifische Bedingungen für die Begründung der Anordnung dieser Maßnahmen fest. Die Gründe für die Genehmigung dieser Maßnahmen machen prospektive Diagnosen sowohl bzgl. der Möglichkeit, materielle Beweismittel oder physische Evidenz zu finden, notwendig als auch bzgl. der Tauglichkeit dieser Beweismittel. Zusätzlich dazu gehört die objektive (faktische) Tatsachenseite, auf denen diese Diagnosen beruhen, zu dem Bereich der strukturell organisierten Kriminalität oder steht mit ihr im Zusammenhang. ${ }^{1098}$

Gerade auf Grund dessen, dass es sich bei den Maßnahmen um solche handelt, die auf prospektiven Verfahren bzgl. des Beibringens von Information und der Tauglichkeit derselben im Bereich der organisierten Kriminalität, wie oben erwähnt, beruhen, wird bezweifelt, dass diese Maßnahmen tatsächlich außergerichtliche Ermittlungsmechanismen darstellen, die von konkreten „Sicherheitserwartungen“ ausgehen. Genauer gesagt handele es sich um Reaktionen gegenüber (vermutlichen) Straftaten, gefährlichen oder riskanten Situationen auf Grund von Ermittlungs-, Kontrollmaßnahmen oder anderen prozessualen Zwangsmaßnahmen. ${ }^{1099}$ Eine repräsentative Konstellation von Fällen, die der Intervention über Sicherheitserwartungen entspricht, kann in der „Analyse und Infiltration krimineller Organisationen“ (Art. 241 CPP) gefunden werden. Wie schon erwähnt, verpflichtet der Wortlaut dieser Vorschrift die Begründung zweier Angelegenheiten. Einerseits muss feststehen, dass der Verdächtigte mit dem organisierten Verbrechen in Verbindung steht. Andererseits muss aus den fundierten Anhaltspunkten gefolgert werden, dass er weiterhin in

${ }^{1097}$ Vgl. Guerrero Peralta, 2007, S. 382; Perdomo Torres, 2009, S. 204. Für eine ausführliche Kritik an der verdeckten Ermittlung als außerordentliches Mittel für die Bekämpfung der organisierten Kriminalität in der spanischsprachigen Strafprozessrechtsdoktrin vgl. Cardoso Pereira, 2003, S. 389 ff., $441 \mathrm{ff}$.

1098 Perdomo Torres, 2009, S. 204 f.; Guerrero Peralta, 2007, S. 393.

${ }^{1099}$ I.d.S. für den deutschen Fall vgl. Zabel ZIS 7-8/2014, S. 346. 
kriminelle Tätigkeiten verwickelt ist. ${ }^{1100}$ Jedoch wird nicht die strafrechtliche Konsequenz des Bruchs der Strafnorm unterstützt, sondern es handelt sich um eine strafrechtliche Reaktion der Beobachtung der Kriminalität mit dem Ziel ihrer Neutralisation. Dies ist der Grund, warum Kritik erhoben wird gegenüber der Rechtfertigung der Infiltration einer Organisation, und zwar in Fällen, in denen der Verdächtigte schon ein Verbrechen begangen hat oder sich darauf vorbereitet, ein (weiteres) zu begehen, indem er noch Teil der kriminellen Organisation ist. Bei derartigen Situationen könne die Meinung vertreten werden, dass belastende fundierte Anhaltspunkte bestehen, von denen aus zumindest eine Beschuldigung ausgesprochen muss, jedoch nicht notwendigerweise eine Sicherheitsmaßnahme ${ }^{1101}$ beantragt werden.

$\mathrm{Zu}$ einer nicht ausartenden Durchführung dieser Maßnahme würde die Bedingung von „materiellen spezifischen Grenzen“ für die Rechtfertigung der Anordnung der FGN führen. Wenn die Meinungen über die Restriktion dieser Maßnahmen in Bezug auf das Verhältnismäßigkeitsprinzip berücksichtigt werden, würde die Durchführung dieser Art von Maßnahmen spezifische Grenzen haben. Die Rechtfertigung der Maßnahme muss nicht nur die Geeignetheit, Erforderlichkeit, Angemessenheit und Verhältnismäßigkeit beinhalten, sondern auch die Fähigkeit haben, die Existenz des Verbrechens zu beweisen und demgemäß die Schlussfolgerung im Inkulpationsgrad stützen. ${ }^{1102}$ Jedoch gerade an der Grenze zwischen der Begründung der Maßnahme und der retrospektiven Diagnose über die Täterschaft und Teilnahme (Schlussfolgerung bzgl. der strafrechtlichen Haftung) öffnet sich der Rahmen für Entscheidungsprozesse bzgl. einer Ermittlungsmaßnahme im Bereich von politisch-kriminellen Werten, die über die Definition von individuellen Verantwortlichkeiten hinausgehen. In diesen Fällen verliert die Bindung der fundierten Anhaltspunkte an eine Schlussfolgerung bzgl. der Täterschaft oder Teilnahme ihren funktionalen Grenzcharakter der Ermittlung und geht in eine Verbindungsfunktion über, als eine Art Scharnier zwischen

\footnotetext{
${ }^{1100}$ Vgl. Morales Támara, 2009, S. 239 ff.; Bernal Cuellar/Montealegre Lynnet, 2013, T. II S. 276; Guerrero Peralta, 2006, S. 144 f.; dazu supra § 5. C. I. Analyse und Infiltrierung einer kriminellen Organisation (Art. 241 CPP).

1101 Guerrero Peralta, 2006, S. 144 f., widerspricht dieser Auslegung, da der Zweck der Maßnahme der Erfolg der Ermittlung im Sinne der Zerlegung organisierter Verbrecherbanden ist; bzgl. der Vorschriften der verdeckten Ermittlung s. Morales Tamara, 2009, S. 239 ff.

1102 Bzgl. des Verhältnismäßigkeitsgrundsatzes und der Tauglichkeit der Beweismittel als materielle Grenze der Ermittlungshandlung vgl. Bernal Cuellar/Montealegre Lynnet, 2013, T. II, S. 273 f.; es sollte hinzugefügt werden, dass im Falle von verdeckten Ermittlern der Gesetzgeber ihre Verwendung für kriminelle Organisationen und für Verbrechen gegen die öffentliche Verwaltung beschränkt (Art. 242A CPP).
} 
gesellschaftlichen Sicherheitserwartungen und der Auflage, Rechtsgüter mit strafgesetzlichen Mitteln zu schützen. ${ }^{1103}$

Daraus ergeben sich verschiedene Konsequenzen bzgl. der Rollen und Kompetenzen der Parteien und Beteiligten dieses Strafverfahrens, unter denen es wichtig ist, Folgendes herauszustellen: Erstens, die Eröffnung dieser Art von Maßnahmen zur Erlangung von ,tauglicher Information“ würde zu der Möglichkeit von kollateralen ungehinderten Unterermittlungen führen. ${ }^{1104}$ Es würde sich nicht um Ermittlungen handeln, die durch die Voraussetzungen einer „Falltheorie“ (teoría del caso) ${ }^{1105}$ geregelt würden, die den gerichtlichen Schluss der Verfahrenswahrheit begrenzt, sondern um eine polizeiliche Ausübung, bei der klare Grenzen fehlen, und deren Ziel es wäre, subjektiven kriminalistischen Vermutungen Verdachtscharakter zu verleihen. ${ }^{106}$ Zweitens erweist es sich als problematisch von Seiten des Schutzgrades gegenüber der Unschuldsvermutung für diejenigen, die von Überwachungstätigkeiten betroffen sind. ${ }^{1107}$ Diese Maßnahmen berechtigen einen hohen Grad bei Eingriffen, ohne Klauseln, die eine unangebrachte Intensität des Eingriffs abgrenzen würden. Dieser Punkt wird nicht nur auf Grund des Fehlens einer verfassungsrechtlichen Grundlage angegriffen, sondern auch auf Grund der mangelnden Effizienz, vor allem im Bereich des Kampfes gegen die organisierte Kriminalität. ${ }^{1108}$ Drittens bestehen wichtige Auswirkungen in Bezug auf die Art, wie eine nachträgliche Kontrolle des Eingriffs ausgeübt wird. Dem JCG wird eine detaillierte Evaluierung der materiellen Durchführung dieser Maßnahme erschwert und gleichzeitig wird in der Verhältnismäßigkeit im engsten Sinne eine Wertung bzgl. des Kriteriums des „Exzessverbots“"1109 erschwert.

\footnotetext{
${ }^{1103}$ Zuluaga, NFP 83 (2015), S. 196; bzgl. des Tatverdachts vgl. Zabel ZIS 7-8/2014, S. 346.

${ }^{1104}$ Hiervor warnen viele Meinungen in der deutschen Strafprozesslehre, welche anzeigen, dass die Ermittlungsüberschreitung zur Gewinnung des Anfangsverdachts und die Spannung zwischen Sachverhaltserforschung und der Aufklärungspflicht des Gerichts mit einer entsprechenden endlosen Ermittlungstätigkeit einhergehen. Vgl. dazu Deiters, 2006, S. 163; i.d.S. Ambos, Jura 2003, S. 680 m.w.N.

${ }^{1105}$ Vgl. dazu Avella Franco, 2007, S. 105 ff.

1106 Ambos, Jura 2003, S. 679 (,die Polizei setzt völlig selbstständig ihre Ermittlungsschwerpunkte proaktiv"). Für die Problematik der Kontrolle der Polizei durch die Staatsanwaltschaft s. Hüls, 2007, S. 229 ff.: bzgl. der Antizipation staatsanwaltschaftlicher Entscheidung seitens der Polizei s. Elsner, 2008, S. 85 ff.

${ }^{1107}$ Für eine Analyse der Leistungen des richterlichen Rechtsschutzes vor Maßnahmen im Kampf gegen die organisierte Kriminalität in Deutschland vgl. Paa, 2013, S. 103 f., 135 f., 168 f., 192 f., 203 f., 216 f., 235 f.

${ }^{1108}$ Für die Infragestellung der Legitimität und Effizienz der Maßnahmen mit hohem Eingriff in die Grundrechte vgl. Kohlmann, 2010, S. 214 ff.; bzgl. der Telekommunikationsüberwachung Dorsch, 2005, S. 309 ff.; krit. bzgl. V-Leuten und schwacher Kontrolle des Ermittlungsrichters Doka, 2008, S. 215 ff.

${ }^{1109}$ I.d.S. Guerrero Peralta, 2006, S. 138. 
Zusammenfassend kann gesagt werden, dass die Regelung der zumutbaren Schlussfolgerungen im Rahmen ihrer Ziele ein zusätzliches Hindernis für die richterliche Überprüfung der fundierten Anhaltspunkte darstellt. Es handelt sich um heterogene Referenzen, die von der Schlussfolgerung zu Täterschaft und Teilnahme bis zu Angelegenheiten der Normalisierung von Sicherheitserwartungen, Gefahrvermutungen oder kollektiven Ängsten reichen. ${ }^{1110}$ Mit anderen Worten, die Berechnungen, die sich aus der Analyse der fundierten Anhaltspunkte ergeben müssen, artikulieren die Interaktion zwischen Sicherheitserwartungen und Verfahrensgarantien. Die Öffnung zu diffusen politisch-kriminellen Referenzen schränkt die Ausübung des gerichtlichen Schutzes der strafrechtlich Verfolgten ein, denn die Rechtfertigungen der Ermittlungsmaßnahmen überschreiten den Rahmen der gerichtlichen Definition der individuellen Verantwortlichkeiten und damit die Verpflichtung zur Konkretion und Determinierung der fundierten Anhaltspunkte einer Ermittlungsmaßnahme.

\section{Lösungsversuch}

Die weitreichenden Auswirkungen der verdeckten Ermittlungen, die sich aus Schlussfolgerungen von Beweisgewinnung ergeben, werfen die Notwendigkeit auf, strengere Bedingungen für die Anordnung einzuführen. Angesichts der Unmöglichkeit einer parallelen Überprüfung der Durchführung dieser Maßnahmen sind die Genehmigungs- und Kontrollbedingungen die externen Grade der Durchführung der Maßnahme, ex ante und ex post, die am geeignetsten sind, den weit gesteckten Rahmen des Ermessens der Kriminalpolizei zu umfassen, welcher auf der Grundlage der Vermutungen der Beweisentdeckungen beruht. Grundsätzlich müssen drei Aspekte verstärkt werden, die sich einerseits auf die Anordnung und andererseits auf die Kontrolle der Maßnahme beziehen. Erstens muss die Genehmigung der Maßnahmen auf einer Inkulpationsschlussfolgerung basieren. Die Analyse dieser Schlussfolgerung scheint wegzufallen, wenn diese Maßnahmen in der Vorermittlungsphase, also vor der Erhebung der Beschuldigung, durchgeführt werden. Die Konsequenz hieraus bedeutet, dass im Befehl für die Durchführung dieser Maßnahme ein minimaler Grad an Überzeugung über die Täterschaft oder Teilnahme des Verdächtigen an einer konkreten Straftat ausgeschlossen werden kann. Diese Kritik ist, wie wir oben gesehen haben, mit den Analyse- und Infiltrationsermittlungen bei kriminellen Organisationen verbunden, in denen der CPP nur eine Analyse der Zugehörigkeit oder einfachen Beziehung

1110 i.d.S. für den Begriff des Tatverdachts in Deutschland Zabel ZIS 7-8/2014, S. 346 m.w.N. 
zu einer kriminellen Organisation erforderlich macht. Zweitens muss die Anordnung im Rahmen einer restriktiven Interpretation der Gründe, die dieselbe begründen, vollzogen werden. Dieser Grad der Interpretation muss auf der Bestimmbarkeit der Beweisgewinnung und der Tauglichkeit der Information basieren. Diese Fähigkeit zur Bestimmbarkeit würde einem Wahrscheinlichkeitsurteil mit hinreichender Sicherheit bzgl. der Informationsgewinnung und des Fehlens von Verfahrenshindernissen im Gebrauch dieser Information als Grundlage für die Anordnung von anderen Maßnahmen oder der Aufnahme als Beweis in die Hauptverhandlung entsprechen. Der dritte zu verstärkende Aspekt ist eine strikte Überprüfung der Durchführung der Ermittlung. Die Kontrollanhörungen müssten als obligatorische Maßnahme die Anwesenheit der Disziplinarstaatsanwaltschaft auf der Grundlage ihrer präventiven Kontrollbefugnis (Art. $111 \mathrm{CPP}$ ) einführen, damit hierdurch ein strikter Widerspruchsgrad beim Fehlen der Verteidigung gewährleistet wird. Dies würde grundsätzlich bei der Durchführung von Ermittlungen im Rahmen der Vorermittlungsphase Anwendung finden, in der noch keine konkrete Beschuldigung des Verdächtigen besteht. Im Folgenden soll einer der angesprochenen Lösungsgrade analysiert werden.

\section{Inkulpationsgrad als Ausgangspunkt}

Wie im vorherigen Kapitel beschrieben, setzt der Inkulpationsgrad der zumutbaren Schlussfolgerung sowohl in objektiver als auch in subjektiver Hinsicht eine minimale Überzeugung bzgl. einer begangenen Straftat und der Täterschaft oder Teilnahme des Verdächtigen voraus. ${ }^{111}$ Wie außerdem erwähnt, ist diese Art von zumutbarer Schlussfolgerung ein Ausgangspunkt für die Anordnung der Maßnahmen, die im Rahmen der Ermittlung im engeren Sinne ablaufen, da diese Phase mit der Beschuldigung beginnt (Art. 287 CPP), die unter der Voraussetzung einer zumutbaren Schlussfolgerung im Inkulpationsgrad erhoben wird. Das Problem der Abkopplung einer Analyse bzgl. der Möglichkeit der Täterschaft oder Teilnahme wird in der Vorermittlungsphase deutlich, nicht allein, weil viele Maßnahmen diese Art von Schlussfolgerungen nicht als Erfordernis für die Anordnung berücksichtigen, sondern auch, weil vielen in dieser Phase bewilligten Maßnahmen prinzipiell dringende Ermittlungsaktivitäten vorausgehen, weshalb das Inkulpationswahrscheinlichkeitsniveau nicht dasselbe ist wie im Rahmen der Beschuldigungserhebung. Die Abgrenzung von Verantwortlichkeitsbereichen, d.h. die Bestimmung des Wahrscheinlich-

1111 i.d.S. auch Guerrero Peralta, 2007 S. 265. 
keitsgrades der Täterschaft oder Teilnahme ist relevant, da sie die Möglichkeit von Eingriffen bei Dritten, auf die keinerlei Strafermittlung ausgeübt wird, einschränkt. ${ }^{112}$

Ein Teil der Doktrin erkennt als materielle Grenze der verdeckten Ermittlungsmaßnahmen den Beweis im Wahrscheinlichkeitsgrad an, dass die ermittelten Personen Täter oder Teilnehmer sind. ${ }^{1113}$ Über den Ansatz der Doktrin hinausgehend ist es auch möglich, aus der Interpretation der Artikel, die diese Maßnahmen regeln, zu folgern, dass der Eingriff in der Deduktion einer Inkulpationsschlussfolgerung begründet sein muss. Genau gesagt ergibt sich dieser Schluss aus Art. 241 CPP, in dem gefordert wird, dass gefolgert werden soll, dass der Verdächtigte in Verbindung mit einer kriminellen Organisation steht. Wenn der CPP sich auf eine Verbindung zu einer kriminellen Organisation bezieht, spricht er grundsätzlich von einer strafrechtlich relevanten Beziehung. Die Schwierigkeit besteht in der Interpretation des Wortes „Verbindung / Beziehung“ (relación), das auf Zugehörigkeit oder Kollaboration mit der Organisation hinweisen könnte. ${ }^{1114}$ Im ersten Fall würde „Zugehörigkeit“" (pertenencia) auf die Mitgliedschaft hinweisen, Teil einer Struktur zu sein, in der eine Funktion oder eine Aufgabe erfüllt wird. Im zweiten Fall, würde „Mitarbeit / Kollaboration“ (colaborar) nicht die Zugehörigkeit zur Organisation bedeuten, obwohl der Begriff beinhalten kann, dass notwendige Hilfen gewährleistet werden, um die Organisation zu unterhalten. Die Tatsache, dass jemand an einer Straftat von Seiten einer Organisation teilnimmt, würde diese Person nicht automatisch zu einem Mitglied derselben machen, wenn die Person nur punktuell mitarbeitet, ohne das Ansinnen zu haben, sich mehr oder weniger langfristig in die organisierte Gruppe zu integrieren.

In jeglicher dieser Situationen muss der Beteiligungsgrad geschlussfolgert werden, sei es als Täter oder als Teilnehmer. Die Beziehung zu der Organisation muss nicht von Seiten der korporativen Parameter verstanden, sondern es muss die Anbindung des Verdächtigen zu den ermittelten Straftaten im Rahmen einer kriminellen Organisation bestimmt werden. Die Schlussfolgerung bzgl. der Teilnahme an der Straftat stellt den normativen Schlüssel des Ermittlungsprogramms dar. Es werden dadurch nicht nur die objektiven Tatbestandsmerkmale abgegrenzt, sondern auch der Beitragsgrad zur Straftat und die Zielsetzung bei der Ausübung derselben. In diesem Sinne etabliert die Inkulpationsschlussfolgerung eine

\footnotetext{
1112 Guerrero Peralta, 2007, S. 388.

1113 Bernal Cuellar/Montealegre Lynett, 2013 T. II S. 273.

${ }^{1114}$ Vgl. Escalante Barreto, 2011, S. 111; Gonzalez Mongui, 2007, S. 282; FGN, 2005, S. 38; Guerrero Peralta, 2007, S. 394; Bernal Cuellar/Montealegre Lynett, 2013 T. II S. 275.
} 
subjektive und objektive Restriktion der Ermittlungen, da sie darüber entscheidet, wer Ermittlungen unterzogen werden soll und welches das Ziel der Maßnahmen ist. Dies ist eine materielle Restriktion, die außerdem dem Verfahrensziel, „taugliche Informationen“ (,,información útil“) für die Ermittlung zu erhalten, Sinn gibt. Wie wir im Folgenden sehen werden, eignet sich die Tauglichkeit der materiellen Beweiselemente sowohl zum Beweis, dass eine konkrete Straftat begangen wurde als auch zum Beweis der Anbindung des untersuchten Subjekts an dieselbe.

\section{Bestimmbarkeit der Tauglichkeit von Informationen}

Die Tauglichkeit von Informationen, die in den Artikeln behandelt wird, die die verdeckten Ermittlungsmaßnahmen regeln, muss auf der Basis von Art. 375 CPP interpretiert werden. Die Folgerungen bzgl. der Tauglichkeit eines materiellen Beweismittels orientieren sich an den Regelungen der von Art. 375 CPP festgelegten Angemessenheit. ${ }^{1115}$ Wie in der Analyse von Art. 221 CPP bzgl. der Beweisgrundlage der fundierten Anhaltspunkte beschrieben, weisen die Beweisfreiheit und die prozessuale Anwendung von Beweismitteln eine Grenze auf, die dem Sachdienlichkeitsprinzip innewohnt. ${ }^{116}$ Diese Bedingung bedingt das Verständnis von Tauglichkeit von materiellen Beweiselementen und physischer Evidenz, die in einer Ermittlungsmaßnahme erbracht werden sollen. Das Analysevorgehen zur Feststellung der Tauglichkeit von Informationen oder Beweismitteln wäre Folgendes: Erstens müsste es eine direkte oder indirekte Beziehung zu dem Sachverhalt oder den Gegebenheiten herstellen, die mit der Durchführung der Straftat und ihren Konsequenzen im Zusammenhang stehen. Zweitens sollte es auf die Identität des Verdächtigen hinweisen. Drittens sollte es auf die strafrechtliche Verantwortlichkeit des Verdächtigen oder Beschuldigten hinweisen. Viertens sollte auch beachtet werden, dass die Informationen auch tauglich sind, wenn sie die Wahrscheinlichkeit der Tatsachenseite oder die Glaubwürdigkeit eines

\footnotetext{
1115 Art. 375 CPP: „Pertinencia. El elemento material probatorio, la evidencia física y el medio de prueba deberán referirse, directa o indirectamente, a los hechos o circunstancias relativos a la comisión de la conducta delictiva y sus consecuencias, así como a la identidad o a la responsabilidad penal del acusado. También es pertinente cuando sólo sirve para hacer más probable o menos probable uno de los hechos o circunstancias mencionados, o se refiere a la credibilidad de un testigo o de un perito." („Sachdienlichkeit. Das Beweismaterial, physischer Beweis und Beweismittel müssen sich direkt oder indirekt auf die Tatsachen oder Umstände im Zusammenhang mit der Begehung von kriminellem Verhalten und seinen Folgen beziehen, sowie auf die Identität oder die strafrechtliche Verantwortlichkeit der Angeklagten. Es ist auch sachdienlich, wenn es nur dazu dient, eine der oben genannten Tatsachen oder Umstände wahrscheinlicher oder weniger wahrscheinlich zu machen, oder sich auf die Glaubwürdigkeit eines Zeugen oder Sachverständigen bezieht“. -dt. Übersetzung d. Verf.-); dazu Bedoya Sierra, 2008, S. 205.

${ }^{1116}$ Vgl. supra § 10. A. II. Die Beweisgrundlageproblematik gemäß Art. 221 CPP.

346
} 
Zeugen oder Sachverständigen verändern (Art. 375 CPP). ${ }^{117}$ Jede einzelne dieser Konstellationen der Tauglichkeit benötigt eine besondere Analyse, sowohl der Fähigkeit der gesammelten Information zum Stützen der faktischen Situation, als auch um die Wertung in Bezug auf die strafrechtliche Verantwortung des Verdächtigen zu unterstützen.

Über die Diskussion der Tauglichkeitsgrade der materiellen Beweiselemente hinausgehend ist die Mehrheit der Meinung, dass die Tauglichkeit dieser Elemente sich an den Hypothesen orientieren muss, die die rechtliche Qualifizierung der ermittelten Straftat stützen. ${ }^{1118}$ In diesem Sinne müssen strukturelle Aspekte des Tatbestands, Straferschwerungs- oder Strafmilderungsgründe und Rechtfertigungsgründe betrachtet werden. Diese normativen Forderungen, die den Freispruch oder die Verurteilung eines Angeklagten bestimmen, sind die Bezugspunkte für die Bewertung der Tauglichkeit der Beweismittel. Es muss darauf hingewiesen werden, dass ein Teil der Doktrin der Meinung zustimmt, dass ein materielles Beweiselement auch dann als tauglich oder angebracht für den Erweis der Evidenz betrachtet werden kann, wenn es die Inhalte anderer Beweismittel bestätigt. ${ }^{1119}$ Gleichzeitig unterstützt ein Teil der Doktrin bei den Betrachtungen zur Feststellung der Tauglichkeit von Beweismitteln die Notwendigkeit der Durchführung von Wahrscheinlichkeitsverfahren im Hinblick auf das Einlegen eines Widerspruchs in der Hauptverhandlung, damit die materiellen Beweiselemente nicht von der anderen Partei entwertet werden können. ${ }^{1120}$ In jedem Fall, wie oben schon angemerkt, muss jedes Tauglichkeitsurteil auf der Rechtmäßigkeit der Beweismaßnahme und der Durchführung der Beweiserhebung aufbauen.

Insofern die Tauglichkeit der Beweiselemente von den normativen Voraussetzungen bedingt ist, die die rechtliche Qualifizierung der Straftat und die Verantwortlichkeit für eine Handlung begrenzen, konkretisiert sich das Bestimmungsverfahren bzgl. der Tauglichkeit in zwei Stufen: vor der Ermittlungsmaßnahme anhand der Ausarbeitung des methodologischen Ermittlungsprogramms und, im Nachhinein derselben, in der Rechtmäßigkeitskontrolle vor dem JCG. In der ersten Phase werden mit dem methodologischen Ermittlungsprogramm die faktischen, rechtlichen und Beweisprobleme abgegrenzt, über die in der

\footnotetext{
${ }^{1117}$ Bedoya Sierra, 2008, S. 205, der als Beispiel die CSJ-Entsch. vom 30.03.2006 (Rad. 24468) zitiert (s. Fn. 142).

${ }^{1118}$ Vgl. Bedoya Sierra, 2008, S. 206; Bedoya Sierra, 2007, S. 75 f. Avella Franco, 2007, S. 75 ff.

1119 Bedoya Sierra, 2007, S. 83; Bernal Cuellar/Montealegre Lynett, 2013 T. II, S. 126 f. (als Bestätigung der Rechtmäßigkeit der Beweiserhebung).

${ }^{1120}$ was bedeutet, dass die Staatsanwaltschaft vorher festlegen muss, wie die Verteidigungsstrategie ist. Vgl. Bedoya Sierra, 2008, S. 206.
} 
Ermittlungsphase entschieden werden soll. ${ }^{1121}$ In diesem Zuge kann die Geeignetheit der Maßnahme festgestellt werden. Diese Abgrenzung erlaubt es gleichzeitig, festzustellen, welche Beweismittel notwendig sind, um die Theorie des Falls, der in der Hauptverhandlung vorgestellt wird, zu unterstützen. Mit dem methodologischen Ermittlungsprogramm werden die Ziele der Ermittlung festgesetzt. Diese Ziele stellen die Referenzpunkte dar, um die Tauglichkeit der materiellen Beweiselemente oder der physischen Evidenz zu bewerten. ${ }^{1122}$ Konkreter ausgedrückt kann man behaupten, dass die Tauglichkeit eines Beweismittels von Seiten der Ermittlungsplanung festgelegt wird, in der die Ziele der Ermittlung abgegrenzt und die Prozessvoraussetzungen für die Durchführung derselben festgelegt werden. In der zweiten Phase erlaubt die Rechtmäßigkeitskontrolle - ex post - bzgl. der Durchführung von Ermittlungsmaßnahmen nicht nur die Überprüfung der Erfüllung des Ermittlungsplans, sondern auch die Identifizierung der Unterschiede zwischen dem Geplanten und letztendlich Durchgeführten. Für die Rechtmäßigkeitskontrolle einer Ermittlungsmaßnahme und die Sachdienlichkeit der gesammelten Beweismittel ist auch wichtig, das methodologische Ermittlungsprogramm mit den Ergebnissen der Maßnahme zu vergleichen. In diesem Sinne findet der JCG einen teleologischen Rahmen, der es ihm erlaubt, nicht nur die Tauglichkeit der Ergebnisse zu bewerten, sondern auch die Eignung der Maßnahme im Rahmen der Verhältnismäßigkeitsprüfung.

\section{Anwesenheitsrecht der Verteidigung}

Zusätzlich zur materiellen Einschränkung, die die Inkulpationsschlussfolgerung und die Planung der Maßnahme als Parameter für die Tauglichkeitsbestimmung der Information voraussetzt, benötigen die an eine Erwartung auf Beweisgewinnung gebundenen zumutbaren Schlussfolgerungen eine strenge Kontrolle. Diese Kontrolle erfordert nicht nur die Überprüfung der Abweichungen zwischen der Planung der Maßnahme und der Durchführung derselben (materielle Kontrolle) oder die Bestätigung der materiellen Beweiselemente oder physischer Evidenz, auf denen die fundierten Anhaltspunkte und die entsprechende Schlussfolgerung aufbauen, sondern zusätzlich muss sie auch als Grundlage mit einem weit gefassten Widerspruch rechnen. Das zentrale Problem beruht in der Interpretation des Art. 237 CPP, der ein eingeschränktes Szenarium bzgl. des Eingreifens der Kontrollanhörung in Bezug auf die Rechtmäßigkeit vorsieht und zweideutig bzgl. der Eingriffsfähigkeiten der

${ }^{1121}$ Vgl. Avella Franco, 2007, S. 26, 72 ff.; dazu supra § 9. B. II. 1. Das sog. „programa metodológico“ (Art. $207 \mathrm{CPP})$.

1122 Bedoya Sierra, 2008, S. 206. 
Verteidigung ist. Obwohl das KVerfG im Urteil C-025 von 2009 seine Rechtsprechung wiederholt wiedergab, der zufolge das Recht auf Verteidigung ab dem Beginn der Vorermittlung ausgeübt werden kann, d.h. vor der Beschuldigungserhebung, ${ }^{1123}$ sind die Einwirkungsmöglichkeiten der Verteidigung in der Kontrollanhörung nicht klar. Zum einen ist die Möglichkeit des Einschreitens fakultativ, d.h. nicht obligatorisch, und zum anderen hängt das Benachrichtigungsrecht der Verteidigung nicht von offiziellen Mitteilungsmechanismen ab, d.h. die FGN ist nicht dazu gezwungen der Verteidigung eine Mitteilung über die Durchführung der Maßnahme zu machen. ${ }^{124}$

Gegenüber der Lücke bzgl. der Formen des Benachrichtigungsrechts über die Durchführung jener Maßnahmen, die erst nachträglich einer Kontrolle unterworfen werden, muss die Diskussion sich darauf richten, wie die Abwesenheit der Verteidigung auf Grund des Fehlens der Benachrichtigung ersetzt wird. Bzgl. dieser Problematik finden sich verschiedene komparative Ansätze. Für den Fall Kolumbien ergeben sich auch die rechtsvergleichende Vorschläge als angemessen und tauglich, die darauf hinauslaufen, die Stellung der Verteidigung und des Verdächtigen zu stärken ${ }^{1125}$, insbesondere die Rechte auf Information und die Rechte auf Akteneinsicht bzw. Einsicht in die vorläufigen Beweisakten, die Teilnahmerechte und das Recht darauf, eigene Ermittlungen anzustellen. Eine vorherrschende Meinung läuft darauf hinaus, dass eine am Grundsatz des kontradiktorischen Verfahrens orientierte Konfiguration der Vorermittlungsphase und der Ermittlung im engeren Sinne zahlreiche Vorteile für das Auffinden der Verfahrenswahrheit bietet. Dazu finden sich verschiedene Vorschläge für das Erreichen dieses Verfahrensziels. ${ }^{1126}$

\footnotetext{
${ }^{1123}$ KVerfG, Entsch. C-025 v. 2009, Abschn. 4.4. f.

${ }^{1124}$ Nach dem KVerG wird das Recht auf Verteidigung vor der Erhebung der Beschuldigung aktiviert: (i) wenn eine Maßnahme wie die Wohnungsdurchsuchung durchgeführt wird; (ii) zur Zeit eines Verkehrsunfalls und bei der Offenkundigkeit einer fahrlässigen Tötung; (iii) vor potenziellen öffentlichen Beschuldigungen, die von der Generalstaatsanwaltschaft, der Polizei oder einem der Teilnehmer in einem Strafverfahren, denen eine Art der strafrechtlichen Verantwortlichkeit zugerechnet wird, erhoben wird (Entsch. C-025 v. 2009 , Abschn. 4.4.: „Hipótesis en las que se Activa el Derecho de Defensa antes que se adquiera la Condición de imputado").

${ }^{1125}$ Hinweise, in denen auch die Ermächtigung der Staatsanwaltschaft und die Notwendigkeit die Verteidigung in der Ermittlungsphase zu stärken, bemängelt wird. Für den deutschen Fall vgl. Schünemann, ZStW 114 (2002), S. 40 ff.; zur Benachrichtigungspflicht im Rahmen neuerer Ermittlungsmaßnahmen im Kampf gegen schweren Kriminalität vgl. Paa, 2013, S. 104, 137, 169; zur Benachrichtigungspflicht als Zugangsvoraussetzungen zum Rechtsweg siehe u.a. Velten, 1995, S. 89 ff.;

1126 So spricht Schünemann z.B. von einer „Kompensation der Prozesslagen“ (Schünemann, ZStW 114 (2002), S. 41.); Kohlmann weist auf eine Kompensierung des Fehlens der Legitimierung durch eine Ermächtigung des Justizvorbehalts für die Bewilligung von Ermittlungsmaßnahmen und die Einführung von retro-
} 
All diese Vorschläge stimmen in der Notwendigkeit überein, dass eine stärkere Kontrolle auf die Ermittlungsbeamten ausgeübt werden soll, vor allem in der Vorermittlung. Dieser Bereich von Vorschlägen könnte im kolumbianischen Strafprozess eine gewisse Anwendung finden. Vor allem durch die Disziplinarstaatsanwaltschaft (Procuraduría) und ihre Delegierten ${ }^{1127}$ könnte ein strikterer Widerspruch in den Fällen der Abwesenheit der Verteidigung erlangt werden und zwar zur Überprüfung der Grundlagen für die Anordnung der FGN zur Durchführung von Eingriffen in Grundrechte (retrospektive Kontrolle). Allerdings hängt die Konkretisierung dieser Vorschläge von der Überwindung vieler anderer Schwachpunkte innerhalb der Logistik und der Infrastruktur des Systems der Justiz ab. Im Folgenden wird analysiert, wie sich die logistischen und strukturellen Schwachstellen und solche, die der Durchführung von den der Rechtskontrolle vorangehenden Anhörungen innewohnen, zu einer Aushöhlung der Garantien des dem JCG innewohnenden Rechtsschutzes konsolidieren.

\section{Ergebnis}

Die Schlussfolgerungen mit der Aussicht auf Beweisgewinnung müssen restriktiv interpretiert werden. Eine restriktive Interpretation muss drei Analysegrade berücksichtigen: Erstens muss sie an eine Inkulpationsschlussfolgerung gebunden sein, die vom materiellen Standpunkt aus die Voraussetzungen der Zwangsmaßnahmen abgrenzt. Zweitens muss sie die Tauglichkeit der zu sammelnden Informationen in Übereinstimmung mit Art. 375 CPP bewerten, der die Parameter für die Tauglichkeit oder Sachdienlichkeit eines materiellen Beweiselements bestimmt. Die Tauglichkeit der Beweismittel wird im methodologischen Ermittlungsprogramm prädeterminiert, wo die normativen und prozessualen Hypothesen festgelegt werden, auf denen die Ermittlung aufbaut. Drittens müssen sich sowohl die schlussfolgernden Inkulpationsanalysen als auch diejenigen, die mit der Tauglichkeit der Beweismittel in Verbindung stehen, einem strikten Widerspruch zugänglich sein. In der Vorermittlung müssen auf Grund des Fehlens von Widerspruch kompensatorische Prozess-

spektiven Kontrollen durch „Ombudsmänner" hin (Kohlmann, 2012, S. 218 ff.); Dedy entwickelt einen weiten Bereich von Teilnahmerechten in der Ermittlungsphase (Dedy, 2002, S. 111 ff.), Combe spricht von einer Kompesation durch eine Erweiterung der Beschuldigtenrechte (Combe, 2007, S. 159 ff.); i.d.S. auch Prittwitz, FS Bemann (1997), S. 603 ff.; auch Richter, StV 1985, S. 387 f., mit früheren Reformüberlegungen zur Realisierung der Verteidigungsrechte. Für Lösungsmöglichkeiten zur Schließung von Rechtsschutzlücken auf der europäischen Gerichtsbarkeit s. Engelhoven, 2009, S. 171 ff.; Für Forderungen de lege ferenda und de lege data zur Effektuierung des Richtervorbehalts s. Helmken, StV 2003, S. 196 ff.

${ }^{1127}$ Vgl. dazu supra § 3. B. III. Disziplinarstaatsanwaltschaft.

350 
schemata in den voraufgehenden Anhörungen ohne die Anwesenheit der Verteidigung in Betracht gezogen werden.

\section{Effektive richterliche Kontrolle der „motivos fundados“?}

\section{Polizeiliche Vormachtstellung in der Bestimmung der „motivos fundados“}

Das reduzierte Potential der Kontrollausübung, das dem fundierten Anhaltspunkt als juristisch unbestimmter Begriff innewohnt, sieht sich noch mehr geschmälert, wenn man bedenkt, dass die Definition dessen, was ein fundierter Anhaltspunkt ist, durch die polizeiliche und staatsanwaltschaftliche Vormachtstellung von wenigstens zwei wesentlichen Elementen durchsetzt ist, die den Bestimmungsprozess dieses Begriffes bedingen. Einerseits besteht ein Definitionsmonopol der Tatsachenseite, von der aus ein fundierter Anhaltspunkt aufgestellt wird. Andererseits wird diese Tatsachenseite von der Übersicht über die materiellen Beweismittel gestützt, von der aus die für jede Ermittlungsmaßnahme geforderte zumutbare Schlussfolgerung entwickelt wird. Dieses Szenario stellt sich besonders im Rahmen der Durchführung von Ermittlungsmaßnahmen mit nachträglicher Kontrolle dar, in denen der Staatsanwaltschaft und der Polizei ein vorbehaltliches flexibles Einschreiten zugesichert wird, welches oftmals auf Grund von präventiv-polizeilichen Abwägungen aktiviert und modifiziert wird.

Die faktisch-objektive Situation wird hauptsächlich auf unilaterale Weise durch die Staatsanwaltschaft und die Kriminalpolizei gebildet. Dies ist normativ in all jenen Fällen möglich, in denen die FGN von Amts wegen ein Ermittlungsverfahren einleiten muss (Art. 66 CPP), was sich in der Justizpraxis in den Fällen konkretisiert, in denen die Staatsanwaltschaft die Information, mit der sie die Anträge stützt, strategisch auswählt und sie unvollendet und taktisch ausgerichtet vorstellt, um Anordnungen oder Bestätigungen von Seiten des JCG zu erhalten. ${ }^{1128}$ Dies bewirkt, dass der JCG Entscheidungen nicht auf der Basis der Abwägung von relevanten Faktoren trifft, sondern von Seiten definierter unilateraler Begründungen durch die FGN. Diese Art Situationen sind leichter voraussehbar in den

\footnotetext{
${ }^{1128}$ Dies ist eine der größten Probleme von Rechtssystemen mit nachträglicher Kontrolle von Ermittlungshandlungen; bzgl. des Bestätigungsverfahrens im deutschen Strafverfahren vgl. dazu Brüning, 2005, S. 222. Für die heutige Situation der Dominaz der Polizei im deutschen Ermittlungsvefahren vgl. u.a. Dallmeyer, FS Heintschel-Heinegg (2015), S. 87 f.; Hüls, 2007, S. 253 ff.; Schaefer, StrafG 2002, S. 118 ff.; Schlachetzki, 2003, S. 45 ff.; zur Entwicklung dieser Tendez König, 1993, S. 20 ff. Für einen Überblick der empirischen Studien zur Rechtswirklichkeit der Rolle der Polizei im Ermittlungsverfahren siehe Elsner, 2008, S. 26 ff.; zur Problematik in Spanien Nieva Fenoll, La defensa penal I (2010-1), S. 63 ff.
} 
vorbehaltenen Anhörungen und sowohl durch Art. 155 CPP als auch durch 237 CPP gerechtfertigt. Diese Vorausnahmen sind nicht auszuschließen, auch trotz des Urteils C-637 von 2005, denn die effektive Beteiligung der Verdächtigen und ihrer Verteidiger wird von vornherein eingeschränkt, auch wenn sie nicht ausgeschlossen wird. Hinzu kommt, dass durch die Rechtsprechung ein Zurückhalten der Daten der Informanten in nicht geringem Ausmaß geduldet wird. ${ }^{1129}$

Die unilaterale Bestimmung der Grundlagen für die Entscheidung des JCG hat sich auch im kolumbianischen Strafprozesssystem durch die Redimensionierung des „integralen bzw. vollständigen Ermittlungsprinzips“ (principio de investigación integral) als funktionale Grenze der Arbeit der FGN ${ }^{1130}$ etabliert. Insofern jene Doktrin, auf Grund derer die Kompetenzen der Staatsanwaltschaft die Sammlung von notwendigem Material für das Erheben der Anklage gegen den Beschuldigten umfassen ${ }^{1131}$, sich verbreitet hat, scheint die „Geheimhaltung“ im Rahmen der durch die FGN erhaltenen materiellen Beweismittel, die jedoch für den Verdächtigen positiv sein können ${ }^{1132}$, ihre Rechtfertigung gefunden zu haben. In diesem Sinne wird die Genese dessen, was ein fundierter Anhaltspunkt ist und die Begründung für vielerlei Eingriffe in Grundrechte des Verdächtigen auf das Ermessen der FGN und der Kriminalpolizei reduziert. ${ }^{1133}$ Dies scheint durch die strukturelle Notwendigkeit bestimmt, dass die Ausübung der Funktionen von Seiten des JCG innerhalb bestimmter Toleranzgrenzen zu verlaufen hat, damit nicht jene Sphären eingeschränkt werden, in denen die Notwendigkeiten des polizeilichen Ermittlungssystems aufgehoben werden können auf Kosten der Entbindung von Kompromissen, die sich in Bezug auf Freiheiten und Rechte von dem Verfassungsmodell ableiten. ${ }^{1134}$

\footnotetext{
${ }^{1129}$ I.d.S. Zuluaga, NFP 83 (2015), S. 199; dazu supra § 7. B. I. 4. 4. Anmerkung zur Entscheidung C-673 von 2005 KVerfG.

${ }^{1130}$ Vgl. Bernal Cuellar/Montealegre Lynnet, 2013, T. II, S. 71 f.; bzgl. der Kollision zwischen effektiver Strafverfolgung und umfassendem Rechtsschutz (Objektivitätsgrundsatz) im deutschen Ermittlungsvefahren vgl. Combe, 2007, S. 136 ff.; bzgl. der Unilateralität der Informationsgrundlage des entscheidenden Richters in Deutschland vgl. Hüls, 2007, S. 288 ff.; Brüning, 2005, S. 222 f.

${ }^{1131}$ KVerfG, Entsch. C-396 v. 2007, Abschn. II. 26.

1132 I.d.S. Bernal Cuellar/Montealegre Lynnet, 2013, T. II, S. 72 mit einer eindeutigen Stellungnahme zugunsten des integralen bzw. vollständigen Ermittlungsprinzips.

${ }^{1133}$ Zuluaga, NFP 83 (2015), S. 199; bzgl. verdeckter Ermittler Morales Támara, 2008, S. 239 und im Rahmen der Beschränkung der Freiheit Vélez Osorio, 2012, S. 59 ff.

${ }^{1134}$ Zuluaga, Co-Herencia Vol. 4 Nr. 6 (2007), S. 135; diese Potenzierung der Strafgewalt und die Minimierung des Richtervorbehalts in seiner Begrenzungsfunktion der staatsanwaltschaftlichen Macht nimmt Gestalt im sog. präventiv-polizeilichen Subsystem an. Dazu ausführlich Ferrajoli, 2004, S. 763 ff.
} 
In der Trennung zwischen dem JCG und den Strafermittlungsorganen könnte man auch schwerwiegende Gründe für die Konsolidierung der polizeilich-staatsanwaltschaftlichen Autonomie während der Ermittlungsphase finden. Ein bestimmender Faktor dafür wäre auch der ungenügende Zugang der Ermittlungsbehörde zum JCG und des gewöhnlichen Bürgers zur Justizverwaltung, vor allem in solchen Gebieten, wo keine Justiz anwesend ist. ${ }^{1135}$ Obwohl mit der Einführung des akkusatorischen Strafprozesssystems versucht wurde, eine ständige Verfügbarkeit des JCG zuzusichern, so wie es das KVerfG selbst gefordert hat, um die Aktivierung von Kompetenzen der FGN zu rechtfertigen ${ }^{1136}$, so ist doch sicher, dass keine konkreten Anweisungen für die Konfiguration eines weit angelegten Zugangssystems zum JCG vorliegen. Diesen Lücken entsprechen z.B. die ständigen Anzeigen auf Grund der Abwesenheit von JCG. ${ }^{1137}$

Die Probleme bzgl. des Zugangs zum JCG werden insbesondere durch die Einführung des „Aushilfs-JCG“ oder ,,ambulanten JCG“ (Juez de Control de Garantías ambulante) deutlich. Gemäß Art. 39 Paragraph 3 CPP wird hierdurch versucht, die ungenügende Verfügbarkeit des JCG zu ersetzen, und zwar

„wird es Aushilfs-JCG geben, die an Orten tätig sein werden, in denen es nur einen Bezirksrichter gibt oder wenn es sich um einen Ort handelt, bei dem die Überführung der Parteien und der Beteiligten aus Transport- oder Entfernungsgründen oder auf Grund höherer Gewalt erschwert ist oder in den Fällen, die bereits durch die Nationale Einheit für Menschenrechte der Generalstaatsanwaltschaft übernommen worden sind oder wenn Gefahren für die Sicherheit der Beamten bestehen. “1138

Hiermit wird vor allem versucht, die Beschleunigung und die Effizienz der Justizverwaltung in den Vordergrund zu stellen und den Parteien und Beteiligten Risiken und Schwierigkeiten zu ersparen. So hat der Oberste Gerichtshof entschieden, der darauf verweist, dass es das Ziel sei, dass der JCG

\footnotetext{
1135 Vgl. CEJ, 2009 S. 2 ff.; auch Castillo/García/Granada/Villamarín, 2008, S. 165 ff.

${ }^{1136}$ Vgl. KVerfG, Entsch. C-185 v. 2008, Abschn. 5 mit einer Auflistung der Varianten zur Verfügbarkeit des JCG auf Grund von Gesetz 1142 von 2007.

${ }^{1137}$ Vgl. Albornoz, AJ 11.12.2014; CEJ, 2010, S. 136.

${ }^{1138}$ Art. 39 Parag. 3 CPP: „Habrá jueces de garantías ambulantes que actúen en los sitios donde sólo existe un juez municipal o cuando se trate de un lugar en el que el traslado de las partes e intervinientes se dificulte por razones de transporte, distancia, fuerza mayor o en casos adelantados por la Unidad Nacional de Derechos Humanos de la Fiscalía General de la Nación o en los que exista problemas de seguridad de los funcionarios.“ (d. Übersetzung d. Verf.); vgl. dazu supra § 4. B. IV. Der Aushilfsrichter zur Kontrolle der Garantien.
} 
„,in möglichst kürzester Zeit eingreift und versucht wird, die mannigfaltigen Schwierigkeiten zu umgehen, die auf Grund des Mangels an Richtern und Staatsanwälten, geographischen Problemen und Problemen der Sicherheit die materielle Möglichkeit erschweren, dass in allen Fällen die Verdächtigen unverzüglich vor den örtlich zuständigen Richter zur Kontrolle von Garantien gebracht werden. “1139

Die Antworten auf die beschränkte Verfügbarkeit des JCG scheinen die Distribution und Organisation derselben zu erleichtern, damit die Effizienz der Justizverwaltung gewährleistet wird. ${ }^{1140}$ Die Bestätigung dieser politisch-prozessualen Orientierung kann aus den durch Art. 48 Gesetz 1453 von 2011 eingeführten Veränderungen der örtlichen gerichtlichen Zuständigkeit entnommen werden. Insofern jeder Strafbezirksrichter die Kontrollfunktion von Garantien ausüben kann, wird der Zugang und die Entscheidung darüber, wer kontrolliert, einem offenen Kriterium unterworfen, d.h. dass dies nach dem Ermessen der Staatsanwaltschaft entschieden werden kann. Diese Möglichkeit, den zuständigen Richter zu bestimmen, lässt im Grunde genommen eine beunruhigende Nachsichtigkeit zwischen JCG und Staatsanwaltschaft wieder aufleben. Die Einfälle der Staatsanwaltschaft könnten sogar legitimiert sein, wenn man bedenkt, dass das Gesetz 1453 von 2011 die Kontrolle von Garantien durch jeglichen Bezirksrichter bewilligt, ohne seine Fachrichtung in Anbetracht zu ziehen, und zwar in den Fällen, in denen kein Strafbezirksrichter vorhanden ist oder ein Hindernisgrund des einzigen zuständigen Beamten vorliegt (Art. 39 Abs. 2 CPP). ${ }^{1141}$ Durch das Spiel mit den Zuständigkeiten und dem Sachverständnis scheint sich eine formell gesehen instrumentelle Kontrolle zu bilden, die der Notwendigkeit und den Ansichten der Staatsanwaltschaft und der Polizei unterstehen, wobei auf die Stellung des JCG als Hüter der Grundrechte verzichtet wird.

\section{Die unzureichende Überprüfung von Ermittlungen}

Logistische Probleme und Probleme bei der Durchführung des Strafprozessmodells führen zur Schwächung der richterlichen Überprüfung der Grundlagen der Eingriffe in Grundrechte während der Strafermittlungsphase und zwar in zwei Stufen. Zum einen Teil ver-

1139 CSJ, Rad. 35704, Entsch. v. 16.02.2011, Berichterstatter Jorge Luis Quintero Milanés, Abschn. „Consideraciones de la Corte“. (,,intervenga dentro del menor tiempo posible, tendiente a sortear las muchas dificultades que por razón de la carencia de jueces y fiscales, limitaciones geográficas y condiciones de seguridad, dificultan la posibilidad material de que en todos los casos los indiciados sean presentados, de manera inmediata, ante el juez de control de garantías con asiento en el lugar de los hechos.") (d. Übersetzung d. Verf.).

${ }^{1140}$ CEJ, 2015, S. 53; CEJ, 2014, S. 11.

${ }^{1141} \mathrm{Vgl}$. dazu supra § 4. B. IV. Der Aushilfsrichter zur Kontrolle der Garantien. 
hindern die logistischen Unzulänglichkeiten und Strukturschwäche ein sofortigeres Eingreifen des JCG gegenüber der Durchführung von Maßnahmen. Auf der anderen Seite konsolidieren sich verschiedene Verfahrenspraxen bei der Durchführung von Kontrollanhörungen, die eine konkretere und effizientere Überprüfung der Maßnahmen der Staatsanwaltschaft von Seiten des JCG verhindern.

Bzgl. der logistischen und infrastrukturellen Probleme beweisen die verschiedenen Berichte und Bilanzen bzgl. des Funktionierens des akkusatorischen Strafverfahrens erstens, dass der „Impuls, den einige Verfahren, die nicht aus frischen Taten hervorgehen, bekommen haben, sich in einer erhöhten Anzahl öffentlicher Anhörungen niedergeschlagen hat, und damit haben sich die Probleme bzgl. ihrer Durchführung notorischer und kritischer dargestellt." ${ }^{1142}$ Diese Situation basiert auf Problemen wie dem Mangel an Koordination zwischen Beteiligten, der besonders die Verteidiger aus dem Nationalen Netz von Ombudsstellen betrifft, die sogar zur selben Stunde zu verschiedenen Anhörungen einberufen werden. ${ }^{1143}$ Auch bestehen erhebliche Mängel in der Überführung von Gefangenen zu den Anhörungen auf Grund des Mangels an Personal und Mitteln der Strafvollzugsverwaltung (INPEC). ${ }^{1144}$ Zweitens existieren beachtliche Probleme in Bezug auf Ressourcen und Infrastruktur. Diese werden sichtbar am Mangel von Gerichtssälen oder von Labors für die Verwaltung von spezifischen materiellen Beweismitteln. Zusätzlich wird allgemein das Fehlen von grundlegenden Mitteln für die verschiedenen Gerichtsbeamten sowie das Verwaltungspersonal bemängelt. ${ }^{1145}$

In Bezug auf die Verfahrenspraxis in der Durchführung von Anhörungen werden einige schlechte Angewohnheiten beim Auftreten der Parteien in Frage gestellt. ${ }^{146}$ So wird z.B. auf die exzessive Rhetorik hingewiesen, den Mangel an Präzision in den Anträgen und Argumenten der Parteien oder das Behandeln von Themen, die nicht zur Anhörung gehö-

\footnotetext{
1142 CEJ, 2014, S. 11: ,[...]impulso que han tenido algunos procesos no provenientes de flagrancias ha derivado en aumento del número de audiencias públicas realizadas y con ellas se han hecho más notorios y críticos los problemas relacionados con su gestión.“ (dt. Übersetzung d. Verf.)

${ }^{1143}$ CEJ, 2015, S. 56-58; CEJ, 2014, S. 12.

1144 viele Justizbehörden haben keine Computer, Drucker, Internet und andere Ergänzungsmittel. Vgl. CEJ, 2015, S. 57; CEJ, 2014, S. 13.

${ }^{1145}$ Für die Einwände gegen die Führungsebenen der $F G N$ und die umfassenden Probleme der strafrechtlichen Ermittlungsstrategie vgl. Comisión Asesora de Política Criminal, 2012, S. 48 ff.

1146 Mit Bezug auf kognitive Unsicherheit der Beweiswürdigung vor dem JCG und die Erhebung der Beschuldigung vgl. Granados Peña, DPC 41 (2012) S. 82 ff.; Arango H., NFP 75 (2010), S. 231-242.
} 
ren. ${ }^{1147}$ Bei den Bilanzen des Strafverfahrens wurde das Beharren einiger zweitinstanzlicher Kammern auf der Transkription der in der ersten Instanz durchgeführten Anhörungen [bemängelt], was eindeutig zur Verzögerung der Arbeit der Beamten und des Beschlusses einer Entscheidung führt. ${ }^{1148}$ Hinzu kommt, dass der JCG nicht über die notwendige Zeit oder Kenntnisse verfügt, um auf rigorose Art und Weise die Anträge für Anordnungen zu überprüfen, ein Grund, warum in vielen Fällen der JCG wortwörtlich die Begründungen der FGN akzeptiert. ${ }^{1149}$ Durch die Emphase auf dem Feld der schriftlichen Formate, Akten und schriftlichen Mitteilungen, scheint die Verfahrensstruktur sich der kritischen Überprüfung der Ermittlungsmaßnahmen zu entziehen und sich als bürokratische und dickhäutige Verfahrenspraxis zu synthetisieren. ${ }^{1150}$

Auf diese Art und Weise stellen die Kontrollanhörungen keinerlei Bedingung für die Rechtssicherheit dar. In der Tat, die Lockerung der Maxime, die eine kontradiktorische Methodologie zusichert, führt zu dem Schluss, dass die Entwicklung der Richterüberzeugung bzgl. dessen, was im Rahmen des Ziels der verschiedenen Anhörungen entschieden wird, von einem Wahrscheinlichkeitsgrad innerhalb von Ermittlungsregeln abhängt. Der logisch-kognitive Status dessen erscheint allgemein ungewiss und vom kulturellen polizeilich-bürokratischen Kontext verseucht, dessen induktive Macht in vielen Fällen nicht genügend widerlegbar und überprüfbar ist; zum einen durch die Geheimnisanforderung, zum anderen durch die unangebrachte Form, in der das Widerspruchsrecht durchgeführt wird. Die logistischen und strukturellen Mängel sowie diejenigen, die der Praxis der Beteiligten in den Anhörungen innewohnen, konstituieren ein System, welches darauf hinausläuft, die grundlegenden Garantien zu entleeren. Das wird noch durch die Unbestimmtheit der faktischen und rechtlichen Begriffe verstärkt, die die Prognose des Richters (Verallgemeinerungen und Vorurteile wie Terrorist, gefährlich, drogenabhängig, etc.) als Kriterium für die Kontrolle der Ermittlungstätigkeiten stützen.

\section{Zusammenfassung}

Bei der Kontrolle der motivos fundados durch den JCG werden zwei grundlegende Probleme diskutiert: die Beweisgrundlage und die Ziele der zumutbaren Schlussfolgerungen.

\footnotetext{
${ }^{1147}$ CEJ, 2015, S. 51; CEJ, 2014, S. 13.

1148 CEJ, 2015, S. 51; CEJ, 2010, S. 115 f.

${ }^{1149}$ Vgl. dazu CEJ, 2014, S. 12 ff.; Velásquez, El Colombiano 12.12.2013.

${ }^{1150}$ Zuluaga, NFP 83 (2015), S. 203; i.d.S und im Rahmen der Psychologie der Entscheidungstätigkeit des Ermittlungsrichters im deutschen Strafverfahren s. Helmken, StV 2003, S. $193 \mathrm{ff}$. 
Einerseits erscheint im CPP keine Generalklausel, die verständlich macht, mit welchen Erkenntnismitteln ein fundierter Anhaltspunkt mit Beweisgrundlage festgestellt werden soll und wie das Vorgehen bei der Feststellung desselben aussieht. Es wird darüber diskutiert, ob die in Art. $221 \mathrm{CPP}$ aufgeführte Vorschrift Allgemeingültigkeit gegenüber anderen vom CPP vorgesehenen Ermittlungsmaßnahmen hat. Es wird erörtert, ob der Bericht der Kriminalpolizei und die eidesstattliche Erklärung von Zeugen oder Informanten als angemessene und effektive Erkenntnismittel für die Aufrechterhaltung der fundierten Anhaltspunkte angesehen werden können. Ebenfalls wird in Frage gestellt, was unter Wahrscheinlichkeit (verosimilitud) nach Art. 221 CPP verstanden wird. In der Diskussion können zwei Positionen identifiziert werden: einerseits setzt das KVerfG auf Grund des Urteils C-673 von 2005 die Beweisgrundlage mit einer Garantie für die Durchführbarkeit der Ermittlungsmaßnahme gleich und legt fest, dass für den Staatsanwalt und den JCG kein eingeschränkter Zugang zu den Beweismitteln bestehen darf, mit denen die fundierten Anhaltspunkte gestützt werden. Andererseits ist es möglich, Art. 221 CPP in Übereinstimmung mit Art. 207 CPP zu interpretieren. Diese Auslegung erlaubt als Beweisgrundlage sowohl Ermittlungstätigkeiten als auch Beweismittel und Ermittlungsergebnisse. Es ist doch zu bemerken, dass jede Ermittlungsmaßnahme verschiedene Voraussetzungen für die Anordnung und Rechtmäßigkeitskontrolle vorschlägt, was zur Folge hat, dass die Kriterien für die Beweisgrundlage von Art. 221 CPP case by case Anwendung finden. Für eine zweite Qualifikation der fundierten Anhaltspunkte können weder der Bericht der Kriminalpolizei noch die eidesstattliche Erklärung von Zeugen oder Informanten als sachdienlich für eine Wahrscheinlichkeitsdefinition angesehen werden. Wegen der Vertraulichkeit der Erklärung der Zeugen oder Informanten und der Verallgemeinerung und Einseitigkeit in der Erstellung des kriminalpolizeilichen Berichts ist die Beweisfähigkeit dieser Erkenntnismittel für die Beweisgrundlage der fundierten Anhaltspunkte eingeschränkt. Eine extensive Interpretation von Art. $221 \mathrm{CPP}$ für die Beweisgrundlage der fundierten Anhaltspunkte muss einen restriktiven Ansatz der Maxime der freien Beweiserhebung in Betracht ziehen. Nur unter dem Gesichtspunkt der Sachdienlichkeit kann ein Erfordernis nach Bestätigung der Beweismittel begründet werden.

Bzgl. der Anordnung von Ermittlungsmaßnahmen ist anzumerken, dass die Regelung der zumutbaren Schlussfolgerungen im CPP nicht nur heterogen ist, sondern auch prädisponierend für den Strafermittlungsapparat für außergerichtliche Ziele. Dies tritt am deutlichsten bei verdeckten Ermittlungstätigkeiten zutage, bei denen die Polizei mit einem weit gesteck- 
ten Ermessen intervenieren kann und die materielle Kontrolle der Ermittlungen tendenziell ungenügend ist. In diesen Fällen ist das Auffinden von tauglicher Information eine transversale Zielsetzung der Regelung der Ermittlungsmaßnahmen im CPP. Das Problem ist, dass diese Schlussfolgerungen insbesondere auf den Erfolg der Ermittlung hinweisen, aber ohne ein Wahrscheinlichkeitsurteil über die Täterschaft oder Teilnahme des Verdächtigen damit zu verbinden. Aus diesem Grund müssen Möglichkeiten für eine restriktive Auslegung dieser Schlussfolgerungen festgelegt werden. Grundsätzlich müssen drei Aspekte verstärkt werden, die sich einerseits auf die Anordnung und andererseits auf die Kontrolle der Maßnahme beziehen. Erstens muss die Anordnung an eine Inkulpationsschlussfolgerung gebunden sein, die vom materiellen Standpunkt aus die Voraussetzungen der Zwangsmaßnahmen abgrenzt. Zweitens muss die Tauglichkeit der zu sammelnden Informationen in Übereinstimmung mit Art. 375 CPP bewertet werden. Drittens müssen sich sowohl die schlussfolgernden Inkulpationsanalysen als auch diejenigen, die mit der Tauglichkeit der Beweismittel in Verbindung stehen, einem strikten Widerspruch zugänglich sein. Eine strikte Auslegung der Schlussfolgerungen ist gerechtfertigt, wenn man bedenkt, dass die Definition dessen, was ein fundierter Anhaltspunkt ist, durch die polizeiliche und staatsanwaltschaftliche Vormachtstellung stark beeinflusst ist. Außerdem führen logistische Probleme und Probleme bei der Durchführung des Strafprozessmodells zur Schwächung der richterlichen Überprüfung der Grundlagen der Eingriffe in Grundrechte durch den JCG. 


\section{Zusammenfassender Ausblick}

Die wesentlichen Ergebnisse der Darstellung des Rechtsschutzsystems im kolumbianischen Ermittlungsverfahren und der wichtigsten Probleme bei der Feststellung der Rechtswidrigkeit von Eingriffen in die Grundrechte sind schon in den Zusammenfassungen der einzelnen Kapitel dargelegt worden und lassen sich im folgenden Überblick umreißen:

1. Die Begrenzung der Ermittlungshandlungen der Staatsanwaltschaft und der Polizei und damit der Schutz der Grundrechte des Verdächtigen stellen das wichtigste Grundmerkmal des richterlichen Rechtsschutzes im Ermittlungsverfahren dar. Sowohl in Deutschland als auch in Kolumbien hat die Ausübung des Rechtsschutzes im Ermittlungsverfahren im Richter ihren wichtigsten Vertreter. Die Kontrolle der Ermittlungshandlungen auf ihre Rechtmäßigkeit erfolgt in der deutschen Strafprozessordnung einerseits durch die Staatsanwaltschaft selbst, andererseits durch den Ermittlungsrichter. Im kolumbianischen Fall ist es die wesentliche Aufgabe des Juez de Control de Garantías (JCG), den Straftatverdächtigen insbesondere vor Grundrechtsverletzungen durch staatliches Handeln im Rahmen der Wahrheitssuche zu schützen sowie die gesammelten Beweise und die Stichhaltigkeit des Straftatverdachts zu überprüfen.

2. Zu dem Rechtsschutzmodell durch den JCG führte die vorherige strafrechtliche Ermittlungspraxis in Kolumbien, die sich auf erweiterte Kompetenzen der Polizei im Ermittlungsverfahren bzw. Befugnisse für Eingriffe in Grundrechte stützte. Dies war die vorherrschende Rechtfertigung der Reformen des kolumbianischen Strafverfahrens und stellte einen der hauptsächlichen Gründe für die Verkündung einer neuen Verfassung im Jahr 1991 zur Verstärkung des richterlichen Grundrechtsschutzes dar. Die bedeutsamste Neuerung in strafverfahrensrechtlicher Hinsicht war die Einrichtung einer Generalstaatsanwaltschaft. Diese wurde im Folgenden auf einfachgesetzlicher Ebene durch das Dekret 2700 von 1991 umgesetzt, das durch weitere Reformen des Straf(prozess)rechts, nämlich durch die Gesetze 81 von 1993 und 600 von 2000, komplementiert wurde. Diese prozessrechtliche Umsetzung geriet in eine Krise, insbesondere wegen der Willkür der Staatsanwaltschaft bei der Anwendung ihrer Ermittlungskompetenzen und der allgemeinen, durch die Anhäufung von Akten verursachten Dauer der Prozesse. Die Antwort hierauf lieferte eine 
Verfassungsreform, die die Grundlage für die Entwicklung eines tendenziell akkusatorischen Systems schuf und am 19.12.2002 durch den Gesetzesakt 03 von 2002 erfolgte.

3. Der Gesetzesakt 03 von 2002 und die entsprechenden Änderungen von Art. 116, 250 und $251 \mathrm{CN}$ setzten den Kompetenzrahmen der Staatsanwaltschaft und der Kriminalpolizei im Ermittlungsverfahren und die Grundlagen für das Einholen und Aufbewahren von Beweismitteln fest. Die Verfassungsreform strebte eine Stärkung des Rechtsschutzes im Ermittlungsverfahren sowohl durch die Einführung des JCG als auch durch die Einführung des Anklagegrundsatzes, des öffentlichen, mündlichen, kontradiktorischen und konzentrierten Hauptverfahrens und die Modifizierung des Beweisrechts an. Zur Umsetzung des Akkusationsprinzips hat die Verfassungsreform auch die Kompetenzen der am Prozess teilnehmenden Akteure modifiziert. Als solche am bedeutsamsten war die Unterwerfung des Ermittlungsverfahrens unter das Legalitätsprinzip und unter die richterliche Kontrolle. Die Kompetenz zum Erlass der Anordnung von Zwangsmitteln liegt seitdem beim JCG. Als allgemeiner Grundsatz dürfen grundrechtsbeschränkende Maßnahmen nur vom Richter zur Kontrolle der Verfahrensgarantien angeordnet werden.

4. Der Gesetzesakt 03 von 2002 schuf den JCG (Art. 250 Nr. 2 CN), dem die Aufgabe zukam, (i) die Staatsanwaltschaft bei der Anwendung des Opportunitätsprinzips zu überwachen; (ii) freiheitsbeschränkende Maßnahme einer Vorabkontrolle zu unterziehen und (iii) Maßnahmen wie Feststellung der persönlichen Daten, Hausdurchsuchungen und Telekommunikationsüberwachungen nachträglich zu kontrollieren. Die Kontrolle von Ermittlungshandlungen durch den JCG zielt darauf ab zu gewährleisten, dass die Prüfung eines Tatverdachts, also im Wesentlichen die Wahrheitssuche durch Beweiserhebung, unter Einhaltung der Rechte und der verfassungsrechtlich geschützten Garantien des Straftatverdächtigen erfolgt. Es handelt sich um eine Kontrolle sowohl der formellen als auch der materiellen Rechtmäßigkeit, die sich am Verhältnismäßigkeitsprinzip orientiert. Die Rechtmäßigkeitskontrolle der Ermittlungsmaßnahmen erfolgt in vorbereitenden Anhörungen, welche in Art. 154 CPP festgelegt sind. Die Maßnahmen, die Gegenstand der vorherigen Kontrolle sind, befinden sich in Art. 250 Nr. 3 CN. Die nachträgliche Kontrolle erfolgt bei Hausdurchsuchungen, Überwachung der Kommunikation und Beschlagnahmen. Umstritten ist der von Art. 48 Paragraph 3 des Gesetzes 1453 von 2011 eingeführte AushilfsJCG oder ambulante JCG, der wegen der Beweisbeschränkungen und anderer logistischer 
Probleme im Ablauf der Ermittlungskontrolle eine mangelhafte Methode zur Kontrolle der Ermittlungshandlungen darstellt.

5. Der hauptsächliche Streitpunkt sowohl in der kolumbianischen Strafrechtspraxis als auch in der Strafrechtswissenschaft ist in diesem Zusammenhang die ex post - Kontrolle von Ermittlungshandlungen. In der ersten Gruppe von Maßnahmen, die intensive Grundrechtsbeeinträchtigungen bewirken, sind diejenigen enthalten, die das Recht auf Privatsphäre beschränken, namentlich die Hausdurchsuchungen (Art. 219-232 CPP), die Personenüberwachung (Art. 239 CPP) und die verdeckten Ermittlungen (Art. 241-243 CPP). Für die Anordnung einer solchen Maßnahme muss eine ausreichende Indizienlage vorliegen (zumutbare fundierte Anhaltspunkte) und bei der Rechtmäßigkeitskontrolle erfolgt eine formelle (Anordnung der Maßnahme) und materielle (Ausmaß der Grundrechtsbeeinträchtigung) Überprüfung der Maßnahme. Aus den fundierten Anhaltspunkten muss sich ergeben, dass der Verdächtige oder Beschuldigte zu ermittlungsrelevanten Informationen führen kann. Bei der Rechtmäßigkeitskontrolle ist zu prüfen, ob fundierte Anhaltspunkte und Indizien gegen den Verdächtigen oder Beschuldigten vorlagen, die mit der Maßnahme gesuchten Informationen gemessen am Stand der Ermittlungen relevant sind und ob der nach der Prüfung der Anordnung genehmigte Rahmen der Maßnahme bei ihrer Durchführung eingehalten wurde. Obwohl die Anhörung zur Kontrolle der Garantien reserviert bzw. ohne Anwesenheitspflicht der Verteidigung durchgeführt werden könnte, ist die h.M. der Auffassung, dass das Recht auf Verteidigung nicht durch den JCG ersetzt werden dürfe und der Verdächtige die Möglichkeit haben müsse, dieses Recht so schnell wie möglich wahrzunehmen.

6. In der zweiten Gruppe von Maßnahmen, die intensive Grundrechtsbeeinträchtigungen zur Folge haben, befinden sich diejenigen, die das Recht auf die Unverletzlichkeit der Kommunikation beschränken, namentlich der Eingriff in die postalische Kommunikation (Art. 233 CPP) und die Telefonüberwachung (Art. 235 CPP). Bei diesen Maßnahmen wird bezweckt, den Inhalt der von den Verdächtigen oder Beschuldigten übermittelten Informationen zu erhalten, der für die Ermittlung nützlich sein kann. Bei der nachträglichen Kontrolle der Telefonüberwachung und des Eingriffs in die postalische Kommunikation ist die Prüfung des Vorliegens fundierter Anhaltspunkte wesentlich, d.h. die Prognose, etwas zu finden, und der Nutzen der gewählten Maßnahme aufgrund der Vorermittlungen durch die Staatsanwaltschaft. Der intensivste Grundrechtseingriff im Ermittlungsverfahren ist die 
Einschränkung der Freiheit. Ausnahmsweise räumt der CPP darüber hinaus die Möglichkeit zur Anordnung der Festnahme durch die Staatsanwaltschaft ohne vorherige richterliche Anordnung ein (Art. 300 CPP). Die Rechtskontrolle durch den JCG erstreckt sich daher auf die folgenden Aspekte: (i). Prüfung der Verbindung zwischen der Tatsache und den Tatbeständen, bei der eine Sicherungsmaßnahme zulässig ist; (ii). Prüfung der RechtmäBigkeit der Festnahmeanordnung; (iii). Prüfung der maximalen Festnahmezeit; (iv). weitere Aspekte wie die Prüfung des Festnahmeverfahrens.

7. Die sog. „fundierten Anhaltspunkte“ (,motivos fundados“) stellen eine Voraussetzung oder ein Mindesterfordernis für die Anordnungen und einen Grund der Bestätigung durch den JCG im Rahmen der nachträglichen Kontrollen von Grundrechtseingriffen in der Ermittlungsphase dar. Als fundierter Anhaltspunkt versteht sich eine Gesamtheit von artikulierten Tatsachen, die durch Beweismittel unterstützt werden, aus denen objektiv geschlossen wird, dass eine Wahrscheinlichkeit bzgl. einer Täterschaft oder Teilnahme an strafbaren Handlungen besteht und nicht das Äquivalent zum bloßen Verdacht oder zur einfachen Überzeugung des polizeilichen Vertreters ist. Die Rechtsprechung zum neuen Strafprozess hat die wesentlichen Aspekte wie Zweck, Notwendigkeit der Konkretisierung, Genauigkeit und Bestimmtheit, Beweisführung und Rechtmäßigkeitskontrolle durch den JCG zu den fundierten Anhaltspunkten weiterentwickelt. Zur Beweisunterstützung führte das KVerfG eine Verpflichtung zur Begründung der Anordnung des Staatsanwalts mit mindestens einem Bericht, einer eidesstattlichen Erklärung oder mit sachlichen Beweismitteln ein.

8. Besonders relevant für eine Analyse der Problematik der motivos fundados in Kolumbien ist der Vergleich mit dem Tatverdacht in der StPO. Damit bezieht sich die StPO auf eine anzustrebende Beweisgrundlage, damit die Staatsanwaltschaft beginnen kann, Zwangsmaßnahmen in der Ermittlungsphase durchzuführen. Obwohl die StPO keine rechtliche Definition des Verdachts enthält, erkennt die h.M. drei Verdachtsgrade an: Anfangsverdacht, dringender und hinreichender Tatverdacht. Um einen Verdacht festzustellen, wird zur Erklärung hauptsächlich auf das Wahrscheinlichkeitsverfahren zurückgegriffen. Der Anfangsverdacht liegt vor, wenn zureichende tatsächliche Anhaltspunkte für eine zu verfolgende Straftat vorliegen. Der Anfangsverdacht aktiviert nicht nur die Erforschungspflicht, sondern grenzt die strafverfahrensrechtliche Befugnis zum Einschreiten ein. Hinsichtlich der Zwangsmaßnahmen, deren Eingriff in die Grundrechte als drastisch und durchgreifend bezeichnet werden kann, fordert die StPO das Vorliegen eines dringenden 
Tatverdachts als Bedingung. Die wichtigste Regelung stellt $§ 112$ StPO bzgl. der Untersuchungshaft dar. Ein dringender Tatverdacht liegt vor, wenn eine hohe Wahrscheinlichkeit besteht, dass der Angeklagte Täter oder Teilnehmer einer Straftat ist. Der hinreichende Tatverdacht ist in den $\S \S 170$ Abs. 1 und 203 StPO enthalten und stellt eine der Voraussetzungen zur Erhebung der Anklage dar. Allgemein wird er als die Wahrscheinlichkeit definiert, mit der der Beschuldigte eine Straftat begangen hat und verurteilt werden wird.

9. Der Vergleich mit dem Verdachtsbegriff der StPO ermöglicht ein besseres Verständnis konkreter Aspekte der Doktrin der motivos fundados in Kolumbien. Der Begriff des Tatverdachts der StPO erläutert einleuchtend, wie die Begründungsgrade im Bereich des Begriffs der motivos fundados zu systematisieren sind. Es können drei Stufen bzgl. der fundierten Anhaltspunkte im CPP unterschieden werden. Eine erste Qualifikation lässt sich in Art. 205 CPP finden. Der anfängliche fundierte Anhaltspunkt (motivo fundado inicial) muss zu einer tatbezogenen Schlussfolgerung bzgl. des Grades der Möglichkeit der Begehung einer Straftat führen. Im Unterschied zum Anfangsverdacht werden aus dem anfänglichen fundierten Anhaltspunkt nur Tätigkeiten abgeleitet, die die Sammlung von Informationen fördern, und keine Zwangsmaßnahmen, die das Einschreiten in Grundrechte beinhalten. In diesem Punkt ist der anfängliche fundierte Anhaltspunkt vergleichbar mit dem sog. Vorverdacht. Das Bestehen einer zweiten Qualifikation der fundierten Anhaltspunkte basiert auf vier Gesichtspunkten: auf der Intensität der von ihnen begründeten Zwangsmaßnahmen, der Ermittlungsbasis (base probatoria), die sie unterstützt, der gerichtlichen Kontrolle und der Täterbezogenheit. Diese Forderung nach unterstützenden Beweisen der fundierten Anhaltspunkte bezieht sich auf einen objektiven Parameter in Art. $221 \mathrm{CPP}$. Eine dritte Qualifikation der fundierten Anhaltspunkte befindet sich in Art. 336 CPP, in dem die Voraussetzungen für die Erhebung der Anklage aufgeführt sind. In diesem Artikel wird die zumutbare Schlussfolgerung der Täterschaft oder Teilnahme, die für die Erhebung der Beschuldigung notwendig ist, mit einer höheren Qualifikation eingeführt, d.h. einer strikteren deduktiven Schlussfolgerung, die vom CPP als Wahrheitswahrscheinlichkeit (probabilidad de verdad) bezeichnet wird.

10. Zwei grundlegende Probleme werden bei der Kontrolle der motivos fundados durch den JCG diskutiert: die Beweisgrundlage der fundierten Anhaltspunkte und die Ziele der zumutbaren Schlussfolgerungen. Einerseits wird darüber diskutiert, ob die in Art. $221 \mathrm{CPP}$ aufgeführte Vorschrift Allgemeingültigkeit gegenüber anderen vom CPP vorgesehenen 
Ermittlungsmaßnahmen hat. Es wird erörtert, welche die angemessenen und effektiven Erkenntnismittel für das Finden der fundierten Anhaltspunkte sind. Ebenfalls wird in Frage gestellt, was unter Wahrscheinlichkeit (verosimilitud) in Art. $221 \mathrm{CPP}$ verstanden wird. Es ist doch festzustellen, dass jede Ermittlungsmaßnahme verschiedene Voraussetzungen für die Anordnung und Rechtmäßigkeitskontrolle vorschlägt, was zur Folge hat, dass die Kriterien für die Beweisgrundlage von Art. $221 \mathrm{CPP}$ case by case Anwendung finden. Für eine zweite Qualifikation der fundierten Anhaltspunkte und die entsprechende Rechtfertigung intensiver Grundrechtseingriffe können weder der Bericht der Kriminalpolizei noch die eidesstattliche Erklärung von Zeugen oder Informanten als sachdienlich für eine Wahrscheinlichkeitsdefinition angesehen werden. Eine extensive Interpretation von Art. 221 CPP für die Beweisgrundlage der fundierten Anhaltspunkte muss einen restriktiven Ansatz der Maxime der freien Beweiserhebung in Betracht ziehen. Nur unter dem Gesichtspunkt der Sachdienlichkeit kann das Erfordernis einer Bestätigung der Beweismittel begründet werden.

Andererseits ist die Regelung der zumutbaren Schlussfolgerungen im CPP sehr umstritten, da sie für die Anordnung von Ermittlungsmaßnahmen nicht nur heterogen, sondern auch prädisponierend für den Strafermittlungsapparat für außergerichtliche Ziele ist. Das Problem ist, dass diese Schlussfolgerungen insbesondere auf den Erfolg der Ermittlung hinweisen, ohne aber ein Wahrscheinlichkeitsurteil über die Täterschaft oder Teilnahme des Verdächtigen damit zu verbinden. Aus diesem Grund müssen Möglichkeiten für eine restriktive Auslegung dieser Schlussfolgerungen festgelegt werden. Grundsätzlich müssen drei Aspekte verstärkt werden, die sich einerseits auf die Anordnung und andererseits auf die Kontrolle der Maßnahme beziehen. Erstens muss die Anordnung an eine Inkulpationsschlussfolgerung gebunden sein, die vom materiellen Standpunkt aus die Voraussetzungen der Zwangsmaßnahmen abgrenzt. Zweitens muss die Sachdienlichkeit bzw. Tauglichkeit der zu sammelnden Informationen in Übereinstimmung mit Art. 375 CPP bewertet werden. Drittens müssen sich sowohl die schlussfolgernden Inkulpationsanalysen als auch diejenigen, die mit der Tauglichkeit der Beweismittel in Verbindung stehen, einem strikten Widerspruch zugänglich sein. Eine strikte Auslegung der Schlussfolgerungen ist gerechtfertigt, wenn man bedenkt, dass die Definition dessen, was ein fundierter Anhaltspunkt ist, durch die polizeiliche und staatsanwaltschaftliche Vormachtstellung stark beeinflusst ist. 


\section{Literatur- und Quellenverzeichnis}

Zitiert:

Ackermann, FS

Ricklin (2007)

Albornoz, AJ

11.12.2014

Ambos, 2010

Ambos, Jura 2003

Ambos, 1993

Ambos, 2010 a

Ambos, 2009

Ambos, Jura 30

(2008)

\section{Literatur:}

Ackermann, Jürg-Beat, Tatverdacht und Cicero - in dubio contra suspicionem maleficii, in Festschrift für Franz Riklin: zur Emeritierung und zugleich dem 67. Geburtstag, M. A. Niggli/José Hurtado Pozo/Nicolas Queloz (Hrsg.), Zürich [u.a.], Schulthess, 2007, S. 319-336.

Albornoz, Catalina, 10 años del sistema penal acusatorio: ¿colapso inminente u obstáculos por superar?, in ámbitojurídico.com, 11.12.2014. Verfügbar unter http://www.ambitojuridico.com/BancoConocimiento/Educaciony-Cultura/noti-141112-03-10-anos-del-sistema-penal-acusatoriocolapso-inmine (zuletzt geprüft am 30.05.2016).

Ambos, Kai, Beweisverwertungsverbote: Grundlagen und Kasuistik - internationale Bezüge - ausgewählte Probleme, Berlin, Duncker \& Humblot, 2010.

Ambos, Kai, Staatsanwaltschaftliche Kontrolle der Polizei, Verpolizeilichung des Ermittlungsverfahrens und organisierte Kriminalität, Jura 2003, S. 674-682. (span. Übersetzung: Control de la policía por el fiscal versus dominio policial de la instrucción, in Derecho Penal Contemporáneo, Bogotá, Oktober - Dezember, 2002, S. 149-178).

Ambos, Kai, Die Drogenkontrolle und ihre Probleme in Kolumbien, Perú und Bolivien: eine kriminologische Untersuchung aus Sicht der Anbauländer unter besonderer Berücksichtigung der Drogengesetzgebung, Freiburg i. Br., Max-Planck-Inst. für ausländisches und internat. Strafrecht, 1993.

Ambos, Kai et al, Procedimiento de la ley de justicia y paz (ley 975 de 2005) y derecho penal internacional. Estudio sobre la facultad de intervención complementaria de la Corte Penal Internacional a la luz del denominado proceso de "justicia y paz" en Colombia, Bogotá, GTZ-Embajada de la República Federal Alemana en Bogotá-Georg-August-Universität Göttingen, 2010.

Ambos, Kai, Proceso penal: perspectiva internacional, comparada y latinoamericana, México, Ubijus, 2009.

Ambos, Kai, Zum heutigen Verständnis von Akkusationsprinzip und -verfahren aus historischer Sicht, in Jura 30 (2008), S. 586594. 
Ambos, Proceso penal y sistemas acusatorios, 2008

Ambos/Zuluaga, $\mathrm{E}+\mathrm{Z}$ 2015/07

Amelung, BGH-FS (2000), Bd. IV

Amelung, 1990

Amelung, NJW 1979

Amelung, 1976

Amelung, StV 2001

Amelung, StV 2002

Aponte Cardona, 2004

Aponte Cardona, 2006 a

Aponte Cardona, 2006 b

Aponte Cardona, 2006
Ambos, Kai, El principio acusatorio y el proceso acusatorio: un intento de comprender su significado actual esde la perspectiva histórica, in Proceso penal y sistemas acusatorios, Lorena Bachmaier Winter (coord.), Madrid, Marcial Pons, 2008, S. 4972.

Ambos, Kai/Zuluaga, John, Kolumbiens Krieg Verstehen, in Entwicklung und Zusammenarbeit (E+Z) 2015/07, Frankfurt a.M., Frankfurter Societäts-Medien, S. 34-35.

Amelung, Knut, Entwicklungen, gegenwärtiger Stand und zukunftsweisende Tendenzen der Rechtsprechung zum Rechtsschutz gegen strafprozessuale Grundrechtseingriffe, in 50 Jahre Bundesgerichtshof: Festgabe aus der Wissenschaft, Bd. IV, Strafrecht und Strafprozessrecht, Roxin, Claus/Widmaier, Gunter (Hrsg.), 2000, S. 911-932.

Amelung, Knut, Informationsbeherrschungsrechte im Strafprozessrecht. Dogmatische Grundlage individualrechtlicher Beweisverbote, Berlin, Duncker \& Humblot, 1990.

Amelung, Knut, Probleme des Rechtsschutzes gegen strafprozessuale Grundrechtseingriffe, in NJW 1979, S. 1687-1692.

Amelung, Knut, Rechtsschutz gegen strafprozessuale Grundrechtseingriffe, Berlin, Dunckler \& Humblot, 1976.

Amelung, Knut, Rechtsschutz gegen strafprozessuale Grundrechtseingriffe und die Rechtsprechung zur Ausweitung des Eingriffsbegriffs bei staatlichen Ermittlungsmaßnahmen, in StV 2001, S. 131-133.

Amelung, Knut/Wirth, Stefan, Die Rechtsprechung des Bundesverfassungsgerichts seit 1990 zum Schutz der materiellen Grundrechte im Strafverfahren, in StV 2002, S. 161-168.

Aponte Cardona, Alejandro David, Krieg und Feindstrafrecht: Überlegungen zum „effizienten“ Feindstrafrecht anhand der Situation in Kolumbien, Baden-Baden, Nomos-Verl.-Ges., 2004.

Aponte Cardona, Alejandro David, Captura y medidas de aseguramiento: El régimen en la nueva estructura procesal penal de Colombia, Bogotá, Consejo Superior de la Judicatura, 2006.

Aponte Cardona, Alejandro David, Guerra y derecho penal de enemigo: reflexión crítica sobre el eficientismo penal de enemigo, Bogotá, Ed. Ibañez, 2006.

Aponte Cardona, Alejandro David, Manual para el juez de control de garantías en el sistema acusatorio penal 2. Aufl., Bogotá, 
Consejo Superior de la Judicatura, 2006.

Arango $H$., NFP 75 (2010)

Arndt, FG-Schmid (1962)

Assalit Vives, Manual de formación continuada 12 (2000)

Asbrock, KritV 1997

Asbrock, ZRP 1998

Aschmann, 1999

Avella Franco, 2007

Avella Franco, $2007 \mathrm{a}$

Bachmann, 1994

Backes/Gusy, 2003

Bastidas, e.V.\& Kolumbienkampagne berlin (Hrsg.) 2007

Bazzani Montoya, in Estado Actual de la justicia colombiana (2003)
Arango H., María Isabel, A propósito del papel del juez de control de garantías en la audiencia de formulación de imputación, in Nuevo Foro Penal 75 (2010), Medellín, EAFIT, S. 231-242.

Arndt, Adolf, Rechtsprechende Gewalt und Strafkompetenz, in Festgabe für Carlo Schmid zum 65 Geburtstag, Eschenborg, Theodor et al (Hrsg.), Tübingen, 1962, S. 5-32.

Assalit Vives, José María, „Las intervenciones postales“, in La prueba en el proceso penal. Manual de formación continuada $\mathrm{Nr}$. 12, Madrid, Consejo General del Poder Judicial, 2000, S. 210249.

Asbrock, Bernd, zum Mythos des Richtervorbehaltes als wirksames Kontrollinstrument im Zusammenhang mit besonderen polizeilichen Eingriffsbefugnissen, in KritV 1997, S. 255-262.

Asbrock, Bernd, Der Richtervorbehalt - prozedurale Grundrechtssicherung oder rechtsstaatliches Trostpflaster?, in ZRP 1998, S. 17-19.

Aschmann, Tjark Erich, Der Richtervorbehalt im deutschen Polizeirecht, Würzburg, Ergon-Verl., 1999.

Avella Franco, Pedro Oriol, Programa metodológico en el sistema penal acusatorio, Bogotá, Fiscalía General de la Nación, 2007.

Avella Franco, Pedro Oriol, Estructura del proceso penal acusatorio, Bogotá, Fiscalía General de la Nación, 2007.

Bachmann, Gregor, Probleme des Rechtsschutzes gegen Grundrechtseingriffe im strafrechtlichen Ermittlungsverfahren, Berlin, Dunckler \& Humbolt, 1994.

Backes, Otto/Gusy, Christoph, Wer kontrolliert die Telefonüberwachung?: eine empirische Untersuchung zum Richtervorbehalt bei der Telefonüberwachung, Frankfurt a.M., Lang, 2003.

Bastidas, William, Demobilisierung: Das Ende des Paramilitarismus in Kolumbien?, in e.V. \& Kolumbienkampagne Berlin (Hrsg.), Autoritärer Staat und paramilitärische Machtnahme in Kolumbien. Die Regierung Uribe und der Krieg gegen die soziale Bewegung, Berlin, FDCL, 2007, S. 22-29.

Bazzani Montoya, Dario, Comentario a la ponencia "intervención del Ministerio Público en el sistema acusatorio", in Bernal Cuellar, Jaime (coord.), Estado actual de la justicia colombiana: diagnóstico y soluciones, Bogotá, Universidad Externado de Colombia, 2003. 
Beck, 2008

Bedoya Sierra, 2008

Benfer/Bialon, 2010

Bernal Cano, 2002

Bernal Cuellar, 1992

Bernal Cuellar, 1995

Bernal Cuellar

Montealegre Lynett, 2002

Bernal Cuellar Montealegre Lynett, 2013 T. I

Bernal Cuellar Montealegre Lynett, 2013 T. II

Bernsmann

/Jansen, StV 1998

Bettermann/

Grundrechte III/2

Beulke, ZStW 103 1991

Beulke, 2012

Blanco Zuñiga, RDUN 16 (2001)
Beck, Katharina, Der Demobilisierungsprozess der Paramilitärs in Kolumbien unter Alvaro Uribe, Saarbrücken, VDM Verlag Dr. Müller, 2008.

Bedoya Sierra, Luis Fernando, La prueba en el proceso penal colombiano, Bogotá, FGN, 2008.

Benfer, Jost/Bialon, Jörg, Rechtseingriffe von Polizei und Staatsanwaltschaft: Voraussetzungen und Grenzen, München, Beck, 2010.

Bernal Cano, Natalia, La excepción de inconstitucionalidad y su aplicación en Colombia, Bogotá, Gustavo Ibáñez, 2002.

Bernal Cuellar, Jaime, Comentarios al nuevo código de procedimiento penal, Medellín, Biblioteca Jurídica Dike, 1992.

Bernal Cuellar, Jaime, El proceso penal 3. Aufl., Bogotá, Universidad Externado de Colombia, 1995.

Bernal Cuellar, Jaime/Montealegre Lynett, Eduardo, El proceso penal 4. Aufl., Bogotá, Universidad Externado de Colombia, 2002.

Bernal Cuellar, Jaime/Montealegre Lynett, Eduardo, El proceso penal. Tomo I: Fundamentos constitucionales y Teoría General, 6. Aulf., Bogotá, Universidad Externado de Colombia, 2013.

Bernal Cuellar, Jaime/Montealegre Lynett, Eduardo, El proceso penal. Tomo II: Estructura y Garantías Procesales, 6. Aulf., Bogotá, Universidad Externado de Colombia, 2013.

Bernsmann, Klaus/Jansen, Kirsten, Heimliche Ermittlungsmethode und ihre Kontrolle - Ein systematischer Überblick -, in StV 1998, S. 217-231.

Bettermann, Karl August, Der Schutz der Grundrechte in der ordentlichen Grichtsbarkeit, in Bettermann/Nipperdey/Scheuner (Hrsg.), Die Grundrechte, Bd. III/2: Rechtspflege und Grundrechtsschutz, Berlin, Duncker \& Humblot, 1959, S. 779 ff.

Beulke, Weiner, Hypothetische Kausalverläufe im Strafverfahren bei rechtswidrigen Vorgehen von Ermittlungsorganen, in ZStW 103, 1991, S. 657-686.

Beulke, Werner, Strafprozessrecht 12. Aufl., Heildelberg, Müller, 2012.

Blanco Zuñiga, Gilberto Augusto, Comentarios a la excepción de inconstitucionalidad y la excepción de ilegalidad en Colombia, in Revista de Derecho de la Universidad del Norte, No 16 - V. 1 2001, S. $268-279$. 
Bohn, 2011

Bonilla, 1993

Böse, FS Amelung (2009)

Bratke, 2013

Brüning, 2005

Brüning, ZIS

$7 / 2008$

Burghardt, JuS

2010

Bustamante Rúa Opin. jurid. vol.9 no.17 (2010)

Calle Calderón, NFP 63 (2000)

Calle Calderón, NFP 67 (2005)

Camargo, 2002
Bohn, Kerstin, Der gesetzliche Richter als rechtsstaatstragendes Prinzip in europäischen Staaten: Eine Untersuchung der Fallzuteilung unter besonderer Berücksichtigung Englands, Frankfurt a.M. [u.a], Lang, 2011.

Bonilla, Guido, La violencia contra la Unión Patriotica: un crimen de lesa humanidad, Bogotá, CEIS, 1993.

Böse, Martin, Die neuen Regelung zum Rechtsschutz gegen strafprozessuale Informationseingriffe und ihre Konsequenzen für die Prozessuale Geltendmachung von Verwertungsverbote, in Böse, Martin (Hrsg.), Grundlegendes Straf- und Strafverfahrensrechts: Festschrift für Knut Amelung zum 70. Geburtstag, Berlin, Duncker und Humbolt, 2009, S. 565-584.

Bratke, Bastian, Die Quellen-Telekommunikationsüberwachung im Strafverfahren: Grundlagen, Dogmatik, Lösungsmodelle, Berlin, Duncker \& Humblot, 2013.

Brüning, Janique, Der Richtervorbehalt im strafrechtlichen Ermittlungsverfahren, Baden-Baden, Nomos, 2005.

Brüning, Janique. Der Ermittlungsrichter - Ein Hilfsorgan der Staatsanwaltschaft? Eine kritische Würdigung der dogmatischen Einordnung ermittlungsrichterlicher Tätigkeit und Prüfungskompetenz bei sog. Ermittlungshanlungen, in ZIS, 7/2008, S. 340-347.

Buermeyer, Volker, Rechtsschutzgarantie und Gerichtsverfahrensrecht: zur Vereinbarkeit rechtlicher und faktischer Erschwernisse in den verwaltungsgerichtlichen Verfahrensordnungen mit Art. 19 Abs. 4 Satz 1 GG, Köln u.a., Heymann, 1975.

Burghardt, Boris, Der Rechtsschutz gegen Zwangsmittel in Ermittlungsverfahren, in JuS 2010 S. 605 ff.

Bustamante Rúa, Mónica María, La relación del estándar de prueba de la duda razonable y la presunción de inocencia desde el garantismo procesal en el Proceso Penal Colombiano, in Opinión jurídica vol. 9 Nr. 17 Jan./Jun. 2010, Medellín, S. 72-91.

Calle Calderón, Armando Luis, Fundamentación políticoconstitucional del debido proceso, in Nuevo Foro Penal 63 (2000), Medellín, Temis, S. 3-28.

Calle Calderón, Armando Luis. Acerca de la reforma procesal penal. Una primera aproximación, in Nuevo Foro Penal 67 (JanJun 2005), Medellín, EAFIT, S. 145-175.

Camargo, Pedro Pablo, El debido proceso, Bogotá, Leyer, 2002. 
Canals Torres RJ UPR (2014)

Castillo

/García/Granada/

Villamarín, 2008

Comisión Asesora de Política Criminal, 2012

Combe, 2007

CSJ, 2005

CSJ, Bericht von 9.08.2005

CEJ, 2015

CEJ, 2014

CEJ, 2010

CEJ, 2009

CEJ, 2003

Cuello Iriarte,
Canals Torres, José M., Causa Probable y Motivos fundados. ¿Sinónimos?, in Revista Jurídica de la Universidad de Puerto Rico Vol. 73:1 (2004), S. 141-184.

Castillo, Camilo / García Villegas, Mauricio / Granada, Soledad / Villamarín, Adriana, La justicia en zonas de conflicto armado, in García Villegas (ed.), Jueces sin Estado. La justicia colombiana en zonas de conflicto, Bogotá, Siglo del Hombre Editores et al., 2008, S. 165-194.

Comisión Asesora de Política Criminal, Informe Final. Diagnóstico y propuesta de lineamientos de política criminal para el Estado colombiano, Bogotá, Comisión Asesora de Política Criminal, 2012.

Combe, Daniel, Stellung und Objektivität des Staatsanwaltschaft im Ermittlungsverfahren, Göttingen, Cuviller, 2007.

Consejo Superior de la Judicatura, El rol de los jueces y magistrados en el sistema penal acusatorio colombiano, Bogotá, USAIDCSJ, 2005.

Consejo Superior de la Judicatura, La captura en el nuevo estatuto procesal penal: regulación general, Bericht von 9.08.2005, (verfügbar unter https://www.ramajudicial.gov.co/web/consejosuperior-de-la-judicatura/portal/servicios-deinformacion/sistema-penal-acusatorio/conversatorio -zuletzt geprüft am 30.05.2016)

Corporación Excelencia en la Justicia, Balance 10 años del funcionamiento del Sistema Penal accusatorio en Colombia (20042014). Análisis de su funcionamiento y propuestas para su mejoramiento, Bogotá, CEJ, 2015.

Corporación Excelencia en la Justicia, Balance del funcionamiento del sistema penal acusatorio. Boletín de actualización 20122014, Bogotá, CEJ, 2014.

Corporación Excelencia en la Justicia, Balance de los primeros cinco años de funcionamiento del sistema acusatorio en Colombia, Bogotá, CEJ, 2010.

Corporación Excelencia en la Justicia, Lineamientos de política pública en materia de acceso a la justicia a partir de un estudio de necesidades jurídicas insatisfechas, Bogotá, CEJ, 2009.

Corporación Excelencia en la Justicia, Reforma Constitucional de la Justicia Penal. Texto del Acto Legislativo 03 de 2002 y documentos de trámite. Tomo II, Bogotá, CEJ, 2003 
2008

Dallmeyer, FS

Heintschel-

Heinegg (2015)

Dedy, 2002

Defensoría del

Pueblo, 2008

Deiters, 2006

Devis Echandía, 2002

GIZ, 2009

Döhring, 1999

Doka, 2008

Dölling, 1987

Doran/Jackson, 2000

Dorsch, 2005

Dudel, 1999

Duttge, FS Heintschel-Heinegg (2015)
Bogotá, Legis, 2008.

Dallmeyer, Jens, Der Richtervorbehalt als Garant staatsanwaltschaftlicher Verfahrensherrschaft im Ermittlungsverfahren, in Bockemühl, Jan (hrsg.), Festschrift für Bernd von HeintschelHeinegg: zum 70. Geburtstag, München, Beck, 2015, S. 87-92.

Dedy, Eva, Ansätze einer Reform des Ermittlungsverfahrens, Berlin, Duncker \& Humblot, 2002.

Defensoría del Pueblo, La prueba en el sistema penal acusatorio colombiano, Modulo IV para defensores públicos, Bogotá, Defensoría del Pueblo - USAID, 2008.

Deiters, Mark, Legalitätsprinzip und Normgeltung, Tübingen, Mohr Siebeck, 2006.

Devis Echandía, Hernando, Teoría general de la prueba judicial. Tomo I, Bogotá, Temis, 2002.

Deutsche Gesellschaft für internationale Zusammenarbeit $\mathrm{GmbH}$ (GIZ-Profis), Manual de procedimientos para Ley de justicia y paz, Bogotá, GTZ-Embajada de la República Federal de Alemania en Colombia, 2009.

Döhring, Silke, Ist das Strafverfahren vom Legalitätsprinzip beherrscht?, Frankfurt a.M., Lang, 1999.

Doka, Siiri Ann, Die Kontrolle von Vertrauenspersonen im Strafprozess, Hamburg, Kovač, 2008.

Dölling, Dieter, Polizeiliche Ermittlungstätigkeit und Legalitätsprinzip: eine empirische und juristische Analyse des Ermittlungsverfahrens unter besonderer Berücksichtigung der Aufklärungs- und Verurteilungswahrscheinlichkeit, Bundeskriminalamt, Wiesbaden, 1987.

Doran, Sean/Jackson, John (Hrsg.), The judicial role in criminal proceedings, Oxford, Hart, 2000.

Dorsch, Claudia, Die Effizienz der Überwachung der Telekommunikation nach den $\S \S 100 \mathrm{a}, 100 \mathrm{~b}$ StPO, Berlin, Duncker \& Humblot, 2005.

Dudel, Bernd, Das Widerspruchserfordernis bei Beweisverwertungsverboten: eine Untersuchung der vom BGH entwickelten Widerspruchslösung und ihrer dogmatischen Rechtfertigung, Baden-Baden, Nomos-Verl.-Ges., 1999.

Duttge, Gunnar, Das „selbstständige Beweisverwertungsverbot“: Beispiel einer weder geglückten noch folgenlosen Straf(prozess)rechtsdogmatik, in Bockemühl, Jan (hrsg.), Fest- 
Duttge, 1995

Dütz, 1970

Ebert, 2000

Eckstein, 2013

Einmahl, NJW 2001

Eiranova Encinas (coord.), 2000

Eisenberg, NJW 1993

Eisenberg/Conen NJW 1998

Ellersiek, 1981

Elsner, 2008

Engelhoven, 2009

Engländer, Jura 2010

Escalante Barreto, 2011 schrift für Bernd von Heintschel-Heinegg: zum 70. Geburtstag, München, Beck, 2015, S. 103-112.

Duttge, Gunnar, Der Begriff der Zwangsmaßnahme im Strafprozessrecht: unter besonderer Berücksichtigung der allgemeinen Handlungsfreiheit, des allgemeinen Persönlichkeitsrechts sowie des Rechts auf informationelle Selbstbestimmung, BadenBaden, Nomos V.G., 1995.

Dütz, Wilhelm, Rechtsstaatlicher Gerichtsschutz im Privatrecht: zum sachlichen Umfang der Zivilgerichtsbarkeit, Bad Homburg v.d.H. [u.a.], Gehlen, 1970.

Ebert, Andreas, Der Tatverdacht im Strafverfahren unter spezieller Berücksichtigung des Tatnachweises im Strafbefehlsverfahren, Frankfurt a.M. [u.a.], Lang, 2000.

Eckstein, Ken, Ermittlungen zu Lasten Dritter, Tübingen, Mohr Siebeck, 2013.

Einmahl, Matthias, Gefahr im Verzug und Erreichbarkeit des Ermittlungsrichters bei Durchsuchungen und Beschlagnahmen, in NJW 2001, S. 1393-1396.

Eiranova Encinas, Emilio (coord.), Codigo penal alemán: StGB; Código procesal penal alemán: StPO, Madrid [u.a.], Pons, 2000.

Eisenberg, Ulrich, Straf (Verfahrens) rechtliche Maßnahmen gegenüber „organisierten Verbrechen“, in NJW 1993, S. 1033.

Eisenberg, Ulrich/Conen, Stefan, § 152 II StPO: Legalitätsprinzip im gerichtsfreien Raum?, in NJW 1998, S. 2241-2249-

Ellersiek, Dirk, Die Beschwerde im Strafprozess, Berlin, Duncker \& Humblot, 1981.

Elsner, Beatrix, Entlastung der Staatsanwaltschaft durch mehr Kompetenzen für die Polizei?: eine deutsch-niederländisch vergleichende Analyse in rechtlicher und rechtstatsächlicher Hinsicht, Göttingen, Univ.-Verl. Göttingen, 2008.

Engelhoven, Peter Philipp, Unzureichende Legitimation von Ermittlungshandlungen der europäische Kommission im EGKartellverfahren: fehlende Rechtsschutzmöglichkeiten bzgl. deren Durchführung, Hamburg, Kovač, 2009.

Engländer, Armin, Die Rechtsbehelfe gegen strafprozessuale Zwangsmaßnahmen, in Jura 2010, S. 414 ff.

Escalante Barreto, Caviedes Estanislao, La indagación y la investigación en el proceso penal: límites constitucionales, Bogotá, Editorial Ibañez, 2011. 
Eser (Hrsg.), 2004 Eser, Albin, Strafjustiz im Spannungsfeld von Effizienz und Fairness: konvergente und divergente Entwicklungen im Strafprozessrecht, Berlin, Dunckler \& Humblot, 2004.

Espitia Garzón, Espitia Garzón, Fabio, Instituciones de derecho procesal penal: 2015 sistema acusatorio 9. Aufl., Bogotá, Legis, 2015.

Everling, EuR-Bei Everling, U., Rechtsschutz in der Europäischen Union nach dem 12009 Vertrag von Lissabon, in EuR Beiheft 1/2009, Schwarze/Hatje (Hrsg.), Der Reformvertrag von Lissabon, S. 71.

Fernández León, Fernández León, Whanda, Procedimiento penal acusatorio y oral. 2005 Una reflexión crítica sobre la Reforma Constitucional de 19 de diciembre de 2002 y la Ley 906 de 2004, nuevo CPP, Bogotá, Ediciones del Profesional, 2005.

Fernández López, Fernández López, Mercedes, La valoración de pruebas personales y Cuadernos electrónicos de filosoel estándar de duda razonable, in Cuadernos electrónicos de filofía del derecho 15 (2007)

Ferraioli, 2001

Ferraiolo, Marzia, Il ruolo di 'garante'del giudice per le indagini preliminari, Milán, Cedam, 2001.

Ferrajoli, $2010 \quad$ Ferrajoli, Luigi, Las fuentes de legitimidad de la jurisdicción, México D.F., Inst. Nacional de Ciencias Penales, México, 2010.

Ferrajoli, $2004 \quad$ Ferrajoli, Luigi, Derecho y Razón. Teoría del Garantismo Penal 6. Aufl., Madrid, Trotta, 2004.

Fezer, Jura 1982 Fezer, Gerhard, Rechtsschutz gegen erledigte strafprozessuale Zwangsmaßnahmen - Dargestellt an den Beispielen der Beschlagnahme und Durchsuchung -, in Jura 1982, S. 18-28, 136138.

Fincke ZStW 95 Fincke, Martin, Zum Begriff des Beschuldigten und den Ver-

FGN, 2005 dachtsgraden, in ZStW 95 (1983), S. 919.

Fiscalía General de la Nación, Manual de procedimientos de fiscalía en el sistema penal acusatorio colombiano, Bogotá, FGN, 2005.

FGN, 2005a

Fiscalía General de la Nación, Manual de Policía Judicial. Parte General, Bogotá, FGN, 2005.

Forero Ramírez, Forero Ramírez, Juan Carlos, Aproximación al estudio del princi2013 pio de oportunidad 2. Aufl., Bogotá, Grupo Editorial Ibañez, 2013. 
Forkert-Hosser, Forkert-Hosser, Sandra, Vorermittlungen im Strafprozessrecht: 2011 Erhebung und Verwendung von Daten vor dem Anfangsverdacht, Frankfurt a.M.[u.a.], Lang, 2011.
Fornauf, $2010 \quad$ Fornauf, Marc, Die Marginalisierung der Unabhängigkeit der Drit- ten Gewalt im System des Strafrechts, Frankfurt a.M. [u.a.], Lang, 2010.

Gallón Giraldo, Gallón Giraldo, Gustavo, Quince años de Estado de Sitio en Co1979 lombia, 1958-1978, Bogotá, Librería y Editorial América Latina, 1979.

García Valencia, García Valencia, Jesús Ignacio, Conferencias sobre el proceso pe2005 nal acusatorio: comentarios al acto legislativo no. 03 de 2002 y al código de procedimiento penal (ley 906 de 2004), Bogotá, Ibañez, 2005.

García Villegas, García Villegas, Mauricio, „Constitucionalismo perverso. NormaCaleidoscopio B. I lidad y anormalidad constitucional en Colombia: 1957-1997“, in 2004

Gärditz, 2003 El caleidoscopio de las justicias en Colombia: análisis sociojurídico Bd. I, Boaventura de Sousa Santos/Mauricio García Villegas (eds.), Bogotá, Siglo de Hombre Ed., 2004, S. 317-370.

Gärditz, Klaus Ferdinand, Strafprozeß und Prävention: Entwurf einer verfassungsrechtlichen Zuständigkeits- und Funktionenordnung, Tübingen, Mohr-Siebeck, 2003.

Gentz, 1968

Gentz, Manfred, Die Unverletzlichkeit der Wohnung: Artikel 13 des Grundgesetzes, Berlin, Duncker und Humblot, 1968.

Geppert, DRiZ 1992

Glaser, 2008

Geppert, Klaus, Kontroll- und Förderungspflicht des Ermittlungsrichters, DRiZ 1992, S. 405-414.

Glaser, Michael, Der Rechtsschutz nach $\S 98$ Abs. 2 Satz 2 StPO: eine methodologische Untersuchung zur Leistungsfähigkeit des $\S 98$ Abs. 2 Satz 2 StPO als allgemeine Rechtsschutzvorschrift gegenüber nicht-richterlich angeordneten Grundrechtseingriffen im Ermittlungsverfahren, Tübingen, Mohr Siebeck, 2008.

Gleß, DriZ $2000 \quad$ Gle $\beta$, Sabine, ,...dass überall dem Gesetz ein Genüge geschehe“ Justizielle Einbindung und Kontrolle des strafrechtlichen Ermittlungsverfahren -, in DriZ 2000, S. 365-375.

Gómez Osorio,

Gómez Osorio, Luis Camilo, Estado actual de la justicia, in Jaime Estado actual de la justicia colombiana, 2003 Bernal Cuellar (coord.), Estado actual de la justicia colombiana: diagnóstico y soluciones, Bogotá, Universidad Externado de Colombia, 2003, S. 107-127.

González Cuervo, El Tiempo,

González Cuervo, Mauricio, Justicia pronta, pronto!, in El Tiempo, 11.10.2003, verfügbar unter 11.10.2003 <http://www.eltiempo.com/archivo/documento/MAM-1017882 
última visita 05.06.2012> (zuletzt geprüft am 30.05.2016)

Gonzalez Mongui, González Monguí, Pablo Elías, La policía judicial en el sistema 2007 penal acusatorio, Bogotá, Doctrina y Ley, 2007.

Gorgass, 2011

Gorgass, Tim, Staatliche Abhörmaßnahmen bei Voice over IP. Eine rechtsvergleichende Untersuchung zwischen Deutschland und den USA, Münster, LIT Verlag, 2011.

Gössel, 2007

Gössel, Karl-Heinz, El derecho procesal penal en el Estado de Derecho. Obras Completas, Bd. I., Buenos Aires, Rubinzal - Culzoni Editores, 2007.

Granados Peña, Granados Peña, Jaime, Breves reflexiones sobre la afectación de DPC 41 (2012) las garantías fundamentales en la formulación de imputación, in Derecho Penal Contemporáneo 41 (Oct.-Dic. 2012), Bogotá, Legis, S. $82 \mathrm{ff}$.

GMH, 2013

Grupo de Memoria Histórica, ¡Basta ya! Colombia: memorias de guerra y dignidad: informe general, Bogotá, Centro Nacional de Memoria Histórica, 2013.

Guerrero Peralta, Guerrero Peralta, Oscar Julián, El juez de control de garantías, in 2004 Reflexiones sobre el nuevo sistema procesal penal. Los grandes desafíos del juez penal Colombiano, Bogotá, Consejo Superior de la Judicatura, 2004, S. 163-214.

Guerrero Peralta, Guerrero Peralta, Oscar Julián, El control de garantías como cons2006 trucción de una función jurisdiccional, Bogotá, Consejo Superior de la Judicatura, 2006.

Guerrero Peralta, Guerrero Peralta, Oscar Julián, Fundamentos teórico constitucio2007 nales del nuevo proceso penal 2. Aufl., Bogotá, Ediciones nueva jurídica, 2007.

Guerrero Peralta, Guerrero Peralta, Oscar Julián, La expectativa razonable de intiDPC 92 (2011) midad y el derecho fundamental a la intimidad en el proceso penal, in Derecho Penal y Criminología 92 (2011), Bogotá, Universidad Externado de Colombia, S. 55-84.

Gusy, GA 2003 Gusy, Christoph, Rechtsgrundlagen der Richtervorbehalte nach $\S$ 100 b StPO, in GA 2003, S. 672-692.

Gusy, JZ 1998 Gusy, Christoph, Verfassungsfragen vorbeugenden Rechtsschutz, in JZ 1998, S. 167-174.

Guzmán Cam- Guzmán Campos, Germán/ Fals Borda, Orlando/ Umaña Luna, pos/Fals Bor- Eduardo, La violencia en Colombia, Bd. I, Bogotá, Aguilar [u.a.], da/Umaña Luna B. 2012.

I, 2012

Haas, 2003

Haas, Günter, Vorermittlungen: die Behandlungen des staatsan- 
waltschaftlichen vorermittlungsverfahren unter besonderer Berücksichtigung von Abgeordneten, Politikern und Prominenten, Frankfurt a.M., Lang, 2003.

Hainmüller, 1966 Hainmüller, Dietmar, Der Anscheinsbeweis und die Fahrlässigkeitstat im heutigen deutschen Schadensersatzprozeß, Tübingen, Mohr, 1966.

Hamm, StV 2001 Hamm, Rainer, Der Einsatz heimlicher Ermittlungsmethoden und der Anspruch auf ein faires Verfahren, StV 2001, S. 81-85.

KK/Bearbeiter Hannich, Rolf (Hrsg.), Karlsruher Kommentar zur Strafprozessordnung mit GVG, EGGVG und EMRK, München, Beck, 2008.

Haratsch, 2007 Haratsch, Andreas, Der kooperative Grundrechtsschutz in der Europäischen Union, in Haratsh, Andreas (Hrsg.), Grundrechtsschutz in der Europäischen Union, Berlin, Berliner Wiss. Verl., 2007, S. 9-30.

Harms, DriZ 2004 Harms, Suen, Kann ein richterlicher Durchsuchung beschlüss auch mündlich erlassen werden?, in DriZ 2004, S. 25-29.

Hartmann /

Hartmann, Arthur/Schmidt, Rolf, Strafprozessrecht: Grundzüge des

Schmidt, 2016

Hassemer, Jahrtausendwende 2000 Strafverfahrens 6. Aulf., Grasberg bei Bremen, Schmidt, 2016.

Hassemer, Winfried, Absehbare Entwicklungen in Prittiwitz/Manoledkis/ (Hrsg.), Strafrechtsdogmatik und Kriminalpolitik, in Strafrechtsprobleme an der Jahrtausendwende, DeutschGriechiches Symposium Rostock 1999, Baden-baden, 2000, S. $17 \mathrm{ff}$.

Hassemer, 1997

Hassemer, Winfried, Crítica al derecho penal de hoy, Bogotá, Universidad Externado de Colombia, 1997.

Hassemer, 2009 Hassemer, Winfried, Verdad y búsqueda de la verdad en el proceso penal, México, Ubijus, 2009.

Hassemer, StV Hassemer, Winfried, Das Schicksal der Bürgerrechte im "effizien1990

Hauck, 2014 ten" Strafrecht, in StV 1990, S. 328 ff.

Hauck, Pierre, Heimliche Strafverfolgung und Schutz der Privatheit: eine vergleichende und interdisziplinäre Analyse des deutschen und englischen Rechts unter Berücksichtigung der Strafverfolgung in der Europäischen Union und im Völkerstrafrecht, Tübingen, Mohr Siebeck, 2014.

Hebrok, 2007

Hebrok, Tanja, Strukturermittlungen im Spannungsfeld von Effizienz der Strafverfolgung zum Rechtsschutz des Einzelnen: dargestellt am Beispiel der Telekommunikationsübermachung, Aachen, Shaker Verl., 2007.

Hecheltjen, 2007 Hecheltjen, Kai Peter, Der Richtervorbehalt im kartellrechtlichen 
Nachprüfungsverfahren der Europäischen Kommission, Frankfurt a.M., Lang, 2007.

Heidebach, 2014 Heidebach, Martin, Grundrechtsschutz durch Verfahren bei gerichtlicher Freiheitsentziehung, Berlin, Duncker \& Humblot, 2014.

Heimgartner, 2011 Heimgartner, Stefan, Strafprozessuale Beschlagnahme. Wesen, Arten und Wirkungen, Zürich, Schulthess, 2011.

Hellmann, 2006

Hellmann, Uwe, Strafprozessrecht 2. Aufl., Berlin, Springer, 2006.

Hellmann, FS

Hellmann, Uwe, Anfangsverdacht und Begründung der Beschul-

Kühne (2013) digteneigenschaft, in Robert Esser (Hrsg.), Festschrift für HansHeiner Kühne zum 70. Geburtstag, Heidelberg, Hamburg [u.a.], C.F. Müller, Verl.-Gruppe Hüthig, Jehle, Rehm, 2013, S. 235249.

Helmken, $\mathrm{StV}$ 2003

Helmken, Dierk, Reform des Richtervorbehalts: vom Palliativum zum effektiven Grundrechtsschutz - zur Psychologie der Entscheidungstätigkeit des Ermittlungsrichter -, in StV 2003, S. 193-198.

Hilger, JR 1990 Hilger, Hans, über den 'Richtervorbehalt' im Ermittlungsverfahren, in JR 1990, S. 485-489.

Hilger, Meyer GS Hilger, Hans, über den „Richtervorbehalt“ im Ermittlungsverfah(1990) ren, in Gedächtnisschrift für Karlheinz Meyer, Geppert, Klaus/Dohnicke, Diether (Hrsg.), Berlin, de Gruyter, 1990, S. 209-225.

Hindte, 1973

v. Hindte, Volker, Die Verdachtsgrade im Strafverfahren, 1973.

Hölscher, 2001

Hölscher, Christine, Der Rechtsschutz und die Mitteilungspflichten bei heimlichen strafprozessualen Zwangsmaßnahmen, Frankfurt a.M., Lang, 2001.

Hößlein, 2007

Hößlein, Marco, Judikatives Unrecht: subjektives Recht, Beseitigungsanspruch und Rechtsschutz gegen den Richter, Berlin, Duncker \& Humblot, 2007.

Hüls, 2007

Iturralde, 2010

Hüls, Silke, Polizeiliche und Staatsanwaltliche Ermittlungstätigkeit: Machtzuwachs und Kontrollverlust, Berlin, BWV, 2007.

Iturralde, Manuel, Castigo, liberalismo autoritario y justicia penal de excepción, Bogotá, Universidad de los Andes-Instituto Pensar-Siglo del Hombre Editores, 2010.

Jahn, 2007

Jahn, Matthias, Der Verdachtsbegriff im präventiv orientierten Strafprozess - Initiativ-, Vor- und Strukturermittlungen der Staatsanwaltschaft und ihre rechtsstaatliche gerichtliche Kontrolle-, in Jenseits des rechtsstaatlichen Strafrechts, Institut für 
Jäger, 2003

Jaramillo, Estudios políticos 10 (1997)

Jasch, 2003

Jehle, 2006

Jozik/Kunze, Jura 1990

Jung, 2001

Kalsbach, 1967

Kaspar, 2014

Kindhäuser, 2016

Kintzl, DriZ 2004

Knauth, JuS 1979

Koessl, 2014

Koller, 1997

Kohlmann, 2012
Kriminalwissenschaften und Rechtsphilosophie Frankfurt a. M. (Hrsg.), Frankfurt a.M. [u.a.], Lang, 2007, S. 545-569.

Jäger, Christian, Beweisverwertung und Beweisverwertungsverbote im Strafprozess, München, Beck, 2003.

Jaramillo, Ana María, „Consideraciones sobre el conflicto armado en el Medellín de los noventa“, in Estudios Políticos 10 (Jan-Jun 1997), Medellín, Universidad de Antioquia, S. 150-159.

Jasch, Michael, Perspektiven der polizeilichen Entscheidungsmacht: Strafverfahrensabschluss und Polizei in Deutschland und England, Norberstedt, Books an Demand, 2003.

Jehle, Jörg Martin, The function of public prosecution within the criminal justice system aim, approach and outcome of a european comparative study, in Jehle, Jörg Martin/Wade, Marianne (Hrsg.), Coping with overloaded criminal justice systems: the rise of prosecutorial power across Europe, Berlin, Springer, 2006.

Jozik, Manuel/Kunze, Wolfgang, Rechtsschutz gegen Maßnahmen der Ermittlungsbehörden, in Jura 1990, S. 294-300.

Jung, Seung Hwang, Richterliche Kontrolle bei Strafvollstreckung und Strafvollzug: Analyse der Rolle des Richters mit Blick auf neue Reformen im Sanktionssystem, Frankfurt a.M., 2001.

Kalsabch, Till, Die gerichtliche Nachprüfung der Maßnahmen der Staatsanwaltschaft in Strafverfahren, Berlin, de Gruyter, 1967.

Kaspar, Johannes, Verhältnismäßigkeit und Grundrechtsschutz im Präventionsstrafrecht, Baden-Baden, Nomos, 2014.

Kindhäuser, Urs, Strafprozessrecht 4. Aufl., Baden-Baden, Nomos, 2016.

Kintzl, Heinrich, Die Tätigkeit des Ermittlungsrichters im Ermittlungsverfahren und Richtervorbehalt, in DRiZ 2004, S. 83-88.

Knauth, Alfons, Beweisverwertungsverbot als Folge einer verfassungswidrigen Beschlagnahmeanordnung, in JuS 1979, S. 339.

Koessl, Manfredo, Gewalt und Habitus: Paramilitarismus in Kolumbien, Berlin/Münster, LIT, 2014.

Koller, Christoph, Die Staatsanwaltschaft - Organ der Judikative oder Exekutivebehörde? Die Stellung der Anklagebehörde und die Gewaltenteilung des Grundgesetzes, Frankfurt a.M., 1997.

Kohlmann, Diana, Online-Durchsuchungen und andere Maßnahmen mit Technikeinsatz, Bedeutung und Legitimation ihres Ein- 
König, 1993

Köster, 1992

Kotsoglou, 2015

Kotzur EuR-Bei 1 2012

Krack, Jura 2001

Kramer, 2009

Krehl, NStZ 2003

AnwK-

StPO/Bearbeiter

Krey, 2006

Krüger, DRiZ 2004

Kühne, 1978 satzes im Ermittlungsverfahren, Baden-Baden, Nomos, 2012.

König, Olaf, Die Entwicklung der strafprozessualen Zwangsmaßnahmen im Ermittlungsverfahren seit 1877 - Tendenzen zur Verpolizeilichung des Ermittlungsverfahrens durch präventiv ausgerichtete Zwangsbefugnisse, Frankfurt a.M., Lang, 1993.

Köster, Ingo, Der Rechtsschutz gegen die vom Ermittlungsrichter angeordneten und erledigten strafprozessualen Grundrechtseingriffe : zum verfassungsrechtlichen Erfordernis der Zulässigkeit eines Fortsetzungsfeststellungsbegehrens gegen ermittlungsrichterliche Grundrechtseingriffe, Berlin, Dunckler \& Humblot, 1992.

Kotsoglou, Kyriakos N., Forensische Erkenntnistheorie: der inferentielle Kontextualismus und die Funktion der kontextrelevanten Zweifel im Strafverfahren zugleich eine analytische Perspektive zur Sachverhaltsfeststellungsdogmatik, Berlin, Duncker \& Humblot, 2015.

Kotzur, Markus, Neuerungen auf dem Gebiet des Rechtsschutzes durch den Vertrag von Lissabon, in EuR-Bei 1 2012, Schawarze, Jürgen (Hrgs.), Der Rechtsschutz vor dem Gerichtshof der EU nach dem Vertrag von Lissabon, Baden-Baden, Nomos, 2012. S. $7-22$.

Krack, Ralf, Rechtsschutz gegen straprozessualle Zwangsmaßnahmen, in Jura 2001, S. 737 ff.

Kramer, Bernhard, Grundbegriffe des Strafverfahrensrechts 7. Aufl., Stuttgart, Kohlhammer, 2009.

Krehl, Christoph, Richtervorbehalt und Durchsuchungen außerhalb gewöhnlicher Dienstzeiten, in NStZ 2003, S. 461-464

Krekeler, Wilhelm/Löffelmann, Markus/Sommer, Ulrich, Anwaltkommentar Strafprozessordnung 2. Aufl., Bonn, DeutscherAnwaltVerlag, 2010.

Krey, Volker, Grundlagen, Verfahrensbeteiligte, Gang des Strafverfahrens, Verfahrensprinzipien, Strafprozessuale Grundrechteingriffe, Stuttgart, Kohlhammer, 2006.

Krüger, Jochen, Der Richtervorbehalt als Königsweg für den Schutz von Grundrechten? - Überlegungen zum Anwendungsbereich des strafprozessualer Zwangsmaßnahmen, in DRiZ 2004, S. 247-250.

Kühne, Hans Heiner, Strafverfahrensrecht als Kommunikationsproblem: Prolegomena einer strafverfahrensrechtlichen Kom- 
munikationstheorie, Heildelberg, kriminalstatik verl., 1978.

Kühne, NJW 1979 Kühne, Hans Heiner, Die Definition des Verdachts als Voraussetzung strafprozessualer Zwangsmaßnahmen, in NJW 1979, S. 617-622.

Kühne, 2015

Kühne, Hans-Heiner, Strafprozessrecht: eine systematische Darstellung des deutschen und europäischen Strafverfahrenschts 9. Aulf., Heildelberg, Müller, 2015.

LaFave, Vol. 2: LaFave, Wayne R., Search and seizure: a treatise on the fourth Sections 3.1 through 4.13 amendment, Vol. 2: Sections 3.1 through 4.13, S.l., Thomson/West, 2004.

Laser, NStZ 2001

Laser, Andrea, Das Rechtsschutzsystem gegen strafprozessuale Zwangsmaßnahmen, in NStZ 2001, S. 120-124.

Lemaitre Ripoll, Lemaitre Ripoll, Julieta, El derecho como conjuro Fetichismo legal, 2009

Lin, 1998

Lippe, 2001 violencia y movimientos sociales, Bogotá, Siglo del Hombre Eds / Universidad de los Andes, 2009.

Lin, Yu-hsiung, Richtervorbehalt und Rechtsschutzes gegen Strafprozessuale Grundrechtseingriffe, Frankfurt a.M., 1998.

Lippe, Sabine von der, Die „Widerspruchslösung“ der Rechtsprechung für strafprozessuale Beweisverwertungsverbote, Hamburg, Kovač, 2001.

Löffelmann, 2008

Löffelmann, Markus, Die normativen Grenzen der Wahrheitsforschung im Strafverfahren: Ideen zu einer Kritik der Funktionsfähigkeit der Strafrechtspflege, Berlin, De Gruyter Recht, 2008.

Lohberger, FS

Lohberger, Ingram, Mittelbare Verwertung sog. ZufallserkenntnisHanack (1999) se bei rechtmäßiger Telefonüberwachung nach $\S \S 100 a, b$ StPO?, in Festschrift für Ernst-Walter Hanack zum 70. Geburtstag am 30. August 1999, Udo Ebert (Hrsg.), Berlin [u.a.], de Gruyter, 1999, S. 253 ff.

Lohner, 1994

Lohner, Erwin, Der Tatverdacht im Ermittlungsverfahren: Begriff, rechtliche Ausgestaltung, praktische Handhabung und Kontrolle am Beispiel der polizeilichen Verdachtsfeststellung, Frankfurt a.M., Lang, 1994.

Londoño Berrio, Londoño Berrio, Hernando, El Estatuto Nacional de EstupefacienNFP 33 (1986) tes. ¡Una política criminal inconveniente!, in Nuevo Foro Penal 33 (1986), Medellín, Temis, S. 289-294.

López Calvo, 2008 López Calvo, Pedro, Investigación criminal y criminalística. Aplicadas al sistema penal con tendencia acusatoria 3. Aufl., Bogotá, Temis, 2008.

Lorenz, Jura 1983 Lorenz, Dieter, Das Gebot effektiven Rechtsschutz der Art. 19 Abs. 
4 GG, in Jura 1983, S. 393-400.

Lorenz, 1973

Lozada Bustos, 2003

LR/Bearbeiter

Lützner, 1999

Maier, 2004

Maier, 2003

Maier /Ambos /

Woischnik (Hrsg.), 2000

Maiwald, 2009

Mangoldt / Klein /

Starck / Bearbeiter

Martínez Rave, 2002

Martínez Sánchez DPC 20 (2010)

Maunz

/Dürig/Bearbeiter,

2016

Meininghaus, 2007

Menger, 1954

Meyer-

Goßner/Schmitt
Lorenz, Dieter, Der Rechtsschutz des Bürgers und die Rechtsweggarantie, München, Beck, 1973.

Lozada Bustos, Edgar, La policía judicial, Bogotá, Leyer, 2003.

Löwe-Rosenberg (Hrsg.), Die Strafprozessordnung und das Gerichtsverfassungsgesetz. Großkommentar 26 Aufl., Berlin, de Gruyter Recht, 2006.

Lützner, Axel, Strafprozessuale Zwangs- und Überwachungsmaßnahmen im Recht der USA und der Bundesrepublik Deutschland, Leipzig, Leipzig Uni-Verl, 1999.

Maier, Julio B. J., Derecho procesal Penal, Bd. I. Fundamentos 2. Aufl., Ed. Del puerto, 2004.

Maier, Julio B. J., Derecho procesal Penal, Bd. II. Parte general. Sujetos procesales, Buenos Aires, Ed. Del puerto, 2003.

Maier, Julio/Ambos, Kai/Woischnik, Jan (Hrsg.), Las reformas procesales penales en América Latina, Buenos Aires, Ad-Hoc [u.a.], 2000.

Maiwald, Manfred, Einführung in das italienische Strafrecht und Strafprozessrecht, Frankfurt a.M., Lang, 2009.

Mangoldt/Klein/Starck, Kommentar zum Grundgesetz. Bd. 1: Präambel, Artikel 1 bis 19. 6., vollst. neubearb. Aufl. / hrsg. von Christian Starck, München, Vahlen, 2010.

Martínez Rave, Gilberto, Procedimiento penal colombiano, Bogotá, Temis, 2002.

Martínez Sánchez, Wilson Alejandro, Consecuencias de la aplicación de la ley 1142 en el régimen de privación preventiva de la libertad en Colombia, in Derecho Penal Contemporáneo 30 (Ene-mar 2010) Bogotá, Legis, S. 69-117.

Maunz, Theodor/Dürig, Günter, Grundgesetz: Kommentar 76 Aufl., München, Beck, 2016.

Meininghaus, Florian, Der Zugriff auf E-Mails im strafrechtlichen Ermittlungsverfahren, Hamburg, Kovac, 2007.

Menger, Christian-Friedrich, System des verwaltungsgerichtlichen Rechtsschutz, Tübingen, 1954.

Meyer-Goßner, Lutz/Schmitt, Bertram, Strafprozessordnung. Gerichtsverfassungsgesetz, Nebengesetze und ergänzende Bestim- 
oder Meyer-

mungen 59. Aufl., München, Beck, 2016.

Goßner/Schmitt

Mestre Ordóñez, 2011

Mestre Ordóñez, José Fernando, La discrecionalidad para acusar: aspectos generales relacionados con el principio de oportunidad y reflexiones en torno a su reglamentación en Colombia, Bogotá, Pontificia Universidad Javeriana, Facultad de Ciencias Jurídicas, 2011.

Michael, 2016

Michael, Lothar, Grundrechte 5. Aufl., Baden-Baden, Nomos, 2016.

Miehe, FS Grünwald (1999)

Miehe, Olaf, Anklage und Eröffnung, in Festschrift für Gerald Grünwald zum siebzigsten Geburtstag, Erich Samson (Hrsg.), Baden-Baden, Nomos-Verl.-Ges., 1999, S. 379-402.

Mittag, 2009

Mittag, Matthias, Außerprozessuale Wirkungen strafprozessualer Grundrechtseingriffe, Berlin, Dunckler \& Humblot, 2009.

Molina Arrubla, 2002

Molina Arrubla, Carlos Mario, Fundamentos de derecho procesal penal, Bogotá, Leyer, 2002.

Molina López,

2012

Molina López, Ricardo, La conformidad en el proceso penal. Bogotá, Grupo Editorial Ibáñez, Universidad de los AndesUniversidad Pontificia Bolivariana, 2012.

Monroy Cabra FP 70 (2008)

Mora Izquierdo/Sánchez Prada, 2007

Morales Támara, 2009

Müller, 2009

Monroy Cabra, Marco Gerardo, Análisis de la ley 1142 de 2007, in Facetas Penales 70 (Jul., 2008), Bogotá, Leyer, S. 29-52.

Mora Izquierdo, Ricardo / Sánchez Prada, María Dolores, La evidencia física y la cadena de custodia en el proceso acusatorio, Editores gráficos de Colombia, Bogotá, D. C., 2007.

Morales Támara, Manuel Alberto, La investigación encubierta con fines judiciales como técnica especial de investigación: análisis constitucional y legal desde la perspectiva de la teoría de la prevención general positiva, Bogotá, Universidad Externado de Colombia, 2009.

Müller, Katharina, Der strafprozessuale Richtervorbehalt: System oder Chaos?, Halle, Univ. Diss., 2009.

Muñoz Tejada, 2015

Muñoz Tejada, Julián Andrés, Saber y poder en la política criminal de la Seguridad Democrática, 2002-2006, Medellín, Colombia: Universidad de Antioquia, Facultad de Derecho y Ciencias Políticas, 2015.

Nell, 1983

Nell, Ernst Ludwig, Wahrscheinlichkeitsurteile in juristischen Entscheidungen, Berlin, Duncker \& Humblot, 1983.

Nelles, 1980

Nelles, Ursula, Kompetenzen und Ausnahmekompetenzen in der Strafprozessordnung - zur organisationsrechtlichen Funktion 
des Begriffs „Gefahr im Verzug“ im Strafverfahrensrecht, Berlin, Duncker \& Humblot, 1980.

Neuling, 2005keit Neuling, Christian-Alexander, Inquisition durch Information: Medien öffentliche Strafrechtspflege im nicht öffentlichen Ermittlungsverfahren, Berlin, Dunckler \& Humblot, 2005.

Nieva Fenoll, La

Nieva Fenoll, Jordi, La protección de derechos fundamentales en defensa penal I

(2010-1)

Nijboer, 2005 las diligencias policiales de investigación del proceso penal, en La defensa penal I 2010-1, Santa Fe (Argentina), RubinzalCulzoni, 2010, S. 63-99.

Nijboer, Johannes Fredikus, Comparative criminal law \& procedure: an introduction, Deventer, Kluwer, 2005.

Nijboer, J.F., in

Doran/Jackson

(Hrsg.) 2000

Noltenius, ZStW

$122(2010)$

Obwexer, 2009

Nijboer, Johannes Fredikus, Comparative perspectives on the judicial role, in The judicial role in criminal proceedings, Doran, Sean; Jackson, John (Hrsg.), Oxford, Hart, 2000.

Noltenius, Bettina, Strafverfahrensrecht als Seismograph der Europäischen Integration - Verfassung, Strafverfahrensrecht und der Vertrag von Lissabon -, in ZStW 122 (2010), S. 604-626.

Obwexer, Walter, Gerichtssysteme und Rechtsschutz, in Waldemar Hummer/Walter Obwexer (Hrsg.), Der Vertrag von Lissabon, Baden-Baden, Nomos-Verl.-Ges. [u.a.], 2009, S. 237-266.

Ollinger, 1997

Ollinger, Thomas, Die Entwicklung des Richtervorbehalts im Verhaftungsrecht: von den Anfänge bis zur Paulskirchenverfassung, Berlin, Dunckler \& Humblot, 1997.

Orozco

Abad/Gómez Al-

Orozco Abad, Ivan/Gómez Albarello, Juan Gabriel, Los peligros del barello, 1999

Ostendorf

/Brüning, NJW

2001, JuS 2001

Ottow, 2014 nuevo constitucionalismo en materia criminal, Bogotá, TemisIEPRI-UNAL, 1999.

Ostendorf, Heribert/Brüning, Janique, Die gerichtliche Überprüfbarkeit des Voraussetzungen von „Gefahr im Verzug“, in BverfG NJW 2001, S. 1121, JuS 2001, S. 1063-1067.

Ottow, Sabine, Grundrechtseingriffe im Ermittlungsverfahren und nach dem Polizeirecht: die Einwirkungen des europäischen Rechts auf das deutsche Strafverfahren, Berlin, Duncker \& Humblot, 2014.

Paa, 2013

$P a a$, Bernhard, Der Zugriff der Strafverfolgungsbehörden auf das Private im Kampf gegen schwere Kriminalität, Heidelberg, Hamburg [u.a.], Müller, 2013.

Paeffen, 1986 Paeffgen, Hans-Ullrich, Vorüberlegungen zu einer Dogmatik des Untersuchungshaft-Rechts, Köln [u.a.], Heymanns, 1986.

Paeffgen, GA Paeffgen, Hans-Ullrich, Gefahr, Anscheindgefahr und Gefahrver- 
2014

Park, 2015

Patz, 2009

Pava Lugo 2009

Pécaut, 2001

Perdomo Torres, 2009

Pérez/Vanegas/

Álvarez, 1997

Pickenpack, 2012

Pineda Estrada, 2004

Pieroth/Schlink, 2014

Prechtel, 1995

Premissl, 2008

Prieto Vera, 2006

Prittwitz, FS Bemann (1997) dacht im Polizeirecht, in GA 2014, S. 638-655.

Park, Tido, Durchsuchung und Beschlagnahme 3. Aufl., München, Beck, 2015.

Patz, Martin, Die Effektivität der Strafrechtspflege, Frankfurt a.M. [u.a.], Lang, 2009.

Pava Lugo, Mauricio, La defensa en el sistema acusatorio, Bogotá, Ediciones Jurídicas Andrés Morales, 2009.

Pécaut, Daniel, Orden y violencia: evolución socio-política de Colombia entre 1930 y 1953, Bogotá [u.a.], Grupo Editorial Norma, 2001.

Perdomo Torres, Jorge Fernando, Estudios penales a partir de libertad y solidaridad, Bogotá, Universidad Externado de Colombia, 2009.

Pérez Toro, William Fredy/Vanegas Yepes, Alba Lucia/ Álvarez Martinez, Carlos Mario, Estado de derecho y sistema penal: la emergencia permanente de la reaccíon punitiva en Colombia, Medellin, Biblioteca Jurídica Dike, 1997.

Pickenpack, Vanessa, Rechtsschutz bei Verletzung von Verfahrensgrundrechten und bei Untätigkeit der Gerichte, Frankfurt a.M. [u.a.], Lang, 2012.

Pineda Estrada, Teófilo, La protección de la libertad y de la intimidad en la lucha contra el terrorismo: consideraciones en torno al fortalecimiento de la capacidad punitiva del estado, Bogotá, Pensamiento Siglo XXI, 2004.

Pieroth, Bodo/Schlink, Bernhard, Grundrechte 30. Aufl., Heidelberg, Müller, 2014.

Prechtel, Günter, Das Verhältnis der Staatsanwaltschaft zum Ermittlungsrichter: eine kritische Betrachtung der Mitwirkung der Richter im Ermittlungsverfahren, insbesondere zur Bedeutung des $§ 162$ StPO, München, VVF, 1995.

Premissl, Karl, Strafrechtsschutz und Grundrechte: Strafrechtliche Legitimierung gesetzwidrigen polizeilichen Freiheitsentziehung und Hausdurchsuchungen?, Wien, Facultas WUV, 2008.

Prieto Vera, Alberto José, Régimen de libertad en el sistema acusatorio colombiano (Ley 906 de 2004), Bogotá, Defensoría del Pueblo, 2006.

Prittwitz, Cornelius, Waffengleichheit im Ermittlungsverfahren, zu teuer bezahlt mit der Entleerung der Hauptverhandlung? Zur Strafverteidigung in der verstrafrechtlichen Gesellschaft, in 
Festschrift für Günter Bemmann zum 70. Geburtstag, Vormbaum, Joachim (Hrsg.), Baden-Baden, Nomos V. G., 1997, S. 596-613.

Proyecto Colombia nunca más, 2003

Rabe von Kühlewein, 2001

Rabe von Kühlewein, GA 2002

Rabe von Kühlewein, NStZ 2015

Ramírez Jaramillo, 2010

Restrepo Medina, 2007

Restrepo Medina Rev. Estud. SocioJuríd.8 (2) 2006

Reyes Medina, 2009

Richter, StV 1985

Rieß, FS Geerds 1995

Rieß/Thym, GA 1981

Rivera Loaiza, RDP 40

Rodríguez Chocontá, 2012

Rogall, ZStW 91
Proyecto Colombia nunca más, Verdad, Memoria y Lucha contra la impunidad 1966-1998. Bogotá, Editorial Colombia nunca más, 2003.

Rabe von Kühlewein, Malte, Der Richtervorbehalt im Polizei- und Strafprozeßrecht, Frankfurt a.M., Lang, 2001.

Rabe von Kühlewein, Malte, Normative Grundlagen der Richtervorbehalte, in GA 2002, S. 637-658.

Rabe von Kühlewein, Malte, Neue Regeln für Wohnungsdurchsuchungen, in NStZ 11/2015, S. 618-625.

Ramírez Jaramillo, Andrés David, El agente encubierto frente a los derechos fundamentales a la intimidad y a la no autoincriminación, Medellín, Universidad de Antioquia, 2010.

Restrepo Medina, Manuel Alberto, El comiso: Análisis sistemático e instrumentación cautelar, Bogotá, Universidad del Rosario, 2007.

Restrepo Medina, Manuel Alberto, Instrumentación cautelar del comiso, in Revista Estudios Socio-Jurídicos, Vol. 08, Nr. 2, JuliDez. 2006, S. 151-170.

Reyes Medina, César, Técnicas del proceso en el sistema penal acusatorio colombiano. Manual general para operadores jurídicos, Bogotá, USAID, 2009.

Richter, Christian, Zum Bedeutungswandel des Ermittlungsverfahrens - Bestandsaufnahme und Reformtendenzen - , in StV 1985, S. 382-389.

Rieß, Peter, Gerichtliche Kontrolle des Ermittlungsverfahrens?, in Geerds FS, Ellen Schlüchter (Hrsg.), Lübeck, Schmidt-Römhild, 1995, S. 501-518.

Rieß, Peter/Thym, Jörg, Rechtsschutz gegen strafprozessuale Zwangsmaßnahmen, in GA 1981, S. 189-212.

Rivera Loaiza, Julián. El Juez de Garantías ¿La dimensión más transparente de la justicia?, in Revista de Derecho Penal, Bogotá, Leyer Nr. 40, S. 121-160.

Rodríguez Chocontá, Orlando Alfonso, El testimonio penal y su práctica en el juicio oral y público, Bogotá, Temis, 2012.

Rogall, Klaus, Gegenwärtiger Stand und Entwicklungstendenzen der Lehre von den Strafprozessualen Beweisverboten, in ZStW 
(1979)

Roxin, StrV 1997
91 (1979), S. 1.

Roxin, Claus, Zur richterliche Kontrolle von Durchsuchungen und Beschlagnahmen, in StrV 1997, S. 654-656.

Roxin/Schünemann, Roxin, Claus/Schünemann, Bernd, Strafverfahrensrecht: ein Stu2014 dienbuch 28. Aufl., München, Beck, 2014.

Rudolph, 2005

Rudolph, Bernd, Antizipierte Strafverfolgung: zum Regelungsstandort der Strafverfolgungsvorsorge unter Beachtung strafverfahrensrechtlich - funktionaler Aspekte, Köln, Heymann, 2005.

Rüping, ZStW 95 Rüping, Hinrich, Das Verhältnis von Staatsanwaltschaft und Polizei (1983) - Zum Problem der Einheit der Strafverfolgung -, in ZStW 95 (1983), S. 894-917.

Sachs/Bearbeiter, Sachs, Michael (Hrsg.), Grundgesezt, Kommentar 7. Aufl., Mün2014 chen, Beck, 2014.

Sánchez Martínez, 2003

Sánchez Martínez, Germán Andrés, Captura sin flagrancia y sin orden judicial. "Captura administrativa”, Bogotá, Leyer, 2003.

Satzger, FS Beulke Satzger, Helmut, Im Anfang war der Verdacht - oder doch nicht? (2015)

Zur Frage, ob die Staatsanwaltschaft ohne Kenntnis einer Straftat gegen einen sich legal verhaltenden Bürger ermitteln darf, in Christian Fahl (Hrsg.), Festschrift für Werner Beulke zum 70. Geburtstag: [ein menschengerechtes Strafrecht als Lebensaufgabe], Heidelberg, Müller, 2015, S. 1009-1023.

Sax/Grundrechte III $/ 2$

Schaefer, StrafG 2002

Schenke, JZ 1988

Sax, Walter, Grundsätze der Strafrechtspflege, in Bettermann/Nipperdey/Scheuner (Hrsg.), Die Grundrechte, Bd. III/2: Rechtspflege und Grundrechtsschutz, Berlin, Duncker \& Humblot, 1959, S. 909-1014.

Schaefer, Christoph, Verpolizeilichung des Ermittlungsverfahrens Entmachtung der Staatsanwaltschaft -, in StraFo 2002, S. 118122.

Schenke, Wölf-Rüdiger, Die Bedeutung der verfassungsrechtlichen Rechtsschutzgarantie des Art. 19 Abs. 4 GG, in JZ 1988, S. $317-$ 326.

Schenke, NJW 1976

Schenke, Wolf-Rüdiger, Rechtsschutz bei strafprozessuale Eingriffen von StA und Polizei, in NJW 1976, S. 1816.

Schenke, JZ 2005 Schenke, Wolf-Rüdiger, Verfassungsrechtliche Garantie eines Rechtsschutzes gegen Rechtsprechungsakte?, in JZ 3/2005, S. 116.

Schima, 2009
Schima, Bernhard, Grundrechtsschutz, in Waldemar Hummer/Walter Obwexer (Hrsg.), Der Vertrag von Lissabon, BadenBaden, Nomos-Verl.-Ges. [u.a.], 2009, S. 325 ff. 
Schlachetzki, 2003 Schlachetzki, Nikolas, Die Polizei - Herrin des Strafverfahrens?: eine Analyse des Verhältnisses von Staatsanwaltschaft und Polizei, Berlin, Mensch \& Buch Verl., 2003.

Schnarr, NStZ 1991

Schnarr, Karl Heinz, Zur Verknüpfung von Richtervorbehalt, staatsantwaltlicher Eilanordnung und richterlicher Bestätigung, in NStZ 1991, S. 209-216.

Schoch, Jura 2001 Schoch, Friedrich, Rechtsschutz gegen polizeiliche Maßnahmen, in Jura 2001, S. 628-634.

Scholz, VVD StRL Scholz, Rupert, Verwaltungsverantwortung und Verwaltungsge34 (1976) richtsbarkeit, in Die Bindung des Richters an Gesetz und Verfassung. Verwaltungsverantwortung und Verwaltungsgerichtsbarkeit. Verhandlungen der Tagung der Vereinigung der Deutschen Staatsrechtslehrer zu Augsburg vom 1. bis 4. Oktober 1975, S. $145 \mathrm{ff}$.

Schmidt-Bleibtreu

Schmidt-Bleibtreu/Hofmann/Henneke, Kommentar zum Grundge/Hofmann setz 13. Aufl., Köln, Heymann, 2014.

/Henneke

/Bearbeiter

Schoreit, DRiZ 1987

Schoreit, Armin, Grundrechte und effektive Strafrechtspflege, Schutz der Allgemeinheit, Schutz des einzelnen, insbesondere unter Berücksichtigung neuer Fahndungstechniken, in DRiZ 1987, S. 464-469.

Schön, 2013

Schön, Stephanie, Ermittlungsmaßnahmen über das Internet: Analyse der Möglichkeiten und Grenzen in rechtlicher und tatsächlicher Hinsicht, Frankfurt a.M., PL Acad. Research, 2013.

Schröder, 1996

Schröder, Lars-Hendrik, Das Verwaltungsrechtlich organisatorische Verhältnis der Strafverfolgenden Polizei zur Staatsanwaltschaft, Frankfurt a.M., 1996.

Schröder, DÖV 2009

Schröder, M., Neuerungen im Rechtsschutz der Europäischen Union durch den Vertrag von Lissabon, in DÖV 2009, S. 61.

Schröder, 1992

Schröder, Svenja, Beweisverwertungsverbote und die Hypothese rechtmäßiger Beweiserlangung im Strafprozess, Berlin, Duncker \& Humblot, 1992.

Schulz, 2001

Schulz, Lorenz, Normiertes Misstrauen: der Verdacht im Strafverfahren, Frankfurt a.M., Klostermann, 2001.

Schünemann, Schünemann, Bernd, Wohin treibt der deutsche Strafprozess?, in ZStW 114 (2002) ZStW 114 (2002), S. 1-62.

Seif, 2003

Seif, Ulrike, Recht und Justizhoheit: historische Grundlagen des gesetzlichen Richters in Deutschland, England und Frankreich, 
Berlin, Duncker \& Humblot, 2003.

Schwarz, Jura 2007

Sotomayor Acosta, NFP 71 (2007)

Steinberg JZ 21 (2006)

Steinforth, 2015

Stelfox, 2009

Stephan, 1967

Stübinger, 2008

Suarez, Principia Iuris 16 (2011)

Suarez López, Temas de Derecho Penal 2008

Suárez Sánchez, 2001

Talaska, 2007

Thiele, EuR 2010

Tonne, 1997

Uprimny Yepes, Caleidoscopio B. I 2004
Schwarz, Kyrill-A., Verfassungsgewährleistungen im Strafverfahren, in Jura 2007, S. 334-342.

Sotomayor Acosta, Juan Oberto, Las recientes reformas penales en Colombia: un ejemplo de irracionalidad legislativa, in Nuevo Foro Penal 71 (2007), Medellín, EAFIT, S. 13-66.

Steinberg, Georg, Verdacht als quantifizierbare Prognose?, in JZ 21/2006, S. 1045-1049.

Steinforth, Sebastian, Die Gefährderansprache im Kontext versammlungsspezifischer Vorfeldmaßnahmen, Frankfurt am Main [u.a.], PL Acad. Research, 2015.

Stelfox, Peter, Criminal investigation: an introduction principles and practice, Cullompton, Willan, 2009.

Stephan, Bodo, Das Rechtsschutzbedürfniss, Berlin, De Gruyter, 1967.

Stübinger, Stephan, Das „idealisierte“ Strafrecht. Über Freiheit und Wahrheit in der Straftheorie und Strafprozessrechtslehre, Frankfurt a.M., Klostermann, 2008,

Suarez, José Leonardo, Inferencia razonable, probabilidad de verdad y conocimiento más allá de toda duda razonable, in Revista Principia Iuris 16 (2011), S. 307-329.

Suarez López, Carlos Alberto, Sobre la naturaleza y la legitimidad de la detención preventiva: ¿una simple medida procesalcautelar o una auténtica pena de prisión sin juicio? A propósito de la Ley 1142 de 2007, in Ricardo Posada Maya (Coord.), Temas De Derecho Penal, Bogotá, Ediciones Uniandes, 2008, S. 331-370.

Suárez Sánchez, Alberto, El debido proceso penal 2. Aufl., Bogotá, Universidad Externado de Colombia. 2001.

Talaska, Claudia Elisabeth, Der Richtervorbehalt: ein sinnvolles Element des Grundrechtsschutzes?, Hamburg, Kovač, 2007.

Thiele, Alexander, Das Rechtsschutzsystem nach dem Vertrag von Lissabon - (K)ein Schritt nach vorn?, in EuR 2010, S. 30 ff.

Tonne, Michael, Effektiver Rechtsschutz durch staatliche Gerichte als Forderung des europäischen Gemeinschaftsrechts, Köln, Heymanns, 1997.

Uprimny Yepes, Rodrigo, El laboratorio colombiano: narcotráfico, poder y administración de justicia, in El caleidoscopio de las justicias en Colombia: análisis socio-jurídico Bd. I, Boaventura 
de Sousa Santos/Mauricio García Villegas (eds.), Bogotá, Siglo de Hombre Ed., 2004, S. 371-413.

Urbano Martínez, Urbano Martínez, José Joaquín, Nueva estructura probatoria del 2011 proceso penal, Bogotá, Ediciones jurídicas Andrés Morales, 2011.

Urbano Martínez, Urbano Martínez, José Joaquín, El control de la acusación: una 2013 reflexión sobre los límites del poder de acusar en el estado constitucional de derecho, Bogotá, Universidad Externado de Colombia, 2013.

Uribe García Ratio Juris 12 (2011)

Vanegas Villa, 2007

Velásquez Velásquez, El Colombiano 12.12.2013.

Velásquez Velásquez, 1989

Velásquez Velásquez, NFP 40 (1988)

Velásquez Velásquez, NFP 51 (1991)

Velásquez Velásquez, Revista Berbiquí 29 (2005)

Vélez Osorio, 2012

Velten, 1995
Uribe García, Saúl de Jesús, ¿se encuentra vigente la detención preventiva administrativa? (captura administrativa), in Ratio Juris Vol. 6. No. 12 (2011), Medellín, Revista de la Universidad Autónoma Latinoamericana, S. 87-117.

Vanegas Villa, Piedad Lucia, Las audiencias preliminares en el sistema penal acusatorio, Bogotá, Fiscalía General de la Nación, 2007.

Velásquez Velásquez, Fernando, Sistema penal acusatorio e injusticia, in El Colombiano, Medellín, 12.12.2013. Verfügbar unter http://www.elcolombiano.com/historico/sistema_penal_acusator io_e_injusticia-HAEC_273756 (zuletzt geprüft am 30.05.2016).

Velásquez Velásquez, Fernando, La legislación colombiana en materia de estupefacientes, in Drogas: problemática actual en España y América; (primer seminario hispano colombiano de derecho penal) Barcelona, Nov. 27-30/1987, Bogota, Ed. Temis, 1989.

Velásquez Velásquez, Fernando, Un estatuto para la defensa de la democracia, in Nuevo Foro Penal 40 (1988), Medellín, Temis, S. 155-157.

Velásquez Velásquez, Fernando, El estatuto para la defensa de la justicia. ¡Un retorno a la inquisición!, in Nuevo Foro Penal 51 (1991), Medellín, Temis, S. 3-14.

Velásquez Velásquez, Fernando, Colombia: hacia un derecho penal expansionista, in Revista Berbiquí 29 (2005), Colegio de Jueces y Fiscales de Antioquia, Medellín, S. 5-20.

Vélez Osorio, Luis Gonzaga, Otra cara del sistema acusatorio colombiano: menosprecio de la libertad personal y autoritarismo penal, Medellín, Universidad de Antioquia, 2012.

Velten, Petra, Befugnisse der Ermittlungsbehörden zu Information: über Umfang und Kontrolle daraus resultierender Macht, Berlin, Duckler \& Humblot, 1995. 
Volk, 2015

Volk/Engländer, 2013

Voßkuhle, 1993

Walder, ZStW 95 (1983)

Waldmann, 2002

Weigend, 1978

Weiß, 2011

Welp, 1976

Wildhagen, 2011

Wittmann, 2014
Volk, Klaus, Curso fundamental. Ordenanza procesal alemana, Übersetzung der 7. Aufl. von Alberto Nanzer, Noelia T. Núñez, Daniel R. Pastor y Eugenio Sarrabayrouse; Revision der Übersetzung von Noelia T. Núñez; Aktualisierung der Literatur von John Zuluaga, Buenos Aires, Argentina, Hammurabi, José Luis Depalma, CEDPAL, 2016.

Volk, Klaus/Engländer, Armin, Grundkurs StPO 8. Aufl., München, Beck, 2013.

Voßkuhle, Andreas, Rechtsschutz gegen den Richter - Zu Integration der Dritten Gewalt in das verfassungsrechtliche Kontrollsystem vor dem Hintergrund des Art. 19 Abs. 4 GG, München, Beck, 1993.

Walder, Hans, Grenzen der Ermittlungstätigkeit, in ZStW 95 (1983), S. $862 \mathrm{ff}$.

Waldmann, Peter, Der anomische Staat: Über Recht, öffentliche Sicherheit und Alltag in Lateinamerika, Wiesbaden, Springer, 2002.

Warntjen, KJ 2005 Warntjen, Maximilian, Der Kernbereich privater Lebensgestaltung und die Telekommunkationsüberwachung gemäß $\S 100$ a StPO, in KJ 2005, S. 276-286.

Weigend, Thomas, Anklagepflicht und Ermessen: die Stellung des Staatsanwalts zwischen Legalitäts- und Opportunitätsprinzip nach deutschem und amerikanischem Recht, BadenBaden,Nomos-Verl.-Ges., 1978.

Weiß, Norman (Hrgs.), Rechtsschutz als Element von Rechtsstaatlichkeit, Baden-Baden, Nomos, 2011.

Welp, Jürgen, Zwangsbefugnisse für die Staatsanwaltschaft, Tübingen, 1976.

Wildhagen, Lars, Persönlichkeitsschutz durch präventive Kontrolle: Richtervorbehalte und nichtrichterliche Kontrollorgane als Ausprägungen des Prinzips der Informationsoptimierung bei Grundrechtseingriffen, Berlin, Duncker \& Humblot, 2011.

Wittmann, Philipp, Der Schutz der Privatsphäre vor staatlichen Überwachungsmaßnahmen durch die US-amerikanische Bundesverfassung. Eine Untersuchung unter besonderer Berücksichtigung des Schutzes der Privatsphäre in der Öffentlichkeit, Baden-Baden, Nomos, 2014.

Zapata Betancur, Zapata Betancur, Carlos Mario, Las audiencias preliminares del 2007 nuevo sistema penal acusatorio 2. Aufl., Medellín, Señal Edito- 
ra, 2007.

Zabel ZIS 7-

$8 / 2014$

Zinecker, 2004

Zuluaga, Co-

Herencia Vol. 4

Nr. 6 (2007)

Zuluaga, Boletin

GLIPGö 5 (2013)

Zuluaga, NFP 83 (2015)

Zuluaga/Koessl, DPC 37 (2012)
Zabel, Benno, Dogmatik und Funktionswandel des Tatverdachts, in ZIS 7-8/2014, S. 340-347.

Zinecker, Heidrun, Drogenökonomie und Gewalt. Das Beispiel Kolumbien, HSFK-Report 5/2004. Frankfurt a.M., 2004.

Zuluaga Taborda, John E., Comentarios a la Función de Control de Garantías. A Propósito de la ley 906 de 2004 o "sistema procesal penal acusatorio", in Co-Herencia Vol. 4-N. 6, Revista de Humanidades - Universidad EAFIT, Medellín, Jan-Jun 2007, S. 133-165.

Zuluaga Taborda, John E., Reflexiones sobre la protección judicial frente a medidas restrictivas de derechos fundamentales durante la investigación penal en Colombia, in Boletín Semestral GLIPGö Nr. 4, Göttingen, Ene-Jun 2013, S. 23 ff.

Zuluaga Taborda, John E., De los motivos "fundados" para la afectación de derechos fundamentales en el proceso penal colombiano, in NFP 83 (2015), Medellín, Temis, S. 167-210.

Zuluaga Taborda, John E./Koessl, Manfredo, Sobre la fase administrativa del procedimiento de la Ley 975 de 2005 o de "Justicia y Paz” (LJP), in Derecho Penal Contemporáneo, Bogotá, Legis S.A., Okt. - Nov. 2011, S. 5-64. 
Literatur- und Quellenverzeichnis 


\section{Rechtsprechungsverzeichnis}

\begin{tabular}{|c|c|c|c|}
\hline Gericht & Entscheidung & Datum & Berichterstatter \\
\hline KVerfG & Entsch. C-156 & v. 06.04.2016 & María Victoria Calle Correa \\
\hline KVerfG & Entsch. C-715 & v. 10.12.2015 & Jorge Ignacio Pretelt Chaljub \\
\hline KVerfG & Entsch. T-293 & v. 20.05 .2015 & Gloria Stella Ortiz Delgado \\
\hline KVerfG & Entsch. C-881 & v. 19.11.2014 & Jorge Ignacio Pretelt Chaljub \\
\hline KVerfG & Entsch. C-870 & v. 13.11.2014 & Luis Guillermo Guerrero Pérez \\
\hline KVerfG & Entsch. T-653 & v. 04.09.2014 & Gabriel Eduardo Mendoza \\
\hline KVerfG & Entsch. C-594 & v. 20.08.2014 & Jorge Ignacio Pretelt Chaljub \\
\hline KVerfG & Entsch. T-439 & v. 04.07.2014 & Gabriel Eduardo Mendoza \\
\hline KVerfG & Entsch. C-390 & v. 26.06 .2014 & Alberto Rojas Ríos \\
\hline KVerfG & Entsch. C-387 & v. 25.06 .2014 & Jorge Iván Palacio Palacio \\
\hline KVerfG & Entsch. C-366 & v. 11.06.2014 & Nilson Pinilla Pinilla \\
\hline KVerfG & Entsch. C-034 & v. 29.01.2014 & María Victoria Calle Correa \\
\hline KVerfG & Entsch. C-838 & v. 20.11 .2013 & Luís Ernesto Vargas Silva \\
\hline KVerfG & Entsch. C-839 & v. 20.11 .2013 & Jorge Ignacio Pretelt Chaljub \\
\hline KVerfG & Entsch. C-303 & v. 22.05 .2013 & Luis Guillermo Guerrero Pérez \\
\hline KVerfG & Entsch. T-293 & v. 21.05 .2013 & María Victoria Calle Correa \\
\hline KVerfG & Entsch. C-258 & v. 07.05 .2013 & Jorge Ignacio Pretelt Chaljub \\
\hline KVerfG & Entsch. C-016 & v. 23.01 .2013 & Gabriel Eduardo Mendoza \\
\hline KVerfG & Entsch. C-012 & v. 23.01.2013 & Mauricio González Cuervo \\
\hline KVerfG & Entsch. C-288 & v. 18.04 .2012 & Luís Ernesto Vargas Silva \\
\hline KVerfG & Entsch. C-239 & v. 22.03 .2012 & Juan Carlos Henao Pérez \\
\hline KVerfG & Entsch. T-508 & v. 30.06.2011 & Jorge Ivan Palacio Palacio \\
\hline KVerfG & Entsch. C-127 & v. 02.03 .2011 & María Victoria Calle Correa \\
\hline KVerfG & Entsch. C-122 & v. 01.03 .2011 & Juan Carlos Henao Pérez \\
\hline KVerfG & Entsch. C-980 & v. 01.12.2010 & Gabriel Eduardo Mendoza \\
\hline KVerfG & Entsch. T-549 & v. 06.07.2010 & Humberto Antonio Sierra Porto \\
\hline KVerfG & Entsch. C-059 & v. 03.02 .2010 & Humberto Antonio Sierra Porto \\
\hline KVerfG & Entsch. C-806 & v. 11.11.2009 & María Victoria Calle Correa \\
\hline erfG & Entsch. T- 520A & v. 31.07.2009 & Mauricio González Cu \\
\hline
\end{tabular}




\begin{tabular}{|c|c|c|c|}
\hline KVerfG & Entsch. C-409 & v. 17.06.2009 & Juan Carlos Henao Pérez \\
\hline KVerfG & Entsch. C-131 & v. 24.02.2009 & Nilson Pinilla Pinilla \\
\hline KVerfG & Entsch. C-070 & v. 12.02.2009 & $\begin{array}{l}\text { Humberto Antonio Sierra Porto } \\
\text { Clara Elena Reales Gutierrez }\end{array}$ \\
\hline KVerfG & Entsch. C-025 & v. 27.01.2009 & Rodrigo Escobar Gil \\
\hline KVerfG & Entsch. C-740 & v. 23.07.2008 & Jaime Araujo Rentería \\
\hline KVerfG & Entsch. T-489 & v. 15.05.2008 & Manuel José Cepeda Espinosa \\
\hline KVerfG & Entsch. C-256 & v. 11.03.2008 & Manuel José Cepeda Espinosa \\
\hline KVerfG & Entsch. C-226 & v. 05.03.2008 & Humberto Antonio Sierra Porto \\
\hline KVerfG & Entsch. C-185 & v. 27.02.2008 & Manuel José Cepeda Espinosa \\
\hline KVerfG & Entsch. C-186 & v. 27.02.2008 & Nilson Pinilla Pinilla \\
\hline KVerfG & Entsch. C-163 & v. 20.02.2008 & Jaime Córdoba Triviño \\
\hline KVerfG & Entsch. C-118 & v. 13.02.2008 & Marco Gerardo Monroy Cabra \\
\hline KVerfG & Entsch. T-158A & v. 15.02.2008 & Rodrigo Escobar Gil \\
\hline KVerfG & Entsch. C-920 & v. 07.11.2007 & Jaime Córdoba Triviño \\
\hline KVerfG & Entsch. C-519 & v. 11.07.2007 & Nilson Pinilla Pinilla \\
\hline KVerfG & Entsch. C-396 & v. 23.05.2007 & Marco Gerardo Monroy Cabra \\
\hline KVerfG & Entsch. C-336 & v. 09.05.2007 & Jaime Cordoba Trivino \\
\hline KVerfG & Entsch. A-089 & v. 18.04.2007 & Rodrigo Escobar Gil \\
\hline KVerfG & Entsch. C-210 & v. 21.03 .2007 & Marco Gerardo Monroy Cabra \\
\hline KVerfG & Entsch. C-095 & v. 14.02.2007 & Marco Gerardo Monroy Cabra \\
\hline KVerfG & Entsch. C-789 & v. 20.09.2006 & Nilson Pinilla Pinilla \\
\hline KVerfG & Entsch. C-370 & v. 18.05.2006 & $\begin{array}{l}\text { Manuel José Cepeda Espinosa } \\
\text { Jaime Córdoba Triviño } \\
\text { Rodrigo Escobar Gil } \\
\text { Marco Gerardo Monroy Cabra } \\
\text { Alvaro Tafur Galvis } \\
\text { Clara Inés Vargas Hernández }\end{array}$ \\
\hline KVerfG & Entsch. C-1260 & v. 05.12 .2005 & Clara Inés Vargas Hernández \\
\hline KVerfG & Entsch. C-1194 & v. 22.11 .2005 & Marco Gerardo Monroy Cabra \\
\hline KVerfG & Entsch. C-1177 & v. 17.11.2005 & Jaime Córdoba Triviño \\
\hline KVerfG & Entsch. C-1154 & v. 15.11.2005 & Manuel José Cepeda Espinosa \\
\hline KVerfG & Entsch. C-1001 & v. 03.10 .2005 & Alvaro Tafur Galvis \\
\hline KVerfG & Entsch. C-822 & v. 10.08.2005 & Manuel Jose Cepeda Espinosa \\
\hline KVerfG & Entsch. C-799 & v. 02.08.2005 & Jaime Araújo Rentería \\
\hline
\end{tabular}




\begin{tabular}{|c|c|c|c|}
\hline KVerfG & Entsch. C-730 & v. 12.07.2005 & Alvaro Tafur Galvis \\
\hline KVerfG & Entsch. C-673 & v. 30.06.2005 & Clara Inés Vargas Hernández \\
\hline KVerfG & Entsch. C-591 & v. 09.06.2005 & Clara Inés Vargas Hernández \\
\hline KVerfG & Entsch. C-592 & v. 09.06.2005 & Alvaro Tafur Galvis \\
\hline KVerfG & Entsch. T-453 & v. 02.05.2005 & Manuel José Cepeda Espinosa \\
\hline KVerfG & Entsch. C-334 & v. 04.04.2005 & Clara Inés Vargas Hernández \\
\hline KVerfG & Entsch. C-1039 & v. 22.10.2004 & Alvaro Tafur Galvis \\
\hline KVerfG & Entsch. C-970 & v. 07.10.2004 & Rodrigo Escobar Gil \\
\hline KVerfG & Entsch. T-687 & v. 22.07.2004 & Clara Inés Vargas Hernández \\
\hline KVerfG & Entsch. T-213 & v. 08.03.2004 & Eduardo Montealegre Lynett \\
\hline KVerfG & Entsch. T-220 & v. 08.03.2004 & Eduardo Montealegre Lynett \\
\hline KVerfG & Entsch. C-013 & v. 20.01.2004 & Marco Gerardo Monroy Cabra \\
\hline KVerfG & Entsch. C-1093 & v. 20.11 .2003 & Alfredo Beltrán Sierra \\
\hline KVerfG & Entsch. C-1092 & v. 19.11.2003 & Alvaro Tafur Galvis \\
\hline KVerfG & Entsch. C-873 & v. 30.09 .2003 & Manuel José Cepeda Espinosa \\
\hline KVerfG & Entsch. T-611 & v. 24.07 .2003 & Marco Gerardo Monroy Cabra \\
\hline KVerfG & Entsch. C-429 & v. 27.05 .2003 & Clara Inés Vargas Hernández \\
\hline KVerfG & Entsch. C-431 & v. 27.05.2003 & Alfredo Beltrán Sierra \\
\hline KVerfG & Entsch. C-033 & v. 28.01.2003 & Eduardo Montealegre Lynett \\
\hline KVerfG & Entsch. C-1024 & v. 26.11 .2002 & Alfredo Beltrán Sierra \\
\hline KVerfG & Entsch. C-805 & v. 01.10 .2002 & Eduardo Montealegre Lynett \\
\hline KVerfG & Entsch. C-802 & v. 02.10 .2002 & Jaime Córdoba Triviño \\
\hline KVerfG & Entsch. T-729 & v. 05.09.2002 & Eduardo Montealegre Lynett \\
\hline KVerfG & Entsch. T-593 & v. 01.08.2002 & Manuel José Cepeda Espinosa \\
\hline KVerfG & Entsch. C-580 & v. 31.07.2002 & Rodrigo Escobar Gil \\
\hline KVerfG & Entsch. C-251 & v. 11.04.2002 & $\begin{array}{l}\text { Eduardo Montealegre Lynett/ } \\
\text { Clara Inés Vargas Hernández }\end{array}$ \\
\hline KVerfG & Entsch. SU-159 & v. 06.03.2002 & Manuel José Cepeda Espinosa \\
\hline KVerfG & Entsch. SU-1184 & v. 13.11.2001 & Eduardo Montealegre Lynett \\
\hline KVerfG & Entsch. C-774 & v. 25.07.2001 & Rodrigo Escobar Gil \\
\hline KVerfG & Entsch. C-775 & v. 25.07.2001 & Alvaro Tafur Galvis \\
\hline KVerfG & Entsch. C-760 & v. 18.07.2001 & $\begin{array}{l}\text { Marco Gerardo Monroy Cabra } \\
\text { Manuel José Cepeda Espinosa }\end{array}$ \\
\hline KVerfG & Entsch. C-646 & v. 20.06 .2001 & Manuel José Cepeda Espinosa \\
\hline
\end{tabular}




\begin{tabular}{|c|c|c|c|}
\hline KVerfG & Entsch. C-053 & v. 24.01.2001 & Cristina Pardo Schlesinger \\
\hline KVerfG & Entsch. C-1711 & v. 12.12 .2000 & Carlos Gaviria Díaz \\
\hline KVerfG & Entsch. C-1643 & v. 29.11.2000 & Jairo Charry Rivas \\
\hline KVerfG & Entsch. C-1315 & v. 26.09.2000 & Alvaro Tafur Galvis \\
\hline KVerfG & Entsch. C-793 & v. 29.06.2000 & Vladimiro Naranjo Mesa \\
\hline KVerfG & Entsch. T-546 & v. 15.05 .2000 & Vladimiro Naranjo Mesa \\
\hline KVerfG & Entsch. C-392 & v. 06.04.2000 & Antonio Barrera Carbonell \\
\hline KVerfG & Entsch. T-181 & v. 23.03.1999 & Fabio Morón Díaz \\
\hline KVerfG & Entsch. T-654 & v. 11.11 .1998 & Eduardo Cifuentes Muñoz \\
\hline KVerfG & Entsch. C-475 & v. 25.09.1997 & Eduardo Cifuentes Muñoz \\
\hline KVerfG & Entsch. C-327 & v. 10.07.1997 & Fabio Morón Díaz \\
\hline KVerfG & Entsch. C-181 & v. 10.04.1997 & Fabio Morón Díaz \\
\hline KVerfG & Entsch, C-217 & v. 16.05.1996 & Jose Gregorio Hernandez Galindo \\
\hline KVerfG & Entsch. T-039 & v. 05.02.1996 & Antonio Barrera Carbonell \\
\hline KVerfG & Entsch. SU-056 & v. 16.02.1995 & Antonio Barrera Carbonell \\
\hline KVerfG & Entsch. C-396 & v. 08.09.1994 & Jose Gregorio Hernandez Galindo \\
\hline KVerfG & Entsch. C-270 & v. 09.06.1994 & Hernando Herrera Vergara \\
\hline KVerfG & Entsch. C-179 & v. 13.04.1994 & Carlos Gaviria Díaz \\
\hline KVerfG & Entsch. C-024 & v. 27.01.1994 & Alejandro Martinez Caballero \\
\hline KVerfG & Entsch. C-412 & v. 28.09 .1993 & Eduardo Cifuentes Muñoz \\
\hline KVerfG & Entsch. T-340 & v. 25.08 .1993 & Carlos Gaviria Díaz \\
\hline KVerfG & Entsch. C-150 & v. 22.04 .1993 & Fabio Morón Díaz \\
\hline $\begin{array}{l}\text { Oberster } \\
\text { Gerichtshof }\end{array}$ & Rad. 26310 & v. 16.05.2007 & Sigifredo Espinosa Perez \\
\hline $\begin{array}{l}\text { Oberster } \\
\text { Gerichtshof }\end{array}$ & Rad. 28906 & v. 23.01.2008 & Yesid Ramirez Bastidas \\
\hline $\begin{array}{l}\text { Oberster } \\
\text { Gerichtshof }\end{array}$ & Rad. 28535 & v. 02.07.2008 & José Leonidas Bustos Ramirez \\
\hline $\begin{array}{l}\text { Oberster } \\
\text { Gerichtshof }\end{array}$ & Rad. 29859 & v. 23.10 .2008 & Yesid Ramirez Bastidas \\
\hline $\begin{array}{l}\text { Oberster } \\
\text { Gerichtshof }\end{array}$ & Rad. 29904 & v. 12.06.2008 & Sigifredo Espinosa Pérez \\
\hline $\begin{array}{l}\text { Oberster } \\
\text { Gerichtshof }\end{array}$ & Rad. 25920 & v. 21.02.2007 & Javier Zapata Ortiz \\
\hline $\begin{array}{l}\text { Oberster } \\
\text { Gerichtshof }\end{array}$ & Rad. 27283 & v. 01.08.2007 & Yesid Ramírez Bastidas \\
\hline $\begin{array}{l}\text { Oberster } \\
\text { Gerichtshof }\end{array}$ & Rad. 30363 & v. 04.02.2009 & María del Rosario González \\
\hline $\begin{array}{l}\text { Oberster } \\
396\end{array}$ & Rad. 24531 & v. 04.05.2006 & Sigifredo Espinosa Pérez \\
\hline
\end{tabular}


Rechtsprechungsverzeichnis

Gerichtshof

Oberster

Gerichtshof

Oberster

Gerichtshof

Oberster

Gerichtshof

Oberster

Rad. 24764

v. 01.06.2006 Sigifredo Espinosa Pérez

Rad. 65256

v. 20.02.2013 Fernando Alberto Castro

Rad. 37877

v. 18.11.2011 Sigifredo Espinosa Pérez

Gerichtshof

Rad. $31280 \quad$ v. 08.07.2009 Julio Enrique Socha Salamanca 
Anlage 1: Der Gang des Strafverfahren (Gesetzt 906 v. 2004)

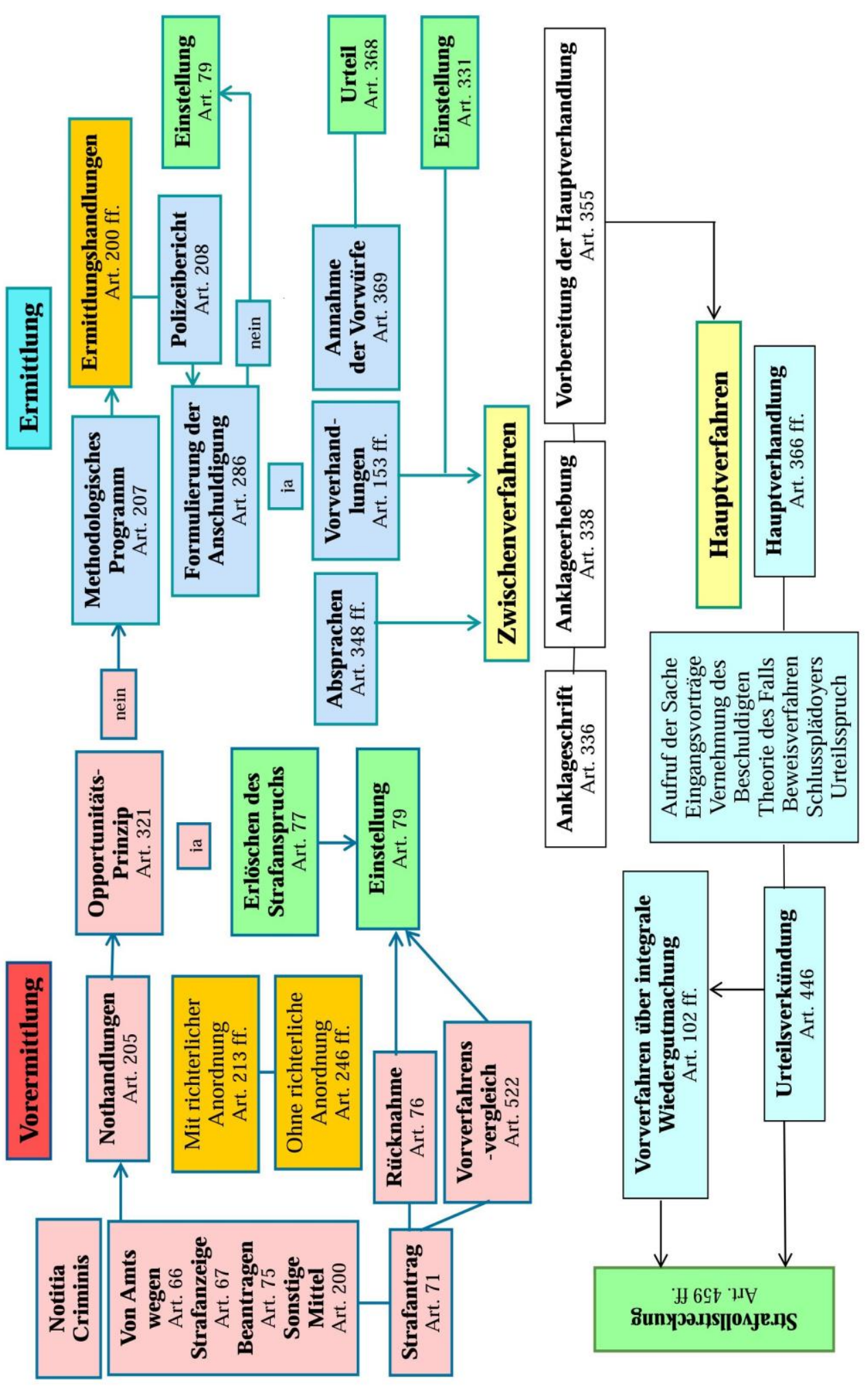




\section{Anlage 2: Übersicht über den Ermittlungsmaßnahmen im kolumbianischen}

\section{Strafverfahren}

\begin{tabular}{|c|c|}
\hline Zuständige Behörde & Ermittlungsmaßnahme \\
\hline $\begin{array}{l}\text { Initiative der Polizei } \\
\text { und nachträgliche } \\
\text { Kontrolle der StA }\end{array}$ & $\begin{array}{l}\text { - Entgegennahme von Beschwerden, Strafanträgen, } \\
\text { Beantragungen oder Berichten über Straftaten } \\
\text { - Begleitung oder Überführung des Opfers für } \\
\text { gerichtsmedizinische Untersuchungen } \\
\text { - Maßnahmen zur gerichtsmedizinischen Untersuchung oder } \\
\text { Identifizierung von Opfern } \\
\text { - Befragung mutmaßlicher Opfer oder Zeugen eines } \\
\text { Verbrechens } \\
\text { - Leicheninspektion } \\
\text { - Befragung der Angeklagten in Anwesenheit eines Anwalts } \\
\text { - Inspektion des Tatorts und Orte, an denen Beweismaterial } \\
\text { vermutet wird } \\
\text { - Identifizierung, Sammlung und Spurensicherung } \\
\text { - Suche und Zusammenstellung von Daten auf magnetischer } \\
\text { oder mechanischer Basis, Aufzeichnung öffentlich zugängli- } \\
\text { cher Informationen }\end{array}$ \\
\hline $\begin{array}{l}\text { Initiative der Polizei } \\
\text { und nachträgliche } \\
\text { Kontrolle durch den } \\
\text { JCG }\end{array}$ & - Festnahme auf frischer Tat \\
\hline $\begin{array}{l}\text { Anordnung der StA } \\
\text { und nachträgliche } \\
\text { Kontrolle durch JCG }\end{array}$ & $\begin{array}{l}\text { - Hausdurchsuchungen (Art. } 219 \text { CPP) } \\
\text { - Überwachung und Aufzeichnung der Kommunikation (Art. } \\
\text { 235, } 237 \text { CPP); } \\
\text { - Wiederbeschaffung von Informationen (Art. 236, } 237 \\
\text { CPP); } \\
\text { - Beschlagnahmen von Gütern (Art. } 84 \text { CPP); } \\
\text { - Personenüberwachung (Art. } 239 \text { CPP); } \\
\text { - Überwachungsmaßnahmen von Sachen (Art. } 240 \text { CPP); } \\
\text { - Analyse und Infiltrierung von kriminellen Organisationen } \\
\text { (Art. } 241 \text { CPP) } \\
\text { - Einsatz verdeckter Ermittler (Art. } 242 \text { CPP) } \\
\text { - Verdeckte Maßnahmen gegen Korruption (Art. } 242 \text { A) } \\
\text { - Verdeckte Überwachung von Transport, Verkauf und Ver- } \\
\text { mietung von Waffen, Sprengstoff, Munition, Falschgeld und } \\
\text { Drogen (Art. } 243 \text { CPP) } \\
\text { * Nach der Entch. C-336 von } 2007 \text { KVerfG sind nur die in Art. } 250 \\
\text { Nr. } 2 \text { CN genannten Maßnahmen ohne vorherige Anordnung des } \\
\text { JCG durchzuführen. }\end{array}$ \\
\hline Maßnahmen nur mit & - Körperliche Untersuchungen- Durchsuchungen von \\
\hline
\end{tabular}




\begin{tabular}{|c|c|}
\hline $\begin{array}{l}\text { Anordnung durch den } \\
\text { JCG }\end{array}$ & $\begin{array}{l}\text { Personen } \\
\text { - Selektive Suche in Datensammlungen } \\
\text { - Die Entnahme und Auswertung von DNA-Proben } \\
\text { - Maßnahmen zur Beweissicherung (Untersuchung auf } \\
\text { Spermaspuren, Blutentnahme) bei Sexualdelikten oder De- } \\
\text { likten gegen die körperliche Unversehrtheit, die eine körper- } \\
\text { liche Untersuchung des Opfers erfordern }\end{array}$ \\
\hline $\begin{array}{l}\text { Sonstige mögliche } \\
\text { Maßnahmen im Er- } \\
\text { mittlungsverfahren }\end{array}$ & $\begin{array}{l}\text { - Identifizierungs-methoden: DNA, zahnärztliche } \\
\text { Aufzeichnungen, Fingerabdrücke, Foto- und Videoanalyse, } \\
\text { Wahllichtbildvorlage, Gegenüberstellung } \\
\text { - Eidesstattliche Erklärung } \\
\text { - Beschlagnahmen von Eigentum } \\
\text { - Rückgabe oder Zerstörung von Eigentum }\end{array}$ \\
\hline
\end{tabular}

